\title{
viruses
}

Family/ridoviridae

Molecular and Ecological

Studies of a Family

Infecting Invertebrates and

Ectothermic Vertebrates

Edited by

V. Gregory Chinchar and Amanda LJ Duffus Printed Edition of the Special Issue Published in Viruses 
Family Iridoviridae: Molecular and Ecological Studies of a Family Infecting Invertebrates and Ectothermic Vertebrates 



\section{Family Iridoviridae: Molecular and Ecological Studies of a Family Infecting Invertebrates and Ectothermic Vertebrates}

Special Issue Editors

V. Gregory Chinchar

Amanda LJ Duffus 
Special Issue Editors

V. Gregory Chinchar

Department of Microbiology and

Immunology, University of Mississippi

Medical Center

USA
Amanda LJ Duffus

Department of Mathematics and Natural

Sciences, Gordon State College

USA

\section{Editorial Office}

MDPI

St. Alban-Anlage 66

4052 Basel, Switzerland

This is a reprint of articles from the Special Issue published online in the open access journal Viruses (ISSN 1999-4915) from 2018 to 2019 (available at: https:/ /www.mdpi.com/journal/viruses/special_ issues/iridoviruses)

For citation purposes, cite each article independently as indicated on the article page online and as indicated below:

LastName, A.A.; LastName, B.B.; LastName, C.C. Article Title. Journal Name Year, Article Number, Page Range.

\section{ISBN 978-3-03921-516-4 (Pbk) \\ ISBN 978-3-03921-517-1 (PDF)}

Cover image courtesy of John Heuser, Dexter Whitley, Robert Sample and V. Gregory Chinchar.

(C) 2019 by the authors. Articles in this book are Open Access and distributed under the Creative Commons Attribution (CC BY) license, which allows users to download, copy and build upon published articles, as long as the author and publisher are properly credited, which ensures maximum dissemination and a wider impact of our publications.

The book as a whole is distributed by MDPI under the terms and conditions of the Creative Commons license CC BY-NC-ND. 


\section{Contents}

About the Special Issue Editors $\ldots \ldots \ldots \ldots \ldots \ldots \ldots$ vii

V. Gregory Chinchar and Amanda L. J. Duffus

Molecular and Ecological Studies of a Virus Family (Iridoviridae) Infecting Invertebrates and Ectothermic Vertebrates

Reprinted from: Viruses 2019, 11, 538, doi:10.3390/v11060538 . . . . . . . . . . . . . . .

Bernardo Saucedo, José M. Serrano, Mónica Jacinto-Maldonado, Rob S.E.W. Leuven, Abraham A. Rocha García, Adriana Méndez Bernal, Andrea Gröne, Steven J. van Beurden and César M. Escobedo-Bonilla

Pathogen Risk Analysis for Wild Amphibian Populations Following the First Report of a Ranavirus Outbreak in Farmed American Bullfrogs (Lithobates catesbeianus) from Northern Mexico

Reprinted from: Viruses 2019, 11, 26, doi:10.3390/v11010026 . . . . . . . . . . . . . . . .

Emily Penny and Craig R. Brunetti

Localization of Frog Virus 3 Conserved Viral Proteins 88R, 91R, and 94L

Reprinted from: Viruses 2019, 11, 276, doi:10.3390/v11030276 . . . . . . . . . . . . . . . . . .

Joy A. Becker, Dean Gilligan, Martin Asmus, Alison Tweedie and Richard J. Whittington Geographic Distribution of Epizootic haematopoietic necrosis virus (EHNV) in Freshwater Fish in South Eastern Australia: Lost Opportunity for a Notifiable Pathogen to Expand Its Geographic Range

Reprinted from: Viruses 2019, 11, 315, doi:10.3390/v11040315 . . . . . . . . . . . . . . .

Eva-Stina Isabella Edholm, Francisco De Jesús Andino, Jinyeong Yim, Katherine Woo and Jacques Robert

Critical Role of an MHC Class I-Like/Innate-Like T Cell Immune Surveillance System in Host Defense against Ranavirus (Frog Virus 3) Infection

Reprinted from: Viruses 2019, 11, 330, doi:10.3390/v11040330 . . . . . . . . . . . . . . . .

Liang Qiu, Xing Chen, Ruo-Heng Zhao, Chen Li, Wen Gao, Qing-Li Zhang and Jie Huang Description of a Natural Infection with Decapod Iridescent Virus 1 in Farmed Giant Freshwater Prawn, Macrobrachium rosenbergii

Reprinted from: Viruses 2019, 11, 354, doi:10.3390/v11040354 . . . . . . . . . . . . . . . 56

Veronica A. Pagowski, Gideon J. Mordecai, Kristina M. Miller, Angela D. Schulze, Karia H. Kaukinen, Tobi J. Ming, Shaorong Li, Amy K. Teffer, Amy Tabata and Curtis A. Suttle Distribution and Phylogeny of Erythrocytic Necrosis Virus (ENV) in Salmon Suggests Marine Origin

Reprinted from: Viruses 2019, 11, 358, doi:10.3390/v11040358 . . . . . . . . . . . . . . . . .

Xing Chen, Liang Qiu, Hailiang Wang, Peizhuo Zou, Xuan Dong, Fuhua Li and Jie Huang Susceptibility of Exopalaemon carinicauda to the Infection with Shrimp Hemocyte Iridescent Virus (SHIV 20141215), a Strain of Decapod Iridescent Virus 1 (DIV1)

Reprinted from: Viruses 2019, 11, 387, doi:10.3390/v11040387 . . . . . . . . . . . . . . . 86

Joseph R. Mihaljevic, Amy L. Greer and Jesse L. Brunner

Evaluating the Within-Host Dynamics of Ranavirus Infection with Mechanistic Disease Models and Experimental Data

Reprinted from: Viruses 2019, 11, 396, doi:10.3390/v11050396 . . . . . . . . . . . . . . . . 101 
Cara West, Florentina Rus, Ying Chen, Anni Kleino, Monique Gangloff, Don B. Gammon and Neal Silverman

IIV-6 Inhibits NF-kB Responses in Drosophila

Reprinted from: Viruses 2019, 11, 409, doi:10.3390/v11050409 . . . . . . . . . . . . . . . . 113

\section{Xiao-Tao Zeng and Qi-Ya Zhang}

Interaction between Two Iridovirus Core Proteins and Their Effects on Ranavirus (RGV)

Replication in Cells from Different Species

Reprinted from: Viruses 2019, 11, 416, doi:10.3390/v11050416 . . . . . . . . . . . . . . . . . 128

Maya A. Halaly, Kuttichantran Subramaniam, Samantha A. Koda, Vsevolod L. Popov, David Stone, Keith Way and Thomas B. Waltzek

Characterization of a Novel Megalocytivirus Isolated from European Chub (Squalius cephalus)

Reprinted from: Viruses 2019, 11, 440, doi:10.3390/v11050440 . . . . . . . . . . . . . . . 141

Estefania J. Valverde, Alejandro M. Labella, Juan J. Borrego and Dolores Castro

Artemia spp., a Susceptible Host and Vector for Lymphocystis Disease Virus

Reprinted from: Viruses 2019, 11, 506, doi:10.3390/v11060506 . . . . . . . . . . . . . . . . 151

Claude Miaud, Véronique Arnal, Marie Poulain, Alice Valentini and Tony Dejean

eDNA Increases the Detectability of Ranavirus Infection in an Alpine Amphibian Population

Reprinted from: Viruses 2019, 11, 526, doi:10.3390/v11060526 . . . . . . . . . . . . . . . . . 161

Amanda L.J. Duffus, Trenton W.J. Garner, Richard A. Nichols, Joshua P. Standridge and Julia E. Earl

Modelling Ranavirus Transmission in Populations of Common Frogs (Rana temporaria) in the

United Kingdom

Reprinted from: Viruses 2019, 11, 556, doi:10.3390/v11060556 . . . . . . . . . . . . . . . 176

Fei Ke, Zi-Hao Wang, Cheng-Yue Ming and Qi-Ya Zhang

Ranaviruses Bind Cells from Different Species through Interaction with Heparan Sulfate

Reprinted from: Viruses 2019, 11, 593, doi:10.3390/v11070593 . . . . . . . . . . . . . . . . . . 189

Tibor Papp and Rachel E. Marschang

Detection and Characterization of Invertebrate Iridoviruses Found in Reptiles and Prey Insects

in Europe over the Past Two Decades

Reprinted from: Viruses 2019, 11, 600, doi:10.3390/v11070600 . . . . . . . . . . . . . . 200 


\section{About the Special Issue Editors}

V. Gregory Chinchar, Ph.D. (Professor) is a graduate of the University of Notre Dame, Notre Dame, IN (B.S. 1972) and earned his Ph.D. degree in the laboratory of Milton Taylor (Indiana University, Bloomington, IN-1978). He was a post-doctoral associate with Allen Portner at St. Jude Children's Research Hospital (SJCRH, Memphis, TN) from 1978-1981, before joining the laboratory of Allan Granoff at SJCRH as a Research Associate and beginning his long-standing interest in iridoviruses. Dr. Chinchar relocated to the University of Mississippi Medical Center in 1984 and has remained there for his academic career. He is involved in teaching medical, dental, and graduate students, has served as an Associate Dean in the School of Graduate Studies, and has conducted research on ranaviruses, specifically frog virus 3 , and immune responses in channel catfish.

Duffus, Amanda Linda Jean (Associate Professor of Biology). Dr. Duffus is a graduate of Queen's University (BSc.Hons.-2004); Trent University (MSc.-2006); and the Institute of Zoology, Zoological Society of London and Queen Mary and Westfield College, University of London (Ph.D.-2010). She joined the faculty of Gordon State College in 2010. Dr. Duffus began studying amphibian ranaviruses in 2004 when she embarked on her MSc. and has been fascinated by them ever since. Although she is at a teaching-focused undergraduate institution, she has managed to develop a small research program for her students and she maintains collaborations with colleagues that permit her to continue to explore her passion for understanding amphibian ranaviruses. 



\title{
Editorial \\ Molecular and Ecological Studies of a Virus Family (Iridoviridae) Infecting Invertebrates and Ectothermic Vertebrates
}

\author{
V. Gregory Chinchar ${ }^{1, *(1)}$ and Amanda L. J. Duffus ${ }^{2}(\mathbb{D}$ \\ 1 Department of Microbiology and Immunology, University of Mississippi Medical Center, Jackson, \\ MS 39216, USA \\ 2 Department of Mathematics and Natural Sciences, Gordon State College, Barnesville, GA 30204, USA; \\ aduffus@gordonstate.edu \\ * Correspondence: vchinchar@umc.edu
}

Received: 29 May 2019; Accepted: 31 May 2019; Published: 9 June 2019

check for updates

Research involving viruses within the family Iridoviridae (generically designated iridovirids to distinguish members of the family Iridoviridae from members of the genus Iridovirus) has markedly increased in recent years. Inspection of data from PubMed indicates that from 1990 to 1999 approximately 60 articles related to this family appeared in the literature, whereas over 850 articles involving various iridovirids were published between 2010 and 2019. The marked upsurge in publications reflects the fact that iridovirids, once viewed as obscure viruses with little economic or ecological impact, are now known to be widely distributed in nature, infect a large and diverse array of invertebrates and ectothermic vertebrates, and trigger marked levels of morbidity and mortality in specific populations (e.g., endangered or commercially-important species) [1].

Currently, six genera comprise the family Iridoviridae: three which infect invertebrates (Iridovirus, Chloriridovirus, and Decapodiridovirus), two that target only bony fish (Lymphocystivirus and Megalocytivirus), and one that infects fish, amphibians, and reptiles (Ranavirus) [2]. Lymphocystis disease has been recognized for over a century among marine and freshwater fish species. However, this clinical presentation was not formally linked to a virus until the 1960s and the inability to propagate the virus easily in cell culture markedly impeded its study [3]. Invertebrate iridescent viruses (IIV) were identified in the mid-1950s and subsequently shown to infect a large number of invertebrate species [4-6]. However, for a variety of reasons (e.g., the absence of significant economic or ecological impact, the paucity of robust in vitro systems), their study has not progressed along with those of their vertebrate virus counterparts. In contrast, the identification of Frog virus 3 (FV3, genus Ranavirus) from North American leopard frogs (Lithobates pipiens) in 1965 by Granoff and coworkers [7] led to the characterization of the family at the molecular level and the identification of a number of characteristic features including a circularly permuted and terminally redundant genome, rapid turnoff of host protein and RNA synthesis triggered by a virion-associated protein, and, among vertebrate viruses, methylation of cytosine residues within the sequence CpG [8]. Moreover, phylogenetic analysis of the complete genomic sequences of over 40 viruses has solidified our understanding of iridovirid taxonomy and has indicated relatedness to other large DNA containing viruses such as ascovirus, mimivirus, and marseillevirus. Recently phylogenetic analysis of isolates from shrimp and crayfish led to the establishment of a third genus (Decapodiridovirus) within the subfamily Betairidovirinae, and studies of fish and reptiles suggest the possible existence of a fourth genus within the Alphairidovirinae encompassing erythrocytic necrosis viruses [9-13].

Morphologically, iridovirids are large, icosahedral double-stranded DNA-containing viruses containing a DNA-protein core surrounded by an internal lipid membrane, an icosahedral protein capsid, and, in those viruses released by budding, a viral envelope that may also display a fringe of 
fibrils [14]. Viral genomes range in size from 100-200 kbp and encode between 100 and 200 putative proteins. Replication involves both the nucleus and cytoplasm. Early viral transcription and 1st stage DNA synthesis take place within the nucleus, whereas late viral transcription and $2^{\text {nd }}$ stage DNA synthesis (concatemer formation) take place in the cytoplasm. Virions assemble within morphologically distinct cytoplasmic assembly sites and are released either by cell lysis or by budding from the plasma membrane [14-17].

In this issue of Viruses, we provide a collection of articles focused on two different aspects of iridovirid biology: the ecology of iridovirus infections and studies using molecular, immunological, and phylogenetic tools to understand the roles of iridovirid proteins, the interaction between iridoviruses and the host immune system, and the taxonomic relationships among members of the family Iridoviridae, nuclear cytoplasmic large DNA viruses (e.g., poxvirus, ascovirus, phycodnavirus, asfivirus), and the newly-identified "Giant Viruses" (e.g., marseillevirus, mimivirus, etc.). Ecological studies have focused on identifying new viral species and hosts, characterizing the pathological outcomes of infection, ascertaining how environmental influences impact the severity of infection, developing models to explain virus spread and disease, and understanding the consequences of infections among wild and cultured species. Molecular and phylogenetic studies center on identifying and determining the function of essential viral replicative genes required for growth both in vivo and in vitro, and in identifying and determining the function of virus-encoded "immune evasion" and "efficiency genes." These latter genes, although not required for replication in cell culture, are absolutely required for replication in vivo. Immune evasion genes function by inhibiting innate and acquired anti-viral responses, whereas efficiency genes permit replication under restrictive cellular environments (e.g., low nucleotide pool levels). Lastly immunological studies attempt to define the elements of the host immune response required to provide a protective response. Collectively, articles found within this issue of Viruses provide a snapshot of ongoing studies in the field.

Conflicts of Interest: The authors declare no conflict of interest.

\section{References}

1. Duffus, A.L.J.; Waltzek, T.B.; Stohr, A.C.; Allender, M.C.; Gotesman, M.; Whittington, R.J.; Hick, P.; Hines, M.K.; Marschang, R.E. Distribution and host range of ranaviruses. In Ranaviruses: Lethal Pathogens of Ectothermic Vertebrates; Gray, M., Chinchar, V., Eds.; Springer OPEN: Heidelberg, Germany, 2015; pp. 9-58. [CrossRef]

2. Chinchar, V.G.; Hick, P.; Ince, I.A.; Jancovich, J.K.; Marschang, R.; Qin, Q.; Subramaniam, K.; Waltzek, T.B.; Whittington, R.; Williams, T.; et al. ICTV Virus Taxonomy Profile: Iridoviridae. J. Gen. Virol. 2017, 98, 890-891. [CrossRef] [PubMed]

3. Weissenberg, R. 50 years of research on the lymphocystis virus disease of fishes (1914-1964). Ann. N. Y. Acad. Sci. 1965, 126, 362-374. [CrossRef] [PubMed]

4. Xeros, N. A second virus disease of the leather jacket, Tipula paludosa. Nature 1954, 174, 562-563. [CrossRef]

5. Williams, T. Natural invertebrate hosts of iridoviruses (Iridoviridae). Neotrop. Entomol. 2008, 37, 615-632. [CrossRef] [PubMed]

6. Williams, T. The iridoviruses. Adv. Virus Res. 1996, 46, 345-412. [PubMed]

7. Granoff, A.; Came, P.E.; Breeze, D.C. Viruses and renal carcinoma of Rana pipiens. I. The isolation and properties of virus from normal and tumor tissue. Virology 1966, 29, 133-148. [CrossRef]

8. Granoff, A. Frog virus 3: A DNA virus with an unusual life-style. Prog. Med. Virol. 1984, 30, 187-198. [PubMed]

9. Qiu, L.; Chen, M.M.; Wang, R.Y.; Wan, X.Y.; Li, C.; Zhang, Q.L.; Dong, X.; Yang, B.; Xiang, J.H.; Huang, J. Complete genome sequence of shrimp hemocyte iridescent virus (SHIV) isolated from white leg shrimp, Litopenaeus vannamei. Arch. Virol. 2018, 163, 781-785. [CrossRef] [PubMed]

10. Li, F.; Xu, L.; Yang, F. Genomic characterization of a novel iridovirus from redclaw crayfish Cherax quadricarinatus: Evidence for a new genus within the family Iridoviridae. J. Gen. Virol. 2017, 98, 2589-2595. [CrossRef] [PubMed] 
11. Emmenegger, E.J.; Glenn, J.A.; Winton, J.R.; Batts, W.N.; Gregg, J.L.; Hershberger, P.K. Molecular identification of erythrocytic necrosis virus (ENV) from the blood of Pacific herring (Clupea pallasii). Vet. Microbiol. 2014, 174, 16-26. [CrossRef] [PubMed]

12. De Matos, A.P.; Caeiro, M.F.; Papp, T.; Matos, B.A.; Correia, A.C.; Marschang, R.E. New viruses from Lacerta monticola (Serra da Estrela, Portugal): Further evidence for a new group of nucleo-cytoplasmic large deoxyriboviruses. Microsc. Microanal. 2011, 17, 101-108. [CrossRef] [PubMed]

13. Wellehan, J.F., Jr.; Strik, N.I.; Stacy, B.A.; Childress, A.L.; Jacobson, E.R.; Telford, S.R., Jr. Characterization of an erythrocytic virus in the family Iridoviridae from a peninsula ribbon snake (Thamnophis sauritus sackenii). Vet. Microbiol. 2008, 131, 115-122. [CrossRef] [PubMed]

14. Chinchar, V.G.; Waltzek, T.B.; Subramaniam, K. Ranaviruses and other members of the family Iridoviridae: Their place in the virosphere. Virology 2017, 511, 259-271. [CrossRef] [PubMed]

15. Chinchar, V.G.; Hyatt, A.; Miyazaki, T.; Williams, T. Family Iridoviridae: Poor viral relations no longer. Curr. Top. Microbiol. Immunol. 2009, 328, 123-170. [PubMed]

16. Jancovich, J.K.; Qin, Q.; Zhang, Q.-Y.; Chinchar, V.G. Ranavirus replication: Molecular, cellular, and immunological events. In Ranaviruses: Lethal Pathogens of Ectothermic Vertebrates; Gray, M., Chinchar, V., Eds.; Springer OPEN: New York, NY, USA, 2015; pp. 105-139.

17. Williams, T.; Barbosa-Solomieu, V.; Chinchar, V.G. A decade of advances in iridovirus research. Adv. Virus Res. 2005, 65, 173-248. [PubMed]

(C) 2019 by the authors. Licensee MDPI, Basel, Switzerland. This article is an open access article distributed under the terms and conditions of the Creative Commons Attribution (CC BY) license (http://creativecommons.org/licenses/by/4.0/). 


\title{
Pathogen Risk Analysis for Wild Amphibian Populations Following the First Report of a Ranavirus Outbreak in Farmed American Bullfrogs (Lithobates catesbeianus) from Northern Mexico
}

\author{
Bernardo Saucedo $^{1}$, José M. Serrano ${ }^{2,3} \mathbb{D}$, Mónica Jacinto-Maldonado ${ }^{4,5}$, Rob S. E. W. Leuven ${ }^{6,7}$, \\ Abraham A. Rocha García ${ }^{8}$, Adriana Méndez Bernal ${ }^{8}$, Andrea Gröne ${ }^{1}$, Steven J. van Beurden ${ }^{1}$ \\ and César M. Escobedo-Bonilla 9,*(D) \\ 1 Department of Pathobiology, Faculty of Veterinary Medicine, Utrecht University, 3584 CL Utrecht, \\ The Netherlands; b.saucedogarnica@uu.nl (B.S.); a.groene@uu.nl (A.G.); \\ steven.vanbeurden@gupta-strategists.nl (S.J.v.B.) \\ 2 Laboratorio de Genética y Evolución, Departamento de Ciencias Ecológicas, Facultad de Ciencias, \\ Universidad de Chile, Las Palmeras, Santiago 3425, Chile; jose.rano@gmail.com \\ 3 Programa de Fisiología y Biofísica, Facultad de Medicina, Universidad de Chile, Santiago 8380453, Chile \\ 4 Wildlife and Laboratory Animals, Department of Ethology, Faculty of Veterinary Medicine, \\ National Autonomous University of Mexico, Mexico City 045010, Mexico; monica.jacinto@c3.unam.mx \\ 5 C3-Complexity sciences Center, Autonomous University of Mexico, Mexico City 045010, Mexico \\ 6 Department of Animal Ecology and Physiology, Institute for Water and Wetland Research, \\ Radboud University, 6500 GL Nijmegen, The Netherlands; r.leuven@science.ru.nl \\ 7 Netherlands Centre of Expertise on Exotic Species, 6500 GL Nijmegen, The Netherlands \\ 8 Department of Pathology 04510, Faculty of Veterinary Medicine, National Autonomous University \\ of Mexico, Mexico City 045010, Mexico; ab_abraham88@hotmail.com (A.A.R.G.); \\ mvzadrimb@gmail.com (A.M.B.) \\ 9 Department of Aquaculture, Instituto Politécnico, Nacional-CIIDIR Unidad Sinaloa, Guasave Sinaloa 81101, \\ Mexico \\ * Correspondence: cescobe@ipn.mx; Tel.: +52-(55)-5729-6000 (ext. 87637)
}

Received: 4 October 2018; Accepted: 24 December 2018; Published: 3 January 2019

\begin{abstract}
Ranaviruses are the second deadliest pathogens for amphibian populations throughout the world. Despite their wide distribution in America, these viruses have never been reported in Mexico, the country with the fifth highest amphibian diversity in the world. This paper is the first to address an outbreak of ranavirus in captive American bullfrogs (Lithobates catesbeianus) from Sinaloa, Mexico. The farm experienced high mortality in an undetermined number of juveniles and sub-adult bullfrogs. Affected animals displayed clinical signs and gross lesions such as lethargy, edema, skin ulcers, and hemorrhages consistent with ranavirus infection. The main microscopic lesions included mild renal tubular necrosis and moderate congestion in several organs. Immunohistochemical analyses revealed scant infected hepatocytes and renal tubular epithelial cells. Phylogenetic analysis of five partial ranavirus genes showed that the causative agent clustered within the Frog virus 3 clade. Risk assessment with the Pandora ${ }^{+}$protocol demonstrated a high risk for the pathogen to affect amphibians from neighboring regions (overall Pandora risk score: 0.619). Given the risk of American bullfrogs escaping and spreading the disease to wild amphibians, efforts should focus on implementing effective containment strategies and surveillance programs for ranavirus at facilities undertaking intensive farming of amphibians.
\end{abstract}

Keywords: amphibians; histopathology; immunohistochemistry; Mexico; outbreak; ranavirus; risk assessment 


\section{Introduction}

Mexico is the fifth ranking nation in terms of amphibian biodiversity with a total of 252 endemic species [1]. Moreover, the country ranks second in number of threatened amphibian species $(n=164)$ [1]. Main causes for amphibian population declines are anthropogenic activities such as deforestation and habitat fragmentation, and infectious diseases [2,3]. The two deadliest amphibian pathogens worldwide are the fungus Batrachochytrium dendrobatidis (Bd) and ranavirus [4]. The fungus $\mathrm{Bd}$ has caused epidemics in amphibian populations from mountainous regions of central and southern Mexico since the 1970s [5]. In contrast, ranaviruses (double-stranded DNA viruses from the family Iridoviridae) [4] have never been reported in Mexico, despite the wide distribution of these pathogens throughout the United States and Central and South America [6]. Insufficient surveillance is suspected to be the main reason for the lack of ranavirus records in Mexico [6].

Ranaviruses have been associated with die-offs of wild amphibians in America, where Ambystoma tigrinum virus (ATV) and frog virus 3 (FV3) are most prevalent [7,8]. In Europe, the common midwife toad viruses (CMTV) prevail in the wild [9-11], whereas in Asia, the tiger frog virus (TFV) and FV3 virus are present in the wild [12,13] and the CMTV strains have only been found in captive populations [14]. In many of these cases, ranavirus outbreaks have affected zoo collections [15], fisheries [16], or laboratory facilities [17].

The present study describes an outbreak of ranavirus disease in a captive colony of American bullfrogs (Lithobates catesbeianus) in the Mexican province of Sinaloa. Sinaloa is located in a transitional zone in the Pacific coast of Mexico and is home to at least 40 amphibian species, among them, salamanders of the families Ambystomatidae (1 species) and Plethodontidae (1 species), and anurans belonging to Bufonidae (9 species), Craugastoridae (4 species), Eleutherodactylidae (4 species), Hylidae (11 species), Leptodactylidae (1 species), Mycrohylidae (3 species), Pelobatidae (1 species), and Ranidae (5 species) [18]. Around 10\% of the species from these families show evidence of population declines, $80 \%$ are considered stable and for the remaining $10 \%$ no information is available [1].

Commercial farming of American bullfrogs (Lithobates catesbeianus) started in Mexico during the 1950 s when the species was introduced from the United States $[19,20]$. This species was first noticed in the wild in the northwestern part of Mexico in 1969 and has since become invasive and a major threat for ecological niches of endemic Mexican amphibians [19,21].

This work describes, for the first time, a ranavirus outbreak in farmed American bullfrogs (Lithobates catesbeianus) from Mexico. In late March of 2017, the rana-culture facility experienced a die-off involving an undetermined number of dead animals at various life stages, particularly juveniles and sub-adults. Macroscopic and microscopic lesions of affected animals, along with immunohistochemical and molecular analyses of the samples, revealed that the die-off was associated with an FV3-like ranavirus.

The aims of this study were to investigate the first ranavirus disease outbreak in Mexico and to analyze the potential risk that this pathogen poses for wild amphibian populations in neighboring areas.

\section{Materials and Methods}

\subsection{General Information on the Rana-Culture Facility}

The farm is located in the city of Guasave, province of Sinaloa (Figure 1). It started operations around 2009. The bullfrogs were originally brought in from a facility in central Mexico (state of Mexico) and were subsequently bred. Afterwards, a batch of frogs raised in the farm was bred to produce their own eggs and tadpoles, closing the culture system. The culture cycle normally lasts four to six months from tadpole to harvest size (120-250 g). The animals are used mainly for educational purposes and not for human consumption. 


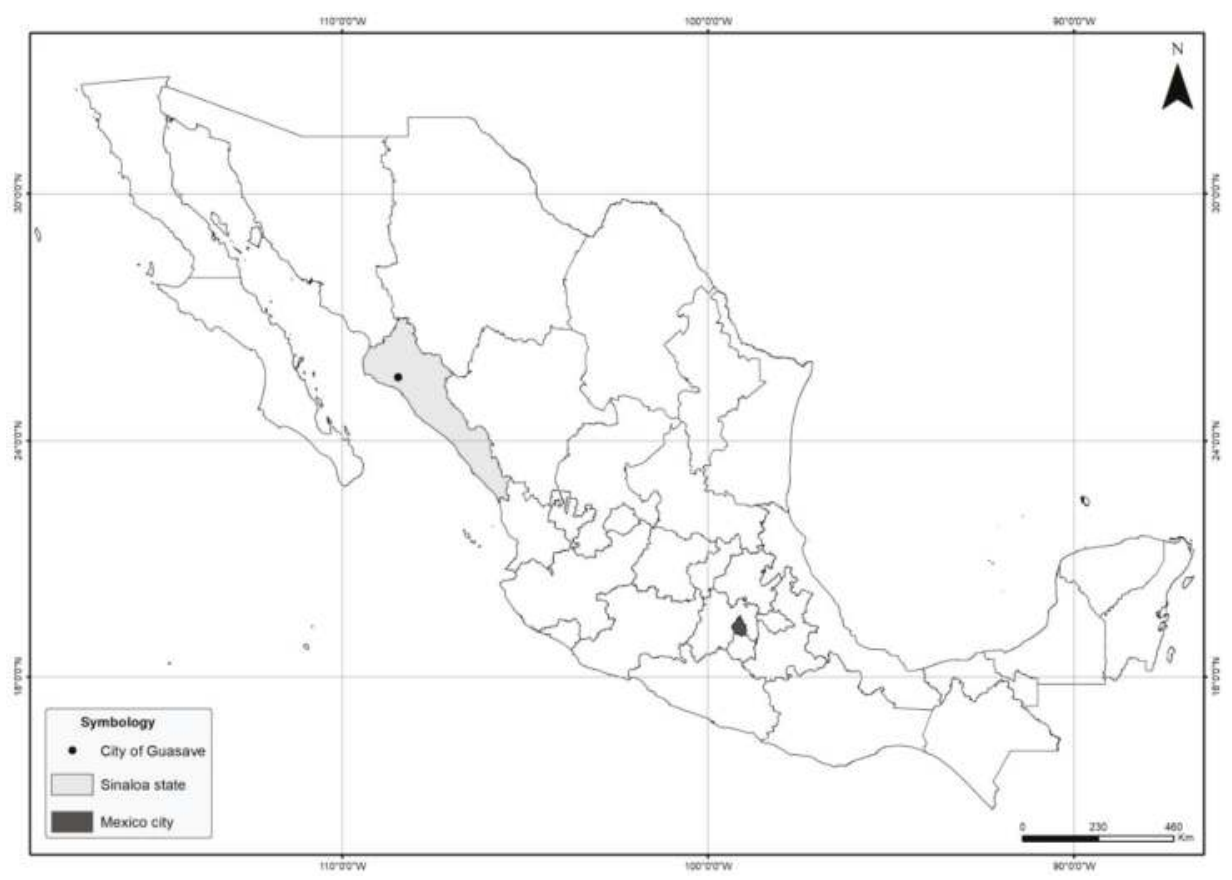

Figure 1. Location of city of the outbreak in Mexico. The city of Guasave is indicated by a black circle within the province of Sinaloa (grey). Mexico City, the place from which the bullfrogs were imported from, is shown in black.

\subsection{Necropsies and Sample Collection}

Animals that reached humane end-points manifested as severe lesions and clinical signs (ulcerations and skin erythema, lethargy,) were euthanized with an overdose of barbiturates (by a licensed veterinarian). Necropsies of five bullfrogs were performed in situ and spleen, kidney, and liver were sampled for histopathology and PCR.

\subsection{Histopathology and Immunohistochemistry}

Fragments of spleen, kidney, and liver were stored in $10 \%$ formalin for $24 \mathrm{~h}$. Subsequently, samples were dehydrated with ascending grades of ethyl alcohol (ETOH), embedded in paraffin blocks (Paraplast, Tissue Embedding Medium, MacCormick Scientific, Chicago, IL, USA), cut at $3 \mu \mathrm{m}$ thickness and stained with hematoxylin and eosin (H\&E) for microscopic examination [22]. Immunohistochemistry was performed based on an established protocol with a polyclonal rabbit anti-European catfish virus antibody (kindly donated by Dr. Anna Toffan, Instituto Zooprofilattico Sperimentale delle Venezie, Italy) with slight modifications [23]. Sections were dewaxed and hydrated through decreasing concentrations of alcohol, and gently washed twice with PBS, $\mathrm{pH} 7.2$, for $5 \mathrm{~min}$. Endogenous peroxidase activity was inhibited by immersion of the slides in $4 \%$ hydrogen peroxide for $30 \mathrm{~min}$. Blocking was done by placing the slides on PBS buffer with $5 \%$ bovine serum albumin (BSA) for $30 \mathrm{~min}$ at room temperature. Antigen retrieval was achieved by incubating the slides with trypsin $\left(0.1 \%\right.$ working solution) at $37^{\circ} \mathrm{C}$ for $20 \mathrm{~min}$. Afterwards, slides were incubated with the polyclonal rabbit anti-European catfish virus antibody diluted to 1:1800 in PBS buffer with 2.5\% BSA for $1 \mathrm{~h}$ at room temperature. After washing three times with PBS-Tween $0.1 \%$, a biotinylated goat anti-rabbit IgG antibody (Vector, Burlingame, CA, USA) diluted to 1:250 in TBS buffer with 2.5\% BSA was added and followed by a 30-minute incubation period. The slides were then washed with PBS-Tween three 
times, incubated with Avidin-Biotin Complex (Dako, Palo Alto, CA, USA) diluted to 1:250 in PBS buffer for $30 \mathrm{~min}$ at room temperature, washed with PBS for $5 \mathrm{~min}$ and a chromogen substrate (AEC) was added (Dako, Palo Alto, CA, USA) for $8 \mathrm{~min}$. Afterwards, the slides were placed in running tap water for $5 \mathrm{~min}$ and counterstained with hematoxylin for $1 \mathrm{~min}$. Finally, after a $10 \mathrm{~min}$ bath in running tap water, the slides were mounted with Aquatex (Merck, Kenilworth, NJ, USA) and examined under a light microscope. Negative controls included tissues from non ranavirus-infected amphibians, tissues omitting primary or secondary antibody and an isotype control.

\subsection{DNA Extraction, PCR and Sequencing}

DNA extraction was performed at the Laboratory of Pathology and Molecular Diagnosis (IPN) in Sinaloa, Mexico. This was done using 3\% acetyl trimethyl ammonium bromide (CTAB) buffer (Tris $\mathrm{HCl} 100 \mathrm{mM}$ pH 8.0, EDTA $20 \mathrm{mM}, \mathrm{NaCl} 1.4 \mathrm{M} \mathrm{CTAB} 3 \% w / v)$ added with $0.2 \%(v / v)$ $\beta$-mercaptoethanol [24].

Each sample was separately ground with a pestle in a $1.5 \mathrm{~mL}$ microtube and incubated at $60{ }^{\circ} \mathrm{C}$ for $30 \mathrm{~min}$. Then, a mix (24:1) of chloroform-isoamyl alcohol was added to denature proteins and centrifuged (13,000 rpm, $10 \mathrm{~min})$ to separate the aqueous phase containing nucleic acids. This was transferred to a new tube and nucleic acids were precipitated with cold isopropyl alcohol and centrifuged as above. The pellet was washed with cold 70\% ethanol, centrifuged and supernatant decanted. Nucleic acids were air dried and dissolved in $70 \mu \mathrm{L}$ nuclease-free water. Concentration was measured by nano-spectrophotometry (nanodrop 2000c, Thermo Scientific, Waltham, MA, USA).

For the PCR analyses, the primers used were those designed by Mao et al., which target a portion of the viral major capsid protein gene [25]. The PCR volume was $50 \mu \mathrm{L}$. A PCR mix was done using a DreamTaq DNA polymerase (Thermo Fisher Scientific, Waltham, MA, USA) containing $5 \mu \mathrm{L}$ of DreamTaq PCR Green buffer $(10 \times)$, the respective forward $(1 \mu \mathrm{L})$ and reverse $(1 \mu \mathrm{L})$ primer pairs and $40.5 \mu \mathrm{L}$ nuclease-free water. One $\mu \mathrm{L}$ of DNA template was added to each reaction. A positive and a negative control (distilled water) were included.

Amplification conditions were: an initial DNA denaturation step at $95{ }^{\circ} \mathrm{C}$ for $3 \mathrm{~min}$, followed by 35 cycles at $95^{\circ} \mathrm{C}$ for $30 \mathrm{~s}$, annealing at $49^{\circ} \mathrm{C}$ for all primers used and extension at $72{ }^{\circ} \mathrm{C}$ for $60 \mathrm{~s}$. A final extension at $72{ }^{\circ} \mathrm{C}$ for min was included. PCR products were resolved in a $1 \%$ agarose gel in tris $\mathrm{HCl}$, acetic acid EDTA (TAE) buffer and visualized in a Gel Doc XR+ documentation system (BioRad, Inc., Hercules, CA, USA).

The resulting PCR products were purified using a ExoSAP-IT ${ }^{\circledR}$ PCR Product Cleanup kit (GE Healthcare, Santa Clara, CA, USA) and sent for Sanger sequencing at (Macrogren, Amsterdam, NL, USA). The sequence was used for multiple sequence alignment and phylogenetic analyses.

\subsection{Phylogenetic Analysis}

For phylogenetic analysis, five partial ranavirus genes were selected (13R, 16L/MCP, 22L, 59R and $82 \mathrm{~L}$ ). The partial gene sequences of the Mexican ranavirus were compared to those of 20 other members of the family Iridoviridae. The DNA sequences were aligned using the software CLUSTAL Omega with default settings (https:/ / www.ebi.ac.uk/Tools/msa/clustalo/) [26]. Maximum likelihood phylogeny was re-constructed with the software MEGA 6.0 using 1000 bootstrap replicates. The best-fit model Kimura 2 parameter + Gamma distribution $(\mathrm{K} 2+\mathrm{G})$ was chosen based on the lowest Bayesian Information Criterion score.

\subsection{Risk Classification Using the PANDORA + Protocol}

To assess the risks that ranavirus would pose for the wild endemic amphibians in Sinaloa, Mexico, the Pandora ${ }^{+}$protocol was used [27]. This protocol is specific for invasive microbes and complies with EU regulations for risk assessment that supports the listing of invasive alien species. This program originates from the Invasive Species Environmental Impact Assessment protocol (ISEIA) [28]. The ISEIA protocol was previously used to perform a risk analysis on ranaviruses 
in The Netherlands [29]. The protocol consists of a questionnaire (20 questions) covering distinct modules which include entry, exposure, and consequences for various targets including environment, plants, domestic animals, and humans. Each question classifies the risk as low, medium, or high with a corresponding low, medium, or high level of confidence. Default settings of the Pandora ${ }^{+}$ program were used. In the default settings, each alternative answer to a question from a module is ranked 0-1 (lowest to highest) and then the arithmetic mean of the questions are calculated to obtain a value for each module. An equal weight value of 1 was allocated to each of the questions. The exposure/entry score is calculated by taking the geometric mean of the emerging/entry and emerging/exposure modules. The scores from the different impact/consequence modules are similarly aggregated to calculate a general consequence score by using the geometric mean from each module. Finally, the overall risk score is calculated by multiplying the exposure/entry score by the consequence score. The overall risk score may be: low (0-0.25), medium (0.25-0.50), high (0.50-0.75), and very high (0.75-1.00). Four of the coauthors, each with a particular area of expertise (biology, virology, veterinary pathology, and ecology) performed the risk assessment separately and later unified criteria to provide a consensus risk score.

\subsection{Level of Wild Species Threat}

The level of ranavirus infection threat from each of the amphibian species within the province of Sinaloa was evaluated by consulting the species status in the IUCN Red List (International Union for Conservation of Nature) [1] and the Environmental Vulnerability Score (EVS), which is an algorithm comprised of three scales of added values which consist of geographical distribution (score range 1-6), ecological distribution based on types of forest formations (score range 1-8), and reproductive mode which takes into account type of wetlands where larvae develop and in which egg masses are laid (score range 1-5). Once these elements are added, the score range can be from 3 to 19, this allows to categorize the threat as low (3-9), medium (10-13), and high (14-19) [30].

\section{Results}

External macroscopic lesions of affected individuals included skin hemorrhages and ulcerations (Figure 2A), while internal inspection of the coelomic cavity revealed multiple lesions including hepato-splenomegaly, hepatic necrosis, and epicardial hemorrhages (Figure 2B).
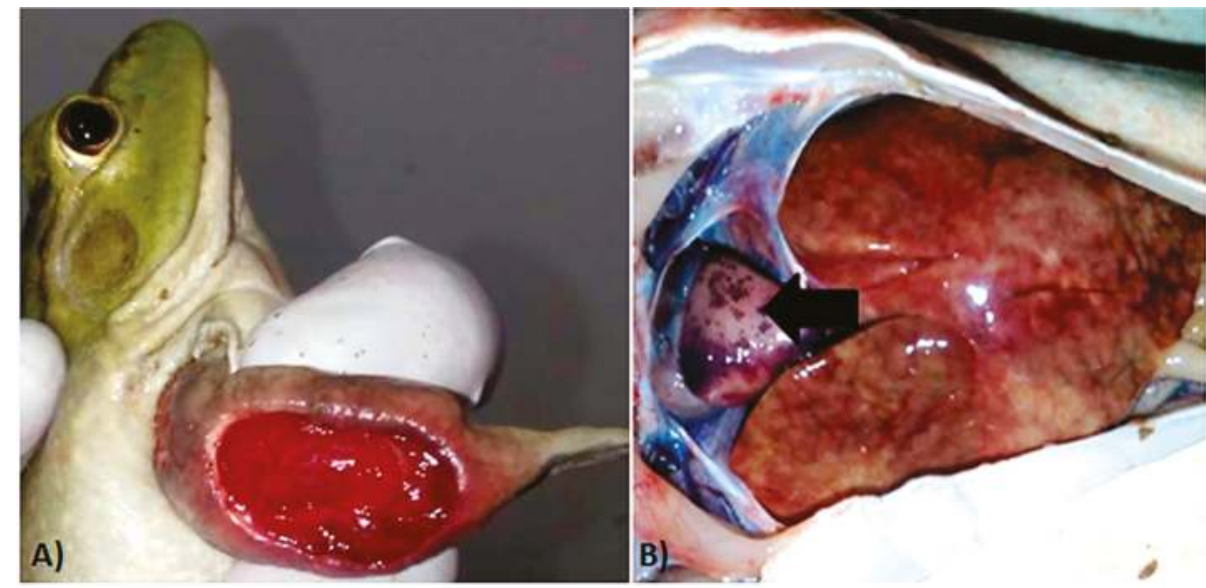

Figure 2. Macroscopic lesions of ranavirus-infected bullfrogs. (A) Extensive ulceration of the forelimb. (B) Extensive hepatic necrosis and epicardial pallor and hemorrhages (black arrow). 
Most of the microscopic lesions in organs from examined specimens were moderate and consisted primarily of congestive changes (Figure $3 \mathrm{~A}$ ) with the exception of the kidney which had multifocal areas of mild tubular necrosis and intraluminal eosinophilic protein casts (Figure 3B).

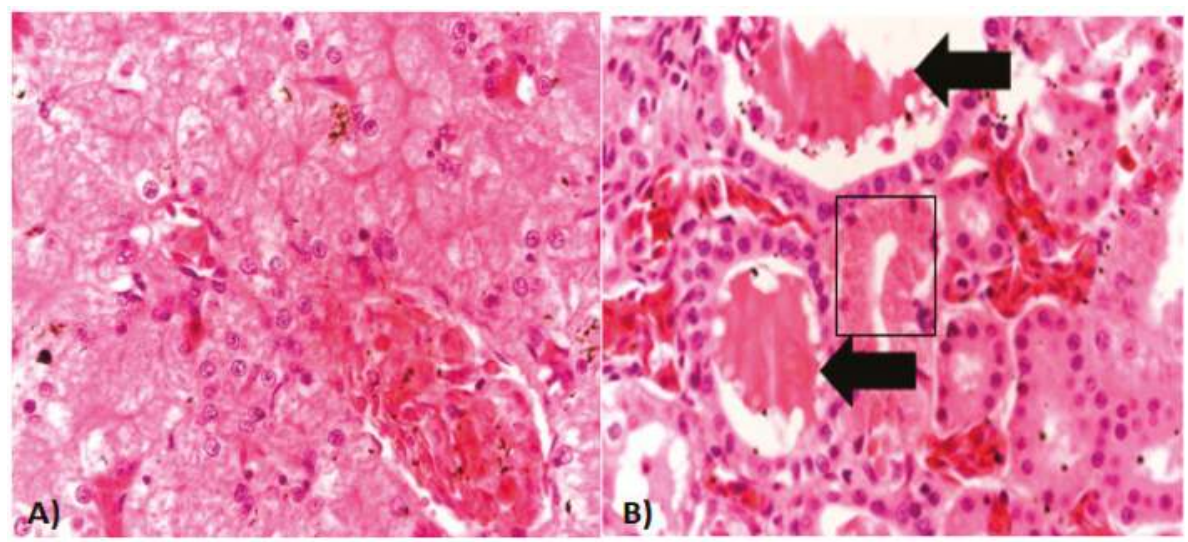

Figure 3. Histopathology of ranavirus-infected American bullfrogs. (A) Liver section from an affected bullfrog with mild congestion of sinusoids. (B) Kidney section shows an area of mild tubular necrosis characterized by cytoplasmic hyper-eosinophilia, loss of nuclei, and mild nuclear pyknosis (black square). Intraluminal protein casts are also seen (black arrows). Hematoxylin/Eosin staining. Magnification for all photos $20 \times / 100 \mu \mathrm{m}$.

Intracytoplasmic inclusion bodies, which are considered the microscopic hallmark of ranavirus disease $[9,10]$, were not observed in any of the specimens examined. Areas of positive immunohistochemical staining were scant and were only found in a few Kupffer cells of the liver (Figure 4A) and in the cortical interstitium of the kidney (Figure 4B). Initial PCR on samples from five frogs showed mild to strong positive signal in both liver and kidney of three frogs, mild positive signal in the liver of one frog, and one frog negative in all organs PCR bands for all five partial genes were from similar size to an FV3 isolate used as a positive control (GenBank no. KT003504) [31] (Figure 5). Phylogeny of five partial ranavirus genes revealed that the Mexican isolate clustered within the FV3 group and was closely related to USA isolates FV3 (AY548484) [32], FV3 SSME (KJ175144) [33], and a Nicaraguan isolate (MF360246) [31] (Figure 6). Sanger sequencing of a portion of the major capsid protein (462 bp) [25] showed that the ranavirus involved in this outbreak shared a 100\% nucleotide homology with the original frog virus 3 isolate from the United States (AY 548484) [31]. The GenBank accession numbers for the Mexican virus sequences and the genomic identity to the ranavirus strains used for phylogeny are available as Supplementary Table S1.

The results of the Pandora ${ }^{+}$protocol showed a high overall risk score for endemic amphibians in neighboring areas (overall risk score 0.619 , confidence level 1). The risk of entry of the pathogen through animals harboring subclinical infections or through virions in water was found to be medium (risk score 0.5, confidence level 1), given that waste water disposal of the farm is through the general sewage system without the water undergoing any prior disinfection treatment. Additionally, there is also the possibility of human-mediated transport and subsequent introduction of the virus if virions persist in footwear from employees. The possibilities of the pathogen to emerge, become established, and affect native amphibian populations were also found to be high (consequence score 0.875 , confidence level 1) due to susceptible amphibian species present in the area. Since the pathogen does not affect plants or warm-blooded domestic animals or humans, the risk score for all these factors was classified as inapplicable. 


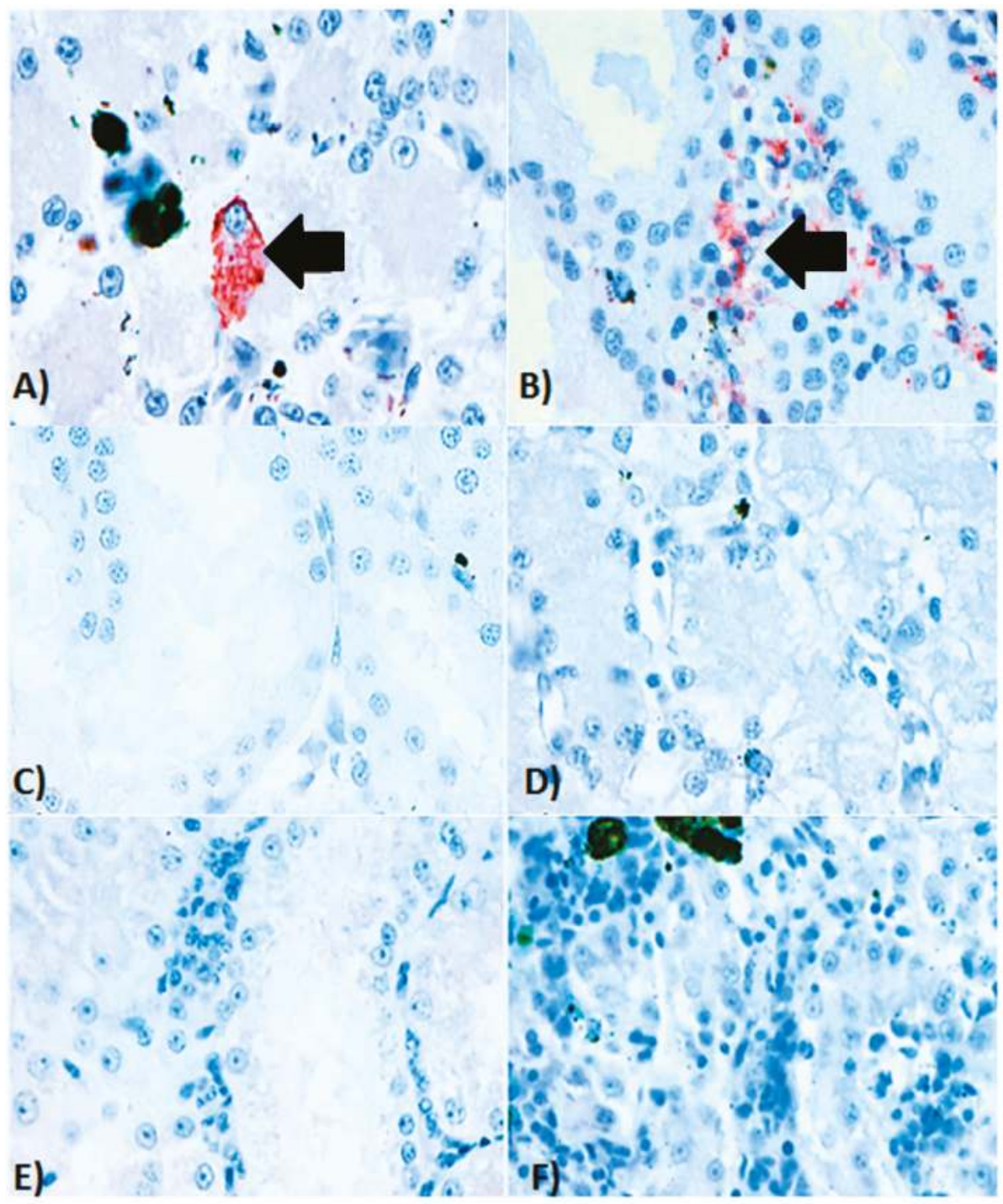

Figure 4. Immunohistochemistry of ranavirus-infected American bullfrogs (Lithobates catesbeianus). (A) Immunohistochemical staining of kidney, in which positive immunolabelling (red staining) is present in the renal cortical interstitium along with areas of necrosis and scant inflammation. (B) Immunohistochemical staining of a liver from an affected bullfrog with a focal area of positive immunolabelling (red staining) in the cytoplasm of a Kupffer cell. (C) Serial section of the kidney from the same animal without secondary antibody (control), (D) Serial section of liver from the same animal without secondary antibody (control). (E) Histological kidney section from an anuran which was PCR negative for ranavirus infection (control). (F) Histological liver section from an anuran which was PCR negative for ranavirus infection (control). Magnification for all photos $40 \times / 50 \mu \mathrm{m}$. 


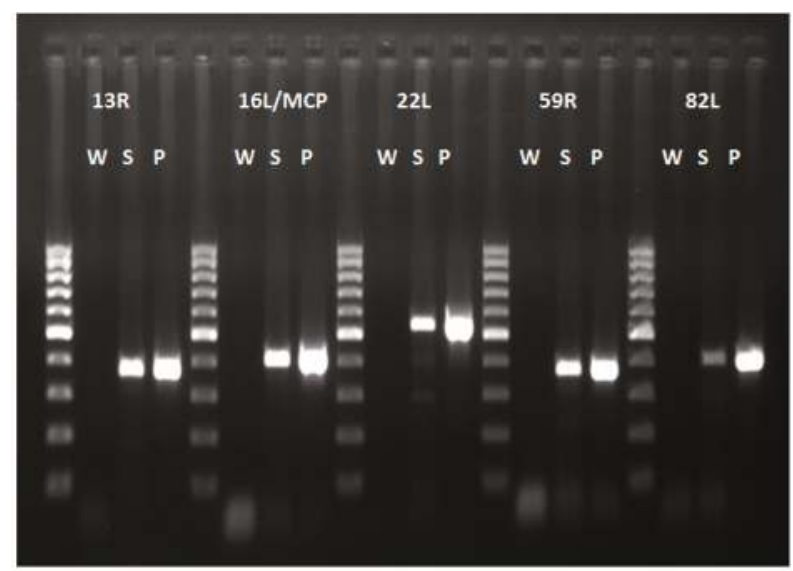

Figure 5. PCR products of five ranavirus genes. All products of the Mexican virus samples (S) are of similar size to those of the FV3 virus positive control (P). Abbreviations: W (water), S (Mexican virus sample), P (Positive control frog virus 3 isolate Oophaga pumilio/2015/Netherlands/UU3150324001 (GenBank no. MF360246)). 100 bp ladder.

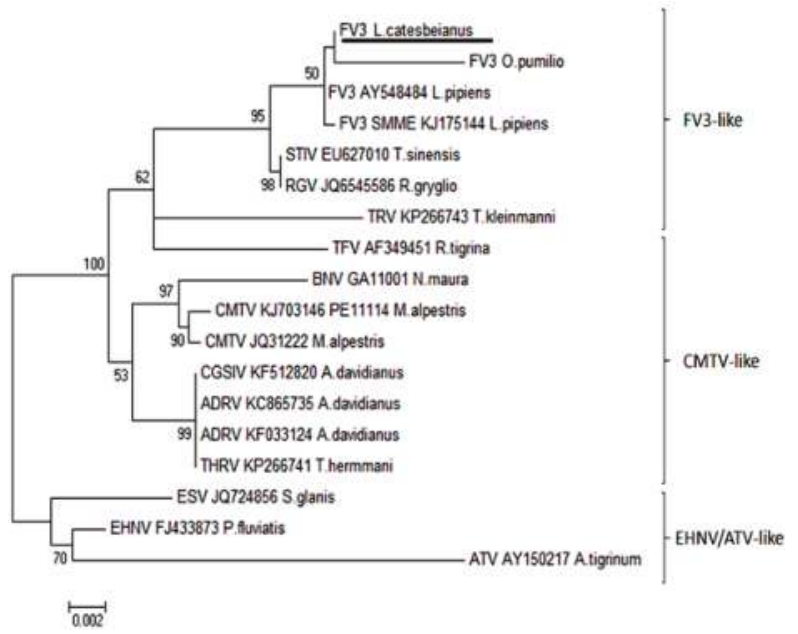

Figure 6. Phylogeny of five partial ranavirus gene sequences (1000 bootstrap values). The Mexican isolate FV3 L. catesbeianus (underlined) clusters closely within the FV3 ranavirus clade. Isolates and Genbank numbers used: Frog virus 3/Lithobates catesbeianus/2018/Mexico (GenBank accession numbers for partial sequences available in Supplementary Table S1), frog virus 3 (AY548484), frog virus 3 isolate SMME (KJ175144), tortoise ranavirus isolate 1 (882/96) (KP266743), Bosca's newt virus isolate GA11001 (KJ703118), frog virus 3 isolate Oophaga pumilio/2015/Netherlands/UU3150324001 (MF360246), common midwife toad ranavirus isolate Mesotriton alpestris / 2008/E (JQ231222), common midwife toad virus isolate P11114 (KJ703146), Testudo hermanni ranavirus isolate CH8/96 (KP266741), tiger frog virus (AF389451), soft-shelled turtle iridovirus (EU627010), European sheatfish virus (JQ724856), epizootic hematopoietic necrosis virus (FJ433873), Ambystoma tigrinum stebbensi virus (AY150217), Andrias davidianus ranavirus isolate (KF033124), Andrias davidianus ranavirus isolate 1201 (KC865735), Chinese giant salamander iridovirus, isolate CGSIV-HN1104, (KF512820), and Rana grylio virus (JQ654586). Only bootstrap values higher than 50 are shown. 
Finally, given the potential effects of ranavirus on the ecosystem, like the disappearance of endangered amphibian specimens or the possible increase in insect plagues, there is a low chance that the pathogen may have an indirect effect on tourism of the area. Furthermore, even though there is no current indication that the farm exports frogs out of Mexico, the risk of virus introduction through trade of sub-clinically infected animals cannot be entirely discarded (low risk, score 0.25 , confidence score 0.5 ). A summary of the results of the scoring and confidence values is provided in Table 1 . The original questionnaires and final risk scores provided by all four experts are available as Supplementary Tables S2-S5.

Table 1. Consensus risk classification of frog virus 3 ranavirus in Mexico. The Pandora ${ }^{+}$questionnaire was solved as a consensus after all four experts had provided their individual results and discussed answers. Total number of questions: 20. Out of these, six questions comprised the initial assessment, one endemic exposure, one emerging/entry, two emerging/exposure, and two questions per each module of impact (environment, plants, animal, human and other). Color scheme and risk classification is based on cut-off values for scores by Schiphouwer et al. [28].

\begin{tabular}{ccccc}
\hline Module & Risk Classification & Risk Score & Certainty & Confidence \\
\hline Emerging/entry & Medium & 0.5 & Medium & 0.5 \\
Emerging/exposure & High & 1 & Medium & 0.75 \\
Environmental score & High & 0.875 & High & 1 \\
Plant score & $\mathrm{n} / \mathrm{a}$ & 0 & High & 1 \\
Animal score & $\mathrm{n} / \mathrm{a}$ & 0 & High & 1 \\
Human score & $\mathrm{n} / \mathrm{a}$ & 0 & High & 1 \\
Other score & Low & 0 & Medium & 0.5 \\
Consequence & High & 0.875 & & \\
Entry exposure & High & 0.707 & & \\
Risk score & High & 0.619 & &
\end{tabular}

$\mathrm{n} / \mathrm{a}$ inapplicable.

Comparison of the information on the threat categories for all 40 amphibian species in Sinaloa based on the IUCN list and the environmental vulnerability scores (EVS) revealed moderate differences in terms of threat classification. The IUCN list showed that $77.5 \%$ of the species were categorized as of least concern, $10 \%$ of them were not listed, $5 \%$ were considered vulnerable, $5 \%$ were classified as endangered and $2.5 \%$ as nearly threatened. On the other hand, in terms of environmental vulnerability, the EVS system categorized $45 \%$ of the species as having low vulnerability, $40 \%$ as medium, and $20 \%$ as high. All families to which the species belonged to, except for Eleutherodactylae and Microhylidae, have been reported to be affected by ranaviruses [6]. Out of the 19 amphibian species within $50 \mathrm{~km}$ or less of the original outbreak, the Tarahumara frog (Lithobates tarahumarae) and the Bell's salamander (Isthmura bellii) were considered vulnerable and the others as least concern by the IUCN red list. With the EVS system, the little Mexican toad (Anaxyrus kelloggi) was considered at high risk (>14 EVS), eight other species were considered as medium risk and the rest as low risk. Information regarding the level of threat of amphibian species in Sinaloa and the approximate distance of species distribution to the outbreak site can be found in Table 2 . 


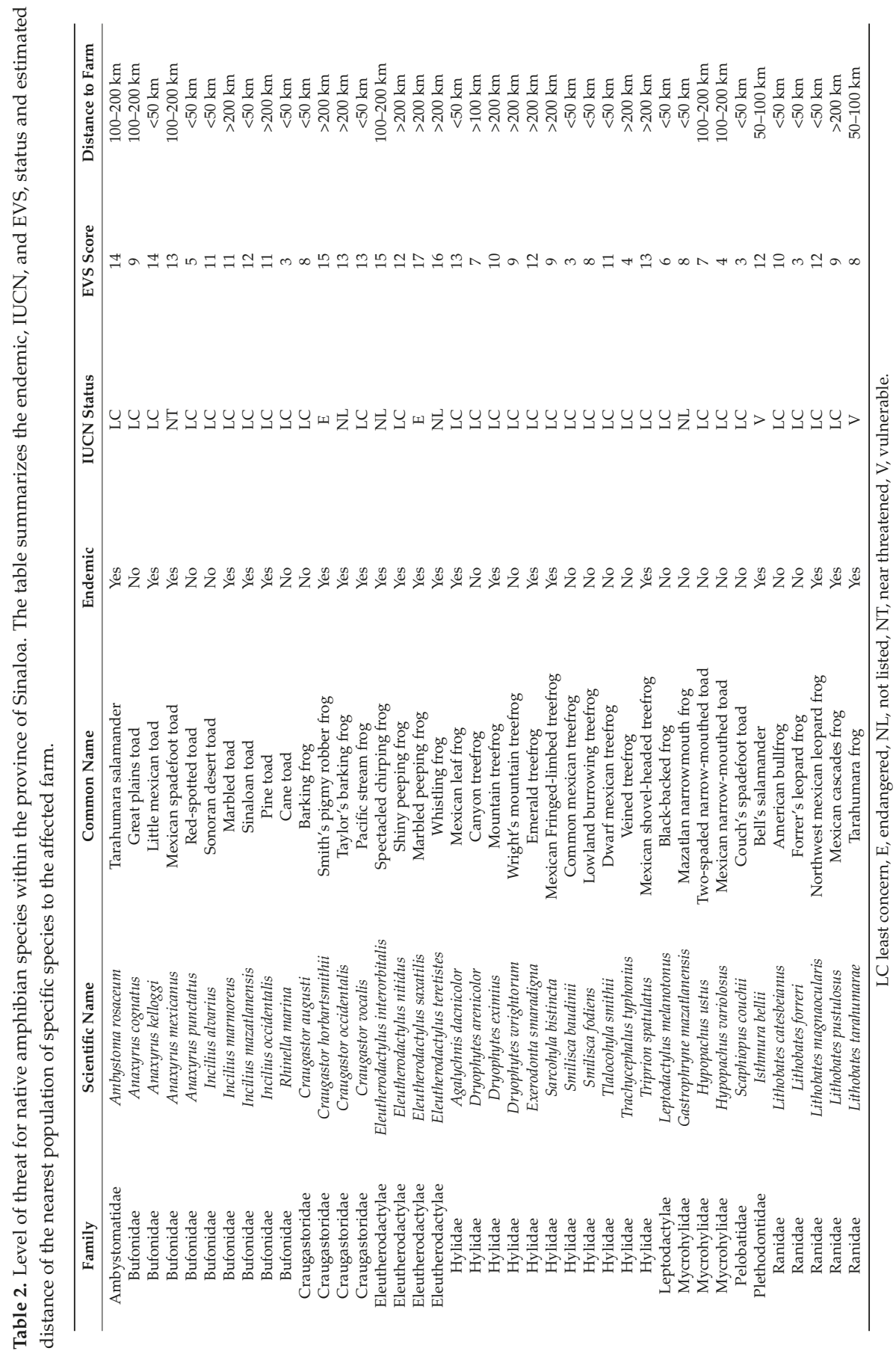




\section{Discussion}

This study investigated the first outbreak of ranavirus infection in Mexico and performed a risk analysis for the endemic wild amphibian species in the area close to the affected farm. The ranavirus outbreak took place in a farmed colony of American bullfrogs and was caused by a ranavirus clustering within the FV3 group, the dominant clade of ranaviruses present on the American continent [6].

One of the most concerning aspects of American bullfrogs is their potential to introduce high-risk pathogens such as ranavirus and Batrachochytrium dendrobatidis into amphibian populations [34]. Breeding facilities for these animals are considered hotspots for ranavirus outbreaks as shown in various countries such as Brazil and Japan [35,36]. Frequently, ranavirus is introduced to captive amphibian populations by means of capture of infected animals from the wild. This has taken place in Switzerland, in which a ranavirus-outbreak in a laboratory colony of water frogs (Pelophylax spp.) was shown to originate from a ranavirus-infected frog captured from a natural pond in Germany [17].

Despite the severe gross lesions (skin ulceration and erythema), affected animals sampled from this farm showed only scant immunohistochemical signal in the liver and kidney and no intracytoplasmic inclusion bodies in histology. The lack of inclusion bodies is a well-known feature of bullfrog ranavirus-associated outbreaks in farms $[35,36]$. The faint immunohistochemical signal observed in the kidneys and liver could be consistent with a chronic presentation of the disease where the most severe lesions have probably resolved in visceral organs, but skin lesions persist as severe ulcerations. This chronic presentation of the disease has also been known as "ulcerative syndrome", reported in common frogs (Rana temporaria) in the United Kingdom infected with FV3-like ranavirus isolates [37]. Investigation focusing on immunohistochemical analyses on animals with this condition revealed overall decrease in signal on visceral organs in comparison to animals with the per-acute or acute presentations of the disease, known as "hemorrhagic syndrome" [37].

Independent assessment of introduction and establishment risk of ranaviruses into Mexican wildlife by all four experts showed similar scoring results in the Pandora + protocol. Consensus analysis suggested that the possibilities of the pathogen being introduced into nature by bullfrogs escaping the facility was moderate (0.5). Bullfrogs are quick to colonize new habitats and capable of long-distance dispersal (>1200 meters in a week) [38]. This phenomenon has occurred precisely in the study area.

In 1956, the American bullfrog was introduced for exploitation as a harvestable food item in the vicinity of Los Mochis, Ahome (approximately $60 \mathrm{~km}$ north of Guasave) [39]. Only six years later, there were several populations among Ahome and Guasave counties established on agricultural irrigation channels and in ponds [40]. Such a colonization presents a threat to native amphibian species as it enables bullfrogs to become into direct contact with susceptible hosts.

Other than introduction through infected hosts, ranavirus can also gain entry into the wild through virion-contaminated water [41]. At the facility where the outbreak took place, untreated water is usually disposed through the general sewage system. It is possible that this potentially contaminated water could reach natural ponds and pools which are home to susceptible host species and are thus apt for ranavirus transmission and persistence.

The probability of the virus becoming endemic within native amphibian populations was found to be high mainly due to the amphibian species present in the area. In total, 17 species are found in the county of Guasave, and most of them live permanently or reproduce in the water, except for Barking frog (Craugastor augusti) that reproduces and lives in a terrestrial environment. Among these species, the little Mexican toad (Anaxyrus kelloggi) was found to possess a high vulnerability score [30]. Members of the family Bufonidae, to which the little Mexican toad belongs to, have been known to develop ranavirus-associated hemorrhagic syndrome when exposed to FV3 ranavirus strains in the UK [37].

The two families of anurans in which the highest amount of infected species have been reported are Ranidae and Hylidae [6]. Within the Ranidae family, one of the most prevalent amphibian species 
in the region is the Northwest Mexican leopard frog (Lithobates magnaocularis) and one of the most vulnerable ones according to the EVS is the Tarahumara frog [30].

Ranavirus has been able to establish itself among populations of other amphibian species from the genus Lithobates, like the Northern leopard frog (Lithobates pipiens) [42] and the Dusky gopher frog (Lithobates sevosus), in which it has caused $100 \%$ mortality under experimental settings [43]. Regarding the family Hylidae, and in contrast to all other endemic amphibian species in Guasave, the Mexican leaf frog (A. dacnicolor) has actually shown evidence of population declines throughout Mexico [1]. This is of particular concern, since other members of Hylidae, like the magnificent tree frog (Litoria splendida) and green tree frog (Hyla cinerea) have suffered severe outbreaks of ranavirus disease under captive settings [44]. Likewise, larval stages of the Cope's gray tree frog (Dryophytes chrysoscelis) have shown a high mortality rate upon experimental exposure to FV3 ranavirus highlighting the species susceptibility to develop lethal infections [45].

However, the risk of ranavirus infection is not only limited to amphibians, and the possibility of transmission from infected amphibians to susceptible fish in neighboring ponds is supported by previous evidence of ranavirus outbreaks affecting both fish and frogs and experimental interspecies transmission of ranaviruses. In the wild in the USA, an FV3-like virus caused a die-off simultaneously involving threespine stickleback fish (Gasterosteus aculeatus) and red-legged frogs (Rana aurora) [46]. Under experimental conditions, Bohle iridovirus (BIV), a ranavirus originally isolated from the ornated burrowing frog (Limnodynastes ornatus), induced infection and mortality of barramundi fish (Lates calcarifer) [47].

There is also a high probability of the virus to persist in the area due to suitable environmental conditions. The climate of the region where the outbreak took place is mostly warm and dry with an average temperature of $24^{\circ} \mathrm{C}$ which can surpass $30^{\circ} \mathrm{C}$ in the summer months [48]. Warm temperatures of around $20^{\circ} \mathrm{C}$, have been shown to favor ranavirus propagation and worsen signs of ranavirus disease under experimental settings [49]. Additionally, virions of Bohle iridovirus, an FV3-like ranavirus, have been known to persist in desiccated soil under a temperature of $45^{\circ} \mathrm{C}$ [50]. Research has also shown that virions are able to remain infectious in waterbodies for up to one or two months in water temperatures ranging from $4{ }^{\circ} \mathrm{C}$ to $20^{\circ} \mathrm{C}$ [41].

There are several measures which could be undertaken to prevent further spread into the wild. Most importantly, culling and re-stocking of animals within the farm would ensure eradication of not only animals harboring active infections but also of sub-clinically infected carriers.

Subsequent disinfection of the facilities, equipment or footgear of employees and especially waste-water treatment with cleaning agents like Virkon (at a 1\% concentration) would aid in eliminating infectious virions present in the water or soil. Monitoring of amphibian populations and molecular analysis of skin swabs from a subset of animals from nearby ponds has shown to be an effective way of gaining information regarding genotype, virulence, and probability of further spread [51]. Another efficient way of monitoring and eventually controlling potential ranavirus disease outbreaks is by informing and encouraging the public to report amphibian die-offs or to keep tract of the number and life-stages of these animals in nearby ponds. Long-term science projects involving citizens have proven to be a successful approach to studying and characterizing this disease in wild amphibians in Great Britain [52].

The current study characterized the first ranavirus outbreak in captive Mexican amphibians through pathology and molecular biology. It also determined a high level of risk of the pathogen to gain entry and become established in neighboring nature areas and potentially affect endemic amphibian species of conservation concern.

Supplementary Materials: The following are available online at http://www.mdpi.com/1999-4915/11/1/26/s1, Table S1: Comparison of genomic identity between Mexican ranavirus and other ranaviruses, Tables S2-S5: Risk assessment $2-5$.

Author Contributions: B.S., M.J.M., R.S.E.W.L., A.A.R.G., A.G. and C.M.E.-B. conceived and designed the experiments; B.S., M.J.M, C.M.E.-B., A.M.B. and J.M.S. performed the experiments B.S., J.M.S., M.J.M., R.S.E.W.L., 
S.J.v.B., C.M.E.-B., and A.M.B. analyzed the data; A.G., R.S.E.W.L., S.J.v.B. and J.M.S. contributed with analysis tools and reagents., B.S. wrote the paper.

Acknowledgments: We thank Alphons van Asten, Jolianne M. Rijks, Margriet Montizaan, Teresa de Jesús López, and Alinda Berends for their excellent technical and logistical support.

Conflicts of Interest: The authors declare no conflict of interest.

\section{References}

1. IUCN 2017. The IUCN Red List of Threatened Species. Version 2017-3. Available online: http://www. iucnredlist.org (accessed on 5 December 2017).

2. Bower, D.S.; Lips, K.R.; Schwarzkopf, L.; Georges, A.; Clulow, S. Amphibians on the brink. Science 2017, 357, 454-455. [CrossRef] [PubMed]

3. Blaustein, A.R.; Kiesecker, J.M. Complexity in conservation: Lessons from the global decline of amphibian populations. Ecol. Lett. 2002, 5, 597-608. [CrossRef]

4. Chinchar, V.G. Ranaviruses (family Iridoviridae): Emerging cold-blooded killers. Arch. Virol. 2002, 147, 447-470. [CrossRef] [PubMed]

5. Mendoza-Almeralla, C.; Burrowes, P.; Parra-Olea, G. Chytridiomycosis in amphibians from Mexico: A revision. Rev. Mex. Biodivers. 2015, 86, 238-248. [CrossRef]

6. Duffus, A.L.J.; Waltzek, T.B. Distribution and Host Range of Ranaviruses. In Ranaviruses: Lethal Pathogenics of Ectothermic Vertebrates, 1st ed.; Gray, M.J., Chinchar, G.V., Eds.; Springer: New York, NY, USA, 2015; Volume 1, pp. 9-57, ISBN 978-3-319-13755-1.

7. Epstein, B.; Storfer, A. Comparative genomics of an emerging amphibian virus. G3 Genes Genom. Genet. 2016, 6, 15-27. [CrossRef] [PubMed]

8. Wheelwright, N.T.; Gray, M.J.; Hill, R.D.; Miller, D.L. Sudden mass die-off of large population of wood frog (Lithobates sylvaticus) tadpoles in Maine, USA, likely due to ranavirus. Herpetol. Rev. 2014, 45, 240-242. [CrossRef]

9. Balseiro, A.; Dalton, K.; del Cerro, A.; Marquez, I.; Cunningham, A.A.; Parra, F.; Prieto, J.M.; Casais, R. Pathology, isolation and molecular characterisation of a ranavirus from the common midwife toad Alytes obstetricans on the Iberian Peninsula. Dis. Aquat. Org. 2009, 84, 95-104. [CrossRef]

10. Kik, M.; Martel, A.; van der Sluijs, A.S.; Pasmans, F.; Wohlsein, P.; Gröne, A.; Rijks, J.M. Ranavirus-associated mass mortality in wild amphibians, The Netherlands, 2010: A first report. Vet. J. 2011, 190, 284-286. [CrossRef]

11. Miaud, C.; Pozet, F.; Gaudin, N.C.G.; Martel, A.; Pasmans, F.; Labrut, S. Ranavirus causes mass die-offs of alpine amphibians in the Southwestern Alps, France. J. Wildl. Dis. 2016, 52, 242-252. [CrossRef]

12. He, J.G.; Lu, L.; Deng, M.; He, H.H.; Weng, S.P.; Wang, X.H.; Zhou, S.Y.; Long, Q.X.; Wang, X.Z.; Chan, S.M. Sequence analysis of the complete genome of an iridovirus isolated from tiger frog. Virology 2002, 292, 185-197. [CrossRef]

13. Lei, X.Y.; Ou, T.; Zhu, R.L.; Zhang, Q.J. Sequencing and analysis of the complete genome of Rana grylio virus (RGV). Arch. Virol. 2012, 157, 1559-1564. [CrossRef] [PubMed]

14. Geng, Y.; Wang, K.Y.; Zhou, Z.Y.; Li, C.W.; Wang, J.; He, M.; Yin, Z.Q.; Lai, W.M. First report of a ranavirus-associated with morbidity and mortality in farmed Chinese giant salamanders (Andrias davidianus). J. Comp. Pathol. 2011, 141, 95-102. [CrossRef] [PubMed]

15. Marschang, R.E.; Becher, P.; Posthaus, H.; Wild, P.; Thiel, H.J.; Müller-Doblies, U.; Kalet, E.F.; Bacciarini, L.N. Isolation and characterization of an iridovirus isolated from Hermann's tortoises (Testudo hermanni). Arch. Virol. 1999, 144, 1909-1922. [CrossRef] [PubMed]

16. Whittington, R.J.; Kearns, C.; Hyatt, A.D.; Hengstberger, S.; Rutzou, T. Spread of Epizootic hematopoietic necrosis virus (EHNV) in red fin perch (Perca fluviatilis) in southern Australia. Aust. Vet. J. 1996, 73, 112-114. [CrossRef] [PubMed]

17. Stöhr, A.C.; Hoffmann, A.; Papp, T.; Robert, N.; Pruvost, N.B.M.; Reyer, H.U.; Marschang, R.E. Long-term study of an infection with ranaviruses in a group of edible frogs (Pelophylax kl. esculentus) and partial characterization of two viruses based on four genomic regions. Vet. J. 2013, 197, 238-244. [CrossRef] [PubMed] 
18. Serrano, J.M.; Berlanga-Robles, C.A.; Ruiz-Luna, A. High amphibian diversity related to unexpected environmental values in a biogeographic transitional area in north-western Mexico. Contrib. Zool. 2014, 83, 151-166.

19. Casas-Andreu, G.; Aguilar-Miguel, X.; Cruz-Aviña, R. La introducción y el cultivo de la rana toro (Rana catesbeiana). ¿Un atentado a la biodiversidad de México? Revista Científica Multidisciplinaria de Prospectiva 2001, 8, 62-67.

20. Cifuentes-Lemus, J.L.; Torres-García, M.P.; Frías-Mondragón, M. El Océano y Sus Recursos XI. Acuicultura, 2nd ed.; Serie La ciencia Para Todos; Fondo de Cultura Económica: México City, Mexico, 1997; pp. 1-97, ISBN 968-16-5242-897.

21. Luja, V.H.; Rodrìguez-Estrella, R. The invasive bullfrog Lithobates catesbeianus in oases of Baja California Sur Mexico: Potential effect in a fragile ecosystem. Biol. Invasions 2010, 12, 2979-2983. [CrossRef]

22. Morales-Salinas, E.; Aguilar-Arriaga, B.O.; Ramírez-Lezama, J.; Méndez-Bernal, A.; López-Garrido, S. Oral fibrosarcoma in a black iguana (Ctenosaura pectinata). J. Zoo Wildl. Med. 2013, 44, 513-516. [CrossRef]

23. Rijks, J.M.; Saucedo, B.; Spitzen-van der Sluijs, A.M.; Wilkie, G.S.; van Asten, A.J.A.M.; van den Broek, J.; Boonyarittichaikij, R.; Stege, M.; Van der Sterren, F.; Martel, A.; et al. Investigation of amphibian mortality events in wildlife reveals an on-going ranavirus epidemic in the North of The Netherlands. PLoS ONE 2016, 11, e0157473. [CrossRef]

24. Zhang, Y.; Uyemoto, J.K.; Kirkpatrick, B.C. A small-scale procedure for extracting nucleic acids from woody plants infected with various phytopathogens for PCR assay. J. Virol. Methods 1998, 71, 45-50. [CrossRef]

25. Mao, J.; Hendrick, R.P.; Chinchar, V.G. Molecular characterization, sequence analysis, and taxonomic position of newly isolated fish iridoviruses. Virology 1997, 229, 212-220. [CrossRef]

26. CLUSTAL Omega. Available online: https://www.ebi.ac.uk/Tools/msa/clustalo/ (accessed on 30 August 2018).

27. D’hondt, B.; Vanderhoeven, S.; Roelandt, S.; Mayer, F.; Versteirt, V.; Ducheyne, E.; San Martin, G.; Grégoire, J.C.; Stiers, I.; Quoilin, S.; et al. Pandora: A Risk Screening Tool for Pathogens and Parasites; Belgian Biodiversity Platform: Brussels, Belgium, 2014; pp. 1-22.

28. Schiphouwer, M.E.; Felix, R.P.W.H.; van Duinen, G.A.; de Hoop, L.; de Hullu, P.C.; Matthews, J.; van der Velde, G.; Leuven, R.S.E.W. Risk assessment of the alien smallmouth bass (Micropterus dolomieu). Rep. Environ. Sci. 2017, 527, 1-60.

29. Rijks, J.M.; Spitzen van-der Sluijs, A.; Leuven, R.S.E.W.; Martel, A.; Kik, M.; Pasmans, F. Risk Analysis of the Common Midwife Toad-Like Virus (CMTV-Like Virus) in The Netherlands; Report 60000784-2013; Netherlands Food and Consumer Product Safety Authority (NVWA), Dutch Ministry of Economic Affairs: Utrecht, The Netherlands, 2012.

30. Wilson, L.D.; Johnson, J.D.; Mata-Silva, V. A conservation reassessment of the amphibians of Mexico based on the EVS measure. Amphib. Reptile Conserv. 2013, 7, 97-127.

31. Saucedo, B.; Hughes, J.; Súarez, N.; Haenen, O.; Kik, M.J.L.; van Beurden, S.J. Complete genome sequence of frog virus 3 isolated from a Strawberry poison frog (Oophaga pumilio) imported from Nicaragua into The Netherlands. Genome Announc. 2017, 5, ee00863-17. [CrossRef] [PubMed]

32. Tan, W.G.; Barkman, T.J.; Chinchar, G.V.; Essani, K. Comparative genomic analyses of frog virus 3, type species of the genus Ranavirus (family Iridoviridae). Virology 2004, 323, 70-84. [CrossRef] [PubMed]

33. Morrison, E.A.; Garner, S.; Echaubard, P.; Lesbarreres, D.; Kyle, C.J.; Brunetti, C.R. Complete genome analysis of a frog virus 3 (FV3) isolate and sequence comparison with isolates of differing levels of virulence. Virol. J. 2014, 12, 11-46. [CrossRef]

34. Kolby, J.E.; Smith, K.M.; Berger, L.; Karesh, W.B.; Preston, A.; Pessier, A.P.; Skerratt, L.F. First evidence of amphibian chytrid fungus (Batrachochytrium dendrobatidis) and ranavirus in Hong Kong amphibian trade. PLOS ONE 2014, 3, 1-6. [CrossRef]

35. Mazzoni, R.; Mesquita, A.J.; Fleury, L.F.F.; Brito, W.; Nunes, I.A.; Robert, J.; Morales, H.; Coelho, A.S.G.; Barthasson, D.L.; Galli, L.; et al. Mass mortality associated with a Frog virus 3-like ranavirus infection in farmed tadpoles Rana catesbeiana from Brazil. Dis. Aquat. Org. 2009, 86, 181-191. [CrossRef]

36. Une, Y.; Sakuma, A.; Matsueda, H.; Nakai, K.; Murakami, M. Ranavirus outbreak in North American bullfrogs (Rana catesbeiana), Japan, 2008. Emerg. Infect. Dis. 2008, 15, 1146-1147. [CrossRef] 
37. Cunningham, A.A.; Temns, C.A.; Russel, P.H. Immunohistochemical demonstration of ranavirus antigen in the tissues of infected frogs (Rana temporaria) with systemic hameorrhagic or cutaneous ulcerative disease. J. Comp. Pathol. 2008, 138, 3-11. [CrossRef] [PubMed]

38. Willis, Y.L.; Moyle, P.B.; Basket, T.S. Emergence, breeding, hibernation, movements and transformation of the bullfrog, Rana catesbeiana, in Missouri. Copeia 1956, 1, 30-41. [CrossRef]

39. Aguilar Ibarra, F. Aspectos Generales sobre las Ranas y su Cultivo. Trab. Div. Inst. Nac. Invest. Biol. Pesq. C 1963, 5, 1-21.

40. Hardy, L.M.; McDiarmid, R.W. The amphibians and reptiles of Sinaloa, Mexico. Univ. Kansas Publ. Mus. Nat. Hist. 1969, 18, 39-252. [CrossRef]

41. Nazir, J.; Spengler, M.; Marschang, R.E. Environmental persistence of amphibian and reptilian ranaviruses. Dis. Aquat. Org. 2012, 98, 177-184. [CrossRef] [PubMed]

42. Echaubard, P.; Paulli, B.D.; Trudeau, V.L.; Lesbarrères, D. Ranavirus infection in northern leopard frogs: The timing and number of exposures matter. J. Zool. 2015, 298, 30-36. [CrossRef]

43. Earl, J.E.; Chaney, J.C.; Sutton, W.B.; Lillard, C.E.; Kouba, A.J.; Langhorne, C.; Krebs, J.; Wilkis, R.P.; Hill, R.D.; Miller, D.L.; et al. Ranavirus could facilitate local extinction of rare amphibian species. Oecologia 2016, 182, 611-623. [CrossRef]

44. Jerett, I.V.; Whittington, R.J.; Weir, R.P. Pathology of a Bohle-like infection in two Australian frog species (Litoria splendida and Litoria caerulea). J. Comp. Pathol. 2015, 152, 248-259. [CrossRef]

45. Brand, M.D.; Hill, R.D.; Brenes, R.; Chaney, J.C.; Wilkes, R.P.; Grayfer, L.; Miller, D.L.; Gray, M.J. Water temperature affects susceptibility to ranavirus. Ecohealth 2016, 13, 350-359. [CrossRef]

46. Mao, J.D.E.; Green, G.; Chinchar, V.G. Molecular characterization of iridoviruses isolated from sympatric amphibians and fish. Virus Res. 1999, 63, 45-52. [CrossRef]

47. Moody, N.; Owens, L. Experimental demonstration of the pathogenicity of frog virus, Bohle iridovirus, for a fish species, barramundi, Lates calcariger. Dis. Aquat. Org. 1994, 18, 95-102. [CrossRef]

48. Rodríguez-Meza, D.; Rodríguez Figueroa, G.; Sapozhnikov, D.; Vargas-Ramírez, C.; Vallejo-Soto, A.; Verdugo-Quiñonez, G.; Michel-Rubio, A. Monitoreo de la calidad del agua del acuífero de Guasave, Sinaloa Mexico. Unpublished work, SIP 2008.

49. Price, S.J.; Leung, W.T.M.; Christopher, J.O.; Sergeant, C.; Cunningham, A.A.; Ballous, F.; Garner, T.W.J.; Nichols, R. A. Temperature is a key driver of a wildlife epidemic and future warming will increase impact. bioRxiv 2018. [CrossRef]

50. Jancovich, J.K.; Chinchar, V.G.; Hyatt, A.; Miyazaki, T.; Zhang, Q.Y. Virus Taxonomy: Ninth Report of the International Committee of Taxonomy of Viruses; King, A.M.Q., Adams, M.J., Carstens, E.B., Lefkowitz, E., Eds.; Elsevier Academic Press: Cambridge, MA, USA, 2012; pp. 193-210.

51. Saucedo, B.; Hughes, J.; Spitzen van der Sluijs, A.; Kruithof, N.; Schils, M.; Rijks, J.M.; Jacinto-Maldonado, M.; Suárez, N.; Haenen, O.L.M.; Voorbergen-Laarman, M.; et al. Ranavirus genotypes in The Netherlands and their potential association with virulence in water frogs (Pelophylax spp.). Emerg. Microbes Infect. 2018, 7, 1-56. [CrossRef] [PubMed]

52. Cunningham, A.A.; Langton, T.E.S.; Bennet, P.W.; Lewing, J.F.; Drury, S.E.N.; Gough, R.E.; MacGregor, E.K. Pathological and microbiological findings from incidents of unusual mortality of the common frog (Rana temporaria). Philos. Trans. R. Soc. Lond. B Biol. Sci. 1996, 351, 1539-1557. [CrossRef] [PubMed]

(C) 2019 by the authors. Licensee MDPI, Basel, Switzerland. This article is an open access article distributed under the terms and conditions of the Creative Commons Attribution (CC BY) license (http:/ / creativecommons.org/licenses/by/4.0/). 


\title{
Brief Report \\ Localization of Frog Virus 3 Conserved Viral Proteins $88 \mathrm{R}, 91 \mathrm{R}$, and $94 \mathrm{~L}$
}

\author{
Emily Penny and Craig R. Brunetti * \\ Biology Department, Trent University, 1600 West Bank Dr, Peterborough, ON K9J 7B8, Canada; \\ emily_penny@hotmail.com \\ * Correspondence: craigbrunetti@trentu.ca
}

Received: 11 February 2019; Accepted: 15 March 2019; Published: 19 March 2019

\begin{abstract}
The characterization of the function of conserved viral genes is central to developing a greater understanding of important aspects of viral replication or pathogenesis. A comparative genomic analysis of the iridoviral genomes identified 26 core genes conserved across the family Iridoviridae. Three of those conserved genes have no defined function; these include the homologs of frog virus 3 (FV3) open reading frames (ORFs) 88R, 91R, and 94L. Conserved viral genes that have been previously identified are known to participate in a number of viral activities including: transcriptional regulation, DNA replication/repair/modification/processing, protein modification, and viral structural proteins. To begin to characterize the conserved FV3 ORFs 88R, 91R, and 94L, we cloned the genes and determined their intracellular localization. We demonstrated that $88 \mathrm{R}$ localizes to the cytoplasm of the cell while 91R localizes to the nucleus and 94L localizes to the endoplasmic reticulum (ER).
\end{abstract}

Keywords: Iridoviridae; frog virus 3; FV3; ranavirus; immunofluorescence; intracellular localization

\section{Introduction}

The viral family Iridoviridae are large ( 120-200 $\mathrm{nm}$ in diameter) icosahedral dsDNA viruses that replicate in the cytoplasm and nucleus of infected cells [1]. Iridoviral genomes are terminally redundant and circularly permuted [2-4]. Iridoviruses are known to infect invertebrates as well as poikilothermic vertebrates such as: fish, amphibians, and reptiles [5]. Members of the Iridoviridae, some of which exhibit very high pathogenicity, have been implicated in significant infection events in wild and captive populations, leading to considerable impacts on wildlife conservation, fish farming, and aquaculture [6]. The family Iridoviridae is currently divided into two subfamilies the Alphairidovirinae and Betairidovirinae. The Alphairidovirinae is composed of three genera Lymphocystivirus, Megaloctyivirus, and Ranavirus while the Betairidovirinae is composed of the Chloriridovirus and Iridovirus genera $[7,8]$.

A comparative genomic analysis of members of the family Iridoviridae demonstrated that there are 26 open reading frames (ORFs) that are conserved across all members of the family [9]. While novel genes generally define the unique aspects of the life cycle of a particular virus species, conserved genes are usually related to or play a role in essential mechanisms of the viral life cycle [9-16]. There are a number of functions that conserved genes are commonly involved in including: RNA and DNA synthesis and modification, viral protein processing, and viral structure and assembly [9-16]. The characterization and further understanding of the function of conserved viral genes is central to developing a greater understanding of important aspects of viral replication or pathogenesis.

Frog virus 3 (FV3) is the type species of the genus Ranavirus and is the most extensively studied iridovirus at the molecular level [6]. The FV3 genome, excluding the terminal redundancy, is 105,903 base pairs long and encodes 98 non-overlapping predicted ORFs, which range in size from 50 to 1293 amino acids in length [15]. Although 26 genes are conserved across the family Iridoviridae [9], 
the products of three of the identified core genes do not appear to have a fully characterized function; these include FV3 ORFs 88R, 91R, and 94L [15]. Though the proteins encoded by these 3 ORFS have yet to be fully characterised within the family Iridoviridae, it is likely that their functions are essential based on their highly conserved nature among the iridoviruses.

Sequence homology provides some insight into potential roles for these genes. FV3 88R has similarity to ERV1/ALR (augmenter of liver regeneration) family of proteins [15]. In mammals, ALR is involved in the reduction of renal damage in liver transplant recipients [17]. In viruses, homologues of the ERV1/ALR family of proteins are highly conserved, though poorly characterized [18,19]. Viral ERV1/ALR homologues are thiol oxidoreductases; which are involved in the formation of disulfide bonds and are usually contained in the endoplasmic reticulum (ER) of normal eukaryotic cells $[18,20]$.

In addition to $88 \mathrm{R}$, basic information can be obtained from FV3 91R and 94L sequences. 91R has sequence similarity to immediate-early protein ICP-46 [15]. The FV3 gene 94L has a KKXX-like ER retrieval motif that was identified at the C-terminal of 94L (LRKV). A KKXX motif is responsible for recycling protein from the Golgi complex to the ER [21] suggesting that $94 \mathrm{~L}$ might be localized to the secretory pathway.

In this paper, we propose to begin to characterize these genes by cloning the putative genes and determining the site of intracellular accumulation of the proteins by ectopic expression and microscopic analysis.

\section{Materials and Methods}

\subsection{Isolation of FV3 DNA}

Fathead minnow (FHM) (ATCC CCL-42) cells grown to approximately $80 \%$ confluence were infected with FV3 (American Type Culture Collection, Manassas, VA, USA) at a multiplicity of infection (MOI) of 0.1. When cytopathic effects (CPE) were observed, the cells were harvested and resuspended in $400 \mu \mathrm{L}$ of water. The cells were freeze $\left(-80^{\circ} \mathrm{C}\right)$-thawed 3 times. An equal volume of phenol/chloroform was added to the cells and after mixing by vortexing, the aqueous phase was transferred to a fresh tube. The phenol/chloroform extraction step was repeated twice more. Following transfer, $10 \%(v / v) 5 \mathrm{M}$ sodium acetate and $200 \%(v / v)$ ethanol $(100 \%)$ was added to the tube and the mixture was incubated on ice for $15 \mathrm{~min}$. The viral DNA was then spun at $10,000 \times g$ for $10 \mathrm{~min}$. The pellet of viral DNA was air dried and resuspended in $50 \mu \mathrm{L}$ of water and stored at $-20^{\circ} \mathrm{C}$.

\subsection{Cloning FV3 88R, $91 R$, and $94 L$ into $p$ GEM-T Easy Vector}

Gene specific oligonucleotide primers were designed for FV3 ORFs 88R, 91R, and 94L. The primers were designed to add a HindIII restriction enzyme site at the $5^{\prime}$ end of each gene and a XhoI restriction enzyme site at the $3^{\prime}$ end of each gene (Invitrogen, Burlington, Canada) (Table 1). PCR was then performed using these gene specific primers. In a PCR reaction tube, $1 \times$ PCR buffer (Invitrogen, Burlington, Canada), $3 \mathrm{mM} \mathrm{MgCl}_{2}$ (Invitrogen, Burlington, Canada), 2.5 units of TAQ DNA polymerase at 5 units $/ \mu \mathrm{L}$ (Invitrogen, Burlington, Canada), $0.2 \mathrm{mM}$ dNTPS, $0.1 \mathrm{mM}$ gene specific forward and reverse primers (Table 1), $1 \mu \mathrm{g}$ FV3 DNA and water to a final volume of $50 \mu \mathrm{L}$. The PCR reaction was then placed in a thermocycler for 30 cycles of $94{ }^{\circ} \mathrm{C}$ for $30 \mathrm{~s}, 52{ }^{\circ} \mathrm{C}$ for $30 \mathrm{~s}$ and $72{ }^{\circ} \mathrm{C}$ for $2 \mathrm{~min}$. The PCR product, amplified DNA encoding each target sequence, was ligated into the pGEM-T Easy vector (Promega, Madison, WI, USA) as per the manufacturer's protocol. The reaction was then stored at $4{ }^{\circ} \mathrm{C}$ overnight to ensure optimal ligation. Plasmid vectors were then transformed into DH5- $\alpha$ E. coli cells (Invitrogen, Burlington, Canada) following the manufacturer's protocol and plated on a LB agar plates prepared with $10 \mathrm{mg} / \mathrm{mL}$ tryptone, $5 \mathrm{mg} / \mathrm{mL}$ yeast extract, $10 \mathrm{mg} / \mathrm{mL} \mathrm{NaCl}, 1.5 \%$ agar and $0.1 \%$ ampicillin $(50 \mathrm{mg} / \mathrm{mL})$. Colonies were isolated and screened for the insert. 
Table 1. Oligonucleotide sequences designed to isolate the conserved genes from the frog virus 3 (FV3) genome. Restriction sites were added 3 base pairs upstream of the start codon (HindIII-AAGCTT) and in the place of the stop codon (XhoI-CTCGAG) was added at the $3^{\prime}$ end of each gene.

\begin{tabular}{cc}
\hline Name & Sequence \\
\hline $88 \mathrm{R}-\mathrm{F}$ & $5^{\prime}$-AAGCTTAAAATGCACGGTTGCAATTG-3 \\
$88 \mathrm{R}-\mathrm{R}$ & $5^{\prime}$-CTCGAGGTTAAAAGTGCTCGTATTTG-3' \\
91R-F & $5^{\prime}$-AAGCTTAACATGGCAAACTTTGTGAC-3 \\
91R-R & $5^{\prime}$-CTCGAGGGCTCTGACCACAAACAG-3 \\
94L-F & $5^{\prime}$-AAGCTTGCAATGGATCCAGAAGGAATG-3' \\
94L-R & $5^{\prime}$-CTCGAGCAGCACCTTTCTCAGGTAC-3 ${ }^{\prime}$ \\
\hline
\end{tabular}

\subsection{Cloning of FV3 88R, 91R, and 94L into a Eukaryotic Expression Vector}

Bacteria containing the pGEM T-easy $88 \mathrm{R}, 91 \mathrm{R}$, or $94 \mathrm{~L}$ was grown in LB media $(10 \mathrm{mg} / \mathrm{mL}$ tryptone, $5 \mathrm{mg} / \mathrm{mL}$ yeast extract, $10 \mathrm{mg} / \mathrm{mL} \mathrm{NaCl}$ ) containing $100 \mu \mathrm{g} / \mathrm{mL}$ ampicillin. Plasmid DNA from the bacteria was extracted using a PureLink HiPure Plasmid DNA Purification Kit (Invitrogen, Burlington, Canada) as per the manufacturer's protocol. A restriction enzyme digest was performed on the plasmid DNA to extract the DNA encoding each ORF of interest and the expression vector pcDNA3.1. Briefly, $20 \mu \mathrm{g}$ of pGEM-T Easy plasmid DNA or pCDNA3.1 was digested with 25 units $\mathrm{XhoI}$ at $10 \mathrm{U} / \mu \mathrm{L}$ (Invitrogen, Burlington, Canada) and 25 units of HindIII at $10 \mathrm{U} / \mu \mathrm{L}$ (Invitrogen, Burlington, Canada), $1 \times$ React 2 reaction buffer, and water to a final volume of $70 \mu \mathrm{L}$. The reaction was incubated at $37^{\circ} \mathrm{C}$ overnight. The product of the restriction enzyme digest had $14 \mu \mathrm{L}$ of gel electrophoresis $20 \%$ loading dye added to the reaction tube and the entire reaction was run on a $1 \%$ agarose gel. The fragments of DNA corresponding with each ORF of interest and pcDNA3.1 were then excised from the gel and the DNA was extracted from the agarose gel using the QIAEX II gel extraction kit (Qiagen, Mississauga, Canada) as per the manufacturer's protocol. The product of the gel extraction for each gene of interest was then ligated into the pcDNA3.1 expression vector using a high efficiency T4 DNA ligase (Invitrogen, Burlington, Canada) as per the manufacturer's protocol. The ligation of each of the genes of interest into pcDNA3.1 created the expression constructs containing the gene of interest in frame with a myc tag and are called pcDNA3-88R-myc, pcDNA3-91R-myc, and pcDNA3-94L-myc.

\subsection{Transfection of Eukaryotic Expression Vector into Eukaryotic Cells}

Baby Green Monkey Kidney (BGMK) cells (BGMK-DAF P17, American Type Culture Collection, Manassas, VA, USA) were cultured at $37^{\circ} \mathrm{C}$ in Dulbecco's Modified Eagle's Medium (DMEM; Gibco, Burlington, Canada), which is supplemented with $7 \%(v / v)$ heat-inactivated fetal bovine serum, $1 \%(v / v)$ L-glutamine and $1 \%(v / v)$ penicillin-streptomycin, on glass cover slips in a 6-well plate, to $90-95 \%$ confluence. Eukaryotic expression vectors, pcDNA3-88R-myc, pcDNA3-91R-myc, or pcDNA3-94L-myc, were transfected into cells using Lipofectamine 2000 (Invitrogen, Burlington, Canada). Specifically, $4 \mu \mathrm{g}$ of DNA was diluted in $250 \mu \mathrm{L}$ of serum-free DMEM (1\% $(v / v)$ L-glutamine, $1 \%(v / v)$ penicillin-streptomycin) and mixed gently. $10 \mu \mathrm{L}$ of Lipofectamine 2000 was diluted in $250 \mu \mathrm{L}$ of serum-free DMEM and incubated for $5 \mathrm{~min}$. The diluted DNA and diluted Lipofectamine 2000 were combined, for a total volume of $500 \mu \mathrm{L}$, mixed gently and incubated at room temperature for $20 \mathrm{~min}$. The $500 \mu \mathrm{L}$ of complexes was then added to each well, containing cells and $2 \mathrm{~mL}$ supplemented DMEM growth medium and mixed by gently rocking the plate back and forth. The transfected cells were incubated at $37^{\circ} \mathrm{C}$ for $48 \mathrm{~h}$.

\subsection{Indirect Immunofluorescence}

The transfected cells were fixed and permeabilized 48 hours post-transfection. Specifically, the wells were each washed twice in $2 \mathrm{~mL}$ of phosphate buffered saline solution (Gibco, Burlington, Canada) with a $\mathrm{pH}$ of 7.4 for two minutes each wash. $1 \mathrm{~mL}$ of a $3.7 \%$ paraformaldehyde solution in PBS 
was applied to each well for $10 \mathrm{~min}$ to fix the cells. Upon removal of the paraformaldehyde solution, the wells were washed twice in $2 \mathrm{~mL}$ of PBS for $2 \mathrm{~min}$ each wash. The cells were then incubated with $1 \mathrm{~mL}$ of a $0.1 \%$ Triton $\mathrm{X}-100$ in PBS for $4 \mathrm{~min}$. The cells were then washed twice in $2 \mathrm{~mL}$ of PBS. The cells were then incubated overnight at $4{ }^{\circ} \mathrm{C}$ with $2 \mathrm{~mL}$ of block buffer $(50 \mathrm{mM}$ Tris $\mathrm{HCl}(\mathrm{pH} 6.8), 150 \mathrm{mM}$ $\mathrm{NaCl}, 0.5 \%(v / v) \mathrm{NP}-40,5.0 \mathrm{mg} / \mathrm{mL}$ BSA). The block buffer was removed and the wells were washed twice with $2 \mathrm{~mL}$ of Wash Buffer (50 mM Tris $\mathrm{HCl}$ (pH6.8), $150 \mathrm{mM} \mathrm{NaCl}, 0.5 \%(v / v) \mathrm{N}-40,1 \mathrm{mg} / \mathrm{mL}$ BSA). The cover slips were removed from the well and the primary antibodies were applied to the cells and incubated for $60 \mathrm{~min}$ at room temperature. The primary antibodies used were rabbit anti-myc (Sigma, Saint Louse, USA) diluted to 1:400 in wash buffer, mouse anti-c-myc (Roche, Mississauga, Canada) diluted to 1:400 in wash buffer, and rabbit anti-protein disulfide isomerase (PDI) (Sigma, Saint Louis, MO, USA) diluted to 1:500 in wash buffer. The cells were then washed 3 times with Wash Buffer. Secondary antibodies goat anti-mouse conjugated Cy3 (Jackson ImmunoResearch Laboratories, Inc., West Grove, PA, USA) diluted to 1:200 in Wash Buffer and goat anti-rabbit conjugated fluorescein (FITC) (Jackson ImmunoResearch Laboratories, Inc., West Grove, USA) diluted to 1:200 in Wash Buffer. The cells were incubated at room temperature for $60 \mathrm{~min}$ and were washed 3 times with Wash Buffer. The cells were then incubated with TO-PRO-3 at a dilution of 1:8000 in water (Molecular Probes, Eugene, OR, USA) for $7 \mathrm{~min}$. The cells were washed 3 times in Wash Buffer and then mounted on slides using Vectashield (Vector Laboratories, Burlingame, CA, USA). The slides were then visualized using a Leica TCS SP2 SE confocal microscope. The localization of each gene was confirmed in at least 3 independent transfections. Multiple examples of each gene were visualized, and results were all consistent. The sample images shown are representative and consistent with the staining pattern observed for each gene.

\section{Results}

\subsection{FV3 ORF 88R Localize to the Cytoplasm of Transfected Cells}

To determine the site of $88 \mathrm{R}$ localization, BGMK cells were transfected with pcDNA3-88R-myc and the proteins were visualized by indirect immunofluorescence. The expression of $88 \mathrm{R}$ was found to be distributed throughout the cytoplasm (Figure 1). In particular, the staining of $88 \mathrm{R}$ was punctate, seeming to be evenly distributed throughout the cell (Figure 1). We examined many examples of $88 \mathrm{R}$ staining and they all shared similar cytoplasmic staining.
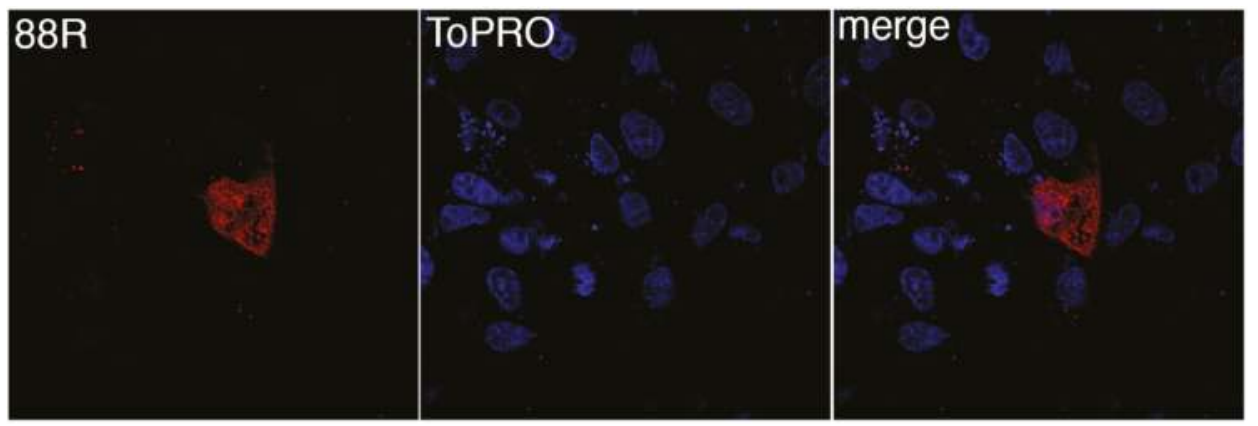

Figure 1. FV3 88R localizes to the cytoplasm. Baby Green Monkey Kidney (BGMK) cells were transfected with pcDNA3-88R. 48 hours post transfection, cells were fixed, and indirect immunofluorescence was performed using rabbit anti-myc antibodies (red) and TO-PRO-3 (blue). Images were captured at $100 \times$ magnification using a confocal microscope.

\subsection{FV3 ORF 91R Localizes to the Nucleus of Transfected Cells}

FV3 91R is another protein known to be conserved across the family Iridoviridae. BGMK cells were transfected with pcDNA3-91R-myc and proteins visualized by indirect immunofluorescence. Figure 2 
demonstrates that 91R colocalizes with the TO-PRO-3 staining demonstrating that 91R localizes to the nucleus. Interestingly, there are pockets within the nucleus that lack both $91 \mathrm{R}$ and TO-PRO-3 expression (white arrows in Figure 2). Since TO-PRO-3 binds to DNA, it is interesting that 91R mimics the expression pattern suggesting that it localizes to the areas of the nucleus where the DNA resides.
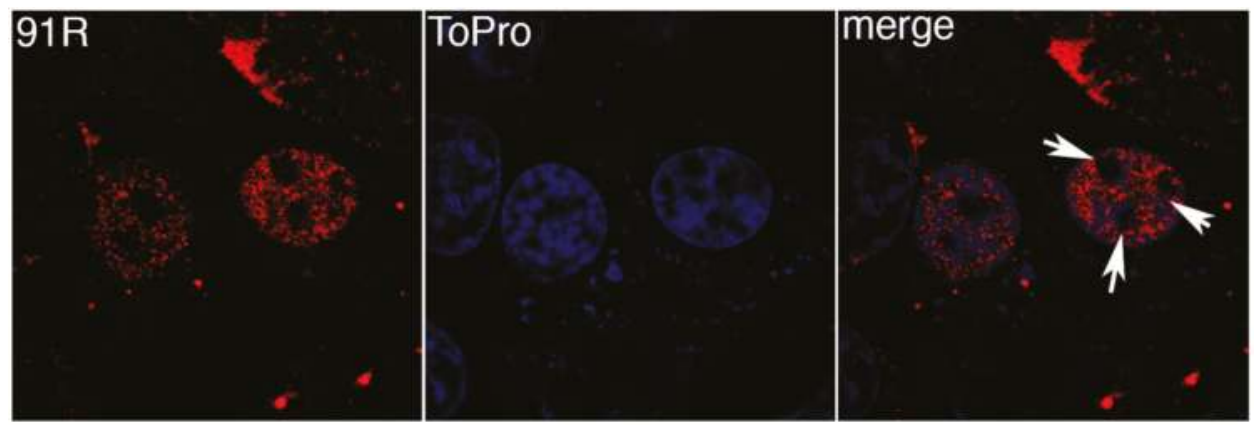

Figure 2. 91R localizes to the nucleus. BGMK cells were transfected with pcDNA3-91R-myc. 48 hours post-transfection, the cells were fixed and indirect immunofluorescence was performed using rabbit anti-myc antibodies (red) and TO-PRO-3 (blue). Images were captured at $100 \times$ magnification using a confocal microscope. White arrows highlight nuclear areas that lack 91R and TO-PRO-3.

\subsection{FV3 ORF 94L Localizes to the ER in Transfected Cells}

To determine the site of intracellular accumulation of 94L, BGMK cells were transfected with pcDNA3-94L-myc. Forty-eight hours post-transfection, the cells were fixed and indirect immunofluorescence was used to visualize 94L-myc protein expression. FV3 94L exhibited strong expression around the nucleus (Figure 3). This perinuclear localization correlated with PDI expression, a marker of the ER [22] (Figure 3). Although the correlation between PDI and 94L expression was not complete, the data does show overlap between the marker and 94L (Figure 3).
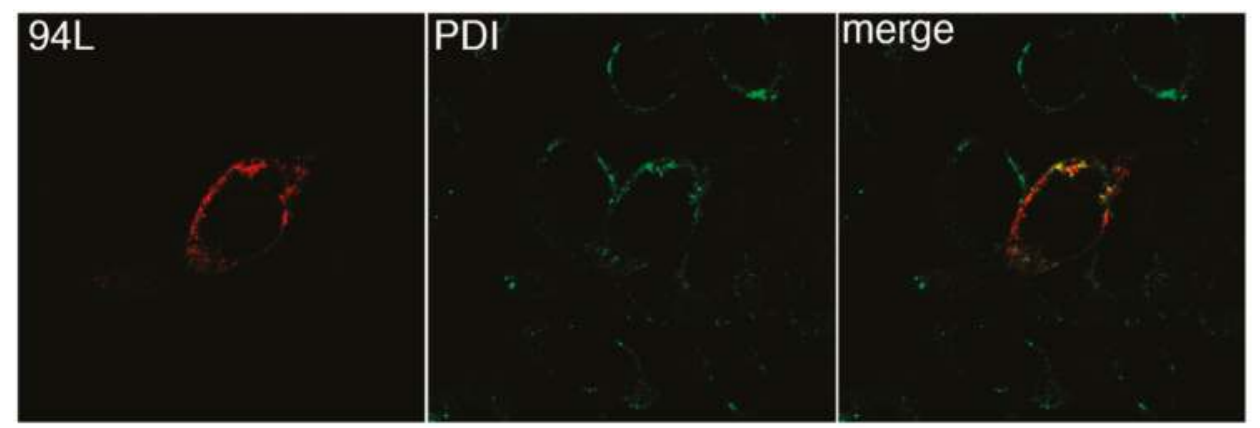

Figure 3. 94L localizes to the Endoplasmic Reticulum. BGMK cells were transfected with pcDNA3-94L-myc. Forty-eight hours post-transfection, the cells were fixed and indirect immunofluorescence was performed using mouse anti-myc antibodies (red) and rabbit anti-PDI antibodies (green). Images were captured at $100 \times$ magnification using a confocal microscope.

\section{Discussion}

The characterization of conserved viral proteins is necessary to gain further insight into the mechanisms of viral infection and replication. Conserved proteins are essential to the viral infection cycle, as their presence in the genomes of multiple members of the same viral family suggest. The purpose of this study was to begin the characterization of the protein products of three FV3 ORFs: 88R, 91R, and 94L. 
Cytoplasmic localization was observed for FV3 88R. FV3 88R has similarity to ERV1/ALR family of proteins [15]. Interestingly, the family Poxviridae contains a cytoplasmic disulfide bond formation pathway that involves vaccinia virus E10, A2.5, and G4 [18,20]. The vaccinia virus E10 protein is an ERV1/ALR homologue that functions in the cytoplasm as part of the poxvirally encoded cytoplasmic pathway of disulfide bond formation $[18,20,23,24]$. The localization pattern exhibited by $88 \mathrm{R}$ is consistent with the cytoplasmic localization of viral ERV1/ALR homologues $[18,20]$. Also, it is known that ERV1/ALR homologues are highly conserved in both the Poxviridae and Afarviridae families, which are some of the most closely related viral families to the family Iridoviridae [20,25]. It is possible that FV3 88R performs a similar function to vaccinia virus E10 and there may also be the potential for the identification of a cytoplasmic pathway of disulfide bond formation in iridoviruses.

The second core gene examined, FV3 91R, localized to the nucleus of transfected cells. 91R has sequence similarity to immediate-early protein ICP-46 [15]. Interestingly, transcriptome analysis of FV3 suggested that 91R is an immediate-early gene [26]. FV3 is known to initiate genomic replication early in the viral replication cycle in the nucleus of infected cells [3]. There is a possibility that $91 \mathrm{R}$ is involved in an early event in FV3 replication which occurs in the nucleus of infected cells immediately following viral entry. Although the function of 91R may not be limited to being involved in the early events of viral replication. For example, the nuclear localization of 91R might also suggest that $91 \mathrm{R}$ regulates viral gene transcription. Therefore there are a number of areas that $91 \mathrm{R}$ could function in the nucleus and more research is required to understand the nuclear function of the gene.

The FV3 94L gene colocalized with the ER marker PDI. Many viruses use the ER and secretory pathway [27-29]. For example, both vaccinia virus and African swine fever virus (ASFV) encode viral proteins that are involved in the modulation of the ER and secretory pathway to accommodate viral replication [27-29]. As previously noted, a KKXX-like ER retrieval motif was identified at the C-terminal of 94L (LRKV). A KKXX motif is responsible for recycling protein from the Golgi complex to ER [21]. Retrieval motifs have been found to modulate secretory pathways and it has been experimentally determined that deletion mutant proteins lacking the double lysine motif are transported downstream to the vesicle [21]. The presence of a KKXX-like motif at the C-terminal of 94L further supports the role for 94L in the viral modulation of the secretory pathways of the host cell and adds further support to a role for $94 \mathrm{~L}$ in the ER. Future research could delete the ER retrieval motif from $94 \mathrm{~L}$ to see if the localization of the gene is altered.

One caveat of the experiments described is that the genes are ectopically expressed in non-host cells. We used the mammalian cell line, BGMK for a number of reasons. For localization studies, it is much easier to use mammalian cell lines, where a variety of intracellular organelle markers exist. In addition, we have used BGMK cells in the past to localize a variety of FV3 genes, and have found that the localization in BGMK cells mimics the localization in amphibian cell lines [30,31]. It is noteworthy that BGMK cells are infectible by FV3 when the cells are incubated at $30^{\circ} \mathrm{C}$ [32]. Although this work was done in a mammalian cell line, it is always possible that the localization of the gene could be altered if the target gene interacts specifically with amphibian proteins. In addition, ectopic expression often results in over-expression of the target protein which may overwhelm intracellular targeting mechanisms resulting in aberrant localization. Finally, it is important to remember that these genes are being expressed outside of an FV3 infection. If 88R, 91R, or 94L interact with other viral proteins, this could also result in altered localization of the gene in and FV3-infected cell.

The results of cellular localization experiments have identified the subcellular expression patterns of the three highly conserved, uncharacterized FV3 proteins included in this study. Based on the results of the localization experiments, possible functions have been assigned to each protein, but these functions are speculative and extensive work is required to describe the actual functions of any of the proteins in an FV3 infection. The further characterization of FV3 88R, 91R, and 94L will provide insight into the cellular cycle of FV3 infection and maybe even certain cellular processes that are modified or commandeered by FV3 in order to successfully infect the host. 
Author Contributions: Conceptualization, C.R.B. and E.P.; Methodology, C.R.B. and E.P.; Investigation, C.R.B. and E.P.; Resources, C.R.B.; Writing - Original Draft Preparation, E.P.; Writing - Review \& Editing, C.R.B.; Visualization, C.R.B. and E.P.; Supervision, C.R.B.; Project Administration, C.R.B.; Funding Acquisition, C.R.B.

Funding: This work was supported by Discovery Grants (Natural Science and Engineering Research Council (NSERC) of Canada) to C.R.B.

Conflicts of Interest: The authors declare no conflict of interest.

\section{References}

1. Goorha, R. Frog virus 3 DNA replication occurs in two stages. J. Virol. 1982, 43, 519-528. [PubMed]

2. He, J.G.; Deng, M.; Weng, S.P.; Li, Z.; Zhou, S.Y.; Long, Q.X.; Wang, X.Z.; Chan, S.M. Complete genome analysis of the mandarin fish infectious spleen and kidney necrosis iridovirus. Virology 2001, 291, 126-139. [CrossRef] [PubMed]

3. Goorha, R.; Murti, K.G. The genome of frog virus 3, an animal DNA virus, is circularly permuted and terminally redundant. Proc. Natl. Acad. Sci. USA 1982, 79, 248-252. [CrossRef] [PubMed]

4. Jakob, N.J.; Muller, K.; Bahr, U.; Darai, G. Analysis of the first complete DNA sequence of an invertebrate iridovirus: Coding strategy of the genome of chilo iridescent virus. Virology 2001, 286, 182-196. [CrossRef] [PubMed]

5. Williams, T. The iridoviruses. Adv. Virus Res. 1996, 46, 345-412. [PubMed]

6. Chinchar, V.G.; Waltzek, T.B.; Subramaniam, K. Ranaviruses and other members of the family iridoviridae: Their place in the virosphere. Virology 2017, 511, 259-271. [CrossRef] [PubMed]

7. Chinchar, V.G.; Hick, P.; Ince, I.A.; Jancovich, J.K.; Marschang, R.; Qin, Q.; Subramaniam, K.; Waltzek, T.B.; Whittington, R.; Williams, T.; et al. Ictv virus taxonomy profile: Iridoviridae. J. Gen. Virol. 2017, 98, 890-891. [CrossRef]

8. Chinchar, V.G.; Yu, K.H.; Jancovich, J.K. The molecular biology of frog virus 3 and other iridoviruses infecting cold-blooded vertebrates. Viruses 2011, 3, 1959-1985. [CrossRef]

9. Eaton, H.E.; Metcalf, J.; Penny, E.; Tcherepanov, V.; Upton, C.; Brunetti, C.R. Comparative genomic analysis of the family iridoviridae: Re-annotating and defining the core set of iridovirus genes. Virol. J. 2007, 4, 11. [CrossRef]

10. Delhon, G.; Tulman, E.R.; Afonso, C.L.; Lu, Z.; Becnel, J.J.; Moser, B.A.; Kutish, G.F.; Rock, D.L. Genome of invertebrate iridescent virus type 3 (mosquito iridescent virus). J. Virol. 2006, 80, 8439-8449. [CrossRef]

11. Gubser, C.; Hue, S.; Kellam, P.; Smith, G.L. Poxvirus genomes: A phylogenetic analysis. J. Gen. Virol. 2004, 85, 105-117. [CrossRef]

12. Iyer, L.M.; Aravind, L.; Koonin, E.V. Common origin of four diverse families of large eukaryotic DNA viruses. J. Virol. 2001, 75, 11720-11734. [CrossRef]

13. McGeoch, D.J. Molecular evolution of the gamma-herpesvirinae. Philos. Trans. R. Soc. Lond B Biol. Sci. 2001, 356, 421-435. [CrossRef]

14. Song, W.J.; Qin, Q.W.; Qiu, J.; Huang, C.H.; Wang, F.; Hew, C.L. Functional genomics analysis of singapore grouper iridovirus: Complete sequence determination and proteomic analysis. J. Virol. 2004, 78, 12576-12590. [CrossRef]

15. Tan, W.G.; Barkman, T.J.; Gregory Chinchar, V.; Essani, K. Comparative genomic analyses of frog virus 3, type species of the genus ranavirus (family iridoviridae). Virology 2004, 323, 70-84. [CrossRef]

16. Zhang, Q.; Gui, J.F. Virus genomes and virus-host interactions in aquaculture animals. Sci. China Life Sci. 2015, 58, 156-169. [CrossRef]

17. Long, F.W.; Liang, S.Y.; Liu, Z.J.; Chen, Y.; Tu, Z.D.; Shi, Y.J.; Bao, J.; Gong, J. Augmentor of liver regeneration ameliorates renal tubular epithelial cell injury after rat liver transplantation. Transplant Proc. 2008, 40, 2696-2699. [CrossRef]

18. Su, H.P.; Lin, D.Y.; Garboczi, D.N. The structure of g4, the poxvirus disulfide oxidoreductase essential for virus maturation and infectivity. J. Virol. 2006, 80, 7706-7713. [CrossRef]

19. Senkevich, T.G.; White, C.L.; Weisberg, A.; Granek, J.A.; Wolffe, E.J.; Koonin, E.V.; Moss, B. Expression of the vaccinia virus a2.51 redox protein is required for virion morphogenesis. Virology 2002, 300, 296-303. [CrossRef] 
20. Senkevich, T.G.; White, C.L.; Koonin, E.V.; Moss, B. A viral member of the erv1/alr protein family participates in a cytoplasmic pathway of disulfide bond formation. Proc. Natl. Acad. Sci. USA 2000, 97, 12068-12073. [CrossRef]

21. Lotti, L.V.; Mottola, G.; Torrisi, M.R.; Bonatti, S. A different intracellular distribution of a single reporter protein is determined at steady state by kkxx or kdel retrieval signals. J. Biol. Chem. 1999, 274, 10413-10420. [CrossRef]

22. Akagi, S.; Yamamoto, A.; Yoshimori, T.; Masaki, R.; Ogawa, R.; Tashiro, Y. Distribution of protein disulfide isomerase in rat hepatocytes. J. Histochem. Cytochem. 1988, 36, 1533-1542. [CrossRef]

23. Senkevich, T.G.; Koonin, E.V.; Bugert, J.J.; Darai, G.; Moss, B. The genome of molluscum contagiosum virus: Analysis and comparison with other poxviruses. Virology 1997, 233, 19-42. [CrossRef]

24. White, C.L.; Senkevich, T.G.; Moss, B. Vaccinia virus g4l glutaredoxin is an essential intermediate of a cytoplasmic disulfide bond pathway required for virion assembly. J. Virol. 2002, 76, 467-472. [CrossRef]

25. Lewis, T.; Zsak, L.; Burrage, T.G.; Lu, Z.; Kutish, G.F.; Neilan, J.G.; Rock, D.L. An african swine fever virus erv1-alr homologue, 9gl, affects virion maturation and viral growth in macrophages and viral virulence in swine. J. Virol. 2000, 74, 1275-1285. [CrossRef]

26. Majji, S.; Thodima, V.; Sample, R.; Whitley, D.; Deng, Y.; Mao, J.; Chinchar, V.G. Transcriptome analysis of frog virus 3, the type species of the genus ranavirus, family iridoviridae. Virology 2009, 391, 293-303. [CrossRef]

27. Husain, M.; Weisberg, A.S.; Moss, B. Existence of an operative pathway from the endoplasmic reticulum to the immature poxvirus membrane. Proc. Natl. Acad. Sci. USA 2006, 103, 19506-19511. [CrossRef]

28. Netherton, C.; Rouiller, I.; Wileman, T. The subcellular distribution of multigene family 110 proteins of african swine fever virus is determined by differences in c-terminal kdel endoplasmic reticulum retention motifs. J. Virol. 2004, 78, 3710-3721. [CrossRef]

29. Tolonen, N.; Doglio, L.; Schleich, S.; Krijnse Locker, J. Vaccinia virus DNA replication occurs in endoplasmic reticulum-enclosed cytoplasmic mini-nuclei. Mol. Biol. Cell 2001, 12, 2031-2046. [CrossRef]

30. Ring, B.A.; Ferreira Lacerda, A.; Drummond, D.J.; Wangen, C.; Eaton, H.E.; Brunetti, C.R. Frog virus 3 open reading frame $97 \mathrm{r}$ localizes to the endoplasmic reticulum and induces nuclear invaginations. J. Virol. 2013, 87, 9199-9207. [CrossRef]

31. Eaton, H.E.; Ferreira Lacerda, A.; Desrochers, G.; Metcalf, J.; Angers, A.; Brunetti, C.R. Cellular litaf interacts with frog virus 3751 protein and alters its subcellular localization. J. Virol. 2013, 87, 716-723. [CrossRef]

32. Eaton, H.E.; Metcalf, J.; Brunetti, C.R. Expression of frog virus 3 genes is impaired in mammalian cell lines. Virol. J. 2008, 5, 83. [CrossRef]

(C) 2019 by the authors. Licensee MDPI, Basel, Switzerland. This article is an open access article distributed under the terms and conditions of the Creative Commons Attribution (CC BY) license (http:/ / creativecommons.org/licenses/by/4.0/). 
Article

\title{
Geographic Distribution of Epizootic haematopoietic necrosis virus (EHNV) in Freshwater Fish in South Eastern Australia: Lost Opportunity for a Notifiable Pathogen to Expand Its Geographic Range
}

\author{
Joy A. Becker ${ }^{1}$, Dean Gilligan ${ }^{2}$, Martin Asmus ${ }^{3}$, Alison Tweedie ${ }^{1}$ and \\ Richard J. Whittington $1,4, *$ \\ 1 Sydney School of Veterinary Science, The University of Sydney, Camden 2570, Australia; \\ joy.becker@sydney.edu.au (J.A.B.); alison.tweedie@sydney.edu.au (A.T.) \\ 2 NSW Industry and Investment, Batemans Bay Fisheries Office, Batemans Bay 2536, Australia; \\ dean.gilligan@dpi.nsw.gov.au \\ 3 NSW Industry and Investment, Narrandera Fisheries Centre, Narrandera 2700, Australia; \\ martin.asmus@dpi.nsw.gov.au \\ 4 OIE Reference Laboratory for Epizootic Haematopoietic Necrosis Virus and Ranavirus Infection of \\ Amphibians, Sydney School of Veterinary Science, The University Sydney, Camden 2570, Australia \\ * Correspondence: richard.whittington@sydney.edu.au; Tel.: +61-2-9351-1619
}

Received: 28 February 2019; Accepted: 28 March 2019; Published: 1 April 2019

\begin{abstract}
Epizootic haematopoietic necrosis virus (EHNV) was originally detected in Victoria, Australia in 1984. It spread rapidly over two decades with epidemic mortality events in wild redfin perch (Perca fluviatilis) and mild disease in farmed rainbow trout (Oncorhynchus mykiss) being documented across southeastern Australia in New South Wales (NSW), the Australian Capital Territory (ACT), Victoria, and South Australia. We conducted a survey for EHNV between July 2007 and June 2011. The disease occurred in juvenile redfin perch in ACT in December 2008, and in NSW in December 2009 and December 2010. Based on testing 3622 tissue and 492 blood samples collected from fish across southeastern Australia, it was concluded that EHNV was most likely absent from redfin perch outside the endemic area in the upper Murrumbidgee River catchment in the Murray-Darling Basin (MDB), and it was not detected in other fish species. The frequency of outbreaks in redfin perch has diminished over time, and there have been no reports since 2012. As the disease is notifiable and a range of fish species are known to be susceptible to EHNV, existing policies to reduce the likelihood of spreading out of the endemic area are justified.
\end{abstract}

Keywords: iridovirus; ranavirus; epidemiology; antibody; ELISA; virus isolation; prevalence; native-fish conservation; biosecurity; endemic disease

\section{Introduction}

Epizootic haematopoietic necrosis virus (EHNV) is an aquatic pathogen that has been of international concern since its emergence in the early 1980s and is listed by the World Organization for Animal Health [1]. Infection with EHNV is systemic and causes epizootic hematopoietic necrosis (EHN), a disease characterized by extensive visceral tissue damage leading to mortality [2,3]. The first epidemics caused by EHNV occurred in freshwater impoundments in central Victoria (VIC), including Lake Mokoan and Nillahcootie in the Broken River catchment. Several populations of wild redfin perch (Perca fluviatilis) were impacted in the period from 1984 to 1986 [4,5]. These first epidemics often resulted in the mortality of tens of thousands of juvenile redfin perch and, in some outbreaks, adult fish 
were also affected. From 1986 to the mid-1990s, outbreaks of EHN in redfin perch and farmed rainbow trout (Oncorhynchus mykiss) were reported across the Murray-Darling Basin (MDB) in southeastern Australia [6].

Taxonomically, EHNV is in the genus Ranavirus within the Alphairidovirinae subfamily, Family Iridoviridae [7]. EHNV is only known in Australia, but similar viruses have been detected in other countries, usually associated with severe diseases in fish or amphibians [8]. EHNV is a double-stranded-DNA virus that can be released from a host cell by lysis (nonenveloped virion) or budding (enveloped virion) [9]. The genome of EHNV is 125 to $127 \mathrm{~kb}$, with 106 to 109 genes, which is larger than amphibian ranaviruses that are usually $105 \mathrm{~kb}[7,10]$. EHNV can be detected by virus isolation in several cell lines [4,11], antigen-capture ELISA [12], and histological sections using specific anti-EHNV antibodies [2]. Further, there are several polymerase chain-reaction (PCR) assays targeting the major capsid protein [13-15] or polymerase gene [16,17].

EHNV is extremely resistant and can survive for months or years in water or frozen fish $[18,19]$. It may persist in sediments and equipment for lengthy periods. Transmission of EHNV between susceptible hosts is possible via water or ingestion of tissue from infected fish [18,20,21]. EHNV infects fish through the skin, gills, or mouth. Infection results in multifocal necrosis of the hematopoietic tissue in the spleen, liver, and kidney $[2,5,22,23]$. Most infected fish quickly succumb and die within a few weeks, but disease expression is highly dependent on water temperature [21] and host $[20,24]$. Experimental challenge studies have demonstrated the potential for EHNV infection in several other species of Australian native fishes, including Murray cod (Maccullochella peelii), Macquarie perch (Macquaria australasica), and Murray River rainbowfish (Melanotaenia fluviatilis) [20]. In addition, freshwater fish native to Europe, such as the black bullhead (Ameiurus melas), pike perch (Sander lucioperca), and northern pike (Esox lucius) are susceptible to EHNV [25-27]. The combined results of Langdon [18] and Becker et al. [20] suggest that susceptibility of fish species does not appear to correlate with taxonomy, so susceptibility of untested species cannot be predicted based on taxonomic relatedness.

The MDB is considered to be one of the largest catchments in the world, with the river system flowing nearly 3750 kilometers from headwaters to the sea. The basin consists of 23 river valleys covering approximately $14 \%$ of Australia's total land mass, with an area of just over one million square kilometers [28]. Mortality rates in initial EHNV epidemics in VIC and NSW were estimated to be $>90 \%$ and, in some smaller water bodies, $100 \%$ mortality in redfin perch was reported [4-6]. From these outbreaks, there was evidence of both downstream and upstream spread of EHNV, as well as an instance outside of the MDB catchments [6]. Mechanisms of spread in redfin perch included fish migration, water movements, translocation of live redfin perch by recreational fishers, and mechanical vector transmission by piscivorous birds [19]. EHNV was distributed between water catchments in NSW with shipments of rainbow-trout fingerlings from two infected hatcheries in NSW in the 1990s [29], leading to biosecurity policy being implemented by the NSW government's fisheries department to prevent this.

The occurrence of EHN has been discontinuous over time and space, with discrete disease events occurring within the endemic regions without a long-term pattern of recurrence. After spreading to new locations, the incidence of disease has been infrequent [10]. There have been no reports of EHNV since an outbreak in redfin perch in NSW since 2009, ACT since 2011, and VIC in 2012 [30].

Despite its significance, very little is known about the natural distribution of EHNV in Australia, or its potential impact on native fish, as no formal surveys have ever been conducted. Impacts of disease are very difficult, time-consuming, and costly to measure in natural aquatic systems, which has deterred research investment. The objective of this study was to investigate the distribution and make inferences about the epidemiology of EHNV in wild populations of fish species in the MDB. These comprise both introduced (alien) species, such as the redfin perch, and many native species. 


\section{Materials and Methods}

\subsection{Study Design}

Fish samples provided for laboratory testing were collected during established research programs by collaborating government agencies. In NSW, the Department of Primary Industries (NSW DPI) collected samples under the MDB Authority Sustainable Rivers Audit (SRA) (Figure 1) [31]. These samples were categorized according to fish species, collection year, river catchment, and altitudinal zone. In each zone, 7 fish sampling sites were chosen using a stratified random procedure, with a minimum of 18 sites per river catchment. Each was the centerpoint of a one-kilometer stream reach. This design was adopted following power and benefit-cost analyses of species-accretion data from the SRA [32]. Fish were sampled by boat-mounted or backpack electrofishing using standardized effort and methods. Sampled catchments in 2008 were Border Rivers, Broken, Darling, Loddon, Lower Murray, Mitta, Murray-Riverina, and Upper Murray. Sampled catchments in 2009 were Avoca, Goulburn, Kiewa, Lachlan, Macquarie-Bogan, Namoi, Paroo, and Warrego. Sampled catchments in 2010 were Campaspe, Castlereagh, Condamine-Culgoa, Gwydir, Murrumbidgee, Ovens, and Wimera-Avon. Other samples in NSW were collected from major impoundments that received an annual stocking of native fish and trout from several other independent research projects, and from disease investigations following notification of mortality events.

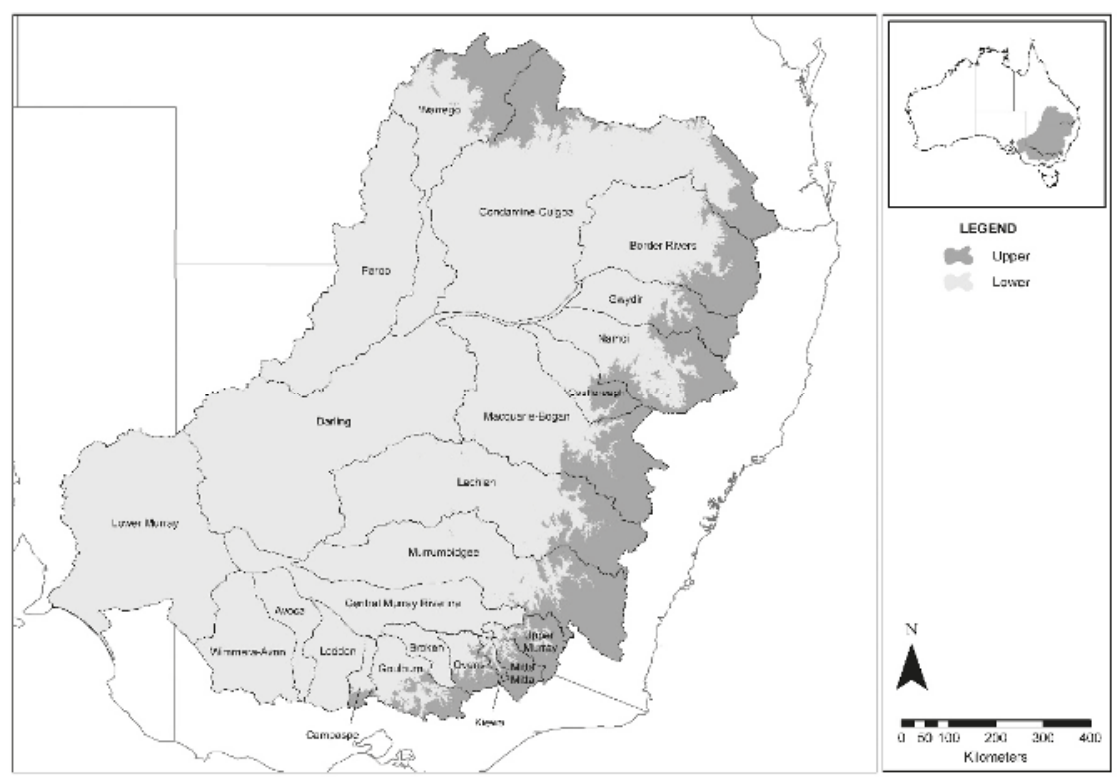

Figure 1. Maximum extent of study area and catchments of the Murray-Darling Basin.

The Arthur Rylah Institute (https:/ / www.ari.vic.gov.au/) conducted annual fish sampling across three catchments, representing three to four altitudinal zones. Australian Capital Territory (ACT) Municipal Services undertook sampling under its Urban Lakes Monitoring Program, as well as specific collections.

Additional sites were sampled because of the presence of species that are potential hosts for EHNV, for example, Cataract Dam in the Nepean catchment, NSW (Macquarie perch); Hunter River, NSW (Australian bass), Snowy River, NSW (rainbow trout); Yarra River, VIC (redfin perch and Macquarie perch) (Figure 2 and Table 1). 
Viruses 2019, 11, 315

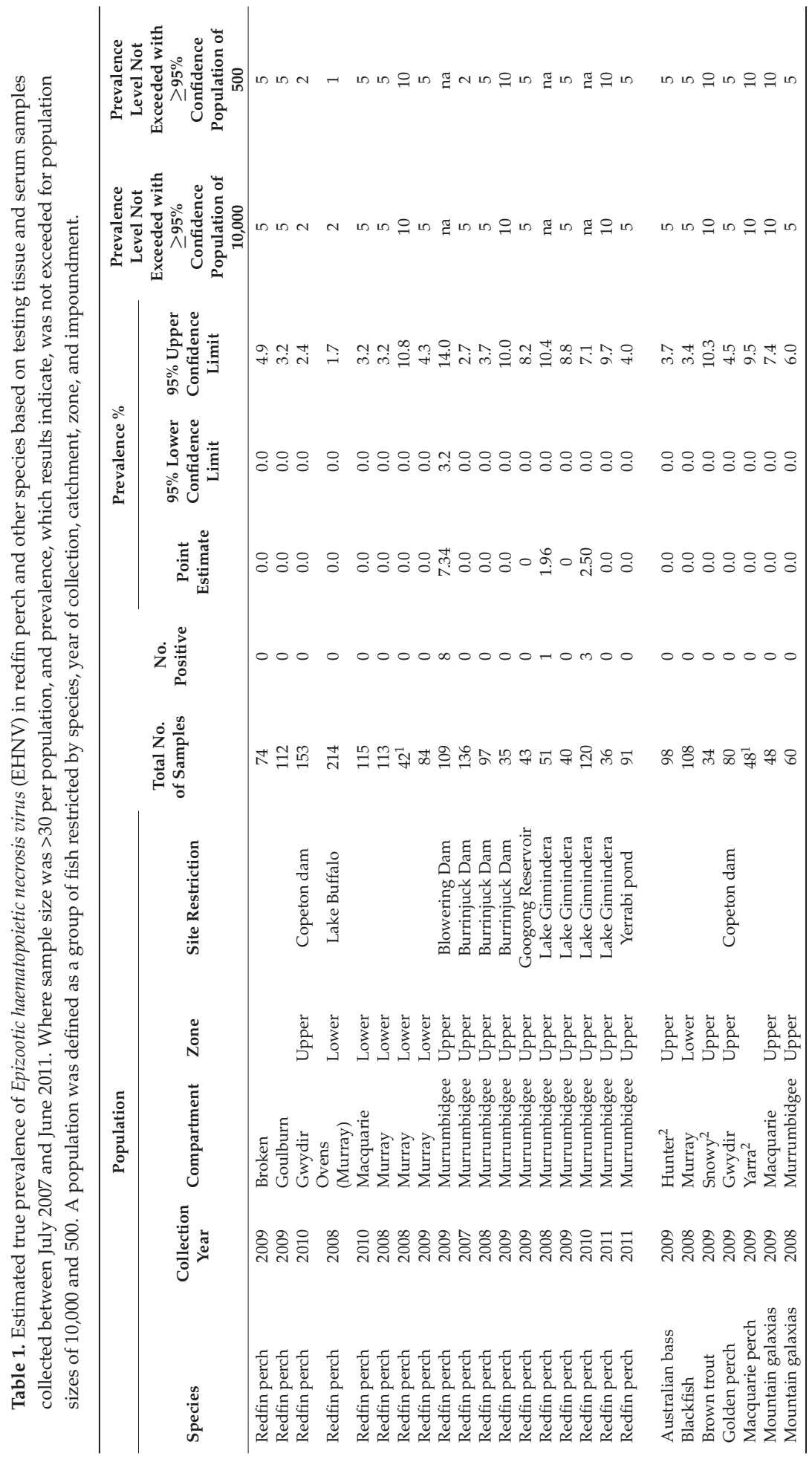


Viruses 2019, 11, 315

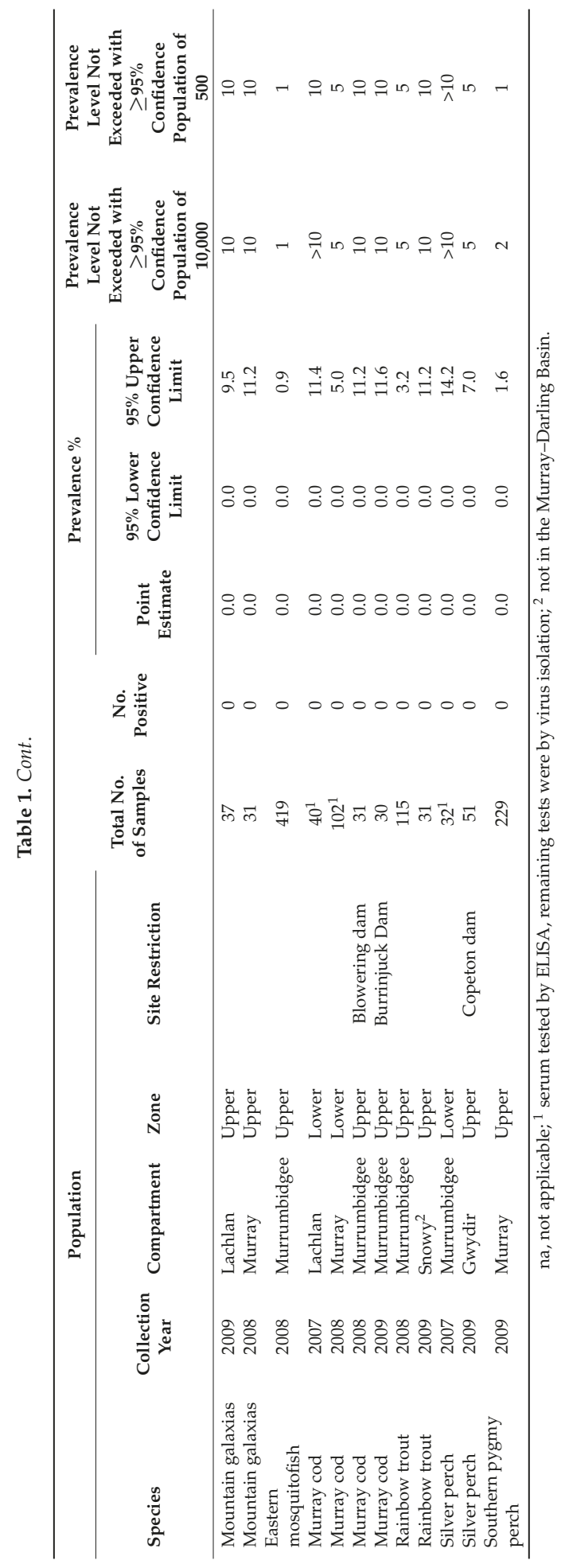




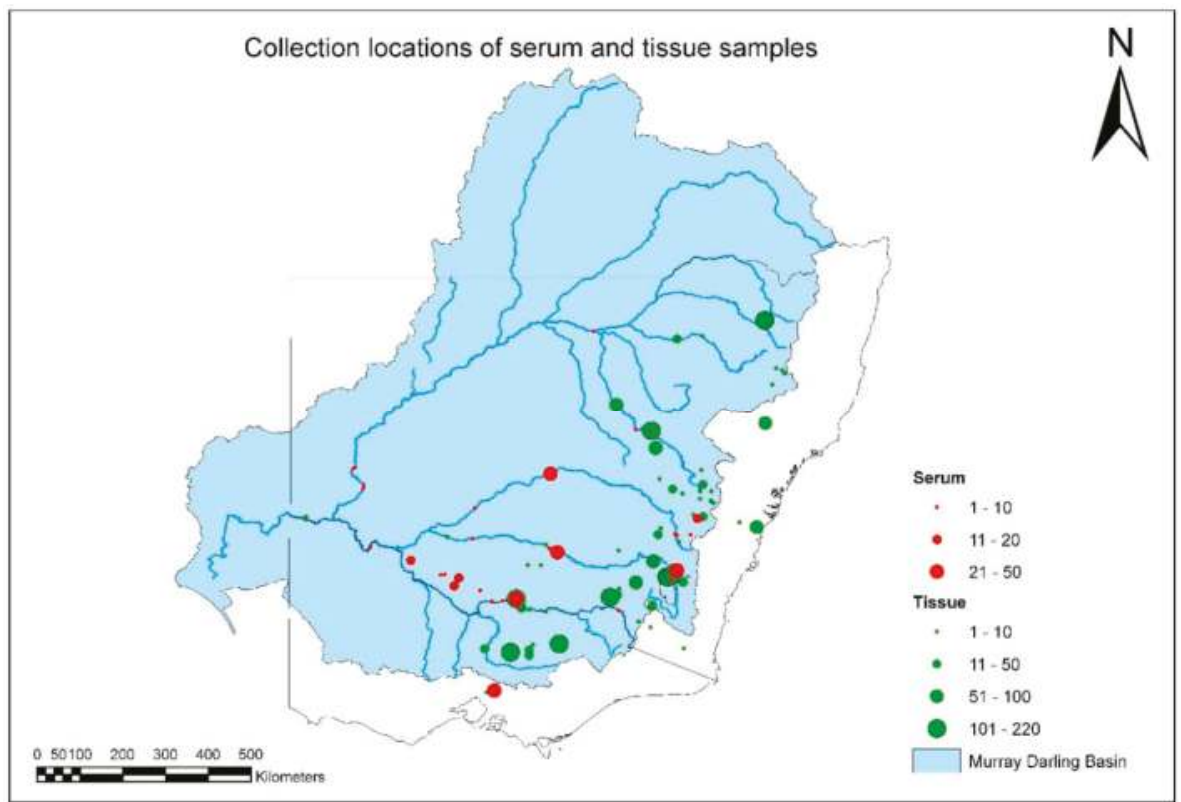

Figure 2. Distribution and number of tissue and serum samples collected from all fish species between July 2007 and June 2011.

\subsection{Collection of Fish Tissue and Serum}

Fish were euthanized and were kept whole or dissected in the field, individually bagged (as practicable) and labeled with collector, date, species, and location details. These samples were held on ice or in portable refrigerators until return to a research station where some were dissected. Alternatively, whole fish were frozen at $-20{ }^{\circ} \mathrm{C}$ until dissection at the University of Sydney (Camden, NSW), usually within six months of collection. For transport, frozen fish or tissue were packed with ice bricks and transported to Camden by road. During dissection, the spleen, posterior kidney, and liver were removed and placed into individual sample vials. All fish tissue was kept frozen at $-20^{\circ} \mathrm{C}$ until it was tested for EHNV.

For serum collection, fish were placed in plastic holding tubs and anesthetized with $20 \mathrm{~mL}$ of AQUI-S®per $100 \mathrm{~L}$ water until there was deep sedation evidenced by limited movement and complete loss of equilibrium. Blood was extracted from the caudal vein using an appropriate needle for the size of the fish (25-19 gauge), and was expelled into a $1.5 \mathrm{~mL}$ polypropylene tube (Eppendorf, Hamburg, Germany). Tubes were labeled and placed on ice or in a portable fridge until return to a research station. Whole blood samples were allowed to clot and were kept chilled for up to 7 days in the field. Samples of clotted blood were centrifuged at 2000 to 10,000 rpm for $10 \mathrm{~min}$. The separated serum was removed to a labelled tube (Eppendorf) and placed at $-20^{\circ} \mathrm{C}$. Serum samples were transported to Camden at $-20^{\circ} \mathrm{C}$, thawed at room temperature, diluted 1:10 in 50\% v/v glycerol in $25 \mathrm{mM}$ Tris, $150 \mathrm{mM} \mathrm{NaCl} \mathrm{pH} 7.4$ with $0.02 \% v / v$ merthiolate (TSGM), and stored at $-20^{\circ} \mathrm{C}$. Moribund or dead fish were sampled for virus isolation. Kidney, liver, and spleen were the target organs, pooled either after dissecting out the viscera, or by using the whole fish with the head and tail removed (for fish $<40 \mathrm{~mm}$ total length).

\subsection{Virus Isolation and Confirmation by PCR}

Tissue samples were placed in sterile microcentrifuge tubes and stored at $-80^{\circ} \mathrm{C}$ if not processed immediately. Each sample was weighed, and $9 \times$ weight/volume of homogenizing medium (HM) 
(minimum essential medium supplemented with $200 \mathrm{IU} / \mathrm{mL}$ penicillin, $200 \mu \mathrm{g} / \mathrm{mL}$ streptomycin, and $5 \mu \mathrm{g} / \mathrm{mL}$ Fungizone) was added. Tissue samples were prepared by grinding in a chilled mortar and pestle with sterile sand and HM, then clarified by centrifuging at $900 \times g$ for $10 \mathrm{~min}$ in a microcentrifuge. A $200 \mu \mathrm{L}$ aliquot of the clarified homogenate was removed for DNA extraction, and a second $500 \mu \mathrm{L}$ aliquot was prepared for virus isolation. It was further diluted 1:4 $v / v$ in $\mathrm{HM}$, passed through a $0.22 \mu \mathrm{m}$ low protein-binding syringe-end filter, and used to inoculate bluegill fry (BF-2) cells in suspension in 24-well tissue culture plates. The cells were prepared by resuspending $80 \%-90 \%$ confluent cell monolayers in minimal essential medium supplemented with $10 \%$ fetal bovine serum (FBS), $200 \mathrm{IU} / \mathrm{mL}$ penicillin, $200 \mu \mathrm{g} / \mathrm{mL}$ streptomycin, and $5 \mu \mathrm{g} / \mathrm{mL}$ Fungizone to $2 \times 10^{5}$ cells $/ \mathrm{mL}$. In duplicate, $150 \mu \mathrm{L}$ of each sample was inoculated directly into a $1.5 \mathrm{~mL}$ cell suspension. Cells were incubated at $22^{\circ} \mathrm{C}$ and examined for development of a cytopathic effect (CPE). If CPE developed, the infected tissue culture supernatant (TCSN) was harvested, $150 \mu \mathrm{L}$ was passaged into a fresh cell suspension, and a $200 \mu \mathrm{L}$ aliquot was reserved for DNA extraction to confirm the presence of EHNV by PCR. Any wells with cells that exhibited no CPE after 7-10 days were freeze-thawed at $-20^{\circ} \mathrm{C}$ overnight, and $150 \mu \mathrm{L}$ of TCSN was passaged by well-to-well transfer into fresh cells. This was repeated after a further 7-10 day incubation to confirm samples as negative. DNA was extracted from $200 \mu \mathrm{L}$ of TCSN using the HighPure Viral Nucleic Acid Extraction Kit (Roche, Basel, Switzerland), and examined using conventional or real-time PCR as described $[1,13]$. Results for individual samples were considered positive when either or both of the duplicates were positive.

\subsection{Serology}

Detection of specific anti-EHNV antibodies in fish serum was based on published methods [23]. All reagents were added to wells in volumes of $50 \mu \mathrm{L}$, and all incubations were at room temperature unless otherwise stated. A plain 96-well ELISA plate (Immulon ${ }^{\circledR}$, Thermo Fisher Scientific, Waltham, MA, USA) was coated with affinity purified rabbit-anti-EHNV antibody in borate coating buffer, incubated for $90 \mathrm{~min}$, then washed 5 times in reverse-osmosis purified water with $0.05 \% v / v$ Tween 20 using a plate washer (Wellwash 96-385, Thermo Electron Corporation, Waltham, MA, USA). Heat-inactivated EHNV antigen was added to pairs of wells in alternate pairs of columns on each plate to enable all sera to be tested in duplicate with and without antigen, and the plate was incubated overnight at $4{ }^{\circ} \mathrm{C}$. After washing as above, the remaining binding sites were blocked in $1 \% w / v$ gelatin in phosphate-buffered saline $\mathrm{pH} 7.2$ with $0.05 \% v / v$ Tween 20 (PBST) solution and incubated for $30 \mathrm{~min}$. After washing, fish serum diluted in $0.01 \% w / v$ gelatin in PBST (PBSTG) was added and incubated for $90 \mathrm{~min}$. Four positive-control sera from redfin perch were included; positive-control sera were not available for other species of fish. After washing, a sheep antifish immunoglobulin reagent appropriate for each species of fish, followed after washing by Donkey antisheep-horseradish peroxidase (HRP) conjugate (KPL) were added; both reagents were diluted in PBSTG, and incubations were for $90 \mathrm{~min}$. After washing, the plate was developed with $1 \mathrm{mM}$ 2,2'azino-bis(3-ethylbenzthiazoline-6-sulfonic acid) (ABTS) for $20 \mathrm{~min}$ before the reaction was stopped with $25 \mu \mathrm{L}$ per well of $0.01 \% w / v \mathrm{NaN}_{3}$ in $0.1 \mathrm{M}$ citric acid. Optical density (OD) was read at $405 \mathrm{~nm}$ with a microplate reader (Multiskan Ascent, Thermo Electron Corporation). Signal-to-noise ratio $(\mathrm{S} / \mathrm{N})$ was determined as the mean OD for duplicate wells, with EHNV antigen divided by the mean OD for duplicate wells without EHNV antigen. A positive sample was defined when $\mathrm{OD} \geq 0.4$ and $\mathrm{S} / \mathrm{N} \geq 2$ except in Macquarie perch, in which it was defined to be when $\mathrm{OD}>0.6$ and $\mathrm{S} / \mathrm{N} \geq 1.5$.

\subsection{Prevalence of EHNV Infection and Likelihood of Freedom of Infection}

Populations were defined as groups of fish restricted by species, year of collection, river catchment, and zone (based on altitude as above or below $400 \mathrm{~m}$ ) with collected fish from impoundments and lakes considered to be in distinct populations from those in rivers. The prevalence of EHNV infection in populations was calculated only where there were $\geq 30$ samples. Maps were created using ArcMap®(ESRI, Redlands, CA, USA). 
A fish was considered positive if a sample from it was positive in either virus isolation or ELISA. The prevalence of EHNV was defined as the proportion of fish samples that tested positive in that population and $95 \%$ exact binomial confidence intervals were determined using Minitab Statistical Software. The diagnostic sensitivity and specificity of virus isolation were both assumed to be $100 \%$ [6], so apparent prevalence equaled true prevalence. For ELISA, true prevalence and Blaker's exact confidence limits were calculated assuming a test sensitivity of $70 \%$ and specificity of $100 \%$ using the calculator at http:/ / www.ausvet.com.au.

For tissue samples tested by virus isolation where all test results were negative, the sample size required to be $95 \%$ certain that the population was free of $\mathrm{EHNV}$ at a specified design prevalence was determined using software at http:/ / www.ausvet.com.au, specifically the modified hypergeometric exact calculation within the FreeCalc analysis results of freedom-testing function provided in the Survey Toolbox package [33]. Sample size was evaluated to obtain $95 \%$ confidence in detecting infection at a specified design prevalence. The following were specified as input parameters: Type I and II error levels, 0.05 ; sensitivity, $99.9 \%$; specificity, $99.9 \%$; population threshold for a binomial calculation, 10,000. For a population size of 10,000, the sample sizes required for design prevalence of $10 \%, 5 \%, 2 \%$, and $1 \%$ were $29,58,145$, and 270 , respectively. For a population of 500 , the sample sizes needed for the same design prevalence were $28,55,124$, and 213 . Where sample size was $\geq 30$, these values were used to infer the prevalence that is not exceeded with $95 \%$ confidence at population sizes of 10,000 and 500 .

For blood samples tested by ELISA, the same method to estimate sample size was used, but test sensitivity was assumed to be $70 \%$. For a population of 10,000, sample sizes for $95 \%$ confidence at design prevalence of $10 \%, 5 \%, 2 \%$, and $1 \%$ were $41,84,211$, and 421 , respectively. For a population of 500, sample sizes were 40, 78, 175, and 298.

\section{Results}

A total of 3622 fish-tissue samples were collected and tested over the duration of project (Figure 2, Table S1). EHNV was not isolated from any fish species other than redfin perch during this study (Tables S1 and S2). The geographic distribution and intensity of sampling is illustrated in Figure 2, and by species in Figures S1-S6. Overall MDB coverage was reasonable, but sample sizes in any year from each species and location were often small (Figure 2, Table 1).

For some populations of species such as the eastern mosquitofish (Gambusia holbrooki) in the upper Murrumbidgee, southern pygmy perch (Nannoperca australisa) in the upper Murray, and redfin perch in Lake Buffalo and the upper Gwydir (Copeton Dam), sample sizes were sufficient to suggest that EHNV is absent. That is, results showed that it is highly unlikely that, if present, EHNV exists in more than $1 \%$ to $2 \%$ of fish in each of these populations. For many other populations, this figure was $<5 \%$ (Table 1).

A total of 1917 tissue and serum samples were collected from redfin perch during the project (Figure 3, Tables S1 and S2). There were several positive tissue samples from redfin perch, and all were from fish in the known endemic area in upper Murrumbidgee River catchment impoundments (Figure 4). One positive redfin perch was collected from Lake Ginninderra, ACT in December 2008 (Table 2). This sample was one of two dead redfin perch collected on 4 December 2008 near a boat ramp in Lake Ginnindera; the other dead fish and four that were electrofished at the site were negative for EHNV. It was unclear whether these fish were involved in an outbreak of EHN (Table 2). A further three positive redfin perch were from a group of 12, collected from Lake Ginninderra on 15 December 2010 (Table 2). Fish size was in the range of $30-63 \mathrm{~mm}$ total length and $0.3-2.6 \mathrm{~g}$ body weight $(n=12)$, and were the young of the year. In December 2009, eight positive redfin perch were identified from Blowering Dam, NSW collected during a fish kill. The estimated true prevalence was $7.3 \%$ (95\% CI: $3.2 \%-14 \%$; Table 1 ). 


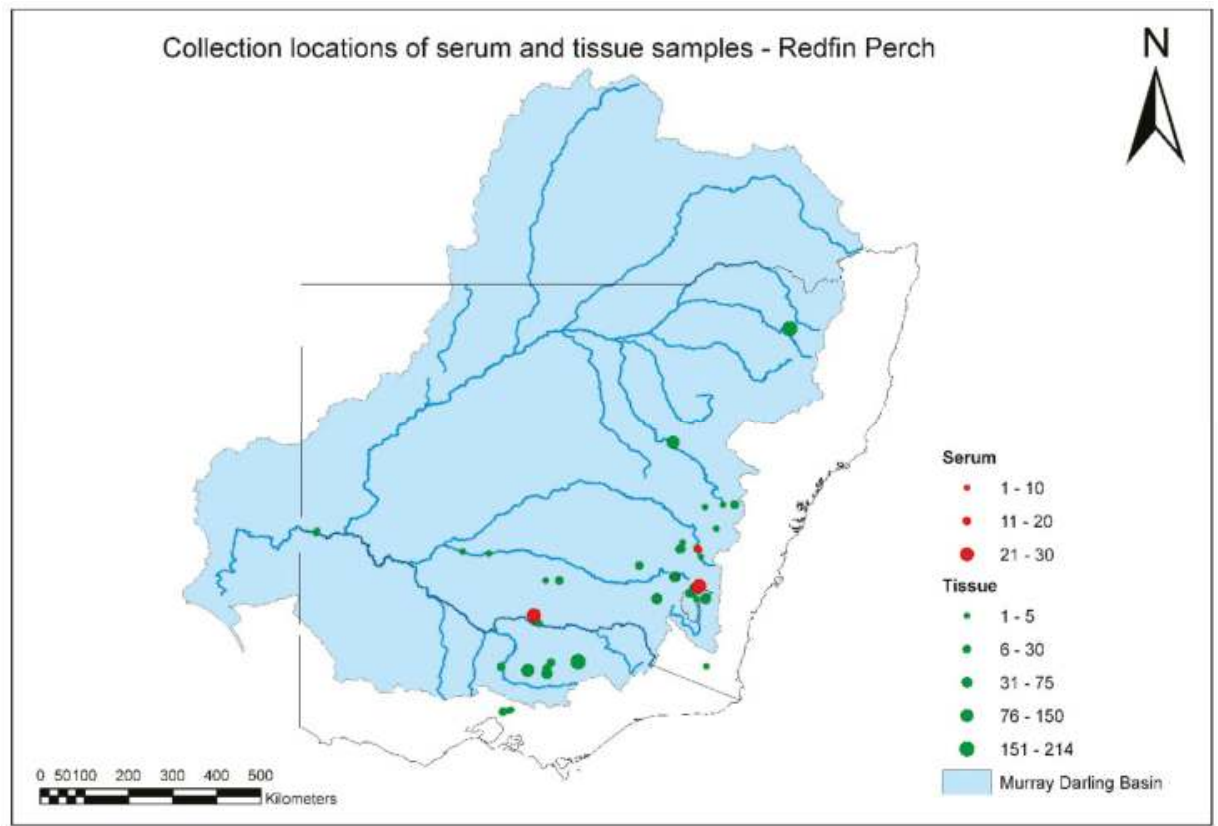

Figure 3. Distribution and number of tissue and serum samples collected from redfin perch between July 2007 and June 2011.

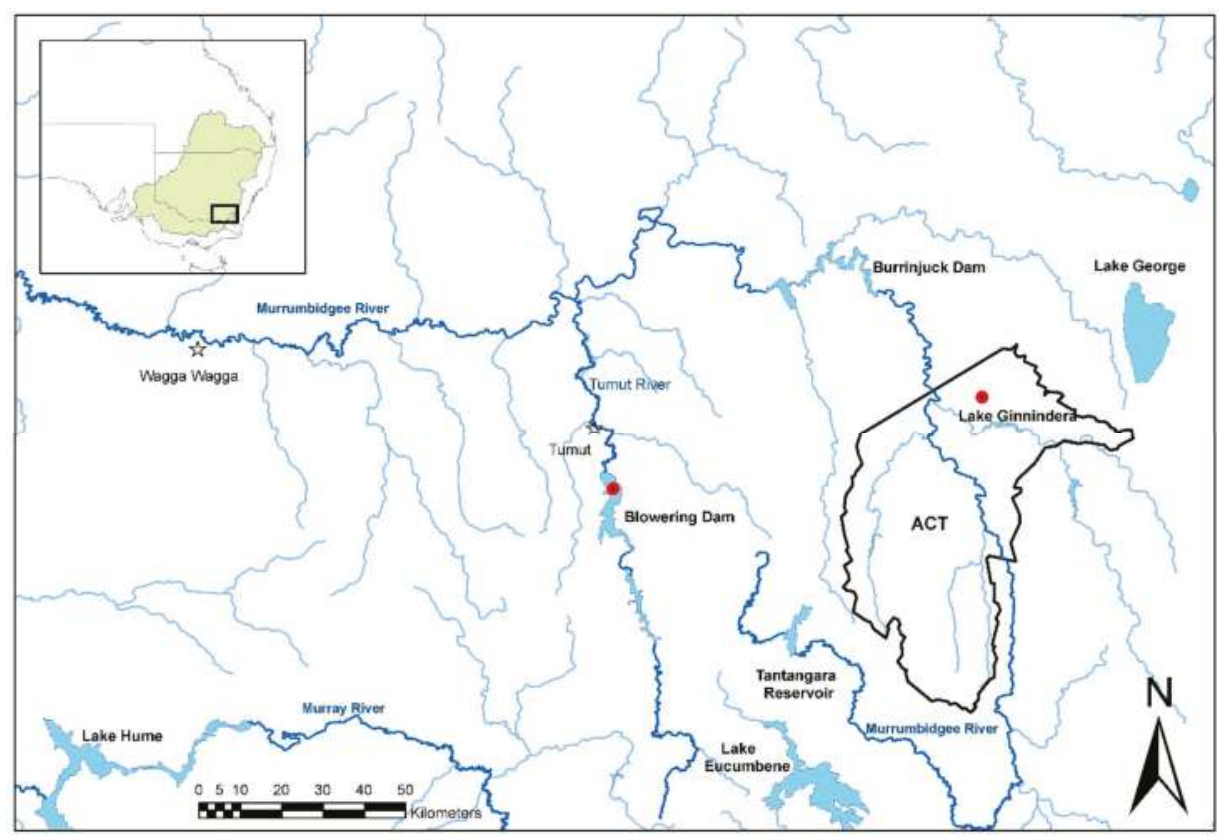

Figure 4. Moribund and dead redfin perch collected from Lake Ginnindera, ACT in December 2008 and 2010, and Blowering Dam, NSW in December 2009 were infected with EHNV. 
Table 2. Summary of results of virus-isolation tests for EHNV conducted on redfin perch tissue collected from Lake Ginninderra, ACT.

\begin{tabular}{lccc}
\hline Date & No. of Fish & Total Length $(\mathbf{m m})$ & EHNV \\
\hline 15 October 2008 & 44 & $190-480$ & not detected \\
5 November 2008 & 1 & 242 & not detected \\
4 December 2008 & 6 & $43-57$ & 1 infected \\
18 March 2010 & 7 & $100-114$ & not detected \\
17 September 2010 & 42 & $92-135$ & not detected \\
15 December 2010 & 12 & $30-63$ & 3 infected \\
15 December 2010 & 35 & $49-189$ & not detected \\
19 December 2010 & 2 & $168-172$ & not detected \\
21 December 2010 & 2 & $125-157$ & not detected \\
21 February 2011 & 36 & $90-167$ & not detected \\
\hline \multicolumn{4}{c}{${ }^{2}$ juvenile young of the year; ${ }^{2}$ adult fish. }
\end{tabular}

Longitudinally collected tissue samples from redfin perch were available from Lake Ginninderra (Table 2). EHNV infection was highly temporally clustered. In both 2008 and 2010, the virus emerged in the population between September/October and the end of December. Based on the sample sizes, the failure to detect EHNV in 44 and 36 adult redfin perch in October 2008 and February 2011 , respectively, is consistent with $<10 \%$ of individuals in those populations being infected at those times. Where EHNV was detected, the upper confidence limits for prevalence were $7.1 \%$ to $14.0 \%$ (Lake Ginninderra and Bowering Dam; Table 1).

A total of 492 blood samples were tested (Table S2). None of the blood samples from native fish was positive for anti-EHNV antibodies (Table S2; Figures S1-S3, S6). There were sufficient samples collected from Macquarie perch in the Yarra River, VIC to be $95 \%$ confident that, if present, EHNV infected $<10 \%$ of fish in the population (Table 1; Figure S3). For Murray cod, there were sufficient samples collected to be $95 \%$ confident that EHNV prevalence was less than $5 \%$ in the lower Murray and $<10 \%$ in the lower Lachlan rivers (Table 1 and Table S1).

A total of 142 serum samples, collected from redfin perch, were tested for anti-EHNV antibodies. The four positive control samples yielded positive results, with OD from 0.4 to $>0.8$, and $\mathrm{S} / \mathrm{N}$ as high as about 6 . There were two positive samples from the survey, both collected from adult redfin perch from Lake Ginninderra in February 2011 (Table S2). There were sufficient samples collected from redfin perch in the lower Murray river to be $95 \%$ confident that, if present, EHNV infected $<10 \%$ of fish in the population (Table 1, Figure 3). As EHNV would be expected to infect a large proportion of redfin perch over time, this may be sufficient evidence to conclude that EHNV was absent from this population.

\section{Discussion}

Surveys to detect pathogens in wild fish in natural ecosystems are notoriously difficult, and methodological approaches are of international interest [34]. The main encountered problems include defining the population and obtaining representative samples. Consequently, it is easy to define the presence of a pathogen in a particular region when a disease is noticed, but very hard to be sure that a pathogen is absent when there are no signs of disease. A field survey to identify whether or not a pathogen is present in a population requires consideration of the likely prevalence of the pathogen if it is present (design prevalence), the sensitivity and specificity of diagnostic tests, the required degree of confidence in the results, and an ability to obtain representative samples, generally through random sampling. International standards for surveys to show that an infectious disease is not present have been proposed [35]. For diseases that are transmitted slowly or at an early stage of an outbreak, a design prevalence of $1 \%$ to $2 \%$ is recommended. For diseases that are highly transmissible, a design prevalence of $5 \%$ or more can be used. The present survey was conducted assuming that EHNV would be present in at least $10 \%$ of fish in a population. This was based on observations in redfin perch where the virus tends to affect a large proportion of the population $[4,5]$. It would be 
desirable to have much greater power of detection, down to $5 \%, 2 \%$, or $1 \%$ prevalence, because, at those levels, claims about freedom from infection could be made with more certainty. An assumption was that the samples were random, but as this cannot be guaranteed, confidence limits may be wider than shown in Table 1. EHNV lacks host specificity so a range of fish species were targeted. However, it was logical to focus surveillance on the most susceptible known species [34], which is why the redfin perch was chosen to be the main target species in this survey.

Based on testing 3622 tissue and 492 blood samples, it was concluded that EHNV is endemic in some parts of the upper Murrumbidgee River catchment in the MDB. Other sites that were known to have infected redfin perch in the past were either not sampled (for example, Lake Hume, VIC) or tested negative (for example, Burrinjuck Dam, NSW, and Googong Reservoir, ACT). Although some samples were obtained from sites in Victoria near those that have previously harbored infected redfin perch (Broken River above and below Lake Nillahcootie in 2009), major potential sites of endemic infection were not sampled (for example, Lake Nillahcootie and Lake Mokoan). Similarly, lakes Albert and Alexandrina, and Mount Bold Reservoir in South Australia, all sites of past outbreaks [19], were not sampled. For these reasons, our current awareness of EHNV distribution in the known endemic region remains incomplete. However, it is reasonable to assume that it persists in places where it once occurred. This is because, during the study, an outbreak of disease due to EHNV occurred in juvenile redfin perch in Blowering Dam, NSW (December 2009), a dead redfin perch infected with EHNV was detected in Lake Ginninderra, ACT (December 2008), and there was an outbreak at this location in December 2010, consistent with prior observations of outbreaks in both locations [19]. There have been anecdotal reports of outbreaks in Blowering Dam and in the ACT since the last cases were formally confirmed in the 1990s. However, not all parts of the upper Murrumbidgee catchment were found to be infected in this study, for example, Cotter Reservoir was not. This is the location of an important population of endangered Macquarie perch, a species experimentally shown to be susceptible to EHNV [18].

The majority of samples from redfin perch came from the known EHNV-endemic area in the southeastern part of the MDB. It was not intended to obtain samples from South Australia or Queensland during this study, and fewer-than-expected samples were collected from redfin perch and any other species from northern catchments. This was partly because of the composition of the species assemblage sampled for the SRA. There are few populations of redfin perch in any of the northern catchments. Exceptions are the upper Gwydir catchment, from where a substantial number of samples of redfin perch were obtained, and a very small area of the upper Beardy River subcatchment of the Border Rivers catchment (Figure 3).

EHNV appeared to be absent from other species of fish in the MDB during the study period. Sufficient data were obtained from some regions of the MDB to be $95 \%$ confident that EHNV was present in $<10 \%$ of individuals in population of the following species: river blackfish (Gadopsis marmoratus), brown trout (Salmo trutta), mountain galaxias (Galaxias olidus), eastern mosquitofish, murray cod, silver perch (Bidyanus bidyanus), southern pygmy perch, rainbow trout, and redfin perch.

The apparent absence of EHNV from most of the MDB and the demonstrated susceptibility of some fish species $[18,20]$ should raise concern about the risk of its introduction. It is possible that the virus has not entered the middle and lower regions of southern MDB, nor its western and northern parts. However, the results of the survey only apply to the period of the survey, and sampling intensity was low for many species in most parts of the MDB.

Serology was applied in this survey, a procedure that is not routine in aquatic-animal health [36]. Two serum samples collected during this study were positive, as were many samples collected from redfin perch that survived experimental infection with $\mathrm{EHNV}$, one of which was carrying the live virus in its organs [24]. The positive-control samples used in the assay had been collected from survivor redfin perch from Lake Mokoan in Victoria in 1991 to 1992, and were tested in 1991-1992 in prototype ELISA assays with similar results to those presented here (Whittington and Hyatt, unpublished). 
Therefore, the antibodies were stable in frozen storage (at $-20{ }^{\circ} \mathrm{C}$ ). These results indicate that serology does have application in field surveys for EHNV. Surveys for EHNV, where outbreaks of disease are intermittent even in endemic regions, reinforces the important role of antibody detection. Antibody detection provides historical evidence of exposure to the virus because antibodies persist in the blood of survivors long after the resolution of an active infection.

The life history of EHNV in nature is unclear. It is unknown whether fish can become infected with EHNV and remain carriers for life, and so is whether meaningful testing could be conducted when the disease is not apparent. It is also unclear whether an environmental reservoir of the virus may exist in river sediments, fish, or, indeed, in species other than fish. As the virus has been shown in laboratory experiments to be highly resistant to drying, and persists in water, on surfaces, and in frozen fish tissue, it has been assumed that it would also be highly resistant in the environment [18]. Whether environmental sources of EHNV are available to fish is completely unknown. It may, for example, persist in river sediments, but be tightly bound to particles and unavailable to fish. The results of examination of samples collected over time from redfin perch in Lake Ginninderra showed that EHNV could only be intermittently detected there. In two separate years, 2008 and 2010, the virus was undetectable in adult fish in September/October, but had appeared by the end of December in the young of the year. It is unknown whether the virus was truly absent from the adults, or whether it was present at a very low level, sufficient to initiate an outbreak in juvenile fish when conditions were appropriate for transmission. Larger sample sizes would be required to disprove a carrier state in adult redfin perch. Alternatively, there may be another reservoir host in Lake Ginninderra.

The spread mechanisms of EHNV in the natural environment are not entirely clear. However, it is certain that trade of infected rainbow trout fingerlings has been responsible for spread between farms in different catchments, for example, the upper Snowy, upper Murrumbidgee, and Shoalhaven Rivers [29], but it is unknown whether this has led to infection of wild fish. On the contrary, it is possible that farmed rainbow trout may become infected not only from infected fingerling trout, but also from wild redfin perch-this may explain annual outbreaks in rainbow trout farmed on the Tumut river adjacent to Blowering Dam [29]. Alternatively, the virus may persist on the farm in between detectable outbreaks. Downstream movement of EHNV seeming to not have historically occurred in the highly susceptible redfin perch population [19] or during this study tends to suggest that movement of the virus with water flow in rivers is unimportant, and that other factors are necessary for spread. These factors could include the anthropogenic movement of fish (live or dead redfin perch) or movement of the virus on equipment, by birds, or other putative vectors. An alternative view is that the disease caused by EHNV is naturally restricted to specific environments, predominantly lakes and impoundments. This is possible, and suggests the involvement of an amplification host or particular risk factors, such as locally high population density to assist transmission, particular temperature gradients, and unknown mechanisms.

The lack of evidence for the downstream spread of EHNV in rivers may be explained by dilution of the virus to a level below an infectious dose, insufficient host density in rivers to initiate propagation of an outbreak, or both, but the exact reasons are not known. Although density requirements and infectious dose are uncertain, it is reasonable to assume that a young redfin perch infected with EHNV could contain $10^{7}$ virions per gram; if the carcase is completely disaggregated in the water column, and the virus is not lost through adsorption to particulates, the concentration of virus in water in a $10 \mathrm{~cm}$ cube around a $10 \mathrm{~g}$ fish would be $10^{4} / \mathrm{L}$, but would decrease rapidly as this water mixes with surrounding water. Assuming fish clustering within an impoundment and large water volume, it is clear that the virus becomes rapidly diluted. It is known that EHNV remains closely associated with fish tissue, in particular, the cell cytoskeleton [37], and so it may not be efficiently released. It may require, for example, ingestion of a fish carcase to transmit efficiently to another host. The natural occurrence of EHN in juvenile redfin perch while they are in dense schools is similar to the occurrence of EHN in rainbow trout in intensive culture. Such host density may be required for transmission between fish to occur, and may explain why outbreaks in native fish have not been seen. Native species 
generally do not occur in high density sympatric with redfin perch. Further research is required on this topic.

\section{Conclusions}

The conclusions from the study are that EHNV was probably confined to the upper Murrumbidgee River and associated impoundments in NSW and the ACT in 2007 to 2011, and these observations comprise the last reports of the virus from these areas. The possibility exists that EHNV is present in other areas of the MDB but was not detected, and in the locations in VIC where it originally emerged, although these were not sampled in this study. The last detection in Australia was in VIC in 2012. The reasons for the apparent disappearance of the virus are unknown, but policies to reduce the risk of exposure to EHNV of fish in the MDB are justifiable. It is logical to prevent or reduce the likelihood of spread from the endemic area to areas that are apparently free. Not all parts of the upper Murrumbidgee catchment, for example, Cotter Reservoir, are infected, and it would be desirable to maintain this freedom to protect the resident Macquarie perch population there. All reports of fish kills in the upper Murrumbidgee catchment region should be investigated and laboratory tests for EHNV undertaken. Routine surveillance of redfin perch populations in the upper Murrumbidgee catchment should be undertaken to determine the occurrence of EHNV. Policies to exclude recreational use of these areas during EHNV outbreaks, close fisheries, or enable compulsory disinfection should be considered.

Supplementary Materials: Supplementary materials can be found at http:/ /www.mdpi.com/1999-4915/11/4/ 315/s1.

Author Contributions: All authors contributed to the design of the study. D.G. and M.A. provided a priori knowledge on fish ecology and led sample collection; R.J.W. and A.T. completed all laboratory testing; R.W. and J.A.B. completed the data analysis; J.A.B. and M.A. completed the mapping; J.A.B. and R.J.W., original draft; A.T., M.A., and D.G., review and editing.

Acknowledgments: This project was conceived by Richard Whittington and Mark Lintermans. This research was funded by the Murray-Darling Basin Authority, grant number MDBA 743. Technical assistance was provided by Rebecca Maurer, Anna Waldron, Craig Kristo, and Satoko Kawaji. We also thank the following individuals who contributed tissue and serum samples: Matthew Beitzel, Luke Pearce, Mark Lintermans, Danswell Starrs, Rhian Clear, Jarod Lyon, Pam Clunie, Joanne Kearns, Koral Hunt, Rod Cockburn, and Peter Cockburn. All research undertaken in this report was approved by the Animal Ethics Committee of University of Sydney: N00/6-2007/3/4619 and NSW DPI P01/0059.

Conflicts of Interest: The authors declare no conflict of interest.

\section{References}

1. OIE. World organisation for animal health (OIE). Chapter 10.1 epizootic haematopoietic necrosis. In aquatic animal health code. Available online: http://www.Oie.Int/en/international-standard-setting/aquaticcode/access-online/ (accessed on 28 February 2019).

2. Reddacliff, L.A.; Whittington, R.J. Pathology of epizootic haematopoietic necrosis virus (EHNV) infection in rainbow trout (oncorhynchus mykiss walbaum) and redfin perch (Perca fluviatilis L.). J. Comparative Pathol. 1996, 115, 103-115. [CrossRef]

3. Hick, P.; Ariel, E.; Whittington, R. Epizootic hematopoietic necrosis and european catfish virus. In Fish Viruses and Bacteria: Pathobiology and Protection; PTK Woo, R.C., Ed.; CABI: Oxfordshire, UK, 2017; pp. 38-50.

4. Langdon, J.S.; Humphrey, J.D.; Williams, L.M.; Hyatt, A.D.; Westbury, H.A. First virus isolation from australian fish: An iridovirus-like pathogen from redfin perch, Perca fluviatilis L. J. Fish Dis. 1986, 9, 263-268. [CrossRef]

5. Langdon, J.S.; Humphrey, J.D. Epizootic haematopoietic necrosis a new viral disease in redfin perch Perca fluviatilis L. In Australia. J. Fish Dis. 1987, 10, 289-298. [CrossRef]

6. Whittington, R.J.; Becker, J.A.; Dennis, M.M. Iridovirus infections in finfish—critical review with emphasis on ranaviruses. J. Fish Dis. 2010, 33, 95-122. [CrossRef] 
7. Chinchar, V.G.; Hick, P.; Ince, I.A.; Jancovich, J.K.; Marschang, R.; Qin, Q.; Subramaniam, K.; Waltzek, T.B.; Whittington, R.; Williams, T.; et al. ICTV virus taxonomy profile: Iridoviridae. J. Gen. Virol. 2017, 98, 890-891. [CrossRef] [PubMed]

8. Mavian, C.; López-Bueno, A.; Somalo, M.P.F.; Alcamí, A.; Alejo, A. Complete genome sequence of the european sheatfish virus. J. Virol. 2012, 86, 6365-6366. [CrossRef] [PubMed]

9. Williams, T.; Barbosa-Solomieu, V.; Chinchar, V.G. A decade of advances in iridovirus research. Adv. Virus Res. 2005, 65, 173-248. [PubMed]

10. Hick, P.M.; Subramaniam, K.; Thompson, P.M.; Waltzek, T.B.; Becker, J.A.; Whittington, R.J. Molecular epidemiology of epizootic haematopoietic necrosis virus (EHNV). Virology 2017, 511, 320-329. [CrossRef] [PubMed]

11. Crane, M.S.J.; Young, J.; Williams, L.M. Epizootic haematopoietic necrosis virus (EHNV): Growth in fish cell lines at different temperatures. Bull. Eur. Assoc. Fish Pathol. 2005, 25, 228-231.

12. Whittington, R.J.; Steiner, K.A. Epozootic hematopeietic necrosis virus (EHNV)—improved ELISA for detection in fish tissues and cell cultures and an efficient method for release of antigen from tissues. J. Virol. Methods 1993, 43, 205-220. [CrossRef]

13. Jaramillo, D.; Tweedie, A.; Becker, J.A.; Hyatt, A.; Crameri, S.; Whittington, R.J. A validated quantitative polymerase chain reaction assay for the detection of ranaviruses (family iridoviridae) in fish tissue and cell cultures, using ehnv as a model. Aquaculture 2012, 356-357, 186-192. [CrossRef]

14. Marsh, I.B.; Whittington, R.J.; O»Rourke, B.; Hyatt, A.D.; Chisholm, O. Rapid differentiation of australian, european and american ranaviruses based on variation in major capsid protein gene sequence. Mol. Cell Probes 2002, 16, 137-151. [CrossRef]

15. Pallister, J.; Gould, A.; Harrison, D.; Hyatt, A.; Jancovich, J.; Heine, H. Development of real-time PCR assays for the detection and differentiation of Australian and European ranaviruses. J. Fish Dis. 2007, 30, 427-438. [CrossRef] [PubMed]

16. Stilwell, N.K.; Whittington, R.J.; Hick, P.M.; Becker, J.A.; Ariel, E.; van Beurden, S.; Vendramin, N.; Olesen, N.J.; Waltzek, T.B. Partial validation of a taqman real-time quantitative pcr for the detection of ranaviruses. Dis. Aquat. Organ. 2018, 128, 105-116. [CrossRef] [PubMed]

17. Holopainen, R.; Ohlemeyer, S.; Schutze, H.; Bergmann, S.M.; Tapiovaara, H. Ranavirus phylogeny and differentiation based on major capsid protein, DNA polymerase and neurofilament triplet h1-like protein genes. Dis. Aquat. Organ. 2009, 85, 81-91. [CrossRef] [PubMed]

18. Langdon, J.S. Experimental transmission and pathogenicity of epizootic haematopoietic necrosis virus (EHNV) in redfin perch, Perca fluviatilis L., and 11 other teleosts. J. Fish Dis. 1989, 12, 295-310. [CrossRef]

19. Whittington, R.J.; Kearns, C.; Hyatt, A.D.; Hengstberger, S.; Rutzou, T. Spread of epizootic haematopoietic necrosis virus (EHNV) in redfin perch (Perca fluviatilis) in southern Australia. Australian Vet. J. 1996, 73, 112-114. [CrossRef]

20. Becker, J.A.; Tweedie, A.; Gilligan, D.; Asmus, M.; Whittington, R.J. Experimental infection of australian freshwater fish with epizootic haematopoietic necrosis virus (EHNV). J. Aquat. Anim. Health 2013, 25, 66-76. [CrossRef] [PubMed]

21. Whittington, R.J.; Reddacliff, G.L. Influence of environmental temperature on experimental infection of redfin perch (Perca fluviatilis) and rainbow trout (oncorhynchus mykiss) with epizootic hematopoietic necrosis virus, an Australian iridovirus. Australian Vet. J. 1995, 72, 421-424. [CrossRef]

22. Langdon, J.S.; Humphrey, J.D.; Williams, L.M. Outbreaks of an EHNV-like irodovirus in cultured rainbow trout, salmo gairdneri, richardson, in Australia. J. Fish Dis. 1988, 11, 93-96. [CrossRef]

23. Whittington, R.J.; Philbey, A.; Reddacliff, G.L.; Macgown, A.R. Epidemiology of epizootic haematopoietic necrosis virus (EHNV) infection in farmed rainbow trout, oncorhynchus mykiss (walbaum): Findings based on virus isolation, antigen capture elisa and serology. J. Fish Dis. 1994, 17, 205-218. [CrossRef]

24. Becker, J.A.; Tweedie, A.; Gilligan, D.; Asmus, M.; Whittington, R.J. Susceptibility of Australian redfin perch Perca fluviatilis experimentally challenged with epizootic hematopoietic necrosis virus (EHNV). J. Aquat. Anim. Health 2016, 28, 122-130. [CrossRef] [PubMed]

25. Bang Jensen, B.; Holopainen, R.; Tapiovaara, H.; Ariel, E. Susceptibility of pike-perch sander lucioperca to a panel of ranavirus isolates. Aquaculture 2011, 313, 24-30. [CrossRef]

26. Bang Jensen, B.; Ersboll, A.K.; Ariel, E. Susceptibility of pike esox lucius to a panel of ranavirus isolates. Dis. Aquat. Organ. 2009, 83, 169-179. [CrossRef] 
27. Gobbo, F.; Cappellozza, E.; Pastore, M.R.; Bovo, G. Susceptibility of black bullhead ameiurus melas to a panel of ranavirus isolates. Dis. Aquat. Organ. 2010, 90, 167-174. [CrossRef] [PubMed]

28. Lintermans, M. Fishes of the Murray Darling Basin; Murray Darling Basin Commission: Canberra, Australia, 2007.

29. Whittington, R.J.; Reddacliff, L.A.; Marsh, I.; Kearns, C.; Zupanovic, Z.; Callinan, R.B. Further observations on the epidemiology and spread of epizootic haematopoietic necrosis virus (EHNV) in farmed rainbow trout oncorhynchus mykiss in southeastern australia and a recommended sampling strategy for surveillance. Dis. Aquat. Organ. 1999, 35, 125-130. [CrossRef] [PubMed]

30. Australia, A.H. Animal Health in Australia 2017; Animal Health Australia: Canberra, Australia, 2018; pp. 93-97.

31. Authority, M.D.B. Sustainable Rivers Audit 2: The Ecological Health of Rivers in the Murray-Darling Basin at the End of the Millennium Drought (2008-2010); Murray-Darling Basin Authority: Canberra, Australia, 2012; pp. 1-100.

32. Commision, M.D.B. Murray-Darling Basin Rivers: Ecosystem Health Check, 2004-2007. A Summary Report Based on the Independent Sustainable Rivers Audit Group's Sra Report 1: A Report on the Ecological Health of Rivers in the Murray-Darling Basin, 2004-2007; Murray-Darling Basin Authority: Canberra, Australia, 2008.

33. Cameron, A. Survey Toolbox for Aquatic Animal Diseases. A Practical Manual and Software Package. Aciar Monograph; Australian Centre for International Agricultural Research: Canberra, Australi, 2002; Volume 94, p. 375.

34. Corsin, F.; Georgiadis, M.; Hammell, K.; Hill, B. Guide for aquatic animal health surveillance. World Organisation for Animal Health (OIE): Paris, France, 2009.

35. Anon. Aquatic Animal Health Code; World Organisation for Animal Health (OIE): Paris, France, 2009; p. 265.

36. Jaramillo, D.; Peeler, E.J.; Laurin, E.; Gardner, I.A.; Whittington, R.J. Serology in finfish for diagnosis, surveillance, and research: A systematic review. J. Aquat. Anim. Health 2017, 29, 1-14. [CrossRef] [PubMed]

37. Eaton, B.T.; Hyatt, A.D.; Hengstberger, S. Epizootic haematopoietic necrosis virus: Purification and classification. J. Fish Dis. 1991, 14, 157-169. [CrossRef]

(C) 2019 by the authors. Licensee MDPI, Basel, Switzerland. This article is an open access article distributed under the terms and conditions of the Creative Commons Attribution (CC BY) license (http:/ / creativecommons.org/licenses/by/4.0/). 


\title{
Article \\ Critical Role of an MHC Class I-Like/Innate-Like T Cell Immune Surveillance System in Host Defense against Ranavirus (Frog Virus 3) Infection
}

\author{
Eva-Stina Isabella Edholm ${ }^{1,2,+}$, Francisco De Jesús Andino ${ }^{1,+}$, Jinyeong Yim ${ }^{1}$, Katherine Woo ${ }^{1}$ \\ and Jacques Robert ${ }^{1, *(D)}$ \\ 1 Department of Microbiology and Immunology, University of Rochester Medical Center, Rochester, NY 14642, \\ USA; eva-stina.i.edholm@uit.no (E.-S.I.E.); Francisco_Dejesus@URMC.Rochester.edu (F.D.J.A.); \\ jyim3@u.rochester.edu (J.Y.); kwoo6@u.rochester.edu (K.W.) \\ 2 The Norwegian College of Fishery Science, University of Tromsø, the Arctic university of Norway, 9037, \\ Tromsø, Norway \\ * Correspondence: Jacques_Robert@urmc.rochester.edu; Tel.: +(585)-275-1722; Fax: +(585)-473-9573 \\ + These authors contributed equally to this work.
}

Received: 18 March 2019; Accepted: 3 April 2019; Published: 6 April 2019

Abstract: Besides the central role of classical Major Histocompatibility Complex (MHC) class Ia-restricted conventional Cluster of Differentiation 8 (CD8) T cells in antiviral host immune response, the amphibian Xenopus laevis critically rely on MHC class I-like (mhc1b10.1.L or XNC10)-restricted innate-like (i)T cells (iV $\alpha 6 \mathrm{~T}$ cells) to control infection by the ranavirus Frog virus 3 (FV3). To complement and extend our previous reverse genetic studies showing that $\mathrm{iV} \alpha 6 \mathrm{~T}$ cells are required for tadpole survival, as well as for timely and effective adult viral clearance, we examined the conditions and kinetics of $\mathrm{iV} \alpha 6 \mathrm{~T}$ cell response against FV3. Using a FV3 knock-out (KO) growth-defective mutant, we found that upregulation of the XNC10 restricting class I-like gene and the rapid recruitment of $\mathrm{iV} \alpha 6 \mathrm{~T}$ cells depend on detectable viral replication and productive FV3 infection. In addition, by in vivo depletion with XNC10 tetramers, we demonstrated the direct antiviral effector function of $\mathrm{iV} \alpha 6 \mathrm{~T}$ cells. Notably, the transitory $\mathrm{iV} \alpha 6 \mathrm{~T}$ cell defect delayed innate interferon and cytokine gene response, resulting in long-lasting negative inability to control FV3 infection. These findings suggest that in Xenopus and likely other amphibians, an immune surveillance system based on the early activation of iT cells by non-polymorphic MHC class-I like molecules is important for efficient antiviral immune response.

Keywords: Unconventional T cell; nonclassical MHC; antiviral immunity; interferon

\section{Introduction}

In mammals, potent adaptive immune response against viral pathogens largely depends on conventional Cluster of Differentiation (CD8) T cell effectors that express a broad T cell receptor (TCR) repertoire capable of recognizing a large array of antigens presented by polymorphic classical Major Histocompatibility Complex (MHC) class I molecules (class Ia). However, it is increasingly appreciated that other unconventional or innate-like $\mathrm{T}$ cell effectors are critically involved in antiviral immunity [1]. These iT cells interact with non-polymorphic MHC class I-like molecules, have a limited or invariant $\mathrm{T}$ Cell Receptor (TCR) repertoire, and are thought to serve as important early responders and immune regulators. One of the best characterized iT cell populations are invariant Natural Killer T (iNKT) cells, which are restricted by the MHC class I-like molecule Cluster of Differentiation CD1d that presents lipids [2,3]. The antiviral role of iNKT cells has been shown for murine cytomegalovirus 
(MCMV; [4]), lymphocytic choriomeningitis virus (LCMV; [5]), herpes simplex virus 1 (HSV1; [6]), HIV and influenza [7], and even for vaccinia virus (VAC; [8]).

In the amphibian Xenopus laevis, while adult frogs exhibit an immune system whose conventional class Ia-restricted CD8 T cell compartment is dominant, as in mammals, tadpoles are immunocompetent but are naturally class Ia-deficient and primarily rely on MHC class I-like and iT cells to mediate immunity [9]. Deep-sequencing repertoire analysis has revealed the over-representation of 6 invariant $\mathrm{TCR} \alpha$ rearrangements, implying the predominance of 6 larval iT cell subsets [10]. One of the 6 putative iT cell subsets, the iV6 T cell subset, expresses the rearranged V $\alpha 6-J 1.43 \mathrm{TCR} \alpha$ chain and requires the MHC class I-like molecule XNC10 (encoded by mhc1b10.1.L) for its thymic development and function [10]. Notably, host immune responses against the ranavirus pathogen Frog Virus 3 (FV3) are significantly impaired by lack of $\mathrm{iV} \alpha 6 \mathrm{~T}$ cells resulting from XNC10 loss-of-function. FV3 is a major pathogen of amphibians, fish, and even reptiles [11]. The dramatic worldwide increases in host ranges (i.e., populations and species infected) and amphibian die-off caused by RVs (see eBook [12]) raise alarming concerns for biodiversity and aquaculture, and pose fundamental issues related to evolution of host/pathogen interactions. As such, the involvement of iT cells in addition to conventional CD8 T cells in antiviral host resistance is of high relevance.

In adult X. laevis, XNC10 deficiency considerably delays viral clearance, resulting in increased tissue damage [13]. As expected from iT cell prevalence in tadpoles, XNC10 deficiency markedly increases the mortality rate, especially at early stages of FV3 infection [10]. The generation of XNC10 tetramers by expressing XNC10 fused to X. laevis beta 2-microglobulin ( $\mathrm{b} 2 \mathrm{~m})$ has permitted a better characterization of the $\mathrm{iV} \alpha 6 \mathrm{~T}$ cell response kinetics and shows a rapid recruitment (within less than $24 \mathrm{~h}$.) at the site of infection. This fast targeted response suggests a sensitive detection mechanism of FV3 infection. However, many facets of this response remain to be investigated, including whether $\mathrm{iV} \alpha 6 \mathrm{~T}$ cells require stimulation by $\mathrm{XNC10}$ bound to viral or other ligands, or can be activated by $\mathrm{XNC10}$-independent co-stimulation signals (e.g., danger signals, interferon [IFN] response). To explore some of these issues, we have taken advantage of our XNC10 tetramer, as well as a FV3 recombinant virus deficient for a putative immune evasion gene, to determine the role of productive versus ablated viral infection, as well as the effect of transiently impairing iV $\alpha 6 \mathrm{~T}$ cell function at early stages of FV3 infection.

\section{Material and methods:}

\subsection{Animals}

All outbred $X$. laevis were from the $X$. laevis research resource for immunology at the University of Rochester (https://www.urmc.rochester.edu/microbiology-immunology/xenopus-laevis. aspx). All animals were handled in accordance with stringent laboratory and University Committee on Animal Research regulations, minimizing suffering (Approval number 100577/2003-151). For all experiments, three-week old tadpoles (stage $55,1.5 \mathrm{~cm}$ long; [14]) and 1 year-old young adult frogs were used.

\subsection{Frog Virus 3 Stocks and Infection}

Baby hamster kidney cells (BHK-21, ATCC No. CCL-10) were maintained in Dulbecco's modified Eagle's medium DMEM (Invitrogen, Thermo Fisher Scientific, Inc. Waltham, MA, USA) containing 10\% fetal bovine serum (Invitrogen), streptomycin $(100 \mu \mathrm{g} / \mathrm{mL})$, and penicillin $(100 \mathrm{U} / \mathrm{mL})$ with $5 \% \mathrm{CO}_{2}$ at $37^{\circ} \mathrm{C}$, then $30^{\circ} \mathrm{C}$ for infection. The generation and characterization of the FV3 knock-out $(\mathrm{KO})$ mutant $\triangle \mathrm{VCARD}$ (or $\triangle 64 \mathrm{R}$ ) has been detailed elsewhere [15-17]. Wild type (WT) and KO FV3 were grown using a single passage through BHK-21 cells and were subsequently purified by ultracentrifugation on a $30 \%$ sucrose cushion. Adult frogs were infected by intraperitoneal (i.p.) injection of $1 \times 10^{6}$ PFUs in $100 \mu \mathrm{L}$ of Amphibian Phosphate buffered saline (APBS) and tadpoles were infected by i.p. injection of 10,000 PFUs in $5 \mu \mathrm{L}$ APBS. Uninfected control animals were mock-infected with an equivalent 
volume of APBS. At different days post-infection (dpi), animals were euthanized using $1 \mu \mathrm{g} / \mathrm{L}$ tricaine methanesulfonate (TMS) buffered with bicarbonate prior to dissection and extraction of nucleic acids from tissues.

\subsection{Quantitative Gene Expression Analyses}

Total RNA was extracted from peritoneal leukocytes and kidneys using Trizol reagent, following the manufacturer's protocol (Invitrogen). The cDNA was synthetized with $0.5 \mu \mathrm{g}$ of RNA in $20 \mu \mathrm{L}$ using the iScript cDNA synthesis kit (Bio-Rad, Hercules, CA, USA), and $1 \mu \mathrm{L}$ of cDNA template was used in all RT-PCRs and $150 \mathrm{ng}$ DNA for PCR. Minus RT controls were included for every primer pair. A water-only control was included in each reaction. The qPCR analysis was performed using the ABI 7300 real-time PCR system with PerfeCT SYBR Green FastMix, ROX (Quanta, Beverly, MA, USA), and ABI sequence detection system (SDS) software. Glyceraldehyde-3-phosphate dehydrogenase (GAPDH) controls were used in conjunction with the $\Delta \Delta \mathrm{CT}$ method to analyze cDNA for gene expression. All primer sequences are listed in Table S1.

\subsection{Viral Load Quantification by $q P C R$ and Plaque Assay}

FV3 viral loads were assessed by absolute qPCR by analysis of isolated DNA in comparison to a serially diluted standard curve. Briefly, an FV3 DNA Pol II PCR fragment was cloned into the pGEM-T Easy vector (Promega, Madison, WI, USA). This construct was amplified in bacteria, quantified, and serially diluted to yield 1010-101 plasmid copies of the FV3 DNA polymerase II. These dilutions were employed as a standard curve in subsequent absolute qPCR experiments to derive the viral genome transcript copy numbers relative to this standard curve. Virus quantification by plaque assay was performed on BHK-21 monolayers in 6-well plates under an overlay of $1 \%$ methylcellulose [18]. Infected cells were cultured for 7 days at $30{ }^{\circ} \mathrm{C}$ in $5 \% \mathrm{CO}_{2}$. Overlay media was aspirated and cells were stained for $10 \mathrm{~min}$ with $1 \%$ crystal violet in $20 \%$ ethanol.

\subsection{XNC10 Tetramer Production}

XNC10 tetramers were generated as previously described [10]. Briefly, beta 2 microglobulin (b2m) was linked via a 23-aa Glycine rich C-terminal flexible linker to the $\alpha 1-\alpha 3$ domains of XNC10 containing a BirA site-specific biotinylation site at the end of the $\alpha 3$ domain and cloned into the pMIBV5-HisA expression vector (Invitrogen). The b2m-linker-XNC10 construct was expressed in Sf9 insect cells and monomeric b2m-linker-XNC10 was purified by Ni-NTA-Agarose Chromatography (Qiagen, Hilden, Germany) and concentrated to $1 \mu \mathrm{g} / \mu \mathrm{L}$ using Amicon Ultra Centrifugal Filter (Millipore, Burlington, MA, USA). BirA enzymatic biotinylation was performed for $18 \mathrm{~h}$. at $30{ }^{\circ} \mathrm{C}$ according to the manufacturer's protocol (Avidity, Aurora, CO, USA), and the purified biotinylated proteins were extensively dialyzed against APBS, $\mathrm{pH} 7.5$, to remove any unbound biotin. XNC10 tetramers were generated by incubating b2m-linker-XNC10 with fluorochrome-labeled streptavidin at a 5:1 ratio at room temperature for $4 \mathrm{~h}$. before use. Purified XNC10 tetramers $(1 \mu \mathrm{g})$ were injected intra i.p. at a volume of $5 \mu \mathrm{L}$.

\subsection{Statistical Analysis}

One way ANOVA followed by Dunn's or Tukey's multiple comparison tests were used for statistical analysis of expression and viral load data. Analyses were performed using a Vassar Stat online resource (http://vassarstats.net/utest.html). Statistical analysis of survival data was performed using a Log-Rank Test (GraphPad Prism 6, San Diego, CA, USA). A probability value of $p<0.05$ was used in all analyses to indicate significance. Error bars on all graphs represent the standard error of the mean (SEM). 


\section{Results}

\subsection{Relationships Between FV3 Infection Magnitude and iV $\alpha 6$ T cell Response in Adult X. Laevis}

We have previously demonstrated that FV3 infection in adult X. laevis elicits a transitory influx of the innate (i)T cell subset $\mathrm{iV} \alpha 6 \mathrm{~T}$ into the peritoneal cavity [13]. To delineate the factors governing iV $\alpha 6$ T cell recruitment during a FV3 infection, we took advantage of the FV3 KO mutant $\triangle \mathrm{vCARD}(64 \mathrm{R})$-FV3 that has previously been shown to have attenuated virulence and growth in vivo, eliciting different host responses $[14,17]$. Accordingly, we i.p infected adult X. laevis with wild type (WT) FV3 or $\Delta 64-F V 3$ for $24 \mathrm{~h}$. before collecting peritoneal leukocytes (PLs) and quantified transcript levels of the specific invariant $\mathrm{V} \alpha 6-\mathrm{J} \alpha 1.43$ rearrangement. As a control we also challenged frogs with heat-killed E. coli. This type of bacterial stimulation has been shown to induce a strong nonspecific inflammatory response but does not stimulate the recruitment or accumulation of $\mathrm{iV} \alpha 6 \mathrm{~T}$ cells in the peritoneal cavity [13]. Because $\mathrm{iV} \alpha 6 \mathrm{~T}$ cells interact with the MHC class I-like molecule XNC10, we also examined its gene expression profile. To evaluate viral loads, we determined the FV3 genome copy number using absolute qPCR. Consistent with previous findings, $\Delta 64-\mathrm{FV} 3$ infection resulted in significantly $(p=0.005)$ lower viral load compared to WT-FV3 already at $1 \mathrm{dpi}$ [17]. All treatments resulted in a significantly increased XNC10 expression compared to PLs collected from APBS-injected control frogs at the same time point, with no difference among the treatment groups (Figure 1B). However, only WT-FV3 infection resulted in significantly elevated $\mathrm{iV} \alpha 6-\mathrm{J} \alpha 1.43$ transcript levels compared to uninfected controls $(p=0.018)$, whereas in frogs injected with heat-killed bacteria, iV $\alpha 6-\mathrm{J} \alpha 1.43$ expression was lower compared to controls, presumably due to the large influx of immune cells into the peritoneal cavity. Although the high individual variation prevented statistical significance among the two FV3 infected groups, $\mathrm{iV} \alpha 6-\mathrm{J} \alpha 1.43$ transcript levels observed with $\triangle 64$-FV3 mutants were elevated above sham-infect APBS controls in only $20 \%$ of frogs (3 out of 15 frogs) compared to $70 \%$ (9 out of 13 ) for WT-FV3 infected frogs, suggesting a correlation between $\mathrm{iV} \alpha 6$ recruitment and the level of viral replication.

\section{Adult peritoneal leukocytes}
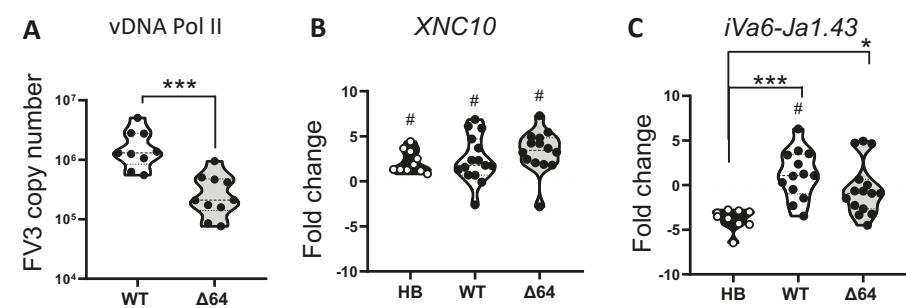

Figure 1. Effects of infection with attenuated knockout $(\mathrm{KO}) \mathrm{FV} 3$ recombinant or bacterial stimulation on $\mathrm{iV} \alpha 6 \mathrm{~T}$ cell response. Peritoneal leukocytes (PLs) were collected at $1 \mathrm{dpi}$ from adult frogs infected with $1 \times 10^{6}$ PFUs of WT-FV3 or $\Delta 64$-FV3, or $100 \mu$ l heat-killed (HB) E. coli. (A) Genome copy number using absolute qPCR with primers against FV3 DNA polymerase II. (B) XNC10 relative gene expression and (C) $\mathrm{iV} \alpha 6-\mathrm{J} \alpha 1.43$ relative gene expression. Gene expression was determined relative to an endogenous control (GAPDH) and fold changes were calculated using the unstimulated sample (injected with equivalent volume of APBS) collected at the same time point. Data are pooled from three independent experiments with $n=4-5$ animals in each experiment and each dot represents an individual animal. The line intersecting the $y$-axis at 0 represents the unstimulated control that the fold changes of the treatments are in relation to; (\#) $p<0.05$ significant differences compared to unchallenged (APBS) injected controls; $\left(^{*}\right) p<0.05$ and $\left({ }^{* * *}\right) p<0.001$ statistically significant differences between the indicated groups (one way ANOVA and Dunns's multiple comparison test).

To obtain additional evidence of the correlation between active viral replication and iV $\alpha 6 \mathrm{~T}$ cell recruitment, we i.p. infected adult X. laevis with WT- and $\Delta 64-F V 3$, and then monitored the transcript 
levels of iV $\alpha 6-\mathrm{J} \alpha 1.43$ and $\mathrm{XNC} 10$ in the peritoneal cavity (the site of infection) and kidney (main site for viral replication) at 1, 3, and 6 dpi (Figure 2). To evaluate viral replication, we determined the genome copy number by absolute qPCR (Figure 2A,B) and to assess productive infection we performed plaque assays (Figure $2 \mathrm{C}$ and Figure S1). Again $\triangle 64-\mathrm{FV} 3$ exhibited a severe replication defect preventing the production of infectious particles (Figure $2 \mathrm{C}$ and Figure S1). Using iV $\alpha 6-\mathrm{J} \alpha 1.43$ expression as a proxy for monitoring the kinetics of $\mathrm{iV} \alpha 6 \mathrm{~T}$ cell recruitment, we detected an increase in $\mathrm{iV} \alpha 6-\mathrm{J} \alpha 1.43$ transcript levels in the peritoneal cavity as early as $1 \mathrm{dpi}$ with WT-FV3 compared to uninfected controls, which became significant by $3 \mathrm{dpi}$, and then returned to low but detectable levels by 6 dpi (Figure 2D). In contrast, $\triangle 64-\mathrm{FV} 3$ infection did not trigger a significant increase in $\mathrm{iV} \alpha 6-\mathrm{J} \alpha 1.43$ transcript levels. In kidneys, iV $\alpha 6-\mathrm{J} \alpha 1.43$ expression was significantly elevated at $3 \mathrm{dpi}$ and then returned to baseline at 6 dpi following infection with WT-FV3 (Figure 2E). In contrast, no significant changes in iV $\alpha 6-J \alpha 1.43$ expression were detected with $\triangle 64-\mathrm{FV} 3$ infection.

The examination of the expression response of the $\mathrm{iV} \alpha 6 \mathrm{~T}$ cell restricting the MHC class I-like XNC10 gene revealed some interesting correlations. In PLs, WT-FV3 infection induced a rapid (from $1 \mathrm{dpi}$ ) and sustained (until $6 \mathrm{dpi}$ ) XNC10 increase (Figure 2F), which was delayed (from 3 to $6 \mathrm{dpi}$ ) in kidneys (Figure $2 \mathrm{G}$ ). Consistent with the poorly induced $\mathrm{iV} \alpha 6-\mathrm{J} \alpha 1.43$ expression, infection with $\triangle 64-F V 3$ also resulted in impaired induction of XNC10 gene expression. Indeed, $\triangle 64-\mathrm{FV} 3$ infection did not induce any significant change in XNC10 gene expression at 3 and $6 \mathrm{dpi}$ in both PLs and kidneys.

Collectively, these data indicate that $\mathrm{XNC} 10$-restricted $\mathrm{iV} \alpha 6 \mathrm{~T}$ cell recruitment is relative to viral burden and requires active viral replication.

A Peritoneal leukocytes

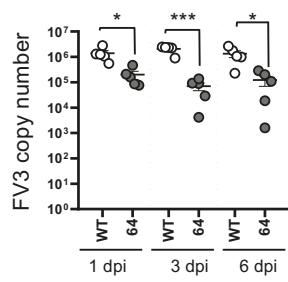

D

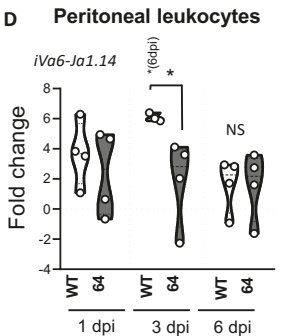

B Kidney

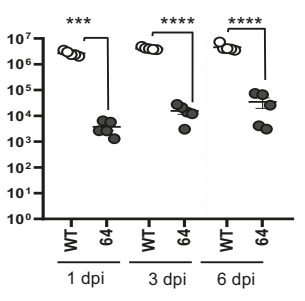

E Kidney 言

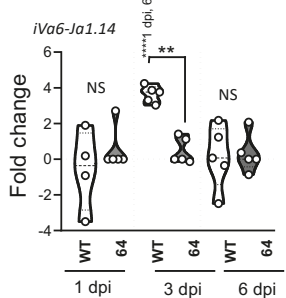

C Kidney

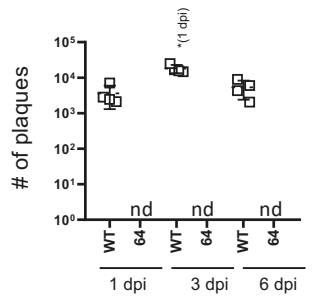

F Peritoneal leukocytes

G Kidney

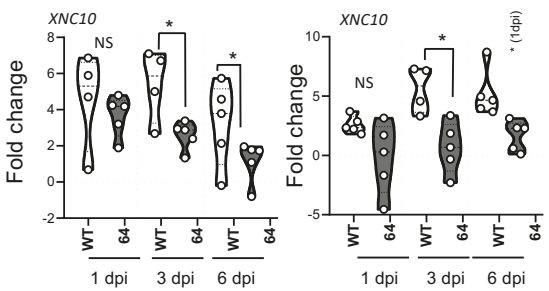

Figure 2. Magnitude of $\mathrm{iV} \alpha 6 \mathrm{~T}$ cell response in adult frogs is associated to the level of viral replication and production of infectious particles. PLs and kidneys were collected at 1, 3, and 6 dpi from adult frogs infected with $1 \times 10^{6}$ PFUs of WT-or $\triangle 64-F V 3$. FV3 genome copy number by absolute qPCR in PLs (A) and kidneys (B) were determined. The total number of infectious particles (nd: not detected) in the kidney was determined by plaque assay (C).Gene expression of $\mathrm{iV} \alpha 6-\mathrm{J} \alpha 1.43$ and XNC10 in PLs $(\mathbf{D}, \mathbf{F})$ and kidneys $(\mathbf{E}, \mathbf{G})$ were determined relative to an endogenous control (GAPDH) and fold changes were calculated using mock-infected frogs as a control. Each dot represents an individual animal $(n=4-5)$. The line intersecting the $y$-axis at 0 represents the APBS control that the fold changes of the treatments are in relation to. Note: ${ }^{*} p<0,05 ;{ }^{* *} p<0.01$; ${ }^{* * *} p<0.001$, and ${ }^{* * * *} p<0.0001$ above the line denotes statistically significant differences between the different treatment groups; significant differences between time points within each treatment group are indicated within parentheses; NS indicates no significant differences (one way ANOVA and Dunns's multiple comparison test). 


\subsection{Relationships Between FV3 Infection Magnitude and iV 66 T Cell Response in Tadpoles}

In contrast to adult frogs that exhibit a prominent conventional antiviral CD8 $\mathrm{T}$ cell response restricted by classical MHC class Ia, tadpoles have barely detectable class Ia surface protein expression and rely heavily on $\mathrm{XNC10}$-restricted $\mathrm{iV} \alpha 6 \mathrm{~T}$ cells [10]. Indeed, $\mathrm{XNC10-deficient} \mathrm{transgenic} \mathrm{tadpoles}$ lacking iV $\alpha 6 \mathrm{~T}$ cells succumb to FV3 infection much faster than controls. This suggests that a rapid $\mathrm{iV} \alpha 6 \mathrm{~T}$ cell response is required during the early stage of FV3 infection. Similar to adult frogs, we postulated that the efficient recruitment of $\mathrm{iV} \alpha 6 \mathrm{~T}$ cells at the site of infection in tadpoles would depend on a productive FV3 infection. Accordingly, we i.p. infected tadpoles with either WT- or $\Delta 64-F V 3$. Consistent with previous reports, $\Delta 64$-FV3 exhibited a severe growth defect in tadpoles, as shown by the very low number of plaques detected, even at 6 dpi (Figure 3A and Figure S2). As expected, WT-FV3 infection elicited an $\mathrm{iV} \alpha 6 \mathrm{~T}$ cell response that was overall comparable to adults, including an early (by $1 \mathrm{dpi}$ ) increase in $\mathrm{iV} \alpha 6-\mathrm{J} \alpha 1.43$, as well as XNC10 transcript levels that were maintained by $3 \mathrm{dpi}$ and then declined close to background levels by $6 \mathrm{dpi}$. In contrast, there were no significant changes in XNC10 and iV $\alpha 6-\mathrm{J} \alpha 1.43$ transcript levels following $\Delta 64$-FV3 infection (Figure 3B,C).

\section{Tadpole kidney}

A Viral loads

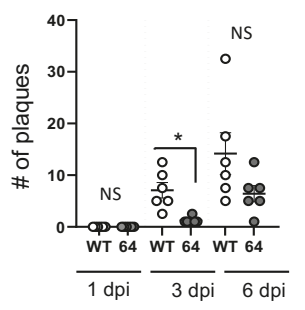

B $\quad$ iVa6-Ja1.43

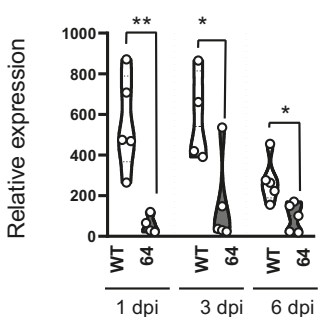

C XNC10

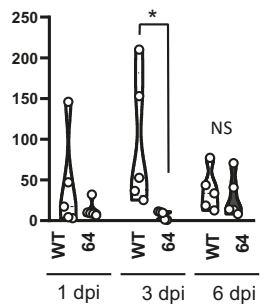

Figure 3. The $\mathrm{iV} \alpha 6 \mathrm{~T}$ cell response in tadpoles depends on active viral replication and productive FV3 infection. Three week-old (stage 55) tadpoles were infected with 10,000 PFUs of WT-or $\Delta 64-\mathrm{FV} 3$. At 1 , 3 , and 6 dpi, kidneys were collected and the total number of infectious particles was determined by plaque assay, respectively (A). Gene expression of iV $\alpha 6-\mathrm{J} \alpha 1.43$ (B) and XNC10 (C) was determined relative to an endogenous control (GAPDH) and relative expression was calculated against the lowest observed expression according to the $\Delta \Delta \mathrm{Ct}$ method $(n=5)$. No iV $\alpha 6-\mathrm{J} \alpha 1.43$ transcripts were detected in the kidney uninfected tadpoles. ${ }^{*} p<0.05$ and ${ }^{* *} p<0.01$ above the line denotes statistically significant differences between treatment groups; NS indicates no significant differences (one way ANOVA and Dunn's multiple comparison test).

\subsection{Targeted iV $\alpha 6 \mathrm{~T}$ cell depletion in vivo}

As mentioned, intraperitoneal (i.p.) infection of X. laevis tadpoles with FV3 results in a rapid and transitory increase in V $\alpha 6-\mathrm{J} \alpha 1.43$ transcript levels, both at the site of infection and in the kidney (main FV3 target organ), consistent with a direct and active involvement of this specific iT cell population in the early anti-FV3 response [13]. In support of this possibility, the developmental disruption of $\mathrm{iV} \alpha 6 \mathrm{~T}$ cells in MHC class I-like XNC10-deficient transgenic tadpoles results in increased susceptibility to FV3 [10]. However, silencing of XNC10 from early embryogenesis is likely to result in biological effects other than those inferred via the reciprocal loss of a unique iT cell population. Therefore, to more directly determine the role of $\mathrm{iV} \alpha 6 \mathrm{~T}$ cells in anti-viral defense against FV3 in the presence of a functional XNC10 gene, we targeted iV $\alpha 6$ T cells using XNC10 tetramers. XNC10 tetramers have been shown to selectively induce $\mathrm{iV} \alpha 6 \mathrm{~T}$ cell death ex vivo and to temporarily ablate V $\alpha 6-\mathrm{J} \alpha 1.43$ transcript levels in vivo (Banach et al., submitted). Accordingly, we injected X. laevis tadpoles with $1 \mu \mathrm{g}$ of XNC10 tetramers 1 day prior and 1 day following i.p. injection with FV3 and quantified transcript levels of the invariant V $\alpha 6-\mathrm{J} \alpha 1.43$ rearrangement in PLs and kidneys at different times following infection (Figure 4). Control groups received injections with an equivalent volume of amphibian PBS at the 
same time points. To evaluate viral loads and dissemination in the different groups, we determined the FV3 genome copy number using absolute qPCR (Figure 4D,E). In addition, we examined the gene expression of XNC10 to evaluate any impact of the injection regime on the expression of this MHC class I-like gene (Figure S3).
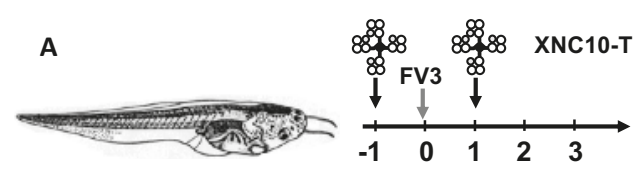

B Peritoneal leukocytes

C Kidney
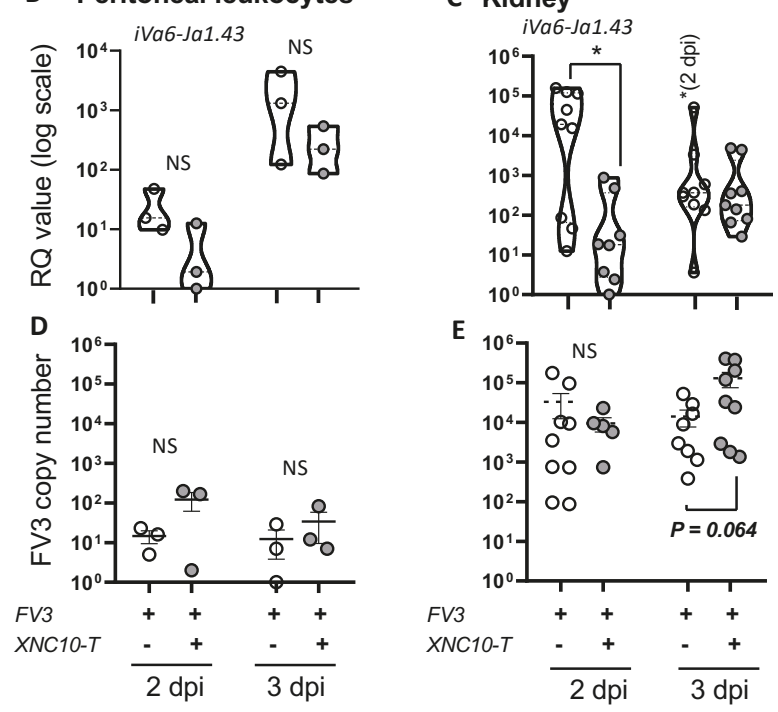

Figure 4. XNC10 tetramer-mediated iV $\alpha 6 \mathrm{~T}$ cell depletion in tadpoles affects $\mathrm{iV} \alpha 6-\mathrm{J} \alpha 1.43$ transcript levels and viral replication. PLs and kidneys were collected from three week-old (stage 55) tadpoles that had been injected with $1 \mu \mathrm{g}$ XNC10 tetramers (XNC10-T) or vehicle control 1 day pre, and 1 day post i.p. injected with 10,000 PFUs of FV3, at the indicated time points $(n=9)$. A schematic of the injection regime is shown in (A). Gene expression of $\mathrm{iV} \alpha 6-\mathrm{J} \alpha 1.43$ in PLs (B) and kidneys (C) is shown. Results are normalized to an endogenous control and presented as relative expression compared with the lowest observed value according to the $\Delta \Delta \mathrm{Ct}$ method. FV3 loads in PLs (D) and kidneys (E) were measured using absolute $\mathrm{QPCR}$ with primers against FV3 polymerase II. For PLs, each dot represents a pool of 3 tadpoles, while for kidneys, each dot represents a single tadpole; ${ }^{*} p<0.05$ denotes statistically significant differences between the indicated groups; NS indicates no significant differences (One way ANOVA followed by Tukey's multiple comparison test).

Consistent with $\mathrm{XNC} 10$ tetramers inducing $\mathrm{iV} \alpha 6 \mathrm{~T}$ cell death, $\mathrm{iV} \alpha 6-\mathrm{J} \alpha 1.43$ transcripts were markedly reduced, albeit not significantly, in the peritoneal cavity (site of infection) at $2 \mathrm{dpi}$, and remained lower than controls at $3 \mathrm{dpi}$. In the kidney, $\mathrm{iV} \alpha 6-\mathrm{J} \alpha 1.43$ transcripts were significantly lower in the XNC10 tetramer treated group at $2 \mathrm{dpi}$, reaching levels equivalent to controls by $3 \mathrm{dpi}$. It is noteworthy that consistent with previous reports, $\mathrm{iV} \alpha 6-\mathrm{J} \alpha 1.43$ transcripts were either undetected or near threshold levels in uninfected tadpoles. Thus, XNC10 tetramer treatment provides an efficient transient depletion of $\mathrm{iV} \alpha 6 \mathrm{~T}$ cells in vivo, providing us with a system to directly investigate the functional roles of $\mathrm{iV} \alpha 6 \mathrm{~T}$ cells. No significant difference was observed in XNC10 expression between the two groups (Figure S3). 
In regard to viral loads, while there was no significant difference in viral genome copy numbers in the peritoneal cavity, XNC10 tetramer treated tadpoles displayed a significantly $(p=0.005)$ higher viral load in the kidneys by 3 dpi (Figure 5B). By 6 dpi, using the same injection scheme as described in Figure $4 \mathrm{~A}$, there were significantly higher viral loads in the kidneys of the XNC10-tetramer treated group compared to vehicle control (Figure 5A). Notably, viral loads were not increased in tadpoles injected with XNC10 monomers, which do not bind to iV $\alpha 6 \mathrm{~T}$ cells [10]. In addition, XNC10 tetramer treatment had only a transitory effect on $\mathrm{iV} \alpha 6 \mathrm{~T}$ antiviral activity, as shown by comparable viral loads detected when FV3 infection occurred 3 days rather than 1 day after XNC10 tetramer injection (Figure 5A). To assess whether this increase in viral loads had an impact on host resistance, we determined the cumulative mortality and mean survival of XNC10 tetramer injected and FV3 challenged tadpoles (Figure 6). Notably, transitory depletion of antiviral iV $\alpha 6 \mathrm{~T}$ cells within $24 \mathrm{~h}$. of FV3 infection resulted in increased mortality rate compared with FV3 infected controls $(p=0.05)$. The seven-fold increase in post-mortem viral loads found in infected XNC10 tetramer-treated tadpoles that died within 6 to $20 \mathrm{dpi}$ compared to vehicle treated infected controls (Table S2) further suggests that the increased mortality was due to an inefficient control of viral infection. These data support the conclusion that $\mathrm{iV} \alpha 6 \mathrm{~T}$ cells are intricately involved in X. laevis anti-FV3 immune responses and highlight the importance of an efficient onset of appropriate anti-viral immune response in order to control and efficiently combat FV3 infection.

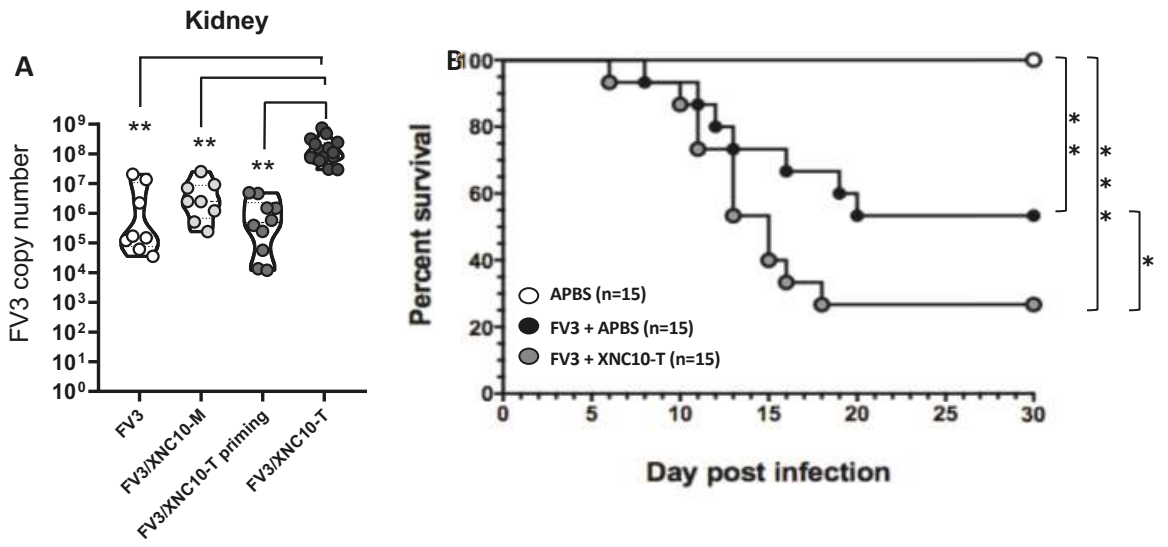

Figure 5. Specificity and long term impact of transitory iV $\alpha 6 \mathrm{~T}$ cell depletion. (A) Three week-old (stage 55) tadpoles were injected with either $1 \mu \mathrm{g}$ XNC10-tetramers (FV3/XNC10-T), $1 \mu \mathrm{g}$ XNC10-monomers (FV3/XNC10-M), or vehicle control (FV3/APBS) 1 day pre and 1 day post i.p. infection with 10,000 PFUs of FV3 $(n=8)$, and kidneys were collected at 6 dpi. The last group (FV3/XNC10-T priming) was first injected with $1 \mu \mathrm{g}$ XNC10-tetramers, then 3 days later infected with FV3, and kidneys were collected at 6 dpi. Viral loads were assessed by absolute qPCR with primers against FV3 polymerase II. The results are combined from two separate experiments, and each dot represents an individual tadpole; ** $p<0.01$ above the line denotes statistically significant differences between the indicated groups (One way ANOVA followed by Tukey's multiple comparison test). (B) Three week-old (stage 55) tadpoles were injected with either $1 \mu \mathrm{g}$ XNC10 tetramers (FV3/XNC10-T) or vehicle control (FV3/APBS) 1 day pre, and 1 day post were i.p injected with 10,000 PFUs of FV3 $(n=15)$ and survival was monitored daily over a 30-day period. Survival was determined using Kaplan-Meier, ${ }^{*} p<0.05,{ }^{* *} p<0.005$, and ${ }^{* * *} p<0.0005$. Uninfected controls (white circle), FV3 infected tadpoles (black circle), and XNC10 tetramer treated FV3 infected tadpoles (grey circle). 

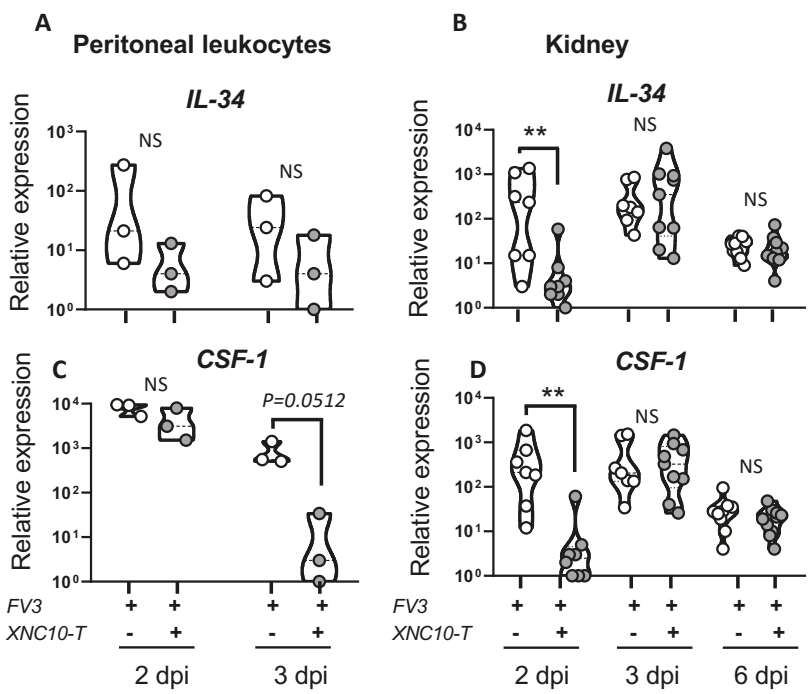

Figure 6. Effect of XNC10 tetramer treatment on the expression of the macrophage stimulating factor genes CSF-1 and IL-34 in the peritoneal cavity and kidneys of FV3 infected tadpoles. PLs and kidneys were collected from three week-old (stage 55) tadpoles that had been injected with $1 \mu \mathrm{g}$ XNC10 tetramers or vehicle control 1 day pre- and 1 day post-i.p. injection with 10,000 PFUs of FV3, at the indicated time points $(n=8-9)$. Quantitative gene expression analysis of IL-34 (A,B) and CSF-1(C,D) were determined relative to a endogenous control (GAPDH), and relative expression was calculated against the lowest observed expression according to the $\Delta \Delta \mathrm{Ct}$ method $(n=9)$; ${ }^{* *} p<0.005$ above the line denotes statistically significant differences between the different treatment groups; NS indicates no significant differences (One way ANOVA followed by Tukey's multiple comparison test).

\subsection{Effects of $i V \alpha 6 T$ cell depletion on PLs and kidney antiviral responses in tadpoles}

We have previously shown that the compromised anti-FV3 response observed in XNC10-deficient transgenic frogs correlates with the induction of macrophages, exhibiting a less potent antiviral state [10]. In particular, XNC10 deficiency hampered the expression of the macrophage growth factor IL-34. Notably, IL-34 has been shown to elicit the differentiation of mononuclear phagocytes into robust type I interferon (type I IFN), producing macrophages exhibiting strong FV3 antiviral activity [19]. These findings prompted us to hypothesize that $\mathrm{iV} \alpha 6 \mathrm{~T}$ cells promote timely and efficient type I IFN-mediated anti-FV3 responses by influencing the polarization of macrophages into a more potent antiviral state. Thus, to further delineate the putative functional roles of iV $\alpha 6 \mathrm{~T}$ cells during FV3 infection, we next determined if direct and transient $\mathrm{iV} \alpha 6 \mathrm{~T}$ cell depletion has an impact on macrophage effector functions. To address this possibility, we monitored the expression profiles of the two macrophage growth factors CSF-1 [20] and IL-34 [19] in PLs and kidneys (Figure 6) from FV3 infected tadpoles, with or without XNC10 tetramer treatment. Both IL-34 and CSF-1 transcription levels were significantly lower in the kidneys of XNC10 tetramer treated tadpoles at 2 dpi, correlating with the reduced iV $\alpha 6-\mathrm{J} \alpha 1.43$ expression, and levels comparable to controls were reached by $3 \mathrm{dpi}$.

Given that the type I IFN response is critical in controlling viral infections and is compromised in XNC10-deficient animals [13], we postulated that a direct impairment of iV $\alpha 6$ T cells should affect type I IFN gene expression to a similar extent. Indeed, unlike control animals, both type I IFN and type III IFN gene expression were magnitudes lower at $3 \mathrm{dpi}$ in PLs of XNC10 tetramer treated animals compared to controls, whereas the levels of type II IFN were highly variable between animals, with no apparent difference in expression between the two groups (Figure 7A-C). Similarly, in kidneys the expression of both type I and type III IFN genes was significantly impaired in XNC10 tetramer treated 
animals at $2 \mathrm{dpi}$, whereas by $3 \mathrm{dpi}$ both treated and control groups exhibited high transcript levels of type I and type III IFN (Figure 7D,E).

In response to a viral infection, protective host response relies on the onset of appropriate cell-mediated immunity to mediate viral clearance. Thus, we next examined the expression of interleukin18 (IL-18) and interleukin 12 (IL-12) upon FV3 infection in PLs and kidneys of control and $\mathrm{iV} \alpha 6 \mathrm{~T}$ cell deficient tadpoles. Both IL-18 and IL-12 are produced by macrophages and act in synergy to promote the development of innate and specific Th1 type immune responses [21-23]. Given that iV $\alpha 6 \mathrm{~T}$ cell deficiency hampers the induction of macrophage differentiating factors, resulting in a delayed interferon response, we postulated that IL-18 and IL-12 cytokine production would be similarly impaired. Indeed, unlike control animals, IL-18 expression was significantly lower at $2 \mathrm{dpi}$ in kidneys of XNC10 tetramer treated animals, whereas at 3 dpi XNC10 tetramer treated tadpoles exhibited elevated IL-18 transcript levels on par with that of controls that were significantly reduced by $6 \mathrm{dpi}$ in both groups (Figure 8). While there was a slight decrease in IL-12 gene expression at $2 \mathrm{dpi}$ in XNC10 tetramer treated animals, it was not statistically significant.

Overall, these findings are in accordance with what had previously been reported for XNC10-deficient transgenic animals (that lack both XNC10 and iV $\alpha 6 \mathrm{~T}$ cells, [13]), suggesting that $i \mathrm{~V} \alpha 6 \mathrm{~T}$ cells are directly and critically involved in mounting an anti-FV3 response, and that acute loss or impairment of these cells result in both a delayed type I and type III IFN antiviral response, as well as a delayed IL-18 response.
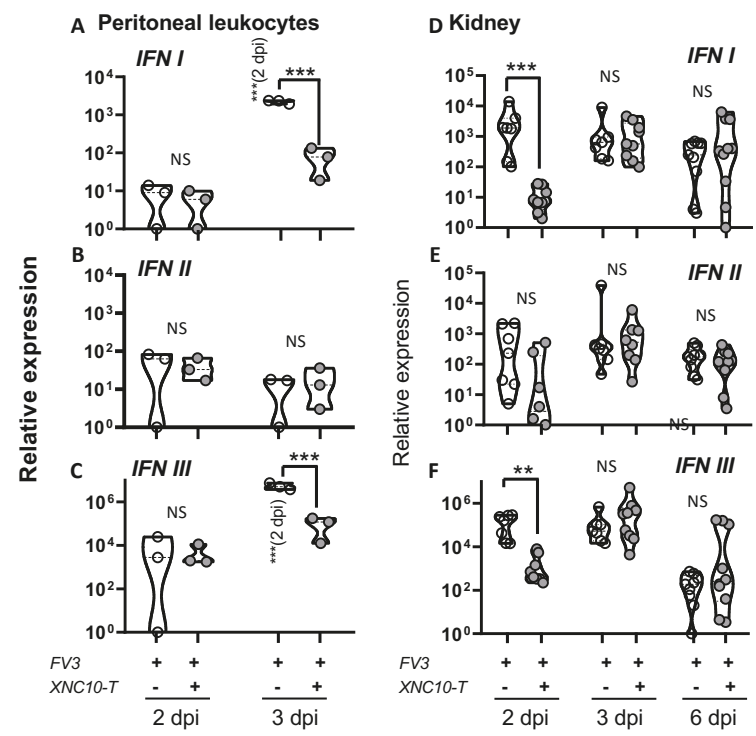

Figure 7. XNC10 tetramer treatment results in a delayed antiviral response in the peritoneal cavity and kidneys of FV3 infected tadpoles. PLs and kidneys were collected from three week-old (stage 55) tadpoles that had been injected with $1 \mu \mathrm{g}$ XNC10 tetramers (XNC10-T) or vehicle control 1 day pre- and 1 day post-i.p. injection with 10,000 PFUs of FV3, at the indicated time points $(n=8-9)$. Quantitative gene expression analysis of type I (A,D), type II (B,E), and type III IFN $(\mathbf{C}, \mathbf{F})$ were determined relative to a endogenous control (GAPDH), and relative expression was calculated against the lowest observed expression according to the $\Delta \Delta \mathrm{Ct}$ method $(n=9) ;{ }^{*} p<0.05,{ }^{* *} p<0.005$, and ${ }^{* * *} p<0.001$ above the line denote statistically significant differences between the different treatment groups; significant differences between time points within each treatment group is indicated within parentheses; NS indicates no significant differences (One way ANOVA followed by Tukey's multiple comparison test). 


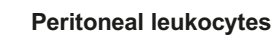

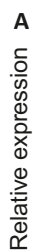
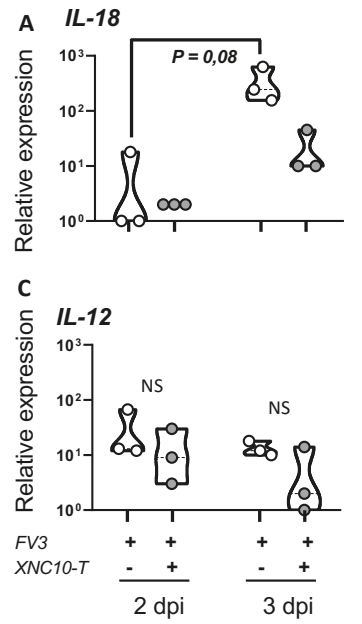
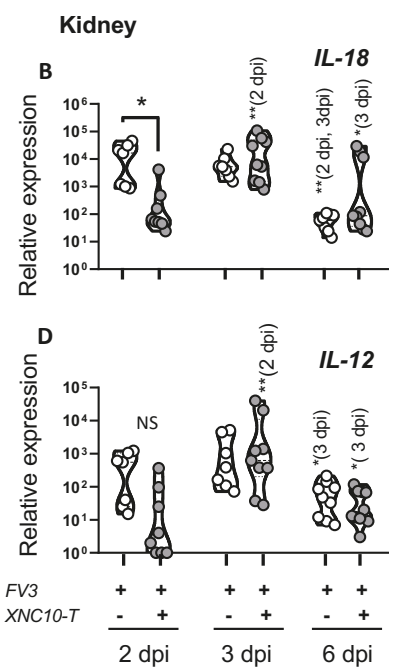

Figure 8. Effects of iV $\alpha 6 \mathrm{~T}$ cell depletion on IL-18 and IL-12 responses. PLs and kidneys were collected from three week-old (stage 55) tadpoles that had been injected with $1 \mu \mathrm{g}$ XNC10 tetramers (XNC10-T) or vehicle control 1 day pre- and 1 day post-i.p. injection with 10,000 PFUs of FV3, at the indicated time points $(n=8-9)$. Quantitative gene expression of IL-18 (A,B) and type IL-12 (C,D) was determined relative to an endogenous control (GAPDH) and relative expression was calculated against the lowest observed expression according to the $\Delta \Delta \mathrm{Ct}$ method $(n=9) ;{ }^{*} p<0.05 ; * *<<0.005$, above the line denotes statistically significant differences between the different treatment groups; significant differences between time points within each treatment group is indicated within parentheses; NS indicates no significant differences (One way ANOVA followed by Tukey's multiple comparisons test).

\section{Discussion}

The present study provides new insights into the requirement for an effective amphibian host response to the ranavirus FV3 trough, an early detection by the MHC class I-like XNC10, and the rapid recruitment of the activated XNC10-restricted innate T cell subset $\mathrm{iV} \alpha 6$. A remarkable feature of this novel antiviral immune surveillance system is that it is prominent in naturally classical MHC class Ia-deficient tadpoles, whereas it is a component in class Ia and conventional $\mathrm{T}$ cell competent adults. Nevertheless, while this antiviral system is central for tadpole survival at early stage of FV3 infection, it is also critical for a timely control of viral burden in adult frogs. To better functionally define this novel antiviral immune surveillance system, we examined the initial conditions of FV3 infection that triggers the iV $\alpha 6 \mathrm{~T}$ cell response by using deficient FV3 recombinants, and we defined the antiviral immune response initiated by $\mathrm{iV} \alpha 6 \mathrm{~T}$ cells.

The critical role of iNKT cells in antiviral immunity is well documented in mammals, where their pre-activated or memory phenotypes allow them to serve as early responders (within hours following infection) without requiring expansion as conventional $\mathrm{T}$ cells $[7,24]$. Similarly, in X. laevis, we have shown a rapid increase of iV $\alpha 6-\mathrm{J} \alpha 1.43$ transcript levels (within $1 \mathrm{dpi}$ ) at the site of FV3 infection in the peritoneum and in the main site of viral replication in the kidney, concomitant with a decrease in the spleen. Notably, the recruitment of these $\mathrm{iV} \alpha 6 \mathrm{~T}$ cells occurs days before significant proliferation of conventional $\mathrm{T}$ cells, which become significant only from 3 dpi onward in the spleen [25]. This strongly suggests that $\mathrm{iV} \alpha 6 \mathrm{~T}$ cells are rapidly activated and recruited from the spleen by FV3 infection [13].

Here, we provide further evidence that $\mathrm{iV} \alpha 6 \mathrm{~T}$ cell recruitment occurs in direct response to FV3 infection and is not indirectly triggered by inflammation induced by heat-killed bacteria or by a replication-defective $\Delta 64$-FV3 recombinant. Furthermore, while both attenuated $\Delta 64-F V 3$ and heat-killed bacterial stimulation induced an early transcriptional induction of the MHC class I-like 
$\mathrm{XNC10}$ that restricts $\mathrm{iV} \alpha 6 \mathrm{~T}$ cells, these elevated expression levels were only maintained in WT-FV3 infected frogs. This suggests a coordinated role of XNC10 and iV $\alpha 6 \mathrm{~T}$ cells in detecting and eliciting a rapid response against ranavirus pathogens. This coordinate response of XNC10 and iV $\alpha 6 \mathrm{~T}$ cells only induced by a productive viral infection is also consistent with the detection of virally-derived products or ligands. It is unknown whether XNC10 binds ligands, and if so the identity of such putative XNC10 ligands is currently unknown, but nucleotide sequence comparisons and 3D-modeling of the putative ligand binding regions indicate that $\mathrm{XNC10}$ could accommodate lipid ligands in a way reminiscent of CD1d $[3,26,27]$. Thus, it is tempting to speculate that XNC10 can be upregulated and bind products and ligands from early FV3 replication or release of assembled viruses to activate iV $\alpha 6$ $\mathrm{T}$ cell response. In this scenario, infection by $\Delta 64$-FV3 would not lead to sufficient production and release of FV3-derived products and ligands to initiate $\mathrm{iV} \alpha 6 \mathrm{~T}$ cell recruitment and activation.

Interestingly, the correlation between defective viral replication, blunted XNC10 gene expression response, and impaired $\mathrm{iV} \alpha 6 \mathrm{~T}$ cell recruitment was more robust in tadpoles. This may be due to the heavier reliance on iT cells in tadpoles. In absence of an efficient classical MHC-I restricted conventional CD8 T cell response, iV $\alpha 6 \mathrm{~T}$ cells are likely to be more directly and critically involved in tadpole host response against FV3. This is evidenced by marked vulnerability of XNC10-deficient transgenic tadpoles lacking iV $\alpha 6 \mathrm{~T}$ cell to FV3 infection, especially at early stages of infection [10]. Our findings using XNC10 tetramer treatment substantiate this initial requirement of $\mathrm{iV} \alpha 6 \mathrm{~T}$ cell response for controlling viral infection and host resistance to FV3. Indeed, a partial and transient depletion of iV $\alpha 6$ $\mathrm{T}$ cells prompted by injection of XNC10 tetramers shortly before and after infection impairs tadpole immune defenses, which not only leads to more severe viral burden but also decreased survival rate.

While the effector functions of $\mathrm{iV} \alpha 6 \mathrm{~T}$ cells are likely to be multifaceted, our previous findings support a role of these cells as immune modulators that influence the polarization of peritoneal macrophages into a more robust anti-viral state [13]. Although XNC10 gene expression is detectable on peritoneal macrophages, in absence of XNC10-specific antibodies, it is currently unknown whether all macrophages express XNC10 molecules at the cell surface and whether macrophages can modulate XNC10 surface expression upon FV3 infection. It is noteworthy that the expression of type I and III IFN, as well as cytokines, such as CSF-1 and IL-18, are transiently altered in parallel to iV $\alpha 6 \mathrm{~T}$ cell depletion. Little is known about the iV $\alpha 6 \mathrm{~T}$ cell mechanism of action, but previous findings have hinted at a modulation of macrophages $[10,13]$. While type I and III IFN is likely produced and released by many cell types, the rapid increase of their transcript levels in the peritoneum and kidneys upon FV3 infection coincides with the recruitment of monocytic phagocytes, both in tadpoles and adult frogs $[18,28,29]$. Infiltration of MHC class II+ leukocytes in kidneys at early stages of FV3 infection is also consistent with infiltration of macrophages [25]. CSF-1 and IL-34 are two key macrophage growth factors acting through the same CSF-1 receptor across jawed vertebrates [30]. In X. laevis, CSF-1 is required for the commitment and maturation of mature macrophage lineage cells [20], whereas IL-34 stimulates a stronger antiviral effector function by macrophages both in tadpoles and adult frogs [19,31]. The acute decrease in type I and III IFN, as well as CSF- 1 and IL-34 at 2 dpi concomitantly with the $\mathrm{XNC} 10$ tetramer-mediated $\mathrm{iV} \alpha 6 \mathrm{~T}$ cell defect, reinforces the postulated functional link between $\mathrm{iV} \alpha 6 \mathrm{~T}$ cells and macrophages. This, of course, does not preclude a possible interaction of $\mathrm{iV} \alpha 6 \mathrm{~T}$ cells with other immune cell effectors, as well as a reciprocal effect of macrophages on $\mathrm{iV} \alpha 6 \mathrm{~T}$ cells. Indeed, macrophages in mammals are known to be important producers of IL-12 and IL-18, two cytokines that stimulate iNKT cells and promote Th1 adaptive immune response [21,22,32]. The transitory blunted expression of IL-18, and to a lesser extent IL-12, that accompanied iV $\alpha 6 \mathrm{~T}$ cell transient defect, besides being consistent with decreased macrophage function, may have amplified XNC10 tetramer-mediated $\mathrm{iV} \alpha 6 \mathrm{~T}$ cell impairment. In any case, it is remarkable that the brief interference of $\mathrm{iV} \alpha 6 \mathrm{~T}$ cell function has a long-lasting negative impact on the tadpole ability to control FV3 infection, and ultimately to survive infection.

Supplementary Materials: The following are available online at http://www.mdpi.com/1999-4915/11/4/330/s1, Figure S1: Viral loads in WT- or $\Delta 64$-FV3 infected adult frogs determined by plaque assay. Figure S2: Viral loads in 
WT- or $\triangle 64$-FV3 infected tadpoles determined by plaque assay. Figure S3: Effects of iVa6T cell depletion on XNC10 transcript levels. Table S1: List of qPCR primer sequences. Table S2: FV3 genome copy number in post-mortem tadpoles treated or not with XNC10-tetramers and infected with FV3.

Author Contributions: Conceptualization, E-S.I.E., F.D.J.A. and J.R.; methodology, E-S.I.E., F.D.J.A., J.Y., K.W. and J.R.; validation, E-S.I.E., F.D.J.A., J.Y. and K.W.; formal analysis, E-S.I.E., F.D.J.A., J.Y., K.W. and J.R.; investigation, E-S.I.E., F.D.J.A., J.Y., and K.W.; resources, J.R.; data curation, E-S.I.E., F.D.J.A.; writing - original draft preparation, E-S.I.E., F.D.J.A., and J.R.; writing—review and editing, E-S.I.E., F.D.J.A., J.Y., K.W. and J.R.; project administration, F.D.J.A and J.R.; funding acquisition, J.R.

Funding: This work was supported by the National Institute of Allergy and Infectious Diseases at the National Institutes of Health (grant number: R24-AI-059830), the National Science Foundation (grant number: IOS- 1456213 and 1754274), and the Tromsø Research Foundation Starting Grant.

Acknowledgments: We thank Tina Martin for animal husbandry.

Conflicts of Interest: The authors declare no conflict of interest.

\section{References}

1. Adams, E.J.; Luoma, A.M. The adaptable major histocompatibility complex (MHC) fold: Structure and function of nonclassical and MHC class I-like molecules. Annu. Rev. Immunol. 2013, 31, 529-561. [CrossRef]

2. Borg, N.A.; Wun, K.S.; Kjer-Nielsen, L.; Wilce, M.C.; Pellicci, D.G.; Koh, R.; Besra, G.S.; Bharadwaj, M.; Godfrey, D.I.; McCluskey, J.; et al. CD1d-lipid-antigen recognition by the semi-invariant NKT T-cell receptor. Nature 2007, 448, 44-49. [CrossRef] [PubMed]

3. Rossjohn, J.; Pellicci, D.G.; Patel, O.; Gapin, L.; Godfrey, D.I. Recognition of CD1d-restricted antigens by natural killer T cells. Nat. Rev. Immunol. 2012, 12, 845-857. [CrossRef] [PubMed]

4. Wesley, J.D.; Tessmer, M.S.; Chaukos, D.; Brossay, L. NK Cell-Like Behavior of V $\alpha 14$ i NK T Cells during MCMV Infection. PLoS Pathog. 2008, 4, e1000106. [CrossRef] [PubMed]

5. Diana, J.; Griseri, T.; Lagaye, S.; Beaudoin, L.; Autrusseau, E.; Gautron, A.-S.; Tomkiewicz, C.; Herbelin, A.; Barouki, R.; von Herrath, M.; et al. NKT Cell-Plasmacytoid Dendritic Cell Cooperation via OX40 Controls Viral Infection in a Tissue-Specific Manner. Immunity 2009, 30, 289-299. [CrossRef] [PubMed]

6. Raftery, M.J.; Winau, F.; Giese, T.; Kaufmann, S.H.; Schaible, U.E.; Schonrich, G. Viral danger signals control CD1d de novo synthesis and NKT cell activation. Eur. J. Immunol. 2008, 38, 668-679. [CrossRef] [PubMed]

7. Juno, J.A.; Keynan, Y.; Fowke, K.R. Invariant NKT cells: Regulation and function during viral infection. PLoS Pathog. 2012, 8, e1002838. [CrossRef]

8. Abboud, G.; Tahiliani, V.; Desai, P.; Varkoly, K.; Driver, J.; Hutchinson, T.E.; Salek-Ardakani, S. Natural Killer Cells and Innate Interferon Gamma Participate in the Host Defense against Respiratory Vaccinia Virus Infection. J. Virol. 2016, 90, 129-141. [CrossRef] [PubMed]

9. Edholm, E.S.; Banach, M.; Robert, J. Evolution of innate-like T cells and their selection by MHC class I-like molecules. Immunogenetics 2016, 68, 525-536. [CrossRef]

10. Edholm, E.S.; Albertorio Saez, L.M.; Gill, A.L.; Gill, S.R.; Grayfer, L.; Haynes, N.; Myers, J.R.; Robert, J. Nonclassical MHC class I-dependent invariant T cells are evolutionarily conserved and prominent from early development in amphibians. Proc. Natl. Acad. Sci. USA 2013, 110, 14342-14347. [CrossRef]

11. Price, S.J.; Garner, T.W.; Nichols, R.A.; Balloux, F.; Ayres, C.; Mora-Cabello de Alba, A.; Bosch, J. Collapse of amphibian communities due to an introduced Ranavirus. Curr. Biol. CB 2014, 24, 2586-2591. [CrossRef] [PubMed]

12. Gray, M.J.; Chinchar, V.G. Ranaviruses; Springer Open: Heidelberg, Germany; New York, NY, USA; Dordrecht, The Netherland; London, UK, 2015.

13. Edholm, E.S.; Grayfer, L.; De Jesus Andino, F.; Robert, J. Nonclassical MHC-Restricted Invariant Valpha6 T Cells Are Critical for Efficient Early Innate Antiviral Immunity in the Amphibian Xenopus laevis. J. Immunol. 2015, 195, 576-586. [CrossRef] [PubMed]

14. Nieuwkoop, P.; Faber, J. Normal Table of Xenopus Laevis (Daudin): A Systematical and Chronological Survey of the Development from the Fertilized Egg Till the End of Metamorphosis, 2nd ed.; North Holland: Amsterdam, The Netherland, 1967.

15. Andino Fde, J.; Grayfer, L.; Chen, G.; Gregory Chinchar, V.; Edholm, E.S.; Robert, J. Characterization of Frog Virus 3 knockout mutants lacking putative virulence genes. Virology 2015, 485, 162-170. [CrossRef] [PubMed] 
16. Chen, G.; Ward, B.M.; Yu, K.H.; Chinchar, V.G.; Robert, J. Improved knockout methodology reveals that frog virus 3 mutants lacking either the $18 \mathrm{~K}$ immediate-early gene or the truncated vIF-2alpha gene are defective for replication and growth in vivo. J. Virol. 2011, 85, 11131-11138. [CrossRef]

17. Jacques, R.; Edholm, E.S.; Jazz, S.; Odalys, T.L.; Francisco, J.A. Xenopus-FV3 host-pathogen interactions and immune evasion. Virology 2017, 511, 309-319. [CrossRef]

18. Morales, H.D.; Abramowitz, L.; Gertz, J.; Sowa, J.; Vogel, A.; Robert, J. Innate immune responses and permissiveness to ranavirus infection of peritoneal leukocytes in the frog Xenopus laevis. J. Virol. 2010, 84, 4912-4922. [CrossRef]

19. Grayfer, L.; Robert, J. Divergent antiviral roles of amphibian (Xenopus laevis) macrophages elicited by colony-stimulating factor-1 and interleukin-34. J. Leukoc. Biol. 2014, 96, 1143-1153. [CrossRef]

20. Grayfer, L.; Robert, J. Colony-Stimulating Factor-1-Responsive Macrophage Precursors Reside in the Amphibian (Xenopus laevis) Bone Marrow Rather than the Hematopoietic Sub-Capsular Liver. J. Innate Immun. 2013, 5, 531-542. [CrossRef]

21. Barbarin, A.; Cayssials, E.; Jacomet, F.; Nunez, N.G.; Basbous, S.; Lefevre, L.; Abdallah, M.; Piccirilli, N.; Morin, B.; Lavoue, V.; et al. Phenotype of NK-Like CD8(+) T Cells with Innate Features in Humans and Their Relevance in Cancer Diseases. Front. Immunol. 2017, 8, 316. [CrossRef]

22. Huber, C.M.; Doisne, J.M.; Colucci, F. IL-12/15/18-preactivated NK cells suppress GvHD in a mouse model of mismatched hematopoietic cell transplantation. Eur. J. Immunol. 2015, 45, 1727-1735. [CrossRef]

23. Zajonc, D.M.; Girardi, E. Recognition of Microbial Glycolipids by Natural Killer T Cells. Front. Immunol. 2015, 6, 400. [CrossRef]

24. Kohlgruber, A.C.; Donado, C.A.; LaMarche, N.M.; Brenner, M.B.; Brennan, P.J. Activation strategies for invariant natural killer T cells. Immunogenetics 2016, 68, 649-663. [CrossRef] [PubMed]

25. Morales, H.D.; Robert, J. Characterization of primary and memory CD8 T-cell responses against ranavirus (FV3) in Xenopus laevis. J. Virol. 2007, 81, 2240-2248. [CrossRef]

26. Edholm, E.S.; Goyos, A.; Taran, J.; De Jesus Andino, F.; Ohta, Y.; Robert, J. Unusual evolutionary conservation and further species-specific adaptations of a large family of nonclassical MHC class Ib genes across different degrees of genome ploidy in the amphibian subfamily Xenopodinae. Immunogenetics 2014, 66, 411-426. [CrossRef] [PubMed]

27. Goyos, A.; Sowa, J.; Ohta, Y.; Robert, J. Remarkable conservation of distinct nonclassical MHC class I lineages in divergent amphibian species. J. Immunol. 2011, 186, 372-381. [CrossRef]

28. De Jesús Andino, F.; Chen, G.; Li, Z.; Grayfer, L.; Robert, J. Susceptibility of Xenopus laevis tadpoles to infection by the ranavirus Frog-Virus 3 correlates with a reduced and delayed innate immune response in comparison with adult frogs. Virology 2012, 432, 435-443.

29. Grayfer, L.; De Jesus Andino, F.; Robert, J. Prominent amphibian (Xenopus laevis) tadpole type III interferon response to the frog virus 3 ranavirus. J. Virol. 2015, 89, 5072-5082. [CrossRef]

30. Droin, N.; Solary, E. Editorial: CSF1R, CSF-1, and IL-34, a "menage a trois" conserved across vertebrates. J. Leukoc. Biol. 2010, 87, 745-747. [CrossRef]

31. Grayfer, L.; Robert, J. Distinct functional roles of amphibian (Xenopus laevis) colony-stimulating factor-1and interleukin-34-derived macrophages. J. Leukoc. Biol. 2015, 98, 641-649. [CrossRef]

32. Yasuda, K.; Nakanishi, K.; Tsutsui, H. Interleukin-18 in Health and Disease. Int. J. Mol. Sci. 2019, 20 , E649. [CrossRef]

(C) 2019 by the authors. Licensee MDPI, Basel, Switzerland. This article is an open access article distributed under the terms and conditions of the Creative Commons Attribution (CC BY) license (http://creativecommons.org/licenses/by/4.0/). 
Article

\title{
Description of a Natural Infection with Decapod Iridescent Virus 1 in Farmed Giant Freshwater Prawn, Macrobrachium rosenbergii
}

\author{
Liang Qiu ${ }^{1,+}\left(\mathbb{D}\right.$, Xing Chen ${ }^{1,2,+}$, Ruo-Heng Zhao ${ }^{1,3}$, Chen Li $^{1}$, Wen Gao ${ }^{1,2}$, Qing-Li Zhang ${ }^{1,2}$ \\ and Jie Huang 1,2,3,* \\ 1 Yellow Sea Fisheries Research Institute, Chinese Academy of Fishery Sciences; Laboratory for Marine \\ Fisheries Science and Food Production Processes, National Laboratory for Marine Science and \\ Technology (Qingdao); Key Laboratory of Maricultural Organism Disease Control, Ministry of Agriculture \\ and Rural Affairs; Qingdao Key Laboratory of Mariculture Epidemiology and Biosecurity, Qingdao 266071, \\ China; qiuliang@ysfri.ac.cn (L.Q.); chenxing910520@163.com (X.C.); ruohengzhao@126.com (R.-H.Z.); \\ lichen@ysfri.ac.cn (C.L.); gaowen1994@163.com (W.G.); zhangql@ysfri.ac.cn (Q.-L.Z.) \\ 2 Shanghai Ocean University, Shanghai 201306, China \\ 3 Dalian Ocean University, Dalian 116023, China \\ * Correspondence: huangjie@ysfri.ac.cn; Tel.: +86-138-0542-1513 \\ + These authors contributed to the work equally and should be regarded as co-first authors.
}

Received: 13 February 2019; Accepted: 16 April 2019; Published: 17 April 2019

\begin{abstract}
Macrobrachium rosenbergii is a valuable freshwater prawn in Asian aquaculture. In recent years, a new symptom that was generally called "white head" has caused high mortality in $M$. rosenbergii farms in China. Samples of $M$. rosenbergii, M. nipponense, Procambarus clarkii, M. superbum, Penaeus vannamei, and Cladocera from a farm suffering from white head in Jiangsu Province were collected and analyzed in this study. Pathogen detection showed that all samples were positive for Decapod iridescent virus 1 (DIV1). Histopathological examination revealed dark eosinophilic inclusions and pyknosis in hematopoietic tissue, hepatopancreas, and gills of $M$. rosenbergii and $M$. nipponense. Blue signals of in situ digoxigenin-labeled loop-mediated isothermal amplification appeared in hematopoietic tissue, hemocytes, hepatopancreatic sinus, and antennal gland. Transmission electron microscopy of ultrathin sections showed a large number of DIV1 particles with a mean diameter about $157.9 \mathrm{~nm}$. The virogenic stromata and budding virions were observed in hematopoietic cells. Quantitative detection with TaqMan probe based real-time PCR of different tissues in naturally infected $M$. rosenbergii showed that hematopoietic tissue contained the highest DIV1 load with a relative abundance of $25.4 \pm 16.9 \%$. Hepatopancreas and muscle contained the lowest DIV1 loads with relative abundances of $2.44 \pm 1.24 \%$ and $2.44 \pm 2.16 \%$, respectively. The above results verified that DIV1 is the pathogen causing white head in $M$. rosenbergii. M. nipponense and Pr. clarkii are also species susceptible to DIV1.
\end{abstract}

Keywords: DIV1; SHIV; CQIV; Macrobrachium rosenbergii; Macrobrachium nipponense; Procambarus clarkii; white head; susceptible species; viral load

\section{Introduction}

Globally, viral diseases have been acknowledged as a huge threat to the shrimp aquaculture industry. Among the viruses reported for crustaceans, Cherax quadricarinatus iridovirus (CQIV) and Shrimp hemocyte iridescent virus (SHIV) are two newly found viruses isolated from red claw crayfish C. quadricarinatus [1] and white leg shrimp Penaeus vannamei [2], respectively. CQIV and SHIV both have a typical icosahedral structure with a mean diameter of about $150 \mathrm{~nm}$ [1,2]. Evidence from 
histopathological study, transmission electron microscope (TEM) of ultrathin sections, and in situ hybridization (ISH) indicated that SHIV may mainly infect the hematopoietic tissue and hemocytes in gills, hepatopancreas, pereiopods, and muscle of P. vannamei [2]. Similarly, the TEM also showed that CQIV could infect hematopoietic tissue and gills in C. quadricarinatus and P. vannameii [1]. Phylogenetic analysis supported that SHIV and CQIV belong to a new genus, which was originally proposed to be named Xiairidovirus or Cheraxvirus, in the family Iridoviridae [2-4]. Alignment of the complete genomic sequences revealed that SHIV and CQIV might be different strains or genotypes of the same viral species [5]. In March 2019, the Executive Committee of the International Committee on Taxonomy of Viruses (ICTV) approved the proposal made by Chinchar et al. [6] that a new species of Decapod iridescent virus 1 (DIV1) in a new genus Decapodiridovirus to include SHIV 20141215 and CQIV CN01 as two isolates. We follow the ICTV's decision to use the formally recognized name for general indication of the virus or newly identified strains, and SHIV 20141215 and CQIV CN01 for individualization of the original isolations. To date, DIV1 has been detected in farmed P. vannamei, P. chinensis, P. japonicus, C. quadricarinatus, Procambarus clarkii, Macrobrachium nipponense, and M. rosenbergii in China since $2014[1,4,7]$, indicating that DIV1 is a new threat to the shrimp farming industry.

The giant freshwater prawn, $M$. rosenbergii, a valuable crustacean species in Asian aquaculture, are widely cultured in tropical and subtropical areas. M. rosenbergii is native to Malaysia and other Asian countries, including Vietnam, Cambodia, Thailand, Myanmar, Bangladesh, India, Sri Lanka, and the Philippines [8,9]. Being popular for its delicious flesh and high nutritional value, the global production of this species has increased from about 3,000 tons in 1980 to more than 220,000 tons in 2014 [10,11]. Generally, $M$. rosenbergii is considered less prone to some viral diseases in aquaculture when compared to penaeid shrimps [12]. Some viral pathogens, such as Macrobrachium hepatopancreatic parvo-like virus (MHPV), Macrobrachium muscle virus (MMV), Infectious hypodermal and hematopoietic necrosis virus (IHHNV), White spot syndrome virus (WSSV), Macrobrachium rosenbergii nodavirus (MrNV), and Extra small virus like particle (XSV), have been reported in prawns [13]. Recently, results of RT-LAMP and histopathological examination indicated that $M$. rosenbergii could be infected with Covert mortality nodavirus (CMNV) [14]. To date, only PCR results showed that cultured M. rosenbergii were DIV1 positive $[2,7]$ and more pathological information is not available.

In recent years, a new symptom that occurred in M. rosenbergii farms in China has been commonly called "white head" or "white spot", due to the diseased prawn exhibited a typical white triangle under the carapace at the base of rostrum [15]. Moribund prawns resting on the bottom in deep water and dead prawns can be found every day, with a cumulative mortality up to $80 \%$. It is noteworthy that many $M$. rosenbergii populations suffering from white head were polycultured with $P$. vannamei [16]. In the present study, we investigated a diseased polyculture pond with $M$. rosenbergii and Pr. clarkii. In the pond, most of the $M$. rosenbergii exhibited typical the white triangle under the carapace at the base of rostrum and appeared moribund or died. One month before we arrived, all of the P. vannamei in an adjacent pond had died. Samples were collected and analyzed in this study.

\section{Materials and Methods}

All the protocols of animal handling and sampling were approved by the Animal Care and Ethics Committee, Yellow Sea Fisheries Research Institute, Chinese Academy of Fishery Sciences, and all efforts were made to minimize the suffering of animals according to recommendations proposed by the European Commission (1997). The study was carried out in accordance with the approved protocol. All the methods were applied in accordance with relevant guidelines.

\subsection{Samples}

Samples of farmed M. rosenbergii $(4-6 \mathrm{~cm})$ and Pr. clarkii $(5-7 \mathrm{~cm})$ were collected from the pond with high mortality in a farm in Jiangsu Province on 20 June 2018. In the same pond, some wild crustaceans, including M. nipponense, M. superbum, and some species of Cladocera, were also sampled 
for further analysis. Dead and dry bodies of $P$. vannamei $(5-7 \mathrm{~cm})$ were collected on the drained bottom of the adjacent pond, which suffered from a severe disease one month before in the farm.

\subsection{DNA and RNA Extraction}

Total DNA and RNA were extracted from $30 \mathrm{mg}$ individual cephalothorax tissue of prawns, shrimp, or crayfish, or $30 \mathrm{mg}$ multiple individuals of Cladocera by TIANamp Marine Animal DNA Kit and RNAprep pure Tissue Kit (TIANGEN Biotech, Beijing, China), respectively, according to the manufacturer's instructions.

\subsection{Pathogen Detection}

DNA samples of $M$. rosenbergii, P. vannamei, Pr. clarkii, M. nipponense, $M$. superbum, and Cladocera were tested for White spot syndrome virus (WSSV), IHHNV, acute hepatopancreas necrosis disease-causing Vibrio parahaemolyticus ( $V p_{\mathrm{AHPND}}$ ), and DIV1 by real-time PCR methods. The RNA samples were tested for Yellow head virus (YHV), Infectious myonecrosis virus (IMNV), and CMNV by RT-real-time PCR methods. All the detection methods were recommended by the World Organization for Animal Health (OIE) [17] or developed before [5,18].

\subsection{Histopathological Sections}

Samples were fixed in Davidson's alcohol-formalin-acetic acid fixative (DAFA) [19] for $24 \mathrm{~h}$ and then changed to $70 \%$ ethanol. Paraffin sections were prepared and stained with hematoxylin and eosin (H\&E) staining according to the procedures of Bell and Lightner [19].

\subsection{In Situ Digoxigenin-Labeled Loop-Mediated Isothermal Amplification (ISDL)}

Samples were fixed in DAFA for $24 \mathrm{~h}$ and changed to $70 \%$ ethanol. The paraffin sections were then prepared and subjected to ISDL assays targeting the gene of the second largest subunit of DNA-directed RNA polymerase II of DIV1, according to the method adapted for DIV1 infection by Chen et al. [20].

\subsection{Transmission Electron Microscopy (TEM)}

Ultrathin sections of the white triangle tissue under cuticle at the base of rostrum (hematopoietic tissue) from diseased $M$. rosenbergii were prepared for observation with TEM. Small pieces of the hematopoietic tissue in $<1 \mathrm{~mm}^{3}$ of sampled animals were fixed in TEM fixative ( $2 \%$ paraformaldehyde, $2.5 \%$ glutaraldehyde, $160 \mathrm{mM} \mathrm{NaCl}$, and $4 \mathrm{mM} \mathrm{CaCl}_{2}$ in $200 \mathrm{mM} \mathrm{PBS}$ ) ( $\mathrm{pH} 7.2$ ) for $24 \mathrm{~h}$ at $4{ }^{\circ} \mathrm{C}$. Before ultrathin sectioning, the fixed tissues were secondarily fixed with $1 \%$ osmium tetroxide for $2 \mathrm{~h}$, then embedded in Spurr's resin and stained with uranyl acetate and lead citrate. Ultrathin sections were laid on collodion-coated grids and examined under a JEOL JEM-1200 electron microscope (Jeol Solutions for Innovation, Japan) operated at $80-100 \mathrm{kV}$ in the Equipment Center of the Medical College of Qingdao University.

\subsection{Quantitative Detection of DIV1 in Different Tissues of Naturally Infected M. rosenbergii}

Total 15 moribund $M$. rosenbergii samples frozen at $-80{ }^{\circ} \mathrm{C}$ were chosen to be defrosted and different tissues were separated, including hematopoietic tissue, antenna, uropods, pleopods, gills, pereiopods, muscle, and hepatopancreas. Total DNA was extracted from different tissues using TIANamp Marine Animal DNA Kit. The DIV1 loads in different tissues were detected by TaqMan probe-based quantitative real-time PCR (TaqMan qPCR) following our published method [5].

\subsection{Relative Abundance of DIV1 in Different Tissues}

In order to evaluate the distribution of DIV1 in different tissues, the relative abundance $\left(R A_{i}\right)$ of DIV1 in different tissues was calculated with the DIV1 load in each tissue $\left(L_{i}\right)$ to compare with the 
total load of DIV1 in the whole body, which were resulted from the sum of the DIV1 loads in all tested tissues $\left(\sum L_{i}\right)$. The calculation is based on the following formula:

$$
R A_{i}=\frac{L_{i}}{\sum L_{i}}
$$

Significance analysis of relative abundance data between each of the two tissues was carried out using the $t$-test for heteroscedasticity hypothesis of two groups of samples with the add-in tool Data Analysis in Microsoft ${ }^{\circledR}$ Excel $^{\circledR} 2016$ MSO 64-bit.

\section{Results}

\subsection{Observation of Clinical Signs of Diseaesd M. rosenbergii}

According to on-farm inquiry, the investigated pond, about 1.5 ha in size was stocked with 45 postlarva $/ \mathrm{m}^{2}$ of prawn M. rosenbergii in the middle of May and some juveniles of crayfish Pr. clarkii one week before. The adjacent pond stocked with shrimp P. vannamei suffered from an unknown disease and died out one month before. No disinfection or other effective control measure was taken for the ponds except drainage of the diseased shrimp pond. Symptoms of "white head" and "yellow gills" in the prawn population were observed two weeks before our arrival. During the first week, the disease developed slowly, but it became more and more severe in the second week. The moribund prawns lost their swimming ability and sank to the bottom of water and were rarely observed in shallow water. Moribund and dead prawns could be found every day in the diseased pond. In the following inquiry, we were told that the cumulative mortality was higher than $80 \%$.

While the samples were taken and processed, it was observed that most of the caught $M$. rosenbergii prawns from the diseased pond exhibited obvious clinical signs, including a distinct white triangle area under the carapace at the base of rostrum, hepatopancreatic atrophy with color fading and yellowing in the section, empty stomach and guts (Figure 1A,B), and some moribund prawns were accompanied by slightly whitish muscle and mutilated antenna.
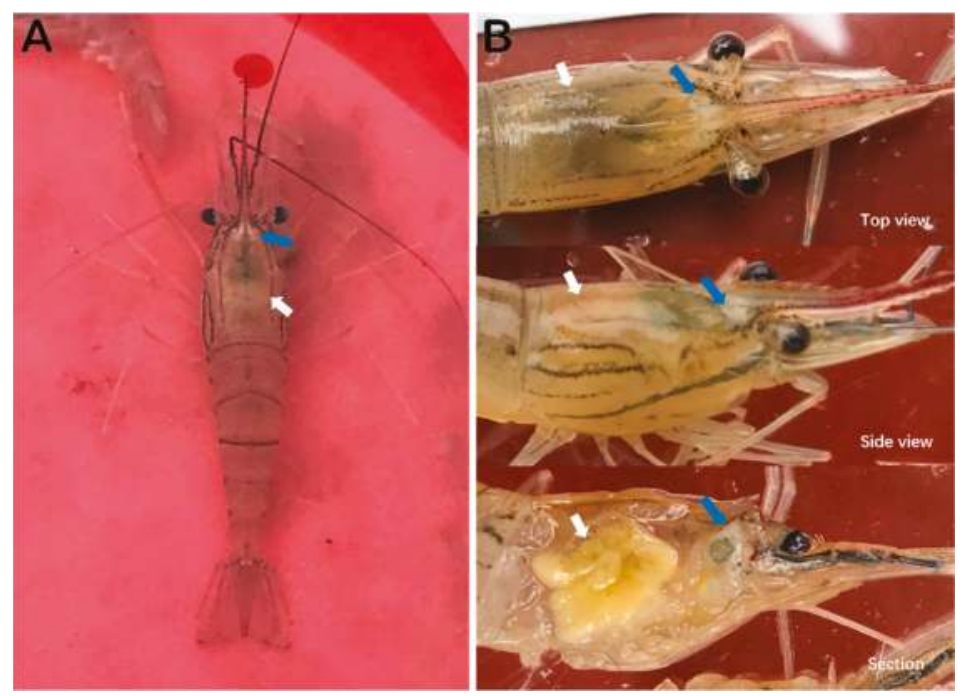

Figure 1. Clinical symptoms of M. rosenbergii (20180620) naturally infected with DIV1. (A) Overall appearance of a diseased prawn in water. (B) Close-up of cephalothoraxes. Blue arrows show white area under the cuticle at the base of rostrum. White arrows indicate hepatopancreas atrophy, color fading, and yellowing. 


\subsection{Pathogen Detection of Samples}

A total of 20 DNA samples extracted from cephalothorax tissues of individual shrimp or multiple Cladocera were tested by real-time PCR or RT-real-time PCR. All samples were negative for WSSV, IHHNV, $V p_{\text {AHPND, }}$ YHV, IMNV, and CMNV, but positive for DIV1. Samples of M. rosenbergii contained the highest DIV1 load range from $3.16 \times 10^{8}$ to $9.83 \times 10^{8}$ copies/ $\mu$ g-DNA. Samples of $M$. superbum contained the lowest DIV1 load (Table 1).

Table 1. Samples detected with the real time PCR for DIV1.

\begin{tabular}{|c|c|c|c|c|}
\hline Species & Positive Samples & Total Samples & 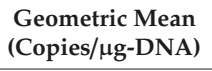 & 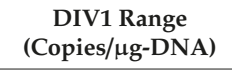 \\
\hline M. rosenbergii & 5 & 5 & $10^{(8.65 \pm 0.21)}$ & $3.16 \times 10^{8}-9.83 \times 10^{8}$ \\
\hline P. vannamei & 3 & 3 & $10^{(5.96 \pm 0.79)}$ & $4.56 \times 10^{5}-7.19 \times 10^{6}$ \\
\hline M. nipponense & 3 & 3 & $10^{(4.17 \pm 1.68)}$ & $1.30 \times 10^{3}-1.30 \times 10^{6}$ \\
\hline Pr. clarkii & 5 & 5 & $10^{(3.82 \pm 0.36)}$ & $2.20 \times 10^{3}-1.57 \times 10^{4}$ \\
\hline Cladocera & 3 & 3 & $10^{(1.10 \pm 0.06)}$ & $1.09 \times 10^{1}-1.43 \times 10^{1}$ \\
\hline M. superbum & 1 & 1 & $10^{(1.04 \pm 0.05)}$ & $1.00 \times 10^{1}-1.18 \times 10^{1}$ \\
\hline
\end{tabular}

\subsection{Histopathology}

Histological examination of DAFA fixed samples showed that dark eosinophilic inclusions mixed with basophilic tiny staining and karyopyknosis existed in hematopoietic tissue (Figure 2A) and hemocytes in hepatopancreatic sinus (Figure 2B) and in gills (Figure 2C) of M. rosenbergii. For M. nipponense, dark eosinophilic inclusions and karyopyknosis were also observed in the hepatopancreas (Figure 2D). No typical histopathological feature was found in the tissue sections of Pr. Clarkii and Cladocera.

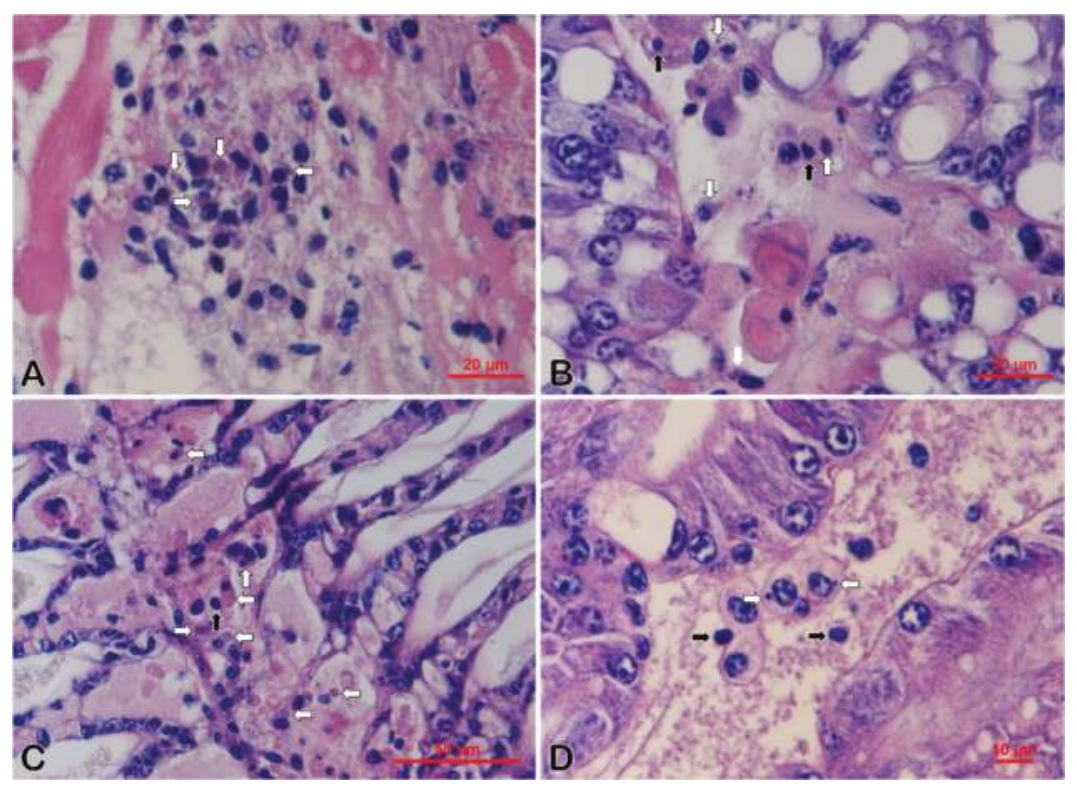

Figure 2. Histopathological features of Davidson's alcohol-formalin-acetic acid fixative (DAFA) fixed M. rosenbergii (A-C) and M. nipponense (D) samples 20180620. White arrows show the eosinophilic inclusions and black arrows show the karyopyknotic nuclei. (A) Hematoxylin and eosin (H\&E) staining of the hematopoietic tissue. (B,D) H\&E staining of hepatopancreas. (C) H\&E staining of gills. Bar, $20 \mu \mathrm{m}(\mathbf{A}, \mathbf{B}), 50 \mu \mathrm{m}(\mathbf{C})$, and $10 \mu \mathrm{m}(\mathbf{D})$, respectively. 


\subsection{ISDL}

ISDL results of $M$. rosenbergii showed that blue signals existed in hematopoietic tissue (Figure 3A), hemocytes in the hepatopancreatic sinus and in gills (Figure 3B,C), some R-cells, and myoepithelial fibers of the hepatopancreas (Figure 3D), coelomosac epithelium of antennal gland (Figure 3E), and epithelium of ovaries (Figure 3F). In addition, similar distribution of positive signals was also observed in the hepatopancreas of M. nipponense (Figure 3G) and hepatopancreas and hematopoietic tissue of Pr. clarkii (Figure $3 \mathrm{H}, \mathrm{I}$ ). No positive signals were observed in sections prepared from Cladocera, and uninfected prawn or crayfish.

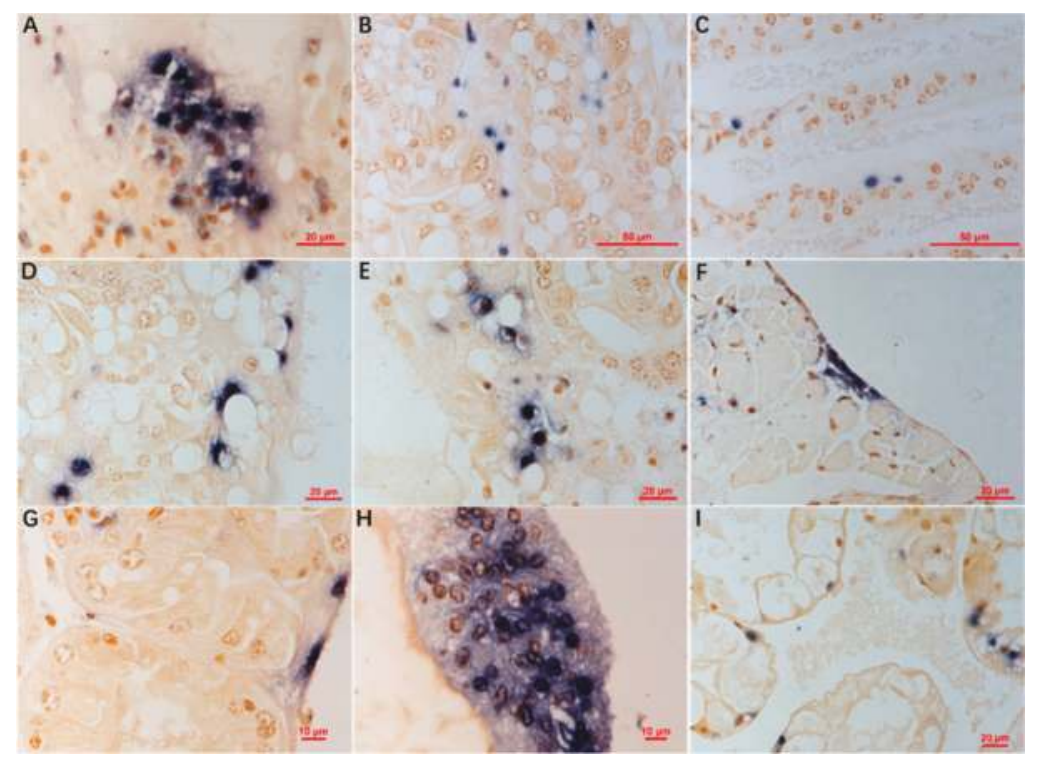

Figure 3. In situ digoxigenin-labeled loop-mediated isothermal amplification (ISDL) targeting the gene of the second largest subunit of DNA-directed RNA polymerase II of DIV1 on histological sections of M. rosenbergii (A-F), M. nipponense (G), and Pr. clarkii (H,I) samples 20180620. (A,H) Hematopoietic tissue; (B,D,G,I) hepatopancreas; (C) gills; (E) antennal gland; (F) ovaries. In (A-C,H), blue signals were observed in hematopoietic tissue, hemocytes in the sinus of the hepatopancreas, and in gills. In (D,G,I), blue signals exist in some hepatopancreatic R-cells and myoepithelial fibers. In (E), blue signals exist in the coelomosac epithelium. In (F), blue signals exist in the epithelium. Bar, $20 \mu \mathrm{m}(\mathbf{A}, \mathbf{D}-\mathbf{F}, \mathbf{I})$, $50 \mu \mathrm{m}(\mathbf{B}, \mathbf{C})$, and $10 \mu \mathrm{m}(\mathbf{G}, \mathbf{H})$, respectively.

\subsection{TEM of Ultrathin Sections}

Visualization with TEM of ultrathin sections of the naturally infected $M$. rosenbergii revealed the presence of a large number of icosahedral particles with typical iridescent viral structure, both inside and outside hematopoietic cells in the tissue (Figure 4A). Non-enveloped virions were $166.3 \pm 14.8 \mathrm{~nm}$ $(N=39)$ vertex to vertex $(\mathrm{v}-\mathrm{v}), 149.4 \pm 13.8 \mathrm{~nm}(n=39)$ from face to face $(\mathrm{f}-\mathrm{f})$, and about $157.9 \mathrm{~nm}$ of an average equivalent diameter, with a nucleoid at $93.5 \pm 9.9 \mathrm{~nm}(n=39)$. At the margin of the cytoplasm, many virions were budding from the plasma membrane, and in budded virions, an outer viral envelope was acquired from the plasma membrane (Figure 4B). Virion formation took place in the cytoplasmic morphologically distinct regions, termed virogenic stromata, which were electron-lucent areas containing numerous immature and empty capsids, few mature virions, and were devoid of cellular organelles, with paracrystalline array of viral particles and budding virions in the same cell (Figure 4C). Assembly of nucleocapsid can be described in three progressive stages (Figure 4D), during 
which crescent-shaped structures of early capsid complexes subsequently assembled into spherical intermediates at stage 1 (Figure $4 \mathrm{E}-\mathrm{G}$, and indicated with 1 on Figure 4D), followed by formation of icosahedral capsids with a small opening at one vertex at stage 2 (Figure $4 \mathrm{H}$, and indicated with 2 on Figure 4D) and recruitment of electron-dense nucleic acid at stage 3 (Figure $4 \mathrm{I}$ and indicated with 3 on Figure 4D). Complete nucleocapsids were observed in a fully filled state (Figure 4J, and indicated with 4 on Figure 4D).

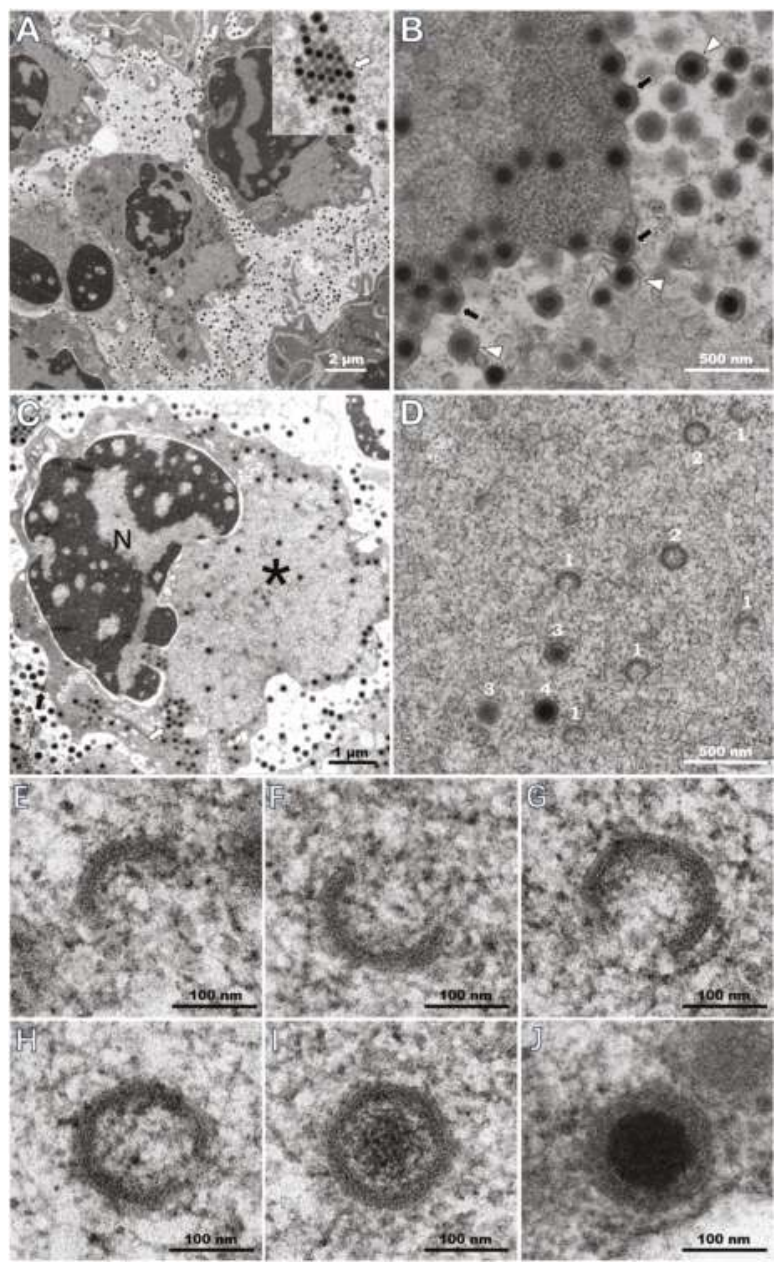

Figure 4. TEM of hematopoietic tissue of naturally infected $M$. rosenbergii samples 20180620. (A) A large numbers of virions in hematopoietic tissue. (B) DIV1 budded and acquired an envelope from the plasma membrane. (C) DIV1 replication and assembly in hematopoietic cells. (D) The stages of nucleocapsid assembly, which are indicated with numbers 1-3, and a complete nucleocapsid is indicated with number 4 . The capsids at stage 2 and 3 should have a small opening at one vertex but may not be visible in the picture due to the ultrathin section. (E) Crescent-shaped structures. (F-I) As the assembling process continues, the crescent-shaped structure curves to form icosahedral capsids. (J) A mature virion with a dense core was eventually formed. N: nucleus; *: a large electron-lucent virogenic stroma; white arrows: paracrystalline array of viral particles; black arrows: budding virions; and white triangles: budded virions that acquired an envelope. 


\subsection{Quantitative Detection of DIV1 in Different Tissues of Naturally Infected M. rosenbergii}

A total of 120 tissues were separated from 15 naturally infected M. rosenbergii prawns. DIV1 loads in tissues of different prawns were examined with TaqMan qPCR. Copies of DIV1 per $\mu \mathrm{g}$ tissue DNA sample were converted to their logarithms for calculation of the geometric means and standard deviations of each tissue. The results showed that hematopoietic tissue samples contained an average DIV1 load of $10^{(7.92 \pm 0.91)}$ copies/ $\mu$ g-DNA, which was the highest load of DIV1 in tissues tested. Antenna had a mean DIV1 load of $10^{(7.84 \pm 0.70)}$ copies/ $\mu$ g-DNA, which approached hematopoietic tissue. Uropods, pleopods, gills, and pereiopods also had high loads of DIV1 above $10^{7.6}$ copies/ $\mu$ g-DNA of geometric means. Moreover, muscles and the hepatopancreas, as the vast majorities of cephalothorax and abdominal segments of the prawn, contained the lowest load of DIV1, which were at $10^{(6.96 \pm 0.57)}$ and $10^{(6.85 \pm 0.72)}$ copies/ $\mu$ g-DNA, respectively (Table 2 ). It was also noted that there were big differences of DIV1 loads by $3-4$ orders of magnitude in all the tissues among different individuals, shown in the range column of Table 2 .

Table 2. DIV1 copies in different tissues detected in DIV1-positive prawns Macrobrachium rosenbergii.

\begin{tabular}{|c|c|c|c|}
\hline Samples & $\mathbf{n}$ & 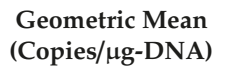 & 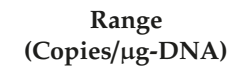 \\
\hline Hematopoietic tissue & 15 & $10^{(7.92 \pm 0.91)}$ & $8.11 \times 10^{4}-6.33 \times 10^{8}$ \\
\hline Antenna & 15 & $10^{(7.84 \pm 0.70)}$ & $1.44 \times 10^{6}-1.03 \times 10^{9}$ \\
\hline Uropods & 15 & $10^{(7.74 \pm 0.71)}$ & $6.45 \times 10^{5}-6.04 \times 10^{8}$ \\
\hline Pleopods & 15 & $10^{(7.77 \pm 0.69)}$ & $4.77 \times 10^{5}-5.30 \times 10^{8}$ \\
\hline Gills & 15 & $10^{(7.69 \pm 0.66)}$ & $4.45 \times 10^{5}-4.10 \times 10^{8}$ \\
\hline Pereiopod & 15 & $10^{(7.62 \pm 0.69)}$ & $6.10 \times 10^{5}-1.05 \times 10^{9}$ \\
\hline Muscle & 15 & $10^{(6.96 \pm 0.57)}$ & $1.87 \times 10^{5}-4.36 \times 10^{7}$ \\
\hline Hepatopancreas & 15 & $10^{(6.85 \pm 0.72)}$ & $2.35 \times 10^{4}-3.18 \times 10^{7}$ \\
\hline
\end{tabular}

\subsection{Relative Abundance of DIV1 in Different Tissues}

As the differences of DIV1 loads in tissues among different individuals reached 3-4 orders of magnitude, direct comparison on DIV1 loads in a specific tissue could be easily upset by a single sample with a very high DIV1 load. Therefore, relative abundance of DIV1 load based on a uniformization of the sum of DIV1 loads in all detected tissues was introduced to evaluate the distribution of DIV1 in different tissues. The relative abundance results showed that more than one-quarter of DIV1 relative load was in hematopoietic tissue, which contained the highest relative abundance at $25.4 \pm 16.9 \%$. Antenna, pleopods, and uropods contained significantly lower DIV1 relative abundances at $18.7 \pm$ $10.3 \%, 14.5 \pm 5.1 \%$, and $13.8 \pm 4.7 \%$, respectively, more than hematopoietic tissue did $(p<0.05)$. Gills and pereiopods contained very significant lower DIV1 relative abundances at $12.1 \pm 4.1 \%$ to $10.7 \pm 5.5 \%$, respectively, more than hematopoietic tissue did $(p<0.01)$. Hepatopancreas and muscle contained the very significantly lowest levels $(p<0.01)$ of the relative abundances of DIV1 at $2.44 \pm 2.16 \%$ and $2.44 \pm$ $1.24 \%$, compared with all other tissues, respectively (Figure 5). When the total DIV1 load in all tissues fell between $10^{8.24}$ to $10^{9.25}$ copies/ $\mu$ g-DNA, most of the relative abundances of DIV1 in hematopoietic tissue fell into $12.2 \%$ to $35.9 \%$, and even $71.7 \%$; however, when the total DIV1 load in all tissues was lower than $10^{7}$ or higher than $10^{9.5}$ copies/ $\mu$ g-DNA, the relative abundances of DIV1 in hematopoietic tissue dropped to about $5 \%$ or lower, while the most DIV1 existed in antenna and pleopods. 


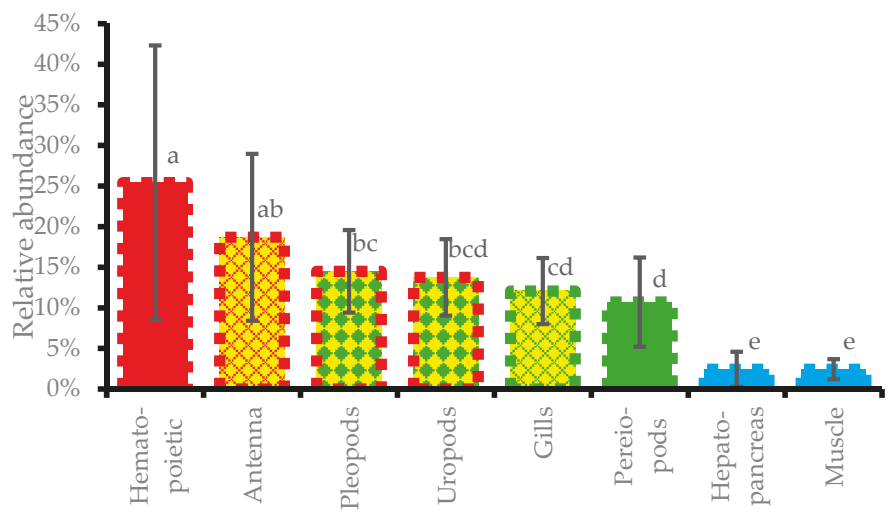

Figure 5. Relative abundance of DIV1 for different tissues of fifteen DIV1-infected M. rosenbergii samples. Columns without sharing of a same letter indicate significant difference of $p<0.05$; columns without a same color indicate a highly significant difference of $p<0.01$.

\section{Discussion}

DIV1 belongs to a novel genus Decapodiridovirus accepted by ICTV, found independently in C. quadricarinatus and P. vannamei as CQIV and SHIV. Target surveillance was started in China in 2017 and revealed that the virus has been detected in 6 provinces out of the 13 surveyed provinces and caused massive economic losses [7].

As far as we know, there was no reported pathological information of $M$. rosenbergii infected with DIV1, but a PCR detection result showed that 5 of 33 cultured $M$. rosenbergii samples were DIV1 positive from 2014 to 2016 [2]. This study reported farmed M. rosenbergii and Pr. clarkii, cohabitating with some wild crustaceans, M. nipponense, M. superbum, and Cladocera in a pond in Jiangsu Province, suffered from severe mortality in June 2018, following the death of the P. vannamei population in the adjacent pond. Diseased giant freshwater prawns have exhibited typical symptom commonly, known as "white head" or "white spot", since 2015 [15]. Real-time PCR results showed that all samples were negative for WSSV, IHHNV, $V p_{\text {AHPND, }}$ YHV, IMNV, and CMNV, but positive for DIV1. Samples of $M$. rosenbergii contained the highest DIV1 loads, ranging from $3.16 \times 10^{8}$ to $9.83 \times 10^{8}$ copies/ $\mu$ g-DNA, which were higher than any other naturally infected species in this and earlier studies [5], indicating that the disease of $M$. rosenbergii in this case was caused by a severe infection with DIV1. This is the first confirmation of the causative agent of "white head" symptoms in farmed M. rosenbergii. In addition, in this case, DIV1 was also proved to be a natural pathogen to P. clarkii and M. nipponense. The disease firstly broke out and caused death of farmed $P$. vannamei population in the adjacent pond two weeks before clinical signs for prawns were found in the pond stocked with $M$. rosenbergii. This provided evidence that the transmitted disease cross ponds and species due to lack of biosecurity in the farm management.

Notably, susceptibilities of $M$. rosenbergii, M. nipponense, $P$. vannamei, and Pr. clarkii to infection with DIV1 and infection with WSSV are different. An earlier study revealed that $M$. rosenbergii and M. nipponense resisted infection with WSSV via intermuscular injection, but Pr. clarkii had high mortality at $94 \%$ [21]. Further challenge studies showed M. rosenbergii could be infected by injection with WSSV stains Thai- 1 and Viet, however, the infectious dose to reach $50 \%$ endpoint in $M$. rosenbergii needed 20-fold and 400-fold more than that in P. vannamei, respectively [22]. The half lethal dose (LD50) of WSSV to M. nipponense by injection was $10^{(3.84 \pm 0.06)} \mathrm{copies} / \mathrm{g}$, which was about 1780 -fold higher than that of $P$. vannamei at $10^{(0.59 \pm 0.22)}$ copies/g [23]. It was demonstrated that $M$. rosenbergii could clear infectious WSSV after 5 to 50 days post-injection [24]. There is no report for the quantitative comparison on the virulence of DIV1 to different species yet. Based on the time course of mortality in intramuscular challenge with DIV1 (CQIV CN01), P. vannamei may be slightly more susceptible to DIV1 
infection than C. quadricarinatus and Pr. clarkii [1]. The disease course observed in the farm for this study indicated that $M$. rosenbergii and M. nipponense have no tolerance to infection with DIV1. Many farms in Jiangsu, Guangdong, and Zhejiang Provinces [16,25], as well as in Southeast Asia [26,27] and Africa [28], have stocked ponds in polyculture mode with $M$. rosenbergii and P. vannamei or P. monodon. As M. rosenbergii has tolerance to infection with WSSV [21], the polyculture mode provides a profitable approach for farmers under the threat of WSSV. However, the emergence of DIV1 has shattered the vision and verified our earlier warning that polyculture with different species of crustaceans may bring risks for spread of disease, increase of susceptible species, and evolution of pathogens, based on our early surveillance on shrimp epidemiology [29].

M. rosenbergii and P. vannamei infected with DIV1 both exhibited hepatopancreatic atrophy with color fading on the surface and in the section, empty stomach, and gut. However, these symptoms are not distinctive, because empty stomach and gut also occurred in some other diseases, such as infection with WSSV [17,30], infection with Taura syndrome virus (TSV) and AHPND [17], and loss color of hepatopancreas is similar to the clinical feature of AHPND [17]. It is worth noting that "white head" is a typical clinical sign for on-site diagnosis of $M$. rosenbergii infected with DIV1. Xu et al. [1] reported that experimentally-challenged individuals of Pr. clarkii showed gross signs, such as cessation of feeding and flaccidity, at day-5 post-infection. In this case, cultured Pr. clarkii naturally infected with DIV1 contained a lower viral load $\left(2.20 \times 10^{3}\right.$ to $1.57 \times 10^{4}$ copies/Mg-DNA) and suffered from an asymptomatic infection, because the juveniles of crayfish were stocked in the pond for only one week and some of them may have just been infected with the virus for a few days. Almost all of the $P$. vannamei shrimp in the adjacent pond died out in two weeks and the pond was abandoned by drainage. It was one month later when we arrived at the farm, and only several dried bodies of $P$. vannamei could be collected from the bottom of a drained pond, which could not be used for observation of gross signs.

Histopathological examination showed the existence of dark eosinophilic inclusions mixed or surrounded with basophilic staining and karyopyknosis in the hematopoietic tissues and hemocytes of gills and hepatopancreatic sinus in $M$. rosenbergii. Similar pathological features also existed in $M$. nipponense collected in this study and Exopalaemon carinicauda experimentally challenged with DIV1 (SHIV 20141215) [20]. The inclusions of DIV1 infection found in P. vannamei in previous research were described as basophilic, but the color of the inclusions on the published pictures was dark eosinophilic mixed with tiny basophilic staining, the same as in this study [2]. The eosinophilic inclusions presented in the cytoplasm of hemocytes or hematopoietic cells, which is very similar to some shrimp cases caused by the iridescent virus reported earlier [31,32], and the karyopyknosis is similar to some fish cases $[33,34]$. Compared with ISH in P. vannamei [2], ISDL also specifically indicated the existence and location of DIV1 in histologic sections. Blue signals were observed in hematopoietic tissue and hemocytes in the sinus of the hepatopancreas and gills in M. rosenbergii, M. nipponense, and Pr. clarkii, which is consistent with the ISH result in sections of infected P. vannamei [2]. However, differing from the results of ISH, positive signals resulted from ISDL were observed in some R-cells and myoepithelial fibers of the hepatopancreas, coelomosac epithelium of antennal glands, and the epithelium of ovaries, which indicated that besides hematopoietic tissues and hemocytes, DIV1 may also infect some other tissues at a lower level. More remarkably, blue signals of ISDL appeared in both the nucleus and cytoplasm of hematopoietic cells, hemocytes, and other infected cells. It signified that DIV1 may employ a replication strategy to include both nuclear and cytoplasmic stages, as Frog virus 3 (FV3), the typical species of genus Ranavirus, does [35-37]. It should be kept in mind that the amplification of target DNA in ISDL results in a similar climax quantity of amplified products, so that the density of positive signals does not relatively reflect the original quantity of the DNA target, and it can only indicate the presence and location of target viral nucleic acid in the cells of various tissues and organs [38].

TEM evidence also proved the diseased prawns M. rosenbergii were infected with DIV1 by viral morphology and cytopathology. The icosahedral morphology and intracytoplasmic location of virions 
are consistent with reports of DIV1 infections in P. vannamei [2] or in C. quadricarinatus, Pr. clarkii, and $P$. vannamei [4]. Non-enveloped virions showed values $166.3 \pm 14.8 \mathrm{~nm}(\mathrm{v}-\mathrm{v})$ and $149.4 \pm 13.8 \mathrm{~nm}$ (f-f), with a nucleoid at $93.5 \pm 9.9 \mathrm{~nm}$, which were $7.7 \mathrm{~nm}, 5.8 \mathrm{~nm}$, and $7.7 \mathrm{~nm}$ larger than previous study in P. vannamei [2]. The different size of virions may result from shrinkage of virions caused by the duration time of tissue samples stored in the TEM fixative and the dehydration and embedding procedures before ultrathin sectioning. Typical electron-lucent virogenic stroma was observed in hematopoietic cells of infected $M$. rosenbergii, containing immature, empty, and mature virions, with paracrystalline array of viral particles and budding virions in the same cell. The appearance and location of virogenic stroma were consistent with the dark eosinophilic inclusions observed on the H\&E stained histopathological slides. Viral nucleic acid, intensive mature virions, and paracrystalline array embedded in and surrounding the virogenic stroma resulted in the dark eosinophilic and tiny basophilic staining. The progressive assembling stages, from the crescent shape complex to filled hexagonal nucleocapsids, are very similar to the forming process of Singapore grouper iridovirus (SGIV) nucleocapsid [39]. This observation was not reported for DIV1 in previous studies.

TaqMan qPCR specifically detected the highest loads of DIV1 in the lesion of whitish hematopoietic tissue at the base of rostrum of diseased M. rosenbergii. This data fills the gap in the previous study, which lacked the DIV1 load in hematopoietic tissue [5]. Unlike M. rosenbergii, P. vannamei has several very small hematopoietic tissues, which makes it hard to be seen and collected for quantitative detection of DIV1. Decapods have separate hematopoietic tissues located above the stomach and at the base of antennas, pereiopods, and gills as appendages of the cephalothorax [19]. That is why appendages under the cephalothorax also contained relatively higher DIV1 load than the main body. It is notable that the high loads of DIV1 were also detected in the appendages of the abdominal segments, including uropods and pleopods, which hinted that these appendages of abdominal segments may be attached with some hematopoietic cells. Muscle and hepatopancreas contained the lowest DIV1 loads, which may be due to the virus in hemocytes and hemolymph in these tissues. The relative abundances of DIV1 load in different tissues calculated based on the results of TaqMan qPCR could be used to quantitatively estimate the virus distribution for a tissue tropism study in comparison with different hosts. Interestingly, the naturally dried bodies of shrimp P. vannamei that had been dead for more than

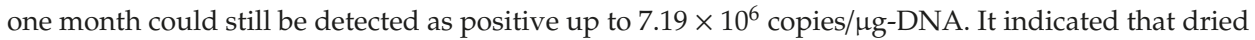
shrimp bodies are still available for DIV1 detection.

\section{Conclusions}

This is a report of a natural occurrence of DIV1 in farmed giant freshwater prawn M. rosenbergii. All if the evidence resulting from symptom description, detection of known pathogens, histopathological and cytopathological observation, in situ DIG-labeled LAMP location, and quantitative detection of tissues consistently confirmed that the "white head" symptom of $M$. rosenbergii is the typical sign caused by infection with DIV1. Additionally, this study also provided evidence to add Pr. clarkii and M. nipponense as susceptible species to DIV1. The disease was likely transmitted from the adjacent pond stocked with P. vannamei, which had died out during the outbreak of infection with DIV1 due to lock of biosecurity in the farm management. The study provides a typical example of how DIV1 threaten the freshwater polyculture modes with different species of crustaceans, which we discourage.

Author Contributions: Conceptualization, L.Q., J.H., and Q.-L.Z.; formal analysis, L.Q. and X.C.; funding acquisition, J.H.; sampling, L.Q., X.C., J.H., and R.-H.Z.; methodology, X.C., R.-H.Z., C.L., and W.G.; sample testing, X.C., R.-H.Z., and W.G.; project administration, J.H. and L.Q.; resources, L.Q., X.C., and R.-H.Z.; supervision, J.H.; writing—original draft, L.Q; revision, J.H. and L.Q.

Funding: This research was financially supported by Projects Under the Pilot National Laboratory for Marine Science and Technology (Qingdao) (QNLM201706), the Marine S\&T Fund of Shandong Province for Pilot National Laboratory for Marine Science and Technology (Qingdao) (2018SDKJ0502-3), China ASEAN Maritime Cooperation Fund Project (2016-2018), China Agriculture Research System (CARS-48), and Special Scientific Research Funds for Central Non-profit Institutes, Yellow Sea Fisheries Research Institute (20603022018014). 
Acknowledgments: We are grateful to Guo-Liang Yang of Jiangsu Shufeng Aquatic Seed Industry Co., Ltd. for connecting the diseased farm, the agent serving the farm, and the farmers in Jiangsu Province for their help during our sampling, as well as all of our laboratory members for their technical advice and helpful discussions.

Conflicts of Interest: The authors declare no conflict of interest. The funders had no role in the design of the study; in the collection, analyses, or interpretation of data; in the writing of the manuscript, and in the decision to publish the results.

\section{References}

1. Xu, L.; Wang, T.; Li, F.; Yang, F. Isolation and preliminary characterization of a new pathogenic iridovirus from redclaw crayfish Cherax quadricarinatus. Dis. Aquat. Organ. 2016, 120, 17-26. [CrossRef]

2. Qiu, L.; Chen, M.M.; Wan, X.Y.; Li, C.; Zhang, Q.L.; Wang, R.Y.; Cheng, D.Y.; Dong, X.; Yang, B.; Wang, X.H.; et al. Characterization of a new member of Iridoviridae, Shrimp hemocyte iridescent virus (SHIV), found in white leg shrimp (Litopenaeus vannamei). Sci. Rep. 2017, 19, 11834. [CrossRef]

3. Qiu, L.; Chen, M.M.; Wang, R.Y.; Wan, X.Y.; Li, C.; Zhang, Q.L.; Dong, X.; Yang, B.; Xiang, J.H.; Huang, J. Complete genome sequence of shrimp hemocyte iridescent virus (SHIV) isolated from white leg shrimp, Litopenaeus vannamei. Arch. Virol. 2018, 163, 781-785. [CrossRef] [PubMed]

4. Li, F.; Xu, L.; Yang, F. Genomic characterization of a novel iridovirus from redclaw crayfish Cherax quadricarinatus: Evidence for a new genus within the family Iridoviridae. J. Gen. Virol. 2017, 98, 2589-2595. [CrossRef] [PubMed]

5. Qiu, L.; Chen, M.M.; Wan, X.Y.; Zhang, Q.L.; Li, C.; Dong, X.; Yang, B.; Huang, J. Detection and quantification of shrimp hemocyte iridescent virus by TaqMan probe based real-time PCR. J. Invertebr. Pathol. 2018, 154, 95-101. [CrossRef] [PubMed]

6. One New Genus with One New Species in the Subfamily Betairidovirinae. Available online: https://talk.ictvonline.org/files/ictv_official_taxonomy_updates_since_the_8th_report/m/animal-dnaviruses-and-retroviruses/8051 (accessed on 10 March 2019).

7. Qiu, L.; Dong, X.; Wan, X.Y.; Huang, J. Analysis of iridescent viral disease of shrimp (SHID) in 2017. In Analysis of Important Diseases of Aquatic Animals in China in 2017; Fishery and Fishery Administration Bureau under the Ministry of Agriculture and Rural Affairs, National Fishery Technical Extension Center, Eds.; China Agriculture Press: Beijing, China, 2018; pp. 187-204, ISBN 978-7-109-24522-8. (In Chinese)

8. Rao, R.; Bhassu, S.; Bing, R.Z.; Alinejad, T.; Hassan, S.S.; Wang, J. A transcriptome study on Macrobrachium rosenbergii hepatopancreas experimentally challenged with white spot syndrome virus (WSSV). J. Invertebr. Pathol. 2016, 136, 10-22. [CrossRef]

9. Hameed, A.S.S. Viral infections of Macrobrachium spp.: Global status of outbreaks, diagnosis, surveillance, and research. Isr. J. Aquac. 2009, 61, 240-247.

10. Ho, K.L.; Gabrielsen, M.; Beh, P.L.; Kueh, C.L.; Thong, Q.X.; Streetley, J.; Tan, W.S.; Bhella, D. Structure of the Macrobrachium rosenbergii nodavirus: A new genus within the Nodaviridae? PLoS Biol. 2018, 16, e3000038. [CrossRef]

11. Macrobrachium rosenbergii (De Man, 1879). Available online: http://www.fao.org/fishery/culturedspecies/ Macrobrachium_rosenbergii/en (accessed on 9 January 2019).

12. Bonami, J.R.; Sri Widada, J. Viral diseases of the giant fresh water prawn Macrobrachium rosenbergii: A review. J. Invertebr. Pathol. 2011, 106, 131-142. [CrossRef]

13. Sahul Hameed, A.S.; Bonami, J.R. White tail disease of freshwater prawn, Macrobrachium rosenbergii. Indian J. Virol. 2012, 23, 134-140. [CrossRef]

14. Zhang, Q.L.; Xu, T.T.; Wan, X.Y.; Liu, S.; Wang, X.H.; Li, X.P.; Dong, X.; Yang, B.; Huang, J. Prevalence and distribution of Covert mortality nodavirus (CMNV) in cultured crustacean. Virus. Res. 2017, 233, 113-119. [CrossRef] [PubMed]

15. Who Is the Ringleader of the "White Spot" Disease in Macrobrachium rosenbergii. Available online: http: //www.shuichan.cc/article_view-41757.html (accessed on 9 January 2019). (In Chinese)

16. Huang, S. Polyculture of Macrobrachium rosenbergii and Litopenaeus vannamei Will Become the Main Mixed Culture Mode in Chaozhou and Shantou of Guangdong Province. Chinese Aquaculture Gateway Web. 2015. Available online: http://www.bbwfish.com/article.asp?artid=173520 (accessed on 9 January 2019). (In Chinese) 
17. Manual of Diagnostic Tests for Aquatic Animals. Available online: http://www.oie.int/en/standard-setting/ aquatic-manual/access-online/ (accessed on 11 September 2018).

18. Zhang, Q.L.; Liu, Q.; Liu, S.; Yang, H.L.; Liu, S.; Zhu, L.L.; Yang, B.; Jin, J.T.; Ding, L.X.; Wang, X.H.; et al. A new nodavirus is associated with covert mortality disease of shrimp. J. Gen. Virol. 2014, 95, 2700-2709. [CrossRef] [PubMed]

19. Bell, T.A.; Lightner, D.V. A Handbook of Normal Penaeid Shrimp Histology; World Aquaculture Society: Tucson, AZ, USA, 1988.

20. Chen, X.; Qiu, L.; Wang, H.L.; Zou, P.Z.; Dong, X.; Li, F.H.; Huang, J. Susceptibility of Exopalaemon carinicauda to the infection with Shrimp hemocyte iridescent virus (SHIV 20141215), a strain of Decapod iridescent virus 1 (DIV1). Viruses 2019, accepted.

21. Huang, C.H.; Shi, Z.L.; Zhang, J.H.; Zhang, L.R.; Chen, D.H.; Bonami, J.R. Establishment of a model for proliferating White spot syndrome virus in vivo. Virol. Sin. 1999, 14, 358-363.

22. Corteel, M.; Dantas-Lima, J.J.; Tuan, V.V.; Thuong, K.V.; Wille, M.; Alday-Sanz, V.; Pensaert, M.B.; Sorgeloos, P.; Nauwynck, H.J. Susceptibility of juvenile Macrobrachium rosenbergii to different doses of high and low virulence strains of white spot syndrome virus (WSSV). Dis. Aquat. Org. 2012, 100, 211-218. [CrossRef]

23. Zhao, C.Y.; Fu, H.T.; Sun, S.M.; Qiao, H.; Zhang, W.Y.; Jin, S.B.; Jiang, S.F.; Xiong, Y.W.; Gong, Y.S. Experimental inoculation of oriental river prawn Macrobrachium nipponense with white spot syndrome virus (WSSV). Dis. Aquat. Org. 2017, 126, 125-134. [CrossRef]

24. Sarathi, M.; Nazeer Basha, A.; Ravi, M.; Venkatesan, C.; Senthil Kumar, B.; Sahul Hameed, A.S. Clearance of white spot syndrome virus (WSSV) and immunological changes in experimentally WSSV-injected Macrobrachium rosenbergii. Fish Shellfish Immunol. 2008, 25, 222-230. [CrossRef]

25. Shen, Y.J.; Zhu, B.K.; Xu, K.C.; Xu, J.F. Pond culture experiment of polyculture with white leg shrimp and Macrobrachium rosenbergii. Xiandai Nongye Keji 2017, 17, 231-241. (In Chinese)

26. Azim, M.E.; Mazid, M.A.; Alam, M.J.; Nurullah, M. The potential of mixed culture of freshwater giant prawn Macrobrachium rosenbergii de Man and tiger shrimp Penaeus monodon Fab. at Khulna region, Bangladesh. Bangladesh J. Fish. Res. 2001, 5, 67-74.

27. Ali, H.; Rahman, M.M.; Rico, A.; Jaman, A.; Basak, S.K.; Islam, M.M.; Khan, N.; Keus, H.J.; Mohan, C.V. An assessment of health management practices and occupational health hazards in tiger shrimp (Penaeus monodon) and freshwater prawn (Macrobrachium rosenbergii) aquaculture in Bangladesh. Vet. Ani. Sci. 2018, 5, 10-19. [CrossRef]

28. Sadek, S.; Moreau, J. Performance of Macrobrachium rosenbergii and Penaeus semisulcatus under mono and mixed culture systems, and their suitability for polyculture with Florida Red Tilapia, in Egypt. J. Aquacult. Trop. 2000, 15, 97-107.

29. Diseases of Farmed Shrimp and Their Biosecurity Control Technologies. Available online: http://www. shuichan.cc/news_view-268040.html (accessed on 9 February 2019). (In Chinese)

30. Escobedo-Bonilla, C.M.; Alday-Sanz, V.; Wille, M.; Sorgeloos, P.; Pensaert, M.B.; Nauwynck, H.J. A review on the morphology, molecular characterization, morphogenesis and pathogenesis of White spot syndrome virus. J. Fish. Dis. 2008, 31, 1-18. [CrossRef]

31. Lightner, D.V.; Redman, R.M. A putative iridovirus from the penaeid shrimp Protrachypene precipua Burkenroad (Crustacea: Decapoda). J. Invertebr. Pathol. 1993, 62, 107-109. [CrossRef]

32. Tang, K.F.J.; Redman, R.M.; Pantoja, C.R.; Groumellec, M.L.; Duraisamy, P.; Lightner, D.V. Identification of an iridovirus in Acetes erythraeus, (Sergestidae) and the development of in situ, hybridization and PCR method for its detection. J. Invertebr. Pathol. 2007, 96, 255-260. [CrossRef]

33. Mahardika, K.; Yamamoto, A.; Miyazaki, T. Susceptibility of juvenile humpback grouper Cromileptes altivelis to grouper sleepy disease iridovirus (GSDIV). Dis. Aquat. Org. 2004, 59, 1-9. [CrossRef] [PubMed]

34. Sudthongkong, C.; Miyata, M.; Miyazaki, T. Iridovirus disease in two ornamental tropical freshwater fishes: African lampeye and dwarf gourami. Dis. Aquat. Org. 2002, 48, 163-173. [CrossRef] [PubMed]

35. Chinchar, V.G.; Hick, P.; Ince, I.A.; Jancovich, J.K.; Marschang, R.; Qin, Q.; Subramaniam, K.; Waltzek, T.B.; Whittington, R.; Williams, T.; et al. ICTV Virus Taxonomy Profile: Iridoviridae. J. Gen. Virol. 2017, 98, 890-891. [CrossRef] [PubMed]

36. Chinchar, V.G.; Hyatt, A.; Miyazaki, T.; Williams, T. Family Iridoviridae: Poor viral relations no longer. Curr. Top. Microbiol. Immunol. 2009, 328, 123-170. [CrossRef] 
37. Williams, T.; Barbosa-Solomieu, V.; Chinchar, V.G. A decade of advances in iridovirus research. Adv. Virus Res. 2005, 65, 173-248. [CrossRef]

38. Jitrakorn, S.; Arunrut, N.; Sanguanrut, P.; Flegel, T.W.; Kiatpathomchai, W.; Saksmerprome, V. In situ DIG-labeling, loop-mediated DNA amplification (ISDL) for highly sensitive detection of infectious hypodermal and hematopoietic necrosis virus (IHHNV). Aquaculture 2016, 456, 36-43. [CrossRef]

39. Liu, Y.; Tran, B.N.; Wang, F.; Ounjai, P.; Wu, J.; Hew, C.L. Visualization of assembly intermediates and budding vacuoles of Singapore grouper iridovirus in grouper embryonic cells. Sci. Rep. 2016, 6, 18696. [CrossRef] [PubMed]

(C) 2019 by the authors. Licensee MDPI, Basel, Switzerland. This article is an open access article distributed under the terms and conditions of the Creative Commons Attribution (CC BY) license (http://creativecommons.org/licenses/by/4.0/). 
Article

\title{
Distribution and Phylogeny of Erythrocytic Necrosis Virus (ENV) in Salmon Suggests Marine Origin
}

\author{
Veronica A. Pagowski ${ }^{1,+}$, Gideon J. Mordecai ${ }^{1, *,+}{ }^{+}$, Kristina M. Miller ${ }^{2, *}$, Angela D. Schulze ${ }^{2}$, \\ Karia H. Kaukinen ${ }^{2}$, Tobi J. Ming ${ }^{2}$, Shaorong Li ${ }^{2}$, Amy K. Teffer ${ }^{3}{ }^{\circledR}$, Amy Tabata ${ }^{2}$ and \\ Curtis A. Suttle 1,4,5,6,*(D) \\ 1 Department of Earth, Ocean and Atmospheric Sciences, University of British Columbia, 2207 Main Mall, \\ Vancouver, BC V6T 1Z4, Canada; v.pagowski@alumni.ubc.ca \\ 2 Pacific Biological Station, Fisheries and Oceans Canada, 3190 Hammond Bay Rd, Nanaimo, BC V9T 6N7, \\ Canada; Angela.Schulze@dfo-mpo.gc.ca (A.D.S.); Karia.Kaukinen@dfo-mpo.gc.ca (K.H.K.); \\ Tobi.Ming@dfo-mpo.gc.ca (T.J.M.); Shaorong.Li@dfo-mpo.gc.ca (S.L.); Amy.Tabata@dfo-mpo.gc.ca (A.T.) \\ 3 Biology Department, University of Victoria, 3800 Finnerty Rd, Victoria, BC V8P 5C2, Canada; \\ akteffer@gmail.com \\ 4 Department of Microbiology and Immunology, University of British Columbia, 2207 Main Mall, Vancouver, \\ BC V6T 1Z4, Canada \\ 5 Department of Botany, University of British Columbia, 2207 Main Mall, Vancouver, BC V6T 1Z4, Canada \\ 6 Institute for the Oceans and Fisheries, University of British Columbia, 2207 Main Mall, Vancouver, \\ BC V6T 1Z4, Canada \\ * Correspondence: gmordecai@eoas.ubc.ca (G.J.M.); Kristi.Saunders@dfo-mpo.gc.ca (K.M.M.); \\ suttle@science.ubc.ca (C.A.S.) \\ + These authors contributed equally to this work.
}

Received: 17 March 2019; Accepted: 16 April 2019; Published: 18 April 2019

\begin{abstract}
Viral erythrocytic necrosis (VEN) affects over 20 species of marine and anadromous fishes in the North Atlantic and North Pacific Oceans. However, the distribution and strain variation of its viral causative agent, erythrocytic necrosis virus (ENV), has not been well characterized within Pacific salmon. Here, metatranscriptomic sequencing of Chinook salmon revealed that ENV infecting salmon was closely related to ENV from Pacific herring, with inferred amino-acid sequences from Chinook salmon being $99 \%$ identical to those reported for herring. Sequence analysis also revealed 89 protein-encoding sequences attributed to ENV, greatly expanding the amount of genetic information available for this virus. High-throughput PCR of over 19,000 fish showed that ENV is widely distributed in the NE Pacific Ocean and was detected in 12 of 16 tested species, including in $27 \%$ of herring, $38 \%$ of anchovy, $17 \%$ of pollock, and $13 \%$ of sand lance. Despite frequent detection in marine fish, ENV prevalence was significantly lower in fish from freshwater $(0.03 \%)$, as assessed with a generalized linear mixed effects model $\left(p=5.5 \times 10^{-8}\right)$. Thus, marine fish are likely a reservoir for the virus. High genetic similarity between ENV obtained from salmon and herring also suggests that transmission between these hosts is likely.
\end{abstract}

Keywords: erythrocytic necrosis virus (ENV); viral erythrocytic necrosis (VEN); Pacific salmon; Pacific herring; British Columbia

\section{Introduction}

Viral erythrocytic necrosis (VEN) is a disease associated with severe blood abnormalities in infected fish which has caused mass mortality in Pacific herring (Clupea pallasii) [1]. The disease is traditionally diagnosed by microscopic examination of stained blood smears for the presence of inclusion bodies within the cytoplasm of infected erythrocytes. Electron microscopy revealed that 
infected erythrocytes contained icosahedral virions, which were named erythrocytic necrosis virus (ENV) [2]. Although first described more than half a century ago, the virus is poorly characterized as attempts to propagate it in fish cell lines have been unsuccessful [3].

Based on the small amount of available ENV genomic sequence, the virus has been assigned to a new putative genus within the Iridoviridae (a family of double-stranded DNA viruses), comprising other erythrocytic viruses from ectothermic hosts [2,4]. Further genomic sequencing of ENV may provide a reference for studying genetic variation geographically, and among fish species. Currently, the only verified ENV sequences available in GenBank encode ATPase, the major capsid protein (MCP), DNA-dependent DNA polymerase, and DNA-dependent RNA polymerase.

In the NE Pacific Ocean, VEN has been described in Pacific herring [1] and in the marine phase of pink (Oncorhynchus gorbuscha), chum (Oncorhynchus keta), coho (Oncorhynchus kisutch), steelhead (Oncorhynchus mykiss), and Chinook (Oncorhynchus tshawytscha) salmon [5,6]. High geographic variability in VEN prevalence and disease susceptibility of chum, coho, sockeye, and Chinook salmon, as well as Pacific herring, suggests that ENV could help explain high year-to-year variability in the population dynamics of these keystone species throughout coastal regions of the NE Pacific Ocean $[1,7,8]$. In the laboratory, VEN has been induced after confining healthy salmon with diseased fish. Among salmonids, disease transmission has been demonstrated in pink and chum salmon [5,8,9]. Chinook, coho, and sockeye salmon appear to be more resistant to infection in challenge studies, as assessed by electron microscopy [5,9], despite natural epizootics in Chinook and coho salmon. To date, an explicit relationship between disease manifestation and viral load has not been described, and ENV isolation has not been accomplished in previous studies reporting disease transmission among species. There is substantial evidence that viruses in different genera within the family Iridoviridae cause different disease manifestation and severity [10-15]; thus, phylogenetic placement and genetic characterization of ENV may offer insight into factors contributing to disease outbreaks.

Considering the high prevalence of ENV in herring and salmon in the NE Pacific Ocean [1,16-20], there is a need to further characterize the virus in at-risk fish populations. Substantial herring stock declines in British Columbia since the 1970s, which have mainly been attributed to overfishing, are of concern as herring are a keystone species that underpin the coastal food web [21,22]. Similarly, Pacific salmon provide an important biological, economic, and cultural resource in British Columbia, and recent stock declines are likely to have large impacts on wildlife and fisheries in the region. The Pacific Salmon Commission, for example, reported a 60\% reduction in Salish Sea Chinook abundance from 1984 to 2010 [23]. Furthermore, the Committee on the Status of Endangered Wildlife in Canada reports that half of the British Columbia Chinook salmon populations are endangered [24].

In the current study, we applied metatranscriptomic sequencing to examine the phylogenetic relationship of ENV in Chinook salmon and investigated the epidemiology and host tropism of ENV using high-throughput PCR. Our results show that ENV is widely prevalent across numerous fish species in the NE Pacific Ocean and that ENV in salmon and herring has high genetic similarity, suggesting that the virus may circulate among these species.

\section{Materials and Methods}

\subsection{Fish Sampling}

In total, 19,652 fish comprising 16 species were sampled from freshwater and marine environments as previously described $[17,25]$. Briefly, 3228 freshwater samples were collected at hatcheries, through beach seining, or by smolt traps for wild salmon. Marine samples were obtained mostly by purse and beach seines, and by trawl. Typically, mixed tissue samples were dissected from fish using sterile procedures in the field [26] and frozen in RNAlater before nucleic acid extraction, although some fish were flash frozen in the field and dissected in the laboratory. Both procedures have been routinely used for examining individual fish for the presence of viral nucleic acids $[16,18,26-28]$. Samples were collected over the course of an 11-year period from 2007-2018 in a region spanning Alaska to 
Northern Washington (Figure S1) as part of a large pathogen-screening effort conducted by Fisheries and Oceans Canada.

\subsection{Data Collection}

The occurrence and abundance of ENV in fish was determined using the Fluidigm BioMark Platform at the Department of Fisheries and Oceans Canada [26]. Briefly, the platform provides an estimate of viral load based on copy number, as assessed by RT-qPCR. Copy numbers are calculated based on serial dilutions of artificial construct DNA standards. The calculated limit of detection (LOD) was applied to identify fish with amplifications above the 95\% detection threshold [26]. ENV assays on this platform show $100 \%$ inclusivity (detection of all known strain variants of the targeted microbe) and $97.9 \%$ exclusivity (no detection of untargeted microbe species). Primers were originally obtained from a $100 \mathrm{bp}$ ATPase-like protein partial gene sequence. Additional details on primer sequences as well as assay specificity and reliability are available in Miller et al. [26]. ENV monitoring was conducted alongside assays for 46 other infective agents on combined RNA and DNA extractions. In this study, ENV prevalence is reported as the proportion of fish with ENV detections, both with and without the LOD criteria applied. When not mentioned explicitly, prevalence values are reported with LOD criteria applied. Statistical analyses were done only on samples with LOD criteria applied.

\subsection{Metatranscriptomic Sequencing and Bioinformatics}

In order to isolate putative ENV sequences, several samples with high-load detections of this virus, as assessed using the Fluidigm BioMark, were selected for transcriptomic sequencing. In total, three aquaculture and one wild Chinook salmon were used to predict ENV proteins. Three additional fish, including an Atlantic salmon, a Chinook salmon, and a herring sample underwent an enrichment step for these predicted ENV proteins before bioinformatic analysis.

All fish except the wild Chinook salmon were sequenced on Illumina Next-Generation Sequencing (NGS) platforms using different RNA-seq protocols, depending on original targets and loads. To avoid DNA contamination from the host reducing the sequencing depth of the target virus, RNA sequencing was used to obtain transcriptomic sequences of the DNA virus. Each of these libraries was single tissue, either heart or spleen. Ribosomal RNA was removed from total RNA using the RiboMinus Invitrogen Eukaryote kit for RNA (Life Technologies, Carlsbad, CA, USA). The RNA-Seq library was prepared using the NEBNext Ultra RNA Library prep kit (New England BioLabs, Ipswich, MA, USA) with an average fragment size of 250-bp and was paired-end sequenced with 100-bp reads on the Illumina HiSeq analyzer (Illumina, San Diego, CA, USA).

For the wild Chinook sample, the ENV contigs were obtained using a similar RNAseq approach. This library was created using pooled tissue (gill, liver, heart, kidney and brain) and prepared with the ScriptSeq Complete Epidemiology NGS library kit (Illumina, San Diego, CA, USA). Briefly, ribosomal RNA was removed from Total RNA using the Epicentre ScriptSeq Complete Gold Kit (Epidemiology) (Illumina, San Diego, CA, USA) according to the manufacturer's instructions. The ScriptSeq Index reverse primers were added to the cDNA during the final amplification step which involved 14 cycles. Finally, a paired-end $125 \mathrm{bp}$ sequencing run was performed on the Illumina HiSeq System.

Finally, in order to enhance our sensitivity (i.e., NGS read depth and coverage) for ENV in the medium load ( 1300 copies) farmed Atlantic salmon sample, and the Chinook and herring samples $\left(\sim 42,670\right.$ and 214,500 copies, respectively) we employed SureSelect ${ }^{\mathrm{XT}}$ enrichment technology (Agilent, Santa Clara, CA, USA). A custom set of RNA target enrichment probes (120 bp in length and staggered along the exome of interest) were designed for ENV as well as many other salmonid viruses assessed on our infectious agent monitoring platform. These sequences (497.266-kbp in total length) and subsequent bait oligonucleotides included all of the suspected ENV contigs previously assembled from high load samples. Baits which failed the SureSelect QA/QC parameters and/or significantly matched salmonid genes via BLAST searches were removed, leaving the final set of enrichment probes at 20,497. The mixed tissue (gill, atrium, ventricle, liver, pyloric caeca, spleen, head kidney, posterior 
kidney) RNA library, was prepared using the SureSelect ${ }^{\mathrm{XT}}$ low input (NGS) target workflow (Agilent, Santa Clara, CA, USA) with a SureSelect ${ }^{\mathrm{XT}}$ RNA Direct/XTHS modified protocol. Approximately 200 ng of total RNA was lyophilized and fed into the SureSelect Strand-Specific RNA library Prep kit (Agilent, Santa Clara, CA, USA) according to the manufacturer's instructions. After the 2nd strand cDNA synthesis and end repair steps, the library prep was moved to the SureSelect ${ }^{\mathrm{XT}}$ low input reagent kit, starting with the end repair and A tailing step. Molecular barcoded adaptors were added using ligation and then amplified for 14 cycles according to manufacturer's instructions to create a pre-capture RNAseq library. Samples were quantified with the Qubit dsDNA HS kit (Invitrogen, Carlsbad, CA, USA), qualified with the DNA12000 chips run on the Agilent 2100 Bioanalyzer (Agilent, Santa Clara, CA, USA), and pooled into a batch of 12 prior to hybridizing $1500 \mathrm{ng}$ to the bait library. Hybridizations were incubated at $65{ }^{\circ} \mathrm{C}$, captured on streptavidin beads (Beckman Coulter, Brea, CA, USA) and washed at $70^{\circ} \mathrm{C}$ according to manufacturer's instructions before a post-capture amplification of 14 cycles. These final libraries were quantified with the Qubit dsDNA HS kit (Invitrogen, Carlsbad, CA, USA) and qualified with the DNA HS chips run on the Agilent 2100 Bioanalyzer (Agilent, Santa Clara, CA, USA). Finally, a paired-end $101 \mathrm{bp}$ v2 300 kit sequencing run was performed on the Illumina Miseq (Illumina, San Diego, CA, USA), which included a 5\% phiX spike in.

After adapter removal, Illumina MiSeq sequencing produced between 53.3 and $59.9 \mathrm{M}$ reads for each Chinook salmon used to predict ENV amino-acid sequences (quality score $>28$ ). These reads were processed as detailed below. Adapters were removed using Trimmomatic [29], and the trimmed reads aligned with genome sequence from Atlantic Salmon [30] using the Burrows-Wheeler Aligner [31]. Unmapped sequences were extracted from the dataset using Samtools [32] and assembled into contiguous sequences (contigs) using SPAdes [33]. The translated contigs were queried against the non-redundant (NR) database in GenBank using DIAMOND [34]. Contigs with top hits to members of the family Iridoviridae were extracted in Microsoft Excel and the Qiime script filter_fasta.py [35] was adapted to retain these contigs as fasta files. GeneMark [36] was used to make protein predictions for putative ENV nucleotide sequences. Predicted proteins were subject to a BLAST search against the NR database [37], the lymphocystis disease virus genome, and a set of 47 conserved genes within Nucleo-Cytoplasmic Large DNA viruses (NCLDVs) [38]. Additionally, contigs of $500 \mathrm{bp}$ in length or greater were extracted and translated into all six frames using Geneious version 9.1.8 [39]. A single, most likely translation frame was selected from the BLAST results, and those with BLAST results mapping to ENV were used to create phylogenies for ATPase, DNA-dependent DNA polymerase, DNA-dependent RNA polymerase, and the MCP. For each of these proteins, phylogenetic trees were mapped using available sequences from closely related iridoviruses using ClustalW for alignments and PhyML with Le Gascuel substitution model for tree creation [40,41]. For each phylogenetic tree, Spodoptera frugiperda ascovirus $1 a$ was used as an outgroup. Assembled contigs have been submitted to GenBank under the accession numbers MK638669-MK638757. To increase confidence that sequences we attributed to ENV belong to this virus, we aligned sequences obtained from the farmed Atlantic salmon (632,935 reads), Chinook salmon (658,241 reads), and herring (800,139 reads) which underwent an enrichment step for ENV viral content to our putative ENV protein-encoding sequences using the using the Burrows-Wheeler Aligner [31].

\subsection{Spatial Epidemiology Analysis}

All statistical analyses and plots were performed in R version 3.5.2 [42]; scripts are available in File S1. For statistical analyses, ENV detection was categorized as positive or negative with LOD criteria applied and viral loads were quantified based on estimated viral copy numbers in host fish, following Miller et al. [26]. For map plotting only, ENV load was quantified by subdividing ENV copy number data into six categorical bins based on value with no LOD criteria $(0,0-5,5-10,10-100$, $100-10,000,>10,000$ viral copies). As sample sizes for other fish were small, statistical analyses were only conducted on herring and salmon. However, ENV prevalence and load was investigated for all sampled fish species. Heat maps were produced with an inverse-distance weighting function, 
using R packages "ggmap" and "gstat" [43,44], while plots were constructed with "ggplot2" [45]. Differences in load among species, age class, and habitat type were assessed using Kruskal-Wallis and post-hoc pairwise Dunn tests with Benjamini-Hochberg adjusted $p$ values for multiple comparisons. Differences in ENV prevalence among categorical variables were assessed using Chi-squared tests of independence. A post-hoc Fisher's exact test and Chi-squared tests with Bonferroni correction were conducted for pairwise comparisons to determine ENV prevalence differences among species and years, respectively, with "rcompanion" [46]. Spearman correlation was conducted to examine correlations among monthly prevalence between species. To account for residual variation in the data, a generalized linear mixed-effects model with Laplace approximation was implemented to examine differences in ENV prevalence between fresh and saltwater, with catch region, species, age class, season, population (hatchery or wild), and year considered as random effects with the $\mathrm{R}$ package "mlmRev" [47,48]. A similar model was used to assess differences in prevalence among age classes (smolt or adult) with habitat type used as an additional random effect instead of age class.

\section{Results}

\subsection{Genetic Characterization}

Metatranscriptomic sequencing of Chinook salmon with high ENV loads revealed high sequence identity between ENV sequences found in Chinook salmon and viral sequences from GenBank associated with Pacific herring. The available ENV sequences from Pacific herring (ATPase, DNA-dependent DNA polymerase, MCP, and DNA-dependent RNA polymerase) showed over $99 \%$ nucleic acid identity to ENV sequences from Chinook salmon in our study (Table 1). Sequences reported in Table 1 originate from heart tissue of one of the aquaculture Chinook salmon samples and from the wild Chinook salmon mixed-tissue specimen, both with a high load ENV detection (CT values of 10.7 and 13.4, respectively). The aquaculture Chinook salmon specimen had jaundice and several co-infections including Paranucleospora theridion, Piscine reovirus, and Renibacterium salmoninarum, as determined by the RT-qPCR assay. Phylogenies based on these genes (Figure 1) from ENV and its relatives (Table 2), showed that viral sequences from herring and salmon form a well-supported clade. A metatranscriptomic approach on a DNA virus only reveals virally expressed transcripts; thus, a full ENV genome could not be assembled. Within the metatranscriptomic sequences, there were 32 putative ENV proteins which consistently mapped to proteins of similar function from viruses in the family Iridoviridae (Table S2), as well as BLAST hits to 21 of the 47 core proteins in NCLDVs [38] (File S2). Putative ENV transcripts typically had between $20 \%$ and $60 \%$ nucleotide identity with other iridoviruses. These values are consistent with nucleotide identities reported between existing ENV sequences and other fish iridoviruses. In total 117 contigs with BLAST hits to iridoviruses were isolated from transcriptomic sequencing. Putative ENV sequences ranged in length from 152 to $4475 \mathrm{bp}$ (File S3). From these, we predicted 89 protein-encoding sequences longer than 200-bp (Accession numbers MK638669-MK638757). When putative ENV protein-encoding sequences were aligned to reads obtained from the Atlantic salmon, Chinook salmon, and Pacific herring enriched for these contigs, we detected 35 of 117 putative ENV sequences. Results from this analysis are summarized in file S4. 
Table 1. Basic Local Alignment Search Tool (BLAST) summary of erythrocytic necrosis virus (ENV) sequences from Chinook salmon compared with available herring derived ENV sequences on GenBank. The origin of each sequence is indicated as aquaculture (Aq.) or wild Chinook salmon. Sequences used in phylogenies are in bold.

\begin{tabular}{|c|c|c|c|c|}
\hline Reference Sequence & Sequence ID & $\begin{array}{c}\text { \% Identity } \\
\text { (Nucleotide) }\end{array}$ & $\begin{array}{c}\% \text { Identity } \\
\text { (Amino Acid) }\end{array}$ & $\begin{array}{l}\text { Sequence Alignment } \\
\text { Length (AA) }\end{array}$ \\
\hline \multirow{4}{*}{$\begin{array}{c}\text { ATPase } \\
\text { KJ730210.1 (partial) }\end{array}$} & 80 (Aq.) & 99.9 & 100 & 849 \\
\hline & 46 (Wild) & 99.6 & 98.7 & 74 \\
\hline & 57 (Wild) & 99.5 & 98.5 & 67 \\
\hline & 54 (Wild) & 100 & 100 & 77 \\
\hline \multirow{3}{*}{$\begin{array}{l}\text { DNA-dependent DNA polymerase } \\
\text { KJ756347.1 (partial) }\end{array}$} & 73 (Wild) & 99.9 & 98.3 & 59 \\
\hline & 79 (Aq.) & 99.8 & 99.7 & 897 \\
\hline & 19 (Wild) & 99.5 & 99.5 & 213 \\
\hline \multirow{2}{*}{$\begin{array}{c}\text { MCP } \\
\text { KT211480.1 (partial, Puget Sound) }\end{array}$} & 86 (Aq.) & 99.6 & 100 & 1436 \\
\hline & 75 (Wild) & 100 & 100 & 175 \\
\hline $\begin{array}{l}\text { DNA-dependent RNA polymerase } \\
\text { KJ756346.1 (partial) }\end{array}$ & 78 (Aq.) & 99.9 & 96.8 & 972 \\
\hline
\end{tabular}

Table 2. GenBank reference sequences and viral species used to create phylogenies, with colors indicating genera groups corresponding to phylogenetic trees in Figure 1.

\begin{tabular}{|c|c|c|c|c|c|}
\hline \multirow[b]{2}{*}{ Abbreviation } & \multicolumn{4}{|c|}{ Accession Numbers } & \multirow[b]{2}{*}{ Taxon } \\
\hline & $\begin{array}{l}\text { DNA-Dependent } \\
\text { DNA Polymerase }\end{array}$ & $\begin{array}{l}\text { DNA-Dependent } \\
\text { RNA Polymerase }\end{array}$ & MCP & ATPase & \\
\hline NA & AAC54632.1 & YP_762407.1 & NC_008361.1 & NC_008361.1 & Spodoptera ascovirus \\
\hline ENV & AIQ77732.1 & AIQ77731.1 & KT211480.1 & AIN76233.1 & Erythrocytic necrosis \\
\hline \multicolumn{6}{|c|}{ Megalocytivirus } \\
\hline RSIV & BAA28669.1 & BAK14252.1 & AB109371.1 & BAK14298.1 & $\begin{array}{c}\text { Red Sea Bream } \\
\text { iridovirus }\end{array}$ \\
\hline ISKNV & CAZ73994.1 & & AF370008.1 & NP_612331.1 & $\begin{array}{l}\text { Infectious spleen and } \\
\text { kidney necrosis virus }\end{array}$ \\
\hline TRBIV & ADE34365.1 & ADE34378.1 & AY590687.2 & ADE34443.1 & $\begin{array}{c}\text { Turbot reddish body } \\
\text { iridovirus }\end{array}$ \\
\hline RBIV & & AAT71848.1 & & & Rock Bream iridovirus \\
\hline \multicolumn{6}{|c|}{ Ranavirus } \\
\hline FV3 & NC_005946.1 & ASH99239.1 & & AHM26101.1 & Frog virus 3 \\
\hline EHNV & ACO25234.1 & YP_009182042.1 & AY187045.1 & YP_009182084.1 & $\begin{array}{c}\text { Epizootic } \\
\text { haematopoietic } \\
\text { necrosis virus }\end{array}$ \\
\hline GIV & AY666015.1 & & KX284838.1 & & Grouper iridovirus \\
\hline ECV & & AMZ05024.1 & & YP_006347705.1 & European catfish virus \\
\hline ATV & & ALN36639.1 & & YP_003852.1 & $\begin{array}{l}\text { Ambystoma } \\
\text { tigrinum virus }\end{array}$ \\
\hline LMRV & & & KM516719.1 & & $\begin{array}{c}\text { Lacerta monticola } \\
\text { ranavirus }\end{array}$ \\
\hline LMBV & & & KU507317.1 & & $\begin{array}{l}\text { Largemouth bass } \\
\text { ranavirus }\end{array}$ \\
\hline \multicolumn{6}{|c|}{ Lymphocystivirus } \\
\hline LCDV(Sa) & & YP_009342128.1 & AY823414.1 & & \multirow{3}{*}{$\begin{array}{l}\text { Lymphocystis disease } \\
\text { virus (various strains) }\end{array}$} \\
\hline LCDV(China) & & YP_073534.1 & NC_005902.1 & YP_073585.1 & \\
\hline LCDV1 & & & & AAX54510.1 & \\
\hline \multicolumn{6}{|c|}{ Iridovirus } \\
\hline IIV6 & NC_003038.1 & AAK82288.1 & & NP_149647.1 & $\begin{array}{c}\text { Invertebrate iridescent } \\
\text { virus } 6\end{array}$ \\
\hline IIV & & & NC_023615.1 & & $\begin{array}{c}\text { Invertebrate iridescent } \\
\text { virus }\end{array}$ \\
\hline AVIV & & & NC_024451.1 & NC_024451.1 & $\begin{array}{l}\text { Armadillium vulgare } \\
\text { iridescent virus }\end{array}$ \\
\hline Aedes taen. & & & NC_008187.1 & & $\begin{array}{l}\text { Aedes taeniorhynchus } \\
\text { iridescent virus }\end{array}$ \\
\hline \multicolumn{6}{|c|}{ Chloriridovirus } \\
\hline IIV3 & YP_654692.1 & YP_654581.1 & & YP_654693.1 & $\begin{array}{c}\text { Invertebrate iridescent } \\
\text { virus } 3\end{array}$ \\
\hline RMIV & CAC84133.1 & & & & $\begin{array}{c}\text { Regular mosquito } \\
\text { iridescent virus }\end{array}$ \\
\hline
\end{tabular}




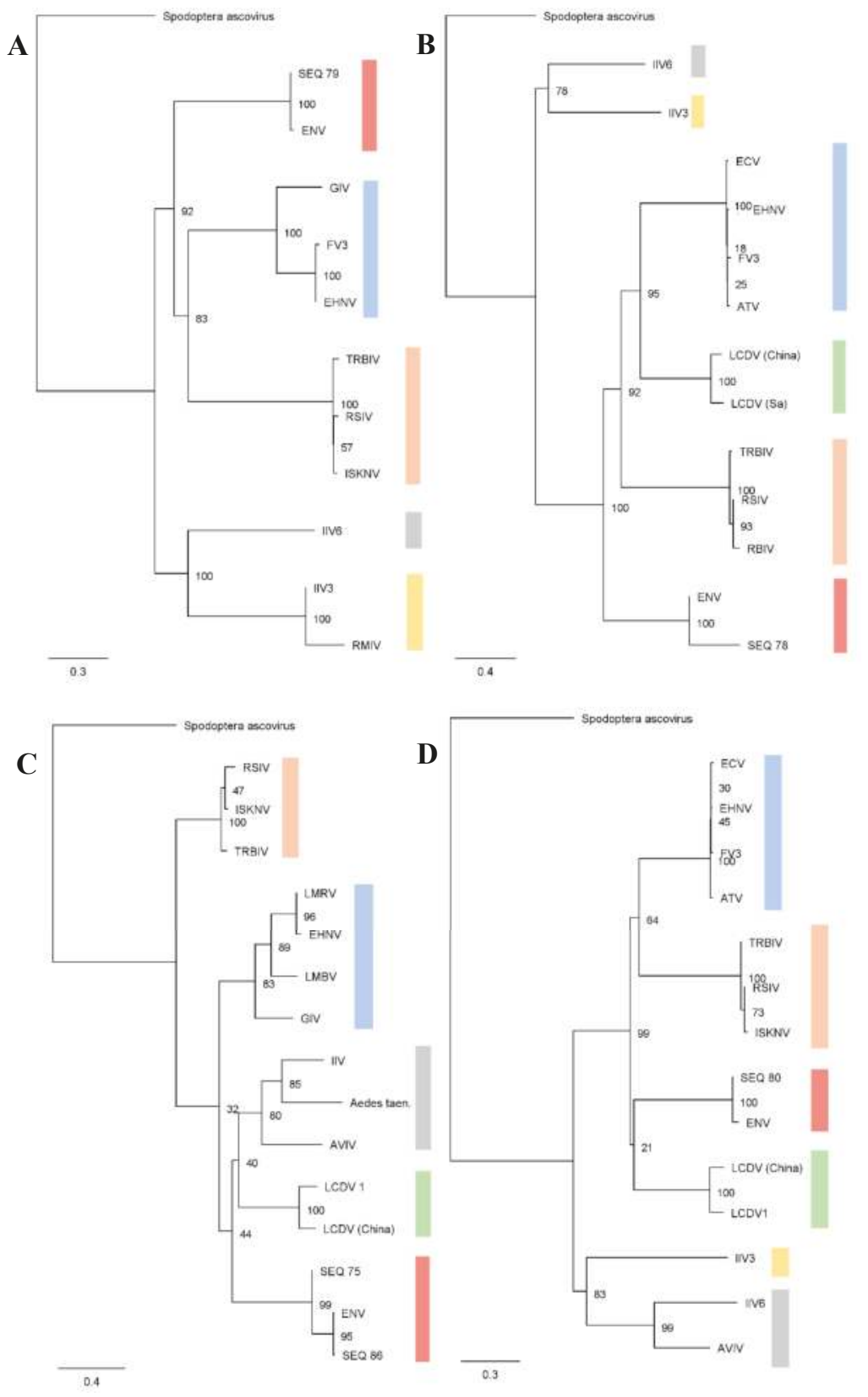

Figure 1. Substitution-rate optimized maximum likelihood phylogenetic trees of putative ENV DNA-dependent DNA polymerase (A), DNA-dependent RNA polymerase (B), major capsid protein (C), and ATPase (D) sequences (SEQ\#) mapped with related iridoviruses. Alignments were based on nucleotide sequences for the major capsid protein and amino acid sequences for all other trees. Branch labels indicate bootstrap support values for 100 re-samplings and the scale bar indicates substitution rate. GenBank reference sequences and contig IDs are listed below (Table 2), with colors indicating genera groups. Putative ENV sequence lengths are listed in Table 1. 


\subsection{Spatial Epidemiology}

ENV is widely distributed in the NE Pacific Ocean and was detected in 12 of 16 tested species (Figure 2) throughout the sampling region. High viral loads were common within the Strait of Georgia, along the west coast of Vancouver Island, and in straits and channels throughout coastal northern British Columbia and southern coastal Alaska (Figure 3). Over 19,000 fish were tested for ENV, from 16 different species collected from marine and fresh waters spanning from Washington to Alaska. ENV prevalence was highest in anchovy and herring, occurring in over $27 \%$ of all sampled fish in these species and in over $37 \%$ of smolts. In herring, the proportion of fish in which ENV was detected was significantly higher than in any salmon species tested. We also report significantly lower ENV prevalence and load within salmon smolt $\left(\mathrm{p}_{\text {prev }}=1.2 \times 10^{-17}\right.$, $\left.\mathrm{p}_{\text {load }}=1.8 \times 10^{-4}\right)$ and greater ENV prevalence among herring smolt $\left(p=4.5 \times 10^{-6}\right)$, when compared to respective adult prevalence. Among fish with detections of ENV, viral load was highest in herring and Chinook salmon and lowest in Atlantic salmon. ENV load also appeared low in chum and pink salmon; however, these differences were not statistically significant (Figure S2, Table S3). Significant differences in ENV load were found between herring and coho, Chinook, sockeye, and Atlantic salmon ( $p$ values are given in Tables S3 and S4).

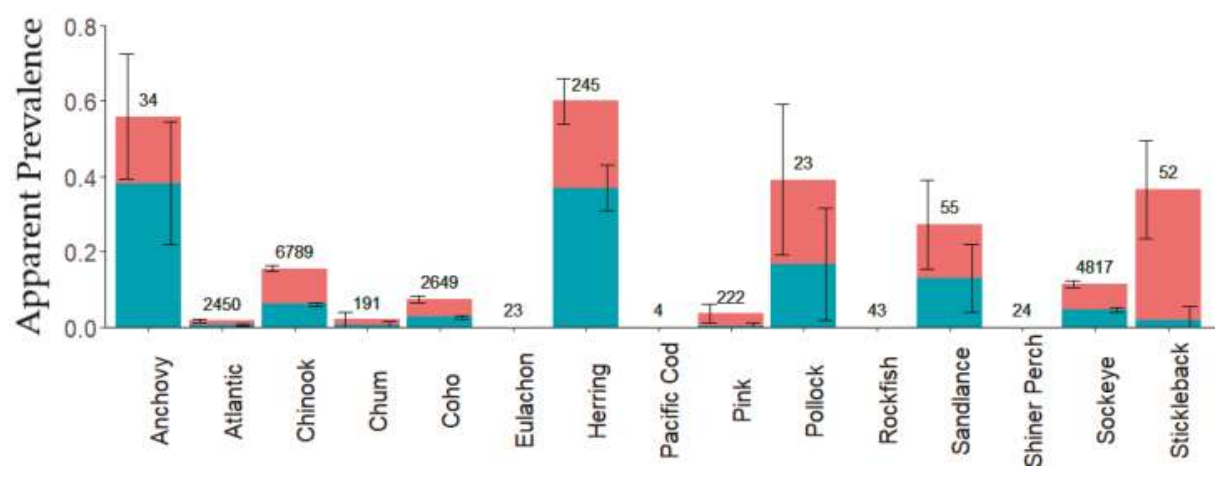

Figure 2. Apparent ENV prevalence in mixed tissue smolt samples by species. Error bars indicate $95 \%$ confidence intervals. Blue bars indicate proportions with limit of detection (LOD) criteria applied and coral bars indicate proportions without LOD criteria applied. Values indicate sample sizes for each species.

Despite high ENV prevalence and load in coastal regions, ENV was rarely detected, and percent prevalence was statistically lower in all species sampled in freshwater $\left(p<2.2 \times 10^{-16}\right)$ (Figure 4). Furthermore, after applying a generalized linear mixed-effects model with Laplace approximation to account for residual variation in the data, categorical classification of habitat type as freshwater or saltwater still had a significant effect on ENV prevalence $\left(p=5.50 \times 10^{-8}\right)$. Given that $98 \%$ of the freshwater detections were below the LOD, these all represent very low-load detections, and are unlikely biologically relevant or may represent "false" positives. As such, all statistical tests are reported for samples with LOD criteria applied only. 

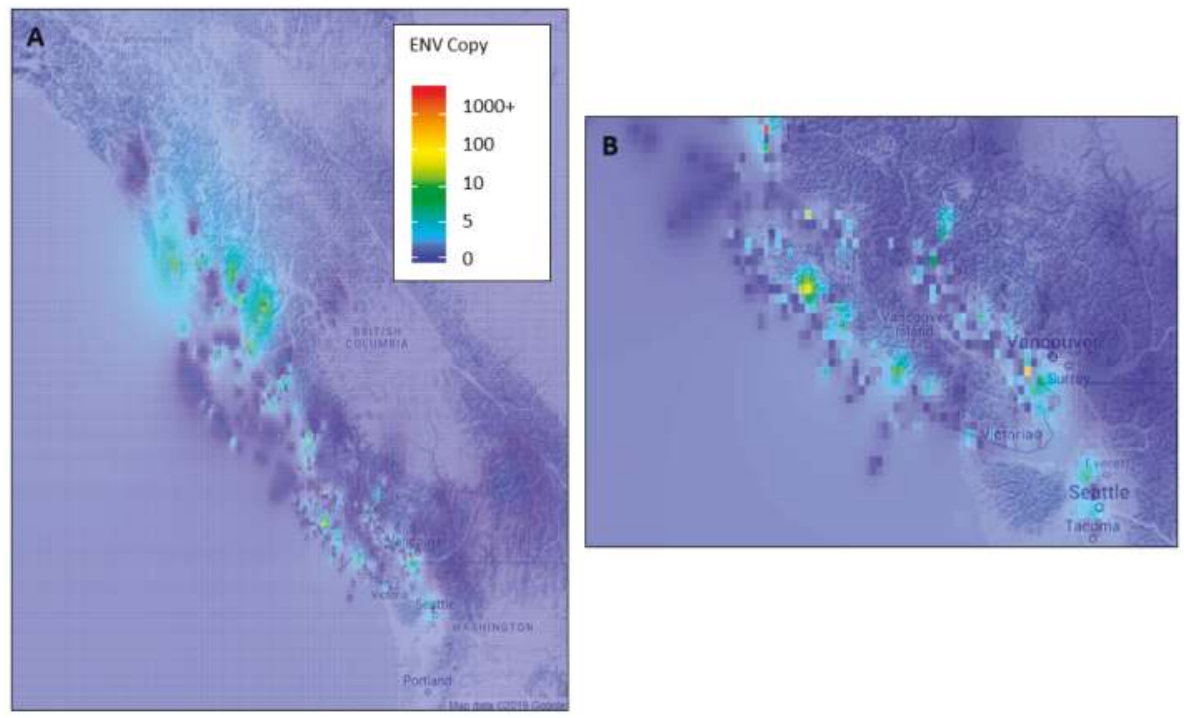

Figure 3. (A) Full sampling area heat map of the mean calculated ENV copy number, based on interpolated values. Copy number values are binned into 6 numerical categories (see color legend), (B) shows Vancouver Island inset map. Adults and smolts of all species are shown and LOD criteria are not applied.

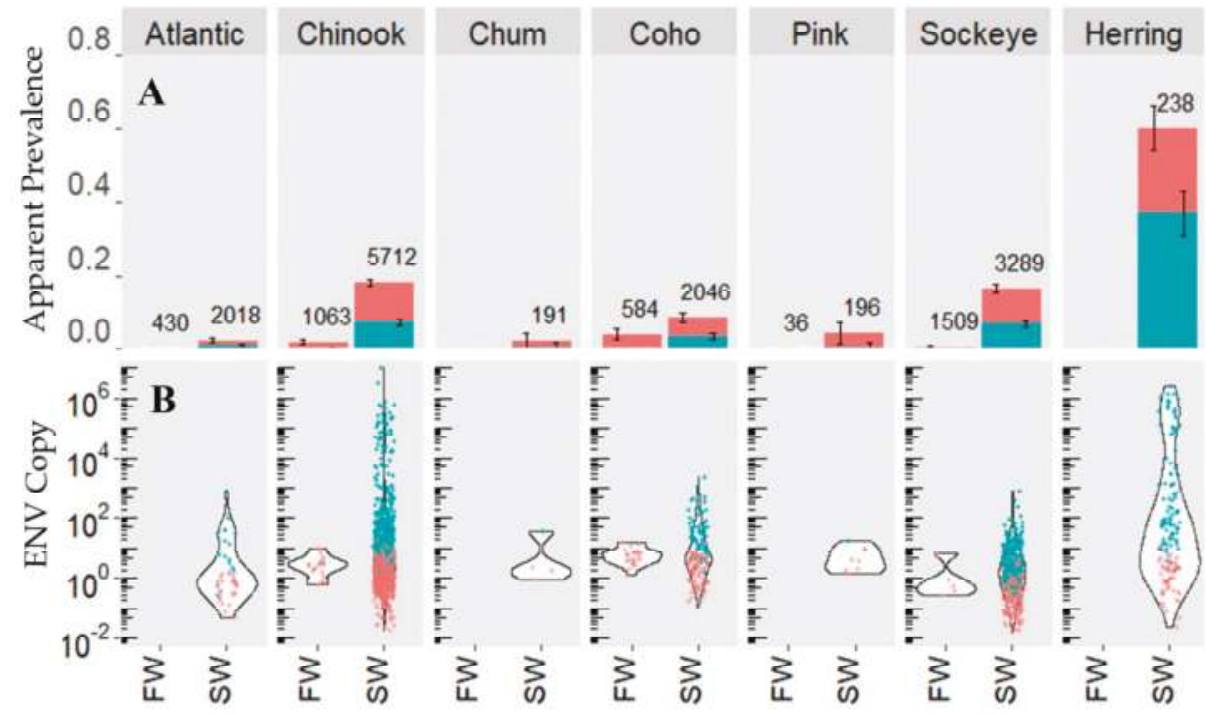

Figure 4. Saline (SW) and freshwater (FW) ENV prevalence (A) and load (B) among salmon species and herring. Samples with LOD criteria applied are in blue and samples without LOD criteria applied are in coral. Printed values indicate sample sizes and error bars indicate $95 \%$ confidence intervals. Only smolts are shown.

\subsection{Seasonal and Yearly Variation}

In Atlantic salmon, ENV prevalence showed seasonal variation, with the lowest prevalence occurring in August, for both smolt and adult fish (Figure S3). A similar seasonal trend was observed 
in smolt sockeye and Chinook salmon. A Spearman correlation coefficient of 0.87 was found between monthly prevalence of ENV in sockeye and Atlantic salmon $(p=0.004)$. Despite very low ENV prevalence in Atlantic salmon (2\%), farmed coho and Chinook salmon showed higher ENV prevalence ( $29 \%$ and $48 \%$, respectively) compared to their wild counterparts ( $3 \%$ and $7 \%$, respectively) (Figure S4). This difference was significant in Chinook salmon $\left(p=2.08 \times 10^{-50}\right)$. Among salmon, changes in ENV prevalence from year to year appear to occur synchronously (Figure S5) and ENV prevalence also varies significantly by year $\left(p<2.2 \times 10^{-16}\right.$, Figure S6). A $63 \%$ decrease from the average prevalence of $5 \%$ is observed after 2013.

\section{Discussion}

The current study expands on sequence available for ENV and demonstrates that the virus is widespread in salmon and herring and is often present at high load in these fish. The low genetic variation among viruses infecting salmon and herring has implications for potential host range and the taxonomic classification of these viruses.

Nucleotide variation of ENV from herring and Chinook salmon was low, with ENV sequences from Pacific herring $[2,4]$ having $>99 \%$ nucleotide identity with the sequence obtained from Chinook salmon in this study, indicating that both viruses belong within the same genus, and likely the same species. High sequence similarity between herring and Chinook salmon could be suggestive of viral spillover between hosts. Moreover, the phylogenetic analysis clearly places ENV within the Iridoviridae, but distinct from other viruses within the family.

After enrichment for putative ENV sequences in the herring, Chinook salmon, and Atlantic salmon samples, we found 35 of 117 predicted protein-encoding sequences, suggesting that not all ENV transcripts are present in every infected fish. This may depend on expression levels and infection stage. Indeed, variable gene expression during different stages of infection occurs commonly among iridoviruses [49-52]. Moreover, our estimates of prevalence are conservative, as the assay is sensitive to sequence variation, so related strains of ENV could be missed.

ENV was widely distributed geographically and among fish species in marine waters of western North America. Despite high ENV prevalence and load in coastal marine environments, viral load and prevalence were consistently low in freshwater environments. Of the 3622 fish analyzed from freshwater, ENV was only detected in one Chinook salmon specimen after LOD criteria were applied. Interestingly, there were few ENV detections in fish from the open waters north of Vancouver Island (Figure 3); whereas ENV was common in coastal areas, i.e., channels, inlets, and straits along coastal British Columbia and southern Alaska (Figure 3). We hypothesize that interspecies transmission may be more likely in these areas, where there are higher densities of salmon and other fish. Greater ENV prevalence in aquaculture Pacific salmon than in wild counterparts (Figure S4) supports the idea that transmission of the virus may be more common in coastal and high-density environments. There is some support for this hypothesis in the literature as previous studies have shown that chum salmon may contract VEN via waterborne exposure [8] and that increased stock density is a predictor of disease progression in fish infected with other iridoviruses [53,54]. We also report significantly lower ENV prevalence among salmon smolts and in adult herring when compared to respective adult and smolt age classes for these species, suggesting that susceptibility to ENV varies by host species and age class. ENV prevalence may not, however, directly correlate with disease manifestation mediated by the virus, as species with low ENV load and prevalence $(<0.5 \%)$ in this study, including chum and pink salmon, are more susceptible to VEN than other salmon species $[55,56]$. Thus, salmon species in which ENV prevalence and load were the greatest (Chinook and coho salmon) may be able to sustain higher viral loads and display fewer clinical symptoms.

We hypothesize that salmon likely contract the virus from marine reservoirs, given the low detection of ENV in freshwater salmon, high sequence similarity between ENV in salmon and herring, and high viral prevalence in several species of marine fish including herring, anchovy, pollock, and sand lance. Furthermore, the prevalence of ENV in Pacific salmon is much higher than in Atlantic 
salmon, suggesting that farmed Atlantic salmon are not a significant reservoir for ENV transmission, despite high-density rearing in this species. Previous research has shown that overall infectious agent diversity and burden increases when sockeye salmon enter the ocean [16], suggesting that ENV could contribute to increased infection stress experienced by out-migrating salmon smolts.

Salmon migration, which varies among species and populations, may help explain yearly and seasonal variation in ENV prevalence. Peaks in ENV prevalence occur during spring and late fall for Chinook and sockeye salmon, with significant drops seen during peak salmon river runs in July and August. A similar pattern is observed in Atlantic salmon, which are stationary throughout the year and therefore may provide a useful sentinel to study seasonal ENV dynamics in wild salmon. Indeed, there is a significant correlation in monthly ENV prevalence between Atlantic and sockeye salmon. However, variation in migration patterns among species and stocks complicates the analysis of seasonal ENV prevalence changes. Migration routes and timing among Chinook salmon stocks, for example, is highly variable $[57,58]$. Furthermore, several sockeye salmon stocks were sampled during different parts of the year. Increases in ENV prevalence in winter may also arise as a result of herring migrations to coastal regions during this time [59]. Overall, monthly ENV prevalence dynamics in salmon were similar to those observed previously in herring [1], further substantiating the hypothesis that interactions with herring promote infection dynamics in wild salmon.

Previously, little was known about the epidemiology of ENV in salmon and marine fish, as most studies focused on ENV in herring. Hershberger et al. detected ENV in up to $67 \%$ of herring, with similar seasonal variation to that which we observed in salmon, with the greatest proportion of fish testing positive for ENV in summer months [1]. They also reported that ENV epizootics can arise and dissipate spontaneously in geographically isolated regions along the North Pacific coastline. Additionally, Teffer et al. investigated ENV prevalence in returning Chinook salmon and detected ENV in $16 \%$ of tagged males and $25 \%$ of females in the Chilliwack River [20]. Together, our research and these studies indicate that the virus is widely distributed on the west coast of British Columbia and Alaska and that salmon are likely infected once they enter the ocean, with herring or other marine fish likely acting as a reservoir for ENV.

\section{Implications}

Detection of ENV has not been conclusively linked to disease onset and further studies are required to characterize this relationship. VEN is a poorly characterized disease in Chinook and sockeye salmon, yet it is relatively common in wild at-risk populations of these species. In contrast, ENV was relatively rare in pink and chum salmon, even though these species are more susceptible to VEN than Chinook and sockeye salmon in challenge studies [5]. However, relatively few pink $(n=222)$ and chum $(n=191)$ salmon were sampled in our study. There were significant differences in viral loads among species, with lowest mean ENV loads occurring in Atlantic salmon. Low viral loads and prevalence could indicate higher virulence, which may lower the chance of transmission and detection compared to persistently infected fish [60]. Alternatively, species with large ranges in ENV copy number, such as herring and Chinook salmon, could carry a persistent infection which becomes virulent at higher loads. These species may transmit the virus to susceptible species such as pink and chum salmon. Future challenge studies which further characterize Chinook salmon infection may elucidate whether infection dynamics appear similar to those of herring, which have the most similar distribution of viral load.

ENV prevalence was lower in salmon smolts and adult herring. Similarly, Hershberger et al. reported more frequent VEN epizootics in juvenile herring, compared to adults [1]. Presumably, lower viral prevalence in smolt salmon arises because fewer smolt have been exposed to marine waters, where we propose the virus originates. Previous studies reported that osmoregulatory stress, such as transitions between saline and freshwater environments, could be implicated in herring mortality in fish infected with VEN $[15,61]$. If viral infection does, indeed, impact osmoregulatory capacity and 
adaptation, the relatively high prevalence and load of ENV detected in salmon soon after ocean entry could diminish their ability to properly acclimate to changes in salinity in their environment.

Numerous studies [10-14] have reported greater disease severity caused by iridoviruses that are closely related to ENV when the temperature increases. It has been suggested that below $20^{\circ} \mathrm{C}$, iridoviruses may remain dormant in teleost hosts [14]. Other members of Iridoviridae that infect fish and show high infection mortality typically occur in warmer climates, such as Southeast Asia and Australia. Similarly, VEN progression is most severe during the summer in Pacific salmon [5]. Changes in temperature were not investigated in this study, but seasonal and yearly variation in ENV prevalence suggests that environmental variables, such as temperature, may be important. A significant drop in ENV prevalence following 2013 coincides with a shift to a positive Pacific Decadal Oscillation Index and warming temperatures in the study region [62].

It is possible that disease progression intensifies at warmer temperatures, such that fewer fish harboring the virus survive. This interpretation is consistent with a decrease in the overall prevalence of salmon infectious agents in the region from 2012 to 2013 reported by Nekouei et al. [16]. Alternatively, fish infected with the virus may be weakened or more susceptible to other diseases at suboptimal temperatures. In the context of climate change, this is an interesting avenue of future research, and directly relevant to salmon populations, as evidence suggests that increasing coastal and oceanic temperatures can have significant and detrimental effects on salmon migration and spawning [63,64]. If VEN has a temperature-dependent onset similar to other diseases caused by iridoviruses, ENV-mediated mortality could further stress at-risk populations of salmon and herring in the NE Pacific Ocean.

\section{Conclusions}

This research demonstrates that ENV is highly prevalent in the NE Pacific Ocean. Low ENV prevalence in freshwater, high prevalence in marine fish, and seasonal variability corresponding to marine migrations of salmon and herring suggest that ENV originates from the marine environment. High prevalence in several marine fish species suggests that the virus is endemic and that these species are reservoirs of the virus. Moreover, the similarity between ENV sequences from Chinook salmon and those from Pacific herring indicates that transmission between these species is possible. Finally, we present 89 new protein-encoding sequences attributed to ENV in this study.

Supplementary Materials: The following are available online at http://www.mdpi.com/1999-4915/11/4/358/s1, Figure S1: Sampling effort and ENV detection map:, Table S1: List of taxa abbreviations used in tables and figures, Table S2: ENV BLAST summary, Figure S2: ENV copy number in mixed tissue samples by species, Table S3: Summary of $p$ values from pairwise tests for differences in load (L) and prevalence (P) among species, Table S4: Summary of $p$ values and sample size for tests reported in this study, Figure S3: Seasonal ENV prevalence by species, Figure S4: ENV prevalence by population, Figure S5: ENV prevalence by year and species, Figure S6: ENV prevalence by year, File S1: R Scripts, File S2: NCVOG Summary, File S3: ENV Contigs, File S4: Enrichment Summary.

Author Contributions: Conceptualization, G.J.M., K.M.M., and C.A.S.; Methodology, V.A.P., G.J.M., A.D.S., K.H.K., T.J.M., S.L., and A.K.T.; Formal analysis, V.A.P.; Investigation, V.A.P., G.J.M., A.D.S.; Resources, K.M.M. and C.A.S.; Data curation, A.T.; Writing — original draft preparation, V.A.P.; Writing—review and editing, G.J.M., C.A.S., and K.M.M.; Visualization, V.A.P.; Supervision, G.J.M., K.M.M., and C.A.S.; Project administration, G.J.M., C.A.S., and K.M.M.

Funding: Funding was provided through the Strategic Salmon Health Initiative co-funded by the Pacific Salmon Foundation, Genome British Columbia, Fisheries and Oceans Canada, and MITACS, as well as the NSERC summer 2018 Undergraduate Student Research Award.

Acknowledgments: We would like to thank Christoph Deeg for feedback on phylogenetic analyses and insightful suggestions.

Conflicts of Interest: The authors declare no conflict of interest. 


\section{References}

1. Hershberger, P.K.; Elder, N.E.; Grady, C.A.; Gregg, J.L.; Pacheco, C.A.; Greene, C.; Rice, C.; Meyers, T.R. Prevalence of Viral Erythrocytic Necrosis in Pacific Herring and Epizootics in Skagit Bay, Puget Sound, Washington. J. Aquat. Anim. Health 2009, 21, 1-7. [CrossRef] [PubMed]

2. $\quad$ Emmenegger, E.J.; Glenn, J.A.; Winton, J.R.; Batts, W.N.; Gregg, J.L.; Hershberger, P.K. Molecular Identification of Erythrocytic Necrosis Virus (ENV) from the Blood of Pacific Herring (Clupea pallasii). Vet. Microbiol. 2014, 174, 16-26. [CrossRef] [PubMed]

3. Winton, J.R.; Hershberger, P.K. Viral Erythrocytic Necrosis: Chapter 2.2.7. In FHS Blue Book: Suggested Procedures for the Detection and Identification of Certain Finfish and Shellfish Pathogens; American Fisheries Society: Bethesda, MA, USA, 2014.

4. Purcell, M.K.; Pearman-Gillman, S.; Thompson, R.L.; Gregg, J.L.; Hart, L.M.; Winton, J.R.; Emmenegger, E.J.; Hershberger, P.K. Identification of the Major Capsid Protein of Erythrocytic Necrosis Virus (ENV) and Development of Quantitative Real-time PCR Assays for Quantification of ENV DNA. J. Vet. Diagn. Investig. 2016, 28, 382-391. [CrossRef] [PubMed]

5. Evelyn, T.P.T.; Traxler, G.S. Viral Erythrocytic Necrosis: Natural Occurrence in Pacific Salmon and Experimental Transmission. J. Fish. Res. Board Can. 1978, 35, 903-907. [CrossRef]

6. Rohovec, J.S.; Amandi, A. Incidence of Viral Erythrocytic Necrosis among Hatchery Reared Salmonids of Oregon. Fish Pathol. 1981, 15, 135-141. [CrossRef]

7. Haney, D.C.; Hursh, D.A.; Mix, M.C.; Winton, J.R. Physiological and Hematological Changes in Chum Salmon Artificially Infected with Erythrocytic Necrosis Virus. J. Aquat. Anim. Health 1992, 4, 48-57. [CrossRef]

8. MacMillian, J.R.; Mulcahy, D. Artificial Transmission to and Susceptibility of Puget Sound Fish to Viral Erythrocytic Necrosis (VEN). J. Fish. Res. Board Can. 1979, 36, 1097-1101. [CrossRef]

9. Eaton, W.D. Artificial Transmission of Erythrocytic Necrosis Virus (ENV) from Pacific Herring in Alaska to Chum, Sockeye, and Pink Salmon. J. Appl. Ichthyol. 1990, 6, 136-141. [CrossRef]

10. International Committee on Taxonomy of Viruses; King, A.M.Q.; International Union of Microbiological Societies; Virology Division. Virus Taxonomy: Classification and Nomenclature of Viruses: Ninth Report of the International Committee on Taxonomy of Viruses; Academic Press: London, UK, 2012; ISBN 978-0-12-384684-6.

11. Huang, S.M.; Tu, C.; Tseng, C.H.; Huang, C.C.; Chou, C.-C.; Kuo, H.-C.; Chang, S.-K. Genetic Analysis of Fish Iridoviruses Isolated in Taiwan during 2001-2009. Arch. Virol. 2011, 156, 1505-1515. [CrossRef]

12. Wang, C.S.; Shih, H.H.; Ku, C.C.; Chen, S.N. Studies on Epizootic Iridovirus Infection Among Red Sea Bream, Pagrus major (Temminck \& Schlegel), Cultured in Taiwan. J. Fish Dis. 2003, 26, 127-133. [PubMed]

13. Liu, H.I.; Lin, Y.C.; Chiou, P.P.; Chou, H.-Y. Temperature-Dependent Pathogenicity of Grouper Iridovirus of Taiwan (TGIV). J. Mar. Sci. Technol. 2016, 24, 637-644.

14. Wang, Y.Q.; Lü, L.; Weng, S.P.; Huang, J.N.; Chan, S.-M.; He, J.G. Molecular Epidemiology and Phylogenetic Analysis of a Marine Fish Infectious Spleen and Kidney Necrosis Virus-like (ISKNV-like) Virus. Arch. Virol. 2007, 152, 763-773. [CrossRef] [PubMed]

15. Meyers, T.R.; Hauck, A.K.; Blankenbeckler, W.D.; Minicucci, T. First report of Viral Erythrocytic Necrosis in Alaska, USA, Associated with Epizootic Mortality in Pacific Herring, Clupea harengus pallasi (Valenciennes). J. Fish Dis. 1986, 9, 479-491. [CrossRef]

16. Nekouei, O.; Vanderstichel, R.; Ming, T.; Kaukinen, K.H.; Thakur, K.; Tabata, A.; Laurin, E.; Tucker, S.; Beacham, T.D.; Miller, K.M. Detection and Assessment of the Distribution of Infectious Agents in Juvenile Fraser River Sockeye Salmon, Canada, in 2012 and 2013. Front. Microbiol. 2018, 9. [CrossRef] [PubMed]

17. Tucker, S.; Li, S.; Kaukinen, K.H.; Patterson, D.A.; Miller, K.M. Distinct Seasonal Infectious Agent Profiles in Life-history Variants of Juvenile Fraser River Chinook Salmon: An Application of High-Throughput Genomic Screening. PLoS ONE 2018, 13, e0195472. [CrossRef] [PubMed]

18. Thakur, K.K.; Vanderstichel, R.; Li, S.; Laurin, E.; Tucker, S.; Neville, C.; Tabata, A.; Miller, K.M. A Comparison of Infectious Agents Between Hatchery-Enhanced and Wild Out-Migrating Juvenile Chinook Salmon (Oncorhynchus tshawytscha) from Cowichan River, British Columbia. FACETS 2018. [CrossRef]

19. Laurin, E.; Jaramillo, D.; Vanderstichel, R.; Ferguson, H.; Kaukinen, K.H.; Schulze, A.D.; Keith, I.R.; Gardner, I.A.; Miller, K.M. Histopathological and Novel High-Throughput Molecular Monitoring Data from Farmed Salmon (Salmo salar and Oncorhynchus spp.) in British Columbia, Canada, from 2011-2013. Aquaculture 2019, 499, 220-234. [CrossRef] 
20. Teffer, A.K.; Bass, A.L.; Miller, K.M.; Patterson, D.A.; Juanes, F.; Hinch, S.G. Infections, Fisheries Capture, Temperature, and Host Responses: Multistressor Influences on Survival and Behaviour of Adult Chinook Salmon. Can. J. Fish. Aquat. Sci. 2018, 75, 2069-2083. [CrossRef]

21. DFO. Stock Assessment Report on Pacific Herring in British Columbia. Canadian Science Advisory Secretariat Science Advisory Report 2009/059. Available online: http://www.dfo-mpo.gc.ca/Library/338390.pdf (accessed on 17 April 2019).

22. Varpe, Ø.; Fiksen, Ø.; Slotte, A. Meta-Ecosystems and Biological Energy Transport from Ocean to Coast: The Ecological Importance of Herring Migration. Oecologia 2005, 146, 443. [CrossRef] [PubMed]

23. Pacific Salmon Commission. 2010 Annual Report of Catches and Escapements; Report TCChinook (11)-2; Pacific Salmon Commission: Vancouver, BC, Canada, 2011.

24. Government of Canada. Summary of COSEWIC Wildlife Species Assessments. November 2018. Available online: https://www.canada.ca/en/environment-climate-change/services/committee-status-endangeredwildlife/assessments/wildlife-species-assessment-summary-nov-2018.html (accessed on 28 January 2019).

25. Miller, K.M.; Teffer, A.; Tucker, S.; Li, S.; Schulze, A.D.; Trudel, M.; Juanes, F.; Tabata, A.; Kaukinen, K.H.; Ginther, N.G.; et al. Infectious Disease, Shifting Climates, and Opportunistic Predators: Cumulative Factors Potentially Impacting Wild Salmon Declines. Evol. Appl. 2014, 7, 812-855. [CrossRef] [PubMed]

26. Miller, K.M.; Gardner, I.A.; Vanderstichel, R.; Burnley, T.; Schulze, A.D.; Li, S.; Tabata, A.; Kaukinen, K.H.; Ming, T.J.; Ginther, N.G. Report on the Performance Evaluation of the Fluidigm BioMark Platform for High Throughput Microbe Monitoring in Salmon; Fisheries and Oceans Canada: Ottawa, ON, Canada, 2016.

27. Di Cicco, E.; Ferguson, H.W.; Kaukinen, K.H.; Schulze, A.D.; Li, S.; Tabata, A.; Günther, O.P.; Mordecai, G.; Suttle, C.A.; Miller, K.M. The Same Strain of Piscine Orthoreovirus (PRV-1) is Involved in the Development of Different, but Related, Diseases in Atlantic and Pacific Salmon in British Columbia. FACETS 2018, 3, 599-641. [CrossRef]

28. Bass, A.L.; Hinch, S.G.; Teffer, A.K.; Patterson, D.A.; Miller, K.M. A Survey of Microparasites Present in Adult Migrating Chinook Salmon (Oncorhynchus tshawytscha) in South-Western British Columbia Determined by High-Throughput Quantitative Polymerase Chain Reaction. J. Fish Dis. 2017, 40, 453-477. [CrossRef]

29. Bolger, A.M.; Lohse, M.; Usadel, B. Trimmomatic: A Flexible Trimmer for Illumina Sequence Data. Bioinforma. Oxf. Engl. 2014, 30, 2114-2120. [CrossRef] [PubMed]

30. Davidson, W.S.; Koop, B.F.; Jones, S.J.; Iturra, P.; Vidal, R.; Maass, A.; Jonassen, I.; Lien, S.; Omholt, S.W. Sequencing the Genome of the Atlantic Salmon (Salmo salar). Genome Biol. 2010, 11, 403. [PubMed]

31. Li, H.; Durbin, R. Fast and Accurate Short Read Alignment with Burrows-Wheeler Transform. Bioinform. Oxf. Engl. 2009, 25, 1754-1760. [CrossRef] [PubMed]

32. Li, H.; Handsaker, B.; Wysoker, A.; Fennell, T.; Ruan, J.; Homer, N.; Marth, G.; Abecasis, G.; Durbin, R. 1000 Genome Project Data Processing Subgroup the Sequence Alignment/Map Format and SAMtools. Bioinforma. Oxf. Engl. 2009, 25, 2078-2079. [CrossRef] [PubMed]

33. Bankevich, A.; Nurk, S.; Antipov, D.; Gurevich, A.A.; Dvorkin, M.; Kulikov, A.S.; Lesin, V.M.; Nikolenko, S.I.; Pham, S.; Prjibelski, A.D.; et al. SPAdes: A New Genome Assembly Algorithm and its Applications to Single-Cell Sequencing. J. Comput. Biol. J. Comput. Mol. Cell Biol. 2012, 19, 455-477. [CrossRef] [PubMed]

34. Buchfink, B.; Xie, C.; Huson, D.H. Fast and Sensitive Protein Alignment using DIAMOND. Nat. Methods 2015, 12, 59-60. [CrossRef] [PubMed]

35. Caporaso, J.G.; Kuczynski, J.; Stombaugh, J.; Bittinger, K.; Bushman, F.D.; Costello, E.K.; Fierer, N.; Peña, A.G.; Goodrich, J.K.; Gordon, J.I.; et al. QIIME Allows Analysis of High-Throughput Community Sequencing Data. Nat. Methods 2010, 7, 335-336. [CrossRef]

36. Borodovsky, M.; Mills, R.; Besemer, J.; Lomsadze, A. Prokaryotic Gene Prediction Using GeneMark and GeneMark.hmm. Curr. Protoc. Bioinform. 2003, 4, 4.5.1-4.5.16. [CrossRef] [PubMed]

37. Altschul, S.F.; Gish, W.; Miller, W.; Myers, E.W.; Lipman, D.J. Basic Local Alignment Search Tool. J. Mol. Biol. 1990, 215, 403-410. [CrossRef]

38. Yutin, N.; Wolf, Y.I.; Raoult, D.; Koonin, E.V. Eukaryotic Large Nucleo-Cytoplasmic DNA Viruses: Clusters of Orthologous Genes and Reconstruction of Viral Genome Evolution. Virol. J. 2009, 6, 223. [CrossRef] [PubMed]

39. Kearse, M.; Moir, R.; Wilson, A.; Stones-Havas, S.; Cheung, M.; Sturrock, S.; Buxton, S.; Cooper, A.; Markowitz, S.; Duran, C.; et al. Geneious Basic: An Integrated and Extendable Desktop Software Platform for the Organization and Analysis of Sequence Data. Bioinformatics 2012, 28, 1647-1649. [CrossRef] [PubMed] 
40. Guindon, S.; Dufayard, J.-F.; Lefort, V.; Anisimova, M.; Hordijk, W.; Gascuel, O. New Algorithms and Methods to Estimate Maximum-Likelihood Phylogenies: Assessing the Performance of PhyML 3.0. Syst. Biol. 2010, 59, 307-321. [CrossRef] [PubMed]

41. Thompson, J.D.; Higgins, D.G.; Gibson, T.J. CLUSTAL W: Improving the Sensitivity of Progressive Multiple Sequence Alignment Through Sequence Weighting, Position-Specific Gap Penalties and Weight Matrix Choice. Nucleic Acids Res. 1994, 22, 4673-4680. [CrossRef] [PubMed]

42. R Core Team R: A Language and Environment for Statistical Computing. Ed. Found. Stat. Comput. Vienna Austria 2013.

43. Pebesma, E.J. Multivariable Geostatistics in S: The gstat Package. Comput. Geosci. 2004, 30, 683-691. [CrossRef]

44. Heuvelink, G.B.M. Spatio-Temporal Interpolation Using gstat by Benedikt Gräler, Edzer Pebesma and Gerard Heuvelink. R J. 2016, 8, 204-218.

45. Kahle, D.; Wickham, H. ggmap: Spatial Visualization with ggplot2. R J. 2013, 5, 144. [CrossRef]

46. Mangiafico, S. rcompanion: Functions to Support Extension Education Program Evaluation [R Statistical Package]. 2016. Available online: https://cran.r-project.org/web/packages/rcompanion/ (accessed on 17 April 2018).

47. Bates, D.; Mächler, M.; Bolker, B.; Walker, S. Fitting Linear Mixed-Effects Models Using lme4. J. Stat. Softw. 2015, 1. [CrossRef]

48. Hothorn, T.; Bretz, F.; Westfall, P. Simultaneous Inference in General Parametric Models. Biom. J. 2008, 50, 346-363. [CrossRef]

49. Teng, Y.; Hou, Z.; Gong, J.; Liu, H.; Xie, X.; Zhang, L.; Chen, X.; Qin, Q.W. Whole-Genome Transcriptional Profiles of a Novel Marine Fish Iridovirus, Singapore Grouper Iridovirus (SGIV) in Virus-Infected Grouper Spleen Cell Cultures and in Orange-Spotted Grouper, Epinephulus coioides. Virology 2008, 377, $39-48$. [CrossRef] [PubMed]

50. Chen, L.M.; Wang, F.; Song, W.; Hew, C.L. Temporal and Differential Gene Expression of Singapore Grouper Iridovirus. J. Gen. Virol. 2006, 87, 2907-2915. [CrossRef] [PubMed]

51. İnce, İ.A.; Özcan, O.; Ilter-Akulke, A.Z.; Scully, E.D.; Özgen, A. Invertebrate Iridoviruses: A Glance Over the Last Decade. Viruses 2018, 10, 161. [CrossRef]

52. Sample, R.; Bryan, L.; Long, S.; Majji, S.; Hoskins, G.; Sinning, A.; Olivier, J.; Chinchar, V.G. Inhibition of Iridovirus Protein Synthesis and Virus Replication by Antisense Morpholino Oligonucleotides Targeted to the Major Capsid Protein, the 18 kDa Immediate-Early Protein, and a Viral Homolog of RNA Polymerase II. Virology 2007, 358, 311-320. [CrossRef] [PubMed]

53. Kurobe, T.; MacConnell, E.; Hudson, C.; McDowell, T.S.; Mardones, F.O.; Hedrick, R.P. Iridovirus Infections among Missouri River Sturgeon: Initial Characterization, Transmission, and Evidence for Establishment of a Carrier State. J. Aquat. Anim. Health 2011, 23, 9-18. [CrossRef]

54. Georgiadis, M.P.; Hedrick, R.P.; Johnson, W.O.; Yun, S.; Gardner, I.A. Risk Factors for Outbreaks of Disease Attributable to White Sturgeon Iridovirus and White Sturgeon Herpesvirus-2 at a Commercial Sturgeon Farm. Am. J. Vet. Res. 2000, 61, 1232-1240. [CrossRef]

55. Traxler, G.; Bell, G. Pathogens Associated with Impounded Pacific Herring Clupea harengus pallasi, with Emphasis on Viral Erythrocytic Necrosis (VEN) and Atypical Aeromonas salmonicida. Dis. Aquat. Organ. 1988, 5, 93-100. [CrossRef]

56. Hershberger, P.; Hart, A.; Gregg, J.; Elder, N.; Winton, J. Dynamics of Viral Hemorrhagic Septicemia, Viral Erythrocytic Necrosis and Ichthyophoniasis in Confined Juvenile Pacific Herring Clupea pallasii. Dis. Aquat. Organ. 2006, 70, 201-208. [CrossRef]

57. Weitkamp, L.A. Marine Distributions of Chinook Salmon from the West Coast of North America Determined by Coded Wire Tag Recoveries. Trans. Am. Fish. Soc. 2010, 139, 147-170. [CrossRef]

58. Myers, K.W.; Klovach, N.V.; Gritsenko, O.F.; Urawa, S.; Royer, T.C. Stock-Specific Distributions of Asian and North American Salmon in the Open Ocean, Interannual Changes, and Oceanographic Conditions; NPAFC: Vancouver, BC, Canada, 2007.

59. Hourston, A.S.; Haegele, C.W. Herring on Canada's Pacific Coast; Department of Fisheries and Oceans: Longueuil, QC, USA, 1980.

60. Schroeder, D.C.; Martin, S.J. Deformed wing virus. Virulence 2012, 3, 589-591. [CrossRef] [PubMed] 
61. Bell, Q.R.; Traxler, G.S. First Record of Viral Erythrocytic Necrosis and Ceratomyxa Shasta Noble, 1950 (Myxozoa: Myxosporea) in Feral Pink Salmon (Oncorhynchus gorbuscha Walbaum). J. Wildl. Dis. 1985, 21, 169-171. [CrossRef] [PubMed]

62. Peterson, W.; Morgan, C.; Casillas, E.; Peterson, J.; Fisher, J.; W Ferguson, J. Ocean Ecosystem Indicators of Salmon Marine Survival in the Northern California Current. 2019. Available online: https://www. fwspubs.org/doi/suppl/10.3996/042010-JFWM-009/suppl_file/10.3996_042010-jfwm-009.s6.pdf (accessed on 17 April 2019)

63. Goniea, T.; Bjornn, T.C.; Peery, C.A.; Bennett, D.H.; Stuehrenberg, L.C. Behavioral Thermoregulation and Slowed Migration by Adult Fall Chinook Salmon in Response to High Columbia River Water Temperatures. Trans. Am. Fish. Soc. 2006, 135, 408-419. [CrossRef]

64. Beacham, T.D.; Murray, C.B. Effect of Female Size, Egg Size, and Water Temperature on Developmental Biology of Chum Salmon (Oncorhynchus keta) from the Nitinat River, British Columbia. Can. J. Fish. Aquat. Sci. 1985, 42, 1755-1765. [CrossRef]

(C) 2019 by the authors. Licensee MDPI, Basel, Switzerland. This article is an open access article distributed under the terms and conditions of the Creative Commons Attribution (CC BY) license (http://creativecommons.org/licenses/by/4.0/). 
Article

\title{
Susceptibility of Exopalaemon carinicauda to the Infection with Shrimp Hemocyte Iridescent Virus (SHIV 20141215), a Strain of Decapod Iridescent Virus 1 (DIV1)
}

\author{
Xing Chen ${ }^{1,2}$, Liang Qiu ${ }^{1} \mathbb{D}$, Hailiang Wang ${ }^{1}$, Peizhuo Zou ${ }^{1}$, Xuan Dong ${ }^{1}$, Fuhua Li $^{3}$ and \\ Jie Huang ${ }^{1,2, *}$ \\ 1 Laboratory for Marine Fisheries Science and Food Production Processes, National Laboratory for Marine \\ Science and Technology (Qingdao); Key Laboratory of Maricultural Organism Disease Control, Ministry of \\ Agriculture and Rural Affairs; Qingdao Key Laboratory of Mariculture Epidemiology and Biosecurity; \\ Yellow Sea Fisheries Research Institute, Chinese Academy of Fishery Sciences, Qingdao 266071, China; \\ chenxing910520@163.com (X.C.); qiuliang@ysfri.ac.cn (L.Q.); whl846130@126.com (H.W.); \\ zoupz1992@163.com (P.Z.); dongxuan@ysfri.ac.cn (X.D.) \\ 2 College of Fisheries and Life Science, Shanghai Ocean University, Shanghai 201306, China \\ 3 Key Laboratory of Experimental Marine Biology, Institute of Oceanology, Chinese Academy of Sciences, \\ Qingdao 266071, China; fhli@ms.qdio.ac.cn \\ * Correspondence: huangjie@ysfri.ac.cn
}

Received: 12 February 2019; Accepted: 15 April 2019; Published: 25 April 2019

\begin{abstract}
In this study, ridgetail white prawns-Exopalaemon carinicauda-were infected per os (PO) with debris of Penaeus vannamei infected with shrimp hemocyte iridescent virus (SHIV 20141215), a strain of decapod iridescent virus 1 (DIV1), and via intramuscular injection (IM with raw extracts of SHIV 20141215. The infected E. carinicauda showed obvious clinical symptoms, including weakness, empty gut and stomach, pale hepatopancreas, and partial death with mean cumulative mortalities of $42.5 \%$ and $70.8 \%$ by nonlinear regression, respectively. Results of TaqMan probe-based real-time quantitative PCR showed that the moribund and surviving individuals with clinical signs of infected E. carinicauda were DIV1-positive. Histological examination showed that there were darkly eosinophilic and cytoplasmic inclusions, of which some were surrounded with or contained tiny basophilic staining, and pyknosis in hemocytes in hepatopancreatic sinus, hematopoietic cells, cuticular epithelium, etc. On the slides of in situ DIG-labeling-loop-mediated DNA amplification (ISDL), positive signals were observed in hematopoietic tissue, stomach, cuticular epithelium, and hepatopancreatic sinus of infected prawns from both PO and IM groups. Transmission electron microscopy (TEM) of ultrathin sections showed that icosahedral DIV1 particles existed in hepatopancreatic sinus and gills of the infected E. carinicauda from the PO group. The viral particles were also observed in hepatopancreatic sinus, gills, pereiopods, muscles, and uropods of the infected E. carinicauda from the IM group. The assembled virions, which mostly distributed along the edge of the cytoplasmic virogenic stromata near cellular membrane of infected cells, were enveloped and approximately $150 \mathrm{~nm}$ in diameter. The results of molecular tests, histopathological examination, ISDL, and TEM confirmed that E. carinicauda is a susceptible host of DIV1. This study also indicated that E. carinicauda showed some degree of tolerance to the infection with DIV1 per os challenge mimicking natural pathway.
\end{abstract}

Keywords: SHIV; DIV1; Decapodiridovirus; Exopalaemon carinicauda; susceptibility; host; ISDL 


\section{Introduction}

The iridescent virus family Iridoviridae contains large icosahedral double-stranded DNA viruses, which is divided into two subfamilies (i.e., Alphairidovirinae and Betairidovirinae) and composed of five known genera: Lymphocystivirus, Megalocytivirus, Ranavirus, Chloriridovirus, and Iridovirus. Of them, the genera Lymphocystivirus, Megalocytivirus, and Ranavirus belong to subfamily Alphairidovirinae, and Chloriridovirus and Iridovirus belong to subfamily Betairidovirinae [1-3]. Iridescent viruses of Alphairidovirinae lead to a high mortality rate in significant fish and amphibians [3], while iridescent viruses of Betairidovirinae infect insects and crustaceans. The first discovery of a possible iridescent virus in crustaceans was published in 1993 [4]. In the same year, Lightner and Redman reported another suspected iridescent virus in penaeid shrimp Protrachypene precipua [5]. Subsequently, Miao et al. [6] reported that a suspected iridescent virus was observed in lymphoid cell cultures from the Chinese white shrimp Penaeus chinensis in 1999. Several years later, Tang et al. [7] identified an iridoviru-i.e., Sergestid iridovirus (SIV)—-diseased sergestid shrimp Acetes erythraeus, which is a likely causative agent evidenced through in situ hybridization and PCR test. Xu et al. [8] reported Cherax quadricarinatus iridovirus (CQIV) isolated from diseased red claw crayfish Cherax quadricarinatus. Qiu et al. [9] identified an iridescent virus named shrimp hemocyte iridescent virus (SHIV), which was isolated from farmed Penaeus vannamei in 2014 and also detected in P. chinensis and Macrobrachium rosenbergii. In March 2019, the Executive Committee of the International Committee on Taxonomy of Viruses (ICTV) approved the proposal made by Chinchar et al. [10] that proposed a new species of decapod iridescent virus 1 in a new genus Decapodiridovirus to include SHIV 20141215 and CQIV CN01 as two isolates.

The range of susceptible hosts is an important part of epidemiology and pathogen ecology. It is also of significant concerned for international trade and control of the disease. In 2014, the World Organization for Animal Health (OIE) has adopted a chapter in The Aquatic Animal Health Code to provide the criteria for determining susceptibility of aquatic animal species to infection with a specific pathogen with emphasis on that the route of transmission is consistent with natural pathways for the infection [11]. Ridgetail white prawn-Exopalaemon carinicauda-is one of the major economic crustaceans in China, which can propagate all year round, and is naturally distributes around the coast of Yellow Sea and Bohai Sea of China [12,13]. E. carinicauda accounts for one-third of the total yields of polyculture ponds in the eastern China [12]. It is also a species of wild prawns and commonly exists in the ponds farming $M$. rosenbergii or penaeid shrimp. To date, there is no report pointing out if E. carinicauda can be infected with iridescent viruses. Owing to the common existence of E. carinicauda in intensive shrimp farming ponds, verifying its susceptibility to DIV1 is a prerequisite for evaluation of the potential transmission routes and possible reservoirs of DIV1 in the nature. As there is no crustacean cell line available, bioassays with susceptible species are the only way to study the infectivity of crustacean viruses. Establishment of infection model with susceptible animals will provide approaches for crustacean virological studies. In this study, E. carinicauda were challenged per os to mimic natural infection according to the OIE standards, while intramuscular injection was used as a positive control. A combination of TaqMan real-time PCR, histopathological observation, in situ DIG-labeling-loop-mediated DNA amplification (ISDL), and ultra-thin transmission electron microscopy were used to confirm the infection with DIV1 in E. carinicauda.

\section{Materials and Methods}

All protocols for animal breeding, handling and sampling were approved by the Animal Care and Ethics Committee, Yellow Sea Fisheries Research Institute, Chinese Academy of Fishery Sciences. Efforts were made to provide a comfortable living environment for the animals and to minimize the suffering of animals during the sampling process, according to recommendations proposed by the European Commission (1997). The study was carried out in accordance with the approved protocol. All the methods were applied in accordance with relevant guidelines. 


\subsection{Animals}

Specific-pathogen-free (SPF) ridgetail white prawns E. carinicauda, $(3.6 \pm 0.4) \mathrm{cm}$ in body length, were reared and bred in the Key Laboratory of Experimental Marine Biology, Institute of Oceanology, Chinese Academy of Sciences. Prawns E. carinicauda were cultivated in a $40 \mathrm{~L}$ plastic tanks containing $20 \mathrm{~L}$ seawater of $30 \mathrm{ppt}$ in salinity with $90 \%$ daily exchange rate, at a water temperature of $27^{\circ} \mathrm{C}$, with continuous aeration, and fed three times per day with the formula feed for a week in our wet lab. For multiplication of DIV1, 30 healthy white leg shrimp P. vannamei of (10.2 \pm 0.8$) \mathrm{cm}$ in body length were purchased from a shrimp farm in Weifang of Shandong Province and then held in $40 \mathrm{~L}$ seawater of 30 ppt salinity with same management above mentioned.

Before and after the challenge testing, the prawns and the shrimp were sampled and examined for potential pathogens, including white spot syndrome virus (WSSV), taura syndrome virus (TSV), yellow head virus (YHV), infectious hypodermal and hematopoietic necrosis virus (IHHNV), and acute hepatopancreatic necrosis disease-causing Vibrio parahaemolyticus ( $V p_{\text {AHPND }}$ ), using the nested PCR or TaqMan probe based quantitative real-time PCR (TaqMan qPCR) methods [14], covert mortality nodavirus (CMNV) using TaqMan qPCR methods [15], and DIV1 using nested PCR [16].

\subsection{Preparation of Viral Inoculum}

To prepare material for the challenge test, 30 healthy shrimp P. vannamei were infected by feeding with DIV1 (strain SHIV 20141215) infected tissue, which was derived from diseased P. vannamei collected at a farm in Zhejiang Province in December 2014 [9]. After 5 days post-infection (dpi), $2.5 \mathrm{~g}$ cephalothoraxes (removing tergites) were taken from DIV1-infected shrimp and subsequently homogenized in $40 \mathrm{~mL}$ pre-cooled PPB-Tris (376.07 mM NaCl, $6.32 \mathrm{mM} \mathrm{K} \mathrm{SO}_{4}$, $6.4 \mathrm{mM} \mathrm{MgSO}$, $14.41 \mathrm{mM} \mathrm{CaCl}_{2}$, and $50 \mathrm{mM}$ Tris- $\mathrm{HCl}, \mathrm{pH}$ 6.5-8.0) [17]. The suspension was centrifuged at 10,000 rpm for $10 \mathrm{~min}$ at $4{ }^{\circ} \mathrm{C}$. The pellet was resuspended in $25 \mathrm{~mL}$ PPB-Tris by homogenization and re-centrifuged. The supernatants from two steps were merged and filtered through a 500-mesh sieve and a $0.45 \mu \mathrm{m}$ filter. The suspension was sampled to detect various pathogens for exclusion of contamination by other viruses and bacteria. DIV1 dose in the suspension was quantified using TaqMan qPCR method [16]. For the challenge test via intramuscular injection, an inoculum containing $10^{4}$ copies/ $\mu \mathrm{L}$ DIV1 was prepared by diluting the suspension with PPB-His (replace $50 \mathrm{mM}$ Tris- $\mathrm{HCl}$ with $50 \mathrm{mM}$ histidine in PPB-Tris) [17], and then the inoculum was dispensed in $100 \mu \mathrm{L}$ aliquots before stored at $-80{ }^{\circ} \mathrm{C}$.

\subsection{Challenge Tests}

Challenge tests were performed with healthy E. carinicauda in four groups, including intramuscular injection (IM), per os (PO), control of intramuscular infection (CIM), and control of per os (CPO). Each group had three replicates with 10 individual prawns per replicate. Each prawn in the IM group was injected with $10 \mu \mathrm{L}$ of viral inoculum ( $10^{5}$ copies $)$. Prawns in the PO group were fed with total $3 \mathrm{~g}$ debris of DIV1-infected P. vannamei tissue (with a viral dose of about $10^{10}$ copies $/ \mathrm{g}$ ). Prawns in the CIM group and the CPO group were injected with $10 \mu \mathrm{L}$ sterile PPB-His and commercial formula feed, respectively. After the challenge operation, the rearing conditions were kept as same as those prior to the challenge.

Significance analysis of cumulative mortalities between any two groups was carried out using the $t$-test for homoscedasticity hypothesis of two group samples with the add-in tool of data analysis in Microsoft ${ }^{\circledR}$ Excel $^{\circledR} 2016$ MSO 64-bit.

For evaluation of the pathogenic model in the infection groups, mortality data were nonlinearly regressed following the three-parameter sigmoid equation

$$
M_{(t)}=\frac{a}{1+e^{-k\left(t-t_{0}\right)}}
$$


which formulates the change of $M_{(t)}$ (cumulative mortality) at $t$ (time, dpi) determined by parameters of $a$ (the maximum mortality), $t_{0}$ (the time to half of the maximum mortality), and $k$ (the instant incidence rate). The real pathogenic model shall deduct the average mortality of control groups.

\subsection{Detection of DIV1 Using TaqMan-Probe-Based Real-Time Quantitative PCR (TaqMan qPCR)}

Total DNA were extracted from the hepatopancreas of samples stored at $-20^{\circ} \mathrm{C}$ using a TIANamp Marine Animals DNA Kit (Tiangen, Beijing, China). TaqMan qPCR, using the total DNA as template, was conducted as described previously [16] to detect and quantify DIV1. The forward and reverse primers were SHIV-F 5'-AGG AGA GGG AAA TAA CGG GAA AAC-3', and SHIV-R 5'-CGT CAG CAT TTGGTT CAT CCA TG-3', respectively. The TaqMan probe (5'-CTG CCC ATC TAA CAC CAT CTC CCG CCC-3') was labeled with 5'-6-carboxyfluorescein (FAM) and 3'-carboxytetramethylrhodamine (TAMRA). Each PCR mixture in $20 \mu \mathrm{L}$ contained $10 \mu \mathrm{L} 2 \times$ FastStart Essential DNA Probes Master (Roche, Indianapolis, IN, USA), $500 \mathrm{nM}$ primer each, $200 \mathrm{nM}$ probe and $100 \mathrm{ng}$ total DNA template. The program started by an initial denaturation at $95^{\circ} \mathrm{C}$ for $10 \mathrm{~min}$, followed by 40 cycles at $95^{\circ} \mathrm{C}$ for $10 \mathrm{~s}$ and $60^{\circ} \mathrm{C}$ for $30 \mathrm{~s}$. The amplification and date analysis were carried out in a CFX-96 Quantitative Fluorescence Instrument (BioRad, Hercules, California, USA).

\subsection{Histopathological Examination}

The cephalothoraxes of E. carinicauda, sampled during the challenge tests, were fixed with Davison's AFA fixative (DAFA) for $24 \mathrm{~h}$ and processed for sectioning and hematoxylin and eosin (H\&E) staining as described by Bell \& Lightner [18]. The histological sections were analyzed and photographed under a light microscopy system (Eclipse 80i, Nikon, Tokyo, Japan).

\subsection{Loop-Mediated Isothermal Amplification (LAMP)}

A set of specific primers, composed of FIP, BIP, LF, LB, F3, and B3, for LAMP detection of DIV1 was designed to target the gene of the second largest subunit of DNA-directed RNA polymerase II in the DIV1 genomic sequence (GenBank accession No. MF599468), using PrimerExplorerV4 (http://primerexplorer.jp/elamp4.0.0/index.html). These primers compared with the database in NCBI (http://blast.ncbi.nlm.nih.gov/Blast.cgi) to analyze sequence similarities. The primers were synthesized by Sangon Biotech (Shanghai, China). Each LAMP mixture contained 1.6 $\mu \mathrm{M}$ each of inner primers FIP and BIP, $0.8 \mu \mathrm{M}$ each of loop primers LF and LB, $0.2 \mu \mathrm{M}$ each of outer primers F3 and B3, $1.4 \mathrm{mM}$ of dNTP mix (TaKaRa, Dalian, China), 1.2 M betaine (Solarbio, Beijing, China), $25 \mu \mathrm{M}$ calcein (Sigma, St. Louis, MO, USA), $500 \mu \mathrm{M} \mathrm{MnCl}_{2}, 6 \mathrm{mM} \mathrm{MgCl}_{2}, 8 \mathrm{U}$ Bst 2.0 DNA polymerase (New England Biolabs Inc., Beverly, USA), $1 \times$ supplied buffer and the specified amount of template DNA in a final volume of $25 \mu \mathrm{L}$. The procedure was 60 cycles for $60^{\circ} \mathrm{C}$, following $5 \mathrm{~min}$ at $85^{\circ} \mathrm{C}$ on the CFX-96 Quantitative Fluorescence Instrument (BioRad, Hercules, CA, USA) using calcein fluorescent channel. Detection specificity of the LAMP primers were examined using $100 \mathrm{ng}$ of the total DNA extracted from uninfected prawns and shrimp infected with other pathogens, including WSSV, $V p_{\mathrm{AHPND}}$, IHHNV, and EHP.

\subsection{In Situ DIG-Labeling-Loop-Mediated DNA Amplification (ISDL)}

ISDL followed the method published by Jitrakorn et al. [19] with some modification to target DIV1. Paraffin sections were dewaxed and rehydrated according to the normal DIG-labeled in situ hybridization method [18-20]. Rehydrated slides were added with $\mathrm{ddH}_{2} \mathrm{O}$ and denatured on a $100{ }^{\circ} \mathrm{C}$ heating block for $2 \mathrm{~min}$, then subsequently placed in a wet box. Total of $150 \mu \mathrm{L}$ LAMP mixture, which has the same constituents as described in paragraph 2.6, except that the dNTP mix was supplemented with $0.1 \mathrm{mM}$ digoxigenin-11-dUTP (DIG-labeled dUTP) and-without template, calcein, and $\mathrm{MnCl}_{2}$-were added dropwise to each slide. The slides were horizontally incubated at $65^{\circ} \mathrm{C}$ for $60 \mathrm{~min}$, followed by $85^{\circ} \mathrm{C}$ for $5 \mathrm{~min}$. Subsequent steps were performed in accordance with the post-hybridization steps of a normal in situ hybridization [20]. Tissue sections of healthy prawns were used as the control. 


\subsection{Transmission Electron Microscopy with Ultrathin Sections}

For transmission electron microscopy (TEM) with ultrathin sections, samples were prepared as previous described [21,22]. Briefly, tissues of hepatopancreas, muscle, pereiopods, uropods, and gills of infected E. carinicauda were placed in TEM fixative (2\% paraformaldehyde, $2.5 \%$ glutaraldehyde, $160 \mathrm{mM}$ $\mathrm{NaCl}$ and $4 \mathrm{mM} \mathrm{CaCl}_{2}$ in $200 \mathrm{mM}$ PBS, pH 7.2) and cut rapidly into $1 \mathrm{~mm}^{3}$ pieces with scalpels, fixed for $1 \mathrm{~h}$ at room temperature, and then post-fixed with $\mathrm{OsO}_{4}$. Specimens were embedded in Spurr's plastic and dyed with uranyl acetate and lead citrate. Ultrathin sections were prepared on collodion-coated grids by the Equipment Center of the Medical College, Qingdao University (Qingdao, China). All grids were examined under a JEM-1200 electron microscope (JEOL, Japan) operating at 80-100 kV.

\section{Results}

\subsection{Clinical Signs and Cumulative Mortality}

The challenge test lasted for 15 days. After 3 dpi, prawns in both intramuscular (IM) and per os (PO) groups showed clinically symptoms, including empty stomach and gut and pale hepatopancreas. Additionally, the hematopoietic tissue at the base of rostrum showed slight cloudy white (Figure 1, IM and PO); while prawns in control groups (i.e., CPO and CIM) displayed normal gross signs, including feed-filled stomach and gut and light brown hepatopancreas. However, the hematopoietic tissue was not visible (Figure 1, CPO).

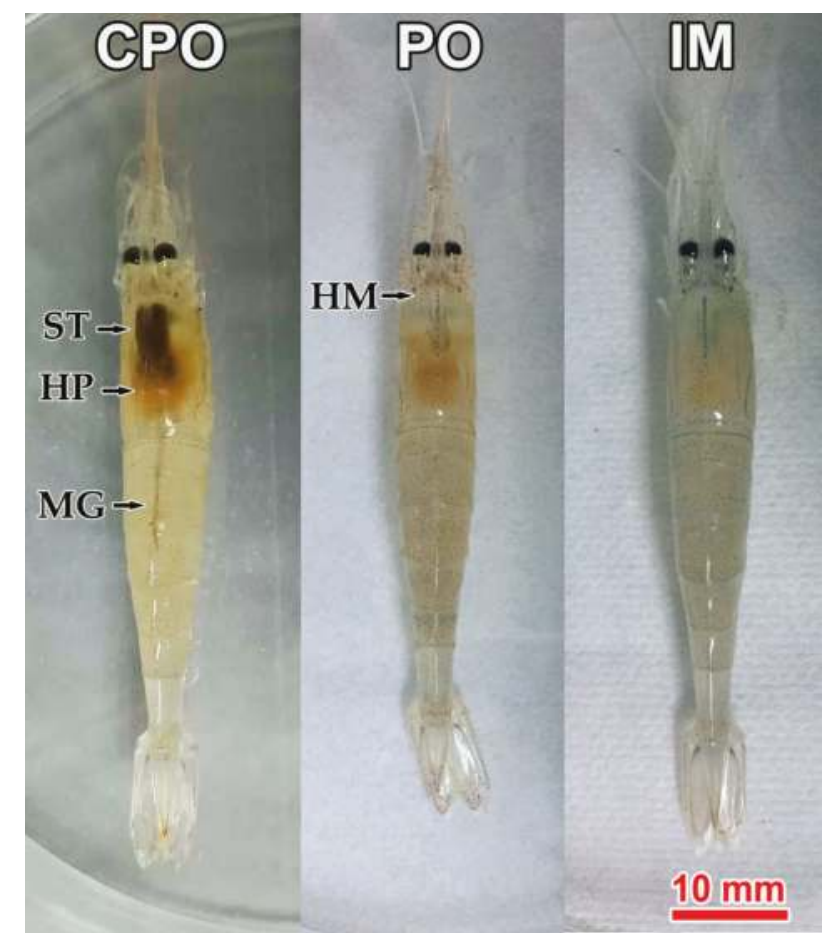

Figure 1. Gross signs of prawns Exopalaemon carinicauda in different groups of the challenge test. CPO: Prawn in per os control group; PO: Prawn in per os group; IM: Prawn in intermuscular injection group. Solid arrows indicate stomach (ST), hepatopancreas (HP), midgut (MG), and hematopoietic tissue (HM). Red bar $=10 \mathrm{~mm}$. 
Prawns in IM and PO groups suffered from a rapid increase in mortality during the period between $2 \mathrm{dpi}$ and $5 \mathrm{dpi}$. The average cumulative mortality stabilized at $(76.7 \pm 18.3) \%$ and $(50.0 \pm 26.5) \%$ in the IM group after $5 \mathrm{dpi}$ and $\mathrm{PO}$ group after $10 \mathrm{dpi}$, respectively. These rates were both significantly higher $(P<0.01)$ than that of CIM and CPO groups which both had an average mortality of $(6.7 \pm 5.8) \%$. Additionally, the cumulative mortality of the IM group was significantly higher $(P<0.05)$ than that of the PO group at $3 \mathrm{dpi}$ and $4 \mathrm{dpi}$ (Figure 2). Significance analysis of the overall data of four groups showed significant differences among IM, PO, and control groups $(P<0.01)$.

Based on the nonlinear regression following the three-parameter sigmoid equation, the pathogenic models of infection with DIV1 on E. carinicauda via IM and PO were

$$
\begin{gathered}
M_{I M(t)}=\frac{70.8 \pm 0.2}{1+e^{-(4.76 \pm 2.49)[t-(2.64 \pm 0.21)]}} \\
\text { and } M_{P O(t)}=\frac{42.5 \pm 1.2}{1+e^{-(0.82 \pm 0.51)[t-(3.83 \pm 0.87)]}},
\end{gathered}
$$

respectively. The functions (2) and (3) indicated the infection of E. carinicauda with DIV1 via IM caused $(70.8 \pm 0.2) \%$ maximum cumulative mortality, while the infection PO caused $(42.5 \pm 1.2) \%$ maximum cumulative mortality. The former reached the half level of the maximum mortality at $(2.64 \pm 0.21) \mathrm{dpi}$ with an instant incidence rate at $(4.76 \pm 2.49) /$ day; and the latter did at $(3.83 \pm 0.87)$ dpi with an instant rate at $(0.82 \pm 0.51) /$ day.

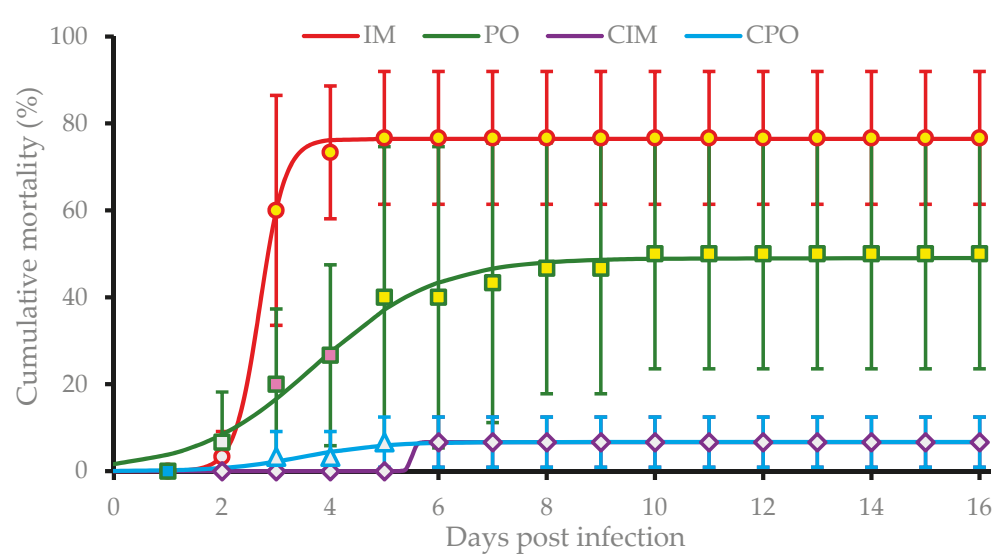

Figure 2. Cumulative mortalities of Exopalaemon carinicauda in the challenge test. IM group, prawns were challenged with filtrated viral suspension via intermuscular injection; PO group, prawns were fed with tissues of DIV1-infected P. vannamei; CIM group, prawns were injected with sterile PPB-His buffer; $\mathrm{CPO}$ group, prawns were fed with commercial feed. Cumulative mortalities are shown as means of data from three replicates for each experimental group (each replicate contained 10 individuals). The mean points with same color indicate no significant difference $(P>0.05)$, and the mean points with different colors indicate a significant difference $(P<0.05)$. Overall analysis indicated there are very significant differences among IM, PO, and the two controls $(P<0.01)$. The curves were drawn based on the nonlinear regression following the three-parameter sigmoid equation.

\subsection{TaqMan $q P C R$ Detection}

Moribund prawns in IM and PO groups were sampled throughout the experimental duration, and all surviving prawns in each group were collected at the end of the challenge experiment. All samples were examined for potential pathogens, using the TaqMan qPCR method. The DIV1-positive rates were $80.0 \%(24 / 30)$ and $46.7 \%(14 / 30)$ in the IM group and PO group, respectively. The results showed that all DIV1 negative prawns of the IM and PO groups survived and all prawns of CIM and 
CPO groups were DIV1 negative. The tests of $V p_{\mathrm{AHPND}}$, IHHNV and WSSV were negative for all samples. The logarithmic DIV1 loads (in copies/ng-DNA) in positive prawns of the IM and PO groups were $5.65 \pm 2.31$ and $3.08 \pm 0.60$, respectively. The viral loads in positive prawns of the IM group were significantly higher $(P<0.01)$ than those of the PO group (Figure 3). The loads of DIV1 in 21 moribund and dead prawns of the IM group were detected to reach $(4.20 \pm 3.88) \times 10^{6}$ copies $/ \mathrm{ng}$-DNA, while that in 3 non-clinical prawns were detected at only $(5.47 \pm 4.16) \times 10^{-1}$ copies/ng-DNA. The loads of DIV1 in 7 dead prawns in the PO group during 5-7 dpi averaged at $(3.63 \pm 1.44) \times 10^{4}$ copies/ng-DNA, which were much higher than that in 7 surviving prawns in the same group at $(3.57 \pm 3.42) \times 10^{2}$ copies/ng-DNA (Figure S1). These results showed that prawns in the IM and PO groups were successfully infected by DIV1. In addition, the results suggested that E. carinicauda may have some resistance to infection with DIV1 per os mimicking a natural exposure pathway.

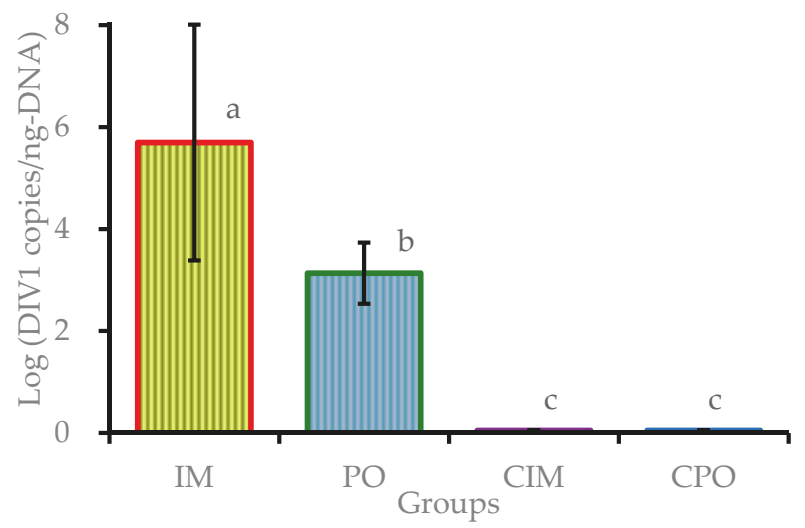

Figure 3. Decapod iridescent virus 1 (DIV1) loads in Exopalaemon carinicauda from the challenge test. Different letters above the bars indicate significant difference $(P<0.01)$. IM: prawn group challenged var intramuscular injection, PO: prawn group challenged per os; CIM: control group of injected with sterile buffer; CPO: control group fed with commercial feed. CIM and CPO were negative.

\subsection{Histopathology}

Histopathological examination of moribund prawns showed nuclear pyknosis and acidophilic inclusions in hemocytes of hepatopancreatic sinus (Figure 4a), hemocytoblasts of hematopoietic tissues (Figure 4c), and cuticular epithelium (Figure 4e); while the control prawns appeared normal in these tissues (Figure $4 \mathrm{~b}, \mathrm{~d}, \mathrm{f}$ ). Typical cytoplasmic and dark eosinophilic inclusions, of which some were surrounded with or contained tiny basophilic staining, appeared beside the nuclei in hematopoietic tissues, hemocytes, and epithelium. The inclusions were more easily found in the infected hematopoietic tissues (Figure $4 b$ ). 

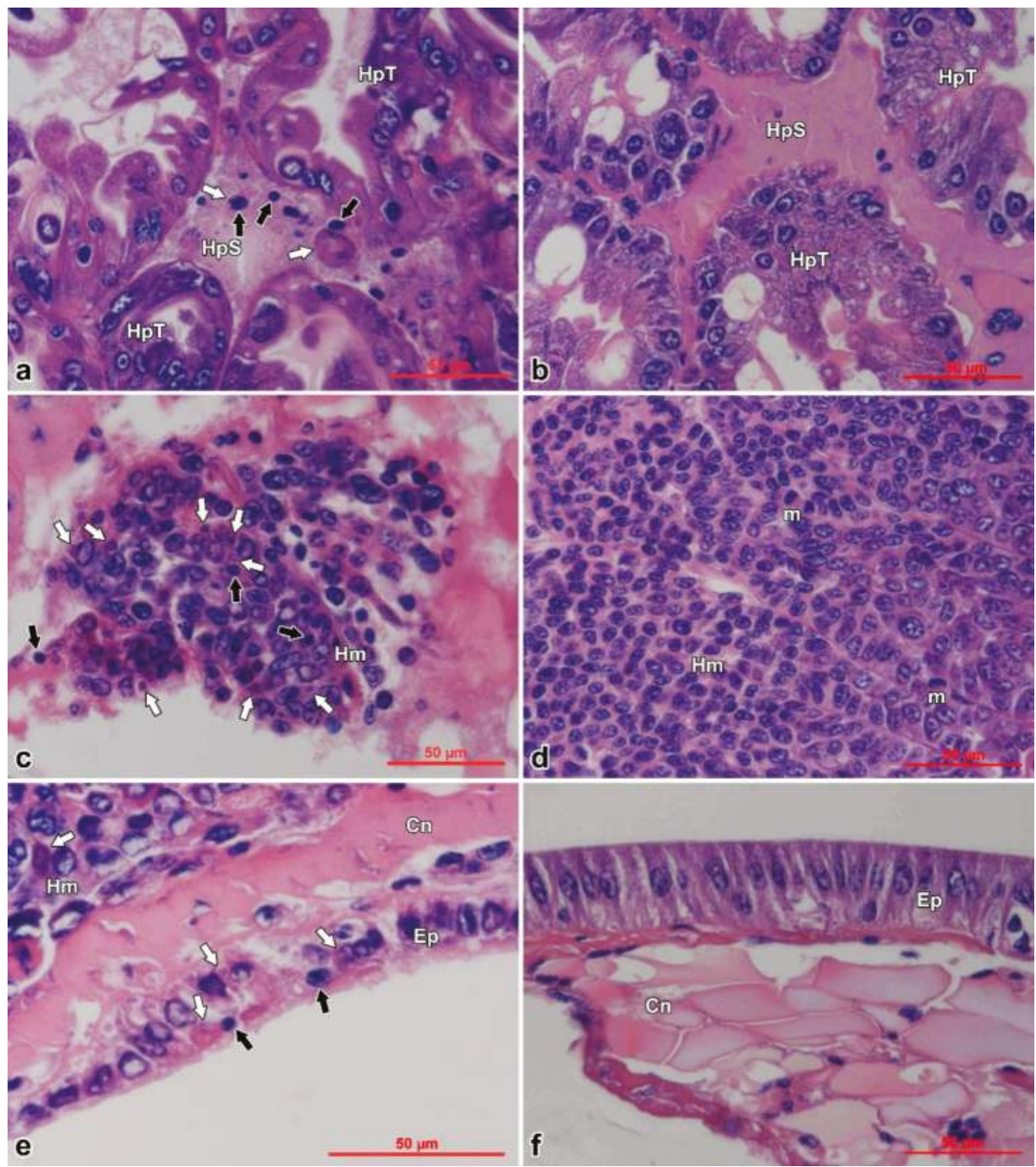

Figure 4. Histopathological examination of Exopalaemon carinicauda tissues infected with DIV1 and controls. Black arrows show karyopyknosis and white arrows show eosinophilic inclusions. Pictures $(\mathbf{a}, \mathbf{b})$ are hepatopancreas; $(\mathbf{c}, \mathbf{d})$ are hematopoietic tissues; and $(\mathbf{e}, \mathbf{f})$ are cuticular epithelium on which the cuticles were removed before dehydration. The pictures in the left column $(\mathrm{a}, \mathrm{c}$, and e) are the tissues of the infected prawn; the pictures in the right column (b, d, and f) are the tissues of the control prawn. HpT: hepatopancreatic tubule; HpS: hepatopancreatic sinus; Hm: hematopoietic tissue; Ep: epithelium; Cn: connective tissue; m: mitotic phase. Bar $=50 \mu \mathrm{m}$. 


\subsection{Primer Design and LAMP Reaction}

Primers for LAMP were designed to target the gene of the second largest subunit DNA-directed RNA polymerase II located between 69047-69263 of SHIV 20141215 genome (GenBank access no. MF599468), of which the sequence was completely complementary to that of CQIV CN01 77416 -77200 (Figure 5). In addition, results of LAMP primer specificity assay showed that the reactions were only positive for DIV1-infected shrimp, while the reactions were negative for WSSV, $V p_{\mathrm{AHPND}}$, IHHNV, or EHP infected shrimps. The reactions indicated that the LAMP primers in this study were specific to DIV1 and should work for ISDL.

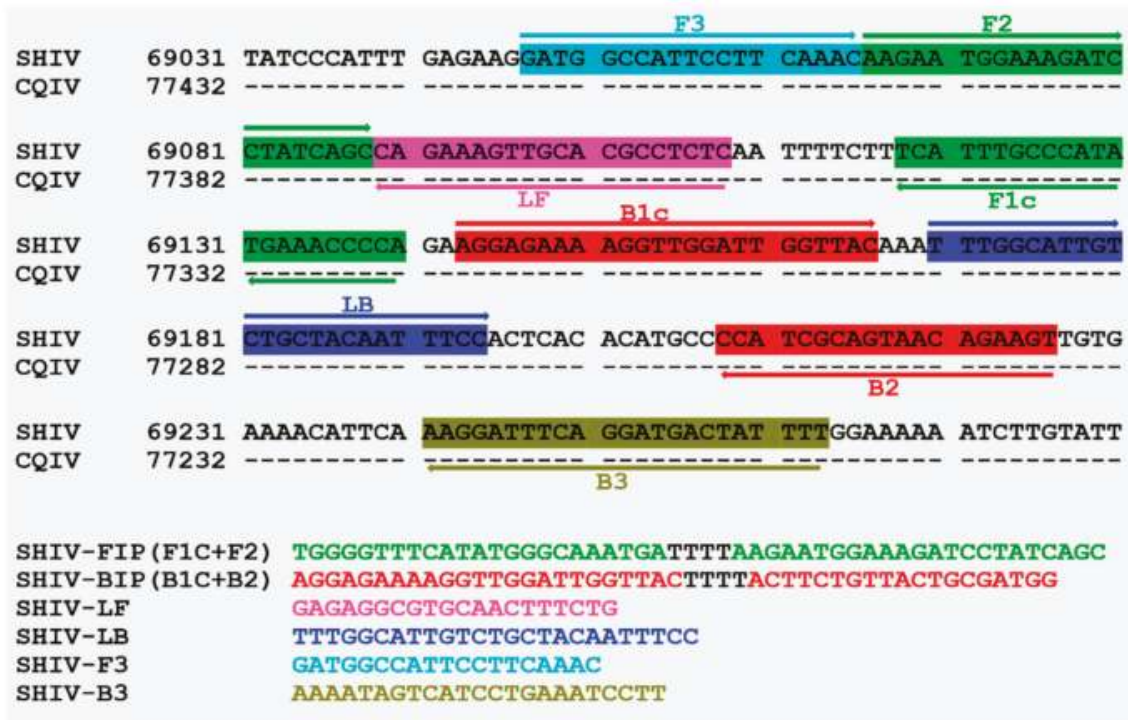

Figure 5. Information on primer design and primers used for Loop-mediated isothermal amplification (LAMP), based on the reference sequence of DIV1. Sequences of Shrimp hemocyte iridescent virus (SHIV 20141215 MF599468) and Cherax quadricarinatus iridovirus (CQIV CN01 MF197913) were obtained from GenBank.

\subsection{ISDL}

For ISDL protocol, a LAMP system was applied to in situ amplification to produce DIG-labeled products and subsequently detected with anti-DIG antibody on histological sections. ISDL results showed that blue-violet hybridization signals were detected in the hepatopancreatic sinus, stomach epithelium, cuticular epithelium, and hematopoietic tissues (Figure $6 a, c, e, g$ ) of prawns in the IM and PO groups, but no signal was detected in the control groups (Figure $6 \mathrm{~b}, \mathrm{~d}, \mathrm{f}, \mathrm{h}$ ). The results of ISDL provided further evidence that prawns in the IM and PO groups were infected by DIV1. 


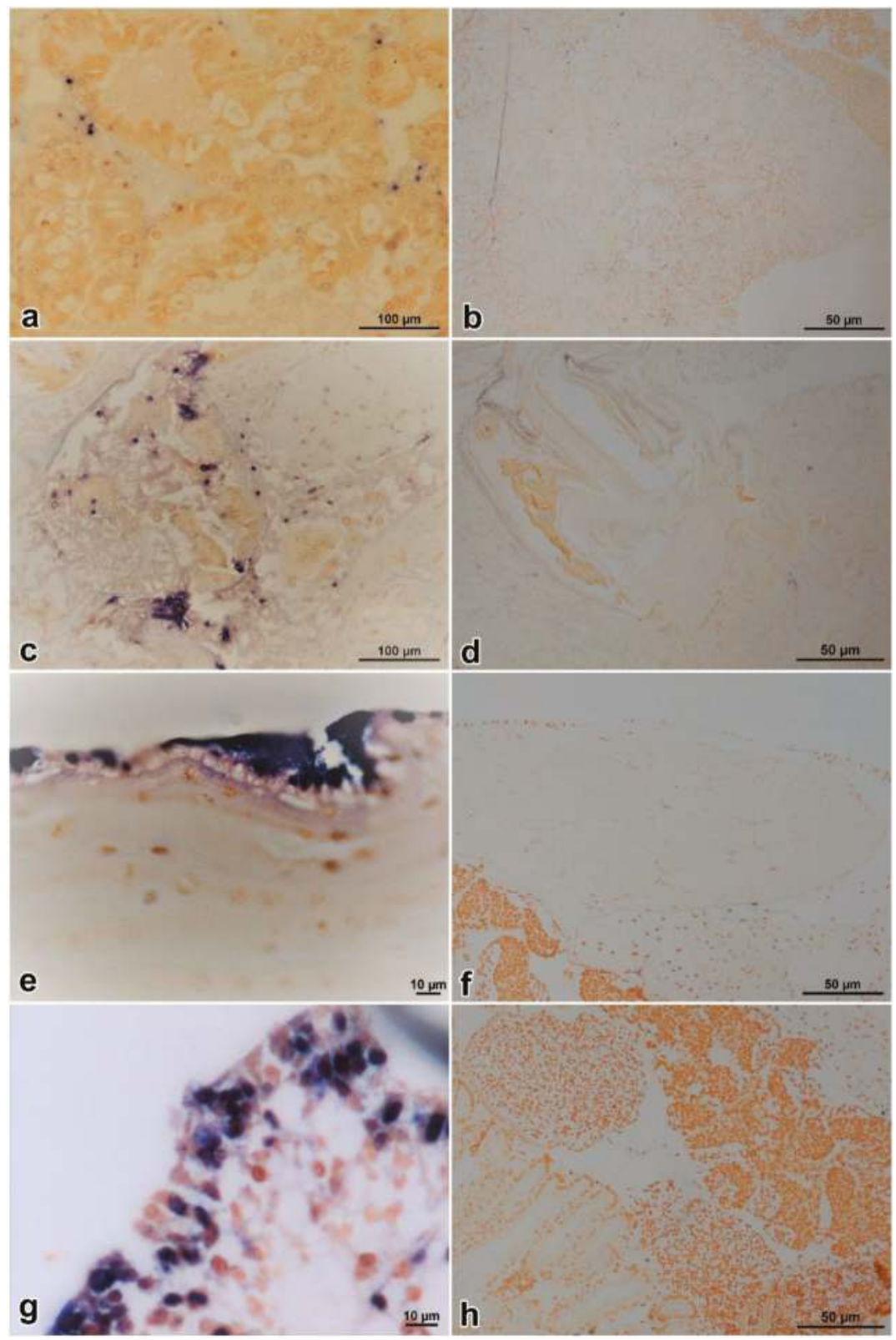

Figure 6. In situ DIG-labeling-loop-mediated DNA amplification (ISDL) micrographs of DIV1-infected and control Exopalaemon carinicauda. Hepatopancreas, stomach, cuticular epithelium, and hematopoietic tissue from a challenged prawn of the PO group, respectively (a, c, e, and $\mathbf{g}$ ); hepatopancreas, stomach, cuticular epithelium, and hematopoietic tissue from a healthy prawn of the CPO group, respectively (b, d, f, and h). In pictures a, c, e, and g, blue-violet signals were observed in hepatopancreatic sinus, stomach epithelium, cuticular epithelium, and hematopoietic tissues of prawns, respectively. In pictures b, d, f, and h, no hybridization signal was seen in the same tissues of DIV1-negative E. carinicauda, except some non-specific signals on gastric sieve of stomach. 


\subsection{TEM}

Icosahedral virions and cytoplasmic inclusions were observed in hepatopancreatic sinus, pereiopods, uropods, muscle, and gills of E. carinicauda of the IM group (Figure 7A-E,H). Assembled virions were mostly distributed outside of the assembling area near cellular membrane of the infected cells (Figure 7A,E). Similarly, virions were observed in the hepatopancreatic sinus and gills of prawns of the PO group (Figure 7F,G). Virions were hexagonal (i.e., icosahedral) and about $150 \mathrm{~nm}$ in diameter, which matched with characteristics of DIV1.

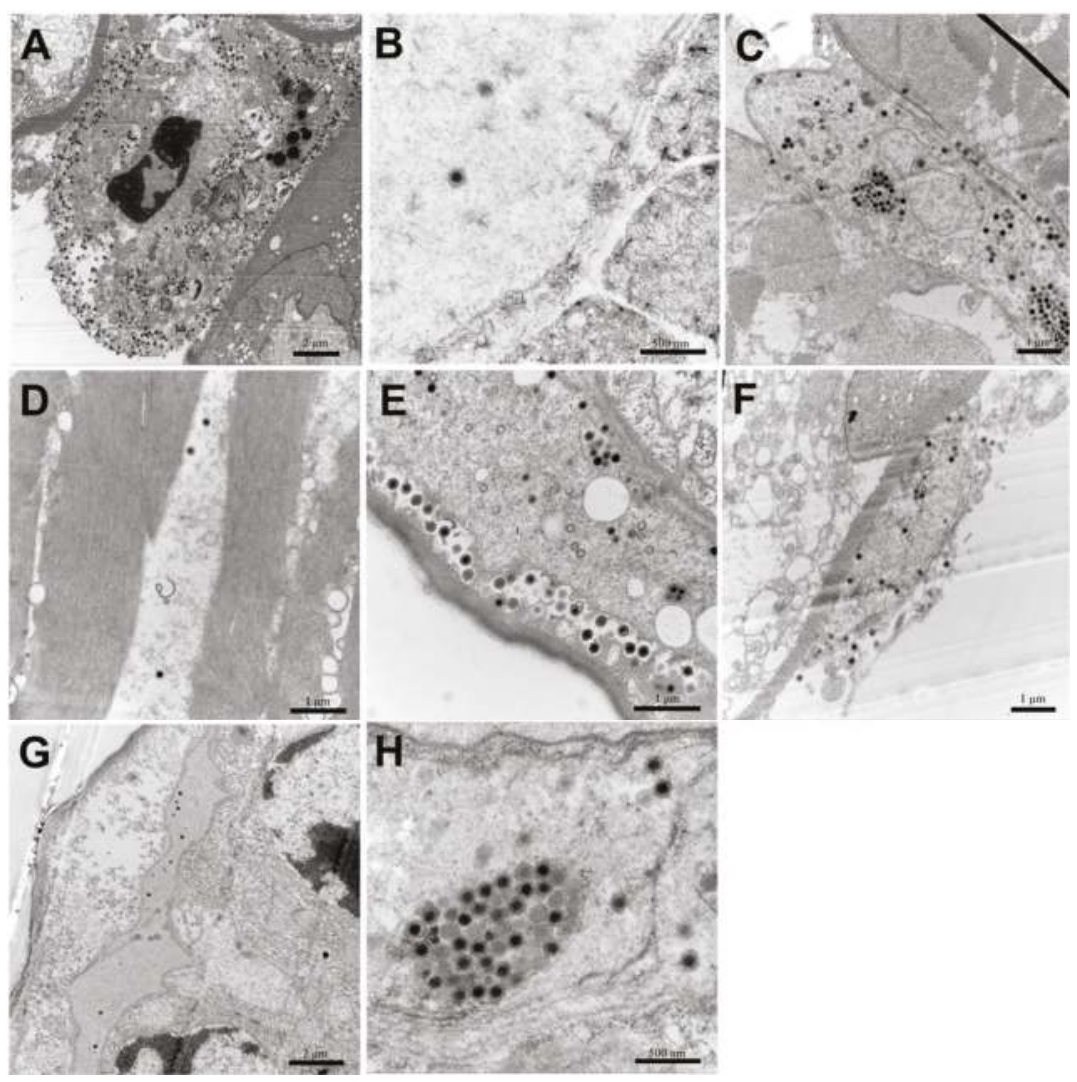

Figure 7. Transmission electron microscopy (TEM) of DIV1-infected Exopalaemon carinicauda. (A-E): hepatopancreatic sinus, pereiopods, uropods, muscle and gills, respectively, of a prawn in the IM group; (F and G): hepatopancreatic sinus and gills, respectively, of a prawn in the PO group; $\mathbf{H})$ : cytoplasmic inclusions with a cluster of viral particles.

\section{Discussion}

The susceptibility of infected species and the host range for a newly found virus are important information for studying both host and virus. From the host aspect, knowing an infectious pathogen of a host species will provide important information for prevention of the relevant disease; from the virus aspect, knowledge of a susceptible host range can be used for identification of virus species, discovering a specific viral replication host or cell line, and understanding of viral ecology. Susceptible host range is also important for international trade to prevent the transboundary spreading of a specific disease. For such purpose, the OIE issued criteria in 2014 to determine susceptibility for specific diseases that requires evidence from either natural infection or experimental challenge mimicking 
natural infection [11]. As a newly found virus, the susceptible host range of DIV1 remains a largely unknown area to be investigated. For the natural infection pathway, positive detections of DIV1 by PCR or qPCR have been reported in different natural samples of crustacean, including P. vannamei [9], P. chinensis [9], M. rosenbergii [9,23], C. quadricarinatus [8], Procambarus clarkii [23,24], P. japonicus [23], M. nipponense [23,24], M. superbum [24], and Cladocera [24]. Severe disease with high mortality has been reported and infection with DIV1 has been demonstrated in C. quadricarinatus, P. vannamei, and M. rosenbergii $[8,9,24]$. All of these have been confirmed as being susceptible species for DIV1, fulfilling the natural infection criteria of OIE standards. The susceptibility of P. chinensis, P. japonicus, and $M$. superbum to DIV1 were not fully confirmed, as the evidence of PCR or qPCR positives $[23,24]$ only supports the existence of DIV1. Confirmation of infection with DIV1 can usually be supported by evidence from histopathological evaluations, TEM, or in situ hybridization. However, they may remain suspicions of susceptibility, as there are confirmed susceptible species in the same genus. Cladocera has been detected as positive by qPCR, but the ISDL result was negative, so that it has been considered as a non-susceptible species [24]. For the experimental infection pathway, experimental challenges of P. vannamei, Pr. clarkii, Chinese mitten crab Eriocheir sinensis, and wild crab Pachygrapsus crassipes with CQIV CN01 have been reported [8,25]. Unfortunately, all these experimental infections only used only intramuscular injection, so the results were not enough to confirm of susceptibility for these species because OIE standards require that the challenge pathway to mimics natural infection. This present study is the first report to confirm a susceptible species to the newly found DIV1 by an experimental pathway mimicking the natural infection that fully follows OIE standards.

Due to an absence of a cell line for crustaceans, it is not possible to use normal plaque purification for crustacean viruses. We used a variety of methods to prove that $E$. carinicauda was successfully infected with DIV1, including molecular detection, histopathological and cytopathological analyses, and in situ DIG-labeling-loop-mediated DNA amplification. The original virus strain SHIV 20141215 has been demonstrated by testing for five major shrimp pathogens, including WSSV, YHV, TSV, IHHNV, and $V p_{\text {AHPND }}$ by PCR or RT-PCR methods [9]. In the previous study, the debris of $P$. vannamei and the purified viral inoculum were re-examined using real-time PCR for WSSV, TSV, YHV, IHHNV, $V p_{\mathrm{AHPND}}, \mathrm{CMNV}$, and DIV1 to exclude the possibility of contamination by other viruses and bacteria. In addition, no other viruses, with the exception of DIV1-like, as well as bacteria, were observed with TEM in samples used in this study.

Natively distributing in Yellow Sea and Bohai Sea and widely cultivated broadly in Jiangsu, Zhejiang, Shandong, and Liaoning Provinces of China, E. carinicauda is one of important economic crustaceans $[12,13]$. It has been reported that E. carinicauda is a natural host of some viral pathogens, such as WSSV [26] and CMNV [27]. E. carinicauda was also considered as a potential model animal for studies of shrimp viral pathogens [28].

In order to investigate the susceptibility of E. carinicauda to DIV1, following the OIE standards, the decapod was experimentally challenged with DIV1 per os and intramuscular injection. After 3 dpi, infected prawns of both the PO and IM groups displayed identical clinical symptoms, including debility, empty guts and stomach, pale hepatopancreas, slight whitish hematopoietic tissue, and death. Much higher doses of DIV1 were detected in hepatopancreatic samples of the moribund and deceased prawns in the IM group than those in the PO group. The significant difference in viral dose may be because the injection of DIV1 caused extensive and synchronous infection in cells of different target tissues. The clinical signs observed in E. carinicauda were similar to those of $P$. vannamei affected by SHIV 20141215 [9] and also similar to those of C. quadricarinatus affected by CQIV CN01 [8]. However, the sign of slightly whitish cloud at base of rostrum was not observed in decapods other than M. rosenbergii, which showed a typical white triangle at the hepatopancreatic locus [24]. The invisibility of this symptom in hematopoietic tissue of some DIV1 infected shrimp and crayfish may be due to interspersion and tininess of hematopoietic tissues of Penaeus species [18] or the opaque cuticles of crayfish. We may still need to search carefully for this symptom in future observation, as all gross signs in other tissues are not be typical for the infection with DIV1. According to the nonlinear regression of 
the challenge tests, in the duration of $16 \mathrm{dpi}$, mean cumulative mortalities of E. carinicauda were $70.8 \%$ and $42.5 \%$ caused by infection with DIV1 via intramuscular and per os, respectively. The pathogenic model (2) and (3) derived from the bioassay revealed that E. carinicauda showed some tolerance to the infection with DIV1 per os challenge mimicking natural infection. Compared with the intramuscular challenge, the per os challenge caused only $(60.1 \pm 6.3) \%$ lower mortality within $(145 \pm 0.35) \%$ longer time spent at $(17.2 \pm 14.0) \%$ slower instant speed. The surviving DIV1 positive prawns in per os challenged group possessed viral loads at $(3.57 \pm 3.42) \times 10^{2}$ copies/ng-DNA, which were about 100 folds lower than that detected in dead prawns. Previous studies showed that the mortalities of $P$. vannamei, C. quadricarinatus, and Pr. clarkii experimentally challenged with DIV1 reached $100 \%[8,9]$. The partial tolerance of E. carinicauda to DIV1 may provide an object for future study on mechanisms and breeding of DIV1 resistance. As E. carinicauda is a broadly distributed native species, the partial tolerance of the ridgetail white prawn to DIV1 may also provide a possible reservoir of the virus after it transports to species in the area of the Yellow Sea, Bohai Sea, and East China Sea.

Positive results of TaqMan qPCR and ISDL provided further evidences of the infection of E. carinicauda by DIV1. According to the results of ISDL, positive signals were detected in the hepatopancreatic sinus, hematopoietic tissue, and cuticular epithelium of infected E. carinicauda. Previous studies showed that cuticular epithelium is a major target tissue of WSSV infection [26,29]. However, cuticular epithelium of P. vannamei is not a susceptible tissue to DIV1 infection. The results exhibit a difference in tissue tropism between E. carinicauda and P. vannamei to DIV1 infection. ISDL [19] is a highly sensitive and time-saving method, compared to normal in situ hybridization (ISH). In addition, the histopathology of diseased E. carinicauda was consistent or similar to that previously reported in P. vannamei, C. quadricarinatus, and Pr. clarkii [8,9]. Moreover, in this study, massive DIV1 virions with dense cores, characterized by icosahedral shape and measuring $150 \mathrm{~nm}$ in diameter and consistent with the report of Qiu et al. [9], were observed in hemocytes of hepatopancreatic sinus and gills of E. carinicauda of the IM and PO groups. The virions primarily existed in cytoplasm of hemocytes and branchial cells. Additionally, in E. carinicauda of the IM group, DIV1 virions were also observed in pereiopods, muscles, and uropods. These results expanded the knowledge of tissue tropism of DIV1.

The combined results of clinical observation, molecular biological diagnosis, histological examination, and TEM supported the assertion that E. carinicauda is a newly confirmed susceptible species to infection with DIV1, following the criteria for listing species as susceptible to infection with a specific pathogen developed by the OIE [11]. Presently, there are no reports of natural infection of E. carinicauda with DIV1 in a farm or in the sea. As E. carinicauda has local economic importance, biosecurity strategies $[30,31]$ should be taken into account, considering the risk that DIV1 can cause disease in E. carinicauda and the risk that the species may become a possible reservoir of DIV1. It also should be ignored that E. carinicauda showed some degree of tolerance to infection with DIV1, especially per os challenge mimicking a natural pathway.

Supplementary Materials: The following is available online at http://www.mdpi.com/1999-4915/11/4/387/s1, Figure S1: Positive data of DIV1 qPCR detection within 40 cycles in IM and PO groups.

Author Contributions: Conceptualization, J.H. and X.C.; Formal analysis, X.C.; Methodology, X.C., H.W., L.Q., P.Z., and X.D.; Writing — Original Draft Preparation, X.C.; Writing—Review \& Editing, J.H., H.W., F.L., and X.C.; Supervision, J.H.; Project administration, J.H. and X.C.; Funding acquisition, J.H.

Funding: This research was financially supported by the Marine S\&T Fund of Shandong Province for Pilot National Laboratory for Marine Science and Technology (Qingdao) (2018SDKJ0502-3), the Pilot National Laboratory for Marine Science and Technology (Qingdao) (QNLM201706), the China ASEAN Maritime Cooperation Fund Project (2016-2018), and the China Agriculture Research System (CARS-48).

Acknowledgments: We are grateful to all the laboratory members for their technical advice and helpful discussions.

Conflicts of Interest: The authors declare no conflict of interest. The funders had no role in the design of the study; in the collection, analyses, or interpretation of data; in the writing of the manuscript, or in the decision to publish the results. 


\section{References}

1. Jun, K.; Kazuhiro, N. Megalocytiviruses. Viruses 2012, 4, 521-538. [CrossRef]

2. Chinchar, V.G.; Yu, K.H.; Jancovich, J.K. The Molecular biology of Frog virus 3 and other Iridoviruses infecting cold-blooded vertebrates. Viruses 2011, 3, 1959-1985. [CrossRef] [PubMed]

3. Chinchar, V.G.; Hick, P.; Ince, I.A.; Jancovich, J.K.; Marschang, R.; Qin, Q.W.; Subramaniam, K.; Waltzek, T.B.; Whittington, R.; Williams, T.; et al. ICTV virus taxonomy profile: Iridoviridae. J. Gen. Virol. 2017, 98, 890-891. [CrossRef] [PubMed]

4. Montanie, H.; Bonami, J.R.; Comps, M. Irido-like virus infection in the crab Macropipus depurator L. (Crustacea, Decapoda). J. Invertebr. Pathol. 1993, 61, 320-322. [CrossRef]

5. Lightner, D.V.; Redman, R.M. A putative iridovirus from the penaeid shrimp Protrachypene precipua Burkenroad (Crustacea Decapoda). J. Invertebr. Pathol. 1993, 1, 107-109. [CrossRef]

6. Miao, H.Z.; Tong, S.L.; Xu, B.; Jiang, M.; Liu, X.Y. Viral and Pathological observation in cultured lymphoid tissues of shrimp Penaeus chinensis. J. Fish. China 1999, 2, 169-173. [CrossRef]

7. Tang, K.F.J.; Redman, R.M.; Pantoja, C.R.; Groumellec, M.L.; Duraisamy, P.; Lightner, D.V. Identification of an iridovirus in Acetes erythraeus (Sergestidae) and the development of in situ hybridization and PCR method for its detection. J. Invertebr. Pathol. 2007, 96, 255-260. [CrossRef]

8. Xu, L.M.; Wang, T.; Li, F.; Yang, F. Isolation and preliminary characterization of a new pathogenic iridovirus from redclaw crayfish Cherax quadricarinatus. Dis. Aquat. Organ. 2016, 120, 17-26. [CrossRef]

9. Qiu, L.; Chen, M.M.; Wan, X.Y.; Li, C.; Zhang, Q.L.; Wang, R.Y.; Cheng, D.Y.; Dong, X.; Yang, B.; Wang, X.H.; et al. Characterization of a new member of Iridoviridae, Shrimp hemocyte iridescent virus (SHIV), found in white leg shrimp (Litopenaeus vannamei). Sci. Rep. 2017, 7. [CrossRef]

10. Chinchar, V.G.; Yang, F.; Huang, J.; Williams, T.; Whittington, R.; Jancovich, J.; Subramaniam, K.; Waltzek, T.; Hick, P.; Ince, I.A.; et al. One new genus with one new species in the subfamily Betairidovirinae. ICTV taxonomic proposal to the Iridoviridae Study Group of International Committee for Taxonomy of Viruses, 2018.004D. ICTV 2018. Available online: https://talk.ictvonline.org/files/ictv_official_taxonomy_ updates_since_the_8th_report/m/animal-dna-viruses-and-retroviruses/8051 (accessed on 10 March 2019).

11. OIE. Chapter 1.5 Criteria for listing species as susceptible to infection with a specific pathogen. In Aquatic Animal Health Code, 21nd ed.; World Organisation for Animal Health: Paris, France, 2018; ISBN 978-92-95108-69-1. Available online: http://www.oie.int/index.php?id=171\&L=0\&htmfile=chapitre_criteria_ species.htm (accessed on 10 March 2019).

12. Xu, W.; Xie, J.; Shi, H.; Li, C. Hematodinium infections in cultured ridgetail white prawns, Exopalaemon carinicauda, in eastern China. Aquaculture 2010, 300, 25-31. [CrossRef]

13. Wang, X.Q.; Yan, B.L.; Ma, S.; Dong, S.L. Study on the biology and cultural ecology of Exopalaemon carinicauda. Shandong Fish. 2005, 8, 21-23.

14. OIE. Manual of Diagnostic Tests for Aquatic Animals, 7th Edition. World Organisation for Animal Health. 2016; ISBN 978-92-9044-887-7. Available online: http://www.oie.int/standard-setting/aquatic-manual/accessonline/ (accessed on 10 January 2019).

15. Li, X.P.; Wan, X.Y.; Xu, T.T.; Huang, J.; Zhang, Q.L. Development and validation of a TaqMan RT-qPCR for the detection of convert mortality nodavirus (CMNV). J. Virol. Methods 2018, 62, 65-71. [CrossRef]

16. Qiu, L.; Chen, M.M.; Wan, X.Y.; Zhang, Q.L.; Li, C.; Dong, X.; Yang, B.; Huang, J. Detection and quantification of shrimp hemocyte iridescent virus by TaqMan probe based real-time PCR. J. Invertebr. Pathol. 2018, 154, 95-101. [CrossRef] [PubMed]

17. Huang, J.; Song, X.L.; Yu, J.; Zhang, L.J. The components of an inorganic physiological buffer for Penaeus chinensis. Methods Cell Sci. 1999, 21, 225-230. [CrossRef]

18. Bell, T.A.; Lightner, D.V. A Handbook of Normal Penaeid Shrimp Histology; World Aquaculture Society: Baton Rouge, LA, USA, 1988; ISBN 0-935868-37-2.

19. Jitrakorn, S.; Arunrut, N.; Sanguanrut, P.; Flegel, T.W.; Kiatpathomchai, W.; Saksmerprome, V. In situ DIG-labeling, loop-mediated DNA amplification (ISDL) for highly sensitive detection of infectious hypodermal and hematopoietic necrosis virus (IHHNV). Aquaculture 2016, 456, 36-43. [CrossRef]

20. Lightner, D.V. A Handbook of Shrimp Pathology and Diagnostic Procedures for Disease of Cultured Penaeid Shrimp; World Aquaculture Society: Baton Rouge, LA, USA, 1996; ISBN 0-962452-99-8. 
21. Graham, L.; Orenstein, J.M. Processing tissue and cells for transmission electron microscopy in diagnostic pathology and research. Nat. Protoc. 2007, 2, 2439-2450. [CrossRef] [PubMed]

22. Panphut, W.; Senapin, S.; Sriurairatana, S.; Withyachumnarnkul, B.; Flegel, T.W. A novel integrase-containing element may interact with Laem-Singh virus (LSNV) to cause slow growth in giant tiger shrimp. BMC Vet. Res. 2011, 7, 18. [CrossRef]

23. Qiu, L.; Dong, X.; Wan, X.Y.; Huang, J. Analysis of iridescent viral disease of shrimp (SHID) in 2017. In Analysis of Important Diseases of Aquatic Animals in China in 2017; Fishery and Fishery Administration Bureau under the Ministry of Agriculture and Rural Affairs, National Fishery Technical Extension Center, Ed.; China Agriculture Press: Beijing, China, 2018; pp. 187-204. ISBN 978-7-109-24522-8. (In Chinese)

24. Qiu, L.; Chen, X.; Zhao, R.H.; Li, C.; Gao, W.; Zhang, Q.L.; Huang, J. Description of a natural infection with decapod iridescent virus 1 in farmed giant freshwater prawn, Macrobrachium rosenbergii. Viruses 2019, 11, 354. [CrossRef]

25. Kun, P.C.; Fang, Y.H.; Tian, W.T.; Feng, Y.; Ming, C.J. Study of Cherax quadricarinatus iridescent virus in two crabs. J. Appl. Oceanogr. 2017, 1, 82-86. [CrossRef]

26. Lei, Z.W.; Huang, J.; Shi, C.Y.; Zhang, L.J.; Yu, K.K. Investigation into the hosts of White spot syndrome virus (WSSV). Oceanologia et Limnologia Sinica 2002, 33, 250-258.

27. Liu, S.; Li, J.T.; Tian, Y.; Wang, C.; Li, X.P.; Xu, T.T.; Li, J.; Zhang, Q.L. Experimental vertical transmission of covert mortality nodavirus in Exopalaemon carinicauda. J. Gen. Virol. 2017, 98, 652-661. [CrossRef]

28. Zhang, J.; Wang, J.; Gui, T.; Sun, Z.; Xiang, J. A copper-induced metallothionein gene from Exopalaemon carinicauda and its response to heavy metal ions. Int J. Biol. Macromol. 2014, 70, 246-250. [CrossRef]

29. Huang, J.; Song, X.L.; Yu, J.; Yang, C.H. Baculoviral hypodermal and hematopoietic necrosis-study on the pathogen and pathology of the explosive epidemic disease of shrimp. Mar. Fish. Res. 1995, 16, 1-10. (In Chinese with English abstract)

30. Huang, J.; Zeng, L.B.; Dong, X.; Liang, Y.; Xie, G.S.; Zhang, Q.L. Trend Analysis and Policy Recommendation on Aqutic Biosecurity in China. Eng. Sci. 2016, 18, 15-21. (In Chinese with English abstract)

31. Huang, J.; Dong, X.; Zhang, Q.L.; Wan, X.Y.; Xie, G.S.; Yang, B.; Wang, H.L.; Yang, Q.; Xu, H.; Wang, X.H. Emerging diseases and biosecurity strategies for shrimp farming. In \#We R Aquaculture, AQUA 2018; The World Aquaculture Society: Monpellier, France, 25-29 August 2018; p. 356.

(C) 2019 by the authors. Licensee MDPI, Basel, Switzerland. This article is an open access article distributed under the terms and conditions of the Creative Commons Attribution (CC BY) license (http://creativecommons.org/licenses/by/4.0/). 
Article

\title{
Evaluating the Within-Host Dynamics of Ranavirus Infection with Mechanistic Disease Models and Experimental Data
}

\author{
Joseph R. Mihaljevic ${ }^{1, *(D)}$, Amy L. Greer ${ }^{2}\left(\mathbb{D}\right.$ and Jesse L. Brunner ${ }^{3}(\mathbb{D}$ \\ 1 School of Informatics, Computing and Cyber Systems, Northern Arizona University, Flagstaff, \\ AZ 86011, USA \\ 2 Department of Population Medicine, University of Guelph, Guelph, ON N1G 2W1, Canada; \\ agreer@uoguelph.ca \\ 3 School of Biological Sciences, Washington State University, Pullman, WA 99163, USA; \\ jesse.brunner@wsu.edu \\ * Correspondence: joseph.mihaljevic@nau.edu; Tel.: +1-928-523-5125
}

Received: 28 February 2019; Accepted: 25 April 2019; Published: 27 April 2019

\begin{abstract}
Mechanistic models are critical for our understanding of both within-host dynamics (i.e., pathogen replication and immune system processes) and among-host dynamics (i.e., transmission). Within-host models, however, are not often fit to experimental data, which can serve as a robust method of hypothesis testing and hypothesis generation. In this study, we use mechanistic models and empirical, time-series data of viral titer to better understand the replication of ranaviruses within their amphibian hosts and the immune dynamics that limit viral replication. Specifically, we fit a suite of potential models to our data, where each model represents a hypothesis about the interactions between viral replication and immune defense. Through formal model comparison, we find a parsimonious model that captures key features of our time-series data: The viral titer rises and falls through time, likely due to an immune system response, and that the initial viral dosage affects both the peak viral titer and the timing of the peak. Importantly, our model makes several predictions, including the existence of long-term viral infections, which can be validated in future studies.
\end{abstract}

Keywords: amphibian; Ranavirus; frog virus 3; mathematical models; Bayesian inference

\section{Introduction}

Understanding the specific interactions between a host's immune system and an infectious agent can be critical for understanding population-level patterns of infection prevalence and the dynamics of prevalence through time [1,2]. Mechanistic models of within-host dynamics use mathematical expressions to represent the processes of pathogen population growth and immune defenses that fight against pathogen growth. These types of models have revealed key insights, especially regarding the effects of various immune strategies on the evolution of pathogen virulence [3,4]. Within-host models also help us to understand the effects of chronic and acute infections on disease progression, pathogen evolution, and the links between within-host and among-host processes [5]. For example, Kennedy et al. [6] showed that models of within-host viral replication and immune processes accurately recapitulate the effects of viral exposure dose on the probability of death in an insect host. Here, we develop within-host models to understand the replication of ranaviruses in their amphibian hosts, and we compare our models' expectations to laboratory data.

Viruses in the genus Ranavirus can be impressively lethal, causing rapid host mortality and mass mortality events, especially in larval amphibians. However, the outcome of infection varies tremendously across host taxa [7,8] and life stage [9-11], as well as dose of exposure and numerous 
environmental factors (reviewed in Reference [12]). Much of this variation is presumably due to variation in the host-virus interaction, where viral replication is countered by immune responses. Indeed, some qualitatively distinct outcomes appear to have their basis in different immune responses. Adult Xenopus laevis, for instance, are refractory to ranavirus infections, while larvae often succumb, and this is due to their distinct immune responses $[13,14]$. The much more effective adult response to infection involves rapid, substantial CD8+ cellular responses, whereas tadpoles' responses are dramatically less effective and slower. Larval X. laevis produce type I and type III interferon responses, which are effective at reducing viral replication, but are eventually overwhelmed by the virus $[15,16]$. However, while there has been great progress in elucidating the components of the immune system that interact with and help control ranavirus, many questions remain.

In particular, the dynamics of viral population growth are largely unknown outside of cell culture experiments. What are the dynamics of the virus population within the host? Does the host's immune system effectively control the virus population, outside of the Xenopus model system? Does the immune response lead to viral clearance or can persistent infections remain? Does this outcome depend on the initial exposure dose? We propose that mathematical models of the within-host dynamics of ranaviruses, which provide a quantitative understanding of the host-virus interaction, will help answer these questions and will provide a means for integrating the numerous factors that appear to be important for the outcome of ranavirus infections. There are several additional advantages of using a mechanistic, model-based approach. First, parameterized disease models yield quantitative insights that can be validated by collecting new data. Second, we can simulate parameterized models under novel scenarios to predict how the system might behave. Third, we can use models to identify which novel sources of data would best inform our understanding under different scenarios. Thus, our approach offers a rigorous method to generate new hypotheses and guide future studies to understand the interactions between ranaviruses and host immune defenses.

To this end we set out to develop several versions of a mechanistic, within-host model that embodied hypotheses about the replication of frog virus 3 (FV3) and the host's immune response to the infection. We then fit these models to a time series of FV3 titers within bullfrog (Lithobates catesbeianus) tadpoles that were experimentally infected with FV3. We used a model-comparison approach to determine the most parsimonious model(s) that could describe the observed viral titer through time and the effects of viral exposure dose. The salient features of these dynamics are: (1) a clear rise and then slower decline in viral titers over time, suggesting viral clearance by the host's immune response and motivating our model-fitting exercise, (2) an earlier and higher peak in viral titers with higher exposure dose, and (3) low-level infections remaining detectable for seven weeks. We then use these models to generate testable hypotheses and guide future studies to understand the interactions between ranaviruses and host immune defenses.

\section{Materials and Methods}

Our goal is to test a set of hypotheses about how ranaviral populations replicate within their larval amphibian hosts and how the virus interacts with the larval host's immune system. Our strategy is to develop mechanistic within-host growth models with various assumptions that correspond to our hypotheses. We then attempt to fit these models to serially-collected data on within-host titers, and we use a model-comparison approach to determine the most parsimonious model structure, and therefore the most parsimonious support for our hypotheses.

\subsection{Experimental Assessment of Within-Host Ranaviral Dynamics}

Details of the experiment can be found in Brunner et al. [17], but the essential details are that tadpoles (Gosner [18] stages 25-28) were exposed in $400 \mathrm{~mL}$ water baths for $24 \mathrm{~h}$ to one of three doses of the ranavirus FV3: a high dose $\left(10^{5}\right.$ plaque-forming units [pfu] $\left.\mathrm{mL}^{-1} ; n=150\right)$, medium-dose $\left(10^{3}\right.$ pfu $\left.\mathrm{mL}^{-1} ; n=150\right)$, or a low, but unknown dose $(n=90$ in "mock" exposure to inadvertently contaminated cell culture media). The tadpoles were assigned to be euthanized and sampled on days 
2, 4, 6, 8, 14, 21, 28, 35, 42, and 49 post exposure ( $n=15$ high-dose, $n=15$ low-dose, and $n=9$ "mock" tadpoles per time point), although some died and were sampled before their assigned date. Viral titers in liver and kidney samples were measured with a quantitative real-time PCR assay [19].

We do not include individuals that died before their pre-determined sampling date, because we focus on how the immune system is functioning against the virus, and we assume that individuals that died due to virus had immune systems that were overwhelmed. However, in the supplement (Table S1, Figures S1-S4), we demonstrate that our results are robust, and that including the dead individuals does not change the rank-order of our models or our general conclusions about the system.

\subsection{Mechanistic Models of Within-Host Dynamics}

We fit models to these time-series data that embodied two assumptions about viral replication and two about the host's immune response. First, we fit models with exponential viral growth $\left(V^{\prime}=\phi V\right)$ or with logistic growth $\left[V^{\prime}=\phi V\left(1-\frac{V}{K}\right)\right]$. In these differential equations, $V^{\prime}$ represents $\frac{d V(t)}{d t}$, where $V$ is the density of virus within the host, $\phi$ is the per capita replication rate of the virus, and $K$ is the viral carrying capacity. In some models, $K$ can be viewed as the viral titer above which the virus kills the host [5]; however, because we are modeling mean-field dynamics, we do not explicitly account for virus-induced host mortality.

We then layer on possible immune system dynamics. From previous experimental work, we know that larval amphibians (at least Xenopus) show interferon type I and type III responses to FV3, although the latter appears more effective $[15,16]$. While we lack detailed knowledge of the immune response to FV3, especially in non-model amphibian species, we begin with the reasonable assumption that the production of the immune components, $\boldsymbol{Z}$, responds to viral infection following the Michaelis-Menten form of enzymatic activity $[20,21]$ :

$$
Z^{\prime}=\psi Z\left(\frac{V}{V+\gamma}\right)
$$

In this case, the engagement of the immune component ramps up to a maximum, $\psi \mathrm{Z}$, as the virus population increases. The rate of immune component production is mediated by $\gamma$, which is the half-saturation constant. In this formulation the density of immune components never returns to pre-infection levels. We therefore also considered a second formulation

$$
Z^{\prime}=\left(N_{Z}-\delta Z\right)+\psi Z\left(\frac{V}{V+\gamma}\right)
$$

Here, $N_{Z}$ is the constant rate of production of the immune components, and $\delta$ is the per-capita background loss of the immune components. Moreover, we define $N_{Z}=\delta Z(0)$, such that, when no virus is present, the immune system stabilizes to a homeostatic level of immune component density equal to $\boldsymbol{Z}(0)$. In other words, we assume a balance of the immune components' production and loss at equilibrium, when no virus is present. This means that there is a constant background level of immune components $(\mathbf{Z}(0))$ in a host, and when a virus infects the host, the production of immune components ramps up until the virus is cleared.

Finally, we assume a mass-action attack rate of the immune system against the virus, which is a Type I Hollings' functional response, such that our most complex model becomes:

$$
\begin{gathered}
V^{\prime}=\phi V\left(1-\frac{V}{K}\right)-\beta V Z \\
Z^{\prime}=\left(N_{Z}-\delta Z\right)+\psi Z\left(\frac{V}{V+\gamma}\right) .
\end{gathered}
$$

We therefore model immune component production in response to virus infection as a fundamentally different process compared to the function of the immune component that limits viral population growth. We further note that all of our models are nested, and Table 1 shows all model 
formulations that we fit to our data set. We divide the models into two classes, A and B, which are differentiated by the assumptions about the immune system's production dynamics. Class A models are mostly distinguished by the fact that, at equilibrium, if the immune system response is strong enough, the virus is driven extinct (i.e., full viral clearance). For Class B models, the virus is not driven extinct, such that the virus persists at low levels within the hosts (Appendix A).

On a less technical note, in some ways our models are not specific about how the immune system of the larval amphibian functions. For example, our model could equally represent a population of immune cells or a population of molecules generated by the immune system (e.g., interferon molecules) that act to control viral replication more or less indirectly. In other words, although we model a mass-action attack rate of the immune system against the virus, we do not necessarily mean that the virus and immune component must come into direct contact. This immune action could be indirect, for instance, by controlling apoptosis of virus-infected cells.

\subsection{Fitting the Models to the Experimental Data}

We employ a Bayesian approach to inference to fit the suite of dynamical models to the time-series of within-host viral titers. Then we use Bayesian information criteria to compare the within-sample predictive accuracy of our models, while penalizing model complexity. In this way, we seek to understand the most parsimonious model structure that captures the main features of the time series. All model-fitting code is available on our open-source Bitbucket repository (https://bitbucket.org/ jrmihalj/ranavirus-within-host-dynamics/src/master/).

We use the open-source statistical programming language, Stan [22], to fit our differential equation models to the time-series data. Stan employs a Hamiltonian Monte Carlo (HMC) algorithm to sample from the model's posterior. For each model, we sampled the posterior using three Markov chains, with a 2000 iteration warm-up, followed by 2000 iterations, for a total of 2000 samples recorded from each chain. We conducted various graphical and quantitative diagnoses of the chain behavior, including inspections for temporal auto-correlation, some of which are shown in the supplement (Figures S5 and S6). We assessed convergence with the Gelman-Rubin statistic, $\hat{\boldsymbol{R}}$ [23]. All models converged after 4000 iterations.

Model dynamics are sensitive to parameter magnitudes. Therefore, in constructing our prior probability distributions for the parameters, we often restricted parameters to vague, but realistic ranges (see open-source model statements). All parameters were restricted to positive values, and for parameters that could take very large values (e.g., $K$ ) we set the parameter on a natural-logarithmic scale. To allow for potential correlations in our model parameters, we assumed that the main model parameters (i.e., $\phi, \beta, K, \delta, \psi$ ) had prior probabilities that were zero-truncated, multivariate normal, with estimated means and an estimated covariance matrix (based on underlying correlations). We used Cholesky Factorization to estimate the correlation structure, assuming vague priors for the correlations. Specifically, we used an LKJ prior on the correlations with a shape parameter equal to 2, which creates a correlation matrix closer to zero correlation (i.e., a conservative assumption) [22]. Additional details on prior structures and model specification can be seen in our open-source code repository.

Besides estimating the model parameters, we also had to estimate the initial conditions of the system: The initial viral titer, $\boldsymbol{V}(0)$, and the initial immune component density, $\mathbf{Z}(0)$. As we have three viral dosage treatments, we estimated three independent $V(0)$. We used a hierarchical prior structure, such that each treatment's initial titer was drawn from a distribution with an estimated mean and variance (see model code). We further assumed that the initial immune component density, $Z(0)$, did not vary among treatments. We therefore assumed that all larval amphibians start with the same average immune system component density that then responds to the invasion of the virus. As the magnitude of $\boldsymbol{V}(0)$ and $\boldsymbol{Z}(0)$ could be large, we again set these parameters on a natural-logarithmic scale.

The viral titer values spanned approximately six orders of magnitude. To improve numerical integration performance, by reducing the error in the integration algorithms due to such large viral 
titer values, we fit the differential equation models using natural log-transformed titer. Assuming that $v=\log (V)$ and $z=\log (Z)$, we can reformulate Equation (3) as follows:

$$
\begin{gathered}
v^{\prime}=\phi\left(1-\frac{e^{v}}{K}\right)-\beta e^{z} \\
z^{\prime}=\left(\frac{N_{Z}}{e^{z}}-\delta\right)+\psi\left(\frac{e^{v}}{e^{v}+\gamma}\right) .
\end{gathered}
$$

Thus, the scaling of the parameters does not change, just the scaling of the state variables. This also allowed us to more reliably assume a Gaussian likelihood for log-transformed viral titer. We further allowed the residual variance to be different for each dosage treatment.

We also note that we only included non-zero titers in our data set for the model-fitting routine. Our reasoning is that a zero titer could represent an individual that never became infected, even upon exposure, or an individual that cleared infection later on. Because we could not distinguish between these two scenarios, we excluded these values. We did re-fit our models to the full data set, including zeros, to understand the effects on our inference. Importantly, this did not change the rank-order of our models using model comparison, but it generally made the models fit more poorly to the data, bringing down the average predicted titer and altering the marginal posterior estimates of the model parameters. We therefore do not consider these model fits further.

\subsection{Model Comparisons}

Our goal for model comparison was to determine the most parsimonious model(s) with the best goodness-of-fit. In practice, this means assessing the within-sample predictive performance of each model and correcting for model complexity. Given that we used a Bayesian approach to fitting our models to the data, we chose to use a Bayesian information theoretic approach to model comparison. Therefore, we calculated the leave-one-out information criterion (LOO-IC) for each model. Analogous to the Akaike information criterion (AIC), we can compare models based on the LOO-IC value, because they follow the deviance scale [24]. Thus, following the rule-of-thumb that $\triangle \mathrm{LOO}-\mathrm{IC}>3$ designates models with significantly different model performance, and where lower LOO-IC values indicate better-fitting, more parsimonious models. 
Viruses 2019, 11, 396

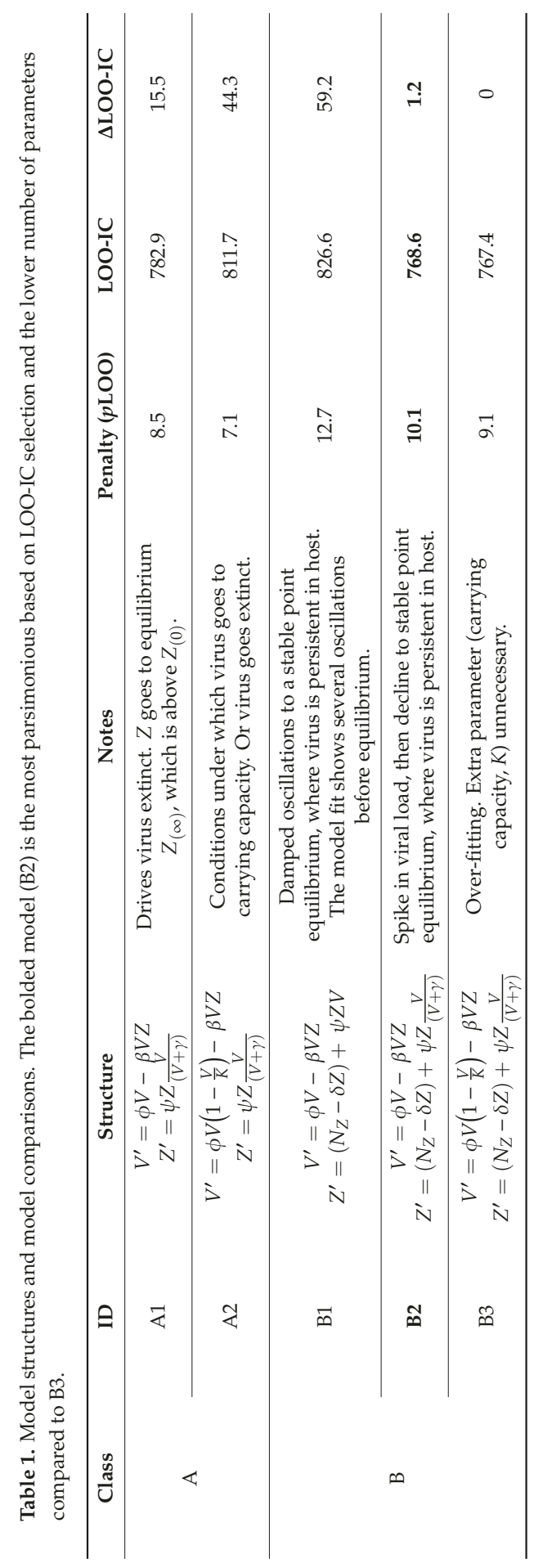




\section{Results}

A full qualitative and statistical analysis of the experimental data can be found in [17]. For our purposes, it is important to note the clear rise and fall of viral titers over time in the medium and high dosage treatments, which suggested a possible immune response that was leading towards viral clearance, and which motivated our modeling-fitting and model comparison routine.

Model B2, our best-fitting and most parsimonious model, fits to the experimental data very well (Figure 1). This model includes exponential growth of the virus population, and an assumption of homeostatic levels of immune components within the host, and the model's parameter estimates are shown in Table 2. Importantly, model B2 captures key features of the data that the other models failed to capture. First, the model correctly predicts that higher initial viral doses lead to higher peaks of within-host titer. Second, the model also shows that, with lower initial doses, the timing of the peak titer is delayed (Figure S7). In other words, it takes longer for the virus population to build up within the host. This is due, in part, to the exponential growth of the virus population and, in part, to the action of the immune system that inhibits viral replication.
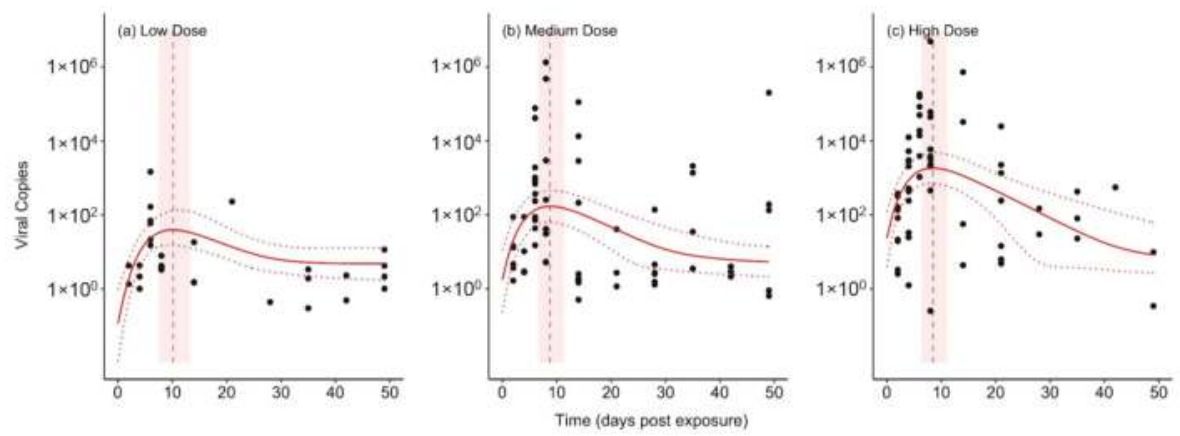

Figure 1. The fit of model B2 to the experimental data. Circles are data points representing the viral DNA copies from individual bullfrog tadpoles that were sampled on a given day. The median model fit (solid red line) and 95\% Bayesian credible interval (CI) of the fit (dashed red lines) are shown. Additionally, the median (dashed vertical line) and 95\% CI (light red polygon) are shown for the time of the maximum viral titer predicted by the model.

Our model-fitting and model comparison approach suggests strong differences between the appropriateness of our different model structures. Models B2 and B3 had indistinguishable model fits (Table 1, Figure S8), but model B3 included an additional parameter, assuming logistic growth of the virus population (i.e., a carrying capacity within the host). This is a classic case of over-fitting, however, because the within-sample prediction for the model with more parameters was indistinguishable from the simpler model. Therefore, we conclude that model B2 is more parsimonious.

We had trouble fitting model A1 to the data, because it fits so poorly to the low-dose treatment. Therefore, the model ends up predicting a more or less linear decline in virus load across time, with high variance (Figure S9). This linear effect allowed the model to fit very well to the data from the low dose treatment, increasing its overall likelihood and improving its LOO-IC value. However, this parameterized version of the model fails to capture basic features of the data set. In contrast, model A2 fits to the data reasonably well (Figure S10). However, this model predicts the same peak titer across dosage treatments, leading to a very poor fit to the data from the low-dose treatment. 
Table 2. Parameter estimates (median and 95\% credible intervals) from the most parsimonious model, B2.

\begin{tabular}{|c|c|c|c|}
\hline Parameter & Description & Units & Estimate \\
\hline$V(0)$ low & & & $0.12(0.01-0.89)$ \\
\hline$V(0)$ medium & Initial viral densities (per dosage) & Viral DNA copy (VC) & $1.47(0.24-11.55)$ \\
\hline$V(0)$ high & & & $24.10(5.31-146.85)$ \\
\hline$Z(0)$ & Initial immune component denisty & Immune component (IC) & $0.35(0.04-4.43)$ \\
\hline$\phi$ & Viral replication rate & day $^{-1}$ & $2.39(1.07-4.63)$ \\
\hline$\beta$ & Mass-action attack rate & $(\mathrm{IC})^{-1}$ day $^{-1}$ & $1.75(0.15-6.28)$ \\
\hline$N_{Z}$ & $\begin{array}{l}\text { Rate of production that ensures return } \\
\text { of immune system to homeostasis }\end{array}$ & (IC) day ${ }^{-1}$ & $N_{Z}=\delta Z(0)$ \\
\hline$\delta$ & $\begin{array}{l}\text { Rate of decline that ensures return of } \\
\text { immune system to homeostasis }\end{array}$ & day $^{-1}$ & $1.29(0.41-3.92)$ \\
\hline$\psi$ & $\begin{array}{l}\text { Immune component growth rate in } \\
\text { response to virus }\end{array}$ & day $^{-1}$ & $0.99(0.19-3.56)$ \\
\hline$\gamma$ & Half saturation constant & $\mathrm{VC}$ & $0.13(0.02-1.02)$ \\
\hline
\end{tabular}

Model B1 also has a decent fit to the data (Figure S11). However, with this model's estimated parameters, the dynamics show damped oscillations towards the endemic equilibrium. This pattern does not seem biologically realistic, as the data do not show any clear oscillations.

We do note that we had difficulty identifying the attack rate parameter $\beta$ using model B2. This is likely because of the strong effects of viral replication rate $\phi$ and the growth rate of the immune components in response to viral density $\psi$ on the overall model dynamics. Future experiments should be used to better estimate the attack rate parameter.

\section{Discussion}

Our study represents an initial step towards making model-based, quantitative predictions about ranavirus growth and immune system functioning within larval amphibian hosts, which complements the history of empirical work in these research areas. The experimental data with bullfrog (Lithobates catesbeianus) tadpoles suggests a non-monotonic relationship between within-host viral titer and time post-exposure. That is, an immune response appears to be reducing the growth of the virus over time. This is broadly consistent with the immunological studies with Xenopus laevis tadpoles, showing a robust interferon response $[15,16]$. Through model comparisons, we identified a model of exponential viral growth and a mass-action immune system response that captures key features of our data and generally fits our data quite well. Importantly, this model-based approach allows us to make predictions and to develop testable hypotheses for follow-up experiments. However, we did not measure immune responses directly in our experiment, and therefore cannot conclude with certainty that the patterns we observe in viral titer are driven by immune system processes. To clarify these mechanisms, below we suggest specific ways to collect and analyze data in future studies.

The best-fitting model predicts that individuals that survive infection should exhibit a viral titer pattern that rises and falls over time. This prediction contrasts with the empirical work that uses Xenopus, because larval Xenopus almost always die from frog virus 3 (FV3) exposure. Even a pre-treatment of type III interferon, which should boost the immune response, only delays mortality in the Xenopus system [16]. Unfortunately, we do not know of any studies that have tested whether similar host immune responses exist in our study organism, the American bullfrog. However, it is well known that the American bullfrog is uncommon in its high resistance and tolerance to multiple diseases, including FV3 [7,25] and the amphibian chytrid fungus (Batrachochytrium dendrobatidis) [26,27]. Therefore, it is not surprising that we could infer a more robust immune response from this species compared to X. laevis. Still, our current data cannot validate that, in surviving individuals, virus loads rise and then fall, because we do not have individual host-level time series of viral load. Future studies could use various sources of eDNA (e.g., swabbing, skin scrapes, or water filtration), which are correlated with internal titers [17], to validate whether there is a rise and fall of viral load in individuals. 
Alternatively, it may be fruitful to experiment with larger-bodied animals that would permit sampling blood repeatedly through time.

Our model also predicts that, if a host does not die from the initial exponential growth of the virus, the immune system will decrease the virus to an endemic equilibrium (Appendix A). In other words, we should see persistent infections with very low levels of virus in some infected bullfrog tadpoles. It is worth noting that this model prediction is not relevant to quiescent virus persisting in particular tissues, such as that found in peritoneal leukocytes in adult Xenopus [28]. Rather, the persistence in our model is due to a dynamic balance between viral replication and host immune responses. In any case, our model predicts low-level infections that would be detectable beyond 60 days from initial exposure time and should be actively replicating. That said, there are also several reasons that an endemic equilibrium may not hold. First, demographic stochasticity in the virus population could cause low-level infections to fade out $[6,29]$. Second, variability in the immune response over time (e.g., waning immunity) could cause fluctuations in viral titer. Third, the costs of continued immune responses could lead to host death even with low levels of infection [30].

Several of the tested model structures predict full viral clearance at equilibrium, but none of these models fit as well to the observed dynamics in bullfrog tadpoles. Future studies that collect time-series data and that have some long-term exposures (e.g., greater than 50 days) will improve our ability to distinguish between viral clearance and viral persistence. Furthermore, because we did not have simultaneous empirical data from the larval immune system, our model fitting algorithm was agnostic to the model's prediction of immune system dynamics. If future studies simultaneously capture time-series data on viral titer and measures of larval immune system, we would have much more power to distinguish between different models of within-host dynamics.

There are key features of the data set that our deterministic modeling scheme does not fully capture, and these are areas for future model development. First, the main process that our model ignores is host mortality due to viral growth. For instance, our current model predicts that immunocompromised individuals would show exponential viral growth, and in reality, this likely lead to death. Future versions of our model could include stochasticity, following Kennedy and Dwyer [6], such that demographic stochasticity in the viral population could lead to the virus exceeding a threshold growth rate or titer that causes host death. Then, we could analyze the probability of this occurring over many realizations of the stochastic model. This would allow us to explicitly evaluate how initial exposure dosage affects the probability of host mortality, from a within-host, mechanistic framework.

Viral titers within a host can be important determinants of the infection dynamics among hosts [3], affecting both the duration of infections and their propensity to be transmitted. Many dose-response experiments, for instance, show that hosts exposed to higher doses of ranaviruses, and so presumably harbor larger viral populations, are more likely to die and die more rapidly [31-33]. More intensely infected individuals may also shed more virus (e.g., Reference [17]) and thus be more infectious. Similar effects of the intensity of infection are common in other host-virus systems [34,35], as well as for other amphibian pathogens (e.g., B. dendrobatidis; [36]). Pathogen titers or intensity of infection can be a natural way in which to link within and between-host dynamics [3,37,38]. Within-host models of host-virus interactions may therefore be a fruitful way of integrating the myriad effects that are known to influence the outcome of ranavirus infections.

Supplementary Materials: The following are available online at http://www.mdpi.com/1999-4915/11/5/396/s1, Figure S1: Fit of model A1 to the data with dead individuals included., Figure S2: Fit of model A2 to the data with dead individuals included., Figure S3: Fit of model B1 to the data with dead individuals included., Figure S4: Fit of model B3 to the data with dead individuals included., Figure S5: Traceplots of the HMC sampler for the five model parameters of model B2, with 3 sampling chains., Figure S6: Comparison of prior probability distributions to marginal posterior samples for the five model parameters of model B2., Figure S7: Effect of dosage on the predicted time of peak viral titer, derived from model B2., Figure S8: Fit of model B3 to the data with no dead individuals., Figure S9: Fit of model A1 to the data with no dead individuals., Figure S10: Fit of model A2 to the data with no dead individuals., Figure S11: Fit of model B1 to the data with no dead individuals., Table S1: Model structures and model comparisons for the data set that includes larvae that died of virus prior to their pre-determined sampling date. 
Author Contributions: Conceptualization, J.R.M., A.L.G., J.L.B.; methodology, J.R.M., A.L.G., J.L.B.; software, J.R.M.; validation, J.R.M.; formal analysis, J.R.M.; investigation, J.R.M., A.L.G., J.L.B.; data curation, J.L.B.; writing—original draft preparation, J.R.M., J.L.B.; writing—review and editing, J.R.M., A.L.G., J.L.B.; visualization, J.R.M.; supervision, J.R.M., A.L.G., J.L.B.; project administration, J.R.M., A.L.G., J.L.B.

Funding: J.R.M. was funded under the State of Arizona Technology and Research Initiative Fund (TRIF), administered by the Arizona Board of Regents, through Northern Arizona University. J.L.B. was supported by National Science Foundation grant 1754474. Data collection were supported by Association of Zoo \& Aquariums CGF grant 14-1263 and a Zoological Medicine \& Wildlife Health Research Grant from the American Association of Zoo Veterinarians to J.L.B. A.L.G. was supported by the Canada Research Chairs Program and the Natural Sciences and Engineering Research Council (NSERC) of Canada.

Conflicts of Interest: The authors declare no conflict of interest. The funders had no role in the design of the study; in the collection, analyses, or interpretation of data; in the writing of the manuscript, or in the decision to publish the results.

\section{Appendix A}

We can express the coexistence equilibrium of model B2 analytically, which defines the amount of virus and host immune components at the stable equilibrium with a persistent infection. Equilibrium values of the state variables, defined by the *, are as follows:

$$
\begin{gathered}
Z^{*}=\frac{\phi}{\beta} \\
V^{*}=\frac{\frac{\gamma}{\psi}\left(\delta-\frac{N_{Z}}{Z^{*}}\right)}{\left(1-\frac{\delta}{\psi}+\frac{N_{Z}}{\psi Z^{*}}\right)}
\end{gathered}
$$

\section{References}

1. Hawley, D.M.; Altizer, S.M. Disease ecology meets ecological immunology: Understanding the links between organismal immunity and infection dynamics in natural populations. Funct. Ecol. 2011, 25, 48-60. [CrossRef]

2. Ezenwa, V.O.; Jolles, A.E. From host immunity to pathogen invasion: the effects of helminth coinfection on the dynamics of microparasites. Integr. Comp. Biol. 2011, 51, 540-551. [CrossRef]

3. Mideo, N.; Alizon, S.; Day, T. Linking within- and between-host dynamics in the evolutionary epidemiology of infectious diseases. Trends Ecol. Evol. 2008, 23, 511-517. [CrossRef]

4. Day, T.; Alizon, S.; Mideo, N. Bridging scales in the evolution of infectious disease life histories: Theory. Evolution (N. Y). 2011, 65, 3448-3461. [CrossRef]

5. Alizon, S.; van Baalen, M. Acute or Chronic? Within-Host Models with Immune Dynamics, Infection Outcome, and Parasite Evolution. Am. Nat. 2008, 172, E244-E256. [CrossRef] [PubMed]

6. Kennedy, D.A.; Dukic, V.; Dwyer, G. Pathogen Growth in Insect Hosts: Inferring the Importance of Different Mechanisms Using Stochastic Models and Response-Time Data. Am. Nat. 2014, 184, 407-423. [CrossRef] [PubMed]

7. Hoverman, J.; Gray, M.; Miller, D. Anuran susceptibilities to ranaviruses: role of species identity, exposure route, and a novel virus isolate. Dis. Aquat. Organ. 2010, 89, 97-107. [CrossRef]

8. Duffus, A.L.J.; Waltzek, T.B.; Stöhr, A.C.; Allender, M.C.; Gotesman, M.; Whittington, R.J.; Hick, P.; Hines, M.K.; Marschang, R.E. Distribution and Host Range of Ranaviruses. In Ranaviruses; Gray, M.J., Chinchar, V.G., Eds.; Springer: Cham, Switzerland, 2015; pp. 9-57, ISBN 978-3-319-13754-4.

9. Hoverman, J.T.; Gray, M.J.; Haislip, N.A.; Miller, D.L. Phylogeny, life history, and ecology contribute to differences in amphibian susceptibility to ranaviruses. Ecohealth 2011, 8, 301-319. [CrossRef]

10. Haislip, N.A.; Gray, M.J.; Hoverman, J.T.; Miller, D.L. Development and disease: how susceptibility to an emerging pathogen changes through anuran development. PLoS ONE 2011, 6, e22307. [CrossRef] [PubMed]

11. Warne, R.W.; Crespi, E.J.; Brunner, J.L. Escape from the pond: Stress and developmental responses to ranavirus infection in wood frog tadpoles. Funct. Ecol. 2011, 25, 139-146. [CrossRef]

12. Brunner, J.L.; Storfer, A.; Gray, M.J.; Hoverman, J.T. Ranavirus Ecology and Evolution: From Epidemiology to Extinction. In Ranaviruses; Gray, M.J., Chinchar, V.G., Eds.; Springer: Cham, Switzerland, 2015; pp. 71-104. 
13. De Jesús Andino, F.; Chen, G.; Li, Z.; Grayfer, L.; Robert, J. Susceptibility of Xenopus laevis tadpoles to infection by the ranavirus Frog-Virus 3 correlates with a reduced and delayed innate immune response in comparison with adult frogs. Virology 2012, 432, 435-443. [CrossRef] [PubMed]

14. Wendel, E.S.; Yaparla, A.; Koubourli, D.V.; Grayfer, L. Amphibian (Xenopus laevis) tadpoles and adult frogs mount distinct interferon responses to the Frog Virus 3 ranavirus. Virology 2017, 503, 12-20. [CrossRef] [PubMed]

15. Grayfer, L.; De Jesus Andino, F.; Robert, J. The Amphibian (Xenopus laevis) Type I Interferon Response to Frog Virus 3: New Insight into Ranavirus Pathogenicity. J. Virol. 2014, 88, 5766-5777. [CrossRef] [PubMed]

16. Grayfer, L.; de Jesús Andino, F.; Robert, J. Prominent Amphibian (Xenopus laevis) Tadpole Type III Interferon Response to the Frog Virus 3 Ranavirus. J. Virol. 2015, 89, 5072-5082. [CrossRef] [PubMed]

17. Brunner, J.L.; Olson, A.D.; Rice, J.G.; Meiners, S.E.; Le Sage, M.J.; Cundiff, J.A.; Goldberg, C.S.; Pessier, A.P. Ranavirus infection dynamics and shedding in American bullfrogs: Consequences for spread and detection in trade. Submitted.

18. Gosner, K.L. A Simplified Table for Staging Anuran Embryos Larvae with Notes on Identification. Herpetologica 1960, 16, 183-190.

19. Stilwell, N.; Whittington, R.J.; Hick, P.; Becker, J.A.; Ariel, E.; van Beurden, S.; Vendramin, N.; Olesen, N. Waltz Partial validation of a TaqMan real-time quantitative PCR for the detection of ranaviruses. Dis. Aquat. Organ. 2018, 128, 105-116. [CrossRef] [PubMed]

20. Menten, L.; Michaelis, M.I. Die kinetik der invertinwirkung. Biochem. Z 1913, $49,5$.

21. Rosenbaum, B.; Rall, B.C. Fitting functional responses: Direct parameter estimation by simulating differential equations. Methods Ecol. Evol. 2018, 9, 2076-2090. [CrossRef]

22. Carpenter, B.; Gelman, A.; Hoffman, M.D.; Lee, D.; Goodrich, B.; Betancourt, M.; Brubaker, M.; Guo, J.; Li, P.; Riddell, A. Stan: A Probabilistic Programming Language. J. Stat. Softw. 2017, 76. [CrossRef]

23. Gelman, A. Inference and monitoring convergence. In Markov Chain Monte Carlo in Practice; Gilks, W., Richardson, S., Spiegelhalter, D., Eds.; CRC Press: Boca Raton, FL, USA, 1996; pp. 131-143.

24. Vehtari, A.; Gelman, A.; Gabry, J. Practical Bayesian model evaluation using leave-one-out cross-validation and WAIC. Stat. Comput. 2016, 27, 1-20.

25. Majji, S.; Lapatra, S.; Long, S.M.; Sample, R.; Bryan, L.; Sinning, A.; Chinchar, V.G. Rana catesbeiana virus Z (RCV-Z ): A novel pathogenic ranavirus. Dis. Aquat. Organ. 2006, 73, 1-11. [CrossRef] [PubMed]

26. Daszak, P.; Strieby, A.; Cunningham, A.A.; Longcore, J.E.; Brown, C.C.; Porter, A.D. Experimental Evidence That the Bullfrog (Rana Catesbeiana) Is a Potential Carrier of Chytridiomycosis, an Emerging Fungal Disease of Amphibians. Herpetol. J. 2004, 14, 201-207.

27. Peterson, A.C.; McKenzie, V.J. Investigating differences across host species and scales to explain the distribution of the amphibian pathogen Batrachochytrium dendrobatidis. PLoS ONE 2014, 9, e107441. [CrossRef] [PubMed]

28. Morales, H.D.; Abramowitz, L.; Gertz, J.; Sowa, J.; Vogel, A.; Robert, J. Innate immune responses and permissiveness to ranavirus infection of peritoneal leukocytes in the frog Xenopus laevis. J. Virol. 2010, 84, 4912-4922. [CrossRef] [PubMed]

29. Kennedy, D.A.; Dwyer, G. Effects of multiple sources of genetic drift on pathogen variation within hosts. PLoS Biol. 2018, 16, 1-17. [CrossRef] [PubMed]

30. Hanssen, S.A.; Hasselquist, D.; Folstad, I.; Erikstad, K.E. Costs of immunity: Immune responsiveness reduces survival in a vertebrate. Proc. R. Soc. B Biol. Sci. 2004, 271, 925-930. [CrossRef] [PubMed]

31. Plumb, J.A.; Zilberg, D. The lethal dose of largemouth bass virus in juvenile largemouth bass and the comparative susceptibility of striped bass. J. Aquat. Anim. Health 1999, 11, 246-252. [CrossRef]

32. Brunner, J.L.; Richards, K.; Collins, J.P. Dose and host characteristics influence virulence of ranavirus infections. Oecologia 2005, 144, 399-406. [CrossRef] [PubMed]

33. Duffus, A.L.J.; Nichols, R.A.; Garner, T.W.J. Experimental evidence in support of single host maintenance of a multihost pathogen. Ecosphere 2014, 5, 1-11. [CrossRef]

34. Cattadori, I.M.; Albert, R.; Boag, B. Variation in host susceptibility and infectiousness generated by co-infection: the myxoma-Trichostrongylus retortaeformis case in wild rabbits. J. R. Soc. Interface 2007, 4, 831-840. [CrossRef] [PubMed]

35. Lowen, A.C.; Mubarka, S.; Steel, J.; Palese, P. Influenza Virus Transmission Is Dependent on Relative Humidity and Temperature. PLoS Pathog. 2007, 3, e151. [CrossRef] [PubMed] 
36. Wilber, M.Q.; Weinstein, S.B.; Briggs, C.J. Detecting and quantifying parasite-induced host mortality from intensity data: method comparisons and limitations. Int. J. Parasitol. 2016, 46, 59-66. [CrossRef] [PubMed]

37. Gog, J.R.; Pellis, L.; Wood, J.L.N.; McLean, A.R.; Arinaminpathy, N.; Lloyd-Smith, J.O. Seven challenges in modeling pathogen dynamics within-host and across scales. Epidemics 2014, 10, 45-48. [CrossRef]

38. Metcalf, C.J.; Graham, A.L.; Martinez-Bakker, M.; Childs, D.Z. Opportunities and challenges of Integral Projection Models for modelling host-parasite dynamics. J. Anim. Ecol. 2016, 85, 343-355. [CrossRef] [PubMed]

(C) 2019 by the authors. Licensee MDPI, Basel, Switzerland. This article is an open access article distributed under the terms and conditions of the Creative Commons Attribution (CC BY) license (http://creativecommons.org/licenses/by/4.0/). 
Article

\title{
IIV-6 Inhibits NF-KB Responses in Drosophila
}

\author{
Cara West ${ }^{1}$, Florentina Rus ${ }^{1}$, Ying Chen ${ }^{2}$, Anni Kleino ${ }^{1}$, Monique Gangloff ${ }^{3}{ }^{(D)}$, \\ Don B. Gammon ${ }^{4}$ and Neal Silverman $1, *$ []
}

1 Division of Infectious Diseases and Immunology, Department of Medicine, University of Massachusetts Medical School, Worcester, MA 01605, USA; Cara.West@umassmed.edu (C.W.);

Florentina.Rus@umassmed.edu (F.R.); anni.kleino@aias.au.dk (A.K.)

2 RNA Therapeutics Institute, University of Massachusetts Medical School, Worcester, MA 01605, USA; cy4896@126.com

3 Department of Biochemistry, University of Cambridge, Cambridge CB2 1GA, UK; mg308@cam.ac.uk

4 Department of Microbiology, University of Texas Southwestern Medical Center, Dallas, TX T5390, USA; Don.Gammon@UTSouthwestern.edu

* Correspondence: neal.silverman@umassmed.edu

Received: 18 March 2019; Accepted: 28 April 2019; Published: 1 May 2019

check for updates

\begin{abstract}
The host immune response and virus-encoded immune evasion proteins pose constant, mutual selective pressure on each other. Virally encoded immune evasion proteins also indicate which host pathways must be inhibited to allow for viral replication. Here, we show that IIV-6 is capable of inhibiting the two Drosophila NF-kB signaling pathways, Imd and Toll. Antimicrobial peptide (AMP) gene induction downstream of either pathway is suppressed when cells infected with IIV-6 are also stimulated with Toll or Imd ligands. We find that cleavage of both Imd and Relish, as well as Relish nuclear translocation, three key points in Imd signal transduction, occur in IIV-6 infected cells, indicating that the mechanism of viral inhibition is farther downstream, at the level of Relish promoter binding or transcriptional activation. Additionally, flies co-infected with both IIV-6 and the Gram-negative bacterium, Erwinia carotovora carotovora, succumb to infection more rapidly than flies singly infected with either the virus or the bacterium. These findings demonstrate how pre-existing infections can have a dramatic and negative effect on secondary infections, and establish a Drosophila model to study confection susceptibility.
\end{abstract}

Keywords: viral immune evasion; immunomodulators; NF-kB; Imd; DNA virus; host-pathogen interactions; IIV-6

\section{Introduction}

The host immune system and the viruses that challenge it face constant, mutual, selective pressure for survival. This perpetual arms race, known as the Red Queen Hypothesis [1], has created a plethora of mechanisms that the cell uses to thwart viral replication, and also a plethora of novel immune evasion tactics that viruses use to evade the immune response, in some cases even stealing genes from their hosts to suit this purpose [2]. In order to evade the innate immune response, viruses-especially large DNA viruses - encode a variety of immune evasion proteins to facilitate their replication. For example, the model poxvirus Vaccinia encodes a variety NF- $\mathrm{kB}$ pathway inhibitors, and a recently identified invertebrate DNA virus, Kallithea virus, is able to inhibit Drosophila Toll signaling [3,4]. Invertebrate Iridescent Virus-6 (IIV-6) is a large DNA virus capable of infecting Drosophila [5,6], with an estimated 215 open reading frames (ORFs) [7]. The large genome of IIV-6 suggests it encodes for many evasion proteins in addition to the characterized suppressor of RNAi (340L) [8], and Inhibitor of Apoptosis Protein (IAP) (193R) [9,10]. The interplay between the virus and host, particularly which pathways the virus devotes its resources to inhibit, provides insight as to which defense mechanisms 
pose the most threat to viral replication. A virus devoting its resources to shutting down a particular host pathway indicates that this pathway has applied selective pressure against the virus.

Whether the Toll and Imd pathways play a role in antiviral defense has been a topic probed in several studies, often with mixed or conflicting results [11-14]. Of course, these two NF-kB signaling pathways are well-known for their roles in anti-bacterial and anti-fungal defense, through the regulation of antimicrobial peptides (AMPs) and other effectors [15-18]. While some studies have argued these two pathways also have some antiviral activities, the antiviral mechanisms have not been elucidated [2,12,19-21]. To address the question of the potential anti-DNA-viral role of the Toll and Imd pathways, we took the approach of using the virus to illuminate which pathways might be antiviral by examining whether IIV-6 inhibits the Toll and Imd pathways. We found that cells infected with IIV-6 have suppressed AMP production, while other immune genes (i.e., Turandots, c-Jun $\mathrm{N}$-terminal kinase (JNK) targets) remain induced, suggesting that this is not a global suppression of host transcription [22]. Surprisingly, the cleavage of both Imd and Relish, key signaling events in the Imd pathway [23,24], remain intact in IIV-6 infected cells. Relish nuclear translocation is also at least partly intact, indicating the blockage in Imd response likely occurs in the nucleus, at the level of promoter binding or transcriptional activation. The inhibition of NF- $\mathrm{kB}$ transcription factor activity may be more general, as the Toll pathway was also blocked by IIV-6 infection. Consistent with the inhibition of these critical antibacterial defense responses, flies infected with IIV-6 were hyper-susceptible to infection with the Gram-negative bacteria Erwinia carotovora carotovora (Ecc15), establishing a system for studying co-infection morbidity in the Drosophila model.

\section{Materials and Methods}

\subsection{RNA Isolation and $q R T-P C R$}

Total RNA from flies or S2* cells was extracted using TRIzol (Invitrogen, Waltham, MA, USA). Samples were then DNase treated (RQ1, Promega, Madison, WI, USA) and RNA re-extracted by phenol-chloroform. The cDNA was synthesized using iScript cDNA Synthesis kit (BioRad, Hercules CA, USA). Alternatively, the gDNAclear cDNA synthesis kit (BioRad) was used following TRIzol purification. The quantitative reverse transcriptase-polymerase chain reaction (qRT-PCR) was analyzed by normalizing to the housekeeping gene $R p 49$.

\subsection{The $n$ Counter Analysis}

The expression levels of 102 Drosophila immune genes (Supplemental Tables S1 and S2) were assayed from 100 nanograms of RNA via a customized Nanostring nCounter codeset. Two biological replicates of S2* cells were analyzed for each treatment and timepoint. The results were analyzed using nSolver 4.0 software according to the manufacturer's instructions (NanoString Technologies, Seattle, WA, USA), and the heatmap was created using nSolver 4.0 software and JavaTree. Shown are the AMPs, p38, JNK, and JAK-STAT targets with counts above background. Figure 3 analyzes data previously presented in West et al. [22].

\subsection{Fly Stocks and In Vivo Studies}

Three to five day old $w^{1118}$ flies, of approximately equal proportions male and female, maintained at $22{ }^{\circ} \mathrm{C}$, were used for all experiments. Flies were injected intrathoracically with $32.2 \mathrm{~nL}$ of virus $\left(1 \times 10^{4}\right.$ TCID50) or vehicle (PBS) using a Nanoject II (Drummond, Broomall, PA, USA). For survival assays, a minimum of fifty flies were used per treatment, per genotype, and the dead were counted daily. Kaplan-Meier curves are shown and significance was determined by Mantel-Cox log-rank using GraphPad Prism.

Erwinia carotovora carotovora 15, also known as Pectobacterium carotovora, was cultured overnight by shaking at 250 RPMs in LB broth, pelleted at $13,000 \times g$ for $10 \mathrm{~min}$ in a microfuge, washed in PBS, and re-pelleted. Infections were performed by dipping a microsurgery needle into the concentrated 
bacterial pellet, and pricking in the thorax. The IIV-6 injection site was identified using melanization, and bacterial pricking was performed on the opposite side of the thorax.

\subsection{Cell Culture}

S2* cells were cultured as previously described $[25,26]$ and were treated with $1 \mu \mathrm{M}$ 20-hydroxyecdysone, $(\mathrm{EcD})$ for $18 \mathrm{~h}$ followed by infection with IIV-6 at a multiplicity of infection (MOI) of 2 for $6 \mathrm{~h}$. Cells were then stimulated with $2 \mu \mathrm{g} / \mathrm{mL}$ PGN for $6 \mathrm{~h}$ to stimulate the Imd pathway, or stimulated with cleaved Spätzle for $18 \mathrm{~h}$ for Toll pathway stimulations, and were harvested for RNA isolation.

\subsection{Immunoblots}

S2* cells were cultured and treated as described above. For protein analysis, cells were then stimulated with $2 \mu \mathrm{g} / \mathrm{mL}$ PGN for $15 \mathrm{~min}$ to stimulate the Imd pathway, and harvested in lysis buffer consisting of $1 \%$ Triton X-100, $20 \mathrm{mM}$ Tris pH 7.5, $150 \mathrm{mM} \mathrm{NaCl}, 2 \mathrm{mM}$ EDTA, and 10\% glycerol, with $1 \mathrm{mM}$ DTT, $1 \mathrm{mM}$ Sodium Vandate, $20 \mathrm{mM} \beta$-glycerolphosphate, and protease inhibitors. Imd or c-Rel antibodies were used as previously described [24,27].

\subsection{Confocal Microscopy}

YFP-Relish over-expressing cells were kept in selection media with hygromycin $(200 \mu \mathrm{g} / \mathrm{mL})$, and cultured as previously described [28]. Cells were treated with EcD for $2 \mathrm{~h}$ before being infected with mCherry-IIV-6 at an MOI of 2 for $18 \mathrm{~h}$. Cells were then plated on Alcian Blue or ConA treated coverslips for $30 \mathrm{~min}$ and stimulated with PGN for $15 \mathrm{~min}$. Cells were fixed in $4 \%$ paraformaldehyde, and stained with anti-lamin Dm0 (Developmental Studies Hybridoma Bank, ADL84.12) and Hoechst 33342.

\subsection{Virus Preparation}

IIV-6 was provided by Luis Teixeira. IIV-6 was propagated and purified on DL-1 cells as previously described [5], with a final resuspension in PBS, and quantified on DL-1 cells by TCID50. Cells were infected at an MOI of 2 unless otherwise noted, while flies were injected with $1 \times 10^{4}$ TCID50, as detailed above.

The $\triangle$ TS-MCP-mCherry-IIV-6 (mCherry-IIV-6) was created by inserting mCherry under the control of the major capsid promoter into the thymidylate synthase locus, using homologous recombination [29]. The major capsid promoter sequence was designed based on the analysis of IIV-6 MCP regulatory sequences by Nalçacioğlu et al. [30]

\section{Results}

\subsection{AMP Production is Suppressed in the Presence of IIV-6}

Given the scarce and somewhat conflicting data on the antiviral effects of the Drosophila NF- $\mathrm{kB}$ pathways in response to viral infections [2,12,19-21], we tested whether IIV-6 inhibits the Imd or Toll pathways. S2* cells were differentiated with $1 \mu \mathrm{M}$ 20-hydroxyecdysone (EcD) for $18 \mathrm{~h}$ followed by IIV-6 infection for $6 \mathrm{~h}$. Treatment with EcD is required to differentiate these cells and induce the expression of the receptor PGRP-LC, making these cells highly responsive to DAP-type peptidoglycan (PGN) stimulation [28]. After $6 \mathrm{~h}$ of IIV-6 infection, cells were then stimulated with $2 \mu \mathrm{g} / \mathrm{mL}$ of PGN for an additional $6 \mathrm{~h}$, and gene expression analyzed by qRT-PCR. IIV-6 infection reduced transcriptional induction of the Imd-dependent AMP gene Diptericin to near background levels (Figure 1A). 
A Diptericin

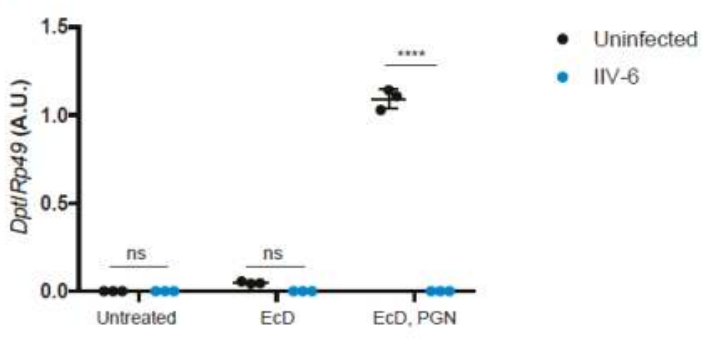

B Drosomycin

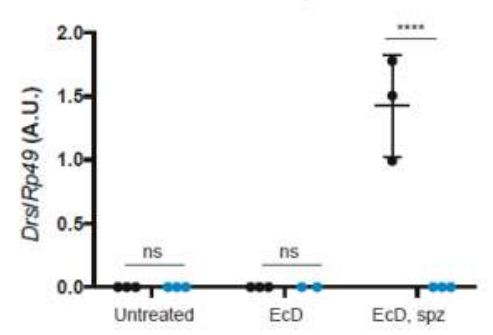

Figure 1. IIV-6 inhibits Imd and Toll Signaling. (A) S2* cells were treated with 20-hydroxyecdysone $(\mathrm{EcD})$ as indicated for 18 hours and then infected with IIV-6 (blue circles) or uninfected (black circles) for six hours. Cells were then stimulated with DAP-type PGN for six hours, where indicated. Diptericin $(D p t)$ levels were monitored by qRT-PCR. (B) S2* cells were treated with 20-hydroxyecdysone (EcD) as indicated for $18 \mathrm{~h}$ and then infected with IIV-6 (blue circles) or uninfected (black circles) for six hours. Cells were then stimulated with cleaved Spätzle (spz) for $18 \mathrm{~h}$, where indicated. Drosomycin (Drs) levels were monitored by qRT-PCR. (A,B) Black bars indicate mean and error bars indicate standard deviation. Statistics were determined using two-way ANOVA and Sidak's multiple comparisons test; ns, not significant; ${ }^{* * * *}, p<0.0001$.

To determine if IIV-6 more generally blocks NF- $\mathrm{kB}$ signaling, we similarly analyzed Toll signaling. S2* cells were cultured in a similar manner, treated with $\mathrm{EcD}$ for $18 \mathrm{~h}$, which upregulates expression of the Toll receptor [28], infected with IIV-6 for $6 \mathrm{~h}$, and then stimulated with the Toll ligand, cleaved Spätzle, for $18 \mathrm{~h}$. Induction of the Toll target gene Drosomycin was strongly inhibited by IIV-6 infection, as analyzed by qRT-PCR (Figure 1B). To examine both of these NF- $\mathrm{kB}$ pathways more broadly, we utilized NanoString nCounter Analysis, with a custom designed codeset probing over 100 immune-related genes, including most known AMP genes. All of the antimicrobial peptides were down-regulated in IIV-6 infected samples when the Imd pathway was stimulated with PGN (Figure 2A, Supplemental Table S1) or Toll pathway stimulated with cleaved Späztzle (Figure 2B, Supplemental Table S2), compared to the mock-infected controls stimulated with Imd or Toll ligands. Notably, other groups of genes were induced by virus infection, including the JNK targets puckered and punch, and the p38-dependent genes upd3 and Ddc [22,31]. The antiviral gene Ars2 was also induced by IIV-6 [32]. Since JNK signaling can be initiated through TAK1, the fact that JNK targets are being transcribed suggests that Imd signaling is being initiated, and signaling successfully occurs through at least TAK1 [33]. The induction of these genes by IIV-6 argues that the virus is not simply shutting down all host transcription, but is specifically targeting the two NF- $\mathrm{kB}$ signaling pathways, Imd and Toll. Additionally, we saw no suppression of GAPDH1 levels (Supplemental Figure S1). 
A

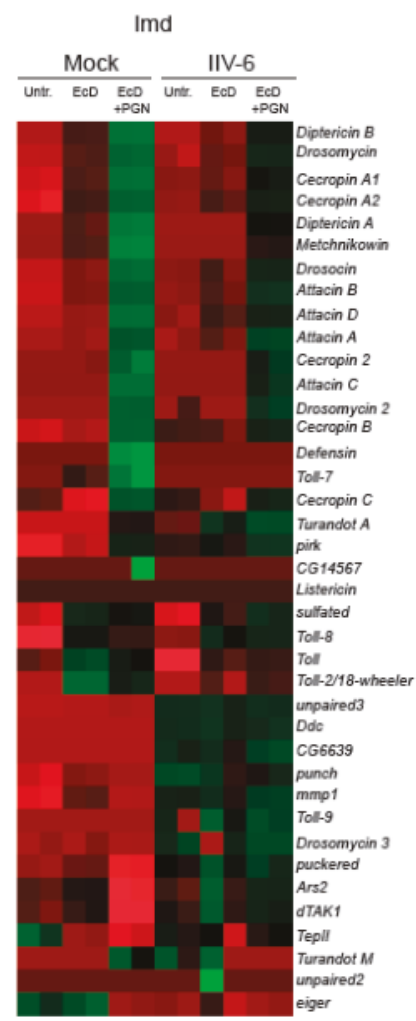

B

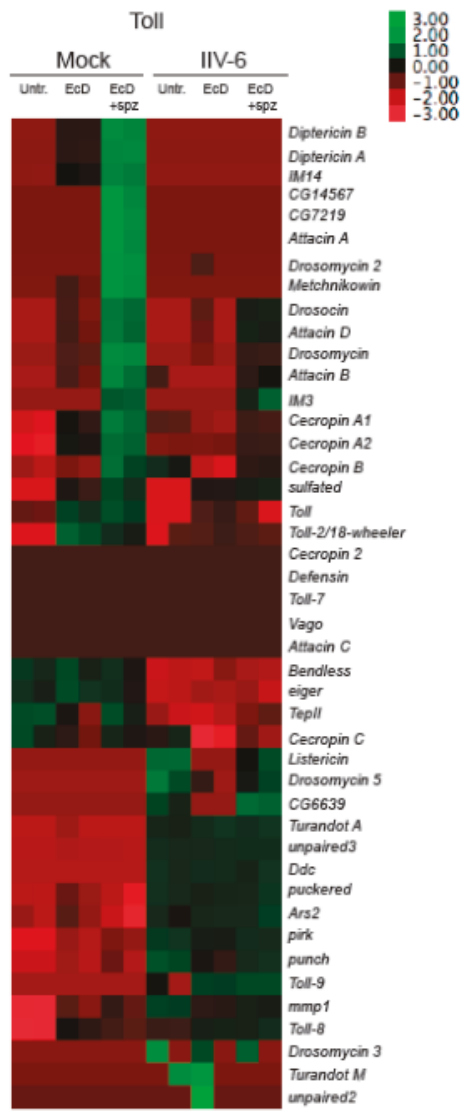

Figure 2. Both Imd and Toll regulated AMPs are suppressed by IIV-6 infection. S2* cells were treated with 20-hydroxyecdysone (EcD) for $18 \mathrm{~h}$, and then infected with IIV-6 for $6 \mathrm{~h}$. (A) Cells were stimulated with peptidoglycan (PGN) for $6 \mathrm{~h}$ prior to RNA isolation. (B) S2* cells were then stimulated with cleaved Spätzle (spz) for $18 \mathrm{~h}$ prior to RNA isolation, and then analyzed by Nanostring nCounter. Heatmaps display $Z$ scores of mRNA levels of immune genes in the presence or absence of virus and pathway stimulation clustered by expression pattern. Biologically independent duplicates are shown. Untr., untreated cells. EcD, cells treated with 20-hydroxyecdysone. EcD + PGN, cells treated with 20-hydroxyecdysone and peptidoglycan. EcD + spz, cells treated with 20-hydroxyecdysone and Spätzle.

IIV-6 inhibition of both NF-kB pathways suggests that these pathways may function to limit viral replication. To examine this possibility, we analyzed an earlier Nanostring dataset from adult flies infected with IIV-6, or injected with a similar volume of PBS, to determine if virus infection induces any of the AMP genes [22]. Indeed, IIV-6 modestly induced AMP gene expression two-fold over PBS-injected controls 12 hours post-infection (Figure 3A, $\mathrm{A}^{\prime}$ ). However, by $24 \mathrm{~h}$, this induction has returned to, or in some instances below, baseline levels. These findings are consistent with an early AMP response, possibly through NF- $\mathrm{kB}$ signaling pathways, which is quickly extinguished by viral inhibitors. 

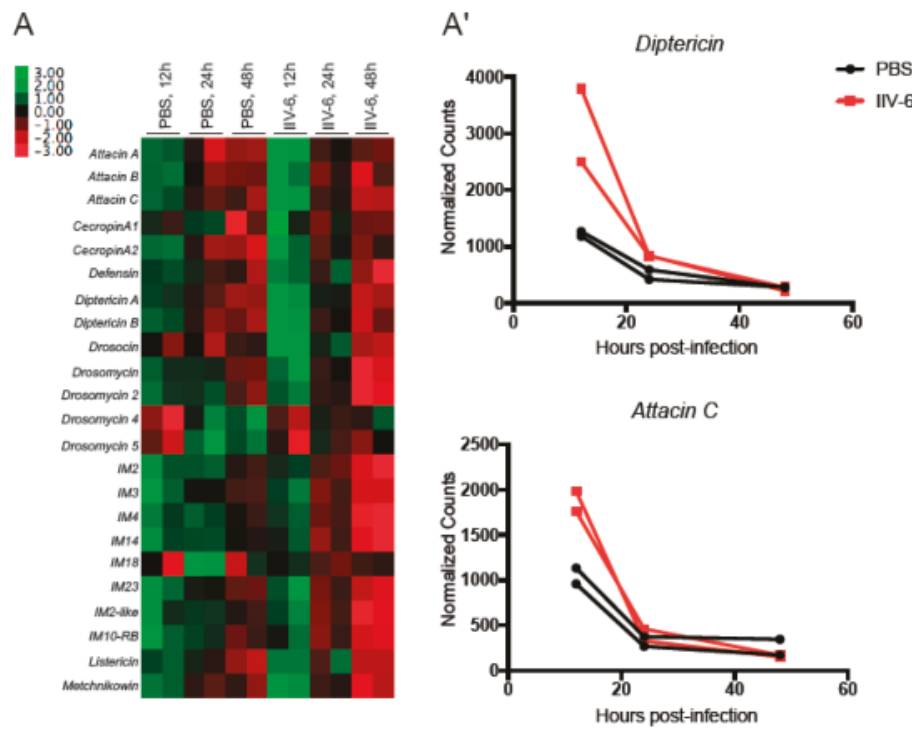

Figure 3. Some AMPs are elevated in vivo upon IIV-6 infection, before returning to baseline. (A) Heatmap of Z score transformed mRNA levels for AMP genes following IIV-6 infection of adult male $w^{1118}$ flies for the indicated timepoints, assayed by Nanostring nCounter. RNA was isolated from PBS-injected flies at the same time points as a control. Biologically independent samples were analyzed in duplicate. (A') Detailed comparison of mRNA levels for selected Imd-regulated AMP genes following IIV-6 infection of adult $w^{1118}$ flies for 12, 24, and $48 \mathrm{~h}$ assayed by Nanostring nCounter.

\subsection{NF-кB Inhibition is Downstream of Imd and Relish}

Next, we focused on the Imd pathway to tease apart the mechanism of NF-kB inhibition by IIV-6. As Imd signaling requires cleavage of Imd by the caspase 8-like Dredd [24,34], we probed for cleaved Imd in IIV-6 infected or uninfected cell lysates. We found robust cleavage of Imd upon PGN stimulation in both the presence and absence of IIV-6, indicating that the blockage of Imd signaling is likely to occur downstream of Imd cleavage (Figure 4A). To probe further downstream, we examined Relish cleavage, another critical event in Imd signaling, utilizing a C-terminal Relish antibody. As expected, samples mock treated or infected with IIV-6 alone show a prominent $110 \mathrm{kD}$ band indicating full-length Relish, and control samples treated with EcD and PGN show complete processing of full-length Relish. Likewise, upon PGN stimulation, Relish was fully cleaved in the presence of IIV-6, even at a relatively high MOI (Figure 4B, lanes 4-6). These results indicate the inhibition of Imd signaling by IIV-6 occurs downstream of Relish cleavage, the key event in the activation of this NF- $\mathrm{kB}$ precursor.

Since Relish is cleaved in the presence of IIV-6, we next sought to determine whether IIV-6 inhibits Imd signaling through blocking Relish nuclear translocation. To this end, we utilized a YFP-Relish over-expressing cell line, and a strain of IIV-6 expressing mCherry under the control of the major capsid protein (MCP). Even with these tools, scoring Relish nuclear translocation after virus infection presented several technical challenges. In particular, viral infected cells adhered poorly to treated coverslips and displayed reduced YFP-Relish signal. However, the levels of endogenous Relish protein are not altered by IIV-6 infection (Figure 4B). Additionally, IIV-6 undergoes massive DNA viral replication in the cytoplasmic viral factories, making it difficult to distinguish the nucleus. In order to identify the nucleus, cells were stained with both Hoechst 33342 and the nuclear envelope marker Lamin to accurately discern the nucleus from the cytosolic viral factory. In control conditions, cells stimulated with PGN showed 35\% nuclear translocation, while Relish remained cytoplasmic in $20 \%$ of cells (Figure 5A, lower left panel, Figure 5B). The remaining $44 \%$ of cells contained a YFP signal in both 
the cytoplasm and nucleus or had a YFP signal too weak to determine localization. In IIV-6 infected cells, we found that approximately $17 \%$ showed nuclear translocation, with $33 \%$ remaining cytoplasmic, while nearly $50 \%$ displayed both cytoplasmic and nuclear Relish or had a YFP signal too weak to determine localization (Figure 5A lower right panel, Figure 5B). While IIV-6 reduces the detected level of PGN-induced Relish nuclear translocation compared to uninfected PGN-stimulated cells, this difference was not significant, suggesting PGN can still trigger some Relish nuclear translocation in virus infected cells. Interestingly, virus infection alone caused some Relish translocation (Figure 5A upper right panel, Figure 5B). These data suggest that IIV-6 does not completely inhibit Relish nuclear translocation, and that viral suppression of Imd signaling likely occurs downstream, either at the level of Relish promoter binding or transcriptional activation.

A
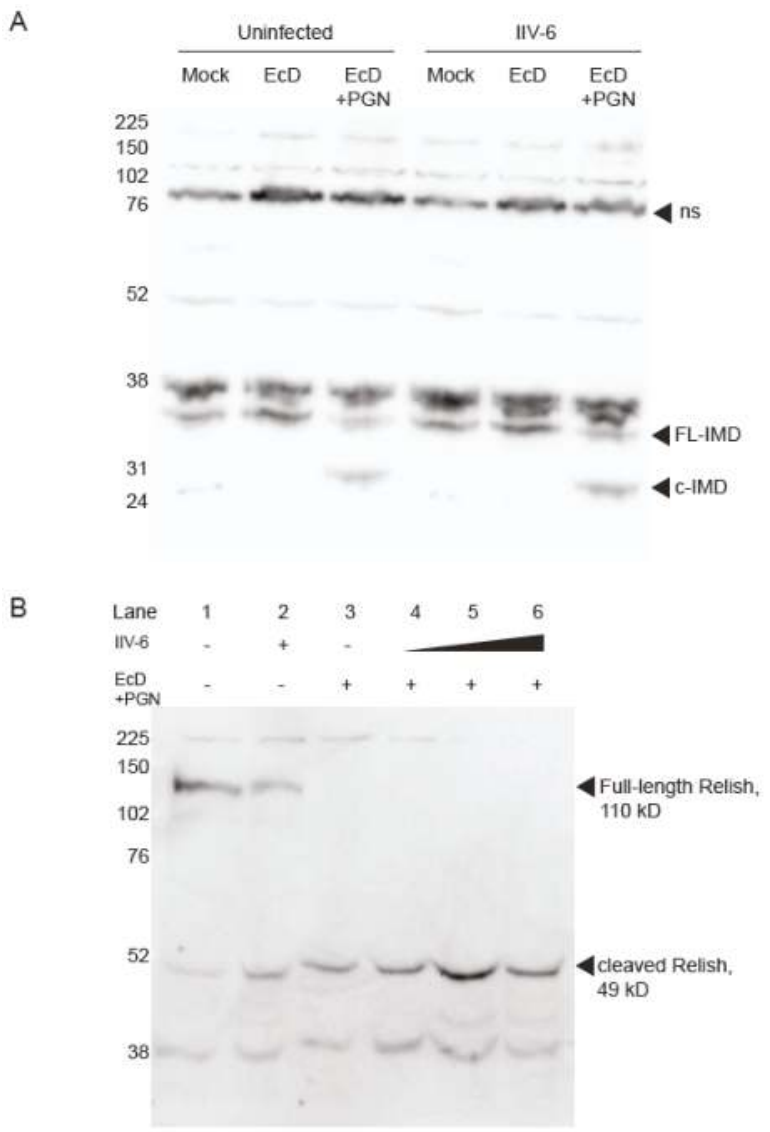

Figure 4. Imd signaling remains intact in the presence of IIV-6. (A) S2* cells were treated with 20-hydroxyecdysone $(\mathrm{EcD})$ for $18 \mathrm{~h}$. Cells were then infected with IIV-6, where indicated, for six hours. Samples were then stimulated with PGN for $15 \mathrm{~min}$, where indicated, and lysed in standard lysis buffer. Endogenous Imd was monitored by immunoblotting; arrows indicate cleaved (c-Imd) or full-length (FL-Imd) Imd; ns, non-specific. (B) Cells were treated with 20-hydroxyecdysone (EcD), where indicated, for $18 \mathrm{~h}$ and infected with IIV-6, as indicated, for six hours. Samples stimulated with EcD were then stimulated with PGN for $15 \mathrm{~min}$, and lysed in standard lysis buffer. Endogenous Relish was probed by immunoblotting using a C-terminal Relish antibody. MOI used was as follows. Lane 2: MOI =2; Lane 4: $\mathrm{MOI}=0.2 ;$ Lane 5: $\mathrm{MOI}=2 ;$ Lane 6: $\mathrm{MOI}=5$. 
A
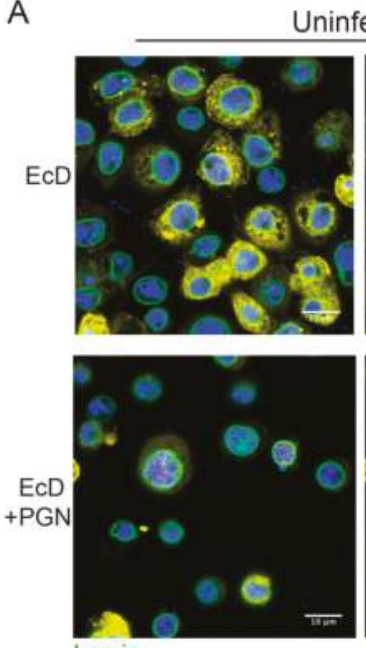

Lamin

YFP-Relish

Hoechst
Uninfected
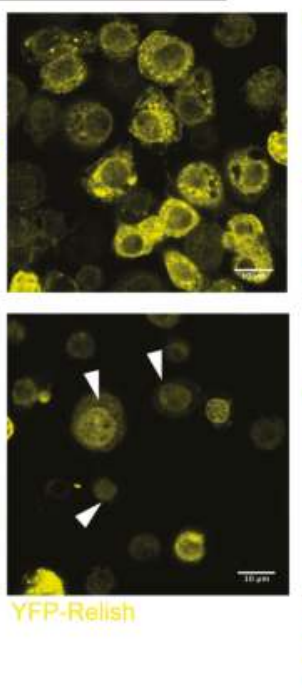

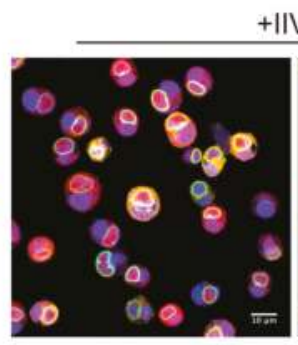

+IIV-6
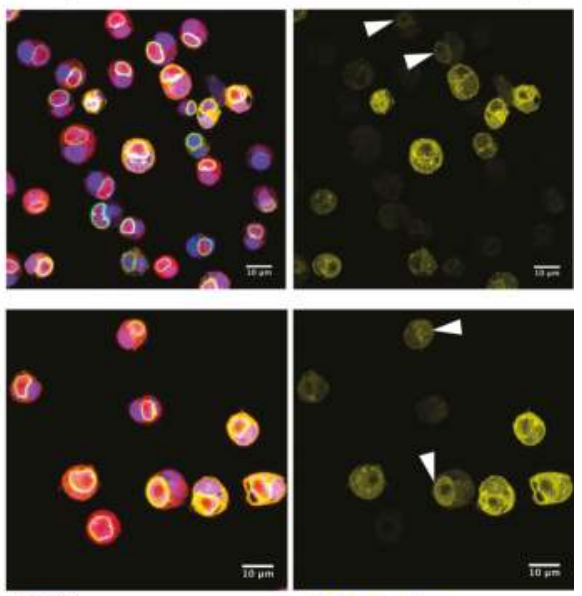

Lamin

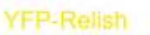

mCherry-IIV-6

Hoechst

\section{B}

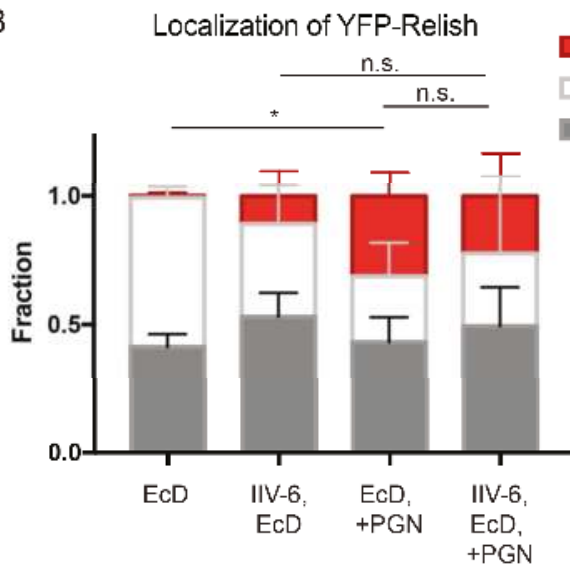

\section{Nuclear}

Cytoplasmic

Indeterminant

Figure 5. Nuclear localization of Relish remains intact in the presence of IIV-6. (A) S2* cells stably expressing YFP-Relish were treated with 20-hydroxyecdysone $(\mathrm{EcD})$ for $2 \mathrm{~h}$ and then infected with mCherry-IIV-6 (right) or left uninfected (left) for $18 \mathrm{~h}$. Cells were then stimulated with DAP-type PGN for 15 min (lower panels), prior to fixation and staining with anti-Lamin (shown in green) and Hoechst 33342 (shown in blue). Representative images from four biologically independent experiments are shown. Arrowheads mark cells with nuclear localized Relish. Left panels display the overlay of YFP-Relish, Hoeschst, Lamin, and mCherry-IIV-6 where applicable, while the right panels exhibit the YFP-Relish alone. Scale bars are $10 \mu \mathrm{m}$. (B) Quantification of Relish nuclear translocation. Between 400-1800 cells were scored for each condition as displaying Relish localization in the nucleus, in the cytoplasm, or as indeterminate when staining was diffuse throughout both compartments or the signal was too weak to discern. Statistics were determined using two-way ANOVA and Tukey's multiple comparisons test; ${ }^{*}, p<0.05 ; \mathrm{ns}$, not significant. Error bars represent standard deviation. 


\subsection{Inhibition of NF- $\kappa B$ Signaling is Mediated by an Immediate Early Gene}

Most-but not all-immune evasion proteins are immediate early genes. Strategically, it is probably most effective, from the virus perspective, to shut down the host defense as quickly as possible and rapidly achieve high levels of replication. In order to determine if IIV6 inhibition of Drosophila NF-KB signaling also involves an early gene product, cells were treated with the viral polymerase inhibitor cidofovir, or infected with heat- or UV-inactivated virus, and then stimulated with PGN to probe Imd signaling. PGN-triggered Diptericin induction was blocked with all three virus-inactivating treatments (Figure 6), indicating that the IIV6-mediated NF-KB inhibition was the result of immediate early genes, or possibly associated with a factor directly delivered with the virion.
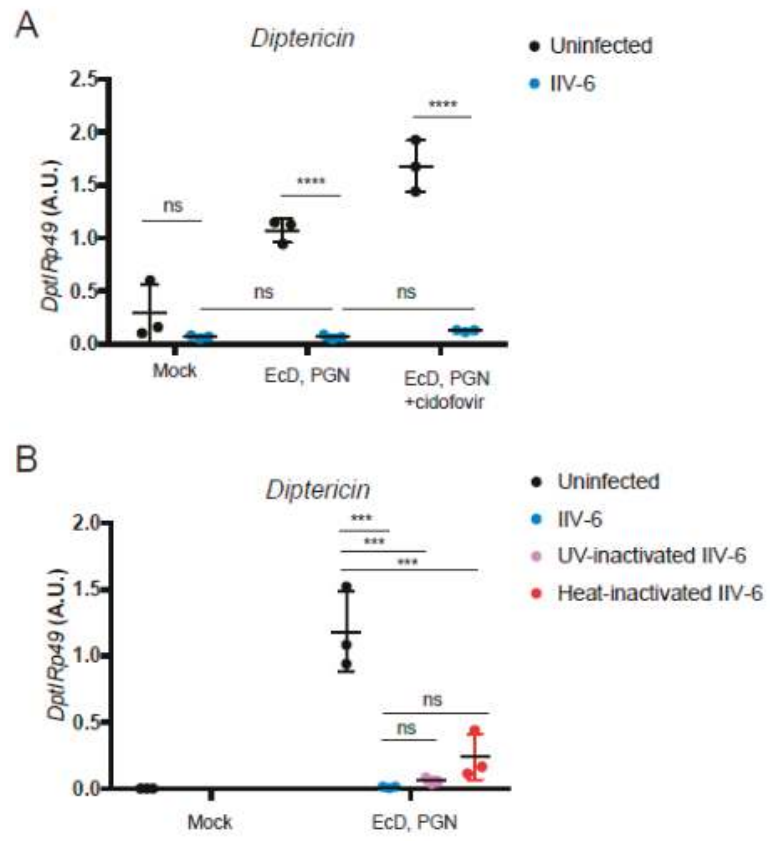

Figure 6. Viral replication is not needed for NF-kB inhibition. (A,B) S2* cells were treated with 20-hydroxyecdysone $(\mathrm{EcD})$ as indicated for $18 \mathrm{~h}$ and then infected with IIV-6 (blue circles) or uninfected (black circles) for six hours. Cells were then stimulated with DAP-type PGN for six hours, where indicated. Diptericin levels were monitored by qRT-PCR. (A) Cells were treated with cidofovir, a viral polymerase inhibitor, where indicated. Mock cells untreated with EcD, PGN, or cidofovir are shown as a control. Each data point is a biologically independent replicate; $n=3$. Error bars represent standard deviation. Statistics were determined using two-way ANOVA and Sidak's multiple comparisons test; ns, not significant; ${ }^{* * * *}, p<0.0001$. (B) S2* cells were infected with IIV-6 (blue circles), or treated with UV- (purple circles) or heat- (red circles) inactivated IIV-6. Uninfected controls are shown in black. Each data point is a biologically independent replicate; $n=3$. Error bars represent standard deviation. Statistics were determined using one-way ANOVA and Tukey's multiple comparisons test; ns, not significant; ${ }^{* *}, p<0.001$.

\subsection{Flies Infected with IIV-6 are more Susceptible to Bacterial Infection}

Together, these results indicate that infection with IIV-6 results in the global suppression of NF- $\mathrm{KB}$ signaling in flies-a major component of the innate immune response to bacterial and fungal infections in flies and mammals. Consistent with our in vitro data showing universally suppressed AMPs, we found that flies infected with IIV-6 also had suppression of NF-KB signaling, as indicated by lower 
mRNA levels of the AMP genes Diptericin and Drosomycin compared to PBS-injected or unmanipulated flies at day 8 post-infection (Figure 7A, Supplemental Figure S2). This suggests that flies infected with IIV-6 should be highly susceptible to other microbial infections. To test this hypothesis, we infected Drosophila adults with IIV-6 for seven days. On day eight post-IIV-6 infection, we pricked one group with a sterile needle, and the other group of flies with a needle dipped in Erwinia carotovora carotovora (Ecc15), a Gram-negative pathogen with limited lethality in healthy, immunocompetent flies. Seven days after this secondary bacterial infection, 50\% of the flies infected with both IIV-6 and Ecc15 had succumbed to infection, with nearly $100 \%$ lethality by day 20 (Figure 7B). In contrast, flies that had been mock-injected with PBS prior to Ecc15 infection had a median survival time of twenty-three days post-secondary (bacterial) infection. The animals injected with IIV-6 followed by a clean prick reached $50 \%$ lethality only at day 18, typical of the IIV-6 survival curve [22]. Together, these data show that an underlying IIV-6 infection can have a dramatic effect on a secondary bacterial infection, causing flies to be far more susceptible to Ecc15 infection than unaffected animals. Given the critical role of the Imd pathway in defending against Ecc15 infection, these results are consistent with the inhibition of Imd signaling observed in IIV-6 infected S2* cells and adult flies.
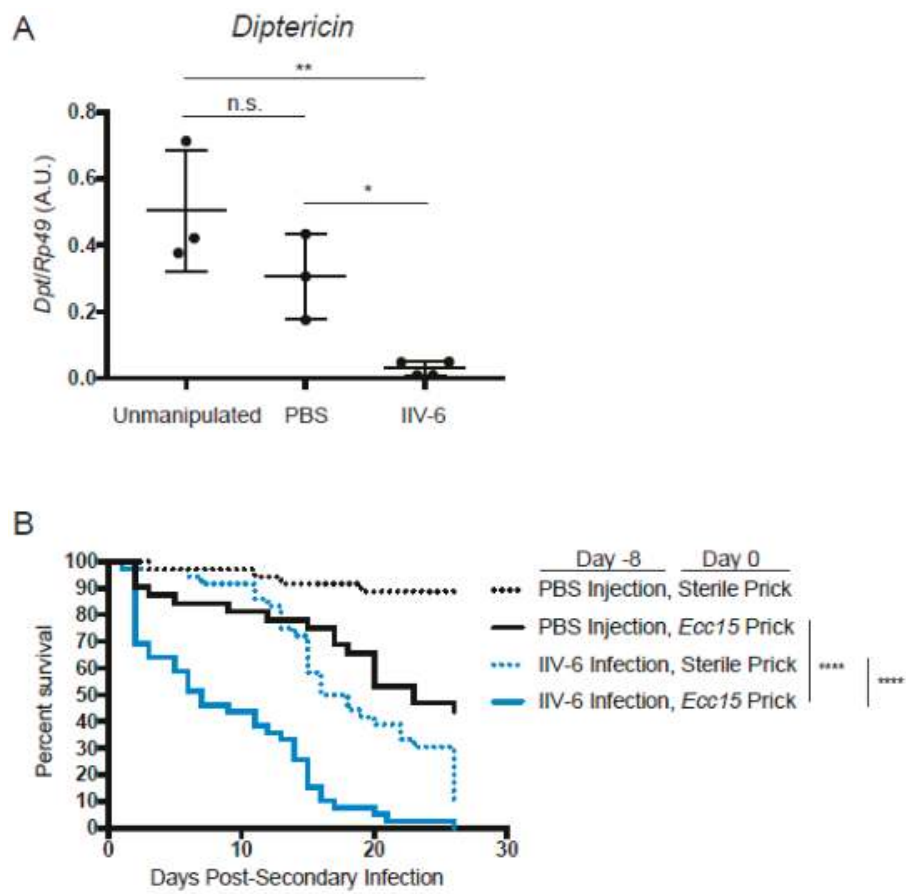

Figure 7. Flies infected with IIV-6 have lower AMP levels. (A) Adult $w^{1118}$ flies were infected with IIV-6, injected with PBS, or left unmanipulated for 7 days, and then snap frozen for RNA isolation. Dpt levels were assayed by qRT-PCR. Black bars indicate mean and error bars indicate standard deviation. Statistics were determined using one-way ANOVA and Tukey's multiple comparisons test; ns, not significant; ${ }^{*}, p=0.0463 ;{ }^{* *}, p=0.0033$. (B) Kaplan-Meier plots of adult $w^{1118}$ flies infected with IIV-6 (blue lines) or PBS-injected (black lines) for 8 days prior to bacterial infection. On day 0, flies were pricked with Ecc15 (solid lines) or were sterile pricked (dashed lines) with a microsurgery needle. Flies were counted daily for survivors. Statistics were determined using log-rank test; ${ }^{* * * *}, p<0.0001$. 


\section{Discussion}

Here, we show that IIV-6 infection interferes with the antimicrobial peptide response mediated through the Toll and Imd NF- $\mathrm{BB}$ pathways. In addition, we find that flies infected with IIV-6 succumb to an otherwise mildly pathogenic bacterial infection in vivo. Together, our data show that an underlying infection with this DNA virus can dampen the immune response and dramatically alter the outcome of a secondary bacterial infection, turning an otherwise innocuous infection into a lethal one.

While it appears that IIV-6 is suppressing the AMP response by actively inhibiting the NF- $\mathrm{kB}$ pathways, the mechanisms of inhibition remain unclear. It is possible that IIV-6 encodes an NF- $\mathrm{KB}$ inhibitor that prevents Relish binding to $\mathrm{kB}$ sites or recruitment of polymerase machinery. Several examples of viral-encoded NF- $\mathrm{kB}$ inhibitory proteins acting within the nucleus have been reported. NF- $\mathrm{kB}$ inhibitors functioning within the nucleus are encoded by vaccinia virus (VACV) [35], as well as African swine fever virus A238L [36]. VACV also encodes an inhibitor of Type 1 IFN, C6, that functions post-STAT1 and 2 nuclear translocation and DNA binding by binding the STAT2 transactivation domain [37]. Another VACV protein, N2 inhibits IRF3 within the nucleus [38]. Future studies will be aimed at examining the effect of IIV-6 on Relish binding at AMP gene $\mathrm{kB}$ sites, as well as the transcriptional activation process.

The timing of suppression also needs to be examined more closely. While our in vivo or in vitro data may suggest a difference in the suppressive effects of IIV-6, it is important to note that a more detailed in vivo time course is required. If there is a true shift in suppression, we hypothesize that this may be due to the fact that the in vitro infections occur at an MOI of 2, and we can more easily synchronize the timing of infection. In vivo, it may be that virus takes longer to diffuse through the hemolymph and replicate, resulting in a difference in response.

It should be noted that IIV-6 does not encode a homolog of Diedel, the putative Imd inhibitor, as other large insect DNA viruses do [2]. Given the role of RHIM-dependent amyloid fibrils in the Imd pathway [39], we also considered that IIV-6 might encode RHIM-inhibitor, similar to Murine cytomegalovirus M45 [40], but found no evidence for such a factor in the IIV-6 genome.

Future studies will be required to determine which viral gene(s) are responsible for NF- $\mathrm{kB}$ inhibition. Our work shows that Imd signaling is inhibited at a step downstream of Relish activation. However, the mechanisms of Toll inhibition have not been investigated yet. IIV-6 may encode more than one NF- $\kappa$ B inhibitor, targeting the Imd and Toll pathways at different points. Since other large DNA viruses, such as VACV, encode multiple inhibitors targeting NF- $\mathrm{kB}$ pathways at various points in mammalian NF- $\mathrm{kB}$ signaling pathways [3], elimination of single viral genes may not reveal any phenotype due to redundancies. Determining which viral genes are responsible for NF-kB inhibition will require both loss and gain of function approaches and will be the subject of future studies.

IIV-6 has a broad host range, infecting a large variety of insects with agricultural and economic importance. The slow replication cycle of this virus results in infected insects surviving for weeks, allowing it to spread amongst a population, and consequently, leaving that population with an increased susceptibility to a secondary bacterial infection that would otherwise be cleared. Given the current decline of honey bees, as well as the entire insect population [41], a persistent viral infection could further damage this already precarious population by increasing susceptibility to a range of other microbial pathogens. While previous studies have ruled out IIV-6 as the causative agent of colony collapse disorder [42], it should be noted that IIV-6 infection may expose other species to increased vulnerability to a secondary infection.

In summary, we have shown that IIV-6 infection results in an inability to mount an NF- $\mathrm{B}$ mediated AMP response upon stimulation of either the Imd or Toll pathways. It appears that IIV-6 infection may briefly induce AMP expression before shutting it down. Suppression of Imd signaling occurs downstream of Relish activation, suggesting a viral inhibitor may act at the level of DNA binding and transcriptional activation. Nanostring data showing that IIV-6 induces transcription of JNK targets suggest that the Imd pathway is being successfully activated through at least the branch point of TAK1 [25]. These results are consistent with the data showing that Relish cleavage and some nuclear 
translocation remain intact and argue that the virally generated block occurs far downstream in this pathway. Strikingly, flies infected with IIV-6 subjected to subsequent infection with Ecc15 died more rapidly than flies singly infected with virus or bacteria, indicating that this virus-mediated block in NF- $\mathrm{KB}$ signaling may have a profound effect on resistance to bacterial infections.

The involvement of the Drosophila NF- $\mathrm{kB}$ pathways in antiviral signaling is a controversial topic. Other studies have suggested an antiviral role for AMPs, examining a recombinant analog of the RNA virus Sindbis virus [21]. Whether or not some AMPs are also potent against DNA viruses, such as IIV-6, will be the focus of future studies, for example by examining the replication of mCherry -expressing virus or by quantifying viral loads from infected flies over-expressing AMPs. It is also possible that AMP induction is simply a by-product of Relish activation, similar to many ISGs that have no direct protective role against the pathogen eliciting their expression. In this case, other Relish target genes may be important for antiviral defense. Additionally, with some picrorna-like viruses, such as Drosophila C virus and Cricket Paralysis virus, some- but not all-Imd pathway components seem to be restrictive $[12,13]$. Identifying a viral-encoded Imd inhibitor would provide more evidence supporting that this pathway induces antiviral activities. However, how Imd signaling is initiated upon virus infection, when the established agonist for this pathway is bacterial peptidoglycan [43,44], and whether all Imd signaling components are necessary, need to be examined in greater detail. For example, as the key receptors in this pathway, PGRP-LC and PGRP-LE, directly bind to DAP-type PGN, it seems unlikely that they will be involved in viral recognition. Antiviral studies implicating Imd signaling should be reevaluated in light of recent work showing that the microbiome plays an important role activating Imd signaling in the gut to prime an antiviral response via ERK following an oral infection route [45]. Whether commensals can act to influence antiviral responses in other organ systems requires further exploration. For example, the Malpighian tubules are organs branching off from the Drosophila gut, which absorb waste from the hemolymph, but have also been shown to serve important roles in immune function, including induction and secretion of AMPs in response to infection [43,46-48]. Whether the Malpighian tubules provide crosstalk between the gut and hemolymph during viral infections should be explored.

Supplementary Materials: The following are available online at http://www.mdpi.com/1999-4915/11/5/409/s1, Figure S1: GAPDH1 levels are not suppressed by IIV-6 infection, Figure S2: Drosomycin is also suppressed by IIV-6 infection in vivo; Table S1: Levels of immune related genes upon PGN treatment in the presence of IIV-6, Table S2: Levels of immune related genes upon PGN treatment in the presence of c-Spz.

Author Contributions: Conceptualization, C.W., D.B.G., and N.S.; formal analysis, C.W.; funding acquisition, N.S.; investigation, C.W., F.R., Y.C., and A.K.; methodology, C.W.; project administration, N.S.; resources, M.G. and D.B.G.; supervision, D.B.G. and N.S.; visualization, C.W.; writing - original draft, C.W.; writing - review and editing, C.W. and N.S.

Funding: This works was supported by NIH grants to AI060025 and AI131695 to NS, and Wellcome Trust (WT100321/z/12/Z) and the Medical Research Council (MR/P02260X/1) grants to MG.

Acknowledgments: The authors thank Luis Texeira for the IIV-6 strain, Deniz Ertürk-Hasdemir for generating the YFP-Relish cell lines, and Niamh Hallinan and Kendi Okuda for technical assistance.

Conflicts of Interest: The authors declare no conflict of interest

\section{References}

1. Valen, L.V. A new evolutionary law. Evol. Theory 1973, 1, 1-30.

2. Lamiable, O.; Kellenberger, C.; Kemp, C.; Troxler, L.; Pelte, N.; Boutros, M.; Marques, J.T.; Daeffler, L.; Hoffmann, J.A.; Roussel, A.; et al. Cytokine diedel and a viral homologue suppress the imd pathway in drosophila. Proc. Natl. Acad. Sci. USA 2016, 113, 698-703. [CrossRef]

3. Smith, G.L.; Benfield, C.T.; Maluquer de Motes, C.; Mazzon, M.; Ember, S.W.; Ferguson, B.J.; Sumner, R.P. Vaccinia virus immune evasion: Mechanisms, virulence and immunogenicity. J. Gen. Virol. 2013, 94, 2367-2392. [CrossRef]

4. Palmer, W.H.; Joosten, J.; Overheul, G.J.; Jansen, P.W.; Vermeulen, M.; Obbard, D.J.; van Rij, R.P. Induction and suppression of nf-kappab signalling by a DNA virus of drosophila. J. Virol. 2019, 93. [CrossRef] 
5. Teixeira, L.; Ferreira, Á.; Ashburner, M. The bacterial symbiont wolbachia induces resistance to rna viral infections in drosophila melanogaster. PLoS Biol. 2008, 6, e1000002. [CrossRef]

6. Bronkhorst, A.W.; Van Cleef, K.W.R.; Vodovar, N.; Ince, I.A.; Blanc, H.; Vlak, J.M.; Saleh, M.-C.; van Rij, R.P. The DNA virus invertebrate iridescent virus 6 is a target of the drosophila rnai machinery. Proc. Natl. Acad. Sci. USA 2012, 109, E3604-E3613. [CrossRef]

7. Ince, I.A.; Boeren, S.A.; van Oers, M.M.; Vervoort, J.J.M.; Vlak, J.M. Proteomic analysis of chilo iridescent virus. Virology 2010, 405, 253-258. [CrossRef]

8. Bronkhorst, A.W.; Van Cleef, K.W.R.; Venselaar, H.; Van Rij, R.P. A dsrna-binding protein of a complex invertebrate DNA virus suppresses the drosophila rnai response. Nucleic Acids Res. 2014, 42, 12237-12248. [CrossRef]

9. Chitnis, N.S.; D'Costa, S.M.; Paul, E.R.; Bilimoria, S.L. Modulation of iridovirus-induced apoptosis by endocytosis, early expression, jnk, and apical caspase. Virology 2008, 370, 333-342. [CrossRef]

10. Chitnis, N.S.; Paul, E.R.; Lawrence, P.K.; Henderson, C.W.; Ganapathy, S.; Taylor, P.V.; Virdi, K.S.; D'Costa, S.M.; May, A.R.; Bilimoria, S.L. A virion-associated protein kinase induces apoptosis. J. Virol. 2011, 85, 13144-13152. [CrossRef]

11. Avadhanula, V.; Weasner, B.P.; Hardy, G.G.; Kumar, J.P.; Hardy, R.W. A novel system for the launch of alphavirus rna synthesis reveals a role for the imd pathway in arthropod antiviral response. PLoS Pathog. 2009, 5, e1000582. [CrossRef]

12. Costa, A.; Jan, E.; Sarnow, P.; Schneider, D. The imd pathway is involved in antiviral immune responses in drosophila. PLoS ONE 2009, 4, e7436. [CrossRef]

13. Goto, A.; Okado, K.; Martins, N.; Cai, H.; Barbier, V.; Lamiable, O.; Troxler, L.; Santiago, E.; Kuhn, L.; Paik, D.; et al. The kinase ikkbeta regulates a sting- and nf-kappab-dependent antiviral response pathway in drosophila. Immunity 2018, 49, 225-234 e224. [CrossRef]

14. Liu, Y.; Gordesky-Gold, B.; Leney-Greene, M.; Weinbren, N.L.; Tudor, M.; Cherry, S. Inflammation-induced, sting-dependent autophagy restricts zika virus infection in the drosophila brain. Cell Host Microbe 2018, 24, 57-68 e53. [CrossRef]

15. Lemaitre, B.; Hoffmann, J. The host defense of drosophila melanogaster. Annu. Rev. Immunol. 2007, 25, 697-743. [CrossRef]

16. Clemmons, A.W.; Lindsay, S.A.; Wasserman, S.A. An effector peptide family required for drosophila toll-mediated immunity. PLoS Pathog. 2015, 11, e1004876. [CrossRef]

17. Lindsay, S.A.; Lin, S.J.H.; Wasserman, S.A. Short-form bomanins mediate humoral immunity in drosophila. J. Innate Immun. 2018, 10, 306-314. [CrossRef]

18. Hanson, M.A.; Dostalova, A.; Ceroni, C.; Poidevin, M.; Kondo, S.; Lemaitre, B. Synergy and remarkable specificity of antimicrobial peptides in vivo using a systematic knockout approach. Elife 2019, 8. [CrossRef]

19. Zambon, R.A.; Nandakumar, M.; Vakharia, V.N.; Wu, L.P. The toll pathway is important for an antiviral response in drosophila. Proc. Natl. Acad. Sci. USA 2005, 102, 7257-7262. [CrossRef]

20. Tsai, C.W.; McGraw, E.A.; Ammar, E.D.; Dietzgen, R.G.; Hogenhout, S.A. Drosophila melanogaster mounts a unique immune response to the rhabdovirus sigma virus. Appl. Environ. Microbiol. 2008, 74, 3251-3256. [CrossRef]

21. Huang, Z.; Kingsolver, M.B.; Avadhanula, V.; Hardy, R.W. An antiviral role for antimicrobial peptides during the arthropod response to alphavirus replication. J. Virol. 2013, 87, 4272-4280. [CrossRef]

22. West, C.; Silverman, N. P38b and jak-stat signaling protect against invertebrate iridescent virus 6 infection in drosophila. PLoS Pathog. 2018, 14, e1007020. [CrossRef]

23. Stoven, S.; Silverman, N.; Junell, A.; Hedengren-Olcott, M.; Erturk, D.; Engstrom, Y.; Maniatis, T.; Hultmark, D. Caspase-mediated processing of the drosophila nf-kappab factor relish. Proc. Natl. Acad. Sci. USA 2003, 100, 5991-5996. [CrossRef]

24. Paquette, N.; Broemer, M.; Aggarwal,K.; Chen, L.; Husson, M.; Ertürk-Hasdemir, D.; Reichhart, J.-M.; Meier, P.; Silverman, N. Caspase-mediated cleavage, iap binding, and ubiquitination: Linking three mechanisms crucial for drosophila nf-kappab signaling. Mol. Cell 2010, 37, 172-182. [CrossRef]

25. Samakovlis, C.; Åsling, B.; Boman, H.G.; Gateff, E.; Hultmark, D. In vitro induction of cecropin genes-an immune response in a drosophila blood cell line. Biochem. Biophys. Res. Commun. 1992, 188, 1169-1175. [CrossRef] 
26. Silverman, N.; Zhou, R.; Stoven, S.; Pandey, N.; Hultmark, D.; Maniatis, T. A drosophila ikappab kinase complex required for relish cleavage and antibacterial immunity. Genes Dev. 2000, 14, 2461-2471. [CrossRef]

27. Ertürk-Hasdemir, D.; Broemer, M.; Leulier, F.; Lane, W.S.; Paquette, N.; Hwang, D.; Kim, C.-H.; Stöven, S.; Meier, P.; Silverman, N. Two roles for the drosophila ikk complex in the activation of relish and the induction of antimicrobial peptide genes. Proc. Natl. Acad.Sci. USA 2009, 106, 9779-9784. [CrossRef] [PubMed]

28. Rus, F.; Flatt, T.; Tong, M.; Aggarwal, K.; Okuda, K.; Kleino, A.; Yates, E.; Tatar, M.; Silverman, N. Ecdysone triggered pgrp-lc expression controls drosophila innate immunity. EMBO J. 2013, 32, 1626-1638. [CrossRef]

29. Ozgen, A.; Muratoglu, H.; Demirbağ, Z.; Vlak, J.M.; van Oers, M.M.; Nalçacioğlu, R. Construction and characterization of a recombinant invertebrate iridovirus. Virus Res. 2014. [CrossRef]

30. Nalçacioğlu, R.; Marks, H.; Vlak, J.M.; Demirbağ, Z.; van Oers, M.M. Promoter analysis of the chilo iridescent virus DNA polymerase and major capsid protein genes. Virology 2003, 317, 321-329. [CrossRef]

31. Davis, M.M.; Primrose, D.A.; Hodgetts, R.B. A member of the p38 mitogen-activated protein kinase family is responsible for transcriptional induction of dopa decarboxylase in the epidermis of drosophila melanogaster during the innate immune response. Mol. Cell. Biol. 2008, 28, 4883-4895. [CrossRef]

32. Sabin, L.R.; Zhou, R.; Gruber, J.J.; Lukinova, N.; Bambina, S.; Berman, A.; Lau, C.-K.; Thompson, C.B.; Cherry, S. Ars2 regulates both mirna- and sirna- dependent silencing and suppresses rna virus infection in drosophila. Cell 2009, 138, 340-351. [CrossRef] [PubMed]

33. Silverman, N.; Zhou, R.; Erlich, R.L.; Hunter, M.; Bernstein, E.; Schneider, D.; Maniatis, T. Immune activation of nf-kappab and jnk requires drosophila tak1. J. Biol. Chem. 2003, 278, 48928-48934. [CrossRef]

34. Kim, C.H.; Paik, D.; Rus, F.; Silverman, N. The caspase-8 homolog dredd cleaves imd and relish but is not inhibited by p35. J. Biol. Chem. 2014, 289, 20092-20101. [CrossRef]

35. Sumner, R.P.; Maluquer de Motes, C.; Veyer, D.L.; Smith, G.L. Vaccinia virus inhibits nf- b-dependent gene expression downstream of p65 translocation. J. Virol. 2014, 88, 3092-3102. [CrossRef] [PubMed]

36. Revilla, Y.; Callejo, M.; Rodriguez, J.M.; Culebras, E.; Nogal, M.L.; Salas, M.L.; Vinuela, E.; Fresno, M. Inhibition of nuclear factor kappab activation by a virus-encoded ikappab-like protein. J. Biol. Chem. 1998, 273, 5405-5411. [CrossRef]

37. Stuart, J.H.; Sumner, R.P.; Lu, Y.; Snowden, J.S.; Smith, G.L. Vaccinia virus protein c6 inhibits type i ifn signalling in the nucleus and binds to the transactivation domain of stat2. PLoS Pathog. 2016, 12, e1005955. [CrossRef]

38. Ferguson, B.J.; Benfield, C.T.; Ren, H.; Lee, V.H.; Frazer, G.L.; Strnadova, P.; Sumner, R.P.; Smith, G.L. Vaccinia virus protein $\mathrm{n} 2$ is a nuclear irf3 inhibitor that promotes virulence. J. Gen. Virol. 2013, 94, 2070-2081. [CrossRef]

39. Kleino, A.; Ramia, N.F.; Bozkurt, G.; Shen, Y.; Nailwal, H.; Huang, J.; Napetschnig, J.; Gangloff, M.; Chan, F.K.; $\mathrm{Wu}, \mathrm{H}$; ; et al. Peptidoglycan-sensing receptors trigger the formation of functional amyloids of the adaptor protein imd to initiate drosophila nf-kappab signaling. Immunity 2017, 47, 635-647 e636. [CrossRef] [PubMed]

40. Upton, J.W.; Kaiser, W.J.; Mocarski, E.S. Cytomegalovirus m45 cell death suppression requires receptor-interacting protein (rip) homotypic interaction motif (rhim)-dependent interaction with rip1. J. Biol. Chem. 2008, 283, 16966-16970. [CrossRef]

41. Hallmann, C.A.; Sorg, M.; Jongejans, E.; Siepel, H.; Hofland, N.; Schwan, H.; Stenmans, W.; Muller, A.; Sumser, H.; Horren, T.; et al. More than 75 percent decline over 27 years in total flying insect biomass in protected areas. PLoS ONE 2017, 12, e0185809. [CrossRef]

42. Tokarz, R.; Firth, C.; Street, C.; Cox-Foster, D.L.; Lipkin, W.I. Lack of evidence for an association between iridovirus and colony collapse disorder. PLoS ONE 2011, 6, e21844. [CrossRef]

43. Kaneko, T.; Goldman, W.E.; Mellroth, P.; Steiner, H.; Fukase, K.; Kusumoto, S.; Harley, W.; Fox, A.; Golenbock, D.; Silverman, N. Monomeric and polymeric gram-negative peptidoglycan but not purified lps stimulate the drosophila imd pathway. Immunity 2004, 20, 637-649. [CrossRef]

44. Kaneko, T.; Yano, T.; Aggarwal, K.; Lim, J.-H.; Ueda, K.; Oshima, Y.; Peach, C.; Erturk-Hasdemir, D.; Goldman, W.E.; Oh, B.-H.; et al. Pgrp-lc and pgrp-le have essential yet distinct functions in the drosophila immune response to monomeric dap-type peptidoglycan. Nat. Immunol. 2006, 7, 715-723. [CrossRef]

45. Sansone, C.L.; Cohen, J.; Yasunaga, A.; Xu, J.; Osborn, G.; Subramanian, H.; Gold, B.; Buchon, N.; Cherry, S. Microbiota-dependent priming of antiviral intestinal immunity in drosophila. Cell Host Microbe 2015, 18, 571-581. [CrossRef] 
46. McGettigan, J.; McLennan, R.K.; Broderick, K.E.; Kean, L.; Allan, A.K.; Cabrero, P.; Regulski, M.R.; Pollock, V.P.; Gould, G.W.; Davies, S.A.; et al. Insect renal tubules constitute a cell-autonomous immune system that protects the organism against bacterial infection. Insect Biochem. Mol. Biol. 2005, 35, 741-754. [CrossRef]

47. Verma, P.; Tapadia, M.G. Immune response and anti-microbial peptides expression in malpighian tubules of drosophila melanogaster is under developmental regulation. PLOS ONE 2012, 7, e40714. [CrossRef]

48. Paik, D.; Monahan, A.; Caffrey, D.R.; Elling, R.; Goldman, W.E.; Silverman, N. Slc46 family transporters facilitate cytosolic innate immune recognition of monomeric peptidoglycans. J. Immunol. 2017, 199, 263-270. [CrossRef]

(C) 2019 by the authors. Licensee MDPI, Basel, Switzerland. This article is an open access article distributed under the terms and conditions of the Creative Commons Attribution (CC BY) license (http://creativecommons.org/licenses/by/4.0/). 
Article

\title{
Interaction between Two Iridovirus Core Proteins and Their Effects on Ranavirus (RGV) Replication in Cells from Different Species
}

\author{
Xiao-Tao Zeng ${ }^{1}$ and Qi-Ya Zhang ${ }^{1,2, *}$ \\ 1 State Key Laboratory of Freshwater Ecology and Biotechnology, Institute of Hydrobiology, Wuhan 430072, \\ China; zengxt@ihb.ac.cn \\ 2 The Innovation Academy of Seed Design, Chinese Academy of Sciences, Beijing 100101, China \\ * Correspondence: zhangqy@ihb.ac.cn; Tel.: +86-027-68780792
}

Received: 1 March 2019; Accepted: 30 April 2019; Published: 4 May 2019

\begin{abstract}
The two putative proteins RGV-63R and RGV-91R encoded by Rana grylio virus (RGV) are DNA polymerase and proliferating cell nuclear antigen (PCNA) respectively, and are core proteins of iridoviruses. Here, the interaction between RGV-63R and RGV-91R was detected by a yeast two-hybrid $(\mathrm{Y} 2 \mathrm{H})$ assay and further confirmed by co-immunoprecipitation (co-IP) assays. Subsequently, RGV-63R or RGV-91R were expressed alone or co-expressed in two kinds of aquatic animal cells including amphibian Chinese giant salamander thymus cells (GSTCs) and fish Epithelioma papulosum cyprinid cells (EPCs) to investigate their localizations and effects on RGV genome replication. The results showed that their localizations in the two kinds of cells are consistent. RGV-63R localized in the cytoplasm, while RGV-91R localized in the nucleus. However, when co-expressed, RGV-63R localized in both the cytoplasm and the nucleus, and colocalized with RGV-91R in the nucleus. 91R $\triangle \mathrm{NLS}$ represents the RGV-91R deleting nuclear localization signal, which is localized in the cytoplasm and colocalized with RGV-63R in the cytoplasm. qPCR analysis revealed that sole expression and co-expression of the two proteins in the cells of two species significantly promoted RGV genome replication, while varying degrees of viral genome replication levels may be linked to the cell types. This study provides novel molecular evidence for ranavirus cross-species infection and replication.
\end{abstract}

Keywords: Rana grylio virus (RGV); iridovirus core proteins; protein interaction; aquatic animals; cross-species transmission; yeast two-hybrid (Y2H); co-immunoprecipitation (Co-IP)

\section{Introduction}

A large number of aquatic viruses regulate population dynamics and community interactions in aquatic ecosystems [1]. They are also involved in aquatic animal diseases. As pathogens, aquatic animal viruses often infect shellfishes, fishes, amphibians, reptiles and aquatic mammals [2-5]. Ranaviruses (Rana grylio virus, RGV) are members of the family Iridoviridae that are large, double-stranded DNA viruses and infect ectothermic vertebrates [6]. Importantly, ranaviruses are capable of crossing species barriers of numerous ectothermic vertebrates and can spread between different species [7-9]. Recent reports have revealed more about the molecular mechanism of aquatic viral disease, including ranaviral disease [10]. Science and technology have been applied to a wide range of studies on aquatic viruses [11]. Different approaches, such as co-immunoprecipitation (co-IP) assays [12], fluorescence microscopy, and yeast two hybrid ( $\mathrm{Y} 2 \mathrm{H})$, have been widely used in the investigation of protein-protein relationships or interactions [13]. Recently, the $\mathrm{Y} 2 \mathrm{H}$ assay was used to analyze protein-protein interactions among the structural proteins of Chilo iridescent virus, a member of genus Iridovirus [14].

DNA polymerases play multiple roles [15]. Its main function is DNA replication and is capable of catalyzing DNA synthesis [16]. DNA polymerases of some large DNA viruses, such as herpesvirus 
and vaccinia virus, play a crucial role in virus genome replication $[17,18]$. Iridoviral DNA polymerases (RGV-63R and its homologous proteins) are believed to be essential components for virus DNA replication $[19,20]$. RGV-91R and its homologous proteins are considered proliferating cell nuclear antigens (PCNAs). This kind of protein is also found in humans as a cofactor of DNA polymerase, which can increase the processivity of DNA strand synthesis during replication [21]. In eukaryotes, PCNA as a sliding clamp protein forms a ring-shaped homo-trimer that encircles double-stranded DNA. It can confer high processivity with respect to replicative DNA polymerase. Moreover, it forms a mobile platform on DNA that recruits many of the proteins involved in DNA replication, repair, and recombination. For example, PCNA interacts with DNA polymerase $\delta$, a member of family B [22,23]. There are 26 core proteins shared in Iridoviridae [24], including RGV-63R, RGV-91R, and some other proteins related to transcription, replication, and nucleotide metabolism. Several RGV encoded proteins involved in gene transcription, viral infection, and assembly have been identified previously [25-28].

However, the ranavirus protein-protein interactions and their effects on virus replication in cross-species transmission remain unaddressed. The goal of this study was to investigate the interactions between ranavirus core proteins, and their effects on virus replication in both fish cells (Epithelioma papulosum cyprinid cells, EPCs) and amphibian cells (Chinese giant salamander thymus cells, GSTCs) through multiple technical approaches, such as Y2H, co-IP assays, fluorescence microscopy, Western blotting and qPCR. Y2H was used to test that the gene products can physically bind to each other, while a fluorescence experiment was used to test whether the gene products had similar co-localization in different host cells. Co-IP was performed to confirm the results from $\mathrm{Y} 2 \mathrm{H}$.

\section{Materials and Methods}

\subsection{Cell Lines and Virus}

Epithelioma papulosum cyprinid cells (EPCs) and Chinese giant salamander thymus cells (GSTCs) [29] were cultured in Medium 199 supplemented with $10 \%$ fetal bovine serum (FBS) at $25^{\circ} \mathrm{C}$. They were used for all work needing cells, except the co-immunoprecipitation (co-IP) assay. Rana grylio virus (RGV) was used in the study and the virus was repeatedly cultured on EPCs for long-term preservation. Human embryonic kidney (HEK293T) cells were grown at $37^{\circ} \mathrm{C}$ in $5 \%$ CO2 in Dulbecco's modified Eagle's medium (DMEM, gibco, Thermo Fisher Scientific, Waltham, MA, USA) supplemented with $10 \%$ FBS, and were only used for the co-immunoprecipitation (co-IP) assay.

\subsection{Plasmid Construction}

RGV propagation in EPC cell cultures, purification, and its genomic DNA preparation were performed as described previously [27]. Different kinds of nucleic-acid fragments were amplified with the corresponding primers (Table 1). The plasmids used for yeast two-hybrid ( $\mathrm{Y} 2 \mathrm{H})$, co-immunoprecipitation (co-IP), fluorescence microscopy and quantitative polymerase chain reaction (qPCR) were constructed. All constructs used in this study were confirmed by DNA sequencing. The operations are as follows: 


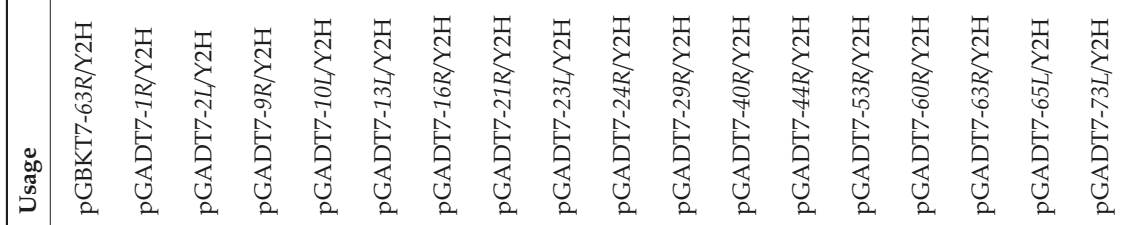

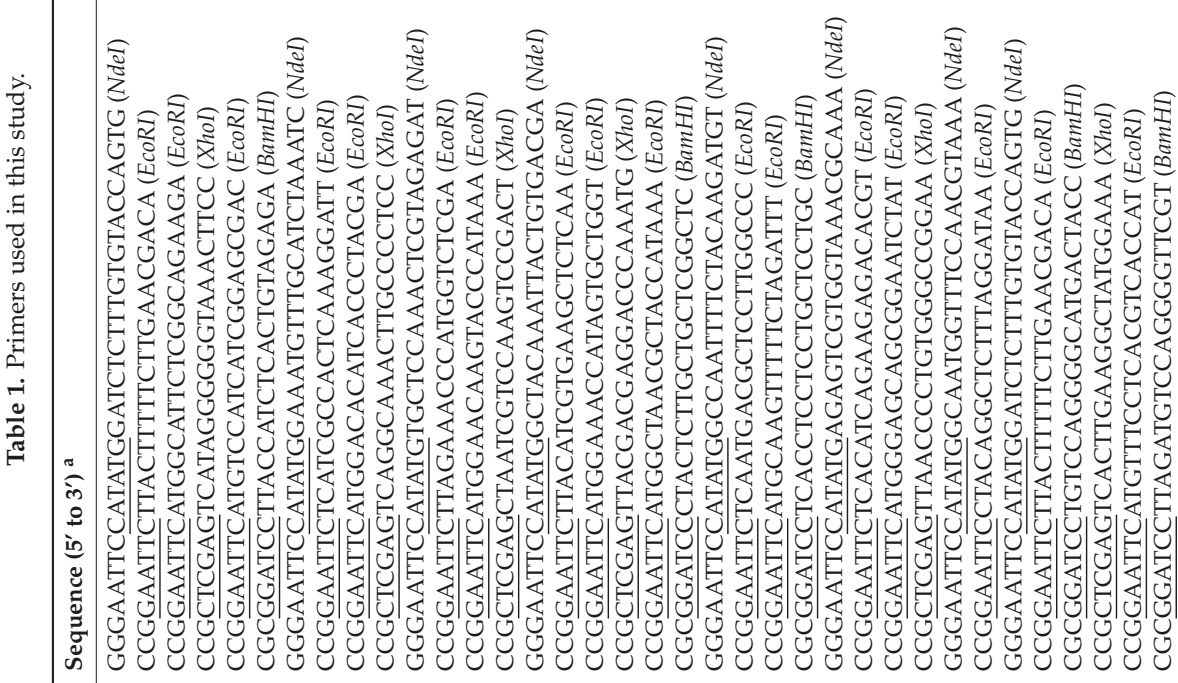

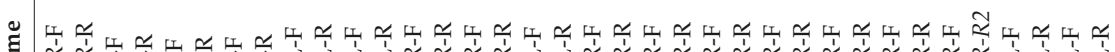

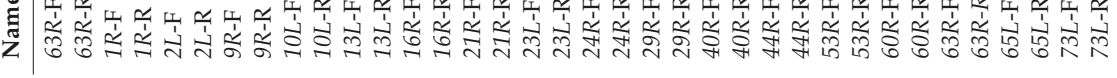




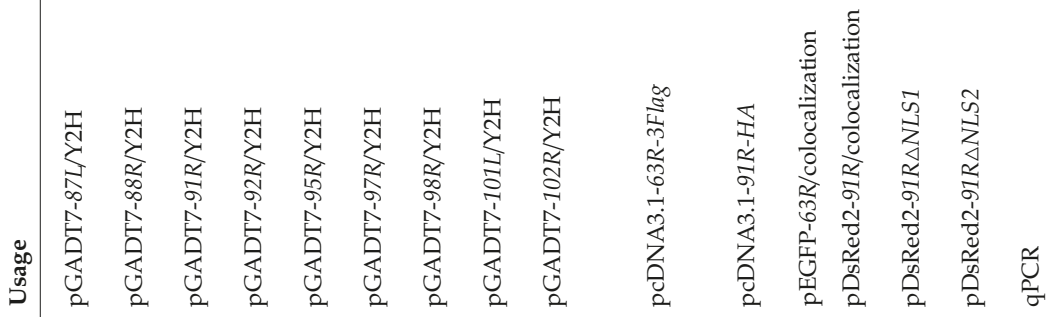

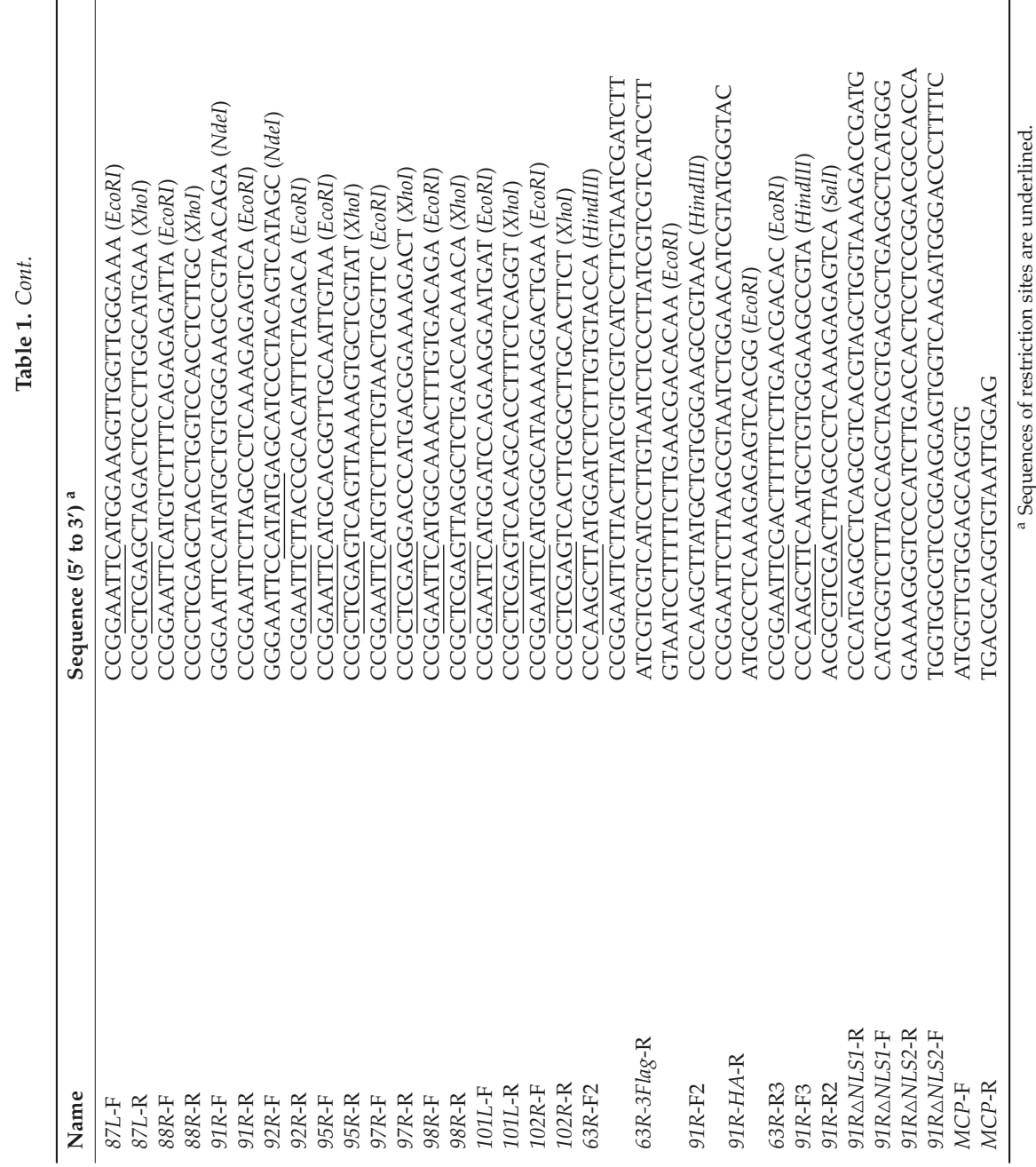


To construct the bait plasmid for screening the interacting protein of RGV-63R, the gene that encodes RGV-63R was amplified with primers $63 R-F / R$ and cloned into pGBKT7 to produce bait plasmid pGBKT7-63R. To construct the prey plasmids containing 26 RGV core genes (x represents the genes, such as $91 R, 97 R, 98 R$, and 102R), fragments were amplified from RGV genomic DNA and cloned into pGADT7 to obtain prey plasmids pGADT7-x.

To generate the plasmids for coimmunoprecipitation (co-IP) assays, $R G V-63 R$ was amplified with primers 63R-F2/63R-3Flag-R and cloned into pcDNA3.1(+) to construct pcDNA3.1-63R-3Flag. $R G V-91 R$ was amplified with primers $91 R-\mathrm{F} 2 / 91 R-H A-\mathrm{R}$ and cloned into pcDNA3.1(+) to construct pcDNA3.1-91R-HA.

To analyze the colocalization between RGV-63R and RGV-91R, the RGV-63R was amplified with primers $63 R-\mathrm{F} / 63 R-\mathrm{R} 3$ and cloned into pEGFP-N3 to construct pEGFP-63R. $R G V-91 R$ was amplified with primers $91 R-\mathrm{F} 3 / 91 R-\mathrm{R} 2$ and cloned into $\mathrm{pDsRed} 2-\mathrm{C} 1$ to produce $\mathrm{pDsRed2}-91 R$.

The RGV-91R (245aa) sequence and structure domains are as follows. Grey shades indicate nuclear localization signals (NLS1 and NLS2):

MLWEAVTDKPVKLKGLLELLLNNMDSARLVVTSQSVSVVDYQSNMAVTASMPSSVFTSYVYKSD AECLYAGLPHAALPDLKSFKAKCNVTLRLMGDPECGQYTMKIIIANASHMSTSINMVVDHGKKEA DRGHPEGAGKSFTLTQQEFNTLCKTFKQGPVNLGVFGGVLVASGGVDGIKVKEVAFGAPDCVTP HVKLCVHAEKMSRLVKMGPFSAGSLTVCVAQGSVTVSTRGHLGSLTVTLFEG.

To analyze the effect of the nuclear localization signal (NLS) on the subcellular location of RGV-91R, two DNA fragments $91 R-N 1$ and $91 R-C 1$ were amplified from RGV genomic DNA with primers $91 R-F 3 / 91 R \triangle N L S 1-R$ and $91 R \triangle N L S 1-F / 91 R-R 2$, respectively. The DNA fragment $91 R \triangle N L S 1$ was amplified via overlap PCR using $91 R-N 1$ and $91 R-C 1$ as templates and cloned into plasmid

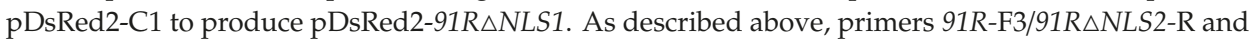
91R $\triangle N L S 2-F / 91 R-R 2$ were used to construct the plasmid pDsRed2-91R $\triangle N L S 2$.

The previously constructed plasmid pMD-MCP [30] was used for a standard curve of qPCR.

\subsection{Yeast Two Hybrid (Y2H) Assays}

The RGV-63R gene was cloned into bait vector pGBKT7 and expressed in the yeast Y2HGold strain and cultured on SD/-Trp plates. Twenty-six RGV core genes (x represents) including 91R, $97 R, 98 R$, and $102 R$, which were considered as iridovirus core genes, were cloned into prey vectors pGADT7 and expressed in the yeast Y187 strain, and cultured on SD/-Leu plates. However, no colony formed when yeast $Y 187$ was separately transformed with pGADT7-73L/95R/101L. The interactions between bait protein $\mathrm{pGBKT7-63R}$ and 23 prey proteins pGADT7- $x$ were then identified using the yeast two-hybrid (Y2H) system and were performed according to the Matchmaker Gold Yeast Two-Hybrid System User Manual (Clontech, Clontech Laboratories, Inc., Mountain View, CA, USA). Three parallel experiments were performed. Y2HGold/pGBKT7-63R and Y187/pGADT7-x were placed in 2×YPDA media and incubated at $30^{\circ} \mathrm{C}$ for $24 \mathrm{~h}$. The mating yeast cells were collected by centrifugation, and resuspended with $0.5 \times$ YPDA media, and they were then cultured on $2 \mathrm{Q}(\mathrm{SD} /$-Trp/-Leu) and 3Q/X (SD/-Trp/-Leu/-His/X- $\alpha$-Gal) plates for 6 days at $30^{\circ} \mathrm{C}$. As a positive control, yeast mating between Y187/pGADT7-T and Y2HGold/pGBKT7-P53 was carried out in the same way, since T interacts with P53. As a negative control, yeast mating between Y187/pGADT7-T and Y2HGold/pGBKT7-Lam was carried out in the same way, since $\mathrm{T}$ does not interact with Lam. Interactions take place if colonies form on both $2 \mathrm{Q}$ and $3 \mathrm{Q} / \mathrm{X}$ plates. As a positive control, many colonies formed on $2 \mathrm{Q}$ and $3 \mathrm{Q} / \mathrm{X}$ plates, and as a negative control, no colonies formed on $3 \mathrm{Q} / \mathrm{X}$.

\subsection{Co-IP Assays}

To further confirm interaction between RGV-63R and RGV-91R detected by Y2H, co-IP assays were performed. Briefly, HEK293T cells seeded in $10 \mathrm{~cm}$ dishes were cotransfected with $5 \mu \mathrm{g}$ of pcDNA3.1-91R-HA and $5 \mu \mathrm{g}$ of pcDNA3.1-63R-3Flag. As a control, $5 \mu \mathrm{g}$ of pcDNA3.1-91R-HA and 
$5 \mu \mathrm{g}$ of empty vector pcDNA3.1 were cotransfected in parallel. At $24 \mathrm{~h}$ post-transfection (hpt), cells were lysed with a radio immunoprecipitation assay (RIPA) buffer containing protease inhibitor cocktail (Roche), and cell lysates were incubated with Red Anti-HA Affinity Gel (Sigma, Sigma-Aldrich LLC., Santa Clara, CA, USA) overnight at $4{ }^{\circ} \mathrm{C}$. The precipitates were collected by centrifugation, washed with ice-cold phosphate-buffered saline (PBS) three times, eluted with $40 \mu \mathrm{L}$ of PBS, and finally subjected to Western blot analysis.

\subsection{Western Blot Analysis}

Western blot analysis was performed as described previously [30]. Protein samples were resolved by SDS-PAGE, followed by electroblotting to polyvinylidene difluoride (PVDF) membrane. The blots were probed with anti-HA mouse monoclonal antibody (1: 1000, Sigma, Sigma-Aldrich LLC., Santa Clara, CA, USA) or anti-Flag rabbit monoclonal antibody (1: 1000, Abbkine, Abbkine Scientific Co., Ltd. Wuhan, China). Peroxidase-conjugated goat anti-mouse or anti-rabbit $\operatorname{IgG}(\mathrm{H}+\mathrm{L})$ antibody was used as the secondary antibody. The signals were detected with a chemiluminescent horseradish peroxidase (HRP) substrate (Millipore, Millipore Corporation, Billerica, MA, USA).

\subsection{Fluorescence Microscopy}

Colocalization assays were performed to confirm the interaction between RGV-63R and RGV-91R. EPCs or GSTCs transfected with plasmid pEGFP-63R or pDsRed2-91R alone or cotransfected with both plasmids were fixed, permeabilized, stained with Hoechst 33342, and observed under a Leica DM IRB fluorescence microscope (objective 100×), as described previously [31].

\subsection{Quantitative Analysis of RGV Genomic DNA}

To investigate the effects of RGV-63R and RGV-91R on RGV replication in cells from different species, the DNA level of RGV in EPCs or GSTCs expressing one protein alone or coexpressing both proteins were measured by qPCR, respectively. A total of $2 \times 10^{5}$ EPCs or GSTCs grown in 24-well plates were transfected with $0.5 \mu \mathrm{g}$ of empty vector pcDNA3.1 or cotransfected with $0.25 \mu \mathrm{g}$ of pcDNA3.1-63R-3Flag and $0.25 \mu \mathrm{g}$ of pcDNA3.1, $0.25 \mu \mathrm{g}$ of pcDNA3.1-91R-HA and $0.25 \mu \mathrm{g}$ of pcDNA3.1, or $0.25 \mu \mathrm{g}$ of pcDNA3.1-63R-3Flag and $0.25 \mu \mathrm{g}$ of pcDNA3.1-91R-HA. The transfected cells at $24 \mathrm{hpt}$ were harvested and subjected to Western blot analysis. For qPCR, at $24 \mathrm{hpt}$, the transfected cells were infected with RGV with an MOI of 0.5 . The infected cells at $48 \mathrm{~h}$ post-infection (hpi) were harvested and washed with PBS three times. The viral genomic DNA was then extracted according to the instructions of TaKaRa MiniBEST Universal Genomic DNA Extraction Kit. Each DNA sample was dissolved in $100 \mu \mathrm{L}$ of elution buffer, and $1 \mu \mathrm{L}$ of each DNA sample was used for each qPCR reaction. Specific primers $M C P-\mathrm{F} / M C P-\mathrm{R}$ for RGV MCP gene was used for qPCR. qPCR was carried out using Fast SYBR Green Master Mix with the StepOneTM Real-Time PCR System (Applied Biosystems, Foster City, CA, USA), as described previously [32].

\section{Results}

\subsection{Interaction between $R G V-63 R$ and $R G V-91 R$ was First Screened by $Y 2 H$}

The interactions between RGV-63R and other 23 proteins from RGV were analyzed by yeast two hybrid. The results of detecting interactions between RGV-63R and 91R, 97R, 98R, or 102R are shown in Figure 1. Only RGV-91R showed interaction with RGV-63R. When the interaction between RGV-63R and RGV-91R was detected, colonies formed on SD/-Trp/-Leu (2Q) and SD/-Trp/-Leu/-His/X- $\alpha-G a l$ $(3 \mathrm{Q} / \mathrm{X})$ plates. When detecting the interactions between RGV-63R and 97R, 98R, or 102R, colonies formed on $2 \mathrm{Q}$ plates, but no colony formed on $3 \mathrm{Q} / \mathrm{X}$ plates. 


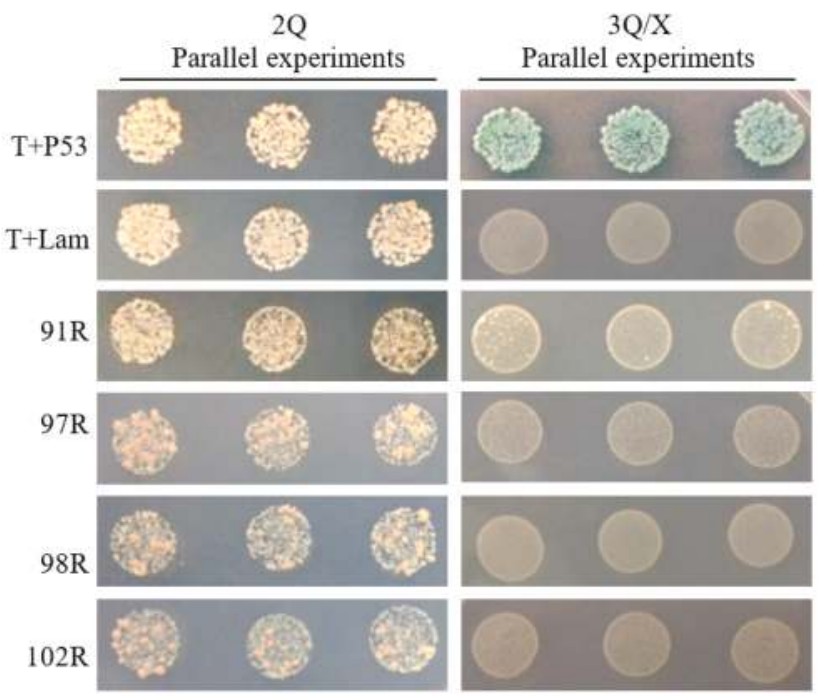

Figure 1. The formed yeast colonies during testing interactions between RGV-63R and four proteins by Y2H. Three parallel experiments were performed. 2Q: SD/-Trp/-Leu. 3Q/X: SD/-Trp/-Leu/-His/X- $\alpha$-Gal. 91R, 97R, 98R, and 102R: RGV proteins, which are encoded by iridovirus core genes, respectively. $\mathrm{T}+\mathrm{P} 53$ : the positive control; $\mathrm{T}+\mathrm{Lam}$ : the negative control.

\subsection{Confirmation of Interaction between RGV-63R and RGV-91R by Co-IP Followed by Western Blotting}

Co-IP assays were used to confirm the interaction between RGV-63R and RGV-91R. The proteins 63R-3Flag and 91R-HA were co-expressed and anti-HA antibody affinity gel was used to precipitate the protein complexes. The result of co-IP followed by western blotting is shown in Figure 2; 63R-3Flag and 91R-HA were detected in cell lysates and immunoprecipitated (IP) protein complexes from HEK293T cells cotransfected with pcDNA3.1-63R-3Flag and pcDNA3.1-91R-HA. However, only 91R-HA was detected in cell lysates and immunoprecipitated protein complexes from pcDNA3.1 and pcDNA3.1-91R-HA cotransfected cells. This further confirmed that RGV-63R interacts with RGV-91R.

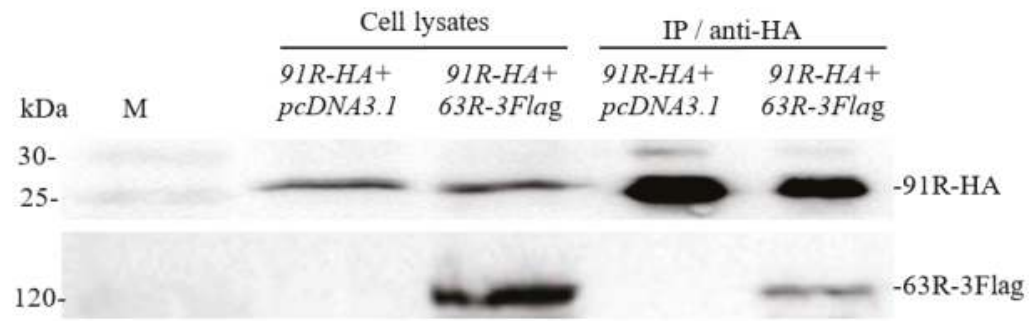

Figure 2. Western blot analysis for sample of testing interaction between RGV-63R and RGV-91R by co-IP. Cell lysates from HEK293T cells cotransfected with indicated plasmids (91R-HA+ pcDNA3.1, 91R-HA+63R-3Flag) and IP (immunoprecipitated) protein complexes with indicated plasmids (91R-HA+ pcDNA3.1, 91R-HA+63R-3Flag) are subjected to Western blot analysis using anti-HA and anti-Flag. Cells lysates and IP showed the bands of 91R-HA and 63R-3Flag. M: protein molecular mass marker.

\subsection{Localization of RGV-63R and RGV-91R in Cells of Different Species}

Fluorescence microscopy was carried out. The protein 63R-EGFP expressed alone localized in the cytoplasm of GSTCs or EPCs. The protein 91R-RFP expressed alone localized in the nucleus of GSTCs 
or EPCs. Obviously, the localizations of the same protein in GSTCs or EPCs from different species were consistent (Figure 3A).

When 63R-EGFP and 91R-RFP were co-expressed, they colocalized in the nucleus of GSTCs. They consistently expressed in EPCs, as shown in Figure 3B. These results not only further confirmed the interaction between RGV-63R and RGV-91R, which alters RGV-63R localization, but also exactly showed the same phenomenon that was observed in cells from two different species. These results indicate that the two proteins of RGV can play the same role in the cells of different species.

A

63R-EGFP in GSTCs

63R-EGFP in EPCs

91R-RFP in GSTCs

91R-RFP in EPCs

91R $\triangle N L S 1-R F P$ in EPCs
Fluorescence

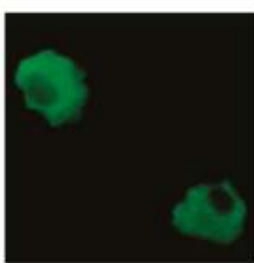

Hoechst 33342
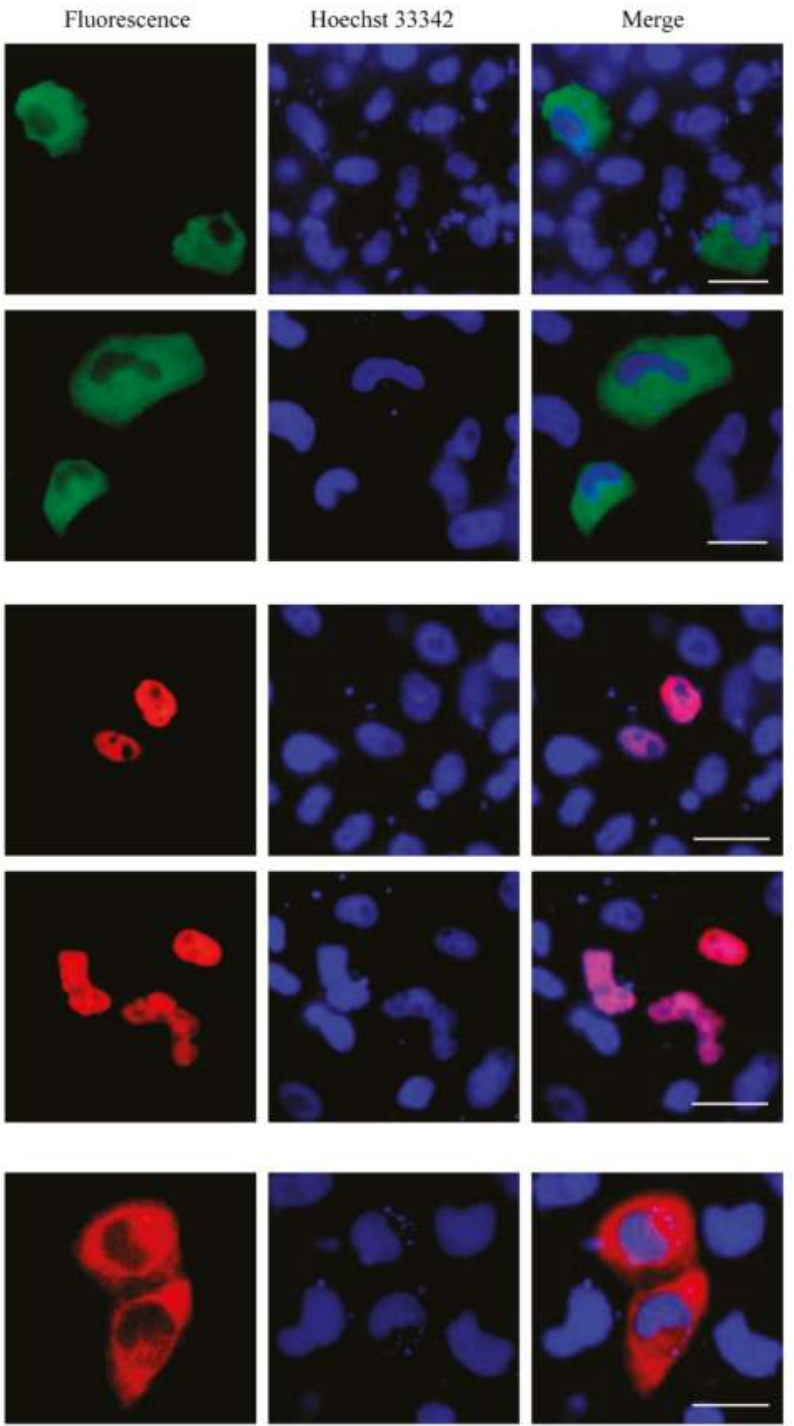

Figure 3. Cont. 
B
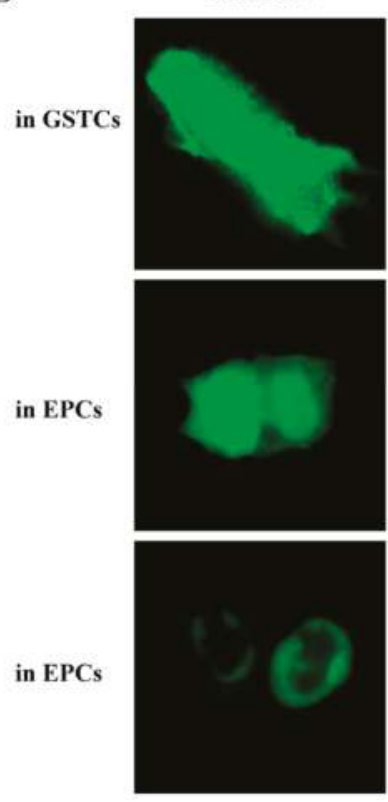

RFP
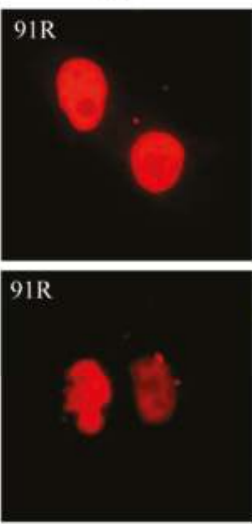

91R $\triangle \mathrm{NLS1}$

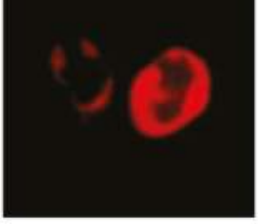

Hoechst 33342
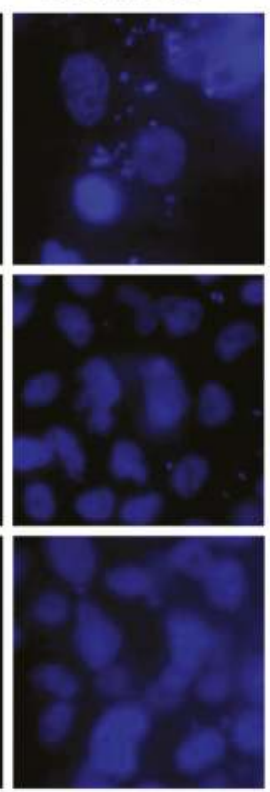

Merge
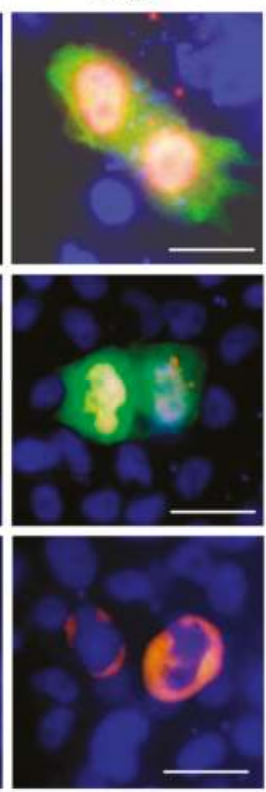

Figure 3. Fluorescence micrographs of cells expressing a single protein or co-expressing two proteins. (A) Expressing proteins 63R-EGFP, 91R-RFP, and 91R $\triangle$ NLS1-RFP alone in giant salamander thymus cells (GSTCs) or Epithelioma papulosum cyprinid cells (EPCs), respectively. (B) Co-expressing two proteins, 63R-EGFP + 91R-RFP and 63R-EGFP + 91R $\triangle$ NLS1-RFP, in GSTCs or EPCs, respectively. 63R-EGFP (green), 91R-RFP (red), 91R $\triangle$ NLS1-RFP (red), nucleus (blue), and colocalization (yellow). Scale bar: $10 \mu \mathrm{m}$.

RGV-91R was predicted to contain two NLSs, namely, NLS1 (60 88 aa) and NLS2 (176 207 aa). When the protein 63R-EGFP was co-expressed with NLS deletion proteins (91R $\triangle \mathrm{NLS1}$-RFP or 91R $\triangle N L S 2-R F P)$, they colocalized in the cytoplasm rather than in the nucleus (Figure 3B). These revealed that the NLS domain of RGV-91R is essential to transporting RGV-63R into the nucleus.

\subsection{Detection of RGV-63R and RGV-91R Expressions by Western Blotting}

The plasmids pcDNA3.1-63R-3Flag and pcDNA3.1-91R-HA were mixed when they were cotransfected into cells. The transfection efficiency was about $10 \%$. There is about $7.6 \%$ cells cotransfected with plasmids pcDNA3.1-63R-3Flag and pcDNA3.1-91R-HA, and about $2.4 \%$ cells transfected with alone plasmid by counting the number of transfected cells using immunofluorescence.

The expressions of RGV-63R and RGV-91R in GSTCs or EPCs at 24 hpt were detected by Western blot analysis. The results were shown in Figure 4. RGV-63R and RGV-91R were detected in GSTCs or EPCs expressing one protein alone or co-expressing two proteins, indicating that RGV-63R and RGV-91R were both successfully expressed. 

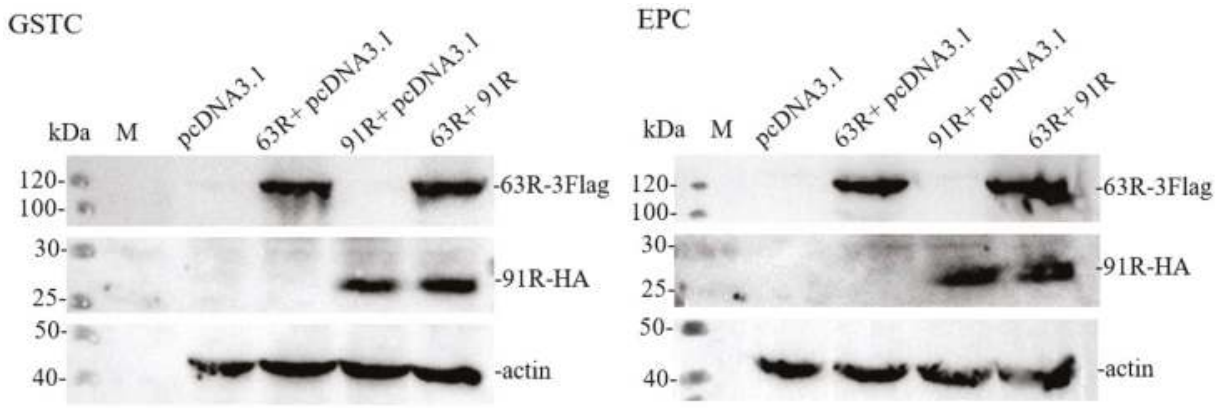

Figure 4. Western blot analysis of protein samples from cells transfected with plasmids for $24 \mathrm{~h}$ using anti-Flag and anti-HA. GSTC: in GSTCs expressing protein RGV-63R (63R + pcDNA3.1) or RGV-91R $(91 R+$ pcDNA3.1) alone or co-expressing two proteins RGV-63R and RGV-91R (63R + 91R), respectively. EPC: in EPCs expressing protein RGV-63R (63R + pcDNA3.1) or RGV-91R (91R + pcDNA3.1) alone or co-expressing two proteins RGV-63R and RGV-91R $(63 R+91 R)$, respectively. The empty vector pcDNA3.1 was used as a control. M: protein molecular mass marker.

\section{5. $R G V-63 R$ and $R G V-91 R$ Promote $R G V$ Genome Replication}

The effect of RGV-63R or RGV-91R on RGV genome replication was analyzed by expressing one protein alone or co-expressing two proteins in GSTCs and EPCs, respectively. qPCR analysis showed that RGV genomic copies in both GSTCs and EPCs expressing RGV-63R or RGV-91R alone or co-expressing the two proteins in EPCs were significantly higher than those in the control (Figure 5). A similar promoting activity is indicated when the two proteins are expressed alone in cells from different species.
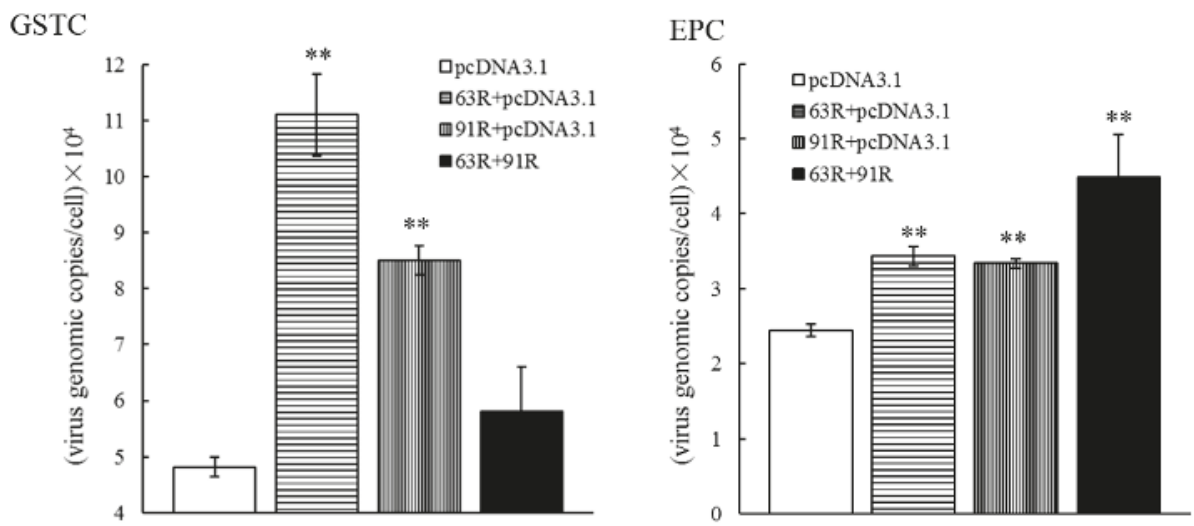

Figure 5. qPCR analysis of RGV genomic copies in GSTCs or EPCs. GSTC: in GSTCs expressing protein RGV-63R (63R + pcDNA3.1) or RGV-91R (91R + pcDNA3.1) alone or co-expressing two proteins RGV-63R and RGV-91R (63R + 91R), respectively. EPC: in EPCs expressing protein RGV-63R (63R + pcDNA3.1) or RGV-91R (91R + pcDNA3.1) alone or co-expressing two proteins RGV-63R and RGV-91R $(63 R+91 R)$, respectively. The empty vector pcDNA3.1 was used as a control. The transfected cells were infected with RGV, and RGV genome DNA was extracted from the cells at 48 hpi and quantified by qPCR. Each data point represents the average value of three independent infections. Error bars indicate standard deviations. ${ }^{* *}$ represents $p<0.01$.

The RGV genomic copies in EPCs co-expressing the two proteins were higher than those expressed alone. However, the genomic copies were lower when the two proteins were co-expressed rather than 
expressed alone in GSTCs (Figure 5), which was in line with expectations because of the long-term preservation of RGV in EPCs, not in GSTCs. This suggests that ranaviruses cross-species transmission were closely related with their adaptability to the host, but how it is affected is still an important unresolved area that needs to be studied.

\section{Discussion}

In this study, the interactions of RGV-63R with other iridoviral core proteins from RGV were tested by a $Y 2 \mathrm{H}$ assay, showing that RGV-63R interacts with RGV-91R. However, only white colonies formed on both SD/-Trp/-Leu and SD/-Trp/-Leu/-His/X- $\alpha$-Gal plates while detecting the interaction between RGV-63R and RGV-91R by Y2H. It is possible that the interaction between RGV-63R and RGV-91R in yeast is weak and only activates the reporter gene HIS3, but does not activate the reporter gene MEL-1 which encodes $\alpha$-galactosidase hydrolyzing chromogenic substrate X- $\alpha$-Gal. Subsequently, the interaction between the two proteins was further confirmed by co-IP.

In this study, 63R-EGFP protein only localized in cytoplasm of GSTCs or EPCs transfected with pEGFP-63R. When 63R-EGFP and 91R-RFP were co-expressed in GSTCs or EPCs, 63R-EGFP localized in both cytoplasm and the nucleus and colocalized with 91R-RFP in the nucleus. This not only further confirmed the interaction between the two proteins, but also implied that the nuclear import of RGV-63R mediated by RGV-91R might be very important for the virus genome synthesis within the nucleus. Nucleus import of macromolecules larger than $60 \mathrm{kDa}$ is an active, energy-dependent process mediated by sequence-specific motif and NLSs [33]. RGV-63R was predicted to encode DNA polymerase with a predicted molecular mass of $114 \mathrm{kDa}$. This implied that the nucleus import of RGV-63R might be mediated by NLSs. Fluorescent microscopy showed that the 91R $\triangle$ NLS-RFP protein localized in cytoplasm and did not mediate the nuclear import of RGV-63R, suggesting that the nuclear import of RGV-63R was dependent on the NLSs of RGV-91R.

Iridoviral DNA polymerase has been considered to be involved in virus genome replication [19]. Iridoviral PCNA was also considered to be involved in nucleic acid synthesis [34]. RGV-91R was identified as a late protein, and its homologue in a member of genus Ranavirus was identified as a structural protein $[35,36]$. In this study, the effects of RGV-63R, RGV-91R, and the interaction between the two proteins on RGV replication in GSTCs or EPCs were further analyzed. The results showed that overexpression of RGV-63R or RGV-91R in both GSTCs and EPCs significantly increased RGV genome copies. This indicated that RGV-63R and RGV-91R both promote RGV replication.

An interesting phenomenon is that the number of RGV genomic copies was lower in GSTCs when the two proteins were coexpressed compared to proteins expressed alone, but it was higher in EPCs when the two proteins were coexpressed. It has been reported that some host proteins inhibit ranavirus replication [37]. It has also been reported that antiviral activities of some cellular proteins are species-specific $[38,39]$. Whether co-expression of the two proteins in GSTCs or EPCs is associated with these similar host proteins needs further research. It also may result from the preparation of virus stocks. Compared with virus replication in EPCs, the virus was always multiplied in GSTCs, implying that the RGV genome replication in GSTCs might be more efficient. However, more experiments are required to confirm and explain this mechanism.

In conclusion, this report is the first confirmation and description of ranaviral protein-protein interactions that promote virus genome replication in cells from different species, which provides novel molecular evidence and insights for ranavirus cross-species infection.

Author Contributions: Q.-Y.Z. conceived and designed the study. X.-T.Z. performed experiments. Q.-Y.Z. and X.-T.Z. analyzed the data and wrote the manuscript. Both authors have read and approved the final manuscript.

Funding: This work is supported by grants from the National Natural Science Foundation of China (31430091, 31772890), the Strategic Pilot Science and Technology of the Chinese Academy of Sciences Project (XDA08030202), and the National Key R\&D Plan of the Ministry of Science and Technology, China (2018YFD0900302).

Conflicts of Interest: The authors declare that they have no conflict of interest. 


\section{References}

1. Zhang, Q.Y.; Gui, J.F. Diversity, evolutionary contribution and ecological roles of aquatic viruses. Sci. China Life Sci. 2018, 61, 1486-1502. [CrossRef]

2. Chinchar, V.G.; Hick, P.; Ince, I.A.; Jancovich, J.K.; Marschang, R.; Qin, Q.W.; Subramaniam, K.; Waltzek, T.B.; Whittington, R.; Williams, T.; Zhang, Q.Y. ICTV Report Consortium. ICTV Virus Taxonomy Profile: Iridoviridae. J. Gen. Virol. 2017, 98, 890-891. [PubMed]

3. Zhang, Q.Y.; Gui, J.F. Virus genomes and virus-host interactions in aquaculture animals. Sci. China Life Sci. 2015, 58, 156-169. [CrossRef] [PubMed]

4. Zhang, Q.Y.; Gui, J.F. Atlas of Aquatic Viruses and Viral Diseases; Science Press: Beijing, China, 2012.

5. Gui, L.; Zhang, Q.Y. A brief review on aquatic animal virology researches in China. J. Fisheries China 2019, 43, 168-187.

6. Stohr, A.C.; Lopez-Bueno, A.; Blahak, S.; Caeiro, M.F.; Rosa, G.M.; Alves de Matos, A.P.; Martel, A.; Alejo, A.; Marschang, R.E. Phylogeny and differentiation of reptilian and amphibian ranaviruses detected in Europe. PLOS ONE 2015, 10, e0118633. [CrossRef] [PubMed]

7. Ke, F.; Gui, J.F.; Chen, Z.Y.; Li, T.; Lei, C.K.; Wang, Z.H.; Zhang, Q.Y. Divergent transcriptomic responses underlying the ranaviruses-amphibian interaction processes on interspecies infection of Chinese giant salamander. BMC Genom. 2018, 19, 211. [CrossRef]

8. Robert, J.; Jancovich, J.K. Recombinant ranaviruses for studying evolution of host-pathogen interactions in ectothermic vertebrates. Viruses 2016, 8, 187. [CrossRef]

9. Ke, F.; Zhang, Q.Y. Aquatic animal viruses mediated immune evasion in their host. Fish. Shellfish Immunol. 2019, 86, 1096-1105. [CrossRef]

10. Gui, L.; Chinchar, V.G.; Zhang, Q.Y. Molecular basis of pathogenesis of emerging viruses infecting aquatic animals. Aquaculture Fisheries 2018, 3, 1-5. [CrossRef]

11. Liu, J.; Yu, C.; Gui, J.F.; Pang, D.W.; Zhang, Q.Y. Real-time dissecting the entry and intracellular dynamics of single reovirus particle. Front. Microbiol. 2018, 9, 2797. [CrossRef] [PubMed]

12. Corthell, J.T. Basic Molecular Protocols in Neuroscience: Tips, Tricks, and Pitfalls; Elsevier Science: Amsterdam, The Netherland, 2014.

13. Striebinger, H.; Koegl, M.; Bailer, S.M. A high-throughput yeast two-hybrid protocol to determine virus-host protein interactions. In Virus-Host Interactions. Methods in Molecular Biology (Methods and Protocols); Bailer, S., Lieber, D., Eds.; Humana Press: Totowa, NJ, USA, 2013; vol 1064, pp. 1-15.

14. Ozsahin, E.; van Oers, M.M.; Nalcacioglu, R.; Demirbag, Z. Protein-protein interactions among the structural proteins of Chilo iridescent virus. J. Gen. Virol. 2018, 99, 851-859. [CrossRef] [PubMed]

15. Halperin, S.O.; Tou, C.J.; Wong, E.B.; Modavi, C.; Schaffer, D.V.; Dueber, J.E. CRISPR-guided DNA polymerases enable diversification of all nucleotides in a tunable window. Nature 2018, 560, 248-252. [CrossRef]

16. Gardner, A.F.; Kelman, Z. DNA polymerases in biotechnology. Front. Microbiol. 2014, 5, 659. [CrossRef]

17. Czarnecki, M.W.; Traktman, P. The vaccinia virus DNA polymerase and its processivity factor. Virus Res. 2017, 234, 193-206. [CrossRef] [PubMed]

18. Zarrouk, K.; Piret, J.; Boivin, G. Herpesvirus DNA polymerases: structures, functions and inhibitors. Virus Res. 2017, 234, 177-192. [CrossRef]

19. Chinchar, V.G.; Waltzek, T.B. Ranaviruses: not just for frogs. PLoS Pathog. 2014, 10, e1003850. [CrossRef]

20. Chinchar, V.G.; Waltzek, T.B.; Subramaniam, K. Ranaviruses and other members of the family Iridoviridae: Their place in the virosphere. Virology 2017, 511, 259-271. [CrossRef] [PubMed]

21. Maga, G.; Villani, G.; Crespan, E.; Wimmer, U.; Ferrari, E.; Bertocci, B.; Hubscher, U. 8-oxo-guanine bypass by human DNA polymerases in the presence of auxiliary proteins. Nature 2007, 447, 606-608. [CrossRef] [PubMed]

22. Dieckman, L.M.; Freudenthal, B.D.; Washington, M.T. PCNA structure and function: insights from structures of PCNA complexes and post-translationally modified PCNA. In The Eukaryotic Replisome: A Guide to Protein Structure and Function; MacNeill, S., Ed.; Springer: Dordrecht, The Netherlands, 2012; pp. 281-299.

23. Baple, E.L.; Chambers, H.; Cross, H.E.; Fawcett, H.; Nakazawa, Y.; Chioza, B.A.; Harlalka, G.V.; Mansour, S.; Sreekantan-Nair, A.; Patton, M.A.; et al. Hypomorphic PCNA mutation underlies a human DNA repair disorder. J. Clin. Invest. 2014, 124, 3137-3146. [CrossRef] [PubMed] 
24. Eaton, H.E.; Metcalf, J.; Penny, E.; Tcherepanov, V.; Upton, C.; Brunetti, C.R. Comparative genomic analysis of the family Iridoviridae: re-annotating and defining the core set of iridovirus genes. Virol. J. 2007, 4, 11. [CrossRef]

25. Zhao, Z.; Ke, F.; Gui, J.F.; Zhang, Q.Y. Characterization of an early gene encoding for dUTPase in Rana grylio virus. Virus Res. 2007, 123, 128-137. [CrossRef] [PubMed]

26. Ke, F.; Zhao, Z.; Zhang, Q.Y. Cloning, expression and subcellular distribution of a Rana grylio virus late gene encoding ERV1 homologue. Mol. Biol. Rep. 2009, 36, 1651-1659. [CrossRef]

27. Lei, X.Y.; Ou, T.; Zhu, R.L.; Zhang, Q.Y. Sequencing and analysis of the complete genome of Rana grylio virus (RGV). Arch. Virol. 2012a, 157, 1559-1564. [CrossRef] [PubMed]

28. Lei, X.Y.; Ou, T.; Zhang, Q.Y. Rana. grylio virus (RGV) 50L is associated with viral matrix and exhibited two distribution patterns. PLoS ONE 2012b, 7, e43033. [CrossRef] [PubMed]

29. Yuan, J.D.; Chen, Z.Y.; Huang, X.; Gao, X.C.; Zhang, Q.Y. Establishment of three cell lines from Chinese giant salamander and their sensitivities to the wild-type and recombinant ranavirus. Vet. Res. 2015, 46, 58. [CrossRef]

30. Zeng, X.T.; Gao, X.C.; Zhang, Q.Y. Rana grylio virus 43R encodes an envelope protein involved in virus entry. Virus Genes 2018, 54, 779-791. [CrossRef]

31. Wang, J.; Gui, L.; Chen, Z.Y.; Zhang, Q.Y. Mutations in the C-terminal region affect subcellular localization of crucian carp herpesvirus (CaHV) GPCR. Virus Genes 2016, 52, 484-494. [CrossRef]

32. Chen, Z.Y.; Li, T.; Gao, X.C.; Wang, C.F.; Zhang, Q.Y. Protective immunity induced by DNA vaccination against ranavirus infection in chinese giant salamander Andrias davidianus. Viruses 2018, 10, 52. [CrossRef]

33. Peters, R. Translocation through the nuclear pore: Kaps pave the way. Bioessays 2009, 31, 466-477. [CrossRef]

34. Chinchar, V.G.; Yu, K.H.; Jancovich, J.K. The molecular biology of frog virus 3 and other iridoviruses infecting cold-blooded vertebrates. Viruses 2011, 3, 1959-1985. [CrossRef]

35. Sun, W. Molecular cloning and characterization of two novel viral genes, $3 \beta-H S D$ and PCNA from Rana grylio virus. Ph.D. Thesis, University of Chinese Academy of Sciences, Wuhan, China, 2007.

36. Li, W.; Zhang, X.; Weng, S.P.; Zhao, G.X.; He, J.G.; Dong, C.F. Virion-associated viral proteins of a Chinese giant salamander (Andrias davidianus) iridovirus (genus Ranavirus) and functional study of the major capsid protein (MCP). Vet. Microbiol. 2014, 172, 129-139. [CrossRef] [PubMed]

37. Wei, J.G.; Guo, M.L.; Ji, H.S.; Yan, Y.; Ouyang, Z.L.; Huang, X.H.; Hang, Y.H.; Qin, Q.W. Grouper translationally controlled tumor protein prevents cell death and inhibits the replication of Singapore grouper iridovirus (SGIV). Fish. Shellfish Immunol. 2012, 33, 916-925. [CrossRef] [PubMed]

38. Lodermeyer, V.; Ssebyatika, G.; Passos, V.; Ponnurangam, A.; Malassa, A.; Ewald, E.; Stürzel, C.M.; Kirchhoff, F.; Rotger, M.; Falk, C.S.; et al. The antiviral activity of the cellular glycoprotein LGALS3BP/90K is species specific. J. Virol. 2018, 92. [CrossRef] [PubMed]

39. Eunhye, K.; Hyunjhung, J.; Joohee, K.; Joohee, K.; Unjoo, P.; Seunghyun, J.; Areum, K.; Sinae, K.; Tan, T.N.; Yongsun, K.; et al. Species specific antiviral activity of porcine interferon- $\alpha 8$ (IFN $\alpha 8$ ). Immune Netw. 2017, 17, 424-436.

(C) 2019 by the authors. Licensee MDPI, Basel, Switzerland. This article is an open access article distributed under the terms and conditions of the Creative Commons Attribution (CC BY) license (http://creativecommons.org/licenses/by/4.0/). 


\title{
Article \\ Characterization of a Novel Megalocytivirus Isolated from European Chub (Squalius cephalus)
}

\author{
Maya A. Halaly ${ }^{1}$, Kuttichantran Subramaniam ${ }^{2}$, Samantha A. Koda ${ }^{2}$, Vsevolod L. Popov ${ }^{3}$, \\ David Stone ${ }^{4}$, Keith Way ${ }^{4}$ and Thomas B. Waltzek ${ }^{2, *}$ \\ 1 Department of Animal Sciences, College of Agricultural and Life Sciences, University of Florida, Gainesville, \\ FL 32611, USA; mayah123@ufl.edu \\ 2 Department of Infectious Diseases and Immunology, College of Veterinary Medicine, University of Florida, \\ Gainesville, FL 32611, USA; kuttichantran@ufl.edu (K.S.); samanthakoda@ufl.edu (S.A.K.) \\ 3 Department of Pathology, University of Texas Medical Branch, Galveston, TX 77555, USA; \\ vpopov@utmb.edu \\ 4 Centre for Environment, Fisheries and Aquaculture Science (CEFAS), Weymouth DT4 8UB, UK; \\ david.stone@cefas.co.uk (D.S.); keith.way@cefas.co.uk (K.W.) \\ * Correspondence: tbwaltzek@ufl.edu; Tel.: +(352)-273-5202
}

Received: 31 March 2019; Accepted: 28 April 2019; Published: 15 May 2019

check for updates

\begin{abstract}
A novel virus from moribund European chub (Squalius cephalus) was isolated on epithelioma papulosum cyprini (EPC) cells. Transmission electron microscopic examination revealed abundant non-enveloped, hexagonal virus particles in the cytoplasm of infected EPC cells consistent with an iridovirus. Illumina MiSeq sequence data enabled the assembly and annotation of the full genome $(128,216$ bp encoding 108 open reading frames) of the suspected iridovirus. Maximum Likelihood phylogenetic analyses based on 25 iridovirus core genes supported the European chub iridovirus (ECIV) as being the sister species to the recently-discovered scale drop disease virus (SDDV), which together form the most basal megalocytivirus clade. Genetic analyses of the ECIV major capsid protein and ATPase genes revealed the greatest nucleotide identity to members of the genus Megalocytivirus including SDDV. These data support ECIV as a novel member within the genus Megalocytivirus. Experimental challenge studies are needed to fulfill River's postulates and determine whether ECIV induces the pathognomonic microscopic lesions (i.e., megalocytes with basophilic cytoplasmic inclusions) observed in megalocytivirus infections.
\end{abstract}

Keywords: megalocytivirus; iridovirus; European chub

\section{Introduction}

The European chub (Squalius cephalus) is a rheophilic cyprinid that is widely distributed throughout Eurasia [1,2]. Although they are omnivores, adults include a greater portion of fish in their diets $[3,4]$. They are popular among amateur anglers because they readily take a variety of live and artificial baits and reach a maximum reported standard length of $60 \mathrm{~cm}$ [4]. Ireland and Italy have raised concerns that the recent introductions of European chub may threaten their native biodiversity $[1,2]$.

Cyprinid fishes are susceptible to a range of RNA and DNA viruses (reviewed in [5]). Iridoviruses have been described in a wide variety of fishes; however, few iridoviruses have been described from cyprinids [6,7]. Although an irido-like virus was isolated from the gills and kidneys of moribund common carp (Cyprinus carpio; i.e., common carp iridovirus; CCIV), the role of CCIV in disease could not be established (reviewed in $[5,8]$ ). In addition, two irido-like viruses were isolated from the swim bladder of healthy goldfish (Carassius auratus), goldfish virus-1 and goldfish virus-2, have been proposed as members of the family Iridoviridae based on biophysical and biochemical analyses [9]. 
Recent studies have reported the detection of the iridovirus, infectious spleen and kidney necrosis virus (ISKNV), in goldfish and common carp traded in Brazil [10] and in zebrafish (Danio rerio) from a research facility in Spain [11]. In addition, a Santee-Cooper ranavirus strain was isolated from diseased koi carp and shown experimentally to induce lethal disease [12].

Members of the family Iridoviridae possess large nucleocapsids that display icosahedral symmetry (120-200 nm in diameter) and encapsidate a linear, double-stranded DNA genome. The family is divided into two subfamilies, Alphairidovirinae and Betairidovirinae [13]. The former consists of three genera (Ranavirus, Lymphocystivirus, and Megalocytivirus) that are known to infect ectothermic vertebrates including fish, amphibians, and reptiles [13,14]. Megalocytiviruses are globally emerging viruses, causing lethal systemic infections in wild and cultured freshwater, brackish, and marine fishes [15]. Recent megalocytivirus phylogenetic analyses based on the major capsid protein (MCP) and ATPase genes revealed that the species, ISKNV, is divided into three genotypes including (1) ISKNV, which was first described from farmed mandarin fish (Siniperca chuatsi) reared for food in China [16,17]; (2) red sea bream iridovirus (RSIV), which was initially reported in cultured red sea bream (Pagrus major) from Japan [18]; and (3) turbot reddish body iridovirus (TRBIV), characterized from flatfishes (order Pleuronectiformes) reared for food in the Yellow Sea in East Asia [19]. In 2012, the threespine stickleback iridovirus (TSIV) was characterized from wild-caught threespine stickleback (Gasterosteus aculeatus) from Canada, and based on genetic and phylogenetic analyses, it was proposed as a novel megalocytivirus species [20]. Recently, an epizootic involving Asian seabass (Lates calcarifer) cultured in Singapore was found to be caused by a divergent megalocytivirus, scale drop disease virus (SDDV; [21]).

In this investigation, we described the in vitro growth characteristics, ultrastructural pathology, and phylogenomic characterization of the first iridovirus isolated from European chub. The cytopathic effect (i.e., enlarged, rounded, refractile cells) induced by this virus and its ultrastructural features are consistent with that of a megalocytivirus. The genetic and phylogenetic analyses further supported this virus as a divergent megalocytivirus, referred to as European chub iridovirus.

\section{Materials and Methods}

\subsection{Case History}

A hatchery located in the English Midlands of the UK, rearing cyprinids for wild stock enhancement, experienced increased mortality in several species, including European chub. Live European chub juveniles were transported to the Center for Environmental Fisheries and Aquaculture Science (CEFAS), in Weymouth, England and were subsequently euthanized after they appeared moribund upon arrival. Internal tissue homogenates were inoculated onto the following cell lines using standard virological methods: bluegill fry (BF-2), epithelioma papulosum cyprini (EPC), chinook salmon embryo (CHSE-214), koi fin (KF-1), and common carp brain (CCB). Cytopathic effects (CPE) were observed as early as $48 \mathrm{~h}$ post-inoculation, resulting in the appearance of enlarged refractile cells in all cell lines at $20^{\circ} \mathrm{C}$.

\subsection{Cell Culture}

The European chub iridovirus (ECIV) isolate grown on EPC cells was sent from CEFAS to the Wildlife and Aquatic Veterinary Disease Laboratory in Gainesville, Florida, USA. The virus isolate was then inoculated onto confluent monolayers of EPC cells maintained in MEM media with $10 \%$ fetal bovine serum and 1\% HEPES (4-(2-hydroxyethyl)-1-piperazineethanesulfonic acid) at $25{ }^{\circ} \mathrm{C}$ and monitored daily for CPE. Flasks of EPC cells displaying CPE were used to characterize the ultrastructural and genetic properties of ECIV.

\subsection{Transmission Electron Microscopy}

The ECIV isolate was propagated in a $75 \mathrm{~cm}^{2}$ flask of EPC cells until CPE was observed. The supernatant from the infected flask was discarded, and the monolayer was fixed in $15 \mathrm{~mL}$ of 
modified Karnovsky's fixative ( $2 \mathrm{P}+2 \mathrm{G}, 2 \%$ formaldehyde prepared from paraformaldehyde and $2 \%$ glutaraldehyde in $0.1 \mathrm{M}$ cacodylate buffer $\mathrm{pH} 7.4$ ) at room temperature for $1 \mathrm{~h}$. The monolayer was then washed in cacodylate buffer, scraped off the flask, and pelleted. The pellet was shipped via PBS overnight on ice packs to the University of Texas Medical Branch Department of Pathology Electron Microscopy Laboratory (UTMB-EML). At UTMB-EML, the cell pellet was washed in cacodylate buffer and left in $2 \mathrm{P}+2 \mathrm{G}$ fixative overnight at $4{ }^{\circ} \mathrm{C}$. The next day, the cell pellet was washed twice in cacodylate buffer, post-fixed in $1 \% \mathrm{OsO}_{4}$ in $0.1 \mathrm{M}$ cacodylate buffer $\mathrm{pH}$ 7.4, en bloc stained with $2 \%$ aqueous uranyl acetate, dehydrated in ascending concentrations of ethanol, processed through propylene oxide, and embedded in Poly/Bed 812 epoxy plastic (Polysciences, Warrington, PA, USA). Ultrathin sections were cut on a Leica ULTRACUT EM UC7 ultramicrotome (Leica Microsystems, Buffalo Grove, IL, USA), stained with $0.4 \%$ lead citrate, and examined in a JEM-1400 electron microscope (JEOL USA) at $80 \mathrm{kV}$.

\subsection{DNA Extraction, Whole Genome Sequencing, and Assembly}

Inoculation of the ECIV isolate onto EPC cells in four $175 \mathrm{~cm}^{2}$ flasks at a high multiplicity of infection provided third-passage material harvested after 21 days post-infection when CPE was extensive. Cell culture supernatant was clarified at $5520 \times g$ for $20 \mathrm{~min}$ at $4{ }^{\circ} \mathrm{C}$. The pelleted virus was obtained by centrifugation of the clarified supernatant at $100,000 \times \mathrm{g}$ for $1.25 \mathrm{~h}$ at $4{ }^{\circ} \mathrm{C}$. The viral pellet was resuspended in $360 \mu \mathrm{L}$ of animal tissue lysis (ATL) buffer prior to extraction of viral genomic DNA using a DNeasy Blood and Tissue Kit (Qiagen, Germantown, MD, USA) according to the manufacturer's instructions. A DNA library was generated using a Nextera XT DNA Kit, and sequencing was performed using a V3 chemistry 600 cycle Kit on a MiSeq sequencer (Illumina, Germantown, MD, USA). De novo assembly of the paired-end reads was performed in SPAdes 3.5.0 genome assembly algorithm [22]. The quality of the genome assembly was verified by mapping the reads back to the consensus sequence in Bowtie 22.1.0 [23] and visually inspecting the alignment in Tablet 1.14.10.20 [24].

\subsection{Genome Annotation, Genetic, and Phylogenetic Analysis}

The viral genome was annotated using GenemarkS [25], and the functions were predicted based on BLASTP searches against the National Center for Biotechnology Information (NCBI) GenBank non-redundant (nr) protein sequence database and conserved domain database. A total of 25 iridovirus core genes were used to conduct the Maximum Likelihood (ML) analysis for 47 iridoviruses, including ECIV (Table 1). The amino acid (AA) sequence alignments were performed for each gene in MAFFT 5.8 using default parameters [26] and concatenated using Geneious R10 [27]. The final dataset contained 19,340 AA characters, and the phylogenetic tree was constructed using IQ-Tree [28] with default parameters. In addition, genetic analyses were performed using the Sequence Demarcation Tool v1.2 with the MAFFT alignment option implemented [29] to compare the nucleotide sequence identity of megalocytiviruses based on the major capsid protein and ATPase gene alignments.

Table 1. GenBank accession numbers for the full genome sequences of iridoviruses used in the 25 iridovirus core gene phylogenetic analysis.

\begin{tabular}{clc}
\hline Species Name (Virus Abbreviation) & \multicolumn{1}{c}{ Genus } & GenBank Acc. No. \\
\hline Anopheles minimus iridovirus (AMIV) & Chloriridovirus & KF938901 \\
Invertebrate iridovirus 22 (IIV-22) & Chloriridovirus & HF920633 \\
Invertebrate iridovirus 22a (IIV-22a) & Chloriridovirus & HF920634 \\
Invertebrate iridescent virus 3 (IIV-3) & Chloriridovirus & DQ643392 \\
Invertebrate iridescent virus 30 (IIV-30) & Chloriridovirus & HF920636 \\
Invertebrate iridescent virus 9 (IIV-9) & Chloriridovirus & GQ918152 \\
Invertebrate iridescent virus 25 (IIV-25) & Chloriridovirus & HF920635 \\
\hline
\end{tabular}


Table 1. Cont.

\begin{tabular}{|c|c|c|}
\hline Species Name (Virus Abbreviation) & Genus & GenBank Acc. No. \\
\hline Invertebrate iridescent virus 31 (IIV-31) & Iridovirus & HF920637 \\
\hline Invertebrate iridescent virus 6 (IIV-6) & Iridovirus & AF303741 \\
\hline Lymphocystis disease virus 1 (LCDV-1) & Lymphocystivirus & L63545 \\
\hline Lymphocystis disease virus 2 (LCDV-C) & Lymphocystivirus & AY380826 \\
\hline Lymphocystis disease virus 3 (LCDV-Sa) & Lymphocystivirus & PRJEB12506 \\
\hline European chub iridovirus (ECIV) & Megalocytivirus & MK637631 \\
\hline Giant seaperch iridovirus (GSIV-K1) & Megalocytivirus & KT804738 \\
\hline Infectious spleen and kidney necrosis virus (ISKNV) & Megalocytivirus & AF371960 \\
\hline Infectious spleen and kidney necrosis virus (RSIV-Ku) & Megalocytivirus & KT781098 \\
\hline Orange-spotted grouper iridovirus (OSGIV) & Megalocytivirus & AY894343 \\
\hline Red seabream iridovirus (RSIV) & Megalocytivirus & AB104413 \\
\hline Red seabream iridovirus (RSIV RIE12-1) & Megalocytivirus & AP017456 \\
\hline Rock bream iridovirus (RBIV-KOR-TY1) & Megalocytivirus & AY532606 \\
\hline Rock bream iridovirus (RBIV-C1) & Megalocytivirus & KC244182 \\
\hline Scale drop disease virus (SDDV) & Megalocytivirus & KR139659 \\
\hline South American cichlid iridovirus (SACIV) & Megalocytivirus & MG570131 \\
\hline Turbot reddish body iridovirus (TRBIV) & Megalocytivirus & GQ273492 \\
\hline Three spot gourami iridovirus (TSGIV) & Megalocytivirus & MG570132 \\
\hline Ambystoma tigrinum virus (ATV) & Ranavirus & AY150217 \\
\hline Andrias davidianus ranavirus (ADRV) & Ranavirus & KC865735 \\
\hline Bohle iridovirus (BIV) & Ranavirus & KX185156 \\
\hline Cod iridovirus (CoIV) & Ranavirus & KX574342 \\
\hline Common midwife toad virus (CMTVM) & Ranavirus & JQ231222 \\
\hline Common midwife toad virus (CMTVVB) & Ranavirus & КР056312 \\
\hline Epizootic haematopoietic necrosis virus (EHNV) & Ranavirus & FJ433873 \\
\hline European catfish virus (ECV) & Ranavirus & KT989885 \\
\hline European sheatfish virus (ESV) & Ranavirus & JQ724856 \\
\hline Frog virus 3 (FV3) & Ranavirus & AY548484 \\
\hline Frog virus 3 isolate SSME (SSME) & Ranavirus & KF175144 \\
\hline German gecko ranavirus (GGRV) & Ranavirus & KP266742 \\
\hline Grouper iridovirus (GIV) & Ranavirus & AY666015 \\
\hline Pike perch iridovirus (PPIV) & Ranavirus & KX574341 \\
\hline Rana grylio iridovirus (RGV) & Ranavirus & JQ654586 \\
\hline Ranavirus maximus (Rmax) & Ranavirus & KX574434 \\
\hline Short-finned eel ranavirus (SERV) & Ranavirus & KX353311 \\
\hline Singapore grouper iridovirus (SGIV) & Ranavirus & AY521625 \\
\hline Soft-shelled turtle iridovirus (STIV) & Ranavirus & EU627010 \\
\hline Testudo hermanni ranavirus (CH8/96) & Ranavirus & KP266741 \\
\hline Tiger frog virus (TFV) & Ranavirus & AF389451 \\
\hline Tortoise ranavirus isolate (ToRV1) & Ranavirus & KP266743 \\
\hline
\end{tabular}

\section{Results}

\subsection{Cell Culture}

The CPE in the EPC cell line consisted of enlarged refractile cells observed within $48 \mathrm{~h}$ post-inoculation (hpi). Extensive CPE of the monolayer was observed by $96 \mathrm{hpi}$, at which point, clumps of affected cells were observed and began to detach from the monolayer (Figure 1). 

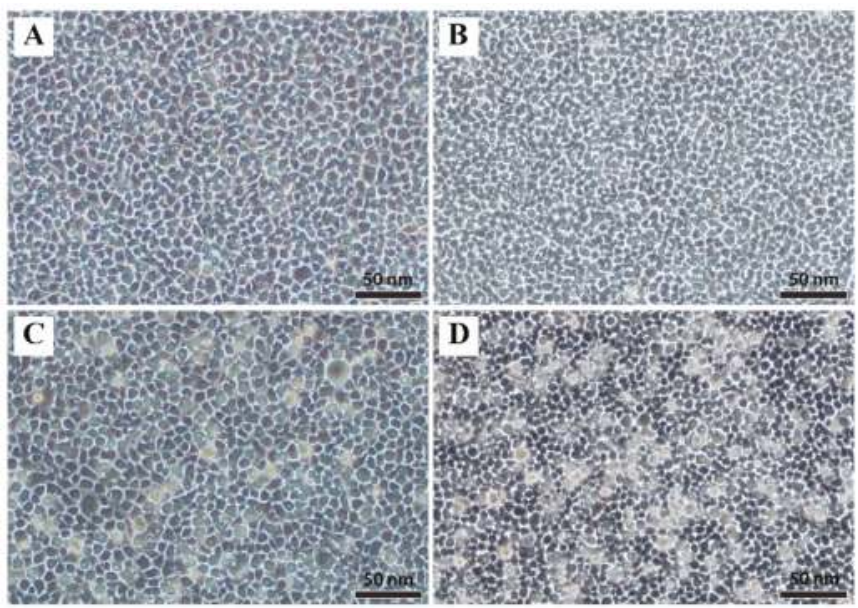

Figure 1. Microscopic examination of epithelioma papulosum cyprini cells infected with European chub iridovirus. (A) Control flask at $48 \mathrm{~h}$ post-inoculation (hpi); (B) control flask $96 \mathrm{hpi}$; (C) infected flask showing enlarged and refractile cells at $48 \mathrm{hpi}$; (D) infected flask showing enlarged and refractile cells at $96 \mathrm{hpi}$. Scale bars are $50 \mu \mathrm{m}$.

\subsection{Transmission Electron Microscopy}

Non-enveloped, hexagonal virus particles with electron-lucent or electron-dense cores were observed within viral assembly sites in the cytoplasm of infected EPC cells (Figure 2). The mean diameter of individual virus particles was $127 \mathrm{~nm}$ from opposite sides $(n=20$, standard deviation $=9)$ and $147 \mathrm{~nm}$ from apex to apex $(n=20$, standard deviation $=10)$.

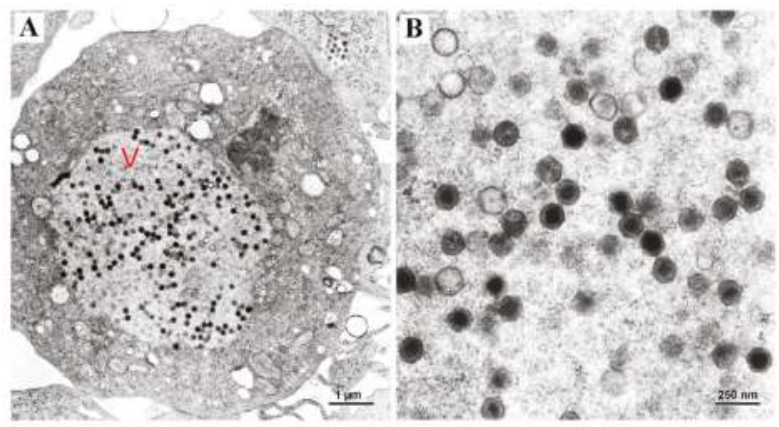

Figure 2. (A) Transmission electron photomicrograph of an epithelioma papulosum cyprini cell infected with European chub iridovirus, displaying numerous non-enveloped, hexagonal viral particles within the viral assembly site (labeled as V) in the cytoplasm. Scale bar is $1 \mu \mathrm{m}$. (B) Higher magnification of the virus particles. Scale bar is $250 \mathrm{~nm}$.

\subsection{Genome Annotation, Genetic and Phylogenetic Analyses}

The de novo assembly of the 14,420,600 paired-end reads recovered a contiguous sequence of $128,216 \mathrm{bp}$ with an overall coverage of 2948 reads/nucleotide. The \%GC of the genome was 38.83 , and a total of 108 open reading frames (ORFs) were predicted (Table S1). Comparative genomic analysis revealed the absence of one iridovirus core gene (ISKNV ORF 32R encoding putative thymidine kinase, GenBank accession number AF371960; SDDV ORF 125L, GenBank accession number KR139659) in Europoean chub iridovirus (ECIV). Eighty-seven genes showed the highest amino acid (AA) sequence 
identity to SDDV, seven genes to various members of the family Iridoviridae, and six genes to other organisms (e.g., eukaryotes including fish and fungi). Eight genes were found to be unique to the ECIV genome and did not display similarity to existing genes within the NCBI GenBank nr protein sequence database. Of these, seven genes (ORFs 2, 5, 18, 58, 65, 82, and 89) were predicted as hypothetical proteins, and ORF 66 predicted to be a chromosome segregation protein (Table S1). As with cherax quadricarinatus iridovirus strain CQIV-CN01 (GenBank acc. MF197913), shrimp hemocyte iridescent virus isolate 20141215 (GenBank accession number MF599468), grouper iridovirus (GenBank accession number AY666015), and Singapore grouper iridovirus (GenBank acc. no. AY521625), the ECIV ORF 84 is predicted to encode an ubiquitin family protein. The ECIV ORFs 31 and 57 were predicted as members of the serpin superfamily and showed the highest AA to SDDV ORFs 97L and 45R, respectively. The ECIV encoded a HIRAN domain containing protein (ORF 49) and a family of ankyrin (ANK) proteins (ORFs 3, 4, 44, 46, 47, 63, 92, 99, and 102) that ranged in size from 143 to 478 AA residues. Each ECIV ANK protein possesses between 1 and 7 ANK motifs. ECIV ORF 97 was predicted to encode an US22 protein and displayed the highest AA sequence identity (39.2\%) to an US22 protein from Asian swamp eel (Monopterus albus). The complete genome sequence of ECIV has been deposited in NCBI GenBank under the accession number MK637631.

The ML analysis of the concatenated 25 iridovirus core gene sequences produced a well-resolved and supported tree (Figure 3). The ECIV was found to be the sister species to the SDDV, which together form the basal branch of the megalocytivirus tree. Genetic comparisons of the ECIV ATPase and MCP nucleotide sequences to other megalocytiviruses ranged from 66.4 to $76.9 \%$ and 62.8 to $73.1 \%$, respectively (Tables S2 and S3). The highest identities were observed between ECIV and SDDV.

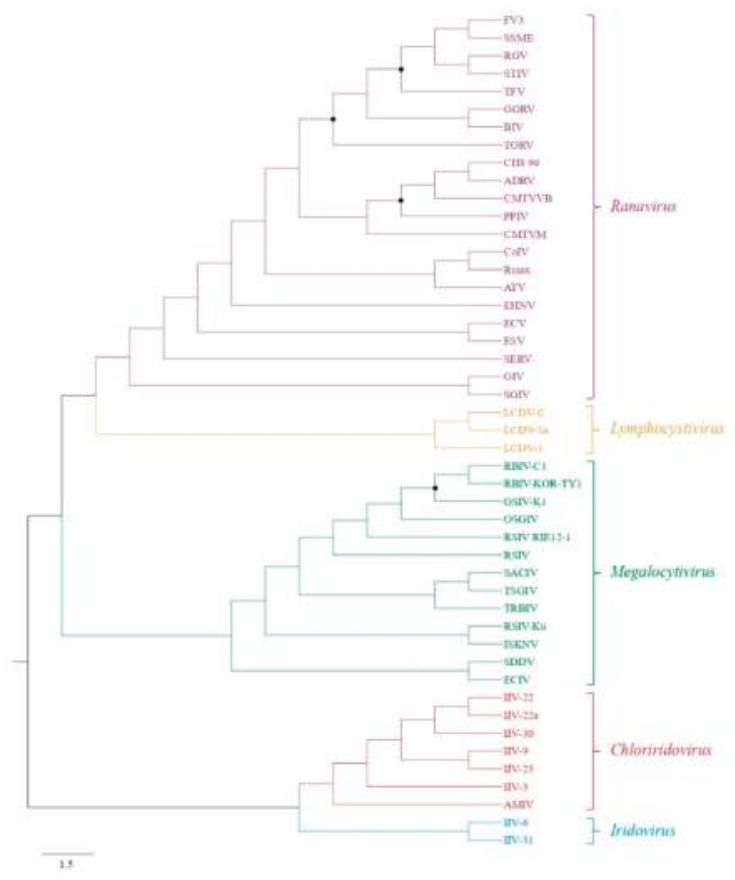

Figure 3. Cladogram depicting the relationship of European chub iridovirus to 47 other members of the family Iridoviridae based on 25 core genes. The Maximum Likelihood tree was generated using 1000 bootstraps and the branch lengths are based on the number of inferred substitutions, as indicated by the scale. All nodes were supported by bootstrap values $>80 \%$ except those labeled with black circles. See Table 1 for virus abbreviations. 


\section{Discussion}

In this investigation, we report the complete genome sequence of a novel iridovirus isolated from moribund European chub (Squalius cephalus) in England. The in vitro characteristics (i.e., enlarged, rounded, and refractile cells), virion ultrastructure and morphogenesis (i.e., non-enveloped hexagonal virus particles within the cytoplasm), and genetic/phylogenetic analyses supported the identification of European chub iridovirus (ECIV) as a divergent megalocytivirus most closely related to the recently described SDDV [21]. To our knowledge, this study represents the first isolation and genomic characterization of a megalocytivirus in a cyprinid fish. The results of these studies add to a growing body of literature on the host range and threat megalocytiviruses pose to wild and cultured fishes, including their potential impacts in cyprinids [7].

The type species of the genus Megalocytivirus (Infectious spleen and kidney necrosis virus; ISKNV) exhibits low host specificity, with strains infecting $>150$ species of freshwater, brackish, and marine fishes [7,30]. The recent characterization of the TSIV from Canadian threespine stickleback (Gasterosteus aculeatus) [20] and SDDV from Asian seabass (Lates calcarifer) [21] have revealed the existence of genetically-divergent megalocytiviruses that have been argued to represent new species. The discovery of iridoviruses distantly related to ISKNV has stimulated discussion by members of the International Committee on Taxonomy of Viruses study group on iridoviruses to begin re-evaluating the criteria used in defining megalocytivirus species [13]. The genome annotation of ECIV revealed that it possesses 108 predicted genes (including eight unique genes), and compared to other fully-sequenced megalocytivirus genomes, ECIV has the longest genome and a low \%GC content similar to SDDV. These data, taken together with the genetic and phylogenetic analyses, suggest ECIV represents yet another novel megalocytivirus, and we propose the formal species designation of European chub iridovirus to be considered for approval by the International Committee on Taxonomy of Viruses.

The HIRAN domain-containing protein (ECIV ORF 49) is not observed in other viruses, except in some bacteriophages [31], and displayed the highest amino acid (AA) sequence identity (39.1\%) to the protein of a zygomycete fungus (Basidiobolus meristosporus). The HIRAN domain has been found as a standalone protein in a wide range of bacteria or fused to other catalytic domains in eukaryotes [31]. The HIRAN domain is predicted to function as a DNA-binding domain that recognizes damaged DNA or stalled replication forks and recruits repair and remodeling enzymes to these sites [31]. Although a variety of DNA viruses encode serpin proteins, lymphocystis disease virus Sa isolate SA9 (ORF 50R; GenBank accession number KX643370), SDDV (ORFs 45R and 97L; GenBank accession number KR139659), and ECIV (ORFs 31 and 57) are the only iridoviruses that possess these genes [32]. Recent studies have demonstrated that poxvirus-encoded serpins subvert host immune responses by inhibiting the inflammatory response and apoptosis [33]. Megalocytiviruses are the only member of the family Iridoviridae to encode ANK repeat proteins, and ECIV encodes the greatest number of copies (ORFs 2, 5, 18, 58, 65, 82, and 89) among members of the genus. ANK repeat proteins have also been described in poxviruses, mimiviruses, and phycodnaviruses. The ISKNV ANK repeat protein (ISKNV ORF 124L; GenBank accession number AF371960) has been shown to interfere with TNF- $\alpha$-induced NF-kB activation, an important immune regulatory pathway [34]. Poxvirus-encoded ANK repeat proteins are suggested to be involved with host cell tropism [35] and manipulation of the host cell ubiquitin-proteasome machinery [36]. The US22 proteins are present in all megalocytiviruses, except in SDDV and ISKNV, and these proteins are believed to counter diverse host immune responses by interacting with specific host proteins [37,38]. The highest AA sequence identity of the ECIV US22 protein (ORF 97) to Asian swamp eel suggests it was acquired from a fish host.

The in vitro cultivation of megalocytiviruses is challenging, with propagation reported in a handful of cell lines including the grunt fin cell line for RSIV and three spot gourami iridovirus [17,30], the mandarin fish fry cell line for ISKNV [39], and the turbot fin cell line for TRBIV [40]. Commonly-used cell lines failed in the propagation of the Banggai cardinalfish iridovirus, a strain of the ISKNV genotype, including the epithelioma papulosum cyprini (EPC), bluegill fry (BF-2), chinook salmon embryo (CHSE-214), and fathead minnow (FHM) cell lines [41]. Similarly, TSIV was refractory to culture on 
EPC, BF-2, and CHSE-214 cell lines [20]. In contrast, ECIV is less fastidious than other megalocytiviruses growing on EPC, BF-2, CHSE-214, KF-1, and CCB cell lines. Whether the related SDDV shares similar in vitro growth characteristics with ECIV remains to be determined as SDDV has only been tested and cultivated in the seabass kidney cell line [21].

Future challenge studies will be needed to determine whether ECIV causes disease in European chub and related cyprinids. These experiments will also help determine whether ECIV induces the pathognomonic microscopic lesions (i.e., megalocytes with basophilic cytoplasmic inclusions) observed in all other megalocytivirus infections to date $[17,20,21,30]$. Finally, the genomic sequence presented here will facilitate the development of molecular diagnostic assays that could be used to determine the prevalence of ECIV among European chub populations across Eurasia.

Supplementary Materials: The following are available online at http://www.mdpi.com/1999-4915/11/5/440/s1, Table S1: Genome annotation of the European Chub iridovirus; Table S2: Genetic relationship among iridoviruses measured as nucleotide sequence identity in the major capsid protein. Values for European chub iridovirus are outlined in red. See Table 1 for virus abbreviations; Table S3: Genetic relationship among iridoviruses measured as nucleotide sequence identity in the ATPase gene. Values for European chub iridovirus are outlined in red. See Table 1 for virus abbreviations.

Author Contributions: Conceptualization, T.B.W.; methodology, M.A.H., K.S., T.B.W.; validation, K.S., S.A.K., T.B.W.; formal analysis, M.A.H., K.S., S.A.K.; investigation, M.A.H., V.L.P.; resources, D.S., K.W., T.B.W.; data curation, M.A.H., K.S., S.A.K.; writing-original draft preparation, M.A.H.; writing-review and editing, K.S., S.A.K., V.L.P., D.S., K.W., T.B.W.; visualization, M.A.H., K.S., S.A.K.; supervision, T.B.W.; project administration, T.B.W.

Acknowledgments: We thank Patrick M. Thompson for his technical assistance throughout the study, and Jeffrey Go for his critical review of the manuscript.

Conflicts of Interest: The authors declare no conflict of interest.

\section{References}

1. Caffrey, J.M.; Acevedo, S.M.; Gallagher, K.; Britton, R. Chub (Leuciscus cephalus): A new potentially invasive fish species in Ireland. Aquatic Invasions 2008, 3, 201-209. [CrossRef]

2. Kottelat, M.; Freyhof, J. Handbook of European Freshwater Fishes; Publications Kottelat: Cornol, Switzerland, 2007.

3. Mann, R.H.K. Observations on the age, growth, reproduction and food of the pike Esox lucius (L.) in two rivers in southern England. J. Fish Biol. 1976, 8, 179-197. [CrossRef]

4. Vitali, R.; Braghieri, L. Population dynamics of Barbus plebejus (Valenciennes) and Leuciscus cephalus cabeda (Risso) in the middle River Po (Italy). Hydrobiologia 1984, 109, 105-124. [CrossRef]

5. Dixon, P.F. Virus diseases of cyprinids. In Fish diseases; Eiras, J.C., Segner, H., Kapoor, B.G., Eds.; Science Publishers: Enfield, NH, USA, 2008; Volume 1, pp. 87-184.

6. Yanong, R.P. Lymphocystis Disease in Fish (FA181). University of Florida Institute of Food and Agricultural Sciences, 2010. Available online: http://edis.ifas.ufl.edu/fa181 (accessed on 11 December 2018).

7. Yanong, R.P.; Waltzek, T.B. Megalocytivirus infections in fish, with emphasis on ornamental species (FA182). University of Florida Institute of Food and Agricultural Sciences, 2010. Available online: http: //edis.ifas.ufl.edu/fa182 (accessed on 3 December 2018).

8. Shchelkunov, I.S.; Shchelkunova, T.I. Infectivity experiments with Cyprinus carpio iridovirus (CCIV), a virus unassociated with carp gill necrosis. J. Fish Dis. 1990, 13, 475-484. [CrossRef]

9. Berry, E.S.; Shea, T.B.; Gabliks, J. Two iridovirus isolates from Carassius auratus (L.). J. Fish Dis. 1983, 6, 501-510. [CrossRef]

10. Maganha, S.R.; Cardoso, P.H.; Balian, S.; Almeida-Queiroz, S.R.; Fernandes, A.M.; de Sousa, R.L. Molecular detection and phylogenetic analysis of megalocytivirus in Brazilian ornamental fish. Arch. Of Vir. 2018, 163, 2225-2231. [CrossRef]

11. Bermúdez, R.; Losada, A.P.; de Azevedo, A.M.; Guerra-Varela, J.; Pérez-Fernández, D.; Sánchez, L.; Padrós, F.; Nowak, B.; Quiroga, M.I. First description of a natural infection with spleen and kidney necrosis virus in zebrafish. J. Fish Dis. 2018, 41, 1283-1294. [CrossRef] 
12. George, M.R.; John, K.R.; Mansoor, M.M.; Saravanakumar, R.; Sundar, P.; Pradeep, V. Isolation and characterization of a ranavirus from koi, Cyprinus carpio L., experiencing mass mortalities in India. J. Fish Dis. 2015, 38, 389-403. [CrossRef]

13. Chinchar, V.R.; Hick, P.; Ince, I.A.; Jancovich, J.K.; Marschang, R.; Qin, Q.; Subramaniam, K.; Waltzek, T.B.; Whittington, R.; Williams, T.; Zhang, Q.; ICTV Report Consortium. ICTV Virus Taxonomy Profile: Iridoviridae. J. Gen. Virol. 2017, 98, 890-891.

14. Jancovich, J.K.; Chinchar, V.G.; Hyatt, A.; Miyazaki, T.; Williams, T.; Zhang, Q.Y. Family Iridoviridae. In Virus Taxonomy: Ninth Report of the International Committee on Taxonomy of Viruses; King, A.M.Q., Adams, M.J., Carstens, E.B., Lefkowitz, E.J., Eds.; Elsevier Academic Press: San Diego, CA, USA, 2012; pp. 193-210.

15. Chinchar, V.G.; Hyatt, A.; Miyazaki, T.; Williams, T. Family Iridoviridae: poor viral relations no longer. Curr. Top. Microbiol. Immunol 2009, 328, 123-170.

16. He, J.G.; Wang, S.P.; Zeng, K.; Huang, Z.J.; Chan, S. Systemic disease caused by an iridovirus-like agent in cultured mandarin fish, Sinipercca chuatsi (Basilewsky), in China. J. Fish Dis. 2000, 23, 219-222. [CrossRef]

17. He, J.G.; Deng, M.; Weng, S.P.; Li, Z.; Zhou, S.Y.; Long, Q.X.; Wang, X.Z.; Chan, S. Complete genome analysis of the mandarin fish infectious spleen and kidney necrosis iridovirus. Virol. J. 2001, 291, 126-139. [CrossRef] [PubMed]

18. Inouye, K.; Yamano, K.; Maeno, Y.; Nakajima, K.; Matsuoka, M.; Wada, Y.; Sorimachi, M. Iridovirus infection of cultured red sea bream, Pagrus major. Fish. Pathol. 1992, 27, 19-27. [CrossRef]

19. Kawato, Y.; Subramaniam, K.; Nakajima, K.; Waltzek, T.; Whittington, R. Iridoviral Diseases: Red Sea Bream Iridovirus and White Sturgeon Iridovirus. In Fish Viruses and Bacteria: Pathobiology and Protection; Woo, P.T.K., Cipriano, R.C., Eds.; CABI Publishing: Wallingford, UK, 2017; pp. 147-159.

20. Waltzek, T.B.; Marty, G.D.; Alfaro, M.E.; Bennett, W.R.; Garver, K.A.; Haulena, M.; Weber, E.S., 3rd.; Hedrick, R.P. Systemic iridovirus from threespine stickleback Gasterosteus aculeatus represents a new megalocytivirus species (family Iridoviridae). Dis. Aquat. Org. 2012, 98, 41-56. [CrossRef]

21. De Groof, A.; Guelen, L.; Dejis, M.; van der Wal, Y.; Miyata, M.; Ng, K.S.; van Grinsven, L.; Simmelink, B.; Viermann, Y.; Grisez, L.; et al. A novel virus causes scale drop disease in Lates calcarifer. PLoS Pathog. 2015, 11, e1005074. [CrossRef] [PubMed]

22. Bankevich, A.; Nurk, S.; Antipov, D.; Gurevich, A.A.; Dvorkin, M.; Kulikov, A.S.; Lesin, V.M.; Nikolenko, S.I.; Pham, S.; Prjibelski, A.D.; et al. SPAdes: A new genome assembly algorithm and its applications to single-cell sequencing. J. Comput. Biol. 2012, 19, 455-477. [CrossRef] [PubMed]

23. Langmead, B.; Salzberg, S.L. Fast gapped-read alignment with Bowtie 2. Nat. Methods 2012, 9, 357-359. [CrossRef]

24. Milne, I.; Bayer, M.; Cardle, L.; Shaw, P.; Stephen, G.; Wright, F.; Marshall, D. Tablet-next generation sequence assembly visualization. Bioinformatics 2010, 26, 401-402. [CrossRef]

25. Besemer, J.; Lomsadze, A.; Borodovsky, M. GeneMarkS: a self-training method for prediction of gene starts in microbial genomes. Implications for finding sequence motifs in regulatory regions. Nucleic Acids Res. 2001, 29, 2607-2618. [CrossRef] [PubMed]

26. Katoh, K.; Toh, H. Recent developments in the MAFFT multiple sequence alignment program. Brief Bioinform. 2008, 9, 286-298. [CrossRef]

27. Kearse, M.; Moir, R.; Wilson, A.; Stones-Havas, S.; Cheung, M.; Sturrock, S.; Buxton, S.; Cooper, A.; Markowitz, S.; Duran, C.; et al. Geneious Basic: An integrated and extendable desktop software platform for the organization and analysis of sequence data. Bioinformatics 2012, 28, 1647-1649. [CrossRef] [PubMed]

28. Trifinopoulos, J.; Nguyen, L.T.; von Haeseler, A.; Minh, B.Q. W-IQ-TREE: A fast online phylogenetic tool for maximum likelihood analysis. Nucleic Acids Res. 2016, 44, W232-W235. [CrossRef] [PubMed]

29. Muhire, B.M.; Varsani, A.; Martin, D.P. SDT: A virus classification tool based on pairwise sequence alignment and identity calculation. PLoS ONE 2014, 9, e108277. [CrossRef]

30. Koda, S.A.; Subramaniam, K.; Francis-Floyd, R.; Yanong, R.P.; Frasca, S., Jr.; Groff, J.M.; Popov, V.L.; Fraser, W.A.; Yan, A.; Mohan, S.; Waltzek, T.B. Phylogenomic characterization of two novel members of the genus Megalocytivirus from archived ornamental fish samples. Dis. Aquat. Org. 2018, 130, 11-24. [CrossRef]

31. Iyer, L.M.; Babu, M.; Aravind, B. The HIRAN domain and recruitment of chromatin remodeling and repair activities to damaged DNA. Cell Cycle 2006, 5, 775-782. [CrossRef] [PubMed]

32. Bao, J.; Pan, G.; Poncz, M.; Wei, J.; Ran, M.; Zhou, Z. Serpin functions in host-pathogen interactions. Peer J. 2018. [CrossRef] [PubMed] 
33. Johnston, J.B.; McFadden, G. Poxvirus immunomodulatory strategies: Current perspectives. J. Virol. 2003, 77, 6093-6100. [CrossRef]

34. Guo, C.J.; Chen, W.J.; Yuan, L.Q.; Yang, L.S.; Weng, S.P.; Yu, X.Q.; He, J.G. The viral ankyrin repeat protein (ORF124L) from infectious spleen and kidney necrosis virus attenuates nuclear factor- $\mathrm{k} B$ activation and interacts with IкB kinase $\beta$. J. Gen. Virol. 2011, 92, 1561-1570. [CrossRef] [PubMed]

35. Werden, S.J.; McFadden, G. The role of cell signaling in poxvirus tropism: the case of the M-T5 host range protein of myxoma virus. Biochim. Biophys. Acta 2008, 1784, 228-237. [CrossRef] [PubMed]

36. Sonnberg, S.; Seet, B.T.; Pawson, T.; Fleming, S.B.; Mercer, A.A. Poxvirus ankyrin repeat proteins are a unique class of F-box proteins that associate with cellular SCF1 ubiquitin ligase complexes. Proc. Natl. Acad. Sci. USA 2008, 105, 10955-10960. [CrossRef] [PubMed]

37. Zhang, D.; Iyer, L.M.; Aravind, L. A novel immunity system for bacterial nucleic acid degrading toxins and its recruitment in various eukaryotic and DNA viral systems. Nucleic Acids Res. 2011, 39, 4532-4552. [CrossRef] [PubMed]

38. Claytor, S.C.; Subramaniam, K.; Landrau-Giovannetti, N.; Chinchar, V.G.; Gray, M.J.; Miller, D.L.; Mavian, C.; Salemi, M.; Wisely, S.; Waltzek, T.B. Ranavirus phylogenomics: Signatures of recombination and inversions among bullfrog ranaculture isolates. Virology 2017, 511, 330-343. [CrossRef]

39. Dong, C.; Weng, S.; Shi, X.; Xu, X.; Shi, N.; He, J. Development of a mandarin fish Siniperca chuatsi fry cell line suitable for the study of infectious spleen and kidney necrosis virus (ISKNV). Virus Res. 2008, 135, 273-281. [CrossRef] [PubMed]

40. Fan, T.J.; Ren, B.X.; Geng, X.F.; Yu, Q.T.; Wang, L.Y. Establishment of a turbot fin cell line and its susceptibility to turbot reddish body iridovirus. Cytotechnology 2010, 62, 217-223. [CrossRef] [PubMed]

41. Weber, E.S.; Waltzek, T.B.; Young, D.A.; Twitchell, E.L.; Gates, A.E.; Vagelli, A.; Risatti, G.R.; Hedrick, R.P.; Frasca, S., Jr. Systemic iridovirus infection in the Banggai cardinalfish (Pterapogon kauderni Koumans 1933). J. Vet. Diagn. Investig. 2009, 21, 306-320. [CrossRef]

(C) 2019 by the authors. Licensee MDPI, Basel, Switzerland. This article is an open access article distributed under the terms and conditions of the Creative Commons Attribution (CC BY) license (http://creativecommons.org/licenses/by/4.0/). 


\title{
Article \\ Artemia spp., a Susceptible Host and Vector for Lymphocystis Disease Virus
}

\author{
Estefania J. Valverde, Alejandro M. Labella, Juan J. Borrego(i) and Dolores Castro *(D) \\ Departamento de Microbiología, Facultad de Ciencias, Universidad de Málaga, 29017 Málaga, Spain; \\ ejv@uma.es (E.J.V.); amlabella@uma.es (A.M.L.); jjborrego@uma.es (J.J.B.) \\ * Correspondence: dcastro@uma.es; Tel.: +34-952134214
}

Received: 8 May 2019; Accepted: 30 May 2019; Published: 1 June 2019

\begin{abstract}
Different developmental stages of Artemia spp. (metanauplii, juveniles and adults) were bath-challenged with two isolates of the Lymphocystis disease virus (LCDV), namely, LCDV SA25 (belonging to the species Lymphocystis disease virus 3) and ATCC VR-342 (an unclassified member of the genus Lymphocystivirus). Viral quantification and gene expression were analyzed by qPCR at different times post-inoculation (pi). In addition, infectious titres were determined at 8 dpi by integrated cell culture (ICC)-RT-PCR, an assay that detects viral mRNA in inoculated cell cultures. In LCDV-challenged Artemia, the viral load increased by 2-3 orders of magnitude (depending on developmental stage and viral isolate) during the first 8-12 dpi, with viral titres up to $2.3 \times 10^{2}$ Most Probable Number of Infectious Units (MPNIU)/mg. Viral transcripts were detected in the infected Artemia, relative expression values showed a similar temporal evolution in the different experimental groups. Moreover, gilthead seabream (Sparus aurata) fingerlings were challenged by feeding on LCDV-infected metanauplii. Although no Lymphocystis symptoms were observed in the fish, the number of viral DNA copies was significantly higher at the end of the experimental trial and major capsid protein $(m c p)$ gene expression was consistently detected. The results obtained support that LCDV infects Artemia spp., establishing an asymptomatic productive infection at least under the experimental conditions tested, and that the infected metanauplii are a vector for LCDV transmission to gilthead seabream.
\end{abstract}

Keywords: Lymphocystis disease virus; Artemia spp.; viral infection; Sparus aurata; viral transmission

\section{Introduction}

The family Iridoviridae comprises two subfamilies and six genera [1]. Three of them, Lymphocystivirus, Megalocytivirus, and Ranavirus (subfamily Alphairidovirinae), infect ectothermic vertebrates (amphibians, reptiles and bony fish), whereas the hosts for the other three genera, Iridovirus, Chloriridovirus, and Decapodiridovirus (subfamily Betairidovirinae), are invertebrates (primarily insects and crustaceans) [1-3].

Members of the genus Lymphocystivirus, collectively named as Lymphocystis disease virus (LCDV), are the causative agents of the Lymphocystis disease (LCD) affecting a wide variety of freshwater, brackish, and marine fish species [4]. The characteristic lesions of LCD are small pearl-like nodules on fish skin and fins, grouped in raspberry-like clusters of tumorous appearance [5,6]. Although this disease is rarely fatal, affected fish cannot be commercialized, provoking important economic losses [7]. LCD is the main viral infection reported in gilthead seabream (Sparus aurata) aquaculture [8] and it is caused by Lymphocystis disease virus 3 (LCDV-Sa). Two more species have been recognized in the genus Lymphocystivirus_Lymphocystis disease virus 1 (LCDV1) and Lymphocystis disease virus 2 (LCDV-C), that infect European flounder (Platichthys flesus) and Japanese flounder (Paralichthys 
olivaceus), respectively-and a number of isolates have been obtained from other LC-diseased fish species, but their taxonomic position is unclear [1].

It is assumed that LCDV transmission occurs through the skin and gills of fish by direct contact or by waterborne exposure $[9,10]$. However, viral transmission via the alimentary canal has been demonstrated for gilthead seabream larvae feeding on LCDV-positive rotifers [11].

The brine shrimp Artemia (Crustacea, Branchiopoda, Anostraca) is an aquatic crustacean frequently used for the feeding of postlarvae fish in aquaculture practice $[12,13]$. Several authors have considered Artemia spp. nauplii as a possible source for the introduction of microorganisms into the rearing systems, including bacteria, viruses, and protozoa [14-19], and in most studies, a mechanical carrier stage, in which the pathogen does not multiplicate into the brine shrimp but accumulates in its alimentary canal, has been proposed $[16,19,20]$.

LCDV has been detected by PCR-based methods in Artemia cysts and nauplii/metanauplii collected in gilthead seabream hatcheries $[21,22]$. In a previous study, we demonstrated that the nauplii become easily contaminated with LCDV by immersion challenge. Furthermore, infectious LCDV persists along the Artemia life cycle, with viral genome and antigens detected not only in the gut of adult specimens, which could be related to a viral bioaccumulation process, but also in the ovisac in females [21]. These findings suggest that Artemia might act as a reservoir of LCDV and could support viral replication.

The aim of the present study was to investigate the susceptibility of different developmental stages of Artemia spp. to LCDV and to elucidate its role as a vector for LCDV transmission to gilthead seabream.

\section{Materials and Methods}

\subsection{Brine Shrimp Culture}

Artemia spp. cysts (Artemia AF, INVE Aquaculture Inc., Salt Lake City, UT, USA) were decapsulated using a mixture of sodium hypochlorite ( $0.5 \mathrm{~g}$ active chlorine per gram of cysts) and sodium hydroxide (0.15 g/g cysts), following a standard procedure [23]. Residual hypochlorite was neutralized with sodium thiosulfate $(0.1 \%, w / v, 5 \mathrm{~min})$. Decapsulated cysts were hatched in sterile seawater $(33 \mathrm{~g} / \mathrm{L}$ salinity) at $26{ }^{\circ} \mathrm{C}$ [12]. After a $48 \mathrm{~h}$ incubation, hatched instar II nauplii were separated from the unhatched and empty cysts and transferred to aquaria with fresh sterile seawater. Nauplii were reared to the adult stage at $26^{\circ} \mathrm{C}$, with continuous aeration and a $24 \mathrm{~h}$ photoperiod, and fed with a commercial phytoplankton-based food (Mikrozell-Hobby, Dohse Aquaristik GmbH, Grafschaft-Gelsdorf, Germany). Different developmental stages (nauplii, metanauplii, juveniles and adults) were taken from this stock at $4,8,14$, and $21 \mathrm{~d}$ post-hatching (dph), respectively, and used in the experimental infections described below.

\subsection{LCDV Infection in Brine Shrimp}

The infectivity of LCDV to different developmental stages of Artemia (metanauplii, juveniles and adults) was tested by immersion challenge, using an inoculum of $10^{2} \mathrm{TCID}_{50} / \mathrm{mL}$ during $24 \mathrm{~h}$ as specified by Cano et al. [21]. After the challenge, animals were filtered through a synthetic net, washed three times for $5 \mathrm{~min}$ each in sterile seawater, transferred to aquaria with fresh sterile seawater, and maintained as specified above.

Two LCDV isolates were used for the challenges-LCDV SA25 from gilthead seabream (belonging to genotype VII and identified as LCDV-Sa) [24,25], and LCDV strain Leetown NFH (ATCC VR-342; genotype VIII). Brine shrimps at the same developmental stages inoculated with Leibovitz's L-15 medium (Gibco, Life Technologies, Carlsbad, CA, USA) were used as control groups.

Pooled samples of brine shrimp, approximately $100 \mathrm{mg}$ in weight, were collected from each experimental group at several times post-inoculation (pi) $(1,3,5,8,12,15$, and $23 \mathrm{dpi})$. The animals were washed with sterile seawater as specified above, gently dried on sterile filter paper, and frozen in 
liquid nitrogen. Samples were ground in liquid nitrogen using a Mixer Mill MM400 (Retsch GmbH, Haan, Germany), and subsequently used for both nucleic acid extraction and virological analysis.

\subsection{Gilthead Seabream Challenge with LCDV-Infected Artemia}

Gilthead seabream fingerlings $(0.5-1 \mathrm{~g})$ were obtained from a research marine aquaculture facility with no record of LCD. Prior to the experiment, 10 fish were randomly collected and analyzed by real-time PCR (qPCR) [22] to ensure that they were LCVD-free. The fish were divided into two groups (50 individuals per group) and stocked at a density of $2 \mathrm{~g} / \mathrm{L}$ in aquaria with filtered seawater. Fish were maintained at $20-22^{\circ} \mathrm{C}$ and a 12-h photoperiod, and fed with commercial pellets (Gemma PG 0.8, Skreeting, Burgos, Spain) at a feeding rate of approximately $5 \%$ fish body weight per day.

Artemia nauplii were inoculated by immersion with LCDV isolate SA25 or Leibovitz's L-15 medium as previously specified. At $8 \mathrm{dpi}$, metanauplii were washed with sterile seawater and used to feed gilthead seabream fingerlings. The presence of LCDV in brine shrimp (two samples of $100 \mathrm{mg}$ per experimental group) was determined by qPCR following the procedure described in Section 2.6.

For the oral challenge, fingerlings were fed once with metanauplii that had been inoculated with LCDV or L-15 medium (challenged and control groups, respectively) at a concentration of $0.2 \mathrm{~g} / \mathrm{L}$. The following day, the commercial diet was resumed, and fish were maintained at the conditions indicated above for $30 \mathrm{~d}$. Fingerlings were euthanized by anaesthetic overdose $(150 \mathrm{mg} / \mathrm{mL}$ MS-222, Sigma-Aldrich, St. Louis, MO, USA). All procedures were carried out following the European Union guidelines for the protection of animals used for scientific purposes (Directive 2010/63/UE).

Seven gilthead seabream fingerlings from both the oral challenged and control groups were randomly sampled at 7, 12, and $24 \mathrm{dpi}$. Samples, consisting of the caudal part of the body (approximately the posterior one third of the fish body), were homogenized in L-15 medium $(10 \%, w / v)$ [26] and used for nucleic acid extraction.

\subsection{Virological Analysis}

A total of $50 \mathrm{mg}$ of brine shrimp tissue powder was suspended in $1 \mathrm{~mL}$ of Leibovitz's L-15 medium supplemented with $2 \%$ L-glutamine, $1 \%$ penicillin-streptomycin and $2 \%$ foetal bovine serum, and clarified by centrifugation $\left(10,000 \times g\right.$ for $5 \mathrm{~min}$ at $4{ }^{\circ} \mathrm{C}$ ) (Rotina 38 R centrifuge, Hettich, Kirchlengern, Germany). These homogenates were used to inoculate SAF-1 cells [27], BF-2 cells for homogenates from LCDV ATCC VR-342 infected animals, or were kept at $-20{ }^{\circ} \mathrm{C}$ until used for virus titration. Cell cultures were maintained at $20^{\circ} \mathrm{C}$ until the appearance of cytopathic effects (CPE) (up to $14 \mathrm{dpi}$ ). Infectious titres were determined in SAF-1 or BF-2 cells using the ICC-RT-PCR assay described by Valverde et al. [25]. Briefly, cells were inoculated in triplicate with ten-fold serial dilutions of the homogenates and harvested at 5 dpi for total RNA extraction using a commercial kit. After DNase I treatment, one step RT-PCR was performed using primers targeting the major capsid protein $(\mathrm{mcp})$ gene. Amplification products were denatured and detected by blot-hybridization using a specific DNA probe. Viral titre, expressed as MPNIU/mL, was estimated using an MPN table with a confidence level of $95 \%$.

\subsection{DNA and RNA Extraction and cDNA Synthesis}

Total DNA and RNA were extracted from $20 \mathrm{mg}$ of tissue powder (brine shrimp samples) or $200 \mu \mathrm{L}$ of homogenate (fish samples) using the Illustra triplePrep Kit (GE Healthcare, Chicago, IL, USA), following the manufacturer's instructions. Total RNA was treated with RNase-free DNase I (Sigma-Aldrich) for $30 \mathrm{~min}$ at $37^{\circ} \mathrm{C}$. RNA purity and quantity were determined using a NanoDrop 1000 (Thermo Scientific, West Palm Beach, FL, USA). After DNase treatment, total RNA was used in the qPCR reaction in order to control for the absence of viral genomic DNA. First-strand DNA synthesis was carried out with $1 \mu \mathrm{g}$ of total RNA and random hexamer primers using the Transcriptor First Strand cDNA Synthesis Kit (Roche Life Science, Indianapolis, IN, USA). DNA and cDNA were stored at $-20{ }^{\circ} \mathrm{C}$ until used as template for qPCR. 


\subsection{LCDV DNA Quantification and Gene Expression}

Viral DNA quantification was carried out by qPCR using the methodology described by Valverde et al. [22]. Viral loads were expressed as copies of viral DNA per milligram of tissue.

The $m c p$ gene expression was analyzed as an indicator of viral productive infection. Relative quantification of $m c p$ gene expression was carried out by RT-qPCR, following the protocol mentioned above but using $20 \mu \mathrm{L}$ final volume reactions and cDNA generated from $200 \mathrm{ng}$ of the original RNA template.

For LCDV-challenged Artemia, relative viral gene expression values were calculated using the comparative delta-Ct method with Artemia actin expression used for normalization. Primers for Artemia actin gene detection by qPCR (Art-actin-F: 5'-GGTCGTGACTTGACGGACTATCT-3', and Art-actin-R: 5' - AGCGGTTGCATTTCTTGTT- $3^{\prime}$ ) were designed using Primer Express Software v3.0 (Applied Biosystems, Life Technologies, Carlsbad, CA, USA) based on the sequence obtained from GenBank (accession no. X52602.1). No significant differences in Ct values were observed for this housekeeping gene between different experimental groups during the course of the infection $(\mathrm{CV}=1.02 \%$, Kruskal-Wallis test $\mathrm{H}=2.27, p=0.13$ ).

In the case of gilthead seabream fingerlings challenged by feeding, normalized relative mcp expression levels were calculated by applying the formula $\mathrm{F}=\log _{10}\left[(\mathrm{E}+1)^{40-\mathrm{Ct}} / \mathrm{N}\right][28]$, where $\mathrm{E}$ is the amplification efficiency of the qPCR, Ct (threshold cycle) corresponds to the PCR cycle number, $\mathrm{N}$ is the maximal number of viral DNA copies/mg of tissue detected minus the number of viral DNA copies/mg of tissue determined by absolute qPCR for the sample, and Ct of 40 arbitrarily corresponds to "no $\mathrm{Ct}$ " by qPCR. In this challenge, results obtained for viral DNA quantification and relative gene expression were analyzed using a Mann-Whitney $U$ test followed by a Holm-Bonferroni correction for multiple comparisons.

\section{Results}

\subsection{Infection of Artemia spp. by LCDV}

To establish if LCDV replicates in Artemia spp. cells, experimental infections were carried out using LCDV SA25 and three developmental stages of Artemia. The time course of the experimental infection was studied by analyzing viral load and mcp gene expression in parallel. In challenged metanauplii, the viral load increased by more than two orders of magnitude from the first to the 8th dpi (from $7.6 \times 10^{0}$ to $1.7 \times 10^{3}$ copies of viral DNA/mg of tissue). The viral load remained above $10^{2}$ copies of viral DNA/mg during the entire sampling period (Figure $\left.1 \mathrm{~A}\right)$. In juveniles and adults, the time course of the infection was similar to that obtained for metanauplii, reaching the maximal value at $8 \mathrm{dpi}\left(6.7 \times 10^{2}\right.$ and $7 \times 10^{2}$ copies of viral DNA/mg of tissue, respectively) (Figure $\left.1 \mathrm{~A}\right)$. Relative expression of viral mcp transcripts showed a similar temporal evolution for the three experimental groups analyzed, reaching the highest value at $8 \mathrm{dpi}$ (Figure 1B). Neither LCDV genomes nor mRNA were detected in brine shrimp inoculated with L-15 medium (control groups). 

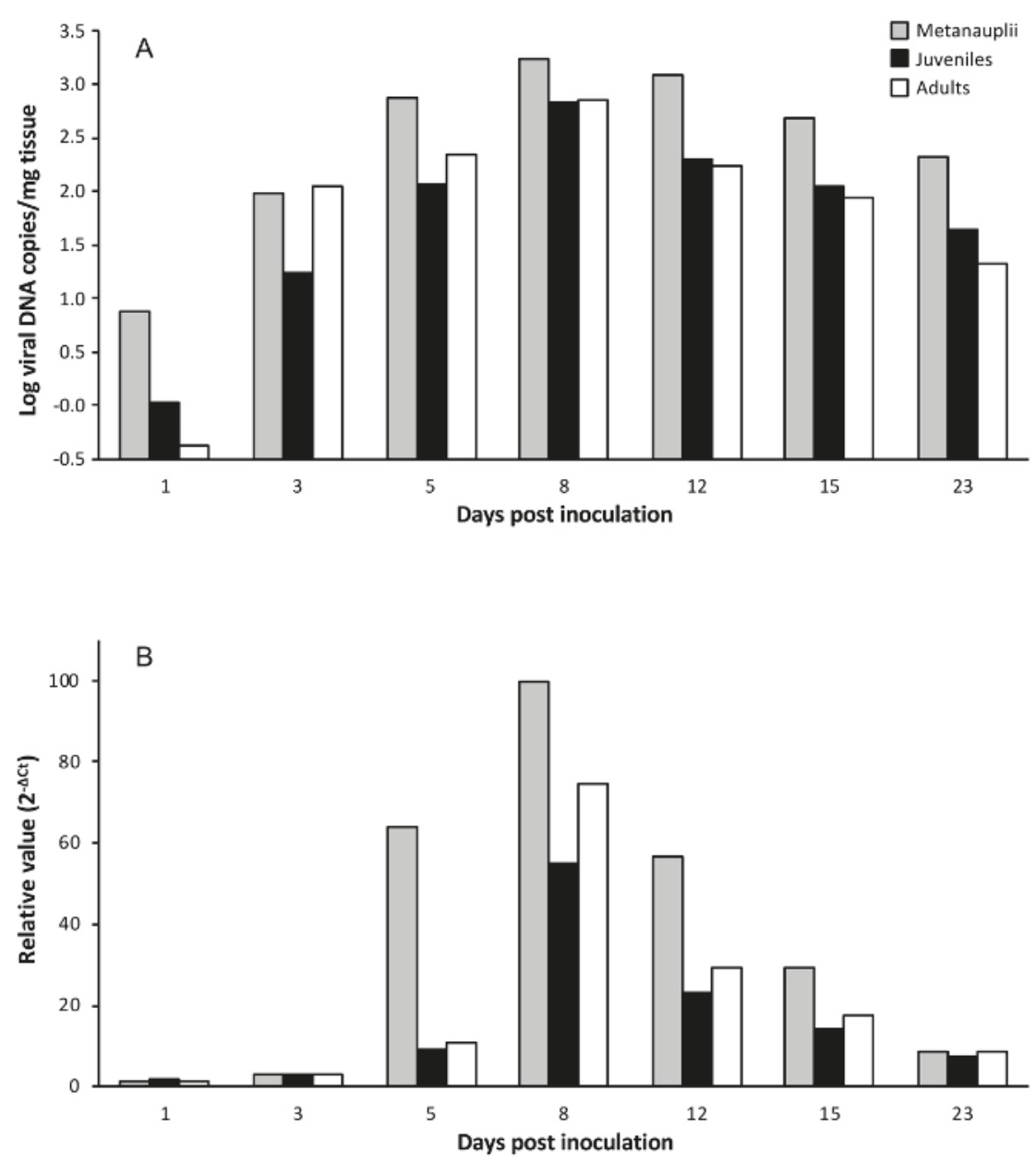

Figure 1. Temporal evolution of viral loads (A) and relative major capsid protein ( $m c p)$ gene expression values (B) in different developmental stages of Artemia inoculated with Lymphocystis disease virus (LCDV) SA25.

No CPE could be observed in cell cultures inoculated with LCDV-infected Artemia homogenates and maintained up to 14 dpi. Nevertheless, by using the ICC-RT-PCR assay, viral infectious titre determination was carried out at $8 \mathrm{dpi}$. The estimated viral titres were $9.3 \times 10^{1} \mathrm{MPNIU} / \mathrm{mg}$ for metanauplii and juveniles, and $2.3 \times 10^{2} \mathrm{MPNIU} / \mathrm{mg}$ for infected adults.

Viral load and mcp gene expression were also investigated in Artemia metanauplii challenged with LCDV ATCC VR-342. Viral load reached the maximal value at $12 \mathrm{dpi}\left(1.7 \times 10^{2}\right.$ copies of viral DNA $/ \mathrm{mg}$ of tissue), and the same was observed for relative viral gene expression (Figure 2). In this case, the viral titre at 8 dpi was $7.5 \mathrm{MPNIU} / \mathrm{mg}$, one order of magnitude lower than obtained in metanauplii infected by LCDV SA25.

In any of the experimental groups, clinical signs or mortality were not observed in the Artemia cultures. 

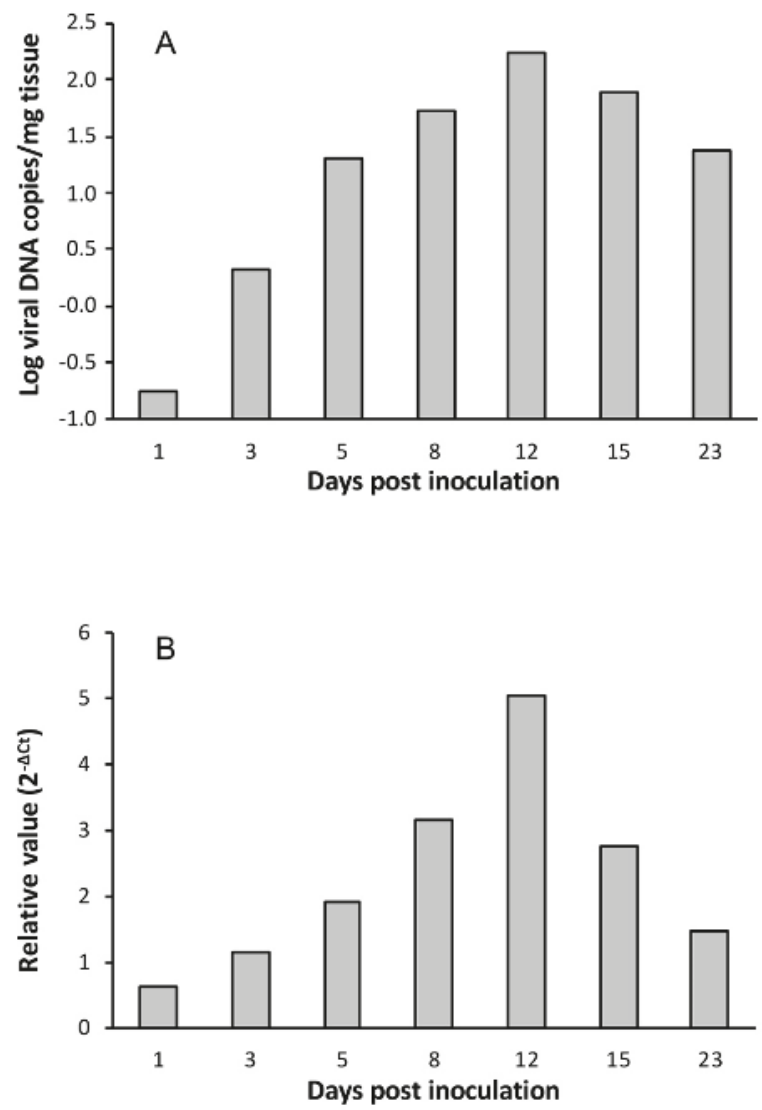

Figure 2. Temporal evolution of viral loads (A) and relative mcp gene expression values (B) in Artemia metanauplii inoculated with LCDV ATCC VR-342.

\subsection{LCDV Transmission to Gilthead Seabream Fingerlings}

Artemia metanauplii used for fingerlings feeding were infected by LCDV, as demonstrated by qPCR, with an estimated viral load of $1.2 \pm(0.1) \times 10^{3}$ copies of viral DNA/mg of tissue, whereas metanauplii in the control group remained LCDV-negative.

In fingerlings fed on the LCDV-positive metanauplii (challenged group), LCDV was detected by qPCR in all fish and at all time points analyzed. At $7 \mathrm{dpi}$, the estimated viral load ranged between 10.6 and 26.8 copies of viral DNA per mg of tissue. Five days later, viral loads were significantly higher $(p<0.01)$, and they remained at similar values at $24 \mathrm{dpi}$ (Figure 2A). No LCD symptoms were observed in these fish at the end of the experiment $(30 \mathrm{dpi})$. The mcp gene expression was also detected in all fish analyzed, with the highest F-value observed at 12 dpi (Figure 3B). Neither LCDV genomes nor mRNA were detected in fish from the control group (i.e., fed on metanauplii inoculated with L-15 medium). 

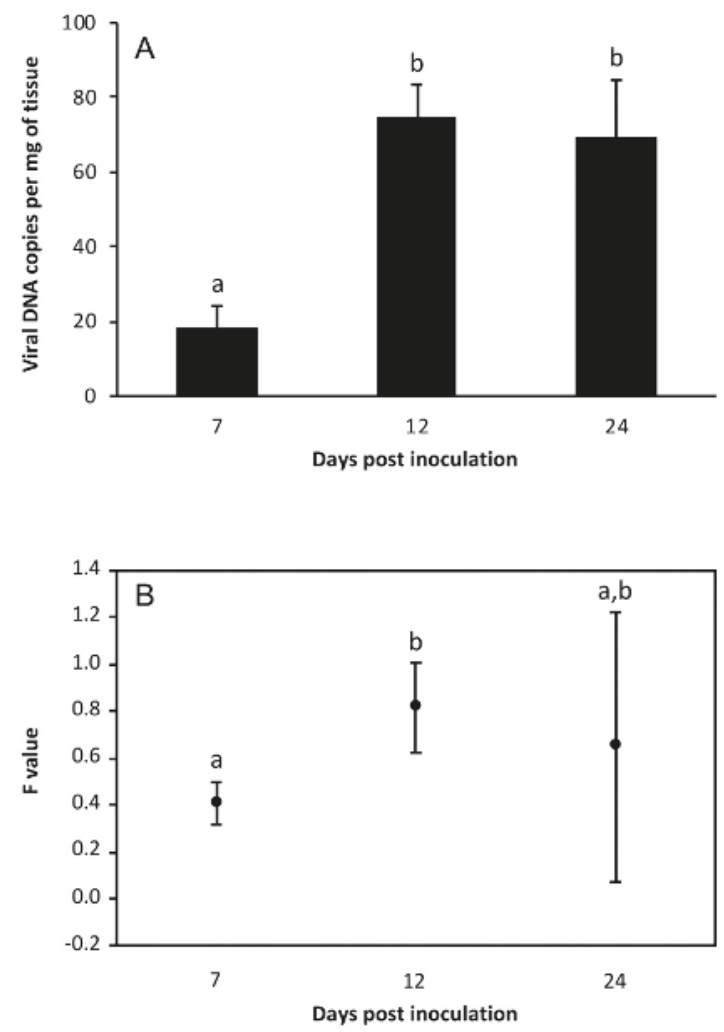

Figure 3. Viral loads (A) and relative $m c p$ gene expression values (B) in gilthead seabream fingerlings orally challenged with LCDV-positive Artemia metanauplii (mean \pm standard deviation; $n=7$ ). Different letters indicate significant differences $(p<0.01$ ) (Mann-Whitney U-test, Holm-Bonferroni correction).

\section{Discussion}

A number of studies have confirmed the role of Artemia nauplii as vectors for several crustacean viruses, such as Macrobrachium rosenbergii nodavirus (MrNV), hepatopancreatic parvo-like virus (HPV), white spot syndrome virus (WSSV), and infectious myonecrosis virus (IMNV) [29-32]. In addition, Artemia appears to be susceptible to some of these viruses, including WSSV and MrNV, with the infection being asymptomatic [33,34]. Regarding fish pathogens, Artemia nauplii have proven to be a mechanical vector only in the case of microsporidia and Vibrio anguillarum [35,36], although some studies have shown that they could also accumulate viral pathogens and protozoa $[16,19,37]$.

Previous studies demonstrated that infectious virus could be detected in Artemia nauplii inoculated with LCDV-Sa by immersion and the virus persisted to the adult stage, and from adults to reproductive cysts [21]. These results led us to consider the hypothesis that Artemia spp. could be susceptible to LCDV infection, acting as reservoir and biological vector for LCDV.

The results obtained in the experimental infections carried out demonstrated that Artemia spp. could be infected by LCDV at different developmental stages, since viral loads increased during the course of the experiments. In addition, viral transcripts were also detected, showing a similar temporal evolution. Thus, Artemia spp. seems to be a susceptible host for LCDV, at least in experimental conditions, with the resulting infection being asymptomatic. This is the first description of a fish virus that also infects invertebrates. Viral loads and infectious titres estimated in LCDV-infected Artemia 
were higher than those previously obtained for subclinically infected gilthead seabream fingerlings or juveniles $[25,28,38]$.

During the course of the experimental infections, particularly in those performed with metanauplii and juveniles, brine shrimps kept growing, doubling or tripling in size, and completed their life cycle, becoming adults. Thus, viral loads expressed per mg of tissue are difficult to interpret, and do not reflect actual viral loads per individual. Taking this into account, the number of genome copies probably increased in each brine shrimp specimen during the experimental trial.

Viral replication kinetics were similar in the experimental infections carried out with different developmental stages of Artemia. Nevertheless, relative viral gene expression values were higher in metanauplii compared to juveniles or adults infected by LCDV SA25, although this difference was not reflected in infectious titres. Differences in relative viral expression values were observed in metanauplii infected by both viral isolates, which might indicate that viral infectivity is variable among LCDV genotypes or that Artemia susceptibility to these isolates differs.

On the other hand, gilthead seabream fingerlings fed on LCDV-infected metanauplii became infected, as demonstrated by the increase in the number of LCDV DNA copies during the experimental period, and the detection of viral transcripts in these animals. Estimated viral loads were consistent with those previously reported for asymptomatic infections in gilthead seabream [25]. These results indicate that Artemia metanauplii can be a vector for LCDV, participating in viral transmission to gilthead seabream via the alimentary route under laboratory conditions that mimics those used in aquaculture farms. Whether Artemia is also a reservoir host for LCDV remains to be investigated.

In conclusion, the results demonstrate that LCDV establishes a productive infection in Artemia spp., at least under the experimental conditions tested, which extend the host range of the genus Lymphocystivirus to crustaceans. Furthermore, our study confirms that Artemia metanauplii act as a vector for LCDV transmission to gilthead seabream fingerlings.

Author Contributions: Conceptualization and experimental design, J.J.B. and D.C.; investigation, E.J.V.; formal analysis and visualization, E.J.V. and A.M.L.; writing-original draft, J.J.B. and D.C.; writing-review and editing, J.J.B., D.C. and A.M.L.; all authors read and approved the final manuscript.

Funding: This study has been supported by a project from Junta de Andalucía (P12-RNM-2261) granted to J.J. Borrego.

Conflicts of Interest: The authors declare no conflict of interest.

\section{References}

1. Chinchar, V.G.; Hick, P.; Ince, I.A.; Jancovich, J.K.; Marschang, R.E.; Qin, Q.; Subramaniam, K.; Waltzek, T.B.; Whittington, R.J.; Williams, T.; et al. ICTV virus taxonomy profile: Iridoviridae. J. Gen. Virol. 2017, 98, 890-891. [CrossRef] [PubMed]

2. Chinchar, V.G.; Kwang, H.Y.; Jancovich, J.K. The molecular biology of Frog virus 3 and other iridoviruses infecting cold-blooded vertebrates. Viruses 2011, 3, 1959-1985. [CrossRef] [PubMed]

3. Jancovich, J.K.; Qin, Q.; Zhang, Q.-Y.; Chinchar, V.G. Ranavirus replication: Molecular, cellular, and immunological events. In Ranaviruses: Lethal Pathogens of Ectotermic Vertebrates; Gray, M.J., Chinchar, V.G., Eds.; Springer OPEN: Heidelberg, Germany, 2015; pp. 71-104.

4. Borrego, J.J.; Valverde, E.J.; Labella, A.M.; Castro, D. Lymphocystis disease virus: Its importance in aquaculture. Rev. Aquac. 2017, 9, 179-193. [CrossRef]

5. Sarasquete, C.; Gonzalez de Canales, M.L.; Arellano, J.; Perez-Prieto, S.I.; Garcia-Rosado, E.; Borrego, J.J. Histochemical study of lymphocystis disease in skin of gilthead seabream, Sparus aurata, from the South Atlantic coast of Spain. Histol. Histopathol. 1998, 13, 37-45. [PubMed]

6. Smail, D.A.; Munro, A.L.S. The virology of teleosts. In Fish Pathology, 3rd ed.; Roberts, R.J., Ed.; W.B. Saunders: Edinburgh, UK, 2011; pp. 169-253.

7. Masoero, L.; Ercolini, C.; Caggiano, M.; Rossa, A. Osservazioni preliminary sulla linfocisti in una maricoltura intensive italiana. Riv. Ital. Piscic. Ittiopatol. 1986, 21, 70-74. 
8. Colorni, A.; Padrós, F. Diseases and health management. In Sparidae: Biology and Aquaculture of Gilthead Sea Bream and Other Species; Pavlidis, M., Mylonas, C., Eds.; Wiley-Blackwell: Oxford, UK, 2011; pp. 321-357.

9. Bowser, P.R.; Wooster, G.A.; Getchell, R.G. Transmission of walleye dermal sarcoma and lymphocystis via the waterborne exposure. J. Aquat. Anim. Health 1999, 11, 158-161. [CrossRef]

10. Wolf, K. Fish Viruses and Fish Viral Diseases; Cornell University Press: Ithaca, NY, USA, 1988.

11. Cano, I.; Valverde, E.J.; Garcia-Rosado, E.; Alonso, M.C.; Lopez-Jimena, B.; Ortiz-Delgado, J.B.; Borrego, J.J.; Sarasquete, C.; Castro, D. Transmission of lymphocystis disease virus to cultured gilthead seabream, Sparus aurata L., larvae. J. Fish Dis. 2013, 36, 569-576. [CrossRef] [PubMed]

12. Lavens, P.; Sorgeloos, P. Manual on the Production and Use of Live Food for Aquaculture; FAO Fisheries Technical Paper No. 361; FAO: Rome, Italy, 1996; 295p.

13. Sorgeloos, P.; Dhert, P.; Candreva, P. Use of the brine shrimp, Artemia spp., in marine fish larviculture. Aquaculture 2001, 200, 147-159. [CrossRef]

14. Austin, B.; Allen, D.A. Microbiology of laboratory hatched brine shrimp (Artemia). Aquaculture 1982, 26, 369-383. [CrossRef]

15. Mendez-Hermida, F.; Gomez-Couso, H.; Ares-Mazas, E. Artemia is capable of spreading oocysts of Cryptosporidium and the cysts of Giardia. J. Eukaryot. Microbiol. 2006, 53, 432-434. [CrossRef]

16. Mortensen, S.; Evensen, O.; Rodseth, O.; Hjeltnes, B. The relevance of infectious pancreatic necrosis virus IPNV in farmed Norwegian turbot Scophthalmus maximus. Aquaculture 1993, 115, 245-252. [CrossRef]

17. Muroga, K.; Higashi, M.; Keitiku, H. The isolation of intestinal microflora of farmed red seabream Pagrus major and black seabream Acanthopagrus schlegeli larval juvenile stages. Aquaculture 1987, 65, 79-88. [CrossRef]

18. Nicolas, J.L.; Robic, E.; Ansquer, D. Bacterial flora associated with a trophic chain consisting of microalgae, rotifers and turbot larvae: Influence of bacteria on larval survival. Aquaculture 1989, 83, 237-248. [CrossRef]

19. Skliris, G.P.; Richards, R.H. Assessment of the susceptibility of the brine shrimp Artemia salina and rotifer Brachionus plicatilis to experimental nodavirus infections. Aquaculture 1998, 169, 133-141. [CrossRef]

20. Overstreet, R.M.; Stuck, K.C.; Krol, R.A.; Hawkins, W.E. Experimental infection with Baculovirus penaei in white shrimp Penaeus vannamei (Crustacea: Decapoda) as a bioassay. J. World Aquac. Soc. 1988, 19, 175-187. [CrossRef]

21. Cano, I.; Lopez-Jimena, B.; Garcia-Rosado, E.; Ortiz-Delgado, J.B.; Alonso, M.C.; Borrego, J.J.; Sarasquete, M.C.; Castro, D. Detection and persistence of lymphocystis disease virus in Artemia sp. Aquaculture 2009, 291, 230-236. [CrossRef]

22. Valverde, E.J.; Cano, I.; Labella, A.; Borrego, J.J.; Castro, D. Application of a new real-time polymerase chain reaction assay for surveillance studies of lymphocystis disease virus in farmed gilthead seabream. BMC Vet. Res. 2016, 12, 71. [CrossRef]

23. Moretti, A.; Fernandez-Criado, M.P.; Cittolin, G.; Guidastri, R. Manual on Hatchery Production of Seabass and Gilthead Seabream; Food and Agriculture Organization of the United Nations (FAO): Rome, Italy, 1999; Volume 1, pp. 75-82.

24. Cano, I.; Valverde, E.J.; Lopez-Jimena, B.; Alonso, M.C.; Garcia-Rosado, E.; Sarasquete, M.C.; Borrego, J.J.; Castro, D. A new genotype of Lymphocystivirus isolated from cultured gilthead seabream, Sparus aurata L., and Senegalese sole, Solea senegalensis (Kaup). J. Fish Dis. 2010, 33, 695-700. [CrossRef]

25. Valverde, E.J.; Borrego, J.J.; Castro, D. Evaluation of an integrated cell culture RT-PCR assay to detect and quantify infectious lymphocystis disease virus. J. Virol. Methods 2016, 238, 62-65. [CrossRef]

26. Alonso, M.C.; Cano, I.; Garcia-Rosado, E.; Castro, D.; Lamas, J.; Barja, J.L.; Borrego, J.J. Isolation of lymphocystis disease virus from sole, Solea senegalensis Kaup, and blackspot sea bream, Pagellus bogaraveo (Brünnich). J. Fish Dis. 2005, 28, 221-228. [CrossRef]

27. Bejar, J.; Borrego, J.J.; Alvarez, M.C. A continous cell line from the cultured marine fish gilt-head sea bream (Sparus aurata L.). Aquaculture 1997, 150, 143-153. [CrossRef]

28. Valverde, E.J.; Borrego, J.J.; Sarasquete, M.C.; Ortiz-Delgado, J.B.; Castro, D. Target organs for lymphocystis disease virus replication in gilthead seabream (Sparus aurata). Vet. Res. 2017, 48, 21. [CrossRef] [PubMed]

29. Da Silva, S.M.B.C.; Lavander, H.D.; De Santana Luna, M.M.; Da Silva, A.O.M.E.; Galvez, A.O.; Coimbra, M.R.M. Artemia franciscana as a vector for infectious myonecrosis virus (IMNV) to Litopenaeus vannamei juvenile. J. Invertebr. Pathol. 2015, 126, 1-5. [CrossRef] [PubMed] 
30. Sivakumar, V.K.; Sarathi, M.; Venkatesan, C.; Sivaraj, A.; Sahul Hameed, A.S. Experimental exposure of Artemia to hepatopancreatic parvo-like virus and subsequent transmission to post-larvae of Penaeus monodon. J. Invertebr. Pathol. 2009, 102, 191-195. [CrossRef] [PubMed]

31. Sudhakaran, R.; Yoganadhan, K.; Ishaq Ahmed, V.P.; Sahul Hameed, A.S. Artemia as a possible vector for Macrobrachium rosenbergii nodavirus (MrNV) and extra small virus transmission (XSV) to Macrobrachium rosenbergii post-larvae. Dis. Aquat. Org. 2006, 70, 161-166. [CrossRef] [PubMed]

32. Zhang, J.S.; Dong, S.L.; Dong, Y.W.; Tian, X.L.; Cao, Y.C.; Li, Z.J.; Yan, D.C. Assessment of the role of brine shrimp Artemia in white spot syndrome virus (WSSV) transmission. Vet. Res. Commun. 2010, 34, $25-32$. [CrossRef]

33. Li, Q.; Zhang, J.; Chen, Y.; Yang, F. White spot syndrome virus (WSSV) infectivity for Artemia at different developmental stages. Dis. Aquat. Org. 2003, 57, 261-264. [CrossRef]

34. Sudhakaran, R.; Ishaq Ahmed, V.P.; Haribabu, P.; Mukherjee, S.C.; Sri Widada, J.; Bonami, J.R.; Sahul-Hameed, A.S. Experimental vertical transmission of Macrobrachium rosenbergii nodavirus (MrNV) and extra small virus (XSV) from brooders to progeny in Macrobrachium rosenbergii and Artemia. J. Fish Dis. 2007, 30, 27-35. [CrossRef]

35. Grisez, L.; Chair, M.; Sorgeloos, P.; Ollevier, F. Mode of infection and spread of Vibrio anguillarum in turbot Scophthalmus maximus larvae after oral challenge through live feed. Dis. Aquat. Org. 1996, 26, 181-187. [CrossRef]

36. Olson, R.E. Laboratory and field studies on Glugea stephani (Hagenmuller), a microsporidan parasite of pleuronectid flatfishes. J. Protozool. 1976, 23, 158-164. [CrossRef]

37. Mendez-Hermida, F.; Gomez-Couso, H.; Ares-Mazas, E. Possible involvement of Artemia as live diet in the transmission of cryptosporidiosis in cultured fish. Parasitol. Res. 2007, 101, 823-827. [CrossRef] [PubMed]

38. Valverde, E.J.; Cano, I.; Castro, D.; Paley, R.K.; Borrego, J.J. Rapid and sensitive detection of Lymphocystis disease virus genotype VII by loop-mediated isothermal amplification. Food Environ. Virol. 2017, 9, 114-122. [CrossRef] [PubMed]

(C) 2019 by the authors. Licensee MDPI, Basel, Switzerland. This article is an open access article distributed under the terms and conditions of the Creative Commons Attribution (CC BY) license (http://creativecommons.org/licenses/by/4.0/). 


\title{
Technical Note \\ eDNA Increases the Detectability of Ranavirus Infection in an Alpine Amphibian Population
}

\author{
Claude Miaud ${ }^{1, *}$, , Véronique Arnal ${ }^{1}$, Marie Poulain ${ }^{1}$, Alice Valentini ${ }^{2}$ and Tony Dejean ${ }^{2}$ \\ 1 CEFE, EPHE-PSL, CNRS, Univ. Montpellier, Univ Paul Valéry Montpellier 3, IRD, Biogeography and \\ Vertebrate Ecology, 1919 route de Mende, 34293 Montpellier, France; veronique.arnal@cefe.cnrs.fr (V.A.); \\ marie.poulain@cefe.cnrs.fr (M.P.) \\ 2 SPYGEN, 17 Rue du Lac Saint-André, 73370 Le Bourget-du-Lac, France; alice.valentini@spygen.com (A.V.); \\ tony.dejean@spygen.com (T.D.) \\ * Correspondence: claude.miaud@cefe.cnrs.fr; Tel.: +33-(0)4-67-61-33-43
}

Received: 15 March 2019; Accepted: 4 June 2019; Published: 6 June 2019

\begin{abstract}
The early detection and identification of pathogenic microorganisms is essential in order to deploy appropriate mitigation measures. Viruses in the Iridoviridae family, such as those in the Ranavirus genus, can infect amphibian species without resulting in mortality or clinical signs, and they can also infect other hosts than amphibian species. Diagnostic techniques allowing the detection of the pathogen outside the period of host die-off would thus be of particular use. In this study, we tested a method using environmental DNA (eDNA) on a population of common frogs (Rana temporaria) known to be affected by a Ranavirus in the southern Alps in France. In six sampling sessions between June and September (the species' activity period), we collected tissue samples from dead and live frogs (adults and tadpoles), as well as insects (aquatic and terrestrial), sediment, and water. At the beginning of the breeding season in June, one adult was found dead; at the end of July, a mass mortality of tadpoles was observed. The viral DNA was detected in both adults and tadpoles (dead or alive) and in water samples, but it was not detected in insects or sediment. In live frog specimens, the virus was detected from June to September and in water samples from August to September. Dead tadpoles that tested positive for Ranavirus were observed only on one date (at the end of July). Our results indicate that eDNA can be an effective alternative to tissue/specimen sampling and can detect Ranavirus presence outside die-offs. Another advantage is that the collection of water samples can be performed by most field technicians. This study confirms that the use of eDNA can increase the performance and accuracy of wildlife health status monitoring and thus contribute to more effective surveillance programs.
\end{abstract}

Keywords: eDNA; Ranavirus; Common frog; Rana temporaria; early detection; virus surveillance

\section{Introduction}

Amphibians are often considered ecosystem health indicators ("the canaries in the coal mine", [1]) due to their permeable skin, their sensitivity to environmental disturbance, and their often biphasic (requiring water and land) life cycle (e.g., [2]). Over $40 \%$ of the more than 7000 species that have been evaluated are classified as threatened today, and the main cause of the disappearance or decline of amphibian populations is the degradation and destruction of their habitats [3]. Emerging infectious diseases (EIDs) are also causing drastic amphibian declines worldwide [4-6], and the chytridiomycosis panzootic has been involved in the decline of at least 501 amphibian species over the past half-century, including 90 presumed extinctions [7]. Ranaviruses (family Iridoviridae)—double-stranded DNA viruses that infect fish, reptiles, and amphibians [8] —are considered the second most common infectious cause of mortality in amphibians $[9,10]$. These viruses have caused amphibian die-offs on 
five continents [11]. The common midwife toad virus (CMTV) [12] is a Ranavirus that has been causing amphibian die-offs since 2005 in Spain [10]. Since then, CMTV-related mortality has been recorded in other European countries, affecting several amphibian species in both Anura and Caudata [13,14].

The rapid and accurate identification of pathogenic microorganisms is essential for the early detection of infection and the deployment of appropriate mitigation measures [15]. Several field studies have reported Ranavirus-infected amphibians that do not present clinical signs or histological changes (e.g., [16]). The use of molecular techniques to identify microbial pathogens (e.g., see reviews in [17] for fungus and [18] for viruses) has considerably improved detection possibilities. Molecular tools applied to environmental samples are now widely used to identify infectious agents [19] and are particularly promising for the early detection of aquatic pathogens that can be introduced by non-native species (e.g., [20]). In the last decade, the DNA detection of pathogens in environmental samples (e.g., in water) has been performed successfully to identify several metazoan parasites, fungi (Chytrid and Oomycota), and Ranaviruses [21-28]. By comparing water samples and the Ranavirus infection status of wood frog tadpoles (Lithobates sylvaticus) in several ponds in north-eastern Connecticut in the United States, Hall et al. (2016) [24] demonstrated a strong relationship between the viral load in environmental DNA (eDNA) and larval tissues, indicating the effectiveness of eDNA-based Ranavirus detection in the field.

In Europe, Ranavirus infections and die-offs have been described in four amphibian families and ten species $[8,13]$. One of these species is the common frog (Rana temporaria), which is experiencing population die-offs in alpine lakes [13]. This study had two key aims: (1) To describe the infection status of different potential hosts of Ranavirus (common frog adults, tadpoles, and insects) and ecosystem compartments (sediment and water) in an alpine lake during the activity period (summer), both prior to and after an observed die-off; and (2) to use the eDNA method to detect Ranavirus during this infection event. We also compared previous studies using eDNA to detect Chytrids and Ranavirus to provide some recommendations for a more effective implementation of water sampling in monitoring programs.

\section{Materials and Methods}

\subsection{Study Area}

The study was conducted in Mercantour National Park in the south-eastern Alps in France. The sampled area consisted of several small lakes and a pond. Balaour pond (44.1082 N, 7.3742 E) is $25 \times 20 \mathrm{~m}$, and $2355 \mathrm{~m}$ a.s.l. It lies at a distance approximately $100 \mathrm{~m}$ from the closest lake. The maximum depth is $1.5 \mathrm{~m}$, and the bottom is granitic rock, partly covered by a shallow ( $\max 0.10 \mathrm{~m}$ ) sedimentary layer of mud. There is no macrophytic vegetation.

The common frog $R$. temporaria uses these kinds of water bodies for breeding and hibernation in this alpine region [29]. In the study area, the common frog is the only amphibian species present, and it breeds only in Balaour pond (no breeding in the neighboring lakes). Many lakes are stocked with brown trout (Salmo trutta), and the common minnow (Phoxinus phoxinus), which is used as bait, has also been introduced in the lakes. However, there are no trout or minnows in the studied pond.

\subsection{Water Temperature}

The water temperature during the study was recorded using two data loggers (model iBCod 21G, Maxim/Dallas Semiconductor Inc., San Jose, CA, USA, accuracy $\left.+/-1{ }^{\circ} \mathrm{C}\right)$. These were attached to a PVC tube (50 mm diameter; $40 \mathrm{~cm}$ in length) with one end glued to a $20 \times 20 \mathrm{~cm}$ polystyrene float. One logger was positioned just below the float, and the other was positioned $25 \mathrm{~cm}$ from the first logger. They were programmed to record the temperature every two hours. The device was set in the field at 14:00 on the first day of the survey (11 June 2016) and remained there until 10:00 on the last day (19 September 2016). To do this, a $2 \mathrm{~m}$ high metallic pole was staked into the ground in the middle of Balaour pond (depth about $1 \mathrm{~m}$ ). The PVC tube was then fitted to the pole with the float at the top. The data loggers were at a depth of about 5 and $30 \mathrm{~cm}$, respectively. The PVC tube and 
float were designed to follow changes in water level so the data loggers recorded temperatures at a constant depth.

\subsection{Amphibian Sampling}

Sampling was carried out at Balaour pond on six dates between June and September in 2016 (Table 1), covering the developmental period of embryos and tadpoles in this region and at this altitude.

Table 1. Sampling at Balaour pond in 2016.

\begin{tabular}{lllllll}
\hline \multirow{2}{*}{ Samples } & \multicolumn{5}{c}{ Date } \\
\cline { 2 - 7 } & 10-11 June & 23-24 June & 08 July & 27 July & 15-16 August & 19 September \\
\hline Tadpole alive & $5(9-11)^{1}$ & $5(24-25)$ & $5(30)$ & $5(35-39)$ & $5(39-41)$ & $5(43-45)$ \\
Tadpole dead & - & - & - & $10(35-39)$ & - & 5 \\
Adult alive $^{2}$ & 5 & 5 & 5 & 0 & 1 & - \\
Adult dead $^{\text {Terrestrial insects }}{ }^{3}$ & 1 & - & - & - & - & 1 \\
Aquatic insects $^{4}$ & 1 & 1 & 1 & 1 & 1 & 1 \\
Sediment $^{5}$ & 1 & 1 & 1 & 1 & 1 & 1 \\
Water $^{6}$ & 1 & 1 & 1 & 1 & 1 & 1
\end{tabular}

${ }^{1}$ Stage of development (based on Gosner stages [30]); ${ }^{2}$ the distal phalange of the second forelimb toe was collected from adults caught in water; ${ }^{3}$ one sample per date, consisting of all flying insects caught with three yellow plates placed around the pond and then pooled together; ${ }^{4}$ one sample per date, consisting of all aquatic insects caught by dip-netting in the pond and then pooled together; ${ }^{5}$ one sample of sediment per date, consisting of 20 subsamples collected around the pond and then pooled together; ${ }^{6}$ one sample of water per date, consisting of 20 subsamples collected around the pond, filtered and pooled together (see M\&M for more details).

The pond was visually scanned to detect tadpoles and adults resting on the bottom. Live tadpoles were caught by a dip-net (mesh $1 \mathrm{~mm})$. They were stored in individual plastic bottles $(1.5 \mathrm{~mL})$ filled with $95 \%$ ethanol. Dead tadpoles were collected and stored similarly. Live adults were caught by a dip-net (5 mm mesh), and the distal phalange of the second forelimb toe was collected and stored individually in a snap-cap tube $(1.5 \mathrm{~mL})$ filled with $95 \%$ ethanol. Disposable gloves were used and changed between each sampling, and the material (scissors and pliers) was soaked in ethanol and passed through a flame between each sample collection. The dead adults were collected with the dip-net and stored in a plastic bottle $(300 \mathrm{~mL})$ filled with $95 \%$ ethanol. Table 1 shows the sample size and developmental stages [30] of the tadpoles and adults collected. The toe clipping allowed us to check that unique adult specimens were sampled during the study period.

\subsection{Insect Sampling}

Both terrestrial and aquatic insects were collected in the six sampling sessions (Table 1). Terrestrial insects were collected using three yellow plastic plates placed on the ground about $10 \mathrm{~m}$ from the edge of the pond. These plates were filled with water and one drop of domestic detergent. After one hour of sampling, the flying insects found dead in the liquid were collected and stored in a $15 \mathrm{~mL}$ plastic bottle filled with $95 \%$ ethanol. Aquatic insects were caught by dip-netting ( $1 \mathrm{~mm}$ mesh), mostly in the shallow area of the pond (less than $0.60 \mathrm{~m}$ deep). To limit contamination with the surrounding water, each specimen was removed with needle-nose pliers and washed with distilled water. The aquatic insects collected on the same date were stored in the same $15 \mathrm{~mL}$ plastic bottle filled with $95 \%$ ethanol.

\subsection{Water Sampling}

The field survey method was modified from that used in [31]. Using a sterile water-sample dipper, a $100 \mathrm{~mL}$ water sample was collected at 20 locations equally spaced around the edge of Balaour pond, resulting in a pooled sample of approximately $2 \mathrm{~L}$ contained in a sterile self-supporting plastic bag. Samples were collected from the top $0.10 \mathrm{~m}$ of the water column preceded by a gentle circular movement with the sampling ladle. Surveyors stood on the pond bank without entering the water to avoid possible contamination from their boots or from stirring up sediment. The $2 \mathrm{~L}$ water sample was 
homogenized by gently shaking the bag to ensure the eDNA was evenly mixed throughout the sample, and the whole $2 \mathrm{~L}$ water sample was then filtered directly in the field through a VigiDNA $0.45 \mu \mathrm{m}$ filter (SPYGEN, Le Bourget du Lac, France) using a sterile $100 \mathrm{~mL}$ syringe. The filter was filled with $80 \mathrm{~mL}$ of a CL1 conservative buffer (SPYGEN) and stored at room temperature before DNA extraction.

\subsection{Sediment Sampling}

At each of the six sampling sessions, sediment (approximately $10 \mathrm{~mL}$ ) was collected from 20 locations evenly distributed around Balaour pond. Each sediment sample was collected approximately $0.5 \mathrm{~m}$ from the shoreline using a sterile syringe $(20 \mathrm{~mL})$ pushed into the top $5 \mathrm{~cm}$ of sediment. The 20 samples were placed into a shared sterile bag, mixed together, and then stored in a sterile wide-neck barrel (1 L).

\subsection{Ranavirus Detection in Frogs, Tadpoles and Insects}

From the adult frogs, a small piece $\left(2 \mathrm{~mm}^{3}\right)$ of tissue was collected: Liver tissue from dead specimens (which were dissected) and toe tissue from live specimens. For small tadpoles, the total tadpole was used (e.g., individuals $<10 \mathrm{~mm}$, Gosner stage 25). For larger tadpoles (Gosner stages $30-45$ ), individuals were dissected, and a total tissue volume of about $2 \mathrm{~mm}^{3}$ was collected, mostly composed of the liver and heart. For both aquatic and terrestrial insects, specimens were grouped per date of sampling and crushed together in $5 \mathrm{~mL}$ of $95 \%$ ethanol. A subsample of $1.5 \mathrm{~mL}$ was collected for DNA analysis.

The DNA was extracted with a REDExtract-N-Amp Plant Kit (Sigma-Aldrich-Merck, Darmstadt, Germany) by incubating a piece of tissue or the bulk of insects in $50 \mu \mathrm{L}$ of extraction solution at $95^{\circ} \mathrm{C}$ for $20 \mathrm{~min}$ after ethanol evaporation $\left(56^{\circ} \mathrm{C}\right.$ for $\left.30 \mathrm{~min}\right)$. An equal volume of dilution solution was added to the extract to neutralize inhibitory substances before a polymerase chain reaction (PCR).

The Taqman real-time quantitative PCRs were performed following the protocol described in detail in [13], using primers and probes designed by Leung et al. (2017) [32]. All assays were performed in triplicate. Ranavirus DNA, provided in several densities by Stephen Price (Zoological Society, London, UK), was used to calibrate the standard curve.

A sample was considered positive if the amplification curves were similar to those in positive controls (i.e., shape, cycle threshold, values, and $>0.1$ genomic equivalent), and at least two replicates gave positive amplification. If only one well resulted in a positive signal, the sample was rerun and was considered positive if at least two wells gave a positive amplification signal. The results were expressed in terms of genomic equivalent (GE) and prevalence (number of positive samples/total number of samples).

\subsection{Ranavirus Detection in Sediment}

The sediment samples were weighed, and a similar weight of a saturated phosphate buffer $\left(\mathrm{Na}_{2} \mathrm{HPO}_{4} ; 0.12 \mathrm{~m} ; \mathrm{pH} \approx 8\right)$ was added, as described in [33]. The DNA extraction was performed using a commercial kit for soil DNA (NucleoSpin ${ }^{\circledR}$ Soil; Macherey-Nagel, Düren, Germany), following the manufacturer's instructions. The PCR amplifications were performed following the protocol previously described for amphibian tissue and insects.

\subsection{Ranavirus Detection in Water}

For the water samples, DNA extraction was performed following the protocol described in [34] in a dedicated room for water DNA extraction equipped with positive air pressure, UV treatment, and frequent air renewal. Before entering this extraction room, personnel used a connecting zone to change into full protective clothing, comprising a disposable body suit with hood, mask, laboratory shoes, overshoes, and gloves. All workbenches were decontaminated with commercial bleach, diluted to achieve a $0.5 \%$ sodium hypochlorite solution, before and after each manipulation. For DNA extraction, each filtration capsule, containing the CL1 buffer, was agitated for $15 \mathrm{~min}$ on an S50 shaker 
(cat Ingenieurbüro ${ }^{\mathrm{TM}}$ ) at $800 \mathrm{rpm}$, and then the buffer was emptied into a $50 \mathrm{~mL}$ tube before being centrifuged for $15 \mathrm{~min}$ at $15,000 \times \mathrm{g}$. The supernatant was removed with a sterile pipette, leaving $15 \mathrm{~mL}$ of liquid at the bottom of the tube. Subsequently, $33 \mathrm{~mL}$ of ethanol and $1.5 \mathrm{~mL}$ of $3 \mathrm{M}$ sodium acetate were added to each $50 \mathrm{~mL}$ tube and stored for at least one night at $-20^{\circ} \mathrm{C}$. The tubes were centrifuged at $15,000 \times \mathrm{g}$ for $15 \mathrm{~min}$ at $6^{\circ} \mathrm{C}$, and the supernatants were discarded. After this step, $720 \mu \mathrm{L}$ of an ATL buffer from the DNeasy Blood \& Tissue Extraction Kit (Qiagen, Hilden, Germany) was added. The tubes were then vortexed, and the supernatants were transferred to $2 \mathrm{~mL}$ tubes containing $20 \mu \mathrm{L}$ of Proteinase K. The tubes were then incubated at $56^{\circ} \mathrm{C}$ for two hours. Subsequently, DNA extraction was performed using NucleoSpin®Soil (MACHEREY-NAGEL GmbH \& Co., Düren, Germany) starting from step 6 and following the manufacturer's instructions. The elution was performed by adding $100 \mu \mathrm{L}$ of a SE buffer twice. After DNA extraction, the samples were tested for inhibition using real-time amplification following the protocol described in Biggs et al. (2015) [31], which involved adding a synthetic DNA sequence to each sample and then trying to amplify it. None of the samples were found to be inhibited. The samples were amplified using primers and probes designed by Leung et al. (2017) [32]. The qPCR was carried out in 12 replicates on a final volume of $25 \mu \mathrm{L}$, using $3 \mu \mathrm{L}$ of template DNA, $12.5 \mu \mathrm{L}$ of TaqMan Environmental Master Mix 2.0 (Life Technologies, Carlsbad, CA, USA), $6.5 \mu \mathrm{L}$ of ddH2O, $1 \mu \mathrm{L}$ of forward primer and reverse primer, and $1 \mu \mathrm{L}$ of probe (MCP_probe) using thermal cycling at $50^{\circ} \mathrm{C}$ for $5 \mathrm{~min}$ and $95^{\circ} \mathrm{C}$ for $10 \mathrm{~min}$, followed by 50 cycles at $95^{\circ} \mathrm{C}$ for $30 \mathrm{~s}$ and $60^{\circ} \mathrm{C}$ for $1 \mathrm{~min}$. To detect potential contamination, qPCR negative controls and DNA extraction controls (with 12 replicates) were amplified in parallel. Standard curve calculations were based on three standards $\left(4.5 \times 10^{7}, 4.5 \times 10^{4}\right.$, and $4.5 \times 10^{1}$ target copies per $\left.3 \mu \mathrm{L}\right)$ made from a plasmid containing the viral MCP target. Samples were run on a BIO-RAD CFX96 Touch real-time PCR detection system in a room dedicated to amplified DNA analysis with negative air pressure and physically separated from the DNA extraction room.

The results were expressed in terms of the number of positive replicates/total number of replicates per sample and the mean number of DNA copies (using the number of copies per Rv+ replicates) per sample.

\subsection{Ranavirus Identification}

Viral DNA was obtained from 1 dead adult, 3 live adults, 5 dead tadpoles, and 5 live tadpoles. These 14 samples were sequenced following the Mao et al. (1999) PCR method [35], using the BigDye Terminator Cycle Sequencing kit (PE Biosystems, Thermo Fisher Scientific, Bleiswijk, Netherlands) on an ABI Prism 3100 (Applied Biosystems, Foster City, CA, USA). The electropherogram was exported and converted to Kodon (Applied Maths, Sint-Martens-Latem, Belgium), and, using the BLAST program (default settings), the sequences were compared to Ranavirus sequences previously identified in this region [15].

\section{Results}

\subsection{Field Observations}

At altitudes above $2000 \mathrm{~m}$, the common frog breeds as soon as a small open body of water is available. The breeding population in Balaour pond has long been observed, but the population size has not been precisely estimated. The number of egg-masses is regularly around several hundred (M.-F. Lecchia, pers.comm.).

At Sampling Session 1 (10-11 June 2016), the breeding season had started, and about 200 egg-masses were counted. The embryos were at stages 9-11. Sixteen adults were observed in the water. One dead frog was observed at the bottom of the pond. At Session 2 (23-24 June), the tadpoles (stages 24 and 25) formed large aggregates on the remains of the spawn (jelly) along the pond shore. Fewer than 10 adults were observed in the water. At Session 3 (8 July), the tadpoles (stage 30) were grouped along the pond shore where the water temperature was highest. Five adults were observed in the water. At Session 4 
(27 July), the tadpoles (stages 35-39) were grouped along the pond shore. Dead tadpoles (about 250 counted) were observed on the bottom of the pond. Several individuals were observed with atypical behaviour, such as slow movements when stimulated, lateral swimming, or lying on their back on the pond bottom (about 50 counted). Most of the dead tadpoles were eaten by their congeners (Figure 1). Only two adults were observed in the water. At Session 5 (15-16 August), the tadpoles (stages 39-41) were more widespread in the pond, i.e., observed swimming beyond the $2 \mathrm{~m}$ strip near the shoreline. While we did not estimate the (relative) density at each session, the number of live tadpoles observed at Session 5 was clearly lower than at Session 4 . No dead tadpoles were observed, nor tadpoles with the previously described atypical behaviour. Only two adults were observed in the pond. At Session 6 (19 September), most of the tadpoles had metamorphosed or were very close to metamorphosis (stages $43-45$ ) and were widespread along the pond shore, both in the water and on land. No dead tadpoles or froglets were observed. Eight adults were observed in the pond.

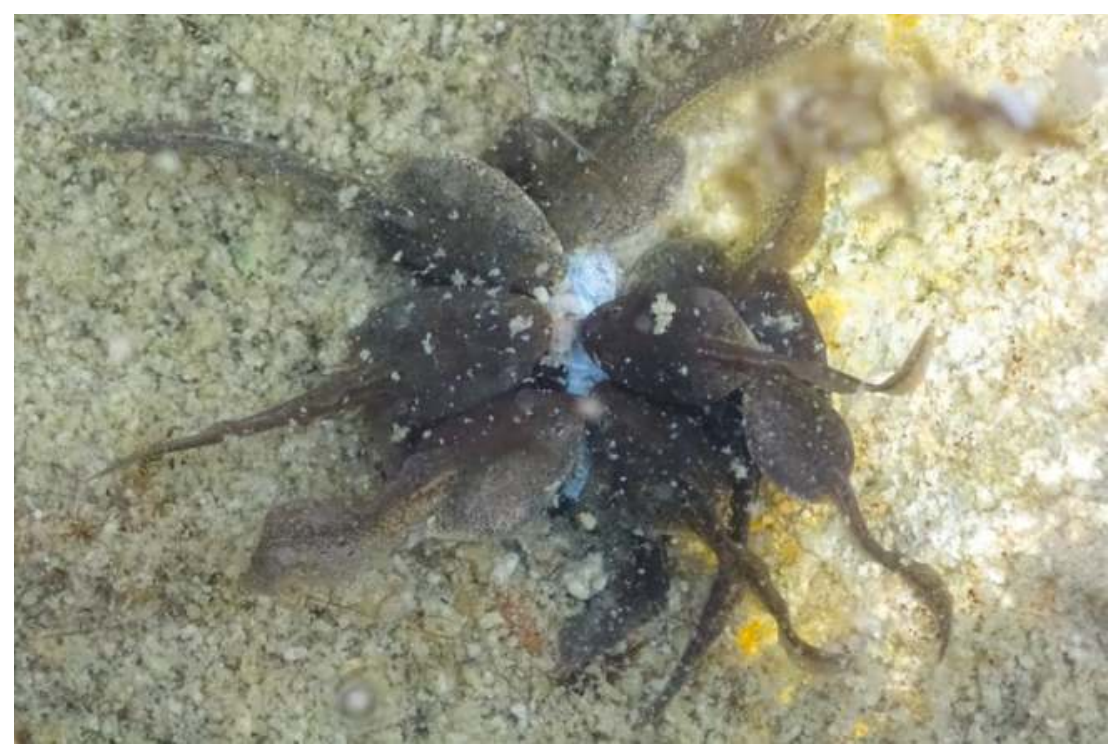

Figure 1. Common frog Rana temporaria tadpoles feeding on their dead congeners (photo L. Miaud).

Terrestrial insects (Diptera, Chironomids, Hymenoptera, Rhopalocera, and ants) and aquatic insects (Diptera, Heteroptera, and Odonata) were present around and in Balaour pond from June to September.

The two data loggers allowed the water temperature to be recorded at the surface and at a depth of $30 \mathrm{~cm}$ (Figure 2). The temperature increased from about $7^{\circ} \mathrm{C}$ in mid-June to $14^{\circ} \mathrm{C}$ at the beginning of July. The mean temperature during the July-August sampling period was $14^{\circ} \mathrm{C} \pm 4.3$, with a maximum of $20.5^{\circ} \mathrm{C}$ (at the surface) and $20^{\circ} \mathrm{C}$ (at a depth of $30 \mathrm{~cm}$ ) in July. In September, the temperature decreased to about $7{ }^{\circ} \mathrm{C}$. 


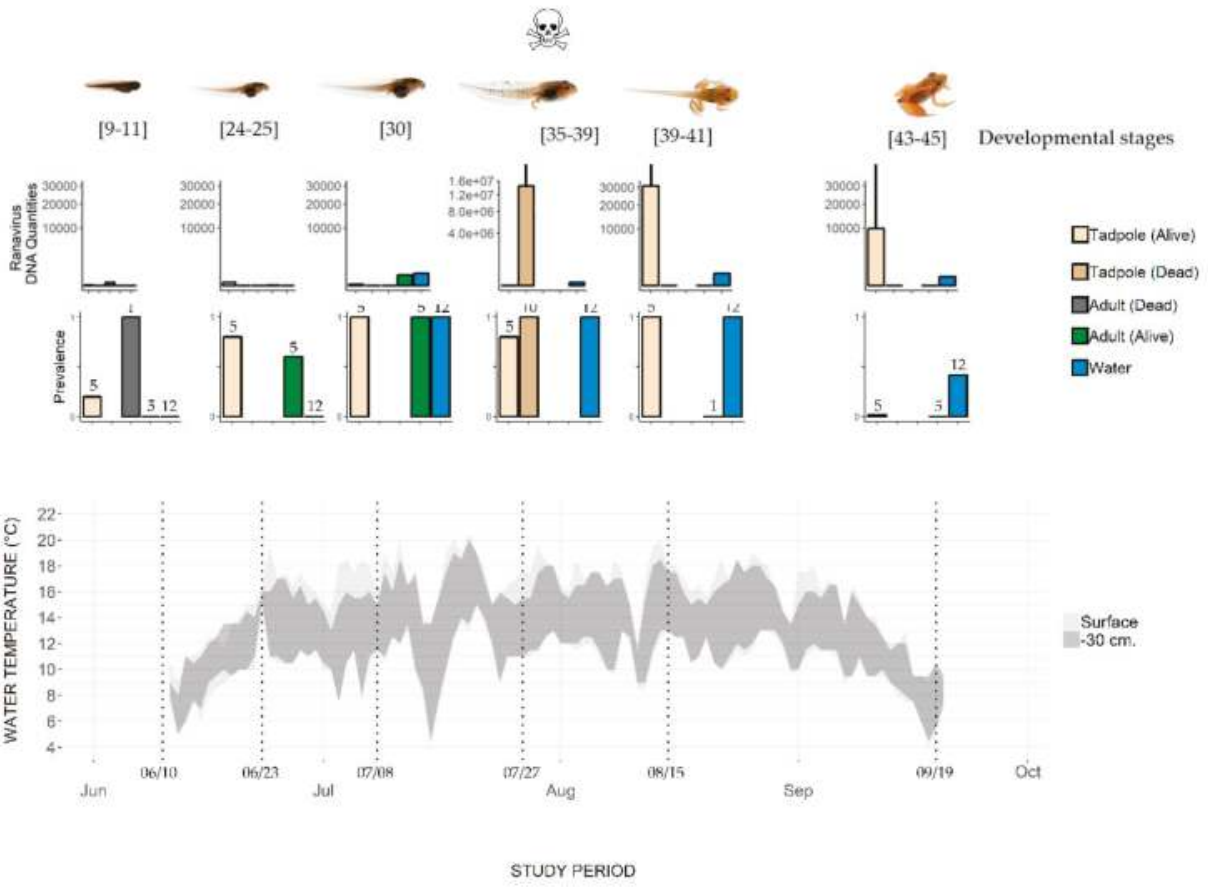

Figure 2. Change in water temperature and Ranavirus prevalence and load in a pond where the mass mortality of common frog tadpoles was observed. Water temperature was recorded at the surface and $30 \mathrm{~cm}$ below the surface. Top row of histograms: Ranavirus DNA quantities in common frogs (adults and tadpoles) and water samples (log scales, mean value, and SD). Bottom row of histograms: Prevalence (number of Ranavirus positive specimens/total number of sampled specimens, with sample size indicated above the bars). Developmental stages are based on Gosner stages; mortality was observed only on July 27.

\subsection{Ranavirus Detection in Organisms}

Ranavirus was detected in several compartments of the studied ecosystem (Supplementary Materials S1 and Figure 2) during the common frog activity period (June-September).

At Sampling Session 1 (10-11 June), the adult frogs present in the pond tested negative for Ranavirus (hereafter $\mathrm{Rv}-$ ). The dead frog found on the pond bottom tested positive for Ranavirus (hereafter $\mathrm{Rv}+$ ) with a genomic equivalent (GE) load of $2.83 \times 10^{1}$ (Supplementary Materials S1 and Figure 2). At Session 2, 12 days later (23-24 June), three out of five adults were $\mathrm{Rv}+$, with a mean GE of $0.43 \pm .1 .45(n=3)$. Adults caught in the water continued to be $\mathrm{Rv}+$ (four out of five testing positive) at Session 3 (8 July), with the highest mean GE $(345 \pm 14.5, n=4$, Figure 2$)$. No adults were sampled at Session 4 (27 July). The individual caught at Session 5 (15-16 August) and the five caught at Session 6 (19 September) were all Rv- (Figure 2). Most of the frogs that reproduce in Balaour pond leave the water after spawning to reach their surrounding terrestrial summer habitats. We did not catch adult frogs on land, so we do not know the infection status of these adults.

One recently hatched tadpole, i.e., hatched for less than one week in the prevailing environmental conditions at this altitude (water temperature about $6{ }^{\circ} \mathrm{C}$, Figure 2 and [29]), of the five tested was $\mathrm{Rv}+$ (Table 2). Thereafter, live tadpoles were $\mathrm{Rv}+$ until metamorphosis (Session 6; 19 September). The prevalence of Ranavirus increased with time, reaching 100\% ( $n=5 / 5)$ at Session 5 (15-16 August), and then dropped to $20 \%(n=1 / 5)$ at Session 6 (19 September) (Figure 2). The variation in mean GE across the tadpole developmental period shows a rather low viral load until Session 4 (27 July) in live 
tadpoles, while the load in dead tadpoles was higher by an order of magnitude of $7\left(10^{7}\right)$. After this date, the GE values in live tadpoles stayed high $\left(10^{4}\right)$.

None of the terrestrial and aquatic insects collected from June to September tested positive for Ranavirus.

\subsection{Ranavirus Detection in Water}

Water samples from the first two sampling sessions were Rv- (Figure 2). From Session 3 (8 July) to Session 5 (15-16 August), the 12 qPCR replicates performed for each water sample were $\mathrm{Rv}+$. Ranavirus was still detected at Session 6 (19 September), though it had the lowest detectability (5/12 replicates). The number of DNA copies (Figure 2) reached its maximum on 27 July (by an order of magnitude of 2), when the dead tadpoles were also observed with a high GE load. However, the GE values in infected live tadpoles and the number of DNA Ranavirus copies in water were not significantly correlated (Spearman rank correlation $R=0.25, p>0.05$ ).

\subsection{Ranavirus in Sediment}

All the qPCR replicates were negative for the samples collected at Sessions 1, 2, 4, and 6. At Sessions 3 and 5, 1 qPCR of the three was positive for both samples; these two samples were rerun. Only one positive replicate was observed again, so the two sediment samples were also considered negative.

\subsection{Ranavirus Identification}

The sequences obtained from the DNA extracted from dead tadpoles $(n=5)$, live tadpoles $(n=5)$, dead adults $(n=1)$, and live adults $(n=3)$ were 100\% identical to the CMTV (GenBank accession number JQ231222) isolated from a common midwife toad (Alytes obstetricans; [12]) and an alpine newt (Ichthyosaura alpestris) in Spain [36]. This Ranavirus has been identified as the etiologic agent of the mass mortality of the common frogs observed in the region [13].

\section{Discussion}

\subsection{Seasonal Dynamics of Ranavirus Epidemics in a Common Frog Population}

The common frogs (tadpoles and adults, dead and alive) testing positive for Ranavirus (CMTV, [12]) in Balaour pond in 2016 confirm the widespread distribution of this pathogen in the south-eastern Alps [13].

At the first sampling session (10 June), egg-masses had been deposited in the pond, but only 16 adults were observed in the water, and they did not exhibit breeding behavior. Spawning in the common frog is synchronous and short in duration [37]. On this date, one dead adult was observed in the water. This specimen was Rv+. Of the live adults, 5 specimens were $\mathrm{Rv}-$, while 1 out of 5 live tadpoles was Rv+. Of the few adults that remained in the pond until July, some were Rv+, but no further adult mortality was observed in the pond. In contrast, tadpoles suffered mass mortality at the end of July, when they reached developmental stages 35-39. Ranavirus was not detected in the sampled insects (aquatic or terrestrial), nor in the sediment collected during the summer activity period.

Sampling different life stages of organisms, as well as biotic and abiotic components, is necessary to provide a comprehensive view of Ranavirus dynamics (e.g., [38]). The observed dynamics in Balaour pond raise several questions: Ranavirus (including CMTV) is often highly pathogenic, and adult mass mortalities in common frog populations have been described in this region [13]. Yet adult mass mortality was not observed in Balaour pond in 2016. The breeding population is estimated to consist of at least 400 breeding adults (based on the observation of approximately 200 egg-masses in the pond and assuming an unbiased sex ratio [39]). Frog mass mortality is easily detectable in these small alpine ponds, so it is unlikely that an adult die-off went undetected. While frog aggregation during breeding can potentially foster pathogen transmission [40,41], the small fraction of adults that remained in the water after breeding was not infected at the beginning of the activity season. We have no data on 
the infection status of adults coming to breed or leaving the water after breeding, and the source and timing of the Ranavirus introduction remain unknown. It is unlikely that Ranavirus persists in the pond water from one year to the next [42], so it may be that sub-lethally infected adults (hibernating in water or on land) expose hatchlings to Ranavirus each year. Other reservoir species may also contribute to seasonal epidemics [43]; Ranavirus has been detected in fish in neighboring lakes [13]. However, the studied pond is free of fish, and the other communities we tested (aquatic and terrestrial insects) were $\mathrm{Rv}$-. The characteristics of Ranavirus persistence from year to year in this pond remain to be studied.

In contrast to adults, tadpoles did suffer mass mortality. Rapid and synchronous mass mortality of tadpoles in frog populations is well known [38]. The sudden introduction of a virus can be the cause of such a die-off, but this does not seem to be the case in Balaour pond, as Ranavirus was detected from the very beginning of the activity season. The existence of a window of host susceptibility mediated by environmental conditions (e.g., temperature) may contribute to this pattern (e.g., [38]). Ranavirus epidemics often occur during late spring or summer and can begin and end within weeks [38,44-47]. Infected tadpoles in Balaour pond were observed throughout the activity season (from June to September), i.e., from early developmental to pre-metamorphosis stages, while tadpoles died in mass only at the end of July, at stages 35-39 (Figure 2). Hall et al. (2018) [38] observed that Ranavirus prevalence reached high levels $(>50 \%)$ in wood frog tadpoles up to six weeks before mass mortality. High prevalence was also observed in the common frog population one month before the mass mortality in our study. In the wood frog [38], mortality occurred when tadpoles reached developmental stages (hind limb formation) that coincide with higher water temperatures $\left(>15^{\circ} \mathrm{C}\right)$. Several studies indicate that the pathogenicity of Ranavirus depends on the individual's developmental stage, with the most susceptible stage varying between species $[10,11,43,44]$. In our study, the tadpole die-off was found to coincide with the highest virus load in tadpole tissue (Figure 2, [48,49]). The accumulation of infectious dead tadpoles may also facilitate transmission (Figure 1, [50-52]). Water temperature, independent of developmental stage, has been shown to increase virus pathogenicity [53]. Common frog tadpoles suffer greater mortality at $20^{\circ} \mathrm{C}$ than at $15^{\circ} \mathrm{C}$, whether exposed to Ranavirus (FV3) or not [54]. The mass mortality of tadpoles observed in Balaour pond corresponded with the highest temperature recorded during the sampling period (Figure 2, $20{ }^{\circ} \mathrm{C}$ at the surface). However, no mortality was observed at the beginning of July or the end of August, when similar high temperatures were recorded. The respective and interacting roles of water temperature and tadpole developmental stage on Ranavirus pathogenicity remain to be studied in this common frog population.

\subsection{Designing Pathogen Surveys Using eDNA and Occupancy Models}

Diagnosing Ranavirus infection in amphibians requires collecting samples from either live individuals (e.g., a piece clipped from the tail or toe or skin swabs [55-57]) or dead individuals (e.g., a sample from the liver) [55]). However, Ranavirus can also resist adverse conditions (e.g., the drying out or freezing of a host carcass) and can then be shed into the water from infected individuals $[58,59]$. While viruses are rapidly degraded by microbes and zooplankton predation in water [42], they can remain detectable for at least seven days [60]. Water sampling and eDNA testing can thus indicate the presence of the pathogen; Hall et al. (2016) demonstrated that in ponds where wood frog tadpoles were $\mathrm{Rv}+$, collected water samples also revealed the presence of Ranavirus DNA [24]. Other pathogens have also been detected using water samples-several metazoan parasites [26,61,62], chytrid fungus $[21-25,27,63,64]$, and the Oomycota fungus Aphanomyces astaci, the causative agent of crayfish plague [28] - demonstrating the usefulness of eDNA for detecting pathogen infections in wildlife. 


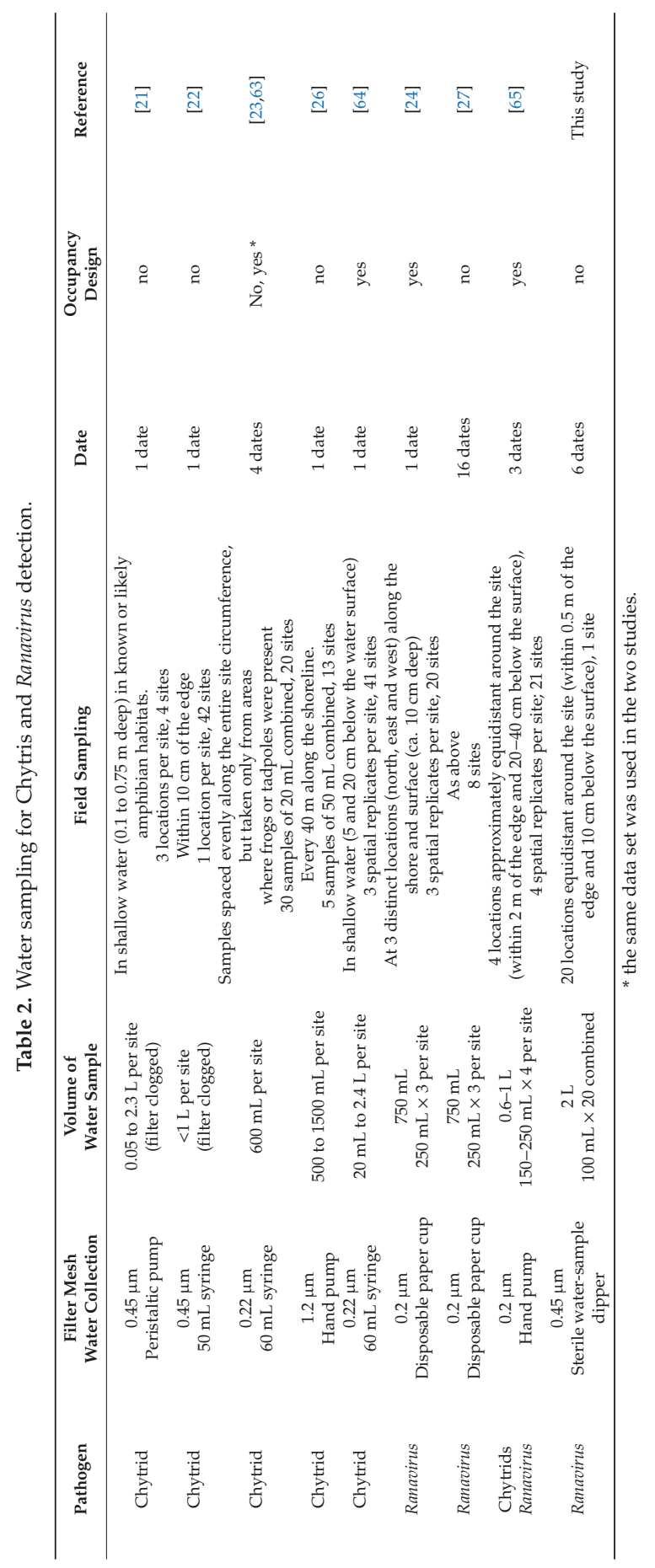


Table 2 summarizes different methods used to collect water for pathogen detection (Chytrids and Ranavirus). The most usual method is to collect water samples that are then filtered in the field. The filters are then stored until DNA extraction and amplification in the laboratory. The sampling design varies, e.g., discrete samples may be filtered separately or combined before filtering (Table 2). The location of the water sampling also differs, from rather exhaustive sampling (e.g., at approximately equidistant locations around the site) to solely where the presence of the pathogen would be expected (e.g., locations where frogs or tadpoles have been present). Water collection and filtering procedures are simple and have been used by non-experts in a citizen science program [65]. Clearly, the detection of a pathogen in water samples depends on its density (DNA quantities) and distribution (e.g., continuous or patchy) in the studied site. Several estimates concerning sampling effort are available; Julian et al. (2019) evaluated that as few as five water samples (Table 2) taken in June or July can detect both Bd and Ranavirus with 95\% confidence [65]. In another study, every pond with Ranavirus-infected tadpoles tested positive with just three $250 \mathrm{~mL}$ water samples (Table 2, [27]). In our study, Ranavirus detection from water samples was effective in four out of six sessions, i.e., $66.6 \%$ detectability. In contrast, mass mortality was observed on only one date, i.e., $16.6 \%$ detectability. When live tadpoles were collected and molecular diagnostics performed, the presence of the pathogen was detected throughout the six sampling dates (100\% detectability). Increasing the number of water samples will increase the cost of the molecular diagnostics, but pooling the samples before filtration allows a good sampling coverage of the study area at a reasonable cost. When the distribution of the pathogen (or the potential hosts) is known, we recommend to perform a pilot study to optimize the number (or volume) of water samples. Without preliminary knowledge, the screening of the site can be based on samples spaced evenly along the entire site circumference, then combined in one water samples which is then filtered to collect DNA.

Nonetheless, most pathogen detection tests are imperfect, resulting in false negatives when a pathogen is present but not detected. False negatives can occur when specimens or water samples are collected in the field, from organs in infected hosts (histological diagnostics) or in PCR replicates (molecular diagnostics). To address this, multi-scale occupancy models [66] can be used to develop a species distribution model to estimate the proportion of sites where a species or a pathogen occurs [67], even when detection is imperfect. This statistical framework is particularly suitable for eDNA analyses in which replicates (and thus detection probability) are present at the different steps of the method [68]; for example, it has been recommended in disease ecology [69]. Table 2 provides some studies that used eDNA to detect Bd or Ranavirus as well as occupancy models to estimate pathogen prevalence. Naïve prevalence (i.e., estimated prevalence without taking into account imperfect detection) can lead to the underestimation of $\mathrm{Bd}$ prevalence in ponds [23]; estimating correct prevalence requires taking multiple samples per site (Table 2). Replicates to evaluate detection probabilities can be temporal (i.e., sampling the same site at least three occasions) or spatial (i.e., sampling in at least three locations in the site) [66].

\section{Conclusions}

Inferring the health status of common frogs or ecologically similar amphibian species based only on the observation of mass mortality events in breeding sites runs the risk of missing potential infections. A better strategy is to sample amphibian tissue (adults and/or tadpoles) during, for example, the tadpole developmental phase and then perform molecular diagnostics. As this requires invasive techniques, administrative authorizations for protected species and/or protected areas and specific materials to collect and store the samples are needed. In some cases, catching frogs and tadpoles can be challenging, and tissue sampling requires a certain level of technical competence (and, sometimes, certified training). In light of these challenges, our results confirm previous findings that eDNA can be an effective alternative, since the temporal window for detecting the pathogen is rather large, collecting water samples is simple and can be performed by most field technicians, and, moreover, no specimen has to be caught, manipulated, or sacrificed. Moreover, applying a sampling design based on occupancy modelling (e.g., replicates allowing the evaluation of detection probability) provides prevalence estimates that are comparable between sites or years. As a biodiversity inventory method 
in marine and freshwater environments, eDNA has been extraordinarily successful; likewise, it holds clear potential for improving disease surveillance programs and increasing the performance of wildlife health status monitoring.

Supplementary Materials: Supplementary materials can be found at http://www.mdpi.com/1999-4915/11/6/526/s1.

Author Contributions: C.M. conceived and designed the experiment. C.M. conducted the experiment in the field. V.A., A.V., M.P., and T.D. performed the pathogen detection analysis. C.M., A.V., and T.D. wrote the paper.

Funding: This work was funded in part by a research convention signed between Mercantour National Park and the French École Pratique des Hautes Études (EPHE).

Acknowledgments: We would like to thank Coralie Barbier, Léo Miaud, Benjamin Viel, and the technicians of the Mercantour National Park for their help in the field, Marie-Laure Leccia for her support in studying the health status of the park's amphibian population, and Stephen Price for the MCP standards and help with the qPCR protocol. Discussions with A. Duffus, T. Garner, W. Leung, S. Price, and F. Pasmans on the design of the longitudinal study were greatly appreciated. Jules Chiffard and Antoine Miaud kindly created Figure 2. Authorisation to collect the tadpoles and to sample tissue from the adults was provided by Mercantour National Park (authorisation $n^{\circ}$ 2016-408, 12 May 2016) and the Alpes-de-Haute-Provence Regional Department of the Environment, Development and Housing (prefectural decree, 20 May 2016). Many thanks to Elise Bradbury (elisebrad@gmail.com) for the text review and editing. A first draft of this manuscript was highly improved by the reviewer's constructive comments.

Conflicts of Interest: The authors declare no conflict of interest.

\section{References}

1. Miaud, C.; Guillaume, O. Are amphibian good biological indicators? In Proceedings of the Abstract of the Fifth World Congress of Herpetology 2005, Stellenbosch, South Africa, 19-24 June 2005; p. 72.

2. Welsh, H.H.; Ollivier, L.M. Stream Amphibians as Indicators of Ecosystem Stress: A Case Study from California's Redwoods. Ecol. Appl. 1998, 8, 1118-1132. [CrossRef]

3. Temple, H.J.; Cox, N.A. European Red List of Amphibians; Office for Official Publications of the European Communities: Luxembourg, 2009.

4. Daszak, P.; Berger, L.; Cunningham, A.A.; Hyatt, A.D.; Green, D.E.; Speare, R. Emerging infectious diseases and amphibian population declines. Emerg. Infect. Dis 1999, 5, 735-748. [CrossRef] [PubMed]

5. Lips, K.R.; Brem, F.; Brenes, R.; Reeve, J.D.; Alford, R.A.; Voyles, J.; Carey, C.; Livo, L.; Pessier, A.P.; Collins, J.P. Emerging infectious disease and the loss of biodiversity in a Neotropical amphibian community. Proc. Natl. Acad. Sci. USA 2006, 103, 3165-3170. [CrossRef] [PubMed]

6. Rachowicz, L.J; Knapp, R.A.; Morgan, J.A.T.; Stice, M.J.; Vredenburg, V.T.; Parker, J.M.; Briggs, C.J. Emerging infectious disease as a proximate cause of amphibian mass mortality. Ecology 2006, 87, 1671-1683. [CrossRef]

7. Scheele, B.C.; Pasmans, F.; Skerratt, L.F.; Berger, L.; Martel, A.; Beukema, W.; Acevedo, A.A.; Burrowes, P.A.; Carvalho, T.; Catenazzi, A.; et al. Amphibian fungal panzootic causes catastrophic and ongoing loss of biodiversity. Science 2019, 363, 1459-1463. [CrossRef] [PubMed]

8. Gray, M.J.; Chinchar, V.G. Ranaviruses: Lethal Pathogens of Ectothermic Vertebrates; Springer Science + Business Media: Berlin, Germany, 2015; ISBN 978-3-319-13755-1.

9. Chinchar, V.G. Ranaviruses (family Iridoviridae): Emerging cold-blooded killers-Brief review. Arch. Virol. 2002, 147, 447-470. [CrossRef] [PubMed]

10. Price, S.J.; Garner, T.W.J; Nichols, R.A.; Balloux, F.; Ayres, C.; Mora-Cabello de Alba, A.; Bosch, J. Collapse of Amphibian Communities Due to an Introduced Ranavirus. Curr. Biol. 2014, 24, 2586-2591. [CrossRef]

11. Miller, D.; Gray, M.; Storfer, A. Ecopathology of Ranaviruses Infecting Amphibians. Viruses 2011, 3, 2351-2373. [CrossRef]

12. Balseiro, A.; Dalton, K.P.; del Cerro, A.; Marquez, I.; Cunningham, A.A.; Parra, F.; Prieto, J.M.; Casais, R. Pathology, isolation and molecular characterisation of a ranavirus from the common midwife toad Alytes obstetricans on the Iberian Peninsula. Dis. Aquat. Organ. 2009, 84, 95-104. [CrossRef]

13. Miaud, C.; Pozet, F.; Gaudin, N.C.G.; Martel, A.; Pasmans, F.; Labrut, S. Ranavirus Causes Mass Die-Offs of Alpine Amphibians in the Southwestern Alps, France. J. Wildl. Dis. 2016, 52, 242-252. [CrossRef] 
14. Saucedo, B.; Hughes, J.; Spitzen-van der Sluijs, A.; Kruithof, N.; Schills, M.; Rijks, J.M.; Jacinto-Maldonado, M.; Suarez, N.; Haenen, O.L.M.; Voorbergen-Laarman, M.; et al. Ranavirus genotypes in the Netherlands and their potential association with virulence in water frogs (Pelophylax spp.). Emerg. Microbes Infect. 2018, 7, 56. [CrossRef] [PubMed]

15. Anonymous. Preventing emerging infectious diseases: A strategy for the 21st century. Overview of the updated CDC plan. MMWR Recomm. Rep. 1998, 47, 1-14.

16. Brunner, J.L.; Schock, D.M.; Davidson, E.W.; Collins, J.P. Intraspecific reservoirs: Complex life history and the persistence of a lethal ranavirus. Ecology 2004, 85, 560-566. [CrossRef]

17. Tibpromma, S.; Hyde, K.D.; Jeewon, R.; Maharachchikumbura, S.S.N.; Liu, J.-K.; Bhat, D.J.; Jones, E.B.G.; McKenzie, E.H.C.; Camporesi, E.; Bulgakov, T.S.; et al. Fungal diversity notes 491-602: Taxonomic and phylogenetic contributions to fungal taxa. Fungal Divers. 2017, 83, 1-261. [CrossRef]

18. Mokili, J.L.; Rohwer, F.; Dutilh, B.E. Metagenomics and future perspectives in virus discovery. Curr. Opin. Virol. 2012, 2, 63-77. [CrossRef] [PubMed]

19. Guy, R.A.; Payment, P.; Krull, U.J.; Horgen, P.A. Real-time PCR for quantification of Giardia and Cryptosporidium in environmental water samples and sewage. Appl. Environ. Microbiol. 2003, 69, 5178-5185. [CrossRef] [PubMed]

20. Ganoza, C.A.; Matthias, M.A.; Collins-Richards, D.; Brouwer, K.C.; Cunningham, C.B.; Segura, E.R.; Gilman, R.H.; Gotuzzo, E.; Vinetz, J.M. Determining risk for severe leptospirosis by molecular analysis of environmental surface waters for pathogenic Leptospira. PLoS Med. 2006, 3, 1329-1340. [CrossRef]

21. Walker, S.F.; Salas, M.B.; Jenkins, D.; Garner, T.W.J.; Cunningham, A.A.; Hyatt, A.D.; Bosch, J.; Fisher, M.C. Environmental detection of Batrachochytrium dendrobatidis in a temperate climate. Dis. Aquat. Organ. 2007, 77, 105-112. [CrossRef] [PubMed]

22. Kirshtein, J.D.; Anderson, C.W.; Wood, J.S.; Longcore, J.E.; Voytek, M.A. Quantitative PCR detection of batrachochytrium dendrobatidis DNA from sediments and water. Dis. Aquat. Organ. 2007, 77, 11-15. [CrossRef]

23. Schmidt, B.R.; Kery, M.; Ursenbacher, S.; Hyman, O.J.; Collins, J.P. Site occupancy models in the analysis of environmental DNA presence/absence surveys: A case study of an emerging amphibian pathogen. Methods Ecol. Evol. 2013, 4, 646-653. [CrossRef]

24. Hall, E.M.; Crespi, E.J.; Goldberg, C.S.; Brunner, J.L. Evaluating environmental DNA-based quantification of ranavirus infection in wood frog populations. Mol. Ecol. Resour. 2016, 16, 423-433. [CrossRef] [PubMed]

25. Kamoroff, C.; Goldberg, C.S. Using environmental DNA for early detection of amphibian chytrid fungus Batrachochytrium dendrobatidis prior to a ranid die-off. Dis. Aquat. Organ. 2017, 127, 75-79. [CrossRef] [PubMed]

26. Sato, M.O.; Rafalimanantsoa, A.; Ramarokoto, C.; Rahetilahy, A.M.; Ravoniarimbinina, P.; Kawai, S.; Minamoto, T.; Sato, M.; Kirinoki, M.; Rasolofo, V.; et al. Usefulness of environmental DNA for detecting Schistosoma mansoni occurrence sites in Madagascar. Int. J. Infect. Dis. 2018, 76, 130-136. [CrossRef] [PubMed]

27. Mosher, B.A.; Huyvaert, K.P.; Bailey, L.L. Beyond the swab: Ecosystem sampling to understand the persistence of an amphibian pathogen. Oecologia 2018, 188, 319-330. [CrossRef] [PubMed]

28. Robinson, C.V.; Uren Webster, T.M.; Cable, J.; James, J.; Consuegra, S. Simultaneous detection of invasive signal crayfish, endangered white-clawed crayfish and the crayfish plague pathogen using environmental DNA. Biol. Conserv. 2018, 222, 241-252. [CrossRef]

29. Miaud, C.; Guyetant, R.; Elmberg, J. Variations in life-history traits in the common frog Rana temporaria (Amphibia: Anura): A literature review and new data from the French Alps. J. Zool. 1999, 249, 61-73. [CrossRef]

30. Gosner, K.L. A Simplified Table for Staging Anuran Embryos and Larvae with Notes on Identification. Herpetologica 1960, 16, 183-190.

31. Biggs, J.; Ewald, N.; Valentini, A.; Gaboriaud, C.; Dejean, T.; Griffiths, R.A.; Foster, J.; Wilkinson, J.W.; Arnell, A.; Brotherton, P.; et al. Using eDNA to develop a national citizen science-based monitoring programme for the great crested newt (Triturus cristatus). Biol. Conserv. 2015, 183, 19-28. [CrossRef]

32. Leung, W.T.M.; Thomas-Walters, L.; Garner, T.W.J.; Balloux, F.; Durrant, C.; Price, S.J. A quantitative-PCR based method to estimate ranavirus viral load following normalisation by reference to an ultraconserved vertebrate target. J. Virol. Methods 2017, 249, 147-155. [CrossRef] 
33. Taberlet, P.; Prud'homme, S.M.; Campione, E.; Roy, J.; Miquel, C.; Shehzad, W.; Gielly, L.; Rioux, D.; Choler, P.; Clement, J.-C.; et al. Soil sampling and isolation of extracellular DNA from large amount of starting material suitable for metabarcoding studies. Mol. Ecol. 2012, 21, 1816-1820. [CrossRef]

34. Pont, D.; Rocle, M.; Valentini, A.; Civade, R.; Jean, P.; Maire, A.; Roset, N.; Schabuss, M.; Zornig, H.; Dejean, T. Environmental DNA reveals quantitative patterns of fish biodiversity in large rivers despite its downstream transportation. Sci. Rep. 2018, 8, 10361. [CrossRef] [PubMed]

35. Mao, J.H.; Green, D.E.; Fellers, G.; Chinchar, V.G. Molecular characterization of iridoviruses isolated from sympatric amphibians and fish. Virus Res. 1999, 63, 45-52. [CrossRef]

36. Mavian, C.; López-Bueno, A.; Balseiro, A.; Casais, R.; Alcamí, A.; Alejo, A. The Genome Sequence of the Emerging Common Midwife Toad Virus Identifies an Evolutionary Intermediate within Ranaviruses. J. Virol. 2012, 86, 3617. [CrossRef] [PubMed]

37. Haapanen, A. Breeding of the Common Frog (rana-Temporaria L). Ann. Zool. Fenn. 1982, 19, 75-79.

38. Hall, E.M.; Goldberg, C.S.; Brunner, J.L.; Crespi, E.J. Seasonal dynamics and potential drivers of ranavirus epidemics in wood frog populations. Oecologia 2018, 188, 1253-1262. [CrossRef] [PubMed]

39. Elmberg, J. Long-Term Survival, Length of Breeding-Season, and Operational Sex-Ratio. Can. J. Zool.-Rev. Can. Zool. 1990, 68, 121-127. [CrossRef]

40. Cunningham, A.A.; Langton, T.E.S.; Bennett, P.M.; Lewin, J.F.; Drury, S.E.N.; Gough, R.E.; MacGregor, S.K. Pathological and microbiological findings from incidents of unusual mortality of the common frog (Rana temporaria). Philos. Trans. R. Soc. Lond. Ser. B Biol. Sci. 1996, 351, 1539-1557.

41. Price, S.J.; Garner, T.W.J.; Cunningham, A.A.; Langton, T.E.S.; Nichols, R.A. Reconstructing the emergence of a lethal infectious disease of wildlife supports a key role for spread through translocations by humans. Proc. R. Soc. B Biol. Sci. 2016, 283, 20160952. [CrossRef] [PubMed]

42. Johnson, A.F.; Brunner, J.L. Persistence of an amphibian ranavirus in aquatic communities. Dis. Aquat. Org. 2014, 111, 129-138. [CrossRef]

43. Duffus, A.L.J.; Pauli, B.D.; Wozney, K.; Brunetti, C.R.; Berrill, M. FROG VIRUS 3-LIKE INFECTIONS IN AQUATIC AMPHIBIAN COMMUNITIES. J. Wildl. Dis. 2008, 44, 109-120. [CrossRef]

44. Green, D.E.; Converse, K.A.; Schrader, A.K. Epizootiology of sixty-four amphibian morbidity and mortality events in the USA, 1996-2001. In Domestic Animal/Wildlife Interface: Issue for Disease Control, Conservation, Sustainable Food Production, and Emerging Diseases; Gibbs, E.P.J., Bokma, B.H., Eds.; New York Acad Sciences: New York, NY, USA, 2002; Volume 969, pp. 323-339. ISBN 978-1-57331-439-8.

45. Gray, M.J.; Miller, D.L.; Hoverman, J.T. Ecology and pathology of amphibian ranaviruses. Dis. Aquat. Org. 2009, 87, 243-266. [CrossRef] [PubMed]

46. Rosa, G.M.; Sabino-Pinto, J.; Laurentino, T.G.; Martel, A.; Pasmans, F.; Rebelo, R.; Griffiths, R.A.; Stoehr, A.C.; Marschang, R.E.; Price, S.J.; et al. Impact of asynchronous emergence of two lethal pathogens on amphibian assemblages. Sci. Rep. 2017, 7, 43260. [CrossRef] [PubMed]

47. Rijks, J.M.; Saucedo, B.; Spitzen-van der Sluijs, A.; Wilkie, G.S.; van Asten, A.J.A.M.; van den Broek, J.; Boonyarittichaikij, R.; Stege, M.; van der Sterren, F.; Martel, A.; et al. Investigation of Amphibian Mortality Events in Wildlife Reveals an On-Going Ranavirus Epidemic in the North of the Netherlands. PLoS ONE 2016, 11, e0157473. [CrossRef] [PubMed]

48. Kik, M.; Martel, A.; Spitzen-van der Sluijs, A.; Pasmans, F.; Wohlsein, P.; Grone, A.; Rijks, J.M. Ranavirus-associated mass mortality in wild amphibians, The Netherlands, 2010: A first report. Vet. J. 2011, 190, 284-286. [CrossRef] [PubMed]

49. Hoverman, J.T.; Gray, M.J.; Miller, D.L.; Haislip, N.A. Widespread Occurrence of Ranavirus in Pond-Breeding Amphibian Populations. EcoHealth 2012, 9, 36-48. [CrossRef] [PubMed]

50. Pearman, P.B.; Garner, T.W.J.; Straub, M.; Greber, U.F. Response of the Italian agile frog (Rana latastei) to a Ranavirus, frog virus 3: A model for viral emergence in naive populations. J. Wildl. Dis. 2004, 40, 660-669. [CrossRef] [PubMed]

51. Harp, E.M.; Petranka, J.W. Ranavirus in wood frogs (Rana sylvatica): Potential sources of transmission within and between ponds. J. Wildl. Dis. 2006, 42, 307-318. [CrossRef] [PubMed]

52. Torrence, S.M.; Green, D.E.; Benson, C.J.; Ip, H.S.; Smith, L.M.; McMurry, S.T. A New Ranavirus Isolated from Pseudacris clarkii Tadpoles in Playa Wetlands in the Southern High Plains, Texas. J. Aquat. Anim. Health 2010, 22, 65-72. [CrossRef] [PubMed] 
53. Echaubard, P.; Leduc, J.; Pauli, B.; Chinchar, V.G.; Robert, J.; Lesbarreres, D. Environmental dependency of amphibian-ranavirus genotypic interactions: Evolutionary perspectives on infectious diseases. Evol. Appl. 2014, 7, 723-733. [CrossRef]

54. Bayley, A.E.; Hill, B.J.; Feist, S.W. Susceptibility of the European common frog Rana temporaria to a panel of ranavirus isolates from fish and amphibian hosts. Dis. Aquat. Org. 2013, 103, 171-183. [CrossRef] [PubMed]

55. Greer, A.L.; Collins, J.P. Sensitivity of a diagnostic test for amphibian ranavinus varies with sampling protocol. J. Wildl. Dis. 2007, 43, 525-532. [CrossRef] [PubMed]

56. St-Ainour, V.; Lesbarreres, D. Genetic evidence of Ranavirus in toe clips: An alternative to lethal sampling methods. Conserv. Genet. 2007, 8, 1247-1250. [CrossRef]

57. Gray, M.J.; Miller, D.L.; Hoverman, J.T. Reliability of non-lethal surveillance methods for detecting ranavirus infection. Dis. Aquat. Org. 2012, 99, 1-6. [CrossRef] [PubMed]

58. Brunner, J.L.; Collins, J.P. Testing assumptions of the trade-off theory of the evolution of parasite virulence. Evol. Ecol. Res. 2009, 11, 1169-1188.

59. Robert, J.; George, E.; Andino, F.D.J.; Chen, G. Waterborne infectivity of the Ranavirus frog virus 3 in Xenopus laevis. Virology 2011, 417, 410-417. [CrossRef] [PubMed]

60. Grizzle, J.M.; Brunner, C.J. Review of largemouth bass virus. Fisheries 2003, 28, 10-14. [CrossRef]

61. Huver, J.R.; Koprivnikar, J.; Johnson, P.T.J.; Whyard, S. Development and application of an eDNA method to detect and quantify a pathogenic parasite in aquatic ecosystems. Ecol. Appl. 2015, 25, 991-1002. [CrossRef] [PubMed]

62. Rusch, J.C.; Hansen, H.; Strand, D.A.; Markussen, T.; Hytterod, S.; Vralstad, T. Catching the fish with the worm: A case study on eDNA detection of the monogenean parasite Gyrodactylus salaris and two of its hosts, Atlantic salmon (Salmo salar) and rainbow trout (Oncorhynchus mykiss). Parasit. Vect. 2018, 11, 333. [CrossRef]

63. Hyman, O.J.; Collins, J.P. Evaluation of a filtration-based method for detecting Batrachochytrium dendrobatidis in natural bodies of water. Dis. Aquat. Org. 2012, 97, 185-195. [CrossRef]

64. Chestnut, T.; Anderson, C.; Popa, R.; Blaustein, A.R.; Voytek, M.; Olson, D.H.; Kirshtein, J. Heterogeneous Occupancy and Density Estimates of the Pathogenic Fungus Batrachochytrium dendrobatidis in Waters of North America. PLoS ONE 2014, 9, e106790. [CrossRef]

65. Julian, J.; Glenney, G.; Rees, C. Evaluating observer bias and seasonal detection rates in amphibian pathogen eDNA collections by citizen scientists. Dis. Aquat. Organ. 2019, 134, 15-24. [CrossRef]

66. MacKenzie, D.I.; Nichols, J.D.; Lachman, G.B.; Droege, S.; Andrew Royle, J.; Langtimm, C.A. Estimating Site Occupancy Rates When Detection Probabilities Are Less Than One. Ecology 2002, 83, 2248-2255. [CrossRef]

67. Colvin, M.E.; Peterson, J.T.; Kent, M.L.; Schreck, C.B. Occupancy Modeling for Improved Accuracy and Understanding of Pathogen Prevalence and Dynamics. PloS ONE 2015, 10, e0116605. [CrossRef] [PubMed]

68. Yoccoz, N.G. The future of environmental DNA in ecology: NEWS AND VIEWS: OPINION. Mol. Ecol. 2012, 21, 2031-2038. [CrossRef] [PubMed]

69. McClintock, B.T.; Nichols, J.D.; Bailey, L.L.; MacKenzie, D.I.; Kendall, W.L.; Franklin, A.B. Seeking a second opinion: Uncertainty in disease ecology: Uncertainty in disease ecology. Ecol. Lett. 2010, 13, 659-674. [CrossRef] [PubMed]

(C) 2019 by the authors. Licensee MDPI, Basel, Switzerland. This article is an open access article distributed under the terms and conditions of the Creative Commons Attribution (CC BY) license (http://creativecommons.org/licenses/by/4.0/). 
Article

\title{
Modelling Ranavirus Transmission in Populations of Common Frogs (Rana temporaria) in the United Kingdom
}

\author{
Amanda L.J. Duffus ${ }^{1, *(\mathbb{D}}$, Trenton W.J. Garner ${ }^{2}$, Richard A. Nichols ${ }^{3}{ }^{\circledR}$, Joshua P. Standridge ${ }^{1}$ \\ and Julia E. Earl 4 \\ 1 Department of Mathematics and Natural Sciences, Gordon State College, Barnesville, GA 30204, USA; \\ js197212@gordonstate.edu \\ 2 Institute of Zoology, Zoological Society of London, London NW1 4RY, UK; trent.garner@ioz.ac.uk \\ 3 School of Biological and Chemical Sciences, Queen Mary, University of London, London E1 4NS, UK; \\ r.a.nichols@qmul.ac.uk \\ 4 School of Biological Sciences, Louisiana Tech University, Ruston, LA 71272, USA; jearl@latech.edu \\ * Correspondence: aduffus@gordonstate.edu
}

Received: 10 April 2019; Accepted: 4 June 2019; Published: 15 June 2019

\begin{abstract}
Ranaviruses began emerging in common frogs (Rana temporaria) in the United Kingdom in the late 1980s and early 1990s, causing severe disease and declines in the populations of these animals. Herein, we explored the transmission dynamics of the ranavirus(es) present in common frog populations, in the context of a simple susceptible-infected (SI) model, using parameters derived from the literature. We explored the effects of disease-induced population decline on the dynamics of the ranavirus. We then extended the model to consider the infection dynamics in populations exposed to both ulcerative and hemorrhagic forms of the ranaviral disease. The preliminary investigation indicated the important interactions between the forms. When the ulcerative form was present in a population and the hemorrhagic form was later introduced, the hemorrhagic form of the disease needed to be highly contagious, to persist. We highlighted the areas where further research and experimental evidence is needed and hope that these models would act as a guide for further research into the amphibian disease dynamics.
\end{abstract}

Keywords: transmission modelling; susceptible-infected (SI) models; emerging infection; ranavirosis; Iridoviridae; disease dynamics

\section{Introduction}

Ranaviruses are double-stranded DNA viruses in the Iridoviridae family that can infect ectothermic vertebrates [1] and are found worldwide [2]. Ranaviruses cause systemic hemorrhaging and edema in amphibian, reptile, and fish hosts [3]. In amphibians, mortality can occur in only three days in very susceptible host species and life history stages [4], resulting in die-offs of both adults and larvae, in Europe [5,6], and tadpoles and metamorphs, in North America [7,8]. Ranaviruses have been shown to alter amphibian population dynamics, with declines of the common frog (Rana temporaria) in the United Kingdom [9] and whole amphibian communities in Spain [10]. Additionally, population simulation models have shown that ranaviruses could potentially cause the local extinction of populations of three, highly susceptible species of the United States anurans [11,12]. However, these models do not include the transmission dynamics, which are not well-understood and could potentially alter host population dynamics. Farrell et al. [13] modeled host population declines in the case of the highly pathogenic Ambystoma tigrinum virus (ATV), but they found that extinction of host populations would not occur even in the cases where the host population was severely reduced. These diverse conclusions 
showed that there were many different possible outcomes of ranavirus infections that influenced disease dynamics, and they appeared to be system-specific.

Mathematical models are helpful tools for understanding transmission dynamics and the persistence of pathogen and host populations [14,15]. Models might help determine which transmission conditions are most likely, given the information about disease dynamics in wild populations. In the case of the ranavirus, Brunner and Yarber [16] developed a model which suggested that ranavirus transmission from water and scavengers are likely minimal in most circumstances. Previous attempts have also been made to formalize the transmission dynamics at, both, the species level [17] and at the community level [18]. Most models have been based on North American amphibian populations or communities. The dynamics of amphibian-ranavirus systems in the UK, the ranavirus-common frog (Rana temporaria) system, are distinctly different from those in North America and thus require specific investigation.

Here, we developed susceptible-infection (SI) models for ranavirus infection in common frogs, in the UK. The ranavirus-common frog system in the UK differs from the infection/disease dynamics seen in North American anuran species, because infections in eggs or tadpoles of wild populations are absent, for the most part [19,20], despite experimental evidence that tadpoles can be infected and have died with signs of ranavirosis. Given this information, the route of transmission in common frogs is most likely among adults. With the benefit of long-term data sets on the persistence of ranavirus infections in common frogs, we know that the ranavirus can persist in adult frog populations for many years [9] and involves at least two distinct disease syndromes (hemorrhagic and ulcerative) with variations in the prevalence of disease, across sites and years [21]. We, therefore, developed SI models to test the hypothesis that ranaviruses have the potential to remain in the UK common frog populations, under various conditions, with only horizontal transmission between adults. We examined scenarios with host population declines that included both ranavirus syndromes.

\section{Basic Model Formulation}

In the simplest case, we used an SI model with no recovery, based on the high mortality rate associated with ranavirus infection. We followed the method for developing mathematical models described by Otto and Day [22]. The population consisted of recruits $\left(A_{R}\right)$, susceptible individuals $\left(A_{S}\right)$, and infected individuals $\left(A_{I}\right)$ and mortality occurred at two different rates-natural mortality $\left(\mathrm{M}_{\mathrm{N}}\right)$ and mortality due to disease $\left(\mathrm{M}_{\mathrm{D}}\right)$. We assumed that the adult population size remained constant (i.e., mortality was fully compensated irrespective of the cause of death), all recruits to the population were susceptible to the ranavirus, and all individuals were equally susceptible to infection. The contact rate $(\Psi)$ was defined as the number of different individuals that one animal physically contacts, the likelihood of transmission $(\sigma)$ was the probability of transmission given the physical contact, and $\mathrm{R}_{0}$ was the basic reproductive rate of the virus. We used a discrete time model, because common frogs aggregate annually for breeding and we assumed that transmission primarily occurred from contacts during breeding. We also assumed that mortality due to disease occurred primarily during summer; ranavirus-associated mortality peaks between mid-July and mid-August, after breeding, has previously been concluded [20]. (See Figure 1 for a schematic view of the important life history events and timing.) Based on the above assumptions, we developed the following equations:

$$
\begin{gathered}
A_{s}(t+1)=A_{s}(t)-\sigma \Psi \cdot A_{S}(t) \cdot A_{I}(t)-M_{N}(t)+A_{R}(t) \\
A_{I}(t+1)=A_{I}(t)+\sigma \Psi \cdot A_{s}(t) \cdot A_{I}(t)-\left[M_{N}(t)+M_{D}(t)\right] \\
R_{0}=\sigma \Psi \cdot A_{s}(t) /\left[M_{N}(t)+M_{D}(t)\right]
\end{gathered}
$$

To determine under what conditions the ranavirus would remain or spread in a population, we modified Equation (3) by removing $M_{D}(t)$ to assume a successful introduction:

$$
\mathrm{R}_{\mathrm{o}}=\sigma \Psi \cdot \mathrm{A}_{\mathrm{s}} / \mathrm{M}_{\mathrm{N}}(\mathrm{t})
$$


The important interactions in this equation are between $\sigma$ and $\Psi$, and this relationship needed to be explored, graphically, to determine when the conditions for $R_{\mathrm{o}} \geq 1$ exist. If we assume a population size of $99\left(A_{S}\right)$, with an initial introduction of one infected individual $\left(A_{I}\right)$ and an $M_{N}$ of $20 \%$ [23] (although other estimates do exist [24]), values of $\sigma$ and $\Psi$ under which $R_{0} \geq 1$ are illustrated in Figure 2. To test if similar assumptions are valid at a smaller population size, we repeated the process using alternative values for $\mathrm{A}_{\mathrm{S}}=49$ and $\mathrm{M}_{\mathrm{N}}=10 \%$ (i.e., 5 individuals/annum) and introduced one infected individual (total population size 50; Figure 2).

\begin{tabular}{|c|c|c|c|c|c|}
\hline \multirow[b]{2}{*}{ Juveniles } & Winter & & Spring & Summer & Eall \\
\hline & & & Larval Development & Metamaphosis & Hibernation \\
\hline Adults & Emergence & Breeding & & & Hibernation \\
\hline Ranavirus & & st Contact Rates & & Disease ind & \\
\hline
\end{tabular}

Figure 1. Annual cycle of important life history events for common frogs (Rana temporaria) and important events for ranavirus infections and diseases, for these animals. Boxes shaded in blue are those that occur in the aquatic environment, green boxes are those that straddle the land and water, grey boxes occur at an unknown location, and mauve boxes are life history events that are known to happen on both the land and in the water.

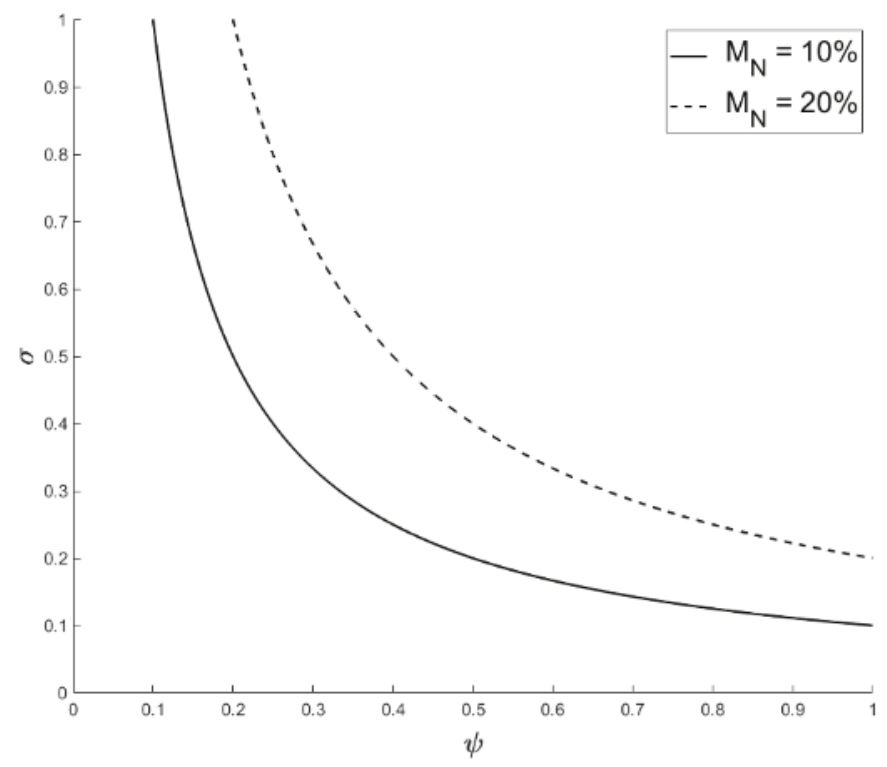

Figure 2. The interaction between $\sigma$ and $\Psi$, under which $R_{O} \geq 1$, when $A_{S}=99$ and an $M_{N}=20 \%$ (upper dashed-curve) and when the initial conditions of $\mathrm{A}_{\mathrm{S}}=49$ and an $\mathrm{M}_{\mathrm{N}}=10 \%$ (lower curve), where $\Psi$ is the contact rate and $\sigma$ is the likelihood of transmission for the model.

After establishing the conditions which permit ranavirus persistence, we next examined the behavior of $A_{S}$ and $A_{I}$ under potential biologically relevant conditions. We used experimental data from ranavirus exposures in the literature, to estimate $\sigma$ (Table 1). It is important to note that the data used to estimate $\sigma$ was extremely variable; the viral titers used in the experiments range from TCID $_{50}$ of $10^{1}$ to $10^{2} \mathrm{~mL}$ for virus obtained from crude organ homogenates to TCID 50 of $10^{4.2}$ to $10^{6.2} \mathrm{~mL}$, for virus produced via tissue culture [25]. This variability made the biological relevance of our estimates less than ideal; however, these are the best estimates that can be made with the available data. 
Table 1. Estimates for $\sigma$ derived from the literature. Note: Experiments where the exposure was via inoculation have not been included in these estimates. No distinction has been made between the types of ranavirus-associated disease that the virus was derived from. Development of disease data, TCID $_{50}$ and type of experiment information are summarized from Cunningham et al. [25]. (HS = Hemorrhagic and US = Ulcerative forms of ranavirosis.).

\begin{tabular}{cccccc}
\hline $\begin{array}{c}\text { Development of Disease } \\
\begin{array}{c}\text { No. with } \\
\text { Disease }\end{array}\end{array}$ & $\begin{array}{c}\text { Total No. } \\
\text { Exposed }\end{array}$ & $\begin{array}{c}\text { Disease } \\
\text { Prevalence }\end{array}$ & Type of Experiment/Exposure Type & Estimate of $\boldsymbol{\sigma}$ & TCID $_{\mathbf{5 0}}$ \\
\hline 3 & 20 & $15 \%$ & $\begin{array}{c}\text { Immersion with virus from naturally } \\
\text { disease tissue, with and without bacteria }\end{array}$ & 0.15 & $10^{1} / \mathrm{mL}$ \\
\hline 9 & 20 & $45 \%$ & $\begin{array}{c}\text { Immersion with virus from naturally } \\
\text { disease tissue homogenate to animals with } \\
\text { skin wounds, with and without bacteria }\end{array}$ & 0.45 & $\begin{array}{c}10^{2} / \mathrm{mL} \mathrm{HS} \\
10^{1.5} / \mathrm{mL} \mathrm{US}\end{array}$ \\
\hline 5 & 10 & $90 \%$ & Immersion in virus from culture & 0.90 & $10^{2} / \mathrm{mL} \mathrm{HS}$ \\
\hline 5 & 5 & $100 \%$ & $\begin{array}{c}\text { Immersion in virus from virus culture to } \\
\text { animals with wounded skin }\end{array}$ & 1 & $\begin{array}{c}10^{5.6} \text { to } \\
10^{6.2} / \mathrm{mL}\end{array}$ \\
\hline 2 & 5 & $40 \%$ & $\begin{array}{c}\text { Immersion in virus from tissue homogenate } \\
\text { from naturally diseased animals to animals } \\
\text { with wounded skin }\end{array}$ & 0.40 & $10^{3} / \mathrm{mL}$ \\
\hline
\end{tabular}

Estimates of $\Psi$ were unavailable, so we arbitrarily chose $\Psi=0.3 \rightarrow 0.6$ (Figure 3). We ignored sex specific contact rates, as male-male contact rates are extremely high and polyandry is common [26]. Additionally, Teacher et al. [9] found that the median population size of common frogs was 31 for those places where ranaviruses have emerged in the UK, so we used an $\mathrm{A}_{\text {Total }}$ of 30 (Figure 4).

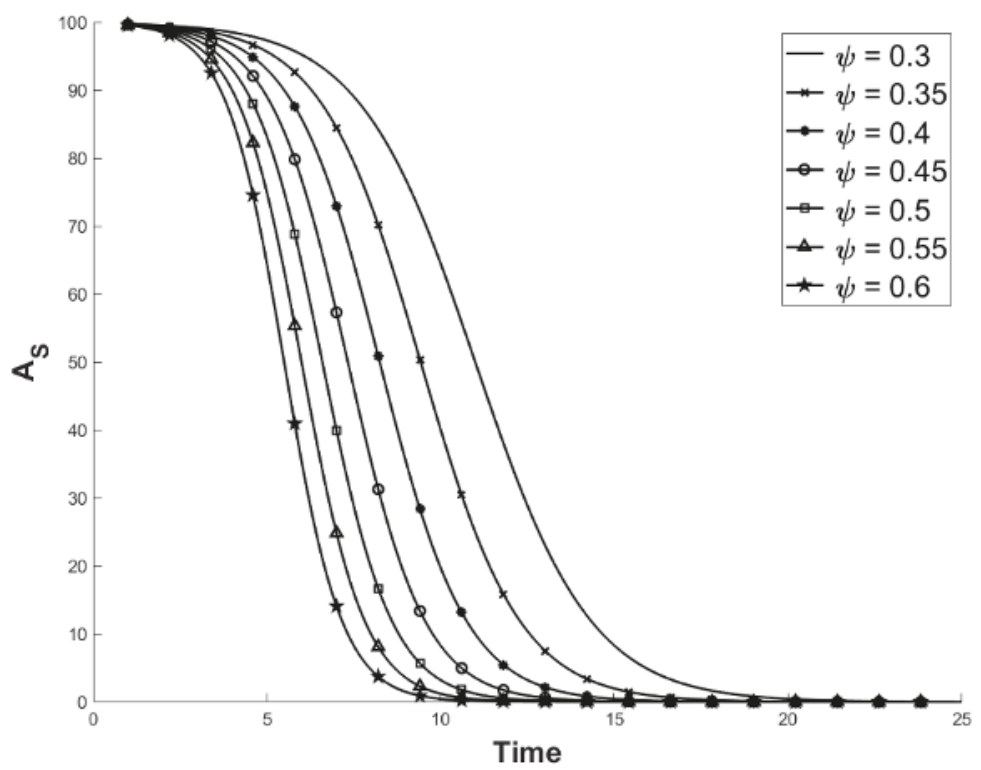

Figure 3. Predicted values of $A_{S}$ with varying values of $\Psi$ while other values remained constant at: $\sigma=0.3 ; \mathrm{M}_{\mathrm{N}}=0.2 ;$ and $\mathrm{M}_{\mathrm{D}}=0.75$. The starting population composition is $\mathrm{A}_{\mathrm{I}}=1$ and $\mathrm{A}_{\mathrm{S}}=99$ and time is in years. $A_{S}$ is the number of susceptible individuals, $\Psi$ is the contact rate, $\sigma$ is the likelihood of transmission, $\mathrm{M}_{\mathrm{N}}$ is the natural mortality rate, and $\mathrm{M}_{\mathrm{D}}$ is the mortality rate associated with ranavirosis. 


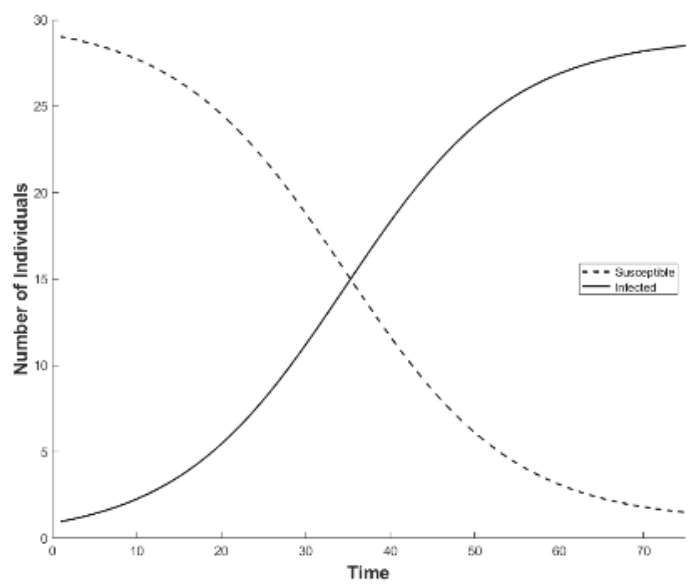

Figure 4. The average expectation of the ranavirus dynamics in a population of adult common frogs (Rana temporaria) through time (years). ( $\Psi=0.45 ; \sigma=0.3 ; \mathrm{M}_{\mathrm{N}}=0.2 ; \mathrm{M}_{\mathrm{D}}=0.775 ;$ starting population comprised of $A_{I}=1$ and $A_{S}=29$.) $A_{I}$ is the number of infected individuals, $A_{S}$ is the number of susceptible individuals, $\Psi$ is the contact rate, $\sigma$ is the likelihood of transmission, $M_{N}$ is the natural mortality rate, and $\mathrm{M}_{\mathrm{D}}$ is the mortality rate associated with ranavirosis.

Since ranaviruses have emerged recently in the UK, and common frogs and the severity of the disease is affected by climate change, it is unlikely that the disease dynamics have reached an equilibrium ([27,28]; Figure 4). Using an estimated $\sigma$ of 0.3 (from data from Table 1), an average $M_{D}$ of 0.775 , an average $\Psi$ value of 0.45 , and an $A_{\text {total }}$ of 30 [9] with the initial conditions of an $A_{s}$ of 29 and an $A_{I}$ of 1 , we found that the interaction between $A_{S}$ and $A_{I}$ requires greater than 60 years to stabilize to post-epidemic dynamics (Figure 5). These results suggest that, under the present conditions, ranavirus in populations of common frogs can be sustained entirely through adult-adult transmission.

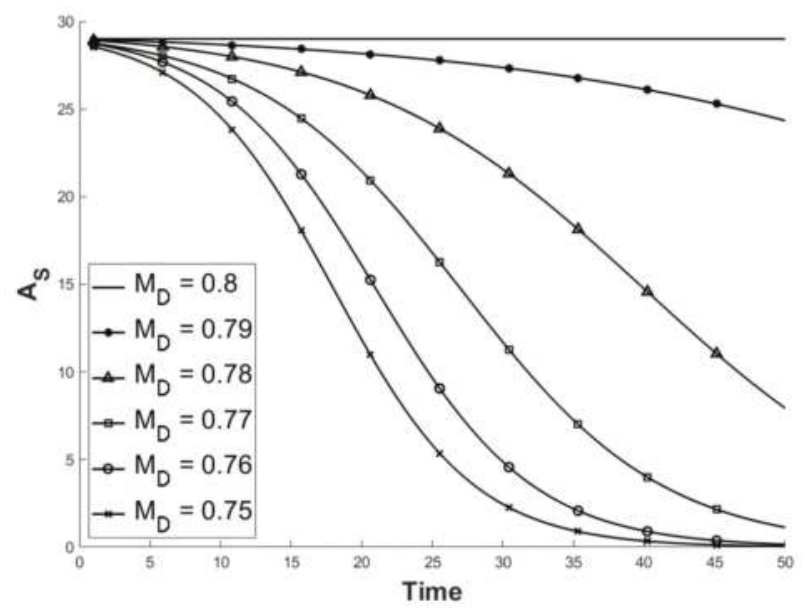

Figure 5. Illustration of the predicted values for $\mathrm{A}_{\mathrm{S}}$ with different disease-induced mortality rates, while other values remained constant at: $\Psi=0.45 ; \sigma=0.3 ; \mathrm{M}_{N}=0.2$; the starting population comprised of $A_{I}=1$ and $A s=29 . A_{s}$ is the number of susceptible individuals, $\Psi$ is the contact rate, $\sigma$ is the likelihood of transmission, $M_{N}$ is the natural mortality rate and $M_{D}$ is the mortality rate associated with ranavirosis. 


\subsection{Factoring in Population Decline}

In UK common frogs, ranavirosis has caused an $81 \%$ decline in some affected populations, over a 10 year period [9]; this appears to be a clear violation of the assumption in the model that population size remains constant. Teacher et al. [9] found that the declines in these populations were proportional to their size (i.e., the larger the population, the larger the decline experienced). This is possibly consistent with the assumption that all adults are equally susceptible, when a ranavirus first invades a population. Contrarily, larger declines in larger populations might be due to density-dependent transmission of the virus. This scenario can also account for the differences among individuals, in their susceptibility to the ranavirus.

However, Teacher et al. [29] report that populations of common frogs maintain allelic diversity through the immigration of adults from nearby ponds. This immigration has two potentially important consequences for the emergence of ranavirosis: (1) the population of adult frogs in the affected population will remain susceptible to infection because of the homogenizing effect of immigration; thus, the immigration of susceptible individuals might dilute the prevalence of the resistance genes, as long as the immigrants come from susceptible populations; and (2) immigration might bolster population numbers and reduce the observed decline. Consequently, the estimates of population decline due to ranavirosis that were made by Teacher et al. [9] might, in fact, be underestimates. In addition, Campbell et al. [30] have found that the population structure shifts from older adult frogs to proportionally more juveniles, with a much smaller total population size in the affected populations. These smaller populations have also been shown to be more susceptible to stochastic events, via population modelling [30]. For simplicity, we assumed that declines of $81 \%$ over a 10 year period, as seen by Teacher et al. [9], correspond to a steady annual decline of $8.1 \%$. Under such conditions, it takes the model approximately 65 years to stabilize, with all adults in the population suffering from ranavirus infections (Figure 6).

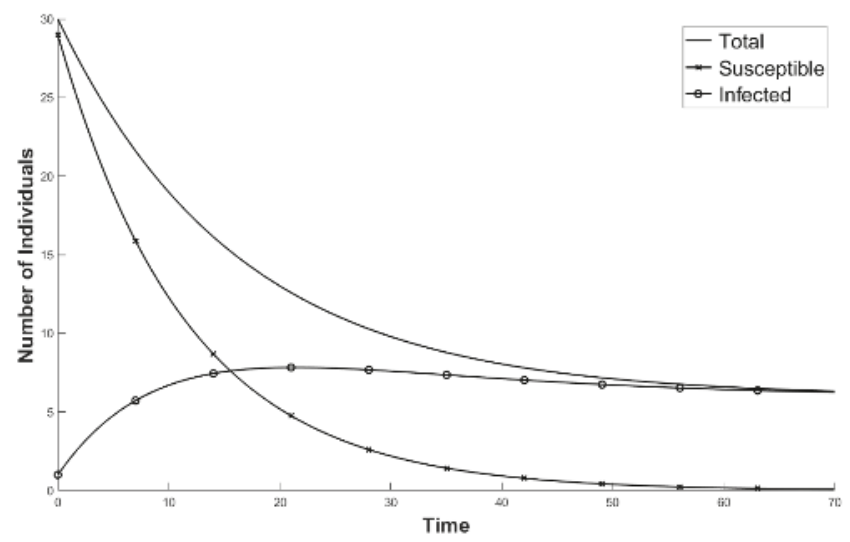

Figure 6. Illustration of the predicted dynamics of a common frog population, with the ranavirus factoring in an annual population decline of $8.1 \%$ for adult common frogs. ( $\Psi=0.45 ; \sigma=0.3 ; \mathrm{M}_{N}=0.2$; $\mathrm{M}_{\mathrm{D}}=0.775$; starting population comprised of $A_{I}=1$ and $A_{S}=29$; time is in years.) $A_{S}$ is the number of susceptible individuals, $\Psi$ is the contact rate, $\sigma$ is the likelihood of transmission, $M_{N}$ is the natural mortality rate, and $M_{D}$ is the mortality rate associated with the ranavirosis.

\subsection{Accounting for Different Disease Syndromes}

Ranavirosis in the UK common frogs presents as two syndromes which are not mutually exclusive. The ulcerative form of the disease is characterized by ulcers of the skin and the skeletal muscle, and sometimes necrosis of the digits, while the hemorrhagic form of the disease is characterized by internal hemorrhages, most commonly involving the gastrointestinal and reproductive tracts ([21]; 
personal observation). Adult common frogs exposed to a tissue homogenate derived from skin ulcers only developed the ulcerative form of the disease (with a prevalence of $\sim 30 \%$; See Table 2; [25]). Conversely, adult frogs exposed to a virus isolate obtained from skin ulcers generated both ulcerative and hemorrhagic signs of the disease, while virus isolated from a hemorrhage caused the hemorrhagic form of the disease in exposed adults [25]. These, and other data, indicate that ranaviruses associated with different pathologies in the UK might have different transmission rates [25]. Our estimates of $\sigma$ for both the ulcerative and hemorrhagic forms can be found in Table 2. If we take the view that infection using viral isolates derived from the cell culture does not mimic the natural process, the other estimates from Table 2 would be preferred, in which case, we estimated $\sigma$ for the ulcerative and hemorrhagic syndromes as 0.33 and 0.20 , respectively.

Table 2. Estimates for $\sigma$ derived from the literature, taking into account the different disease syndromes and type of syndrome that the virus was obtained from. U indicates the ulcerative form of the disease; $\mathrm{H}$ is the hemorrhagic form. The estimate of $\sigma$ is simply the prevalence of the disease based on the presence of the signs of disease when the experiment terminated. The average estimate of $\sigma$ is simply the mean of the estimates for each type of virus used for exposure. Development of disease data and type of experiment information are summarized from Tables 3-5 of Cunningham et al. [25].

\begin{tabular}{|c|c|c|c|c|c|c|}
\hline \multicolumn{4}{|c|}{ Development of Disease } & \multirow{2}{*}{$\begin{array}{l}\text { Type of Experiment/ } \\
\text { Exposure Type }\end{array}$} & \multirow{2}{*}{ Estimate of $\sigma$} & \multirow{2}{*}{$\begin{array}{c}\text { Average } \\
\text { Estimate of } \sigma\end{array}$} \\
\hline No. with $U$ & No. with $\mathrm{H}$ & No. with $\mathrm{U} \& \mathrm{H}$ & Total Exp. & & & \\
\hline 2 & 0 & 0 & 5 & $\begin{array}{l}\text { Immersion with virus from } \\
\text { naturally disease tissue with } \\
\text { bacteria (Ulcerative) }\end{array}$ & 0.4 & \multirow{5}{*}{0.36} \\
\hline 1 & 0 & 0 & 5 & $\begin{array}{c}\text { Immersion with virus from } \\
\text { naturally disease tissue without } \\
\text { bacteria (Ulcerative) }\end{array}$ & 0.2 & \\
\hline 2 & 0 & 0 & 5 & $\begin{array}{l}\text { Immersion with virus from } \\
\text { naturally disease tissue to animals } \\
\text { with skin wounds with bacteria } \\
\text { (Ulcerative) }\end{array}$ & 0.4 & \\
\hline 0 & 0 & 0 & 5 & $\begin{array}{c}\text { Immersion with virus from } \\
\text { naturally disease tissue to animals } \\
\text { with skin wounds without bacteria } \\
\text { (Ulcerative) }\end{array}$ & 0 & \\
\hline 2 & 2 & 0 & 5 & $\begin{array}{c}\text { Immersion in virus isolated from } \\
\text { naturally diseased animals from } \\
\text { virus culture (RUK 13, Ulcerative) }\end{array}$ & 0.8 & \\
\hline 0 & 0 & 0 & 5 & $\begin{array}{l}\text { Immersion with virus from } \\
\text { naturally disease tissue without } \\
\text { bacteria (Hemorrhagic) }\end{array}$ & 0 & \multirow{5}{*}{0.44} \\
\hline 0 & 0 & 0 & 5 & $\begin{array}{c}\text { Immersion with virus from } \\
\text { naturally disease tissue with } \\
\text { bacteria (Hemorrhagic) }\end{array}$ & 0 & \\
\hline 1 & 1 & 1 & 5 & $\begin{array}{c}\text { Immersion with virus from } \\
\text { naturally disease tissue to animals } \\
\text { with skin wounds with bacteria } \\
\text { (Hemorrhagic) }\end{array}$ & 0.6 & \\
\hline 0 & 3 & 1 & 5 & $\begin{array}{l}\text { Immersion with virus from } \\
\text { naturally disease tissue to animals } \\
\text { with skin wounds without bacteria } \\
\text { (Hemorrhagic) }\end{array}$ & 0.8 & \\
\hline 1 & 2 & 1 & 5 & $\begin{array}{c}\text { Immersion in virus isolated from } \\
\text { naturally diseased animals from } \\
\text { virus culture (RUK 11, } \\
\text { Hemorrhagic) }\end{array}$ & 0.8 & \\
\hline
\end{tabular}

We investigated three scenarios applying different values of $\sigma$, where the first two versions explored the two syndromes in isolation (ulcerative form, $\mathrm{A}_{\mathrm{U}}$, and hemorrhagic form, $\mathrm{A}_{\mathrm{H}}$, present, respectively, in Figure 7A,B), represented by Equations (5)-(9) for the initial frequencies and Equations (10)-(14) at time ( $t$ ). Then we developed a new series of equations for when both disease syndromes are present and including individuals that show signs of both forms of the disease, $\mathrm{A}_{\mathrm{U}+\mathrm{H}}$. For simplicity, we 
assumed that all animals are equally susceptible to both forms of the disease (Figure 8) and that there was no difference in the disease-induced mortality rate between syndromes:

$$
\begin{array}{r}
A_{S}(t)=A_{S}(i)-\left[\sigma_{1} \Psi \cdot A_{S}(i) \cdot A_{U}(i)+\sigma_{2} \Psi \cdot A_{S}(i) \cdot A_{(U+H)}(i)+\sigma_{3} \Psi \cdot A_{S}(i) \cdot A_{H}(i)\right]-M_{N}(i)+A_{R}(i) \\
A_{U}(t)=A_{U}(i)+\left[\sigma_{1} \Psi \cdot A_{S}(i) \cdot A_{U}(i)\right]-\left[\sigma_{1} \Psi \cdot A_{U}(i) \cdot A_{H}(i)+\sigma_{3} \Psi \cdot A_{H}(i) \cdot A_{U}(i)\right]-\left[M_{N}(i)+M_{D(U)}(i)\right] \\
A_{(U+H)}(t)=A_{(U+H)}(i)+\left[\sigma_{2} \Psi \cdot A_{S}(i) \cdot A_{(U+H)}\right]+\left[\sigma_{1} \Psi \cdot A_{U}(i) \cdot A_{H}(i)\right]+\left[\sigma_{3} \Psi \cdot A_{H}(i) \cdot A_{U}(i)\right] \\
-\left[M_{N}(i)+M_{D(U+H)}(i)\right] \\
A_{H}(t)=A_{H}(i)+\left[\sigma_{3} \beta \cdot A_{S}(i) \cdot A_{H}(i)\right]-\left[\sigma_{1} \beta \cdot A_{U}(i) \cdot A_{H}(i)+\sigma_{3} \beta \cdot A_{H}(i) \cdot A_{U}(i)\right]-\left[M_{N}(i)+M_{D(H)}(i)\right] \\
A_{S}(t+1)=A_{S}(t)-\left[\sigma_{1} \Psi \cdot A_{S}(t) \cdot A_{U}(t)+\sigma_{2} \Psi \cdot A_{S}(t) \cdot A_{(U+H)}(t)+\sigma_{3} \Psi \cdot A_{S}(t) \cdot A_{H}(t)\right]-M_{N}(t)+A_{R}(t) \\
A_{U}(t+1)=A_{U}(t)+\left[\sigma_{1} \Psi \cdot A_{S}(t) \cdot A_{U}(t)\right]-\left[\sigma_{1} \Psi \cdot A_{U}(t) \cdot A_{H}(t)+\sigma_{3} \Psi \cdot A_{H}(t) \cdot A_{U}(t)\right] \\
-\left[M_{N}(t)+M_{D(U)}(t)\right] \\
A_{(U+H)}(t+1)=A_{(U+H)}(i)+\left[\sigma_{2} \Psi \cdot A_{S}(i) \cdot A_{(U+H)}\right]+\left[\sigma_{1} \Psi \cdot A_{U}(i) \cdot A_{H}(i)\right]+\left[\sigma_{3} \Psi \cdot A_{H}(i) \cdot A_{U}(i)\right] \\
-\left[M_{N}(i)+M M_{D(U+H)}(i)\right] \\
A_{H}(t+1)=A_{H}(t)+\left[\sigma_{3} \Psi \cdot A_{S}(t) \cdot A_{H}(t)\right]-\left[\sigma_{1} \Psi \cdot A_{U}(t) \cdot A_{H}(t)+\sigma_{3} \Psi \cdot A_{H}(t) \cdot A_{U}(t)\right] \\
-\left[M_{N}(t)+M_{D(H)}(t)\right]
\end{array}
$$

A)
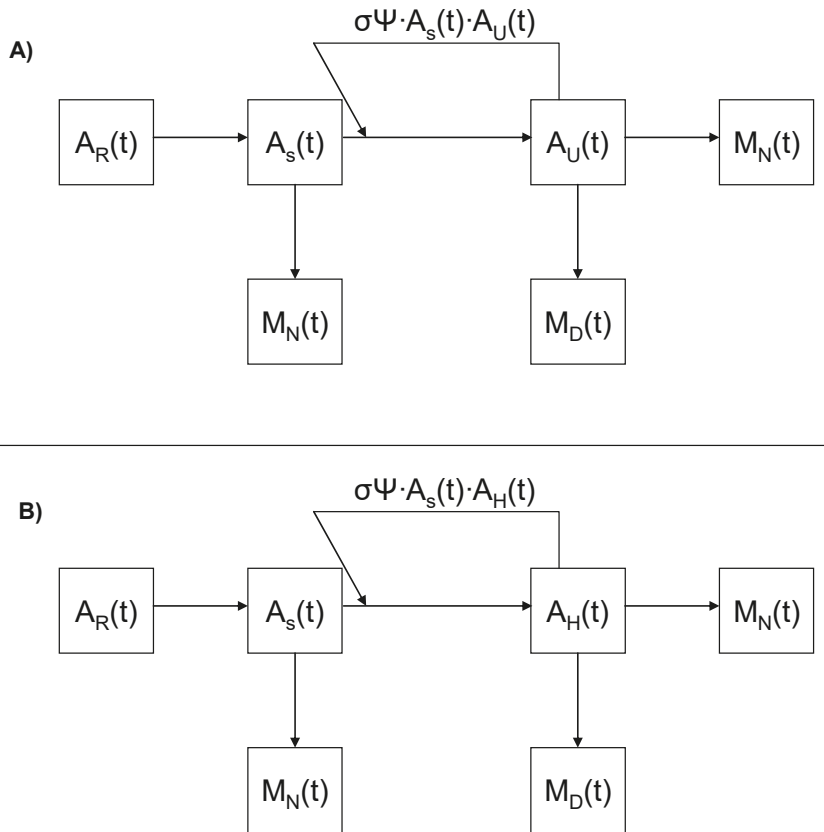

Figure 7. Diagrammatic representations of the transmission dynamics of the ranavirus when only the $\mathrm{A}_{\mathrm{S}}$ or $\mathrm{A}_{\mathrm{H}}$ causing isolate of the ranavirus is present. (A) When only the ulcerative form of the ranavirus is present within the population. (B) When only the hemorrhagic form of the disease is present in the population. All of the variables present are the same as described above and all have a time component associated with them. Where $A_{s}$ is the number of susceptible individuals, $\Psi$ is the contact rate, $\sigma$ is the likelihood of transmission, $\mathrm{M}_{\mathrm{N}}$ is the natural mortality rate, and $\mathrm{M}_{\mathrm{D}}$ is the mortality rate associated with ranavirosis. 


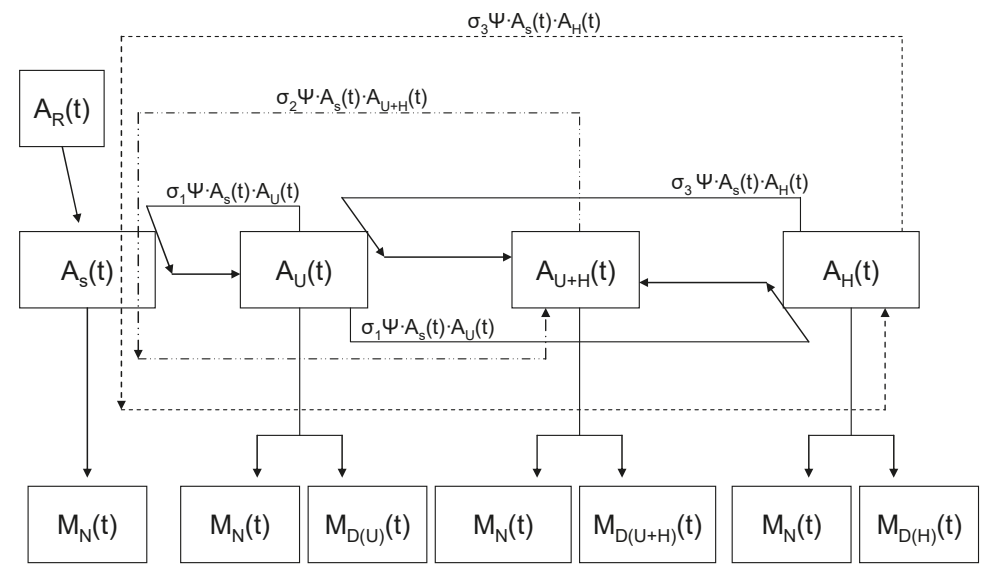

Figure 8. Illustration of the complex transmission dynamics of the ranavirus, when both of the observed disease syndromes are present in the population. Dashed lines are used to make the disease syndrome-specific vectors of the transmission easier to follow. The box sizes are not representative of the number of individuals in each category. The order of the boxes does not indicate when the given disease syndrome was introduced. All parameters have time components associated with them. $A_{s}$ is the number of susceptible individuals, $\Psi$ is the contact rate, $\sigma$ is the likelihood of transmission, $M_{N}$ is the natural mortality rate, and $\mathrm{M}_{\mathrm{D}}$ is the mortality rate associated with ranavirosis.

Ulcerative Syndrome

$$
\mathrm{R}_{\mathrm{oU}}=\sigma_{1} \Psi\left[\mathrm{A}_{\mathrm{S}}(\mathrm{t})+\mathrm{A}_{\mathrm{H}}(\mathrm{t})\right] / \mathrm{M}_{\mathrm{N}}(\mathrm{t})+\mathrm{M}_{\mathrm{D}(\mathrm{U})}(\mathrm{t})+\mathrm{M}_{\mathrm{D}(\mathrm{H})}(\mathrm{t})
$$

Hemorrhagic Syndrome

$$
\mathrm{R}_{\mathrm{oH}}=\sigma_{3} \Psi\left[\mathrm{A}_{\mathrm{S}}(\mathrm{t})+\mathrm{A}_{\mathrm{U}}(\mathrm{t})\right] / \mathrm{M}_{\mathrm{N}}(\mathrm{t})+\mathrm{M}_{\mathrm{D}(\mathrm{H})}(\mathrm{t})+\mathrm{M}_{\mathrm{D}(\mathrm{U})}(\mathrm{t})
$$

Under the assumptions that $\mathrm{A}_{\mathrm{S}}=28 \rightarrow 14, \mathrm{~A}_{\mathrm{H}}=1 \rightarrow 14$, with the introduction of $1 \rightarrow 5 \mathrm{~A}_{\mathrm{U}}$, $M_{D(U)}=M_{D(H)}=0.775, \sigma_{1}=0.3, \sigma_{3}=0.25, \Psi=0.45$, and $M_{N}=0.2$, based on the $R_{O}$ values, $A_{U}$ and $A_{H}$ should not coexist over the long term. It does not matter if $A_{U}$ is introduced into a population with $A_{H}$ or vice-versa (Figure 9). Both of these disease syndromes co-occur in nature [21] and in experimental infections [25].

Increasing the number of $A_{U}$ individuals in a population requires a higher transmission rate at each contact, for $A_{H}$ to become established (i.e., $R_{0} \geq 1$ ). However, establishment does not guarantee coexistence over the long term. While at first this might seem counter intuitive, it can be explained as follows-when there are more $A_{U}$ individuals in the population there is a greater overall mortality rate because $M_{D(U)}>>M_{N}$. Hence, there are actually fewer individuals to infect. Even when all of the population $(n=29)$ is composed of $\mathrm{A}_{\mathrm{U}}$ individuals, $\mathrm{A}_{\mathrm{H}}$ can become established $\left(\sigma_{3} \approx 0.85\right.$; see Figure 10). Although this is a high transmission rate, it is not unlikely in the situation where animals have broken skin (see [25]; adult common frogs with broken skin are more likely to become infected), which is characteristic of the ulcerative form of the ranaviral disease. The above analysis demonstrates that the two disease syndromes could persist in the short term, in the same population, by adult-to-adult transmission, albeit under conditions which have been estimated from data that are incomplete and not necessarily biologically relevant, based on the differing $R_{o}$ values. 


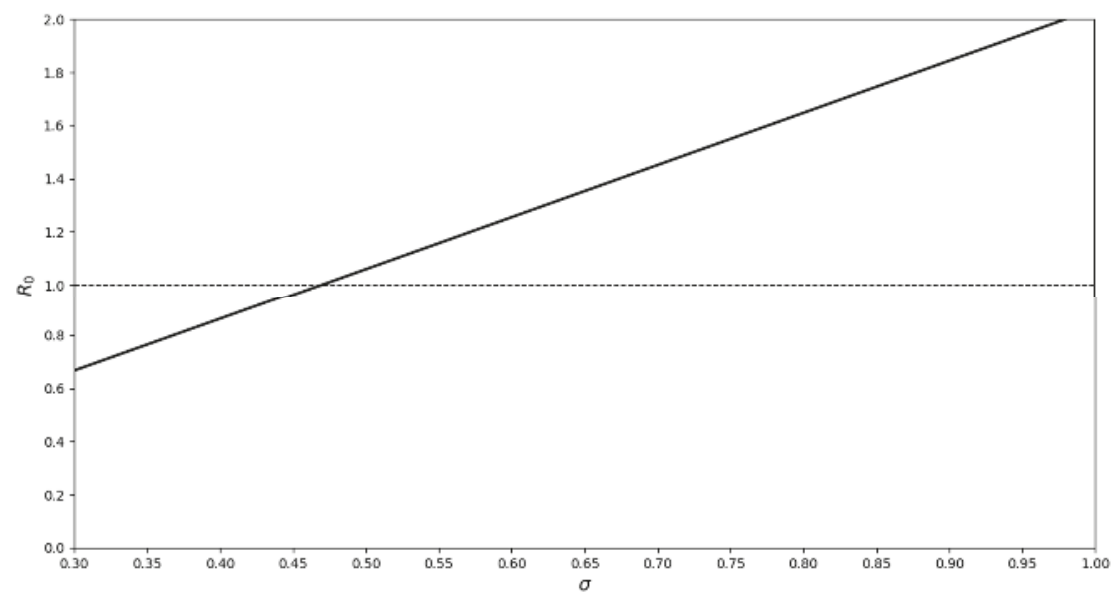

Figure 9. $\mathrm{R}_{\mathrm{O}}$ values for the introduction of one $\mathrm{A}_{\mathrm{H}}$ individual into a population of $\mathrm{A}_{\mathrm{S}}=28$ and $\mathrm{A}_{\mathrm{U}}=1$ $\left(\mathrm{M}_{\mathrm{D}(\mathrm{U})}=\mathrm{M}_{\mathrm{D}(\mathrm{H})}=0.775, \Psi=0.45, \mathrm{M}_{\mathrm{N}}=0.2\right)$. $\mathrm{A}_{\mathrm{S}}$ is the number of susceptible individuals, $\Psi$ is the contact rate, $\sigma$ is the likelihood of transmission, $M_{N}$ is the natural mortality rate, and $M_{D}$ is the mortality rate associated with ranavirosis.

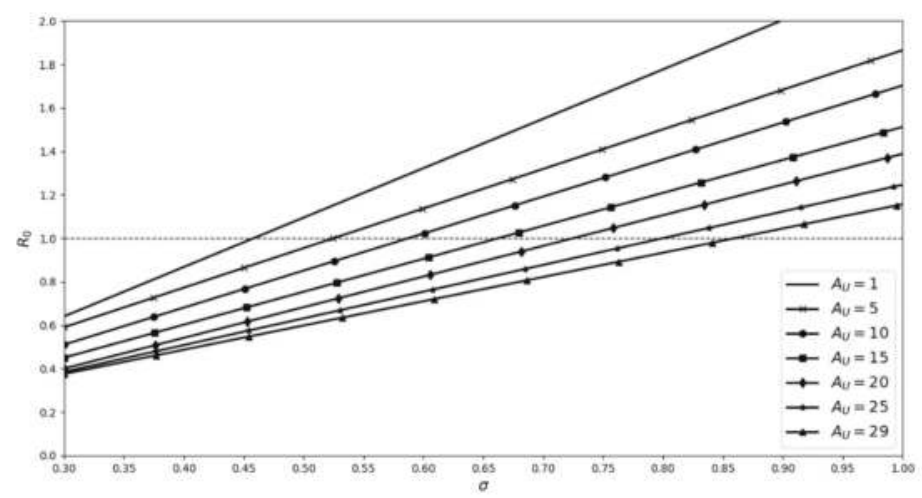

Figure 10. Ro values for the introduction of one $A_{H}$ individual to populations with differing numbers of $A_{U}$, while the total population size remains constant at 30. The number associated with each line indicates the number of $A_{U}$ individuals present in the population. $\left(\mathrm{M}_{\mathrm{D}(\mathrm{U})}=0.775, \Psi=0.45, \mathrm{M}_{\mathrm{N}}=0.2\right)$ $A_{s}$ is the number of susceptible individuals, $\Psi$ is the contact rate, $\sigma$ is the likelihood of transmission, $\mathrm{M}_{\mathrm{N}}$ is the natural mortality rate, and $\mathrm{M}_{\mathrm{D}}$ is the mortality rate associated with ranavirosis.

\section{Discussion}

Transmission dynamics are key to understanding host and pathogen persistence. In amphibian ranavirus systems, transmission can occur through direct contact, from scavenging, from virus particles persisting in the environment, and even between vertebrate classes, as seen in laboratory experiments. However, there is little understanding of the transmission routes that are most important in natural communities. In North America, ranavirus transmission appears to be primarily through direct contact with minimal transmission from water and scavenging, in most circumstances [16]. Our model is consistent with these results, demonstrating that the ranavirus(es) present in the UK common frog populations might persist in the short-term through horizontal, adult-to-adult transmissions alone.

When the declines of $8.1 \%$ per annum-observed by Teacher et al. [9] in the common frog populations where ranavirosis have emerged-are factored into the model, it took approximately 
65 years for all adults in the population to become infected. This model did not take into account immigration, which has been noted by Teacher et al. [29] or the change in population structure that is caused by the emergence of ranavirosis, as described by Campbell et al. [30]. These additional factors, along with the effects of climate change [28], might change the outcomes of the models, and perhaps even require adjustments to the model parameters.

Strict adult-to-adult transmission of ranaviruses appears to be relatively rare. It is likely to have occurred in a mass mortality event of over 1000 adult and metamorphic water frogs (Pelophylax spp.) in the Netherlands, caused by a strain of Common Midwife Toad Virus (CMTV) [31]. In this case, there were also common newts (Lissotriton vulgaris) involved in the mortality event [31], but they made up only approximately $1 \%$ of the animals killed, and ranavirus transmission to the newts might be best attributed to pathogen spillover. In North America, reports of adult anurans infected with ranavirus are rare (e.g., only one adult wood frog [18]); morbidity and mortality events tend to occur in the tadpole stage. However, in the UK, adult-only mortality and morbidity events are typical, therefore, adult-to-adult transmission must play a major role in the transmission, which is consistent with our model results. This is an important finding since, there often is a lack of tadpoles in the ponds at the time of the adult mortality events [20]. However, other species might act as a reservoir of hosts that can infect common frogs [32], such as common toads, common newts (Lissotriton vulgaris) and the introduced common midwife toad (Alytes obstetricans). Future models and studies should explore interspecies transmission and subsequent population dynamics, especially since the presence of other species, namely common toads (Bufo bufo), can reduce disease risk in common frogs [5,27].

Our models showed that both disease syndromes can co-exist in the short term, despite competition between the ranavirus(es) associated with the different disease syndromes. This is not surprising if there are multiple strains of ranavirus present in the population. Exposure to different ranaviruses has been shown to result in enhanced viral infectivity in larval amphibians in the USA [33], and it is possible that this same pattern is occurring in the adult UK common frogs. The susceptibility of the host might depend on which ranavirus strain (ulcerative or hemorrhagic) is first introduced into the population. A similar effect has been previously observed in tadpoles exposed to Frog virus 3 (FV3) and Ambystoma tigrinum virus [33]. This might be the case in the UK, because there are at least two different types of ranaviruses present [27]. CMTV-like and FV3-like ranaviruses have been previously identified in the UK populations of common frogs [27]; however, no association with the distinct disease syndromes were found in this study. In a previous study, molecular differences between two of the isolates (RUK 11 and RUK 13) were found, both of which were responsible for different disease syndromes. Duffus et al. [34] found that while the major capsid protein sequences for these two isolates were similar to FV3, the partial sequence of open reading frame $57 \mathrm{r}$ (an eIF- $2 \alpha$ homologue) was similar to that found in an isolate of Chinese giant salamander virus (a common midwife toad-like virus). These differences could be indicative of larger scale molecular differences between the RUK isolates that result in the different ranaviral syndromes seen in common frogs in the UK.

Our models were greatly limited by a lack of robust parameter estimates. The contact rates were unknown for common frogs and the transmission coefficients were based on experiments with small sample sizes and unrealistic viral titres. Better parameter estimation (e.g., contact rates, individual susceptibility to ranavirosis, and disease-induced mortality in adults) would be key to improving the predictive values of all presented models.

Author Contributions: A.L.J.D. conceived the models. T.W.J.G. and R.A.N. provided valuable guidance to A.L.J.D. on model development. J.P.S. ran and modified the original models, as necessary. A.L.J.D., J.E.E., and T.W.J.G. wrote the manuscript. All authors edited the manuscript and approved it.

Funding: Support for this work from 2006 to 2010 was provided by a Queen Mary, University of London Studentship to A.J.L.D., an Overseas Research Scholarship to A.L.J.D., and a Natural Science and Engineering Council (NSERC) of Canada PGS-D3 Grant to A.L.J.D. T.W.J.G. was supported by a RCUK fellowship and R.A.N. and T.W.J.G. were supported by NERC (NE/M00080X/1 and NE/M000338/1, respectively).

Acknowledgments: We would like to thank Robert Knell for the helpful discussions about model development and two anonymous reviewers who's comments and suggestions greatly improved the quality of the manuscript. 
Conflicts of Interest: The authors declare no conflict of interest. The funders had no role in the design of the study, in the collection, analyses, or interpretation of data; in the writing of the manuscript or in the decision to publish the results.

\section{References}

1. Gray, M.J.; Chinchar, V.G. Introduction: History and future of ranaviruses. In Ranaviruses: Lethal Pathogens of Ectothermic Vertebrates; Gray, M.J., Chinchar, V.G., Eds.; Springer: New York, NY, USA, 2015; pp. 1-7.

2. Duffus, A.L.J.; Waltzek, T.B.; Stöhr, A.C.; Allender, M.C.; Gotesman, M.; Whittington, R.J.; Hick, P.; Hines, M.K.; Marschang, R.E. Distribution and host range of ranviruses. In Ranaviruses: Lethal Pathogens of Ectothermic Vertebrates; Gray, M.J., Chinchar, V.G., Eds.; Springer: Secaucus, NJ, USA, 2015.

3. Miller, D.L.; Pessier, A.P.; Hick, P.; Whittington, R.J. Comparative pathology of ranaviruses and diagnostic techniques. In Ranaviruses: Lethal Pathogens of Ectothermic Vertebrates; Gray, M.J., Chinchar, V.G., Eds.; Springer: Secaucus, NJ, USA, 2015.

4. Hoverman, J.T.; Gray, M.J.; Haislip, N.A.; Miller, D.L. Phylogeny, life history, and ecology contribute to differences in amphibian susceptibility to ranaviruses. EcoHealth 2011, 8, 301-319. [CrossRef] [PubMed]

5. North, A.C.; Hodgson, D.J.; Price, S.J.; Griffiths, A.G.F. Anthropogenic and ecological drivers of amphibian disease (ranavirosis). PLoS ONE 2015, 10, e0127037. [CrossRef] [PubMed]

6. Balseiro, A.; Dalton, K.P.; del Cerro, A.; Marquez, I.; Cunningham, A.A.; Parra, F.; Prieto, J.M.; Casais, R. Pathology, isolation and molecular characterisation of a ranavirus from the common midwife toad Alytes obstetricans on the iberian peninsula. Dis. Aquat. Org. 2009, 84, 95-104. [CrossRef] [PubMed]

7. Green, D.E.; Converse, K.A.; Schrader, A.K. Epizootiology of sixty-four amphibian morbidity and mortality events in the USA, 1996-2001. Ann. N. Y. Acad. Sci. 2002, 969, 323-339. [CrossRef] [PubMed]

8. Muths, E.; Gallant, A.L.; Grant, E.H.C.; Battaglin, W.A.; Green, D.E.; Staiger, J.S.; Walls, S.C.; Gunzburger, M.S.; Kearney, R.F. The Amphibian Research and Monitoring Iniative (ARMI): 5-Year Report; US Geological Survey Scientific Investigations Report 2006-5224; USDOI, USGS, Eds.; US Geological Survey: Reston, VA, USA, 2006; p. 77.

9. Teacher, A.G.F.; Cunningham, A.A.; Garner, T.W.J. Assessing the long-term impact of ranavirus infection in wild common frog populations. Anim. Conserv. 2010, 13, 514-522. [CrossRef]

10. Price, S.J.; Garner, T.W.J.; Nichols, R.A.; Balloux, F.; Ayres, C.; Mora-Cabello de Alba, A.; Bosch, J. Collapse of amphibian communities due to an introduced ranavirus. Curr. Biol. 2014, 24, 1-6. [CrossRef] [PubMed]

11. Earl, J.E.; Gray, M.J. Introduction of ranavirus to isolated wood frog populations could cause local extinction. EcoHealth 2014, 11, 581-592. [CrossRef]

12. Earl, J.E.; Chaney, J.C.; Sutton, W.B.; Lillard, C.E.; Kouba, A.J.; Langhorne, C.; Krebs, J.; Wilkes, R.P.; Hill, R.D.; Miller, D.L.; et al. Ranavirus could facilitate local extinction of rare amphibian species. Oecologia 2016, 182, 611-623. [CrossRef]

13. Farrell, A.P.; Collins, J.P.; Greer, A.L.; Thieme, H.R. Times from infection to disease-induced death and their influence on final population sizes after epidemic outbreaks. Bull. Math. Biol. 2018, 80, 1937-1961. [CrossRef]

14. Anderson, R.M.; May, R.M. Population biology of infectious disease. Nature 1979, 280, 361-461. [CrossRef]

15. May, R.M.; Anderson, R.M. Population biology of infectious diseases: Part II. Nature 1979, 280, 455-461. [CrossRef] [PubMed]

16. Brunner, J.L.; Yarber, C.M. Evaluating the importance of environmental persistence for Ranavirus transmission and epidemiology. Adv. Virus Res. 2018, 101, 129-148. [PubMed]

17. Brunner, J.L.; Schock, D.M.; Davidson, E.W.; Collins, J.P. Intraspecific reservoirs: Complex life history and the persistence of a lethal ranavirus. Ecology 2004, 85, 560-566. [CrossRef]

18. Duffus, A.L.J.; Pauli, B.D.; Wozney, K.; Brunetti, C.R.; Berrill, M. Frog virus 3-like infections in aquatic amphibian communities. J. Wildl. Dis. 2008, 44, 109-120. [CrossRef] [PubMed]

19. Duffus, A.L.J.; Nichols, R.A.; Garner, T.W.J. Experimental evidence in support of single host maintenance of a multihost pathogen. Ecosphere 2014, 5, 1-11. [CrossRef]

20. Duffus, A.L.J.; Nichols, R.A.; Garner, T.W.J. Investigations into the life history stages of the common frog (Rana temporaria) affected by an amphibian ranavirus in the United Kingdom. Herpetol. Rev. 2013, 44, 260-263. 
21. Cunningham, A.A.; Langton, T.E.S.; Bennett, P.M.; Lewin, J.F.; Drury, S.E.N.; Gough, R.E.; MacGregor, S.K. Pathological and microbiological findings from incidents of unusual mortality of the common frog (Rana temporaria). Philos. Trans. R. Soc. Lond. B Biol. Sci. 1996, 351, 1539-1557.

22. Otto, S.P.; Day, T. A Biologist's Guide to Mathematical Modeling in Ecology and Evolution; Princeton University Press: Princeton, NJ, USA, 2007; p. 732.

23. Miaud, C.; Guyetant, R.; Elmberg, J. Variations in life-history traits in the common frog Rana temporaria (Amphibia: Anura): A literature review and new data from the French Alps. J. Zool. 1999, 249, 61-73. [CrossRef]

24. Gibbons, M.M.; McCarthy, T.K. Growth, maturation and survival of frogs Rana temporaria L. Holarct. Ecol. 1984, 7, 419-427. [CrossRef]

25. Cunningham, A.A.; Hyatt, A.D.; Russell, P.; Bennett, P.M. Emerging epidemic diseases of frogs in britain are dependant on the source of ranavirus agent and the route of exposure. Epidemiol. Infect. 2007, 135, 1200-1212. [CrossRef] [PubMed]

26. Vieites, D.R.; Nieto-Román, S.; Barluenga, M.; Palanca, A.; Vences, M.; Meyer, A. Post-mating clutch piracy in an amphibian. Nature 2004, 431, 305-308. [CrossRef] [PubMed]

27. Price, S.J.; Wadia, A.; Wright, O.N.; Leung, W.T.; Cunningham, A.A.; Lawson, B. Screening of a long-term sample set reveals two ranavirus lineages in british herpetofauna. PLoS ONE 2017, 12, e0184768. [CrossRef] [PubMed]

28. Price, S.J.; Leung, W.T.M.; Owen, C.; Puschendorf, R.; Sergeant, C.; Cunningham, A.A.; Balloux, F.; Garner, T.W.J.; Nichols, R.A. Effects of historic and projected climate change on the range and impacts of an emerging wildlife disease. Glob. Chang. Biol. 2019, in press. [CrossRef] [PubMed]

29. Teacher, A.G.F.; Garner, T.W.J.; Nichols, R.A. Evidence for directional selection at a novel major histocompatability class i marker in wild common frogs (Rana temporaria) exposed to a viral pathogen (Ranavirus). PLoS ONE 2009, 4, e4616. [CrossRef]

30. Campbell, L.J.; Garner, T.W.J.; Tessa, G.; Scheele, B.C.; Griffiths, A.G.F.; Harrison, X.A. An emerging viral pathogen truncates population age structure in a european amphibian and may reduce population viability. PeerJ 2018, 6, e5949. [CrossRef] [PubMed]

31. Kik, M.; Martel, A.; Spitzen-van der Sluijs, A.; Pasmans, F.; Wohlsein, P.; Gröne, A.; Rijks, J.M. Ranavirus-associated mass mortality in wild amphibians, the netherlands, 2010: A first report. Vet. J. 2011, 190, 284-286. [CrossRef]

32. Duffus, A.L.J.; Nichols, R.A.; Garner, T.W.J. Detection of a frog virus 3-like ranavirus in native and introduced amphibians in the United Kingdom in 2007 and 2008. Herpetol. Rev. 2014, 45, 608-610.

33. Mihaljevic, J.R.; Hoverman, J.T.; Johnson, P.T.J. Co-exposure to multiple ranavirus types enhances viral infectivity and replication in a larval amphibian system. Dis. Aquat. Org. 2018, 132, 23-35. [CrossRef]

34. Duffus, A.L.J.; Garner, T.W.J.; Davis, A.R.; Dean, A.W.; Nichols, R.A. Phylogentic analysis of 24 ranavirus isolates from English amphibians using 2 partial loci. J. Emerg. Dis. Virol. 2017, 3. [CrossRef]

(C) 2019 by the authors. Licensee MDPI, Basel, Switzerland. This article is an open access article distributed under the terms and conditions of the Creative Commons Attribution (CC BY) license (http://creativecommons.org/licenses/by/4.0/). 
Article

\title{
Ranaviruses Bind Cells from Different Species through Interaction with Heparan Sulfate
}

\author{
Fei Ke ${ }^{1,2}$, Zi-Hao Wang ${ }^{1}$, Cheng-Yue Ming ${ }^{1}$ and Qi-Ya Zhang ${ }^{1,2, *}$ \\ 1 State Key Laboratory of Freshwater Ecology and Biotechnology, The Innovation Academy of Seed Design, \\ Institute of Hydrobiology, Chinese Academy of Sciences, Wuhan 430072, China \\ 2 College of Modern Agriculture Sciences, University of Chinese Academy of Sciences, Beijing 100049, China \\ * Correspondence: zhangqy@ihb.ac.cn; Tel.: +86-027-68780792
}

Received: 30 May 2019; Accepted: 28 June 2019; Published: 29 June 2019

check for updates

\begin{abstract}
Ranavirus cross-species infections have been documented, but the viral proteins involved in the interaction with cell receptors have not yet been identified. Here, viral cell-binding proteins and their cognate cellular receptors were investigated using two ranaviruses, Andrias davidianus ranavirus (ADRV) and Rana grylio virus (RGV), and two different cell lines, Chinese giant salamander thymus cells (GSTC) and Epithelioma papulosum cyprinid (EPC) cells. The heparan sulfate (HS) analog heparin inhibited plaque formation of ADRV and RGV in the two cell lines by more than $80 \%$ at a concentration of $5 \mu \mathrm{g} / \mathrm{mL}$. In addition, enzymatic removal of cell surface HS by heparinase I markedly reduced plaque formation by both viruses and competition with heparin reduced virus-cell binding. These results indicate that cell surface HS is involved in ADRV and RGV cell binding and infection. Furthermore, recombinant viral envelope proteins ADRV-58L and RGV-53R bound heparin-Sepharose beads implying the potential that cell surface HS is involved in the initial interaction between ranaviruses and susceptible host cells. To our knowledge, this is the first report identifying cell surface $\mathrm{HS}$ as ranavirus binding factor and furthers understanding of interactions between ranaviruses and host cells.
\end{abstract}

Keywords: ranavirus; virus binding; heparan sulfate; Andrias davidianus ranavirus; Rana grylio virus; envelope protein

\section{Introduction}

Interspecies transmission and infection have been reported in several viruses that infect humans [1, 2]. Likewise, aquatic animal viruses can also infect and cause disease in a wide range of aquatic animals [3,4]. Specifically, the interspecies infection was reported following ranavirus infection $[5,6]$. However, the basis for the broad ranavirus host range is not clear [7,8]. Ranaviruses are large double-stranded DNA viruses within the family Iridoviridae [9]. Ranaviruses target aquatic animals globally and have been isolated from reptiles [10,11], amphibians [12-15], and bony fish [16,17]. Among them, several isolates represent great threats to the development of the aquaculture industry and wild animal populations [18]. Aside from infecting several species within a given taxonomic class (e.g., frog virus 3 infects diverse amphibian species), ranaviruses may also infect members of different classes (e.g., frog virus 3-like agents have been isolated from both amphibians and fish) [19].

Binding susceptible host cells is the first step in viral infection and is one of the key factors responsible for determining host range [20]. Diverse cellular receptors and viral envelope and capsid proteins are involved in the process. For example, vaccinia virus utilizes four viral proteins that bind to glycosaminoglycans (GAGs) or laminin on the cell surface [21-25].

Cell surface GAGs consist of complex linear polysaccharides, which are ubiquitously expressed in most cell types [26]. Heparan sulfate (HS), chondroitin sulfate (CS), and dermatan sulfate comprise the 
main types of GAGs on the cell surface. Besides vaccinia virus, GAGs are involved in the binding of adenovirus [27], various alphaviruses [28,29], bunyaviruses [30,31], filoviruses [32], flavivirus [33], hepacivirus [34], herpesvirus [35], papillomaviruses [36], and rhabdoviruses [37]. It has been shown that cell surface GAGs, especially HS, serve as initial receptors in infections with these viruses. However, there is little information on the role of HS in ranavirus binding.

Rana grylio virus (RGV) and Andrias davidianus ranavirus (ADRV) are ranaviruses isolated from diseased pig frogs R. grylio (anura amphibian) and Chinese giant salamanders (CGS) A. davidianus (urodele amphibian), respectively [12,13]. The complete genomes of the two viruses have been sequenced, and several functional proteins have been characterized [38-45]. For example, RGV-53R, a homolog of ADRV-58L, was identified as an envelope protein [38]. Decreased expression of RGV-53R, or its frog virus 3 (FV3) homolog FV3-53R impaired virus replication in cultured cells [45,46]. In this report, we examine the role of HS in ranavirus entry. Furthermore, since ranavirus viral envelope proteins [38-40,45-48] are likely involved in the initial interaction between virus and host, we examined the ability of RGV-53R and its ADRV homolog, ADVR-58L, to bind heparin-Sepharose beads.

\section{Materials and Methods}

\subsection{Viruses and Cells}

ADRV isolated from diseased Chinese giant salamanders (CGS) [13] and RGV isolated from the diseased pig frog R. grylio [12] were maintained in our laboratory and used in the present study. CGS thymus cells (GSTC) [49] and Epithelioma papulosum cyprinid (EPC) cells [39] were cultured in M199 medium supplemented with 10\% bovine calf serum.

\subsection{Virus Purification}

ADRV and RGV were purified, as described previously [50]. Briefly, GSTC cells were infected with ADRV and RGV at a multiplicity of infection (MOI) of $0.1 \mathrm{PFU} /$ cell, respectively, and incubated at $25^{\circ} \mathrm{C}$. The cell cultures were harvested when cytopathic effects (CPE) reached approximately $90 \%$. The viral suspensions were frozen at $-20^{\circ} \mathrm{C}$, thawed three times, and then centrifuged at $5000 \times g$ for $20 \mathrm{~min}$. The resulting supernatants were ultracentrifuged at 110,000 $\times g$ (Beckman, SW41, Brea, CA, USA) for $90 \mathrm{~min}$. The pellets were resuspended in TE buffer (10 mM of Tris-HCl, $1 \mathrm{mM}$ of EDTA, pH 7.4) and further purified in a discontinuous sucrose gradient $(30 \%, 40 \%, 50 \%$, and $60 \%$ ) at $110,000 \times g$ for $60 \mathrm{~min}$. The viral bands were collected, centrifuged to remove residual sucrose, and the resulting viral pellets were resuspended in TE buffer and stored at $-80^{\circ} \mathrm{C}$.

\subsection{Plaque Reduction Assay}

Heparin is a structural homolog of highly sulfated HS and has been used as a surrogate for cell surface HS in research studies examining binding [51]. The effect of heparin on viral plaque formation was tested in assays using GSTC and EPC cells for the purpose of analyzing the effect of soluble glycosaminoglycans on viral infection. The indicated cells were seeded in 24-well plates $24 \mathrm{~h}$ prior to infection. Heparin (Sangon Biotech, Shanghai, China, from porcine intestinal mucosa, molecular weight range of 6-20 kDa) was diluted in cell culture medium and incubated with ADRV or RGV for $1 \mathrm{~h}$ at $4{ }^{\circ} \mathrm{C}$. At a concentration of $10 \mu \mathrm{g} / \mathrm{mL}$, the color of the growth medium (using phenol red as an indicator) did not change, indicating a stable $\mathrm{pH}$. Cell culture media was removed and $100 \mu \mathrm{L}$ of the virus-heparin solution, containing approximately $50 \mathrm{PFU}$ of the indicated virus, was added to each well for $1 \mathrm{~h}$ at $25^{\circ} \mathrm{C}$. Three replicate wells were used in each treatment. After $1 \mathrm{~h}$, the inoculum was removed, the cells were washed twice with fresh medium, and overlaid with culture media containing $0.7 \%$ agarose. Fresh medium was added to the well after agarose solidification. Plaques were counted after three days of incubation at $25^{\circ} \mathrm{C}$. Based on the results obtained from the heparin treatment, two other glycosaminoglycans, heparan sulfate and chondroitin sulfate (Sigma, St. Louis, MO, USA), were tested by the method described above. 


\subsection{Heparinase Treatment}

To further investigate its role in virus binding, target cells were treated with heparinase to remove cell surface heparan sulfate. Heparinase I cleaves the linkages between hexosamines and the O-sulfated iduronic acids of heparin and HS. GSTC cells were seeded in 24-well plates $24 \mathrm{~h}$ prior to infection. Medium was removed before the assay, and the cells were incubated with different concentrations of heparinase I from Flavobacterium heparinum (Sigma) in $20 \mathrm{mM}$ of Tris- $\mathrm{HCl}$ (pH 7.5), $4 \mathrm{mM}$ of $\mathrm{CaCl}_{2}$, $50 \mathrm{mM}$ of $\mathrm{NaCl}$, and $0.01 \%$ bovine serum albumin (BSA) for $1 \mathrm{~h}$ at $15^{\circ} \mathrm{C}$ and then washed twice with fresh medium. One hundred microliters of medium containing ADRV or RGV (50 PFU) were added and incubated for another $1 \mathrm{~h}$ at $15^{\circ} \mathrm{C}$. The supernatant was removed, the cells washed twice with fresh medium, and overlaid with medium containing $0.7 \%$ agarose, as described above. After incubation for three days at $25^{\circ} \mathrm{C}$, the plaques were counted.

\subsection{Cell Binding Assay}

To investigate the effect of heparin on virus-cell binding, quantitative real-time PCR (qPCR) analysis that has been used in the detection of hepatitis C virus (HCV) genomes [34] was used to determine the relative quantity of virus bound to the cell surface. Both purified virions, isolated following separation on a sucrose step gradient, and a crude viral suspension, obtained by lysis of cells infected by the virus, were used in these assays. GSTC cells were seeded in 24-well plates $24 \mathrm{~h}$ prior to infection. Heparin was diluted in medium and mixed with the viral suspension or purified virions for $30 \mathrm{~min}$ at $4{ }^{\circ} \mathrm{C}$, and then $100 \mu \mathrm{L}$ of the mixture containing approximately 1000 PFU of the indicated virus was added to cells for $1 \mathrm{~h}$ at $4{ }^{\circ} \mathrm{C}$, as described above. The inoculum was removed after incubation. The cells, washed twice with fresh medium, were collected by centrifugation, and DNA was extracted with the TakaRa MiniBEST Universal Genomic DNA Extraction Kit (TakaRa, Tokyo, Japan). Bound viral genomes, based on detection of the relative numbers of major capsid protein gene $(\mathrm{MCP})$, were detected by $\mathrm{qPCR}$, which was conducted using a StepOne Real-Time PCR system (The Applied Biosystems, Foster City, CA, USA). Each qPCR mixture contained $1 \mu \mathrm{L}$ of DNA, $12.5 \mu \mathrm{L}$ of SYBR Premix $(2 \times), 0.5 \mu \mathrm{L}$ of forward and reversed primers (for each primer, 5'-CACCTCCATCCCAGTCAGCA-3'/5'-AATCCCATCGAGCCGTTCA-3'), and $10.5 \mu \mathrm{L}$ of ultrapure water. The qPCR conditions were as follows: $95^{\circ} \mathrm{C}$ for $10 \mathrm{~min} ; 40$ cycles of $95^{\circ} \mathrm{C}$ for $15 \mathrm{~s}$ and $60{ }^{\circ} \mathrm{C}$ for $1 \mathrm{~min}$; and a melt curve analysis at $95^{\circ} \mathrm{C}$ for $15 \mathrm{~s}, 60^{\circ} \mathrm{C}$ for $1 \mathrm{~min}$, and $95^{\circ} \mathrm{C}$ for $15 \mathrm{~s}$. The $\beta$-actin gene, used in a previous study [52], was used as a loading control. qPCR efficiency was evaluated with a standard curve, based on serially diluted DNA samples using the $\beta$-actin gene primers, which showed that there were no obvious differences on the qPCR efficiencies among samples treated with different concentrations of heparin. For the MCP detection, MCP levels were normalized to $\beta$-actin levels in each sample. The level of bound virus (MCP level) in the treated group versus that in the control group (no heparin) was calculated by the $2^{-\Delta \Delta C T}$ method [53].

\subsection{Protein Expression and Purification}

Considering the pivotal roles that viral envelope proteins play in virus attachment and entry, we determined whether viral envelope proteins interacted with HS by monitored the binding of purified recombinant proteins to heparin-Sepharose beads as described by Chung et al. [22]. Previous studies demonstrated that RGV-53R is 522 amino acid (aa) envelope protein with two predicted transmembrane (TM) domains (aa 193-211 and aa 218-237) [38]. ADRV-58L is the ADRV homolog of RGV-53R. The aa sequence identity between ADRV-58L and RGV-53R is $99.2 \%$ [13]. In the present assay, TM helices and topology of the two proteins were predicted with the online tools HMMTOP (http://www.enzim.hu/hmmtop/html/submit.html) and TMHMM (http://www.cbs.dtu.dk/services/TMHMM-2.0/) that presented on ExPASy. The primers 5'-GTAGAATTCATGGGAGCAGCGGAA-3' and 5'-GATAAGCTTTTATGTGGTGGGGTCCAGGCC-3' were used for amplifying DNA sequences encoding the N-terminal region (1-192) of 58L 
and the N-terminal region (1-192) of 53R, respectively. The other pair of primers (5'-GGCGAATTCCCCAGGCCCGTCAAGA-3' $/ 5^{\prime}$-CTATAAGCTTTTAACCCCTGTGGGC-3') was used for amplifying the DNA sequences for the C-terminal region (238-522) of 58L. Because the amino acid sequence of the C-terminal regions of ADRV-58L and RGV-53R are identical, only the C-terminal region of ADRV-58L was expressed in the present study. The resulting fragments were digested using EcoR I and Hind III, and ligated into pET32a or pET28a vectors that had been digested with the same enzymes. Successful cloning was validated by DNA sequencing.

For protein expression and purification, the plasmids obtained above were used to transform Escherichia coli BL21 (DE3). Positive clones were cultured in LB medium and induced with $0.1 \mathrm{mM}$ isopropyl- $\beta$-D-thiogalactopyranoside (IPTG) for $4 \mathrm{~h}$ at $24^{\circ} \mathrm{C}$. The bacterial pellets were lysed by sonication. The recombinant protein was purified using the HisBind Purification Kit (Novagen, Billerica, MA, USA) according to the manufacturer's instructions. The purified protein was dialyzed against PBS, the concentration determined using a BCA Protein Assay Kit (Beyotime, Wuhan, China), and stored at $-80{ }^{\circ} \mathrm{C}$.

\subsection{Heparin-Sepharose Binding Assay}

Heparin-Sepharose beads 6FF and control Sepharose beads (Purchased from SMART lifesciences, Changzhou, China, particle diameter range of 45-165 $\mu \mathrm{m}$ ) were equilibrated with binding buffer (50 mM Tris- $\mathrm{HCl}, 10 \mathrm{mM}$ sodium citrate, $\mathrm{pH}$ 7.4) before use. The purified recombinant protein $(5 \mu \mathrm{g})$ was mixed with or without heparan sulfate $(100 \mu \mathrm{g} / \mathrm{mL})$ and incubated in binding buffer with 100 $\mu \mathrm{L}$ of beads for $1 \mathrm{~h}$ at $4{ }^{\circ} \mathrm{C}$. The supernatant was collected after centrifugation for $1 \mathrm{~min}$ at $1800 \times g$. The beads were washed with binding buffer $(100 \mu \mathrm{L})$ five times, and bound protein was eluted with binding buffer containing $2 \mathrm{M} \mathrm{NaCl}$. The samples were analyzed by $12 \%$ SDS-PAGE and subsequently transferred to a PVDF membrane (Millipore, Burlington, MA, USA). A monoclonal antibody against the His tag (Santa Cruz, Dallas, Texas, USA) was used as the primary antibody, horseradish peroxidase (HRP)-conjugated goat anti-mouse IgG (H + L) (Merck, Kenilworth, NJ, USA) as the secondary antibody, and antibody binding detected by chemiluminescence (Millipore).

\section{Results}

\subsection{Heparin and HS Inhibit Infection by ADRV and RGV}

The effect of heparin on virus infection was tested by monitoring viral plaque formation following incubation of ADRV and RGV in the presence of increasing concentrations of heparin. As shown in Figure 1, the number of plaques formed by either ADRV or RGV was reduced by heparin in a concentration-dependent manner. For ADRV, infectivity was reduced by approximately $70 \%$ by pre-exposure to heparin at $0.1 \mu \mathrm{g} / \mathrm{mL}$ and by more than $80 \%$ at $5 \mu \mathrm{g} / \mathrm{mL}$. A similar phenomenon was observed in RGV-infected cells, which exhibited a $57 \%$ inhibition at $0.1 \mu \mathrm{g} / \mathrm{mL}$ and more than $75 \%$ at $5 \mu \mathrm{g} / \mathrm{mL}$. Moreover, inhibition was detected regardless of the cell line used. The results indicate that heparin-like GAGs were involved in ADRV and RGV binding.
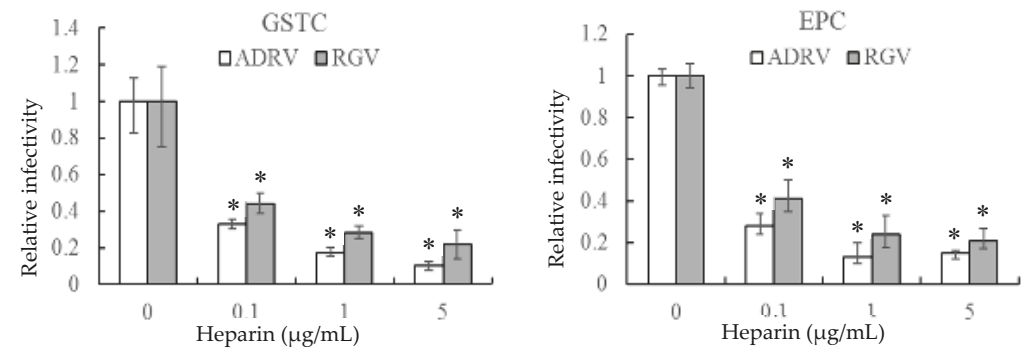

Figure 1. Soluble heparin inhibits Andrias davidianus ranavirus (ADRV) and Rana grylio virus (RGV) infection of giant salamander thymus cells (GSTC) and Epithelioma papulosum cyprinid (EPC) cells. 
Cells were infected with ADRV or RGV that had been pre-incubated in the presence of different concentrations of heparin. The number of plaques obtained in the absence of heparin was set as 1 . The data represent triplicate results and was analyzed with Student's $t$-test. Significant differences (versus virus without heparin) are marked with * $(p<0.05)$.

In a second experiment, HS and CS, linear polysaccharides that constitute two major classes of cell surface GAGs, were monitored for their ability to reduce plaque formation. As with heparin, HS reduced the number of plaques formed by the two viruses in GSTC and EPC cells in a concentration-dependent manner (Figure 2a). For both viruses, plaque formation was inhibited by more than $80 \%$ in GSTC cells and more than $60 \%$ in EPC cells at $5 \mu \mathrm{g} / \mathrm{mL}$ (Figure $2 \mathrm{a}$ ). In contrast, a significant inhibitory effect was only seen at the highest concentration when CS was substituted for HS (Figure 2b). These results indicate that cell surface GAGs, including HS, likely play important roles in plaque formation by both ADRV and RGV.
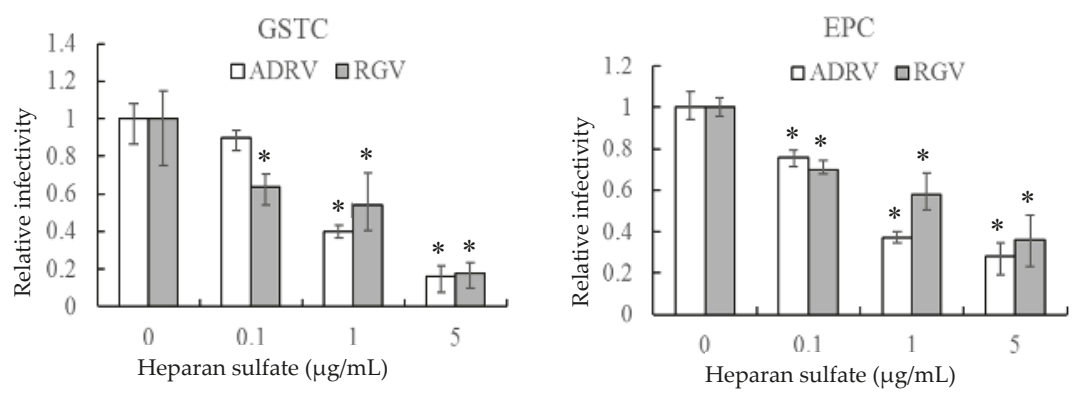

(a)
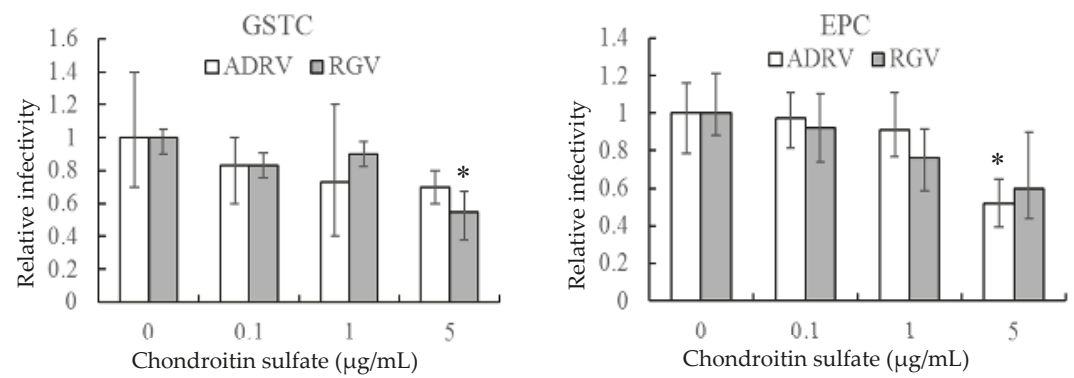

(b)

Figure 2. Heparan sulfate (a) and chondroitin sulfate (b) inhibit ADRV and RGV infection of GSTC and EPC cells. GSTC and EPC cells were infected with ADRV or RGV in the presence of different concentrations of heparan sulfate and chondroitin sulfate. The number of plaques obtained without glycosaminoglycans (GAGs) was set as 1. Experiments were conducted in triplicate and analyzed using Student's $t$-test. Significant differences (versus virus without exposure to GAGs) are marked with * $(p<0.05)$.

\subsection{Enzymatic Removal of Cell Surface HS Reduced Viral Infection}

If the interaction between heparin-like GAGs and viral particles is needed for viral infection, removal of GAGs should inhibit infection. To accomplish that task, heparinase I was used to remove cell surface HS. As shown in Figure 3, the number of plaques formed by the two viruses was markedly reduced in GSTC cells pretreated with heparinase I. The reduction was more than $50 \%$ at a heparinase concentration of $1.25 \mathrm{U} / \mathrm{mL}$ and slightly more at higher enzyme concentrations. Thus, the ability of 
heparinase treatment to reduce viral plaque formation supports the view that cell surface HS is a receptor for the two viruses.

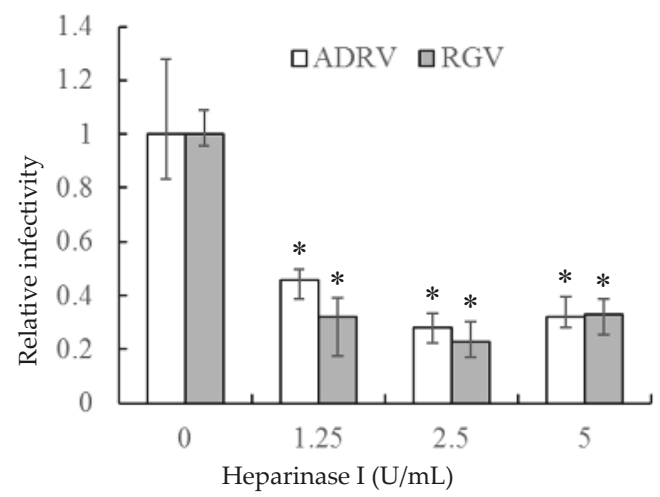

Figure 3. Heparinase I treatment reduced ADRV and RGV plaque formation in GSTC cells. Cells were infected with ADRV or RGV after treatment with different concentrations of heparinase I and plaque formation monitored. Plaque numbers obtained in the absence of heparinase treatment were set as 1 . Triplicate results were analyzed by Student's $t$-test, and significant differences are marked with * $(p<0.05)$.

\subsection{Heparin Inhibits Virus-Cell Binding}

To further verify the role of cell surface HS on virus-cell binding, heparin was used to inhibit the binding of the two viruses competitively. The number of bound virions was determined by measurement of viral DNA copy number by qPCR to monitor binding. As shown in Figure 4, binding of either crude (viral suspension) or purified virions was inhibited by pre-exposure to heparin. Binding of crude suspensions of either ADRV or RGV were reduced to $20-30 \%$ of control levels at a concentration of $10 \mu \mathrm{g} / \mathrm{mL}$. Similar results were obtained with purified virions. The inhibitory effect of heparin on virus-cell binding supports the finding that cell surface HS is a viral receptor.
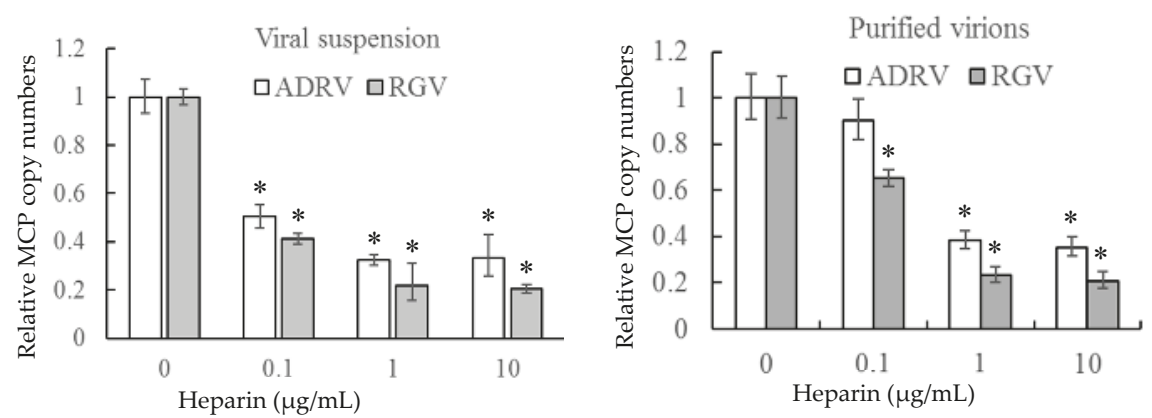

Figure 4. Soluble heparin inhibits virus binding to GSTC cells. Viral suspensions or purified virions were added to GSTC cells in the presence of different concentrations of heparin. After incubation, virion binding was assessed by determining the number of bound viral genomes by qPCR. DNA levels observed in the absence of heparin pre-treatment were set as 1 . The data were obtained from three experiments and analyzed with Student's $t$-test. Significant differences are marked with $*(p<0.05)$.

\subsection{Recombinant Envelope Proteins Bind Heparin Beads In Vitro}

As shown above, cell surface HS is an important receptor for both ADRV and RGV. Here we examine the role that viral envelope proteins play in this process by monitoring the interaction of purified 
recombinant viral envelope protein with heparin-Sepharose beads. To accomplish this, the amino terminal 192 amino acids of ADRV-58L and RGV-53R and the C-terminal region of ADRV-58L (amino acids 238-522) were cloned into pET32a and pET28a and expressed in E. coli (Figure 5a). Because the amino acid sequences of the C-terminal regions of ADRV-58L and RGV-53R are identical, only the C-terminal region of ADRV-58L was expressed. Note the recombinant proteins were increased in size, due to a $17 \mathrm{kDa}$ Trx-His-S tag in pET32a, and a 4 kDa His-T7 tag in pET28a. As shown in Figure 5b,c, recombinant proteins of the expected sizes were generated using the two expression systems. Subsequently, purified recombinant proteins were isolated and incubated with heparin-Sepharose beads or control beads lacking heparin. The three recombinant proteins (r58L-N, r53R-N, and r58L-C), expressed using either pET32a or pET28a, bound heparin-sepharose beads and were eluted in the presence of a high salt wash. In contrast, all three recombinant proteins failed to bind sepharose beads lacking heparin, and, as a result, were present in the unbound supernatant (S) fraction (Figure 5d). When considered together, these results support the view that HS is a cellular receptor for both ADRV and RGV and the binding fashion may be similar to the interaction between 53R/58L and heparin that occurred in vitro.

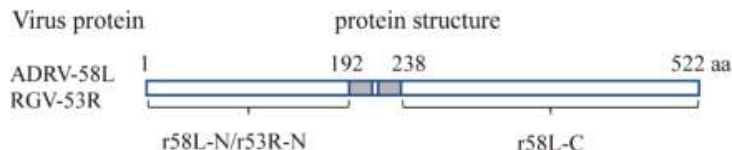

(a)

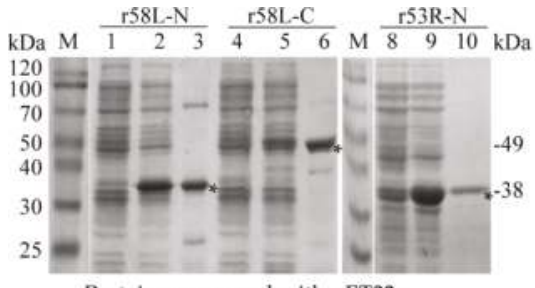

Proteins expressed with pET32a

(b)

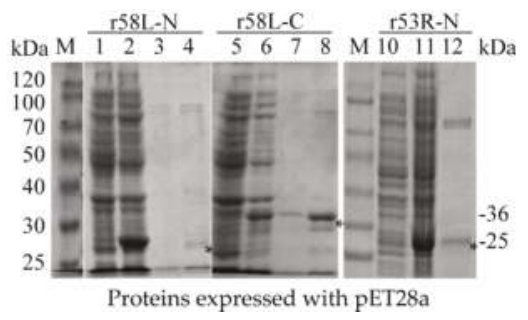

(c)

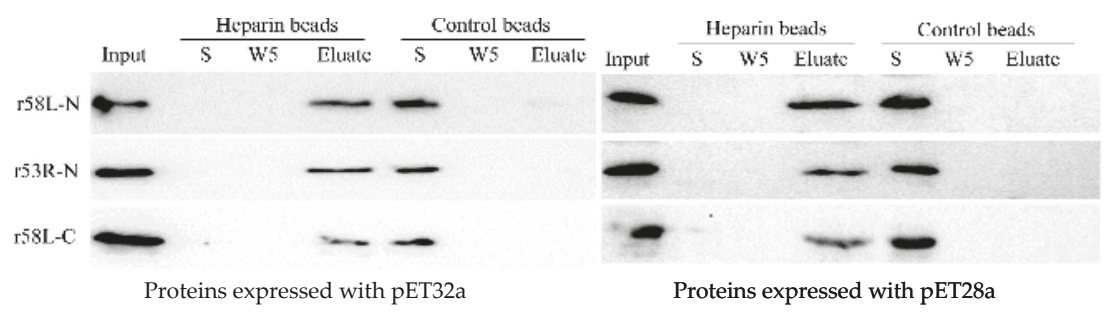

(d)

Figure 5. Recombinant proteins bind heparin-Sepharose beads. (a) Schematic diagram of the recombinant proteins: The N-terminal domain of ADRV-58L (r58L-N), the N-terminal domain of RGV-53R (r53R-N), and the C-terminal domain of ADRV-58L (r58L-C) were expressed using pET32a or pET28a. The predicted transmembrane region is shown in the grey box. (b) Expression and purification of the three proteins (r58L-N, r53R-N, and r58L-C) with pET32a vector. M: protein marker; 1, 4, 8: Bacteria without induction; 2, 5, 9: Bacteria with induction; 3, 6, 10: Purified proteins. The recombinant proteins are indicated with asterisks, and their predicted molecular weights are shown on the right. 
(c) Expression and purification of the three proteins using pET28a. M: Protein marker; 1, 5, 10: Cacteria without induction; 2, 6, 11: Cacteria with induction; 3, 4, 7, 8, 12: Purified proteins. The recombinant proteins are indicated with asterisks, and their predicted molecular weights are shown on the right. (d) Binding of recombinant proteins and heparin-Sepharose beads. Recombinant proteins were incubated with heparin-Sepharose or Sepharose beads. The fractions of input (Input), supernatant after incubation (S), the fifth wash solution (W5), and the eluate (Eluate) were detected by Western blot with the anti-His antibody. Recombinant proteins expressed with pET32a or pET28a vectors were used. Recombinant proteins were observed in the Input and Elute fractions from heparin-Sepharose beads and S fraction from control beads.

\section{Discussion}

In this study, we tested the ability of heparin and two other GAGs (HS and CS) to inhibit plaque formation in fish and amphibian cell lines. These and other results showed that cell surface HS is an important receptor for the binding of ADRV and RGV to target cells. As far as we know, it is the first report describing the role of cell surface HS in iridovirus infection.

Previously we identified RGV-53R as an envelope protein [38]. Here we tested whether RGV-53R, or its ADRV homolog (58L), could bind HS. Our data showed that recombinant 53R and 58L proteins specifically bound heparin-Sepharose beads in vitro and that this binding could be inhibited by the presence of excess HS. The envelope protein 53R and its homologs among other members of the family constitute one of 26 core proteins and likely function in viral entry. Additional studies will be needed to identify the protein domains involved in 53R-heparan sulfate interaction.

Multiple steps are involved in virion entry and initiation of a successful infection. Binding to cell surface GAGs, including HS, has proved to be the initial event in the entry of several mammalian viruses [27-37]. Because GAGs are linked to proteins and usually exist as proteoglycans in vivo [26], viral envelope proteins may bind to cell surface heparan sulfate-linked proteins and facilitate attachment between the virus and potential host cells. Our results suggest that binding of cell surface HS is required for initiation of productive infection by ranaviruses. However, since competition by increasing concentrations of heparin or HS, or treatment with heparinase did not completely inhibit plaque formation, it appears that HS is not the sole cellular receptor for ranaviruses. A similar phenomenon has been observed in the binding of the vaccinia virus, which uses cell surface GAGs and cellular matrix laminin as receptors [22-25]. A recent study showed that class A scavenger receptors are utilized by frog virus 3, the type species of the genus Ranavirus [54]. Additional ranavirus binding factors and specific cellular protein receptors may be involved in viral attachment and entry. In addition, although the host range of ranaviruses could be determined by binding to other cellular proteins, binding to cell surface GAGs likely plays an important role in the initial interaction between virus and host cell.

It is worth noting that there are two types of virions for iridoviruses. One contains a central core surrounded by an internal membrane and a viral capsid. The other type has an outer viral envelope after the virions bud from the plasma membrane [9]. The two types of viral particles may have different cellular receptors when they infect cells. Thus, the existence of different virions that have an outer envelope or not could be another reason for the incomplete inhibition efficiency in the present study.

This is a report showing that iridoviruses bind cells of different species through the interaction between cell surface GAGs and envelope proteins. However, it remains to be determined whether binding to GAGs is both necessary and sufficient for subsequent virion entry, or whether virus-GAG interaction precedes binding to a second specific cellular receptor.

Author Contributions: Conceptualization, Q.-Y.Z.; methodology, F.K., Z.-H.W. and C.-Y.M.; writing-original draft preparation, F.K.; writing-review and editing, F.K. and Q.Y.Z.; supervision, funding acquisition, Q.-Y.Z.

Funding: This work was supported by the National Natural Science Foundation of China $(31430091,31772890)$, Strategic Pilot Science and Technology of the Chinese Academy of Sciences Project (XDA08030202), the National Key R\&D Plan of the Ministry of Science and Technology, China (2018YFD0900302), and the fund of the Institute of Hydrobiology (Y85Z02-1-3-1).

Acknowledgments: We acknowledge the editorial assistance of V.G. Chinchar. 
Conflicts of Interest: The authors declare no conflict of interest.

\section{References}

1. Long, J.S.; Mistry, B.; Haslam, S.M.; Barclay, W.S. Host and viral determinants of influenza A virus species specificity. Nat. Rev. Microbiol. 2018. [CrossRef] [PubMed]

2. $\quad$ Li, W.; Hulswit, R.J.G.; Kenney, S.P.; Widjaja, I.; Jung, K.; Alhamo, M.A.; van Dieren, B.; van Kuppeveld, F.J.M.; Saif, L.J.; Bosch, B.J. Broad receptor engagement of an emerging global coronavirus may potentiate its diverse cross-species transmissibility. Proc. Natl. Acad. Sci. USA 2018, 115, E5135-E5143. [CrossRef] [PubMed]

3. Zhang, Q.Y.; Gui, J.F. Diversity, evolutionary contribution and ecological roles of aquatic viruses. Sci. China Life Sci. 2018, 61, 1486-1502. [CrossRef] [PubMed]

4. Gui, L.; Zhang, Q.Y. A brief review on aquatic animal virology researches in China. J. Fish. China 2019, 42, $1-20$.

5. Bandin, I.; Dopazo, C.P. Host range, host specificity and hypothesized host shift events among viruses of lower vertebrates. Vet. Res. 2011, 42, 67. [CrossRef] [PubMed]

6. Price, S.J.; Ariel, E.; Maclaine, A.; Rosa, G.M.; Gray, M.J.; Brunner, J.L.; Garner, T.W.J. From fish to frogs and beyond: Impact and host range of emergent ranaviruses. Virology 2017, 511, 272-279. [CrossRef] [PubMed]

7. Gui, L.; Chinchar, V.G.; Zhang, Q.Y. Molecular basis of pathogenesis of emerging viruses infecting aquatic animals. Aquac. Fish. 2018, 3, 1-5. [CrossRef]

8. Gui, L.; Zhang, Q.Y. Disease prevention and control. In Aquaculture in China: Success Stories and Modern Trends; Gui, J.F., Tang, Q.S., Li, Z.J., Liu, J.S., Sena, S.S.D., Eds.; Wiley-Blackwell: Chichester, UK, 2018; pp. 577-598.

9. Chinchar, V.G.; Hick, P.; Ince, I.A.; Jancovich, J.K.; Marschang, R.; Qin, Q.; Subramaniam, K.; Waltzek, T.B.; Whittington, R.; Williams, T.; et al. ICTV virus taxonomy profile: Iridoviridae. J. Gen. Virol. 2017, 98, 890-891. [CrossRef]

10. Marschang, R.E.; Becher, P.; Posthaus, H.; Wild, P.; Thiel, H.J.; Müller-Doblies, U.; Kalet, E.F.; Bacciarini, L.N. Isolation and characterization of an iridovirus from Hermann's tortoises (Testudo. hermanni). Arch. Virol. 1999, 144, 1909-1922. [CrossRef]

11. Huang, Y.; Huang, X.; Liu, H.; Gong, J.; Ouyang, Z.; Cui, H.; Cao, J.; Zhao, Y.; Wang, X.; Jiang, Y.; et al. Complete sequence determination of a novel reptile iridovirus isolated from soft-shelled turtle and evolutionary analysis of Iridoviridae. BMC Genom. 2009, 10, 224. [CrossRef]

12. Zhang, Q.Y.; Xiao, F.; Li, Z.Q.; Gui, J.F.; Mao, J.; Chinchar, V.G. Characterization of an iridovirus from the cultured pig frog Rana. grylio with lethal syndrome. Dis. Aquat. Organ. 2001, 48, 27-36. [CrossRef]

13. Chen, Z.Y.; Gui, J.F.; Gao, X.C.; Pei, C.; Hong, Y.J.; Zhang, Q.Y. Genome architecture changes and major gene variations of Andrias. davidianus ranavirus (ADRV). Vet. Res. 2013, 44, 101. [CrossRef] [PubMed]

14. Chinchar, V.G.; Yu, K.H.; Jancovich, J.K. The molecular biology of frog virus 3 and other iridoviruses infecting cold-blooded vertebrates. Viruses 2011, 3, 1959-1985. [CrossRef] [PubMed]

15. Jancovich, J.K.; Mao, J.; Chinchar, V.G.; Wyatt, C.; Case, S.T.; Kumar, S.; Valente, G.; Subramanian, S.; Davidson, E.W.; Collins, J.P.; et al. Genomic sequence of a ranavirus (family Iridoviridae.) associated with salamander mortalities in North America. Virology 2003, 316, 90-103. [CrossRef] [PubMed]

16. Whittington, R.J.; Becker, J.A.; Dennis, M.M. Iridovirus infections in finfish—critical review with emphasis on ranaviruses. J. Fish. Dis. 2010, 33, 95-122. [CrossRef]

17. Qin, Q.W.; Chang, S.F.; Ngoh-Lim, G.H.; Gibson-Kueh, S.; Shi, C.; Lam, T.J. Characterization of a novel ranavirus isolated from grouper Epinephelus. tauvina. Dis. Aquat. Org. 2003, 53, 1-9. [CrossRef] [PubMed]

18. Zhang, Q.Y.; Gui, J.F. Virus genomes and virus-host interactions in aquaculture animals. Sci. China Life Sci. 2015, 58, 156-169. [CrossRef]

19. Chinchar, V.G.; Waltzek, T.B. Ranaviruses: not just for frogs. PLoS Path. 2014, 10, e1003850. [CrossRef]

20. Maginnis, M.S. Virus-receptor interactions: the key to cellular invasion. J. Mol. Biol. 2018, 430, 2590-2611. [CrossRef]

21. Moss, B. Poxvirus cell entry: How many proteins does it take? Viruses 2012, 4, 688-707. [CrossRef]

22. Chung, C.S.; Hsiao, J.C.; Chang, Y.S.; Chang, W. A27L protein mediates vaccinia virus interaction with cell surface heparan sulfate. J. Virol. 1998, 72, 1577-1585. [PubMed] 
23. Chiu, W.L.; Lin, C.L.; Yang, M.H.; Tzou, D.L.; Chang, W. Vaccinia virus 4c (A26L) protein on intracellular mature virus binds to the extracellular cellular matrix laminin. J. Virol. 2007, 81, 2149-2157. [CrossRef] [PubMed]

24. Hsiao, J.C.; Chung, C.S.; Chang, W. Vaccinia virus envelope D8L protein binds to cell surface chondroitin sulfate and mediates the adsorption of intracellular mature virions to cells. J. Virol. 1999, 73, 8750-8761. [PubMed]

25. Lin, C.L.; Chung, C.S.; Heine, H.G.; Chang, W. Vaccinia virus envelope H3L protein binds to cell surface heparan sulfate and is important for intracellular mature virion morphogenesis and virus infection in vitro and in vivo. J. Virol. 2000, 74, 3353-3365. [CrossRef] [PubMed]

26. Aquino, R.S.; Park, P.W. Glycosaminoglycans and infection. Front. Biosci. (Landmark Ed.) 2016, 21, 1260-1277. [PubMed]

27. Dechecchi, M.C.; Tamanini, A.; Bonizzato, A.; Cabrini, G. Heparan sulfate glycosaminoglycans are involved in adenovirus type 5 and 2-host cell interactions. Virology 2000, 268, 382-390. [CrossRef] [PubMed]

28. Byrnes, A.P.; Griffin, D.E. Binding of Sindbis virus to cell surface heparan sulfate. J. Virol. 1998, 72, 7349-7356. [PubMed]

29. Ciano, K.A.; Saredy, J.J.; Bowers, D.F. Heparan sulfate proteoglycan: an arbovirus attachment factor integral to mosquito salivary gland ducts. Viruses 2014, 6, 5182-5197. [CrossRef]

30. Riblett, A.M.; Blomen, V.A.; Jae, L.T.; Altamura, L.A.; Doms, R.W.; Brummelkamp, T.R.; Wojcechowskyj, J.A. A haploid genetic screen identifies heparan sulfate proteoglycans supporting rift valley fever virus infection. J. Virol. 2016, 90, 1414-1423. [CrossRef]

31. Murakami, S.; Takenaka-Uema, A.; Kobayashi, T.; Kato, K.; Shimojima, M.; Palmarini, M.; Horimoto, T. Heparan sulfate proteoglycan is an important attachment factor for cell entry of akabane and schmallenberg viruses. J. Virol. 2017, 91, e00503-17. [CrossRef]

32. Salvador, B.; Sexton, N.R.; Carrion, R., Jr.; Nunneley, J.; Patterson, J.L.; Steffen, I.; Lu, K.; Muench, M.O.; Lembo, D.; Simmons, G. Filoviruses utilize glycosaminoglycans for their attachment to target cells. J. Virol. 2013, 87, 3295-3304. [CrossRef] [PubMed]

33. Kim, S.Y.; Zhao, J.; Liu, X.; Fraser, K.; Lin, L.; Zhang, X.; Zhang, F.; Dordick, J.S.; Linhardt, R.J. Interaction of zika virus envelope protein with glycosaminoglycans. Biochemistry 2017, 56, 1151-1162. [CrossRef] [PubMed]

34. Xu, Y.; Martinez, P.; Seron, K.; Luo, G.; Allain, F.; Dubuisson, J.; Belouzard, S. Characterization of hepatitis C virus interaction with heparan sulfate proteoglycans. J. Virol. 2015, 89, 3846-3858. [CrossRef] [PubMed]

35. Herold, B.C.; WuDunn, D.; Soltys, N.; Spear, P.G. Glycoprotein C of herpes simplex virus type 1 plays a principal role in the adsorption of virus to cells and in infectivity. J. Virol. 1991, 65, 1090-1098. [PubMed]

36. Giroglou, T.; Florin, L.; Schäfer, F.; Streeck, R.E.; Sapp, M. Human papillomavirus infection requires cell surface heparan sulfate. J. Virol. 2001, 75, 1565-1570. [CrossRef] [PubMed]

37. Sasaki, M.; Anindita, P.D.; Ito, N.; Sugiyama, M.; Carr, M.; Fukuhara, H.; Ose, T.; Maenaka, K.; Takada, A.; Hall, W.W.; et al. The role of heparan sulfate proteoglycans as an attachment factor for rabies virus entry and infection. J. Infect. Dis. 2018, 217, 1740-1749. [CrossRef] [PubMed]

38. Zhao, Z.; Ke, F.; Huang, Y.H.; Zhao, J.G.; Gui, J.F.; Zhang, Q.Y. Identification and characterization of a novel envelope protein in Rana. grylio virus. J. Gen. Virol. 2008, 89, 1866-1872. [CrossRef] [PubMed]

39. He, L.B.; Ke, F.; Wang, J.; Gao, X.C.; Zhang, Q.Y. Rana. grylio virus (RGV) envelope protein 2L: subcellular localization and essential roles in virus infectivity revealed by conditional lethal mutant. J. Gen. Virol. 2014, 95, 679-690. [CrossRef] [PubMed]

40. Zeng, X.T.; Gao, X.C.; Zhang, Q.Y. Rana grylio virus 43R encodes an envelope protein involved in virus entry. Virus Genes 2018, 54, 779-791. [CrossRef]

41. Lei, X.Y.; Ou, T.; Zhu, R.L.; Zhang, Q.Y. Sequencing and analysis of the complete genome of Rana. grylio virus (RGV). Arch. Virol. 2012, 157, 1559-1564. [CrossRef]

42. Sun, W.; Huang, Y.H.; Zhao, Z.; Gui, J.F.; Zhang, Q.Y. Characterization of the Rana. grylio virus 3beta-hydroxysteroid dehydrogenase and its novel role in suppressing virus-induced cytopathic effect. Biochem. Biophys. Res. Commun. 2006, 351, 44-50. [CrossRef] [PubMed]

43. Huang, X.; Fang, J.; Chen, Z.; Zhang, Q. Rana. grylio virus TK and DUT gene locus could be simultaneously used for foreign gene expression. Virus Res. 2016, 214, 33-38. [CrossRef] [PubMed]

44. Lei, X.Y.; Ou, T.; Zhang, Q.Y. Rana. grylio virus (RGV) 50L is associated with viral matrix and exhibited two distribution patterns. PLoS ONE 2012, 7, e43033. [CrossRef] [PubMed] 
45. He, L.B.; Gao, X.C.; Ke, F.; Zhang, Q.Y. A conditional lethal mutation in Rana grylio virus ORF 53R resulted in a marked reduction in virion formation. Virus Res. 2013, 177, 194-200. [CrossRef] [PubMed]

46. Whitley, D.S.; Yu, K.; Sample, R.C.; Sinning, A.; Henegar, J.; Norcross, E.; Chinchar, V.G. Frog virus 3 ORF 53R, a putative myristoylated membrane protein, is essential for virus replication in vitro. Virology 2010, 405, 448-456. [CrossRef] [PubMed]

47. Zhou, S.; Wan, Q.; Huang, Y.; Huang, X.; Cao, J.; Ye, L.; Lim, T.K.; Lin, Q.; Qin, Q. Proteomic analysis of Singapore grouper iridovirus envelope proteins and characterization of a novel envelope protein VP088. Proteomics 2011, 11, 2236-2248. [CrossRef] [PubMed]

48. Huang, X.; Gong, J.; Huang, Y.; Ouyang, Z.; Wang, S.; Chen, X.; Qin, Q. Characterization of an envelope gene VP19 from Singapore grouper iridovirus. Virol. J. 2013, 10, 354. [CrossRef] [PubMed]

49. Yuan, J.D.; Chen, Z.Y.; Huang, X.; Gao, X.C.; Zhang, Q.Y. Establishment of three cell lines from Chinese giant salamander and their sensitivities to the wild-type and recombinant ranavirus. Vet. Res. 2015, 46, 58. [CrossRef]

50. Zhang, Q.Y.; Zhao, Z.; Xiao, F.; Li, Z.Q.; Gui, J.F. Molecular characterization of three Rana. grylio virus (RGV) isolates and Paralichthys. olivaceus lymphocystis disease virus (LCDV-C) in iridoviruses. Aquaculture 2006, 251, 1-10. [CrossRef]

51. Rabenstein, D.L. Heparin and heparan sulfate: structure and function. Nat. Prod. Rep. 2002, 19, 312-331. [CrossRef]

52. Zhu, R.; Chen, Z.Y.; Wang, J.; Yuan, J.D.; Liao, X.Y.; Gui, J.F.; Zhang, Q.Y. Extensive diversification of MHC in Chinese giant salamanders Andrias. davidianus (Anda-MHC) reveals novel splice variants. Dev. Comp. Immunol. 2014, 42, 311-322. [CrossRef] [PubMed]

53. Livak, K.J.; Schmittgen, T.D. Analysis of relative gene expression data using real-time quantitative PCR and the $2^{-\Delta \Delta C t}$ Method. Methods 2001, 25, 402-408. [CrossRef] [PubMed]

54. Vo, N.T.K.; Guerreiro, M.; Yaparla, A.; Grayfer, L.; DeWitte-Orr, S.J. Class A scavenger receptors are used by frog virus 3 during its cellular entry. Viruses 2019, 11, 93. [CrossRef] [PubMed]

(C) 2019 by the authors. Licensee MDPI, Basel, Switzerland. This article is an open access article distributed under the terms and conditions of the Creative Commons Attribution (CC BY) license (http://creativecommons.org/licenses/by/4.0/). 
Article

\title{
Detection and Characterization of Invertebrate Iridoviruses Found in Reptiles and Prey Insects in Europe over the Past Two Decades
}

\author{
Tibor Papp ${ }^{1}$ and Rachel E. Marschang ${ }^{2, *(1)}$ \\ 1 Institute for Veterinary Medical Research, Centre for Agricultural Research, Hungarian Academy of Sciences, \\ Hungaria krt 21, H-1143 Budapest, Hungary \\ 2 Cell Culture Lab, Microbiology Department, Laboklin GmbH \& Co. KG, 97688 Bad Kissingen, Germany \\ * Correspondence: rachel.marschang@gmail.com
}

Received: 26 April 2019; Accepted: 25 June 2019; Published: 2 July 2019

check for updates

\begin{abstract}
Invertebrate iridoviruses (IIVs), while mostly described in a wide range of invertebrate hosts, have also been repeatedly detected in diagnostic samples from poikilothermic vertebrates including reptiles and amphibians. Since iridoviruses from invertebrate and vertebrate hosts differ strongly from one another based not only on host range but also on molecular characteristics, a series of molecular studies and bioassays were performed to characterize and compare IIVs from various hosts and evaluate their ability to infect a vertebrate host. Eight IIV isolates from reptilian and orthopteran hosts collected over a period of six years were partially sequenced. Comparison of eight genome portions (total over $14 \mathrm{kbp}$ ) showed that these were all very similar to one another and to an earlier described cricket IIV isolate, thus they were given the collective name lizard-cricket IV (Liz-CrIV). One isolate from a chameleon was also subjected to Illumina sequencing and almost the entire genomic sequence was obtained. Comparison of this longer genome sequence showed several differences to the most closely related IIV, Invertebrate iridovirus 6 (IIV6), the type species of the genus Iridovirus, including several deletions and possible recombination sites, as well as insertions of genes of non-iridoviral origin. Three isolates from vertebrate and invertebrate hosts were also used for comparative studies on pathogenicity in crickets (Gryllus bimaculatus) at 20 and $30{ }^{\circ} \mathrm{C}$. Finally, the chameleon isolate used for the genome sequencing studies was also used in a transmission study with bearded dragons. The transmission studies showed large variability in virus replication and pathogenicity of the three tested viruses in crickets at the two temperatures. In the infection study with bearded dragons, lizards inoculated with a Liz-CrIV did not become ill, but the virus was detected in numerous tissues by $\mathrm{qPCR}$ and was also isolated in cell culture from several tissues. Highest viral loads were measured in the gastro-intestinal organs and in the skin. These studies demonstrate that Liz-CrIV circulates in the pet trade in Europe. This virus is capable of infecting both invertebrates and poikilothermic vertebrates, although its involvement in disease in the latter has not been proven.
\end{abstract}

Keywords: lizard; bearded dragon; Pogona vitticeps; cricket; Gryllus bimaculatus

\section{Introduction}

The word "irido" is derived from Iris, the name of a Greek goddess who personified the rainbow. This is due to the "rainbow like" iridescence observed in heavily infected insects as mature virions accumulate within the cytoplasm of their infected cells in large paracrystalline arrays. In current taxonomy, the family Iridoviridae is divided into two subfamilies, Alphairidovirinae and Betairidovirinae [1]. The former contains three genera (Ranavirus, Megalocytivirus and Lymphocystivirus) whose members 
infect primarily ectothermic vertebrates, and the latter comprises three genera (Iridovirus, Chloriridovirus and Decapodiridovirus [2]) that infect mainly invertebrates such as insects and crustaceans. To avoid confusion, in this paper we will follow the suggestion of Vetten and Haenni [3], and generally members of the family Iridoviridae will be referred to as iridovirids (in short: IV) to distinguish them from the sensu stricto-invertebrate-iridoviruses (IIVs), which belong to Betairidovirinae.

Members of the family possess linear, double-stranded DNA genomes, which vary in size from approximately $100 \mathrm{kbp}$ (genus Ranavirus) to over $200 \mathrm{kbp}$ (genus Iridovirus). Iridovirid genomes are unique among animal viruses in that they are circularly permuted and terminally redundant. Many representatives have relevance for agriculture or nature conservation, but their inability to infect mammalian hosts somewhat limited the study of this diverse virus family, and especially that of the IIVs. Comprehensive reviews have been written about research progress on this group of viruses over the last decades [4-6].

The first invertebrate iridescent virus was reported in the mid 1950s from insects $[7,8]$. Further viruses were found in a wide range of invertebrates, mainly arthropods, but there have also been a few reports from other taxa (mollusks, an annelid and a nematode) [9,10]. For a while, the name of the host from which an IIV was first isolated was used in the nomenclature, later the viruses were assigned type numbers based on the chronological order of the reports [11]. The major capsid protein $(M C P)$ gene used to be the part of the genome most commonly used for the classification of IIV isolates [12,13], and the largest number of IIV sequences in GenBank is from this gene. Many date back more than 20 years and were published in a single study [14]. In that study, a molecular comparison of fragments of the MCP gene of eighteen diverse isolates revealed that IIVs of the Iridovirus genus clustered into three groups/clades. The so called "crusteceoiridovirus group" contained two isolates, which were closely related phylogenetically, but had been isolated at distant locations from evolutionarily distant arthropod hosts, and later were grouped together in the species Invertebrate iridescent virus 31. The "oligoiridovirus group" contained a single established member, Invertebrate iridescent virus 6 (IIV6; synonym: Chilo iridescent virus, CIV), which was initially isolated from a stem borer (Chilo supressalis) lepidopteran in Japan, but other isolates have also been reported. IIV6 was assigned as the type species of the genus. All other isolates, which were obtained from different insect hosts collected on five continents, clustered into the polyiridovirus group [10]. Subsequent studies added a few further sequences and branches to this tree [15]. The genus Chloriridovirus for a long time contained a single member, which was later assigned to the species Invertebrate iridescent virus 3 (IIV3), and separated from the genus Iridovirus based on differences in phenotypic traits (e.g., larger particle size: $180 \mathrm{~nm}$ ) and on its narrower host range [16]. However, the study of Wong et al. [17], based on the analysis of 26 core genes [18] demonstrated that IIV3 clusters with the polyiridovirus group, indicating that the genus Chloriridovirus may need to be re-evaluated, integrating the polyiridoviruses. This revision was further supported by MCP protein-based analyses of novel polyiridoviruses $[19,20]$. Most recently, viruses found in three distinct crustacean species have been proposed either to represent a novel genus (Decapoiridovirus) within the subfamily Betairidovirinae [21-23], or even cluster outside of it [24].

Natural transmission of IIVs has been recorded across insect orders and even phyla, and consequently several IIVs have been suggested as agents for pest control both as wild type viruses (e.g., [25-28]), or as a recombinant vector, encoding a toxin [29]. Patent infections of IIVs are often associated with macroscopic iridescence in the animals and are mostly lethal. However, non-lethal covert (or inapparent) infections are also common, and can manifest in reduced lifespans and/or reproduction rates [10]. Despite descriptions of IIVs in many different hosts on all continents except Antarctica, full genome sequences are currently only available from nine IIV isolates [6].

At the beginning of our sequencing studies, full genome sequences were available from only two viruses: IIV3 and IIV6 [16,27,30]. The genome of IIV6 was found to be ca. $212 \mathrm{kbp}$ (unique portion) long with $28.6 \% \mathrm{G}+\mathrm{C}$ content and comprises 468 open reading frames (ORFs), of which 234 are non-overlapping. These ORFs were numbered from $001 R$ to $468 R$, which indicates their orientation 
(left or right transcribing) in the genome as well. Core IIV genes were defined in IIV6 [31], which include those involved in 1) nucleic acid biosynthesis, e.g., DNA polymerase (037L), RNA polymerase II (176R, 428L), RNAse III (142R), a helicase (161L) and a DNA topoisomerase II (045L) gene; 2) nucleotide metabolism, such as ribonucleotide reductase $(085 \mathrm{~L}, 376 \mathrm{~L})$, dUTPase (438L), thymidylate synthase (225R), thymidylate kinase $(251 L)$ and thymidine kinase (143R) genes; 3 ) virion formation, such as the major capsid protein (MCP or $274 L)$ or the myristilated membrane protein gene $(118 \mathrm{~L}, 458 R)$ and 4$)$ other genes coding for proteins of known function including inhibition of apoptosis (e.g., 157L, 193R). Other notable non-core putative genes identified in IIV6 include an NAD-dependent DNA ligase gene (205R) and a putative homolog of the sillucin $(160 \mathrm{~L})$ gene coding for a cysteine-rich antibiotic peptide, the first described viral antibiotic (VAB) $[27,30]$.

Around the millennium, a new isolate was added to the oligoiridovirus group. This IIV was originally detected in insects bred for the pet trade in Europe and named cricket iridovirus (CrIV) or Gryllus bimaculatus iridovirus (GbIV) after its first known host [25,32], and its wide host range was demonstrated amongst different insect orders [25]. In addition to the primary findings in crickets, closely related viruses have been repeatedly detected in lizards [33,34]. It has been hypothesized that lizards become infected with the virus when fed IIV infected prey insects. In 2001, a German group reported the isolation of IIV-like viruses from the lung, liver, kidney and intestine of two bearded dragons (Pogona vitticeps) and a chameleon (Trioceros [Chamaeleo] quadricornis) and from the skin of a frilled lizard (Chlamydosaurus kingii) on viper heart cells (VH-2) at $28{ }^{\circ} \mathrm{C}$ [33]. The frilled lizard showed pox-like skin lesions and one of the bearded dragons had pneumonia. The other lizards had died with non-specific signs. Part of the $M C P$ gene of the isolates was sequenced and had $97 \%$ identity to the nucleotide sequence of IIV6, and 100\% identity to the nucleotide sequence of GbIV. A host-switch of this virus from prey insects to the predator lizards was postulated [33]. It was later demonstrated in our laboratory at the time that an IIV isolate from a lizard host is capable of infecting crickets [35]. Another study described the detection of similar viruses in skin swabs and organs from different amphibian species kept in captivity in several European countries [36]. Skin swabs as well as organ samples were found positive for IIV by PCR and/or virus isolation in 12 specimens originating from anurans representing five families (Ranidae, Hylidae, Dendrobatidae, Leptodactylidae and Bufonidae) as well as from a caudate (Lake Urmia newt; Salamandridae).

Detection of IIV in vertebrate hosts has been carried out by isolation in cell culture and by conventional PCR (nPCR) $[33,35,36]$. A qPCR, targeting a portion of the $M C P$ gene was developed in our laboratory and was found to reliably detect and quantify IIVs of the oligoiridovirus group in tissues from vertebrate and invertebrate hosts both with high and low copy numbers [37].

The present paper summarizes parts of our work performed over the past two decades in connection with IIV isolates from reptiles and arthropods as well as diagnostic testing of reptiles, amphibians and arthropods. In addition to listing the species affected, it includes animal infection studies performed with invertebrate hosts (crickets) in order to compare the pathogenicities of several isolates, as well as transmission studies with vertebrate hosts (bearded dragons). New sequence data obtained from eight isolates from six vertebrate and two invertebrate hosts as well the draft genome sequence analysis of a chameleon isolate are also presented.

\section{Materials and Methods}

\subsection{Iridovirus Isolates Used}

Eight different IIV isolates, originating from four different lizard species, a scorpion and the prey cricket species fed to these pets were used for molecular biological comparison and for bioassays (Table 1). All of the viruses were isolated in reptile cell lines at $28^{\circ} \mathrm{C}$ as described elsewhere [35]. 
Table 1. Invertebrate iridovirus (IIV) isolates used in sequencing studies and bioassays. Grey colored ID refers to laboratory notebook number, the final number is the year of collection. Of all positive organs listed, the origin of the isolates used in the sequence comparison is printed in italics. Isolates compared in a cricket bioassay are underlined.

\begin{tabular}{|c|c|c|c|c|c|}
\hline & Host Species & ID, No. & Owner & IIV Positive Organs & Case History \\
\hline \multirow{6}{*}{ Squamata, } & $\begin{array}{l}\text { High-casqued chameleon } \\
\text { (Trioceros/Chamaeleo/hoehnelii) }\end{array}$ & $\begin{array}{c}\text { Ir.iso.1 } \\
100 / 2001\end{array}$ & A & $\begin{array}{l}\text { Kidney, liver, spleen, } \\
\text { lung, intestine }\end{array}$ & $\begin{array}{c}\text { Emaciation, } \\
\text { kerato-conjunctivitis }\end{array}$ \\
\hline & Bearded dragon (Pogona vitticeps) & $\begin{array}{r}\text { Ir.iso.2 } \\
66 / 2003\end{array}$ & B & Lung, heart, tongue & Unknown \\
\hline & Bearded dragon (Pogona vitticeps) & $\frac{\text { Ir.iso.3 }}{64 / 2003}$ & B & $\begin{array}{l}\text { Lung, brain, tongue, } \\
\text { stomach, intestine }\end{array}$ & Unknown \\
\hline & Spiny tailed lizard (Uromastyx sp.) & $\begin{array}{l}\text { Ir.iso. } 4 \\
08 / 2004\end{array}$ & B & Skin & Hyperkeratosis \\
\hline & $\begin{array}{l}\text { Four-horned chameleon } \\
\text { (Trioceros quadricornis) }\end{array}$ & $\begin{array}{l}\text { Ir.iso.5 } \\
626 / 2000\end{array}$ & C & Liver & $\begin{array}{c}\text { Emaciation, several } \\
\text { animals died suddenly }\end{array}$ \\
\hline & Green iguana (Iguana iguana) & $\begin{array}{c}\text { Ir.iso.6 } \\
1125 / 2000\end{array}$ & $\mathrm{D}$ & Skin & Hyperkeratosis \\
\hline \multirow{2}{*}{ Arthropoda } & House cricket (Acheta domesticus) & $\frac{\text { Ir.iso.7 }}{52 / 2003}$ & $\mathrm{E}$ & Whole body & $\begin{array}{l}\text { Prey insects, } \\
\text { died suddenly }\end{array}$ \\
\hline & $\begin{array}{l}\text { Emperor scorpion } \\
\text { (Pandinus imperator) }\end{array}$ & $\frac{\text { Ir.iso.8 }}{25 / 2006}$ & $\mathrm{~F}$ & $\underline{\text { Abdominal organs }}$ & Loss of UV colouration \\
\hline
\end{tabular}

\subsection{Diagnostic Screening of Vertebrate and Invertebrate Samples for IIVS}

Between 2009 and 2018, samples from a total of approximately 900 reptiles, amphibians and invertebrates submitted for diagnostic testing were regularly screened for the presence of IIVs. Between 2009 and 2013, testing was carried out by virus isolation and, in some cases, conventional PCR (nPCR) [35]. From 2014 onward, samples were screened by real-time PCR (qPCR) according to Papp et al. [37]. No background information was available for most of the samples submitted.

\subsection{Cell Culture-Based Methods (Isolation, Propagation and Purification)}

Isolation of viruses was carried out on iguana heart cells (IgH-2, ATCC:CCL-108) and/or Russell's viper heart cells (VH-2, ATCC:CCL-140) depending on the origin of the sample. Cell types in closest phylogenetic relationship to the virus host were preferred. Small pieces of tissues or the cotton heads of swabs were sonicated in $3 \mathrm{~mL}$ Dulbecco's modified Eagle's medium (DMEM) (Biochrom AG, Berlin, Germany) supplemented with antibiotics. The samples were centrifuged at low speed $(1500 \times g, 10 \mathrm{~min})$ for the removal of cell debris and bacteria, then $200 \mu \mathrm{L}$ of the homogenate was inoculated onto approximately $70 \%$ confluent cell monolayers in $30 \mathrm{~mm}$ diameter Cellstar ${ }^{\circledR}$ tissue culture dishes (Greiner Bio-One GmbH, Frickenhausen, Germany). In cases in which centrifugation of the samples was insufficient to avoid contamination with bacteria, samples were filtered with $0.45 \mu \mathrm{m}$ filters FP 30/0.45 CA-S (Schleicher and Schuell MicroScience, Dassel, Germany). After incubating for $2 \mathrm{~h}$ at $28^{\circ} \mathrm{C}, 2 \mathrm{~mL}$ nutrient medium (DMEM supplemented with $2 \%$ fetal calf serum, FCS, $1 \%$ non-essential amino acids, NEA, and antibiotics, AB) was added to each dish. Cells were examined for cytopathic effects (CPE) approximately every third day with an inverted light microscope (Wilovet, Wetzlar, Germany), and dishes were frozen when extensive CPE was seen. Cultures showing no CPE were frozen after two weeks of incubation for blind passaging. Two additional passages were performed from each dish after a freeze and thaw cycle and low speed centrifugation.

For the purpose of the animal infection studies or the genome sequencing experiments, in which higher virus yield or pure concentrated DNA was required, IIV isolates were further propagated in $175 \mathrm{~cm}^{2}$ tissue culture flasks using the same cell line as described above. For the sequencing experiments, purification and concentration was performed by ultracentrifuge pelleting in a Beckman XL-90 instrument using a 60 Ti rotor. After a freeze and thaw cycle, cell debris was first removed from the cell culture supernatants by low speed centrifugation $\left(1500 \times \mathrm{g}, 10 \mathrm{~min}, 4^{\circ} \mathrm{C}\right)$, and viruses were then 
concentrated by ultracentrifugation $\left(60,000 \times g, 2 \mathrm{~h}, 4^{\circ} \mathrm{C}\right)$. Supernatants were decanted, and pellets were resuspended in PBS.

Infectivity titers of the isolates were determined on 96-well cell culture plates (Greiner Bio-One $\mathrm{GmbH}$ ). Overnight cultures of the identical cell lines were infected at a confluence of approximately $70 \%$ with a 10 -fold dilution row of the virus isolate in nutrient medium. Each well of the decanted plates was inoculated with $100 \mu \mathrm{L}$ from each dilution step of the row, with four repetitions, as well as with virus-free control medium. Plates were checked for the appearance of virus specific CPE every third day and finally evaluated after two weeks. TCID 50 titers were calculated using the Spearman-Kärber estimation formula [38].

\subsection{Animal Infection Studies}

\subsubsection{Cricket Bioassay}

An iridovirus negative colony of field crickets (Gryllus bimaculatus) was established at the Institute for Environmental and Animal Hygiene at the University of Hohenheim in Stuttgart. The first animals were obtained courtesy of Dr. Regina Kleespies, Biologische Bundesanstalt für Land- und Forstwirtschaft, Darmstadt, Germany, who had already tested them negative for IIV. The crickets had no contact with other insects, were fed with salad and dog food (Matzinger Hundeflocken, Nestlé Purina Pet Care, Euskirchen, Germany) and were regularly tested negative for IIV by nested PCR.

To study the virulence of IIVs from different hosts, a bearded dragon (Pogona vitticeps) "lizard" isolate (Ir.iso.3), a scorpion (Pandinus imperator) isolate (Ir.iso.8) and a cricket isolate (Ir.iso.7; Table 1) were propagated on IgH-2 to an equal titer of $\mathrm{TCID}_{50} 10^{5.5-6} / \mathrm{mL}$. Per os transmission experiments were carried out with a sub adult (last instar nymph) or young adult Gryllus bimaculatus. A total of 20 nymphs were completely immersed in virus suspension for approximately $30 \mathrm{~s}$ (Figure 1A). Ten crickets were dipped into IgH-2 supernatant as negative controls. In view of the cannibalistic behavior of this species, all animals were housed individually in beakers (diameter, $8.5 \mathrm{~cm}$; height, $9.5 \mathrm{~cm}$, Figure 1B). The animals were kept at either $20^{\circ} \mathrm{C}$ or $30^{\circ} \mathrm{C}$ in cooling-heating thermostat chambers with an adjusted 12/12 h light and dark cycle (Figure 1C). Tests were run for 60 days and mortality was recorded every 1-2 days, fresh food was provided as necessary (every 3-4 days). Fat body samples were collected from dead crickets and prepared for cell culture isolation, PCR and electron microscopy (EM). Half bodies of crickets were embedded in paraffin for histological examination. The surviving crickets at the end of each study were killed by snap freezing and decapitation and were also tested.
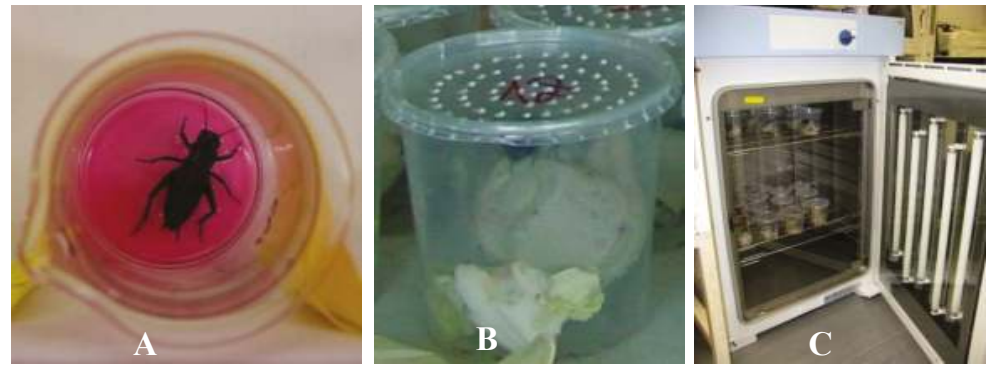

Figure 1. (A) Infection of a cricket by dipping into virus suspension. (B) Individual beaker with a cricket used in the infection studies. (C) Beakers were kept in a thermoregulated incubator with lights.

\subsubsection{Bearded Dragon Transmission Study}

As parents for the bearded dragons used in the transmission study, six bearded dragons (three pairs) were bred. These animals were raised in separate facilities of the Institute for Environmental and Animal Hygiene at University of Hohenheim in Stuttgart from eggs. Thei parents had tested negative for IIV 
in oral and cloacal swabs. All animals had also repeatedly tested negative for IIV in oral and cloacal swabs and had been previously fed IIV negative crickets only. Eggs were collected from these pairs and incubated at $28{ }^{\circ} \mathrm{C}$ in a Jaeger-Kunstglucke FB 50M incubator in the laboratory. The hatched bearded dragons had no contact to other reptiles and were fed IIV negative crickets from our own colony before the start of the study. Organs of five young animals that died soon after hatching were negative for IIV by nPCR and virus isolation.

Fifteen young bearded dragons at the age of five months were put into individual terrariums. The lizards were divided into three groups. The terrariums for negative control animals (NK) and infected animals (A and B) were kept in separate facilities away from each other and necessary hygienic measures implemented to avoid contamination of negative lizards during the infection trial. Animals were infected using the lizard IIV isolate Ir.iso.3 (Table 1) from a bearded dragon lung, propagated on IgH-2 cells to a titer of $\mathrm{TCID}_{50} 10^{6.5} / \mathrm{mL}$. Supernatant was purified first by centrifugation of the cell debris (see above) and further by three consecutive dialyzations against PBS for $20 \mathrm{~h}$ through 12 $\mathrm{kDa}$ cellulose membrane sacs (Spectrum Labs) in order to eliminate possible toxic or allergenic components of the supernatant. The virus titer in the purified suspension was checked again on IgH-2 cells and did not change with this treatment. For negative controls, DMEM supplemented with $2 \%$ FCS, $1 \%$ NEA and AB was treated the same way.

Two months before the beginning of the bearded dragon study, a batch of crickets was infected with the same lizard virus. Dead crickets were frozen and stored at $-80{ }^{\circ} \mathrm{C}$, the rest were killed at the end of the 60 day period and stored alike. In order to obtain a quasi-homogenous food-portion for each lizard, thawed crickets were dissected and predominantly, the iridescent ones were used in small cut pieces to feed the lizards. For the negative control lizards, negative crickets were prepared similarly.

Since the natural route of infection was unknown, several routes were chosen, including oral application of a cell culture isolate, feeding of infected crickets and intracoelomic injection. Bearded dragons of group A were given $1 \mathrm{~mL}$ of the virus containing solution administered through sterile cat catheters into the stomach (Figure 2A) and were force-fed with infected dead crickets (Figure 2B). Lizards in group B were also given virus suspension in the stomach and fed infected crickets, and an additional $1 \mathrm{~mL}$ of virus suspension was injected into their coelomic cavities. It was hypothesized that intracoelomic injection might provoke infection in the lizards if oral infection did not. Negative control lizards received the same treatment with the mock-solutions.

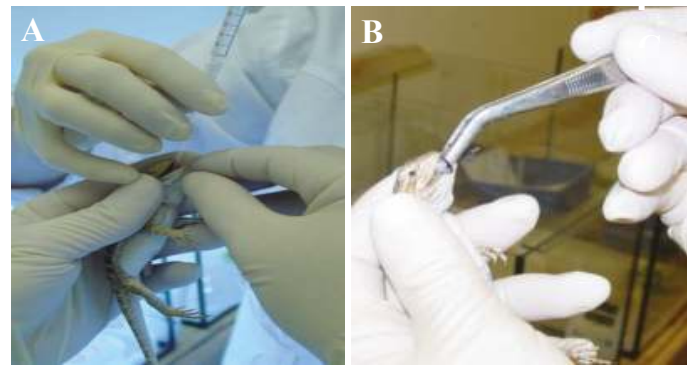

Figure 2. Transmission study of IIV in bearded dragons (Pogona vitticeps). (A) Administering virus preparate with an intra-gastric tube. (B) Force feeding with cricket-preparation. Note the bluish iridescence of the cricket preparate at the tip of the forceps.

Animals were kept at $21-26^{\circ} \mathrm{C}$ and $28 \%-38 \%$ relative humidity, using desert UVB fluorescent lamps without spot bulbs (in order to avoid an increase in body-temperature by basking which could adversely affect virus replication), and were checked daily. The lizards were fed with green salad and force-fed with the prepared crickets supplemented with mineral-vitamin powder (Korvimin ZVT + Reptil) every 2-3 days. Two weeks before the end of the study (from 46 days post infection (dpi)) no more crickets were fed. Oral and cloacal swabs were collected every week and changes in weight were also 
recorded (Supplementary Table S1). Swabs were examined for the presence of IIVs by cell-culture based and PCR methods. After 60 days, animals were euthanized by ketamine hydrochloride injection i.m. (Ursotamin, Bernburg AG, ca. $1000 \mathrm{mg} / \mathrm{kg}$ ) and dissected. Gross pathology was performed and 12 different organs (brain, gonad, kidney, skin, lung, heart, fat-body, liver, tongue, stomach, ileum and colon) were collected for further assays as described above. Organs were collected under sterile conditions with different instruments used for the gastrointestinal tract than for all other tissues, and all instruments were washed in sterile distilled water, then in ethanol and flamed, then again in distilled water, before use on the next tissue in order to avoid contamination. The bearded dragon infection study received authorization from the Regierungspräsidium Stuttgart (No. V 195/2003) and was controlled by the Animal Welfare Committee of the University of Hohenheim.

\subsubsection{Microscopic Techniques}

Following post mortem examination, organs from the bearded dragons as well as longitudinally dissected body halves of crickets in the transmission study were fixed for $48 \mathrm{~h}$ in Bouin's solution of $714.3 \mathrm{~mL} / 1$ picrin acid, $238.1 \mathrm{~mL} / 1$ formalin $(36 \%)$ and $47.6 \mathrm{~mL} / 1$ acetate acid (all Merck, Darmstadt, Germany), and/or in $4 \%$ buffered paraformaldehyde solution and routinely processed for histology, cut at $3 \mu \mathrm{m}$ and stained with hematoxylin-eosin (HE).

Examined organs of bearded dragons and fat body samples from selected crickets were fixed in $2.5 \%$ glutaraldehyde (Plano, Wetzlar, Germany) in cacodylate buffer ( $0.1 \mathrm{M}$ sodium-cacodylate, $\mathrm{pH}=7.4$ ). After fixation, the samples were washed three times in sodium cacodylate buffer, and fixed in a $1 \%$ solution of osmium tetroxide in $0.1 \mathrm{M}$ sodium cacodylate buffer for $1 \mathrm{~h}$ at $4{ }^{\circ} \mathrm{C}$. The samples were washed three times with $0.1 \mathrm{M}$ acetic acetate buffer, followed by contrast staining with a saturated uranyl acetate solution (5\%) in 70\% ethanol for $2 \mathrm{~h}$ at room temperature. Dehydration in an ascending row with alcohol followed. Propylene oxide (Serva, Heidelberg, Germany) was used as an intermediate matrix. The samples were then embedded in an epoxy resin combination (Plano, Wetzlar). After $48 \mathrm{~h}$ in an incubator at $60{ }^{\circ} \mathrm{C}$, the blocks were polymerized, routinely cut, adsorbed onto 300 mesh copper grids and examined in a JEM-100SX electron microscope (Jeol LTD, Tokyo, Japan) at $80 \mathrm{kV}$ by Prof. Dr. Alves de Matos in the Curry Cabral Hospital, Lisbon, Portugal.

\subsection{Molecular Biological Techniques}

\subsubsection{DNA Extraction}

DNA was extracted from virus suspensions, sample homogenates of the animal infection studies, and from field samples submitted before 2013 with the DNeasy ${ }^{\circledR}$ kit (Qiagen $\mathrm{GmbH}$, Hilden, Germany) following the manufacturer's protocols and using $100 \mu \mathrm{l}$ of final elution volume. For diagnostic samples submitted after 2013, DNA was extracted directly from dry swabs or tissues using a commercial kit (MagNA Pure 96 DNA and viral NA small volume kit, Roche) according to the manufacturer's instructions. DNA of the ultracentrifuge pelleted virions was extracted using the phenol-chloroform-isoamylalcohol method [39].

Concentration and purity of the DNA extracts (also of purified plasmids, see later) was determined with the spectrophotometric method (Ultrospec 2100 pro, Amersham Biosciences Europe GmBH, Freiburg, Germany and Nanodrop, ThermoFisher Scientific) at 230, 260 and $280 \mathrm{~nm}$ absorbance.

\subsubsection{Conventional PCRs (nPCR)}

For comparative sequence studies, fourteen primers targeting six different genes were taken from the literature [40]. Further fifteen primers targeting IIV6-VAB (160L) and flanking genes as well as six primers targeting the $M C P$ gene and flanking region were newly designed. Another thirteen primers targeting the DNA polymerase $(037 \mathrm{~L})$ gene and twenty-three targeting the exonuclease $(012 \mathrm{~L})$ gene were newly designed. All primer sequences are listed in a Supplementary File (Supplementary Table S2). 
PCRs described previously $[25,40]$ were performed according to the protocols described there. All other PCRs with novel primers were performed in $25 \mu \mathrm{L}$ reaction mixtures, containing $1 \times$ concentration of Taq buffer with $\left(\mathrm{NH}_{4}\right)_{2} \mathrm{SO}_{4}, 1-3 \mathrm{mM}$ of $\mathrm{MgCl}_{2}, 200 \mu \mathrm{M}$ of each dNTP, $1 \mu \mathrm{M}$ from both forward and reverse primers and $0.5-1.25 \mathrm{U}$ of Taq polymerase (all from MBI Fermentas, St Leon-Rot, Germany). The mixtures were amplified with an initial denaturation at $95^{\circ} \mathrm{C}$ for $5 \mathrm{~min}$ followed by $35-45$ cycles at $95{ }^{\circ} \mathrm{C}$ for $30 \mathrm{~s}, 45-60{ }^{\circ} \mathrm{C}$ for $30-60 \mathrm{~s}$ and $72{ }^{\circ} \mathrm{C}$ for $1-4 \mathrm{~min}$. There was a final extension at $72{ }^{\circ} \mathrm{C}$ for $7 \mathrm{~min}$. In the amplification cycles, the annealing temperatures for specific primers were set to $\mathrm{T}_{\mathrm{m}}-4^{\circ} \mathrm{C}$, but not lower than the standard for the degenerated primers at $45^{\circ} \mathrm{C}$. Elongation times were set according to the expected product size, calculating $1 \mathrm{~min}$ for $1 \mathrm{kbp}$. Products were separated on 1\%-1.5\% agarose gels (Bioenzym, Oldendorf, Germany) in TAE puffer containing $0.5 \mu \mathrm{g} / \mathrm{mL}$ ethidium-bromide and visualized under $320 \mathrm{~nm}$ UV light.

\subsubsection{DNA sequencing (Sanger-, MPS)}

Gel purified PCR amplicons (Invisorb Spin DNA Extraction Kit; Invitek GmbH, Berlin, Germany) and kit purified plasmids were sequenced using a BigDye Terminator Cycle Sequencing Kit v.3.1 or v.1.1 applying the PCR primers and pJET-F and -R primers for the PCR amplicons and cloned amplicons, respectively. Sequencing reactions were analyzed on an ABI prism 310 automated DNA sequencer (both Applied Biosystems, Foster City, CA, USA) at the Institute for Environmental and Animal Hygiene of Hohenheim University. Occasionally, commercial service providers (Biolux GmBH, Stuttgart; Eurofins, MWG Operon, Ebersberg, Germany; Biological Research Centre, Szeged, Hungary) were hired.

If direct sequencing of PCR products was unsuccessful or gave dubious results, then purified PCR amplicons were blunt-end cloned into pJET 1.2 vector (Fermentas, St Leon-Rot, Germany) following the manufacturer's recommendations. Five $\mu \mathrm{L}$ of the ligated mixture was heat-shock transformed at $42{ }^{\circ} \mathrm{C}$ for $40 \mathrm{~s}$ into chemically competent Escherichia coli Top10F strain (Invitrogen, Life Technologies $\mathrm{GmbH}$, Darmstadt, Germany). Transformed bacteria were plated on standard selective LB agar, containing ampicillin $(100 \mu \mathrm{g} / \mathrm{mL})$ and incubated at $37^{\circ} \mathrm{C}$. Selected colonies were propagated in selective LB broth and mini-preparations of the plasmid DNA were obtained with the alkaline method [41] or using a Plasmid Mini Kit (Qiagen GmbH, Hilden, Germany).

Multiple parallel sequencing (MPS) of the high casqued chameleon IV isolate (Ir.iso.1) was attempted from the ultracentrifuge pelleted virions. Phenol-chloroform extracted total DNA was sequenced by the Illumina technology by our service laboratory using the manufacturer's recommendations (MiSeq platform at the Vet. Med Res. Inst, CAR, HAS, Budapest). CLC Genomics Workbench 8.5.1 was used for the downstream data analysis. After quality trimming of the paired-end reads, the corresponding algorithms of CLC Genomics were used to assemble de novo draft contigs, applying strict parameters $($ mismatch/insertion/deletion costs $=3$ for each, length fraction $=0.8$; similarity fraction $=1.0)$. Reads were also randomly mapped to the IIV6 reference sequence (NC_003038) using less strict criteria (no masking, mismatch cost $=2$, insertion cost $=3$, deletion cost $=3$, length fraction $=0.5$, similarity fraction $=0.8$ ).

\subsubsection{Analysis of Sequences}

Raw sequences obtained by Sanger sequencing method were processed by the ABI Sequence Analysis Program 5.1.1 (Applied Biosystems, Foster City, USA) then edited, assembled and compared using the STADEN Package version 2003.0 Pregap4 and Gap4 programs [42]. The sequences were compared to the data in GenBank (National Center for Biotechnology Information, Bethesda, USA) online (www.ncbi.nih.gov) using the BLASTN and BLASTX homology search programs. Homologous sequences were retrieved from GenBank, whereas the concatenated core genes alignment was retrieved from the current online International Committee on Taxonomy of Viruses (ICTV) report home page [1]. Multiple alignments of sequences were performed with ClustalW and MAFFT algorithms [43] of the Geneious and the CLC Main Workbench 8 programs using default settings. 
Phylogenetic molecular evolutionary analyses were conducted using MEGA version 10.0.2 [44], Topali v2.5 [45] and ExaBayes 1.5 [46] software, constructing Bayesian and maximum likelihood (ML) trees. Bayesian trees were constructed using the nucleotide (nt) and deduced amino acid (aa) alignments, selecting Hasegawa-Kishino-Yano (HKY) and Whelan and Goldman with gamma distribution (WAG + G) models, respectively $[47,48]$. Two independent runs were performed for $10^{6}$ generations. Every tenth tree was sampled out of which $25 \%$ was discarded as burn-in. SimPlot and BootScan analyses of the sequenced genes with their homologs retrieved from GenBank were performed using the SimPlot for Windows v.3.5.1 program.

\subsubsection{Real-Time PCR (qPCR)}

Real-time PCR was carried out on diagnostic samples submitted after 2014 and on tissue and swab samples from animals in the transmission studies. Assays were carried out using primers, probe and conditions described previously [37]. Purified PCR products of the house cricket isolate (Ir.iso.7) and the clone of pJET plasmid inserted 1st round MCP products (primers F1 and R4) of a spiny tailed lizard IIV isolate (Ir.iso.4) were used as references in different dilutions for the quantification of viral DNA in the transmission studies [37].

\section{Results}

\subsection{Diagnostic Testing}

In addition to those in our previously published work [34,36,37], IIVs were detected in samples from 82 animals between 2009 and 2018 (Supplementary Table S3), including lizards, snakes, amphibians and insects. Of the samples tested by qPCR after 2014 (total 83), 32 (38.6\%) were positive. Other viruses were also detected in several cases, most often adenoviruses (in 12 cases). In those cases in which a clinical history or pathology were provided, there were very variable changes noted, ranging from no clinical disease, to animals with general health issues (e.g., weight loss, apathy), to changes affecting their behavior, skin, intestines and/or liver, as well as central nervous signs. Sequences of nPCR products were identical to the corresponding sequences of CrIV (GbIV) partial $M C P$ gene in all cases.

\subsection{Sanger Sequencing Comparison of Isolates}

We genetically characterized IIVs isolated over the course of six years from crickets and insectivorous pets fed with crickets (Table 1) based on complete and partial gene sequences. Full coding sequence (CDS) were obtained from eight genes: The exonuclease II gene (IIV6-ORF012L ortholog), the DNA polymerase gene $(037 \mathrm{~L}), 155 \mathrm{~L}, 157 \mathrm{~L}, 159 \mathrm{~L}, 160 \mathrm{~L}$ (the sillucin viral antibiotic peptide gene, $V A B$ gene), the major capsid protein gene ( $M C P$ or $274 L$ ) and the upstream flanking $281 R$ (Figure 3 ). Partial CDS were determined from seven other genes: ATPase (075L), helicase (161L), DNA-ligase (205R), thymidilate synthase (225R), an apparently non-coding region (WIV ORF011 homolog) downstream of the MCP, ORF282R and immediate early protein gene (IE, ORF 393L; see red dotted rectangles in Figure 3). Identity values in these regions, compared to corresponding IIV6 ORFs are shown in Supplementary Table S4. The overall summarized length of the determined portions for the different isolates exceeded $14 \mathrm{kbp}$.

The isolates included in this study were all identical to GenBank cricket iridoviruses: GbIV [32] and CrIV [40] based on the available partial MCP gene data. The studied isolates were found to be identical to one another by comparing sequences of several genes $(075 \mathrm{~L}, 160 \mathrm{~L}$ and flanking genes, $205 \mathrm{~L}$, $225 \mathrm{~L}, \mathrm{MCP}$ and flanking genes, $393 \mathrm{~L}$ ). However, a very low inter-isolate variance (up to $0.4 \%$ ) was detected in genes coding for DNA synthesis and degrading enzymes (DNA polymerase, exonuclease). The studied reptilian and invertebrate IIVs are therefore considered to represent a single virus type and are hereafter referred to as lizard and cricket IV variant (Liz-CrIV). 


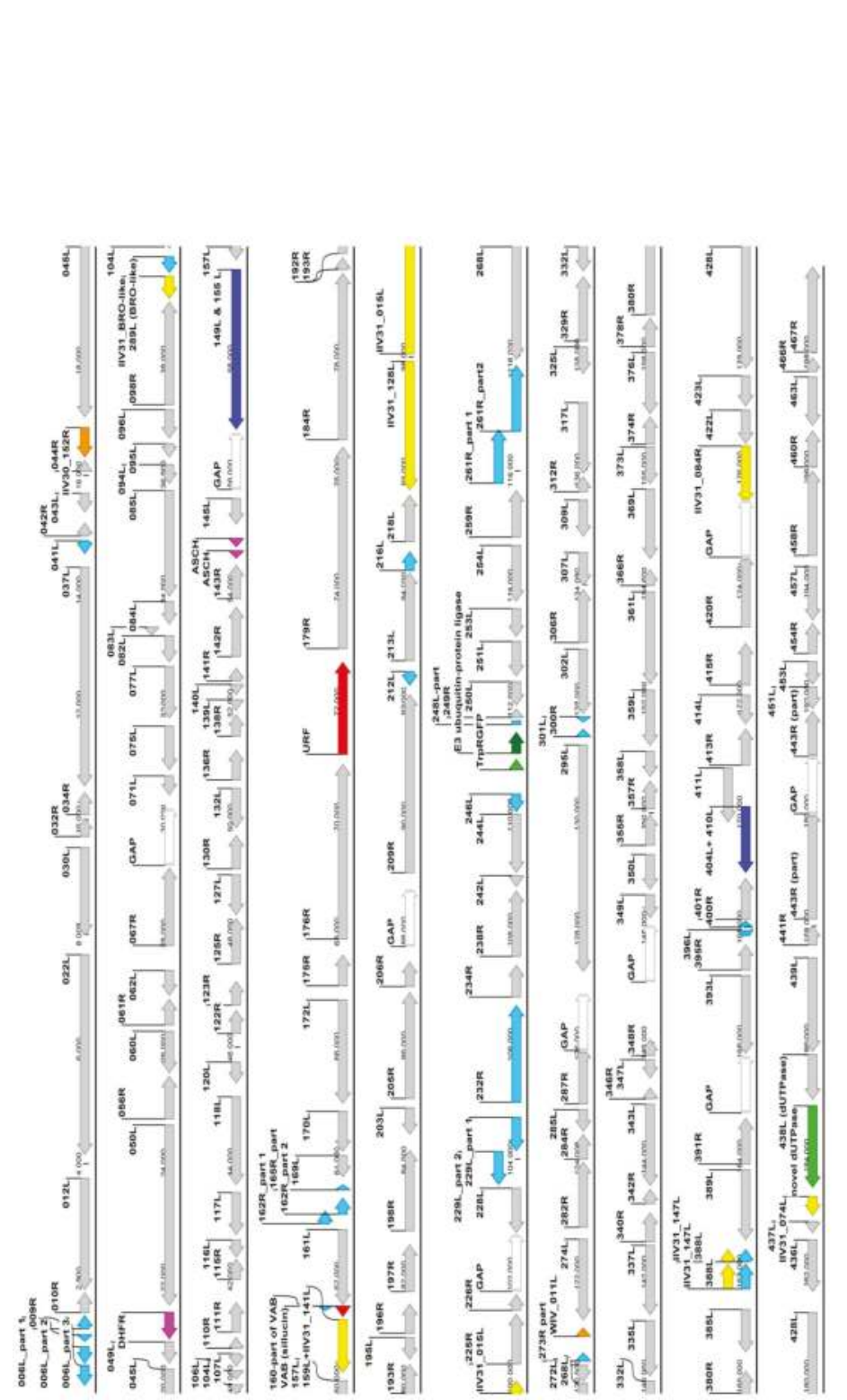

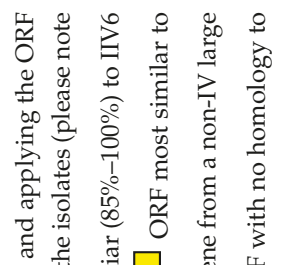

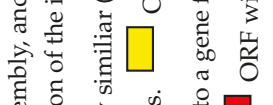

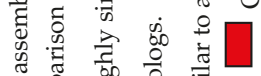
究运 चै

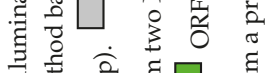

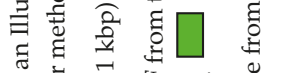

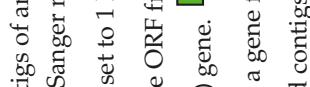

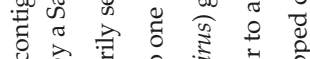

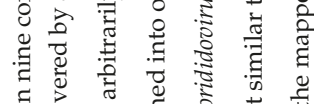
हี

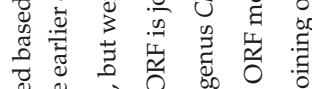

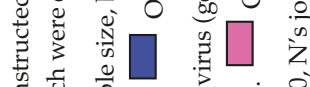
के उ .

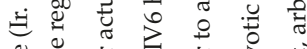

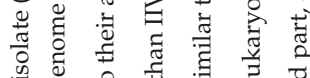

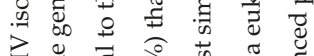
引

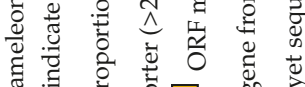

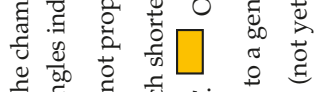

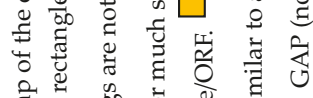

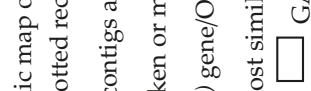

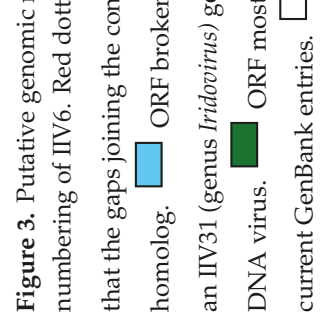




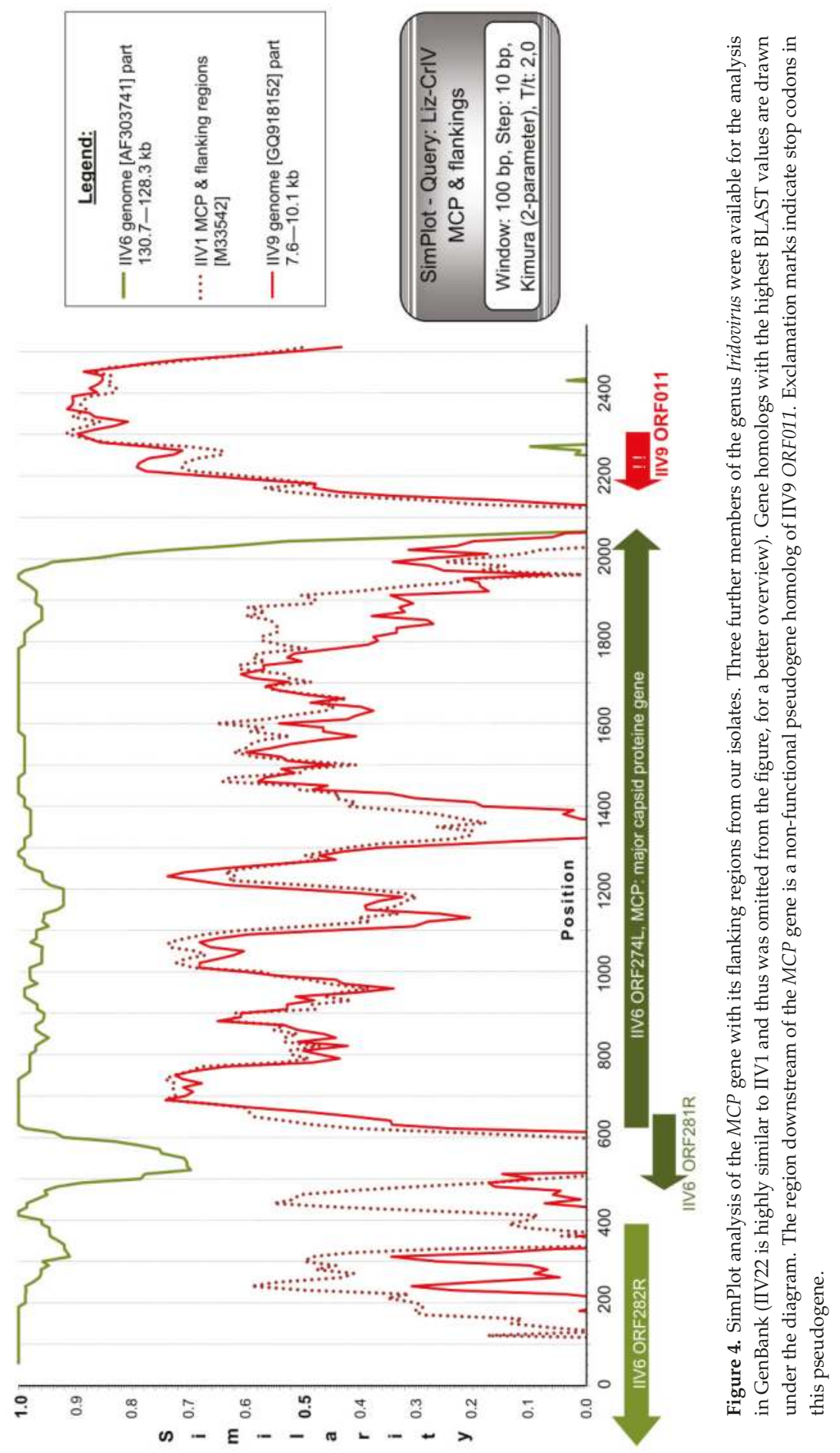


The MCP gene of Liz-CrIV with approx. $500 \mathrm{nt}$ flanking regions on both sides (total of $2543 \mathrm{nt}$ ) was completely determined. CDS for the MCP was found to be $1428 \mathrm{nt}(475 \mathrm{aa})$ long, and a putative recombination of ca. $500 \mathrm{nt}$ was identified downstream of it. This correlates to the MCP flanking sequences of polyiridovirus group (genus Chloriridovirus) members (IIV1, -9, -22; Acc.Nos: M39542, GQ918152, M32799) and not those of IIV6 (Figure 4). A phylogenetic tree based on the complete MCP gene data has shown a considerably longer twig separating Liz-CrIVs from IIV6, than those projected from partial gene data (Supplementary Figure S1).

In the region of the sillucin homolog gene, the viral antibiotic peptide (VAB) found in IIV6, all of our eight isolates were found to be identical to one another. The putative protein product is 65 aa long (53 aa in IIV6). The N-terminal signal peptide sequence has three point mutations and a $7 \mathrm{nt}$ long deletion near the cleavage site compared to IIV6-VAB (Supplementary Figure S2). This latter results in a frame shift and the putative translation of a longer (42/30 aa) non-homologous peptide, with no BLAST homology to any GenBank entry.

The adjacent ORF downstream showed even larger dissimilarity to its IIV6 homolog (ORF159). In the Liz-CrIV, this ORF is shorter (930 nt) than it is in IIV6 (1428 nt) and only its first third has high similarity to IIV6 ORF159 (80\%), whereas for its middle part counterparts were found in the IIV31 and IIV9 genomes. The second half of the gene has very limited (up to 30\%) similarity to any known iridovirus sequence. This second and last third of ORF159L in the Liz-CrIV is a hypothetical recombination site (Figure S2). The following genes downstream are again highly similar to their corresponding ones in IIV6, but one is formed as a fusion of two IIV6 ORFs (155L and 149L) due to a point mutation and loss of a stop codon.

\subsection{Genome Sequencing of the Chameleon Isolate}

The Illumina paired-end sequencing of the chameleon IIV isolate resulted in nine non-overlapping de novo assembled contigs (lengths between: 7.2 and $38.8 \mathrm{kbp}$ ), which contained altogether $190.5 \mathrm{kbp}$, presumably over $90 \%$, of the complete Liz-CrIV genome. The coverage of these strictly assembled contigs was relatively low, around 100. Yet, the reliability of the assembly was substantiated by the fact that all previously acquired (Sanger methods) sequences (see above) were $100 \%$ identical to the matching regions assembled by the MPS method. An overall $89 \%-98 \%$ nt identity to the corresponding genome parts of IIV6 was found in the different contigs, with their GC content ranging from $26 \%$ to $29.5 \%$. In each contig the order and orientation of the orthologous ORFs was apparently collinear with that of IIV6. Thus, a schematic map of the chameleon IIV genome was drawn by merging the contigs so that delineating unknown sequence "gaps" (runs of 1000 N's) joined them (Figure 3). Based on the finding within each contig, we assumed a complete collinearity of the ortholog genes between the two viruses, and ORF numbers, where applicable, were kept according to the numbering of IIV6. The merged assembled genome sequence was submitted to GenBank and received the accession number: MN081869.

Regarding the core genes, in each case, BlastX gave the highest values to their IIV6 orthologs. Identity/similarity ranged from $88 \% / 90 \%$ to $99 \% / 100 \%$ in these protein sequences. Consequently, on the phylogenetic tree constructed based on the set of 25 core genes, Liz-CrIV and IIV6 clustered on two short twigs at the end of the same branch (Supplementary Figure S3). The apparent phylogenetic distance between them is larger than that of two variants (IIV22, IIV22A) and similar to that of two types (IIV22 and IIV30) in genus Chloriridovirus. Among ranaviruses, e.g., Grouper iridovirus (GIV) and Singapore grouper iridovirus (SGIV) show a comparable distance.

So far we have also identified 18 ORFs $(019 R, 029 R, 100 L, 101 L, 200 R, 211 L, 219 L, 221 L, 224 L$, $236 \mathrm{~L}, 247 \mathrm{~L}, 308 \mathrm{~L}, 313 \mathrm{~L}, 315 \mathrm{~L}, 368 \mathrm{R}, 384 \mathrm{~L}, 426 \mathrm{R}$ and $468 \mathrm{R})$ that are missing in the Liz-CrIV, and 17 further ORFs $(006 \mathrm{~L}, 009 R, 041 \mathrm{~L}, 162 R, 165 R, 212 \mathrm{~L}, 216 \mathrm{~L}, 229 \mathrm{~L}, 232 \mathrm{~L}, 246 \mathrm{~L} .261 R, 273 R, 300 R, 301 \mathrm{~L}, 322 R$, $388 R, 396 \mathrm{~L}$ and $400 R$ ) that are broken or truncated (Figure 3$)$. In two cases $(149 \mathrm{~L}+155 \mathrm{~L}, 404 \mathrm{~L}+410 \mathrm{~L})$ ORFs merged to single ones from two adjacent IIV6 orthologs. At least eight presumed recombination spots were detected in the genome, with the acquisition of 14 non-IIV 6 orthologs, half of which have 
homologs in other IIVs, yet the rest are of supposed other viral, bacterial or eukaryotic origin (Table 2). Non-IIV homologs contain a second viral dUTPase with an intein splicing domain, a putative E3 ubiquitin protein ligase (similar to that in vertebrates), further algal and bacterial protein homologs and a 539 aa long putative protein with no BLAST homology to any current GenBank entry.

Table 2. Non-IIV6-like open reading frames (ORFs) in the chameleon IV sequence (names are according to those in Figure 3).

\begin{tabular}{|c|c|c|c|c|}
\hline Name & $\begin{array}{l}\text { Length in } \\
\text { Liz-CrIV (aa) }\end{array}$ & $\begin{array}{l}\text { Length of } \\
\text { Homolog ORF } \\
\text { (aa) }\end{array}$ & $\begin{array}{l}\text { aa } \\
\text { Identity/Similarity } \\
(\%)\end{array}$ & Comment/Function \\
\hline IIV30_152R & 176 & 173 & $55 / 68$ & Hypothetical protein of IIV30 \\
\hline DHRF & 158 & 159 & $50 / 73$ & $\begin{array}{c}\text { Dihidrofolate reductase of Labilithrix } \\
\text { luteola (Protobacterium) }\end{array}$ \\
\hline IIV31_BRO-like & 133 & 416 & $89 / 85$ & $\begin{array}{l}\text { Ortholog of IIV31_198R and IIV6_189L } \\
\text { C-terminal regions }\end{array}$ \\
\hline ASCH containing/1 & 48 & 137 & $50 / 66$ & $\begin{array}{l}\text { Thermococcus sp. ASCH and Gonium } \\
\text { pectorale (alga) hypothetical protein }\end{array}$ \\
\hline ASCH containing/2 & 53 & 137 & $53 / 69$ & $\begin{array}{l}\text { ASCH containing protein (RNA binding) } \\
\text { of Dependentiae bacterium }\end{array}$ \\
\hline VAB (sillucin) & 65 & NA & NA & $\begin{array}{l}\text { NO BLAST homology (only N-terminal } \\
\text { part is similar to IIV6_160L (VAB = viral } \\
\text { antibiotic peptide) }\end{array}$ \\
\hline URF & 539 & NA & NA & $\begin{array}{l}\text { NO BLAST homology to any GenBank } \\
\text { entry (ca. } 2 \mathrm{kbp} \text { insert of foreign DNA, } \\
\text { compared to IIV6 genome) }\end{array}$ \\
\hline IIV31_128L & 748 & 771 & $44 / 62$ & $\begin{array}{l}35 \% / 55 \% \text { identity/similarity to } \\
\text { a hypothetical protein of Klosneuvirus }\end{array}$ \\
\hline IIV31_015L & 699 & 676 & $62 / 78$ & $\begin{array}{l}\text { Polynucleotide kinase/ligase (PK) } \\
\text { and a pseT superfamily domain }\end{array}$ \\
\hline TrpRGFP & 66 & 260 & $54 / 69$ & $\begin{array}{l}\text { Tryptophan repeat gene family protein of } \\
\text { an entomopoxvirus and a Kaumoebavirus }\end{array}$ \\
\hline $\begin{array}{l}\text { E3 ubiquitin protein } \\
\text { ligase (RNFT1) }\end{array}$ & 127 & 252 & $33 / 48$ & $\begin{array}{l}\text { C-terminal half ( } 63 \mathrm{aa} \text { ) shows highest } \\
\text { similarity to homolog gene of Python } \\
\text { bivittatus and other snake homologs, it } \\
\text { contains a ring-finger domain }\end{array}$ \\
\hline IIV31_084R & 318 & 269 & $57 / 74$ & $\begin{array}{l}\text { Not completely covered, contains } \mathrm{ABC} \\
\text { type AA transport/signal transduction } \\
\text { system domain }\end{array}$ \\
\hline IIV31_074L & 115 & 116 & $37 / 52$ & Hypothetical protein of IIV31 \\
\hline Novel dUTPase & 478 & 349 & $46 / 63$ & $\begin{array}{l}\text { Most similar homolog found in } \\
\text { Pithovirus; contains an intein splicing } \\
\text { domain (N-terminal part), and a trimeric } \\
\text { dUTPase domain (C-terminal part) }\end{array}$ \\
\hline
\end{tabular}

\subsection{Cricket Infection Study}

The results of the cricket bioassay are summarized in Figure 5, Table 3 and are shown in detail in a Supplementary Figure S4. Unfortunately, due to technical problems with the cricket housing incubator, not all planned bioassays could be performed (e.g., cricket isolate $30{ }^{\circ} \mathrm{C}$ is missing). We found rates of mortality varying between $15 \%$ and $60 \%$ in the infected groups and $0 \%$ to $40 \%$ mortality in the negative groups. In the case of the negative control animals, however, the deaths of the crickets were never associated with virus propagation. All negative control animals were negative by cell-culture, nPCR and qPCR methods.

In the infected groups, apparent signs of infection were increased activity, swollen abdomen and molting abnormalities (Figure 6). The so-called "patently" infected crickets with very high virus loads and most often showing blue iridescence proved to have virus DNA copy numbers as high as $10^{7}$ to $10^{10}$ according to $\mathrm{qPCR}$, while the so-called covertly infected animals had considerably lower $\left(10^{2}-10^{4}\right)$ copy numbers in their fat bodies. 

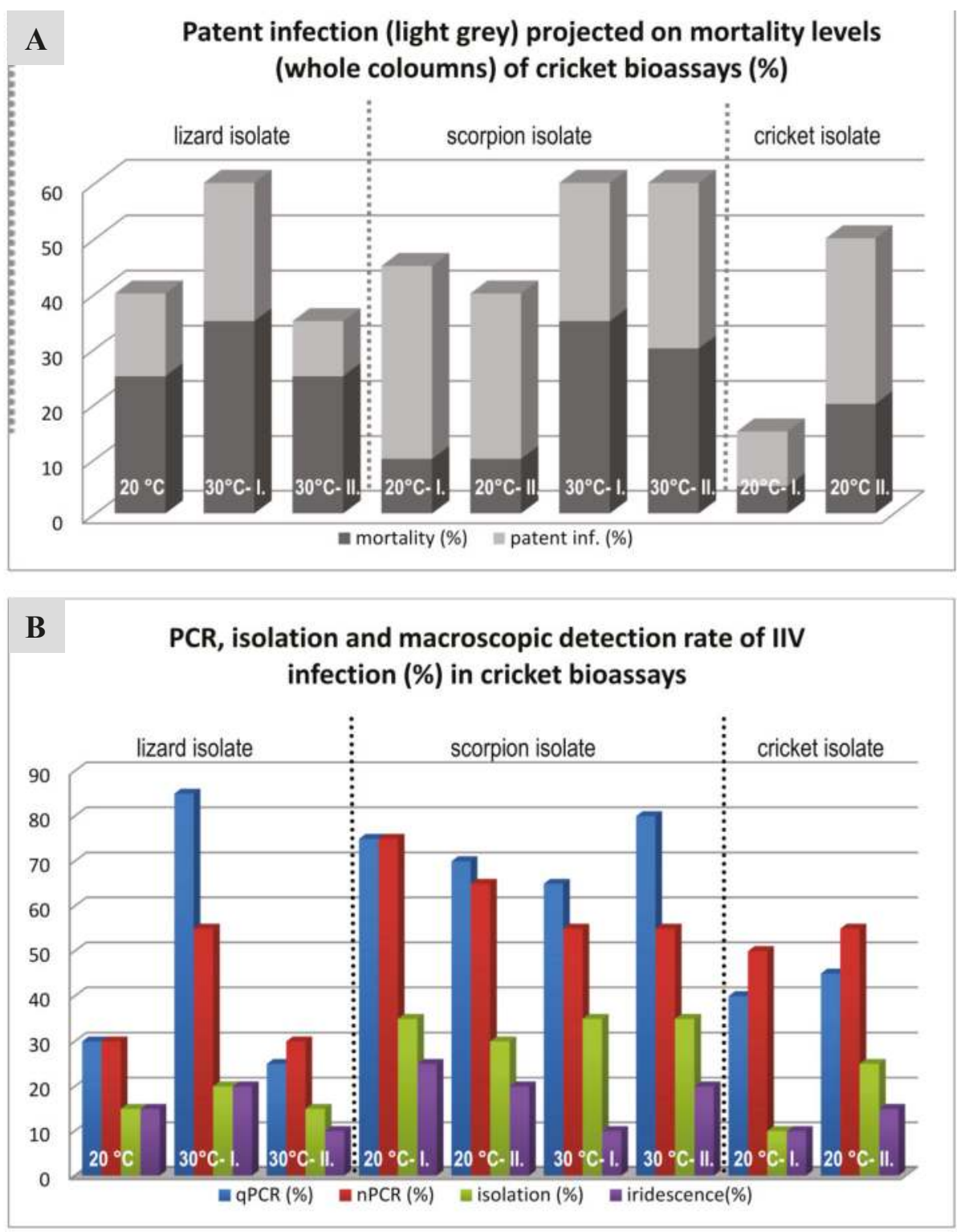

Figure 5. Graphic comparison of cricket bioassay results with different isolates at different temperatures. (A) Patent infection rates projected on mortality rates. (B) IIV infection rates detected by different methods. 
Table 3. Comparison of the (A) here described controlled-temperature cricket bioassay results with (B) those of three replicates (I-III) of an earlier study in our laboratory [35], which was performed with non-controlled temperatures.

\begin{tabular}{|c|c|c|c|c|c|c|c|c|c|}
\hline \multicolumn{10}{|c|}{ A. } \\
\hline & \multicolumn{3}{|c|}{ Lizard Isolate } & \multicolumn{4}{|c|}{ Scorpion Isolate } & \multicolumn{2}{|c|}{ Cricket Isolate } \\
\hline & $20^{\circ} \mathrm{C}$ & $30^{\circ} \mathrm{C} \mathrm{I}$ & $30^{\circ} \mathrm{C} \mathrm{II}$ & $20^{\circ} \mathrm{C} \mathrm{I}$. & $\begin{array}{c}20^{\circ} \mathrm{C} \\
\text { II. }\end{array}$ & $30^{\circ} \mathrm{C} \mathrm{I}$. & $\begin{array}{l}30^{\circ} \mathrm{C} \\
\text { II. }\end{array}$ & $20^{\circ} \mathrm{C} \mathrm{I}$. & $\begin{array}{c}20^{\circ} \mathrm{C} \\
\text { II. }\end{array}$ \\
\hline Mortality (\%) & 40 & 60 & 35 & 45 & 40 & 60 & 60 & 15 & 50 \\
\hline Patent inf. (\%) & 15 & 25 & 10 & 35 & 30 & 25 & 30 & 10 & 30 \\
\hline MST $^{*}$ (days) & 42 & 38.6 & 36.5 & 34 & 24.2 & 24.4 & 34.2 & 35 & 42 \\
\hline qPCR (\%) & $30(15)$ & $85(15)$ & $25(5)$ & $75(10)$ & $70(5)$ & $65(15)$ & $80(20)$ & $40(40)$ & $45(20)$ \\
\hline nPCR (\%) & $30(15)$ & $55(15)$ & 30 & $75(5)$ & $65(5)$ & $55(25)$ & $55(25)$ & $50(10)$ & $55(10)$ \\
\hline Isolation (\%) & 15 & $20(5)$ & 15 & 35 & 30 & 35 & 35 & $10(5)$ & 25 \\
\hline Iridescence (\%) & 15 & 20 & 10 & 25 & 20 & 10 & 20 & 10 & 15 \\
\hline \multicolumn{10}{|c|}{ B. } \\
\hline & \multicolumn{9}{|c|}{ Weinmann et al. [35] } \\
\hline & \multicolumn{3}{|c|}{ I. } & \multicolumn{4}{|c|}{ II. } & \multicolumn{2}{|c|}{ III. } \\
\hline Mortality (\%) & \multicolumn{3}{|c|}{35} & \multicolumn{4}{|c|}{20} & \multicolumn{2}{|c|}{20} \\
\hline Patent inf. (\%) & \multicolumn{3}{|c|}{$\mathrm{NA}$} & \multicolumn{4}{|c|}{ NA } & \multicolumn{2}{|c|}{ NA } \\
\hline MST (days) & \multicolumn{3}{|c|}{ NA } & \multicolumn{4}{|c|}{ NA } & \multicolumn{2}{|c|}{ NA } \\
\hline qPCR (\%) & \multicolumn{3}{|c|}{$\mathrm{NA}$} & \multicolumn{4}{|c|}{ NA } & \multicolumn{2}{|c|}{ NA } \\
\hline nPCR (\%) & \multicolumn{3}{|c|}{75} & \multicolumn{4}{|c|}{15} & \multicolumn{2}{|c|}{30} \\
\hline Isolation (\%) & \multicolumn{3}{|c|}{45} & \multicolumn{4}{|c|}{5} & \multicolumn{2}{|c|}{25} \\
\hline Iridescence (\%) & \multicolumn{3}{|c|}{25} & \multicolumn{4}{|c|}{5} & \multicolumn{2}{|c|}{10} \\
\hline
\end{tabular}

${ }^{*}$ MST (mean survival time) was calculated for the proven patently infected animals. Data in brackets refer to samples with dubious results in the different tests: $\mathrm{qPCR}=1-5$ copies/ $\mu$ l detected, $\mathrm{nPCR}=$ faint bands on agarose gel, isolation $=$ inconsistent results in the repeats. $\mathrm{NA}=$ not analysed .
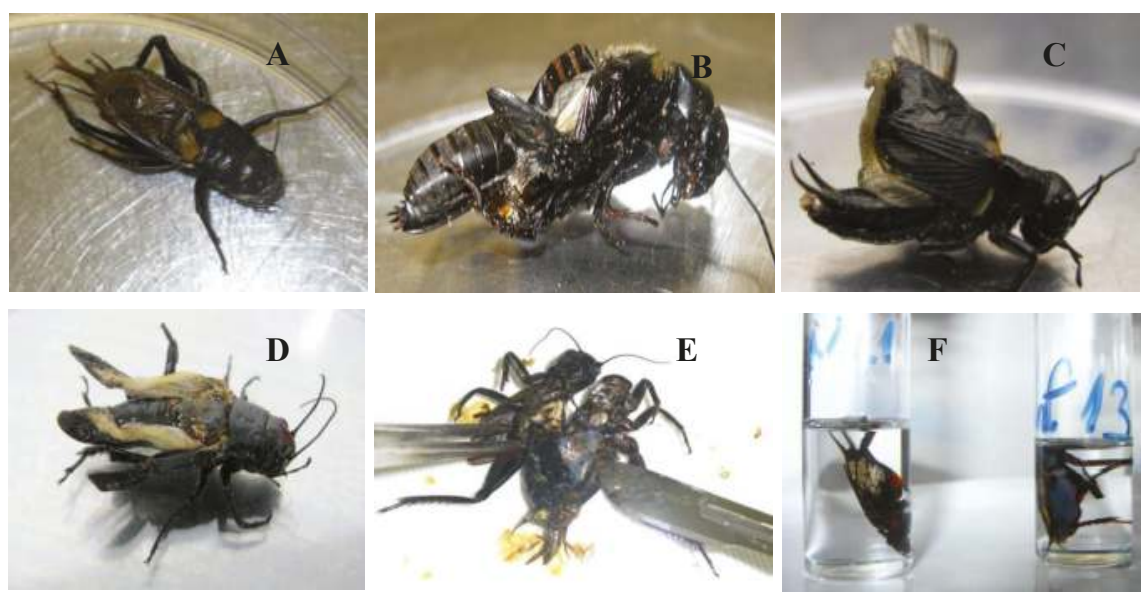

Figure 6. Malformations associated with IIV infection in crickets. (A) Negative control cricket. (B) Inability to complete ecdysis. (C,D) Distorted development of the wings in patently infected crickets. $(\mathrm{E}, \mathrm{F})$ Bluish iridescence in the fat body of patently infected crickets (on picture F right side of tube is infected, left is the negative control). 


\subsection{Transmission Study with Bearded Dragons}

None of the bearded dragons included in the study showed any signs of clinical disease during the course of the study. They continued eating normally and gaining weight during the entire 60-day period (Table S1). There were, however, drops in body weight up to $12 \%$ recorded from one week to the other due to shedding. In group A, animal A5 started to lose weight (with 15\% loss) during the second week and showed no appetite. It died emaciated on day 16 post infection (dpi) and was dissected. Gross pathology did not reveal remarkable alterations, except for a yellowish friable liver with glycogen deposits and lipidosis in histopathology.

Virus was detectable by isolation and PCRs from the oral and cloacal swabs of the infected animals from the first week after the beginning of infection, while the negative control lizards remained negative in these tests. The fourteen surviving animals were dissected at the end of the study. No changes were noted on gross pathology. A1 and A4 showed similar liver changes to those seen in A5.

No virus was detected in any of the negative control animals. In the infected animals, however, virus reisolation was successful mostly from the skin, the gastro-intestinal tract organs and in three cases in the liver and/or the brain as well. PCRs were positive from practically every organ (for details see Supplementary Figure S5). However, no specific macroscopic or histological changes were detected in any of these organs. EM was unable to detect virons in most tissues, but did detect individual virions in tissues with high viral copy numbers (according to qPCR) in individual cases. Comparing the virus loads (according to qPCR data) of these lizard tissues to those found in patently infected crickets showed three- to six-fold lower values, and the values of the gastro-intestinal tract organs and the skin were the highest in the infected bearded dragons (Figure S5).

\section{Discussion}

Our iridovirus studies were based on the findings of two German research groups. In 2001, isolation of IIV-like viruses was reported from the lung, liver, kidney and intestine of two bearded dragons (Pogona vitticeps) and a four horned chameleon (Trioceros [Chamaeleo]quadricornis) and from the skin of a frilled lizard (Chlamydosaurus kingii) [33]. Partial sequencing of the MCP gene of those isolates showed $100 \%$ identity to the nucleotide sequence of the cricket iridovirus CrIV [25,32]. In a parallel study by Marschang et al. [34], similar IIVs were isolated from two chameleons (Trioceros, T. [Chamaeleo] hoehnelii) and an iguana (Iguana iguana). The chameleons were cachectic, whereas the iguana had skin lesions. Later, our laboratory isolated further IIVs from insectivorous hosts (lizards and a scorpion) and from prey crickets (Table 1). A host-switch of this virus from prey insects to the predator lizards was postulated [33]. IIVs were also described in several different amphibian species [36]. In some cases, the animals were considered clinically healthy, while in others, increased mortality had been noted in a collection. Crickets fed to one of the amphibian groups also tested positive. Questions regarding the origin of this virus, its ability to switch hosts and infect vertebrates, its host range, possible transmission routes and genetic relationships among these viruses found in pet animals and other IIVs were raised by these previous reports, and our studies were undertaken to obtain answers to some of these questions.

An analysis of diagnostic testing for IIV in reptile, amphibian and insect samples in our lab from 2009 to 2018 shows that these viruses are still present in both captive bred insects and in reptiles and amphibians in captivity in Europe, and lengthens the list of species in which these viruses have been detected to include several new species including some snakes. It is, however, important to note that the results of some of this testing should be interpreted skeptically, since in many cases oral and/or cloacal swabs were tested. In cases in which vertebrates were fed infected insects, it is possible that virus detection in the oral cavity or even in the feces could reflect contamination from the insects rather than actual infection. On the other hand, tissues were also tested positive in several cases, including from animals that are not insectivorous, such as an Asian water monitor (Supplementary Table S3, No. 49) and an Indian rock python (Table S3, No. 57). It is not known how these animals might have come 
into contact with the virus. The majority of vertebrates in which these viruses have been reported are, however, wholly or occasionally insectivorous.

\subsection{Comparison of Genome Fragments of Different IIV Isolates}

The isolates included in this study (Table 1) were all identical to GenBank cricket iridoviruses: GbIV [32] and CrIV [40] based on the available partial MCP gene data. Additional genetic information was necessary in order to determine whether the viruses being diagnosed in vertebrate and invertebrate animals in the pet trade in Europe were related or represented a mix of viruses, possibly including invertebrate and vertebrate specific strains. The CrIV isolate kindly sent to our laboratory by Dr. Kleespies (Federal Biological Research Centre for Agriculture and Forestry, Institute for Biological Control, Darmstadt, Germany) has identical sequences to our isolates in the four analyzed genome regions $(012 \mathrm{~L}, 037 \mathrm{~L}, \mathrm{MCP}, V A B)$, and also in a PCR-restriction fragment length polymorphism (RFLP) analysis (author's unpublished work). Despite the presence of several insertions, deletions and recombination sites throughout the genome of $\mathrm{Liz}-\mathrm{CrIV}$, all of our isolates studied were closely related or identical to one another in the studied genomic regions. Among our isolates there was a very low inter-isolate variance (up to $0.4 \%$ ), only detected in two of the examined genes $(012 \mathrm{~L}, 037 \mathrm{~L})$. Since the isolates studied were obtained from six different species, including lizards and arthropods over the course of six years, this indicates that CrIV has evolutionarily stable variants circulating in Europe. In this paper we referred to it as lizard-cricket iridescent virus (Liz-CrIV) or simply CrIV, since its primary host is invertebrate and the infections of vertebrate hosts appeared due to (a) single or multiple host switch(es). Which insect species the original host could be is not clear in view of the finding that the recently disclosed genome sequence of a social insect [49], Jerdon's jumping ant (Harpegnathos saltator), apparently harbors several mRNA and unmapped DNA sequences identical to our Liz-CrIV fragments. This suggests that this native Indian ant species is either a natural host for the CrIV or that it has been infected by the virus, e.g., during sample processing in laboratories in the USA or China $[49,50]$. This also shows that this virus is present on continents other than Europe.

The MCP gene sequence of Liz-CrIV is $1428 \mathrm{nt}$ (coding $475 \mathrm{aa}$ ) long, the second longest reported in the family after IIV9 (484 aa; genus Chloriridovirus) [17] and shrimp hemocyte IV (SHIV, 477 aa; genus Decapodiridovirus) [21,23]. The MCP of Liz-CrIV is not only 8 aa longer than that of IIV6, but it has 13 additional mutation sites (Figure S1). This rate of MCP divergence (5.5\%/4.5\% for nt/aa) is smaller than that found between two separate types/species: E.g., IIV1 (Tipula iridescent virus; TIV) and IIV22 (Simulium iridescent virus; SIV; 19.8\%/9.7\%) [51], but much greater than those between two variants of the same type e.g., IIV22 and IIV22A (1.3\%/0\%) [52] or IIV31 and PjIV. Similarity plot analysis supported the hypothesis of recombination downstream of the MCP gene and the closest relationship of this region to the homologous regions of polyiridoviruses, e.g., IIV9 ORF011, adjacent to the IIV9 MCP gene (ORF010). In Liz-CrIV, however, this region is a pseudogene, a non-functional homolog of IIV9 ORF011, with two stop codons in the deduced protein sequence (Figure 4). The changes in the $V A B$ sequence in Liz-CrIV result in a frame shift and a deduced active peptide sequence, which has no homology to any present GenBank entry. These changes indicate that the VAB gene in Liz-CrIV is functionally different from that found in IIV6. These changes in the gene, its transcriptional pattern, and its expression as a protein should be further investigated. The adjacent ORF downstream of VAB gene (ORF159), revealed another hypothetical recombination site (Supplementary Figure S2).

Despite the high similarity (97\%) of the DNA polymerase gene of Liz-CrIV (037L) to its homolog in IIV6, the majority of the mutations and insertions in this gene clustered in close proximity, similar to the findings in the MCP gene. The structure and function of eukaryotic DNA polymerases have been characterized extensively [53], and were found to contain three active centers. The mutations of Liz-CrIV clustered in the region of the DEDDy domain, which is responsible for substrate specificity and DNA repair. 


\subsection{Genome Sequencing of the Chameleon Isolate, Differences from the IIV6 Genome}

Based on the genetic differences between Liz-CrIV and IIV6 detected in the above described studies, it seemed worthwhile to attempt to determine the whole genome sequence of one of our IIV isolates. The chameleon isolate (Table 1, Ir.iso. 1) was chosen, as the one used in bioassays with both lizards and crickets. All core protein genes were covered by the assembly, thus a required state of the art phylogenetic tree reconstruction could be performed (Figure S3). As expected based on the previous studies, the Liz-CrIV clustered together with IIV6 in close proximity, yet the observed aa difference between the two viruses for this set of proteins was somewhat higher than $5 \%(5.4 \%)$. The overall nt identity between the determined part of the draft genome and the IIV homolog region was also found to be lower than the cut-off limit of $90 \%$ for the same virus species, at $76.9 \%$. This is due to the numerous ORF deletions (18 missing and 17 broken or truncated) and ORF insertions (six from other IIVs, seven from other sources, Table 2), which will be discussed below.

The current taxonomical position of CrIV as a variant of IIV6 was based on biological and genetic data [40] with high similarity between the two viruses in susceptible insect host species and sequence data of seven homologous genes ( $93 \%-98 \%$ and $90 \%-97 \%$ identity for nt and aa). However, the genomic organizations of CrIV and IIV6 were earlier compared indirectly using RFLP [25] and were found to differ from one another. During our first studies comparing a more limited number of sequences from a higher number of isolates, lower $(44 \%-98 \%$ and $46 \%-100 \%)$ sequence identities were found between our Liz-CrIV isolates and IIV6 across the examined genes. Early phylogenetic tree reconstruction based on $M C P$ gene data (Supplementary Figure S1) has shown nt/aa differences smaller than those between two species (e.g., IIV1 and IIV22), yet larger than those between two variants (e.g., IIV22 or IIV31). In accordance with these findings the multiple parallel sequencing of the genome revealed that the set of core proteins differ from each other in the Liz-CrIV isolate and IIV6 a bit above the recently set [54] species demarcation criterion of 5\%. Among the additional features to be considered for the demarcation, (1) phylogenetic relatedness, (2) a co-linear arrangement of genes, (3) similar genomic size and (4) similar G $+C$ content [54] only genomic size difference (deletion of several ORFs) could be argued as a separating phenomenon between Liz-CrIV and IIV6. This is, however, not yet based on the full Liz-CrIV genome sequence, and final classification of Liz-CrIV as a species or an IIV6 variant should be postponed until the full genome sequence is available.

Virus evolution is achieved mainly by two processes: On one hand, random point mutations accumulate in the genome and eventually lead to a pool of virus mutants from which the most successful pathogen is selected by its ability to multiply best in a particular host organism. On the other hand, major alterations occur in the viral genome by recombination, deletion or insertion and can result in a virus with completely different properties in a very short period of time $[55,56]$. The limited number of mutational changes in the nucleotide sequences of the conserved ORFs and the evidence for multiple deletions and insertions/recombinations is compatible with the hypothesis that Liz-CrIV evolved relatively recently from IIV6.

What selection forces enabled the emergence of the Liz-CrIV is still a puzzle. Clues that could help solve it include the non-IIV6-like ORFs (Table 2), which occur in the Liz-CrIV genome and likely represent evidence of former recombination events. However, these insertions must be double-checked by PCR and Sanger sequencing in order to assure that they represent true genomic changes in the viral genome, and not assembly failures because of the relatively low coverage. Moreover, it is beyond the scope of the present paper to try and find answers for the important questions raised by these ORFs, e.g., (1) are these ORFs transcribed and translated in any or all Liz-CrIV infected cells? (2) What is their exact function and when do they switch on? This is relevant, since a number of these enzymes could play a role in the cell-cycle regulation (e.g., ASCH containing ORFs, IIV31_084R homolog) and/or the nucleotide metabolism (e.g., DHFR, IIV31_015R homolog, E3 ubiquitin protein ligase, dUTPase). (3) Why does the virus need a second dUTPase gene adjacent to its apparently functional IIV6 specific one (ORF 438L)? (4) Could the presence of an apparently reptile-related E3 ubiquitin protein ligase have any connection with the appearance of the Liz-CrIV in reptile hosts? Answering some of these 
questions will require experimental data, others can be answered using in silico analyses. There are reports in the literature proving that (regarding question 3), the same IIV genome can contain two active genes with the same enzymatic function [57], or (regarding question 4), that nucleocytoplasmatic large DNA viruses often contain host-derived genes [58,59].

\subsection{Comparison of Three IIV Isolates in a Cricket Bioassay}

The cricket bioassays were designed following previous studies in which extreme interassay variability was found in cricket mortality rates and in virus detection rates between trials with a single isolate (Table 1, Ir.iso.1; Table 3). We hypothesized that this variability could be due to changes in temperature between the individual trials. In addition, we hoped to determine biological differences between isolates from different hosts. However, standardization of the environmental temperatures (at 20 and $30^{\circ} \mathrm{C}$ ) did not lead to a clear reduction in the interassay variability (Table 3, for details see Figure 4), making the interpretation of differences between the isolates used for the cricket bioassays difficult to impossible. The mortality rates for all three isolates and both temperatures were all comparable to those from the previous study [35] and much lower than the $93 \%$ reported by Kleespies et al. [25] using the same infection method and a cricket isolate. However, the initial titer used by Kleespies was five-fold higher $\left(2.2 \times 10^{11}\right.$ particles $\left./ \mathrm{mL}\right)$ than that used in our studies, and was propagated in an insect cell line.

According to our data, the higher temperature $\left(30^{\circ} \mathrm{C}\right)$ does not seem to affect the ratio of patently or covertly infected crickets, although the mean survival time (MST) of the infected animals was slightly shorter at this temperature. The highest temperature at which IIV6 replication is still possible in in vitro systems is $32{ }^{\circ} \mathrm{C}$ [5], so it was of interest to determine whether a temperature close to that limit $\left(30^{\circ} \mathrm{C}\right)$ would adversely affect these lizard-cricket IIVs in their replication in vivo. The fact that it did not is also of interest considering the finding of these viruses in reptile species that thermoregulate to these and higher temperatures.

\subsection{Bearded Dragon Transmission Study}

IIV detection in lizards has been associated with a variety of clinical signs. These have included cachexia, keratoconjunctivits, hepatic hyperemia, splenomegaly, small white growths in the skeletal musculature, myxoid spindle cell sarcomas, liver lesions, apathy, CNS signs, bloody stool, hypoglycemia, sclerotic liver, stomatitis and sudden death $[33,35,37]$. Skin lesions have been reported in the greatest number of cases, including pox-like skin lesions, hyperkeratosis, loss of scales and cheilitis $[33,37,60,61]$. In some cases, virus has been detected in apparently healthy animals. Since IIVs have been detected in a variety of internal organs of lizards, it was hypothesized that these viruses infect the lizards. In many cases in which IIVs were detected, they were found in conjunction with other possible pathogens, including adenoviruses and ranaviruses [60,61]. The route of transmission for IIVs to vertebrates is unknown, but oral transmission via contaminated prey insects has been postulated [33]. Therefore, the bearded dragons were given both infected crickets and virus suspension per os. A second group also received virus suspension intracoelomically. Only one of the bearded dragons included in the study showed any signs of clinical disease during the course of the study. Virus was detectable by isolation and PCRs from the oral and cloacal swabs of the infected animals from the first week on after the beginning of infection. The finding of virus in oral and cloacal swabs was not surprising, since the alimentary route of infection was chosen, and cannot be interpreted as a sign of infection. However, continued detection after the animals were no longer being fed with virus positive crickets over a two week period indicates that virus either survived for a long period of time in the lizards or was replicating.

No direct connection was found between the early death of lizard "A5", the smallest animal included in the study, and the virus inoculation. However, the successful re-isolation of virus from every tissue and the positive nPCR results suggested viremia. This was partly supported by the qPCR results. Solitary viral particles were found in several tissues in the EM examination. However, no viral 
assembly sites were detected, in contrast to the findings in infected crickets [35]. This indicates that virus replication in lizards is much lower than in invertebrates, a finding supported by the results of the DNA quantification by qPCR. The fact that CrIV [33,35], and even IIV6 [62] are capable of replication on poikilothermic vertebrate (reptile) cell lines below $30^{\circ} \mathrm{C}$ supports this conclusion. It is also known that IIV6 inhibits cellular DNA, RNA and protein synthesis [63] and stimulates an immune response [64] in non-permissive vertebrate cells.

The highest viral loads were found in the gastrointestinal tract, with the highest overall concentrations found in the large intestine (colon) both by virus isolation and qPCR. This was expected due to the presence of possible remnants of the infected food-crickets, despite the two weeks of vegetable diet at the end of the study. The finding of relatively high virus loads by qPCR (and virus isolation) in the proximal portions of the digestive tract of some lizards, however indicates either a great capacity of these viruses to remain within the entire digestive tract over an extended period of time, or that virus replication took place here. Other organs (lung, heart, liver and skin) also had high virus loads (by qPCR) and in some cases, the virus was also isolated from these tissues. These findings indicate that virus did spread throughout the bodies of the infected lizards.

These results are in harmony with the findings in routine diagnostic lizard samples analyzed in recent years in our laboratory [37], including those presented in this paper (Supplementary Table S3) or other laboratories [33] where these organs were sources for IIV isolation from diseased lizards. Skin has also often been reported to be affected. However, no macroscopic or histological changes could be detected in any of these organs. The yellowish friable liver, as a sole pathological finding, resulted from glycogen deposition and lipidosis, and might be an indication of hepato-toxic effects of the viral proteins, as has been described in mice injected with IIV6 [65].

Comparing the virus loads (according to qPCR data) in the lizard tissues to those found in patently infected crickets infected with the same isolate, the values were in a three- to six-fold lower range, which could explain the difficulties encountered in finding the virus in the tissues in situ, since the sensitivity of EM is much lower than the sensitivity of e.g., virus isolation $[35,66]$.

The results of these transmission studies support the hypothesis that CrIV-like viruses are able to infect vertebrates and replicate in a variety of tissues. However, when applied orally and intracoelomically, they did not induce disease. Since these viruses have been found together with other viruses in diseased lizards in several cases [60,61], including those described here, it is possible that they play a role in multi-factorial disease processes not mimicked in this study. The frequent detection of these viruses in skin samples and in animals with skin lesions could also indicate that virus transmission does not occur via the alimentary tract, but through wounds or imperfections in the skin. In invertebrates, IIVs often cause covert infections [5]. It is possible that this is also the case in vertebrates, and that patent infections only occur at low rates or under specific circumstances, e.g., low environmental temperatures. Further studies are necessary to better understand this.

\section{Conclusions}

A specific strain of IIV, here called Liz-CrIV has been shown to be circulating among invertebrates in the pet trade in Europe for at least the past two decades and is also regularly found in a wide range of poikilothermic vertebrate hosts including squamate reptiles and amphibians. This virus is closely related to IIV6, the type species of the genus Iridovirus, but shows several interesting differences in its genomic sequence, incorporating novel ORFs (potential genes) with diverse homology to other viral, prokaryotic and eukaryotic sequences, and mostly unknown functions, which remain to be analyzed in subsequent research projects. Transmission studies with crickets have indicated that several factors, including environmental temperature, influence the rate of virus replication and the development of disease in invertebrate hosts. Some of these factors have not yet been elucidated. Infection studies with bearded dragons indicate that viral DNA may replicate in vertebrate hosts, but could not be associated directly with disease, or that disease development may depend on unknown circumstances. 
Evidence for the ability of these viruses to infect vertebrate hosts includes the regular detection of Liz-CrIV in diagnostic samples from vertebrates, detection of signification quantities of Liz-CrIV DNA as well as virus isolation from various tissues of bearded dragons following experimental infection, and the finding of a putative reptile-derived gene in the Liz-CrIV genome. Many details of the epidemiology of these IIVs in vertebrates as well as their possible impact on animal health require further study.

Supplementary Materials: The following are available online at http:/www.mdpi.com/1999-4915/11/7/600/s1, Figure S1: Phylogenetic tree based on the complete MCP gene data, Figure S2: SimPlot analysis of the sillucin gene homolog with its flanking regions; Figure S3: Phylogenetic tree reconstruction of Iridoviridae based on 25 core genes; Figure S4: Detailed results of the cricket bioassay; Figure S5: Detailed results of the bearded dragon infection study; Table S1: Animals of the bearded dragon infection study; Table S2: Primers used for PCRs and Sanger sequencing; Table S3: IIV detection in diagnostic samples, 2009-2018, Table S4: Sequence identity values (\%) between Liz-CrIV and IIV6.

Author Contributions: Conceptualization, T.P. and R.E.M.; methodology, T.P. and R.E.M.; validation, T.P. and R.E.M.; formal analysis, T.P.; investigation, T.P. and R.E.M.; resources, T.P. and R.E.M.; data curation, T.P. and R.E.M.; writing—original draft preparation, T.P.; writing—review and editing, T.P. and R.E.M.; visualization, T.P.; supervision, R.E.M.; project administration, R.E.M.; funding acquisition, T.P. and R.E.M.

Acknowledgments: This project was partially financed by a grant from the German Research Foundation to REM (MA 2534/2-5). Funding (for parts of the project) was also received from the Hungarian National Research, Development and Innovation Office (NN128309). A Researcher's Grant (BO/00569/15) from the Bolyai Research Fellowship of the Hungarian Academy Sciences helped TP. The authors thank Regina Kleespies for the Gryllus bimaculatus used in the studies, Antonio Pedro Alves de Matos and Renáta Pop (Univ. Vet. Med., Budapest) for support of the EM studies, Jens Teifke for support of the histological studies, and Dirk Spann for support of the Sanger sequencing studies.

Conflicts of Interest: REM is employed by a commercial laboratory that offers diagnostic testing for veterinarians. The authors declare no other conflicts of interest. Neither the employers nor the funders had any role in the design of the study; in the collection, analyses, or interpretation of data; in the writing of the manuscript, or in the decision to publish the results.

\section{References}

1. Chinchar, V.G.; Hick, P.; Ince, I.A.; Jancovich, J.K.; Marschang, R.; Qin, Q.; Subramaniam, K.; Waltzek, T.B.; Whittington, R.; Williams, T.; et al. ICTV virus taxonomy profile: Iridoviridae. J. Gen. Virol. 2017, 98, 890-891. [CrossRef] [PubMed]

2. Chinchar, V.G.; Yang, F.; Huang, J.; Williams, T.; Whittington, R.; Jancovich, J.; Subramaniam, K.; Waltzek, T.; Hick, P.; Ince, I.A.; et al. ICTV proposal 2018.004d: Short title: One new genus with one new species in the subfamily Betairidovirinae. 2018. Available online: https://talk.ictvonline.org/ (accessed on 10 April 2019).

3. Vetten, H.J.; Haenni, A.L. Taxon-specific suffixes for vernacular names. Arch. Virol. 2006, 151, 1249-1250. [CrossRef] [PubMed]

4. Williams, T. The iridoviruses. In Advances in Virus Research; Academic Press: Cambridge, MA, USA, 1996.

5. Williams, T.; Barbosa-Solomieu, V.; Chinchar, V.G. A decade of advances in iridovirus research. Adv. Virus Res. 2005, 65, 173-248. [PubMed]

6. İnce, İ.; Özcan, O.; Ilter-Akulke, A.Z.; Scully, E.D.; Özgen, A. Invertebrate iridoviruses: A glance over the last decade. Viruses 2018, 10, 161. [CrossRef] [PubMed]

7. Smith, K.M.; Xeros, N. An unusual virus disease of a dipterous larva. Nature 1954, 173, 866-867. [CrossRef] [PubMed]

8. Smith, K.M.; Williams, R.C. A crystallizable insect virus. Nature 1957, 179, 119-120. [PubMed]

9. Williams, T. Iridoviruses of invertebrates. In Encyclopedia of Virology; Mahy, B.W.J., Van Regenmortel, M.H.V., Eds.; Elsevier: Oxford, UK, 2008; pp. 161-167.

10. Williams, T. Natural invertebrate hosts of iridoviruses (Iridoviridae). Neotrop. Entomol. 2008, 37, 615-632. [CrossRef]

11. Tinsley, T.W.; Kelly, D.C. An interim nomenclature system for the iridescent group of insect viruses. J. Invertebr. Pathol. 1970, 16, 470-472. [CrossRef]

12. Williams, T. Comparative studies of iridoviruses: Further support for a new classification. Virus Res. 1994, 33, 99-121. [CrossRef] 
13. Williams, T.; Cory, J.S. Proposals for a new classification of iridescent viruses. J. Gen. Virol. 1994, 75 Pt 6, 1291-1301. [CrossRef]

14. Webby, R.; Kalmakoff, J. Sequence comparison of the major capsid protein gene from 18 diverse iridoviruses. Arch. Virol. 1998, 143, 1949-1966. [CrossRef] [PubMed]

15. Tang, K.F.; Redman, R.M.; Pantoja, C.R.; Groumellec, M.L.; Duraisamy, P.; Lightner, D.V. Identification of an iridovirus in Acetes erythraeus (Sergestidae) and the development of in situ hybridization and PCR method for its detection. J. Invertebr. Pathol. 2007, 96, 255-260. [CrossRef] [PubMed]

16. Delhon, G.; Tulman, E.R.; Afonso, C.L.; Lu, Z.; Becnel, J.J.; Moser, B.A.; Kutish, G.F.; Rock, D.L. Genome of invertebrate iridescent virus type 3 (mosquito iridescent virus). J. Virol. 2006, 80, 8439-8449. [CrossRef] [PubMed]

17. Wong, C.K.; Young, V.L.; Kleffmann, T.; Ward, V.K. Genomic and proteomic analysis of invertebrate iridovirus type 9. J. Virol. 2011, 85, 7900-7911. [CrossRef] [PubMed]

18. Eaton, H.E.; Ring, B.A.; Brunetti, C.R. The genomic diversity and phylogenetic relationship in the family Iridoviridae. Viruses 2010, 2, 1458-1475. [CrossRef]

19. Muttis, E.; Miele, S.A.; Belaich, M.N.; Micieli, M.V.; Becnel, J.J.; Ghiringhelli, P.D.; García, J.J. First record of a mosquito iridescent virus in Culex pipiens 1. (Diptera: Culicidae). Arch. Virol. 2012, 157, 1569-1571. [CrossRef] [PubMed]

20. Huang, Y.; Li, S.; Zhao, Q.; Pei, G.; An, X.; Guo, X.; Zhou, H.; Zhang, Z.; Zhang, J.; Tong, Y. Isolation and characterization of a novel invertebrate iridovirus from adult Anopheles minimus (AMIV) in China. J. Invertebr. Pathol. 2015, 127, 1-5. [CrossRef]

21. Qiu, L.; Chen, M.M.; Wang, R.Y.; Wan, X.Y.; Li, C.; Zhang, Q.L.; Dong, X.; Yang, B.; Xiang, J.H.; Huang, J. Complete genome sequence of shrimp hemocyte iridescent virus (SHIV) isolated from white leg shrimp, Litopenaeus vannamei. Arch. Virol. 2018, 163, 781-785. [CrossRef]

22. Available online: Https://talk.Ictvonline.Org//taxonomy/p/taxonomy-history?Taxnode_id=201856294 (accessed on 10 April 2019).

23. Li, F.; Xu, L.; Yang, F. Genomic characterization of a novel iridovirus from redclaw crayfish Cherax quadricarinatus: Evidence for a new genus within the family Iridoviridae. J. Gen. Virol. 2017, 98, 2589-2595. [CrossRef]

24. Toenshoff, E.R.; Fields, P.D.; Bourgeois, Y.X.; Ebert, D. The end of a 60-year riddle: Identification and genomic characterization of an iridovirus, the causative agent of white fat cell disease in zooplankton. G3 Genes Genomes Genet. 2018, 8, 1259-1272. [CrossRef]

25. Kleespies, R.G.; Tidona, C.A.; Darai, G. Characterization of a new iridovirus isolated from crickets and investigations on the host range. J. Invertebr. Pathol. 1999, 73, 84-90. [CrossRef] [PubMed]

26. Hernández, O.; Maldonado, G.; Williams, T. An epizootic of patent iridescent virus disease in multiple species of blackflies in chiapas, mexico. Med. Vet. Entomol. 2000, 14, 458-462. [CrossRef] [PubMed]

27. Jakob, N.J.; Müller, K.; Bahr, U.; Darai, G. Analysis of the first complete DNA sequence of an invertebrate iridovirus: Coding strategy of the genome of chilo iridescent virus. Virology 2001, 286, 182-196. [CrossRef] [PubMed]

28. Henderson, C.W.; Johnson, C.L.; Lodhi, S.A.; Bilimoria, S.L. Replication of chilo iridescent virus in the cotton boll weevil, Anthonomus grandis, and development of an infectivity assay. Arch. Virol. 2001, 146, 767-775. [CrossRef] [PubMed]

29. Nalcacioglu, R.; Muratoglu, H.; Yesilyurt, A.; van Oers, M.M.; Vlak, J.M.; Demirbag, Z. Enhanced insecticidal activity of chilo iridescent virus expressing an insect specific neurotoxin. J. Invertebr. Pathol. 2016, 138, 104-111. [CrossRef] [PubMed]

30. Jakob, N.J.; Darai, G. Molecular anatomy of chilo iridescent virus genome and the evolution of viral genes. Virus Genes 2002, 25, 299-316. [CrossRef] [PubMed]

31. Eaton, H.E.; Metcalf, J.; Penny, E.; Tcherepanov, V.; Upton, C.; Brunetti, C.R. Comparative genomic analysis of the family Iridoviridae: Re-annotating and defining the core set of iridovirus genes. Virol. J. 2007, 4, 11. [CrossRef]

32. Just, F.T.; Essbauer, S.S. Characterization of an iridescent virus isolated from Gryllus bimaculatus (Orthoptera: Gryllidae). J. Invertebr. Pathol. 2001, 77, 51-61. [CrossRef]

33. Just, F.; Essbauer, S.; Ahne, W.; Blahak, S. Occurrence of an invertebrate iridescent-like virus (Iridoviridae) in reptiles. J. Vet. Med. 2001, 48, 685-694. [CrossRef] 
34. Marschang, R.E.; Becher, P. Isolation and characterization of iridoviruses from lizards. In Proceedings of the 5th International Symposium on Viruses of Lower Vertebrates, Seattle, WA, USA, 27-30 August 2002.

35. Weinmann, N.; Papp, T.; Pedro Alves de Matos, A.; Teifke, J.P.; Marschang, R.E. Experimental infection of crickets (Gryllus bimaculatus) with an invertebrate iridovirus isolated from a high-casqued chameleon (Chamaeleo hoehnelii). J. Vet. Diagn. Investig. 2007, 19, 674-679. [CrossRef]

36. Stöhr, A.C.; Papp, T.; Marschang, R.E. Repeated detection of an invertebrate iridovirus in amphibians. J. Herpetol. Med. Surg. 2013, 26, 54-58. [CrossRef]

37. Papp, T.; Spann, D.; Marschang, R.E. Development and use of a real-time polymerase chain reaction for the detection of group ii invertebrate iridoviruses in pet lizards and prey insects. J. Zoo Wildl. Med. 2014, 45, 219-227. [CrossRef] [PubMed]

38. Hierholzer, J.C.; Killington, R.A. Virus isolation and quantitation. In Virology Methods Manual; Mahy, B.W., Kangro, H.O., Eds.; Academic Press: London, UK, 1996; pp. 25-46.

39. Sambrook, J.; Russell, D.W. Purification of Nucleic Acids by Extraction with Phenol:Chloroform; Cold Spring Harbor Laboratory Press: Suffolk, NY, USA, 2006.

40. Jakob, N.J.; Kleespies, R.G.; Tidona, C.A.; Müller, K.; Gelderblom, H.R.; Darai, G. Comparative analysis of the genome and host range characteristics of two insect iridoviruses: Chilo iridescent virus and a cricket iridovirus isolate. J. Gen. Virol. 2002, 83, 463-470. [CrossRef] [PubMed]

41. Sambrook, J.; Fritsch, E.F.; Maniatis, T. Molecular Cloning: A Laboratory Manual, 2nd ed.; Cold Spring Harbor Laboratory Press: Suffolk, NY, USA, 1989.

42. Bonfield, J.K.; Smith, K.; Staden, R. A new DNA sequence assembly program. Nucleic Acids Res. 1995, 23, 4992-4999. [CrossRef] [PubMed]

43. Golubchik, T.; Wise, M.J.; Easteal, S.; Jermiin, L.S. Mind the gaps: Evidence of bias in estimates of multiple sequence alignments. Mol. Biol. Evol. 2007, 24, 2433-2442. [CrossRef] [PubMed]

44. Kumar, S.; Stecher, G.; Li, M.; Knyaz, C.; Tamura, K. Mega x: Molecular evolutionary genetics analysis across computing platforms. Mol. Biol. Evol. 2018, 35, 1547-1549. [CrossRef] [PubMed]

45. Milne, I.; Lindner, D.; Bayer, M.; Husmeier, D.; McGuire, G.; Marshall, D.F.; Wright, F. Topali v2: A rich graphical interface for evolutionary analyses of multiple alignments on HPC clusters and multi-core desktops. Bioinformatics 2009, 25, 126-127. [CrossRef]

46. Aberer, A.J.; Kobert, K.; Stamatakis, A. Exabayes: Massively parallel Bayesian tree inference for the whole-genome era. Mol. Biol. Evol. 2014, 31, 2553-2556. [CrossRef]

47. Huelsenbeck, J.P.; Ronquist, F. Mrbayes: Bayesian inference of phylogenetic trees. Bioinformatics 2001, 17, 754-755. [CrossRef]

48. Ronquist, F.; Teslenko, M.; van der Mark, P.; Ayres, D.L.; Darling, A.; Höhna, S.; Larget, B.; Liu, L.; Suchard, M.A.; Huelsenbeck, J.P. Mrbayes 3.2: Efficient Bayesian phylogenetic inference and model choice across a large model space. Syst. Biol. 2012, 61, 539-542. [CrossRef]

49. Shields, E.J.; Sheng, L.; Weiner, A.K.; Garcia, B.A.; Bonasio, R. High-quality genome assemblies reveal long non-coding rnas expressed in ant brains. Cell Rep. 2018, 23, 3078-3090. [CrossRef] [PubMed]

50. Bonasio, R.; Zhang, G.; Ye, C.; Mutti, N.S.; Fang, X.; Qin, N.; Donahue, G.; Yang, P.; Li, Q.; Li, C.; et al. Genomic comparison of the ants Camponotus floridanus and Harpegnathos saltator. Science 2010, 329, 1068-1071. [CrossRef] [PubMed]

51. Tidona, C.A.; Schnitzler, P.; Kehm, R.; Darai, G. Is the major capsid protein of iridoviruses a suitable target for the study of viral evolution? Virus Genes 1998, 16, 59-66. [CrossRef] [PubMed]

52. Piégu, B.; Guizard, S.; Yeping, T.; Cruaud, C.; Couloux, A.; Bideshi, D.K.; Federici, B.A.; Bigot, Y. Complete genome sequence of invertebrate iridovirus IIV22A, a variant of IIV22, isolated originally from a blackfly larva. Stand. Genomic Sci. 2014, 9, 940-947. [CrossRef] [PubMed]

53. Rothwell, P.J.; Waksman, G. Structure and mechanism of DNA polymerases. Adv. Protein Chem. 2005, 71, 401-440. [PubMed]

54. Chinchar, V.; Hick, J.; Jancovich, J.; Subramaniam, K.; Waltzek, T.; Whittington, R.; Williams, T. ICTV proposal 2018.007d: Short title: 8 new species in the family Iridoviridae; removal of 3 existing species. 2018. Available online: https://talk.ictvonline.org/ (accessed on 10 April 2019).

55. Shackelton, L.A.; Holmes, E.C. The evolution of large DNA viruses: Combining genomic information of viruses and their hosts. Trends Microbiol. 2004, 12, 458-465. [CrossRef] [PubMed] 
56. Villarreal, L.P.; Witzany, G. Viruses are essential agents within the roots and stem of the tree of life. J. Theor. Biol. 2010, 262, 698-710. [CrossRef] [PubMed]

57. Yesilyurt, A.; Muratoglu, H.; Demirbag, Z.; Nalcacioglu, R. Chilo iridescent virus encodes two functional metalloproteases. Arch. Virol. 2019, 164, 657-665. [CrossRef] [PubMed]

58. Filée, J.; Pouget, N.; Chandler, M. Phylogenetic evidence for extensive lateral acquisition of cellular genes by nucleocytoplasmic large DNA viruses. BMC Evol. Biol. 2008, 8, 320. [CrossRef]

59. Filée, J.; Chandler, M. Gene exchange and the origin of giant viruses. Intervirology 2010, 53, 354-361. [CrossRef]

60. Behncke, H.; Stöhr, A.C.; Heckers, K.O.; Ball, I.; Marschang, R.E. Mass-mortality in green striped tree dragons (Japalura splendida) associated with multiple viral infections. Vet. Rec. 2013, 173, 248. [CrossRef] [PubMed]

61. Stöhr, A.C.; Blahak, S.; Heckers, K.O.; Wiechert, J.; Behncke, H.; Mathes, K.; Günther, P.; Zwart, P.; Ball, I.; Rüschoff, B.; et al. Ranavirus infections associated with skin lesions in lizards. Vet. Res. 2013, 44, 84. [CrossRef] [PubMed]

62. McIntosh, A.H.; Kimura, M. Replication of the insect chilo iridescent virus (CIV) in a poikilothermic vertebrate cell line. Intervirology 1974, 4, 257-267. [CrossRef] [PubMed]

63. Cerutti, M.; Devauchelle, G. Inhibition of macromolecular synthesis in cells infected with an invertebrate virus (iridovirus type 6 or CIV). Arch. Virol. 1980, 63, 297-303. [CrossRef] [PubMed]

64. Ahlers, L.R.; Bastos, R.G.; Hiroyasu, A.; Goodman, A.G. Invertebrate iridescent virus 6, a DNA virus, stimulates a mammalian innate immune response through RIG-I-like receptors. PLoS ONE 2016, 11, e0166088. [CrossRef] [PubMed]

65. Lorbacher de Ruiz, H.; Gelderblom, H.; Hofmann, W.; Darai, G. Insect iridescent virus type 6 induced toxic degenerative hepatitis in mice. Med. Microbiol. Immunol. 1986, 175, 43-53. [CrossRef] [PubMed]

66. Weinmann, N. Experimental infection of crickets (Ggryllus bimaculatus) with an invertebrate iridovirus isolated from a high-casqued chameleon (Chamaeleo hoehnelii), and trial on infecting bearded dragons (Pogona vitticeps) by feeding with infected crickets (Vet. Med. dissertation in German); Justus-Liebig-Universität: Giessen, Germany, 2007.

(C) 2019 by the authors. Licensee MDPI, Basel, Switzerland. This article is an open access article distributed under the terms and conditions of the Creative Commons Attribution (CC BY) license (http://creativecommons.org/licenses/by/4.0/). 

MDPI

St. Alban-Anlage 66

4052 Basel

Switzerland

Tel. +41616837734

Fax +41 613028918

www.mdpi.com

Viruses Editorial Office

E-mail: viruses@mdpi.com www.mdpi.com/journal/viruses

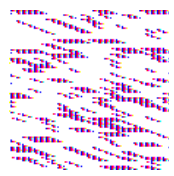



MDPI

St. Alban-Anlage 66

4052 Basel

Switzerland

Tel: +41 616837734

Fax: +41 613028918

www.mdpi.com 